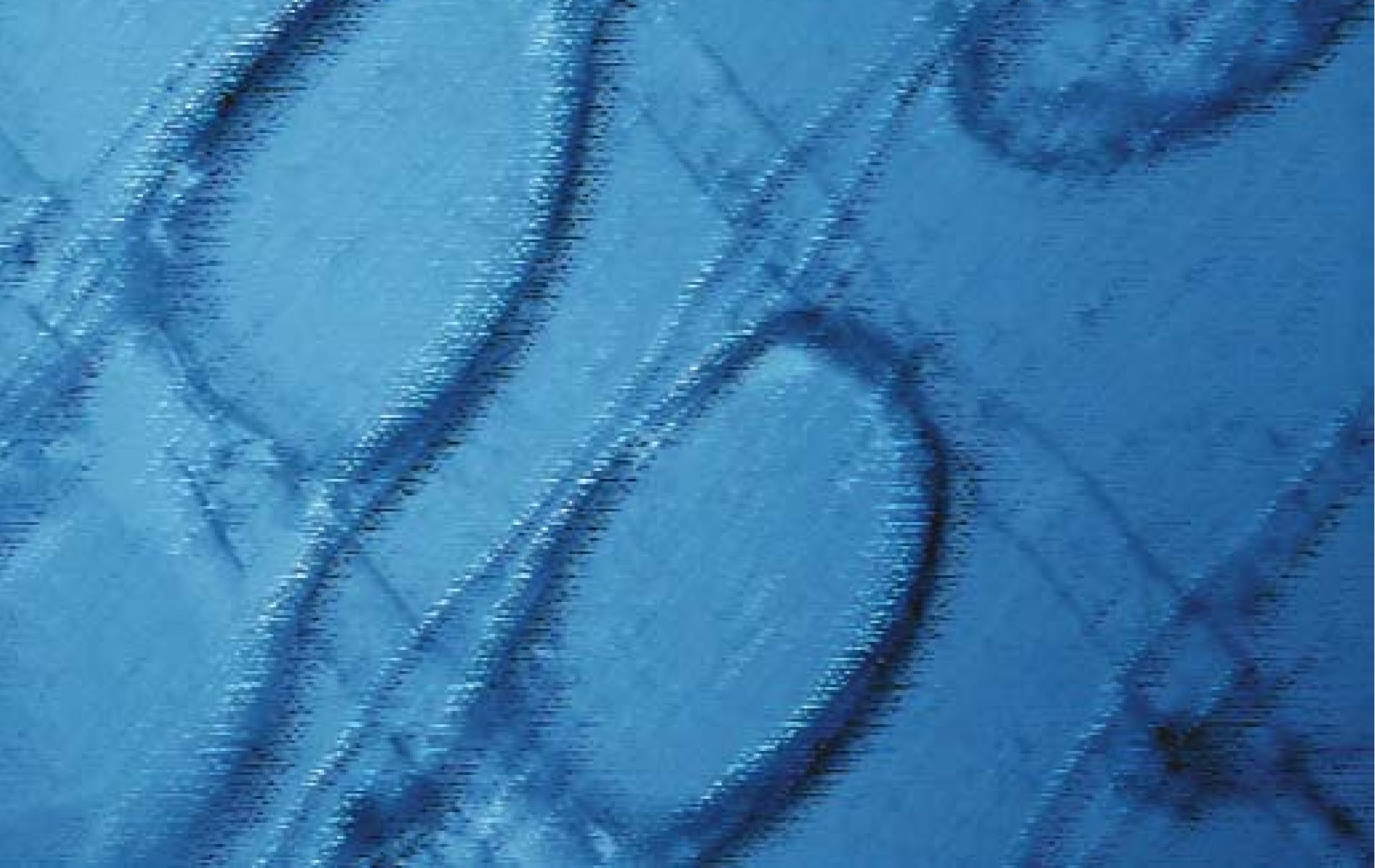


Two-phase flow for fouling control in membranes 
This research was performed in the cooperation framework of Wetsus, centre of excellence for sustainable water technology (www.wetsus.nl). Wetsus is co-funded by the Dutch Ministry of Economic Affairs and Ministry of Infrastructure and Environment, the European Union Regional Development Fund, the Province of Fryslân, and the Northern Netherlands Provinces. KWR Watercycle Research Institute, the Joint Research Programme for the Dutch water companies (BTO), Van Remmen BV, Hattenboer Water, and Aquacare BV of the research theme "Clean Water Technology" are acknowledged for the fruitful discussions and the financial support.

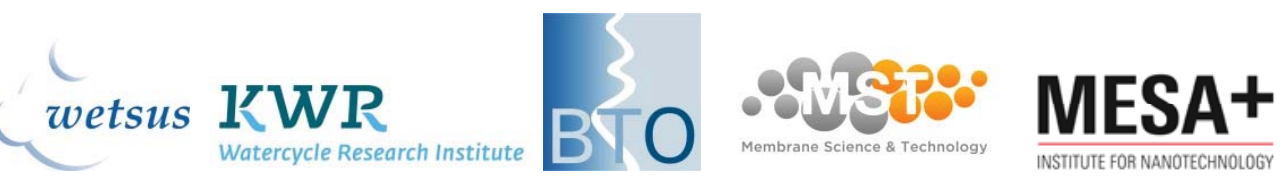

\section{Promotion committee}

\section{Chairman:}

prof.dr. G. Mul University of Twente

Promotor:

prof.dr.ir. D.C. Nijmeijer University of Twente

Co-promotor:

dr.ir. A.J.B. Kemperman University of Twente

Members:

prof.dr. C. Cabassud prof.dr.ir. W.G.J. van der Meer dr.ir. E.R. Cornelissen prof.dr.ir. R.G.H. Lammertink prof.dr. F. Mugele

Institut National des Sciences Appliquées of Toulouse Delft University of Technology

KWR Watercycle Research Institute

University of Twente

University of Twente

Cover design: Yusuf Wibisono

Front and back cover: Bubble flow in spacer-filled channel captured by high-speed camera

Two-phase flow for fouling control in membranes

ISBN: 978-90-365-3717-9

DOI: $10.3990 / 1.9789036537179$

URL: http://dx.doi.org/10.3990/1.9789036537179

Printed by Ipskamp Drukkers, Enschede

(C) 2014 Yusuf Wibisono, Enschede, The Netherlands 


\title{
TWO-PHASE FLOW \\ FOR FOULING CONTROL IN MEMBRANES
}

\section{DISSERTATION}

to obtain

the degree of doctor at the University of Twente,

on the authority of the rector magnificus,

prof. dr. H. Brinksma,

on account of the decision of the graduation committee,

to be publicly defended

on Thursday the $11^{\text {th }}$ of September 2014 at 14.45

by

\author{
Yusuf Wibisono \\ born on January $7^{\text {th }}, 1980$ \\ in Blitar, Indonesia
}


This thesis has been approved by:

prof. dr. ir. D.C. Nijmeijer (promotor)

dr. ir. A.J.B. Kemperman (co-promotor) 
Untuk Bapak (almarhum) dan Ibu Untuk yang tersayang: Muh, Bib dan Um Untuk Wie 



\section{Contents}

\section{Chapter 1}

\section{Introduction}

Abstract

1.1 NF/RO membrane systems

1.2 Fouling in spiral-wound membrane modules

1.3 Failure of chemical cleaning

1.4 Two-phase flow cleaning for fouling mitigation

1.5 Problem definition

1.6 Scope and outline of the thesis

References

\section{Chapter 2}

Two-phase flow in membrane processes: a critical review

2.1 Introduction

2.2 Two-phase flow in membrane elements 25

2.2.1 Introduction $\quad 25$

2.2.2 Two-phase flow patterns 25

2.2.3 Influence of particles and dissolved surface active solutes 30

2.3 Application of two-phase flow in various membrane processes $\quad 35$

$\begin{array}{lll}\text { 2.3.1 } & \text { Microfiltration } & 37\end{array}$

$\begin{array}{ll}\text { 2.3.2 Ultrafiltration } & 44\end{array}$

$\begin{array}{lll}2.3 .3 & \text { Nanofiltration } & 61\end{array}$

2.3.4 Reverse osmosis $\quad 64$

2.3.5 Membrane bioreactors 66

2.3.6 Membrane contactors and membrane distillation 67

$\begin{array}{lll}2.3 .7 & \text { Ion-exchange membrane processes } & 71\end{array}$

$\begin{array}{lll}2.3 .8 & \text { Summary } & 73\end{array}$

2.4 Analysis of two-phase flow in membrane modules $\quad 80$

$\begin{array}{lll}2.4 .1 & \text { Introduction } & 80\end{array}$

2.4.2 Flat sheet membranes $\quad 82$

2.4.3 Effect of gas and liquid velocities on flux enhancement in hollow fiber membranes 85

2.4.4 Effect of gas and liquid velocities on the feed channel pressure drop in spiralwound membranes

2.4.5 Effect of gas and liquid flow on the rejection $\quad 87$

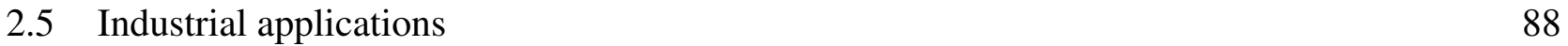

2.5.1 MBRs for wastewater treatment and reuse $\quad 88$

2.5.2 NF/RO processes in drinking water industries 90

$\begin{array}{lll}2.6 & \text { Conclusions and perspective } & 94\end{array}$

2.6.1 Optimum operation conditions 99

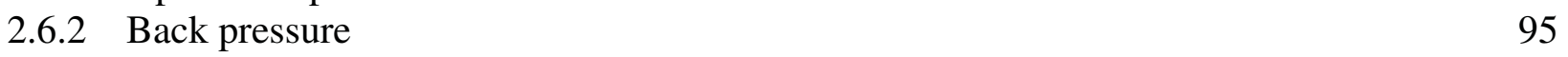

2.6.3 Energy cost $\quad 96$

2.6.4 Effect of bubble size $\quad 96$

2.6.5 Membrane deterioration 96

$\begin{array}{lll}2.6 .6 & \text { Perspective } & 97\end{array}$

$\begin{array}{ll}\text { References } & 97\end{array}$ 


\section{Chapter 3}

Efficiency of two-phase flow cleaning in spiral-wound membrane elements

Abstract

3.1 Introduction

3.2 Experimental

3.2.1 Materials

3.2.2 Experimental setup 116

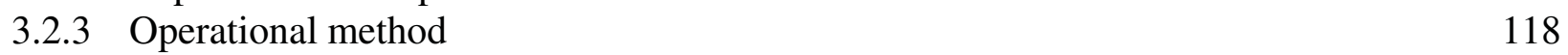

3.2.4 Direct-visual observation and scanning electron microscopy 120

3.3 Results and Discussion $\quad 121$

$\begin{array}{lll}3.3 .1 & \text { Humic acid fouling } & 121\end{array}$

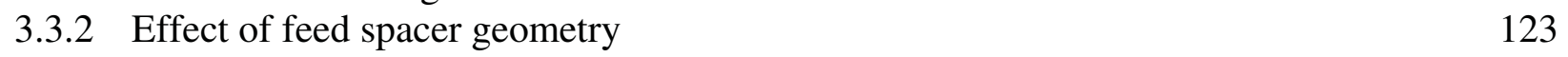

$\begin{array}{lll}3.3 .3 & \text { Effect of feed spacer orientation } & 125\end{array}$

3.3.4 Effect of gas/liquid ratio and liquid velocity 130

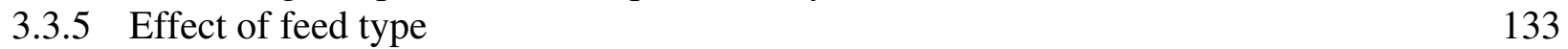

\begin{tabular}{ll}
3.3 .6 & General discussion \\
\hline
\end{tabular}

$\begin{array}{ll}3.4 \text { Conclusions } & 135\end{array}$

References $\quad 136$

\section{Chapter 4}

Biofouling removal in spiral-wound nanofiltration elements using twophase flow cleaning

4.1 Introduction 141

4.2 Theory 143

4.2.1 Increase of feed channel pressure drop (FCP) 143

4.2.2 FCP increase thresholds during fouling in spiral-wound elements 145

$\begin{array}{lll}4.2 .3 & \text { Flux decline } & 146\end{array}$

4.2.4 Normalized water flux 148

4.2.5 Concentration of nutrient solution 149

$\begin{array}{ll}\text { 4.2.6 Gas/liquid ratio } & 149\end{array}$

4.2.7 Efficiency of two-phase flow cleaning 150

\begin{tabular}{ll}
4.2 .8 & Bubble velocity \\
\hline
\end{tabular}

4.3 Material and methods $\quad 151$

$\begin{array}{lll}\text { 4.3.1 Materials } & 151\end{array}$

4.3.2 Two-phase flow nanofiltration setup 151

$\begin{array}{lll}\text { 4.3.3 } & \text { Flow cell simulator } & 153\end{array}$

4.3.4 Preliminary experiments 154

4.3.5 Protocols main experiments $\quad 154$

4.3.6 Nutrient dosing $\quad 156$

4.3.7 Liquid velocity and gas/liquid ratio 156

$\begin{array}{ll}\text { 4.3.8 Summary of experimental conditions } & 157\end{array}$

4.3.9 Observation of biofouling development and removal 157

4.4 Results and discussion $\quad 160$

4.4.1 Preliminary experiments 160

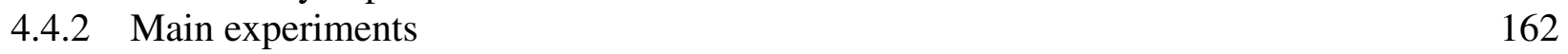

4.4.3 Effect of feed spacer geometry, gas/liquid ratio and applied pressure 166

$\begin{array}{ll}\text { 4.4.4 Effect of liquid velocity } & 169\end{array}$

$\begin{array}{ll}4.5 \text { Conclusions } & 174\end{array}$

$\begin{array}{ll}\text { References } & 175\end{array}$ 


\section{Chapter 5}

Hydrogel-coated feed spacers in two-phase flow cleaning in spiral-wound membrane elements: a novel platform for eco-friendly biofouling mitigation 179

Abstract

5.1 Introduction

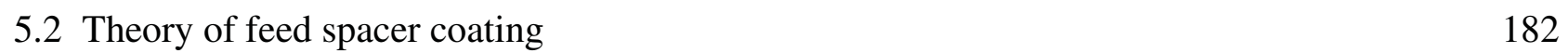

$\begin{array}{ll}5.3 \text { Experimental section } & 183\end{array}$

$\begin{array}{lll}\text { 5.3.1 Materials } & 183\end{array}$

\begin{tabular}{ll} 
5.3.2 & Plasma-mediated UV-polymerization \\
\hline
\end{tabular}

$\begin{array}{lll}\text { 5.3.3 Polymer characterization } & 186\end{array}$

5.3.4 Polymer stability test 186

$\begin{array}{lll}\text { 5.3.5 } & \text { Bacterial attachment assay } & 187\end{array}$

$\begin{array}{lll}\text { 5.3.6 Filtration tests } & 188\end{array}$

$\begin{array}{ll}5.4 \text { Results and Discussion } & 191\end{array}$

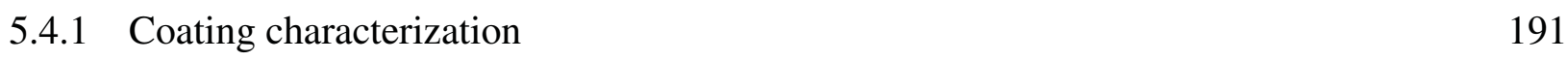

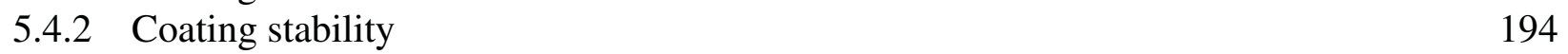

5.4.3 Bacterial adhesion test 196

5.4.4 Filtration test and two-phase flow cleaning 199

$\begin{array}{ll}\text { 5.4.4.1 Dynamics of feed channel pressure drop and water flux } & 199\end{array}$

$\begin{array}{lll}\text { 5.4.4.2 Daily OCT observation } & 200\end{array}$

5.4.4.3 Efficiency of two-phase flow cleaning 202

$\begin{array}{lll}\text { 5.4.5 Post-filtration analysis } & 204\end{array}$

5.5 Conclusion 206

$\begin{array}{ll}\text { References } & 207\end{array}$

\section{Chapter 6}

Dominant factors controlling the efficiency of two-phase flow cleaning in spiral-wound membrane elements

6.1 Introduction 213

6.2 Experimental 214

$\begin{array}{lll}6.2 .1 & \text { Materials } & 214\end{array}$

$\begin{array}{ll}\text { 6.2.2 Liquid velocity and gas/liquid ratio } & 216\end{array}$

6.2.3 Experimental factors and levels 216

$\begin{array}{ll}\text { 6.2.4 Operational protocol } & 217\end{array}$

6.2.5 Taguchi Method 218

$\begin{array}{ll}6.3 \text { Results and Discussion } & 220\end{array}$

$\begin{array}{lll}\text { 6.3.1 Particle size and particle size distribution } & 220\end{array}$

6.3.2 Pressure drop recovery 221

$\begin{array}{lll}\text { 6.3.3 S/N ratio analysis } & 222\end{array}$

$\begin{array}{lll}6.3 .4 & \text { ANOVA analysis } & 227\end{array}$

6.3.5 Final remarks 228

$\begin{array}{ll}6.4 \text { Conclusions } & 229\end{array}$

$\begin{array}{ll}\text { References } & 229\end{array}$ 


\section{Chapter 7}

Conclusion and Outlook

Abstract

7.1 Conclusions

7.2 Outlook

References

Abbreviations and symbols 


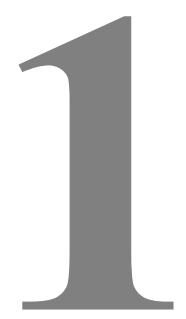

Introduction 
Abstract

The objective of this research is to investigate and optimize the effect of two-phase flow cleaning in spiral wound membrane elements to control fouling. It aims at providing a fundamental understanding of the underlying mechanisms and the effect of the different parameters in order to improve the effectiveness of two-phase flow cleaning applied in spiralwound membrane elements and to determine the optimum operating conditions of NF/RO systems for water treatment. This chapter provides a brief introduction on the potential of two-phase flow cleaning technology to control fouling in spiral-wound membrane elements. The scope and outline of the thesis are presented as well. 
Water is a precious resource and a basic need for mankind. Human beings require water for drinking, individual hygiene, sanitation, and food preparation [1]. Clean and safe water is essential and its demand rises continuously. In arid regions where physical water scarcity exists, the development of methods to provide an alternative fresh water supply from new sources, like seawater and brackish water, is extremely important. In areas that are relatively water rich, removal of pathogens and emerging contaminants from water resources is a crucial aspect. Membrane-based water treatment is a promising technology to meet those demands with membranes tailored to separate undesirable substances. It is extensively used worldwide for water purification and desalination [2].

\subsection{NF/RO membrane systems}

High-pressure membrane processes like reverse osmosis (RO) and nanofiltration (NF) together can separate almost all unwanted contaminants. RO has gained popularity for desalting saline water with a $44 \%$ share in production capacity worldwide, among other membrane processes like NF or electrodialysis (ED) and thermal processes like multi-stage flash (MSF) and multi-effect distillation (MED) [3-5]. Nanofiltration (NF), which is operated at a lower pressure than $\mathrm{RO}$, offers advantages in term of lower operational and maintenance expenditures and a higher flux compared to RO, while still removing microorganisms, organics, nanoparticles and multivalent salts [6]. NF however, does not retain monovalent ions and is not used for desalination. NF is extensively used to treat surface water, ground water and wastewater.

The most common operational membrane module used in NF/RO processes is the spiralwound type of membrane module (Fig. 1.1). Each spiral-wound module contains at least a pair of spaced semipermeable membrane sheets, each enclosed in an individual element. In each element, every two membrane sheets are glued together at three sides to form an envelope that is interposed between porous mesh spacers. These spacers are used to keep the membrane sheets apart, both at feed and permeate side. All sheets together are subsequently spirally wound around and their open end is connected to a central tube that collects the permeate water [7-9]. 


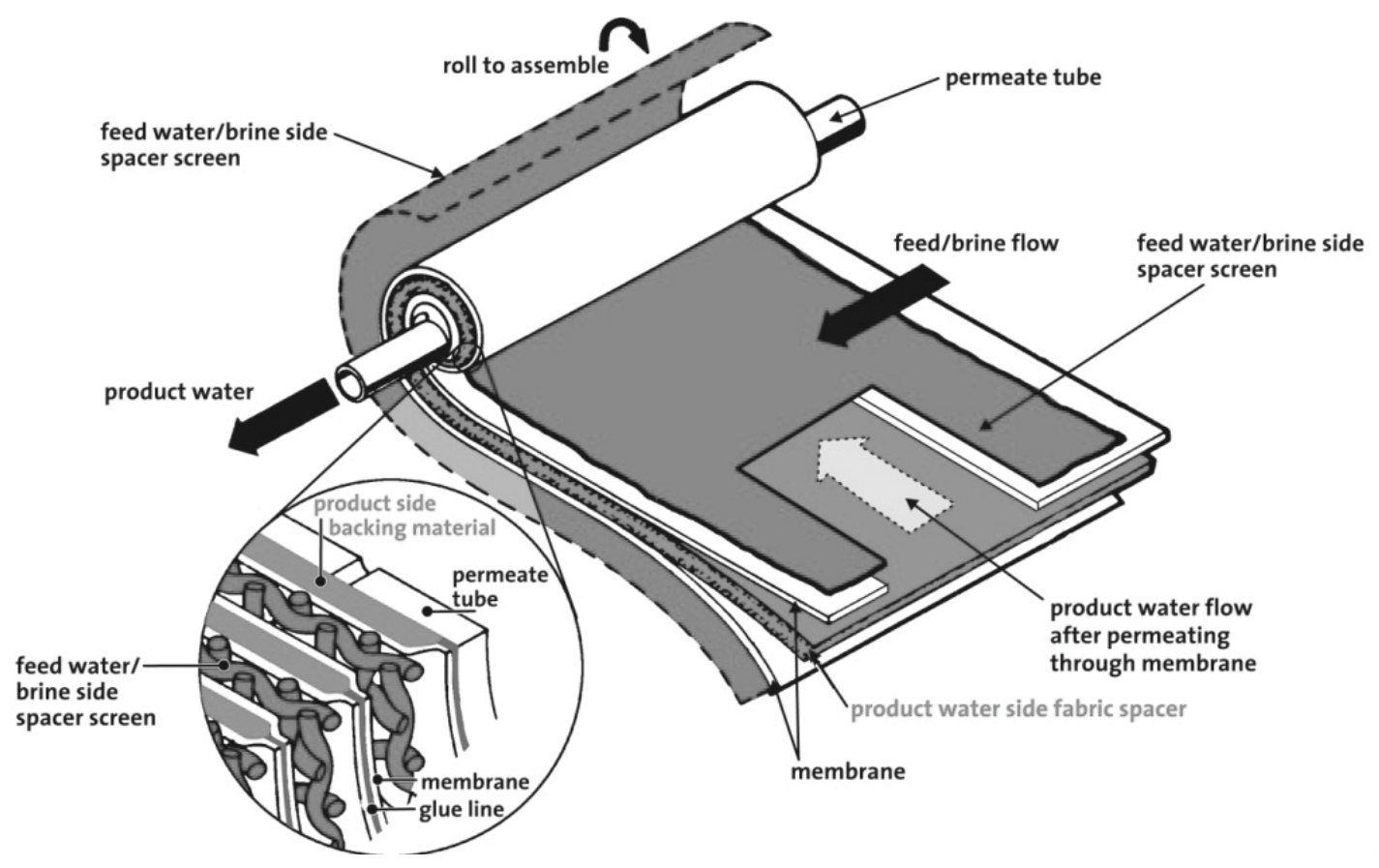

Fig. 1.1. Assembly of a spiral-wound membrane module from a pair of membrane leaves, a feed side spacer, a permeate side spacer, rolled around a permeate central tube [9].

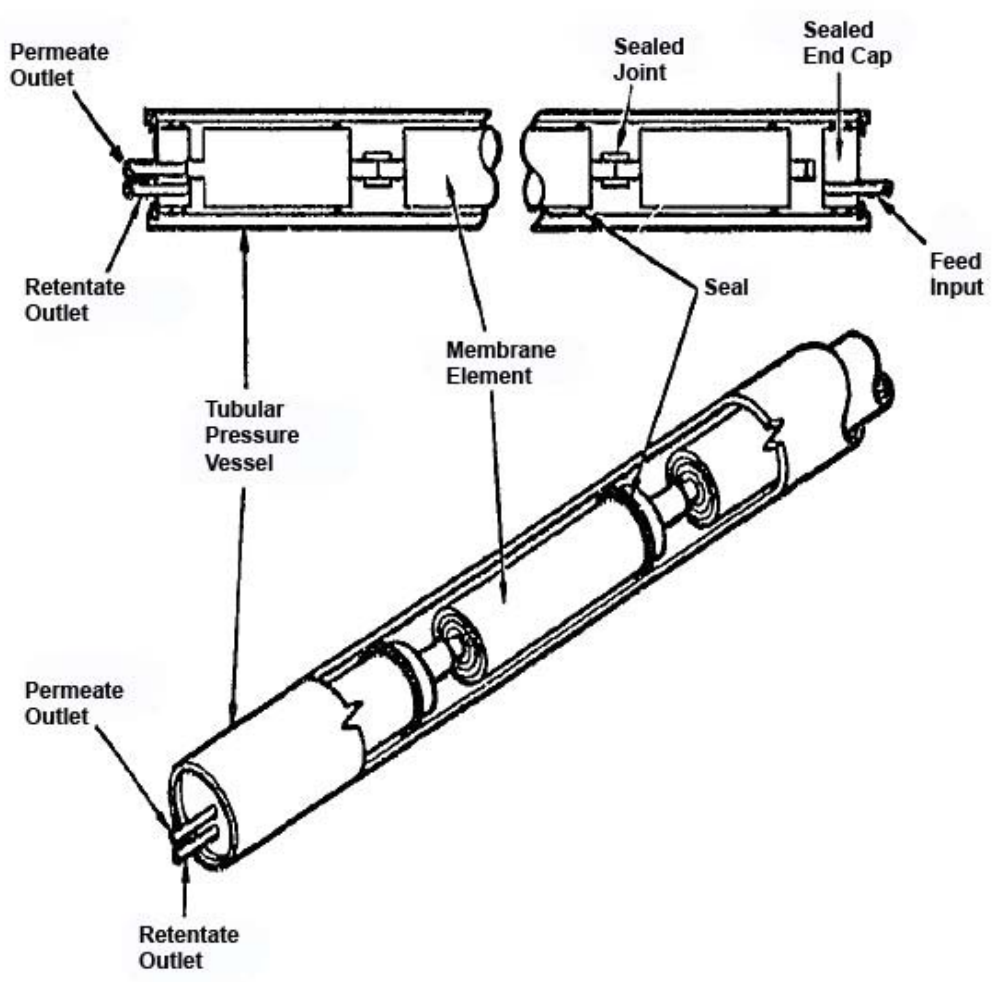

Fig. 1.2. A typical pressure vessel containing several spiral wound membrane elements, adapted from [8]. 
Multiple spiral-wound membrane elements are generally connected in a pressure vessel to increase the total water production (increase recovery). A typical configuration of a RO membrane system is in tapered stages with 6-8 elements per pressure vessel, connected in series and placed in a horizontal position (Fig. 1.2). Yet, the optimum configuration of a spiral-wound membrane module installation depends on several factors, such as operating conditions (temperature, feed pressure, feed type and concentration), type of membrane system (RO or NF membranes, membrane permeability, number of membrane leaves per spiral wound element, membrane area, feed and channel height), and permeate stream variations (a traditional single-feed stream and two output product streams, i.e. retentate and permeate streams, or a split partial second pass design) [10-13].

\subsection{Fouling in spiral-wound membrane modules}

The real challenge of the use of RO/NF spiral-wound membrane modules in water treatment is membrane fouling. According to the International Union of Pure and Applied Chemistry (IUPAC), fouling is defined as a 'process resulting in loss of performance of a membrane due to deposition of suspended or dissolved substances on its external surfaces, at its pore openings, or within its pores' [14].

Fouling in NF/RO is commonly caused by adsorption of organic molecules [15], precipitation and crystallization of salts such as $\mathrm{CaSO}_{4}$ or $\mathrm{CaCO}_{3}$ [16], and adhesion of viable organisms on the membrane surfaces (see Fig. 1.3) [17, 18].

While organic and inorganic dissolved particles can be removed by a proper pretreatment, biofouling is more difficult to control and easily grows in the membrane feed channel [19]. As fouling usually occurs on the nanoscale, combined with the complex geometry of spiralwound membrane modules, fouling problems in NF/RO systems are more complicated than in low pressure membrane processes, e.g. microfiltration (MF) and ultrafiltration (UF) [20]. Especially the presence of feed spacer materials is believed to enhance the development of biofouling in spiral-wound membrane elements [21]. 


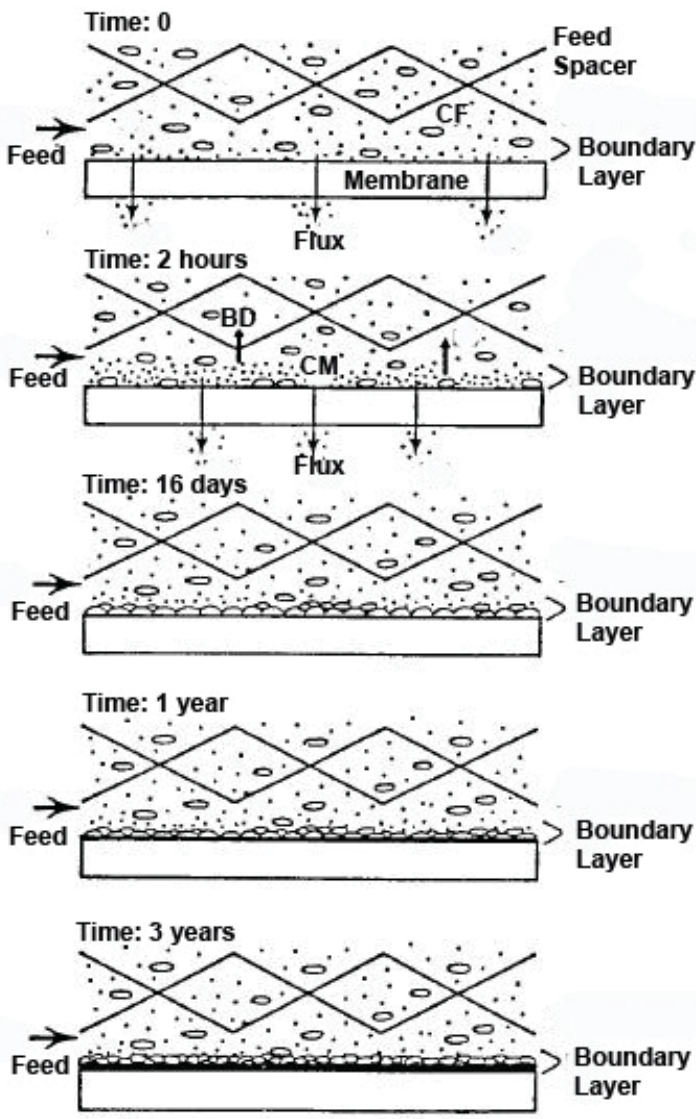

Fig. 1.3. Fouling evolution in the feed channel of spiral wound membrane elements after certain years of operation time $(\mathrm{CF}=$ concentration of dissolved and suspended solids in feed, $\mathrm{CM}=$ concentration of dissolved and suspended solids at the membrane surface, $\mathrm{BD}=$ back diffusion, $\therefore=$ dissolved or suspended solids, and $\circ=$ bacteria), adapted from [18].

\subsection{Failure of chemical cleaning}

Reducing membrane fouling is a must during operation of $\mathrm{NF} / \mathrm{RO}$ membranes in order to minimize product loss and operational costs. Periodical cleaning is needed to relieve unwanted materials from the membrane surface and the feed channel. Membrane cleaning involves physical cleaning (from apparent solid substances), chemical cleaning (from any contaminants), and biological cleaning (from attached microorganism) of the membrane surface and feed channel [22]. Physical reversible fouling in NF/RO processes is preferably prevented by a proper pretreatment (MF/UF/ozonation or activated carbon) and is traditionally removed by flushing (backflush, forward flush, reverse flush). Physical irreversible fouling (especially biofouling) needs to be tackled by a chemical cleaning [20]. 
Chemical cleaning is carried out by using cleaning agents (alkalines, acids, biocides, enzymes, chelating agents, and detergents) that promote a cleaning reaction like hydrolysis, peptization, saponification, chelation, sequestering and suspending [22-24].

Yet, chemical agents are found to be ineffective to control biofouling and many studies revealed the survival of microbial cells after chemical cleaning. According to Bridier et al., reasons for chemical cleaning being ineffective against biofouling include:

(a) chemical agents oppose non-specifically against multiple structures or metabolic processes in microbial cells;

(b) in wet environments, microbes live in an extracellular polymeric substances (EPS) matrix termed as biofilm. However, these cells embedded in the biofilms, have phenotypes different than those of their planktonic counterparts. As a consequence they may have different properties, including an increased resistance towards chemical cleaning agents.

(c) mature biofilms have multiple layers of cells and EPS that form complex and compact structures. Chemical agents may not be able to diffuse into these structures and reach the internal layers. As a consequence, only a low amount of chemical agents are able to interact with the deeper regions and biofilms;

(d) as a direct response to the chemical gradients in the biofilm, the cells physiologically adapt (including gene transformations and mutations), causing that cells located at the periphery of the three-dimensional structure of the biofilm have access to nutrients and oxygen, while colonies buried below them experience low nutrient environments;

(e) Biofilms consist of mixtures of different species rather than a single model species of biostructures [25].

A magnetic resonance imaging (MRI) study of biofouling development and removal using chemical agents in spiral wound membrane elements revealed insufficient cleaning. The MRI measurements were carried out on a customized spiral-wound module like flow cell, used to identify biofilm development and removal. Three types of chemical agents were used: (i) $\mathrm{NaOH}$ at $\mathrm{pH} 12$, (ii) $10 \mathrm{mM}$ SDS, and (iii) $10 \mathrm{mM} \mathrm{SDS}+\mathrm{NaOH}$ at $\mathrm{pH} 12$. The results were presented as 2D structural images (Fig. 1.4) [26].

As shown in Fig. 1.4, 2D structural MRI images revealed that, although chemical cleaning, reduced the amount of biofouling, still a significant amount of the biofilm remained. A higher degree of cleaning was visually observed after cleaning with $\mathrm{NaOH}$ alone (Fig. 1.4(a)), while 
a lower cleaning efficiency was noticed for SDS and SDS+NaOH cleaning (Fig. 1.4(b)). Despite the variation in chemical cleaning strategies used in this study, none of these were successful in removing all biofouling present in the membrane feed channels.
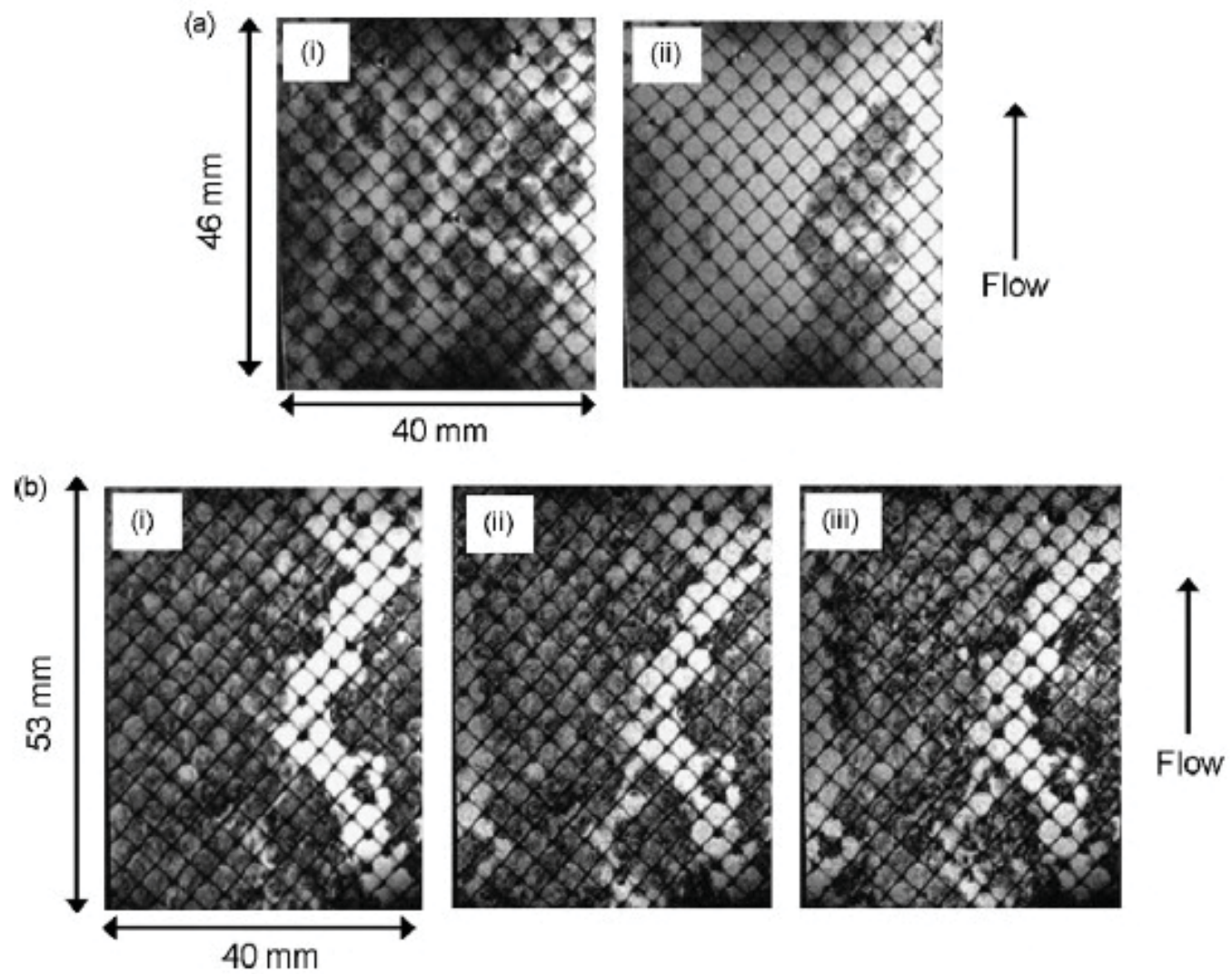

Fig. 1.4. (a) 2D structural MRI images of spacer-filled feed channels: (i) biofouled feed channel, and (ii) cleaned feed channel using $\mathrm{NaOH}$ (pH 12); (b) 2D structural MRI images of spacer-filled feed channels: (i) biofouled feed channel, (ii) cleaned feed channel using SDS, and (iii) cleaned feed channel using SDS $+\mathrm{NaOH}(\mathrm{pH}$ 12) [26].

A more detailed study employed a combination of molecular (FISH, DGGE, clone libraries and sequencing) and microscopic (FESEM, CLSM) analyses, during short and long-term operations in a RO water purification plant. The work showed that bacterial colonization of the disrupted biofilm layers (by chemical treatment) starts directly after chemical cleaning by attachment and growth of primary colonizers from the intake and re-growth of microorganisms that survived the chemical cleaning within the collapsed biofilm layer (Fig. 1.5). Samples were taken from four high-pressure (12 bar) flow cells connected parallel to a fullscale RO plant operated for a year. The chemical treatment consisted of sequential cleaning: 
RO permeate $\left(20-25^{\circ} \mathrm{C}\right)$, biocide $\left(30 \%\right.$ sodium bisulfite solution, $30-40^{\circ} \mathrm{C}, \mathrm{pH} 10-11$, during 2-3 hours) and mixed acid detergent descaler (Divos 2) [27].

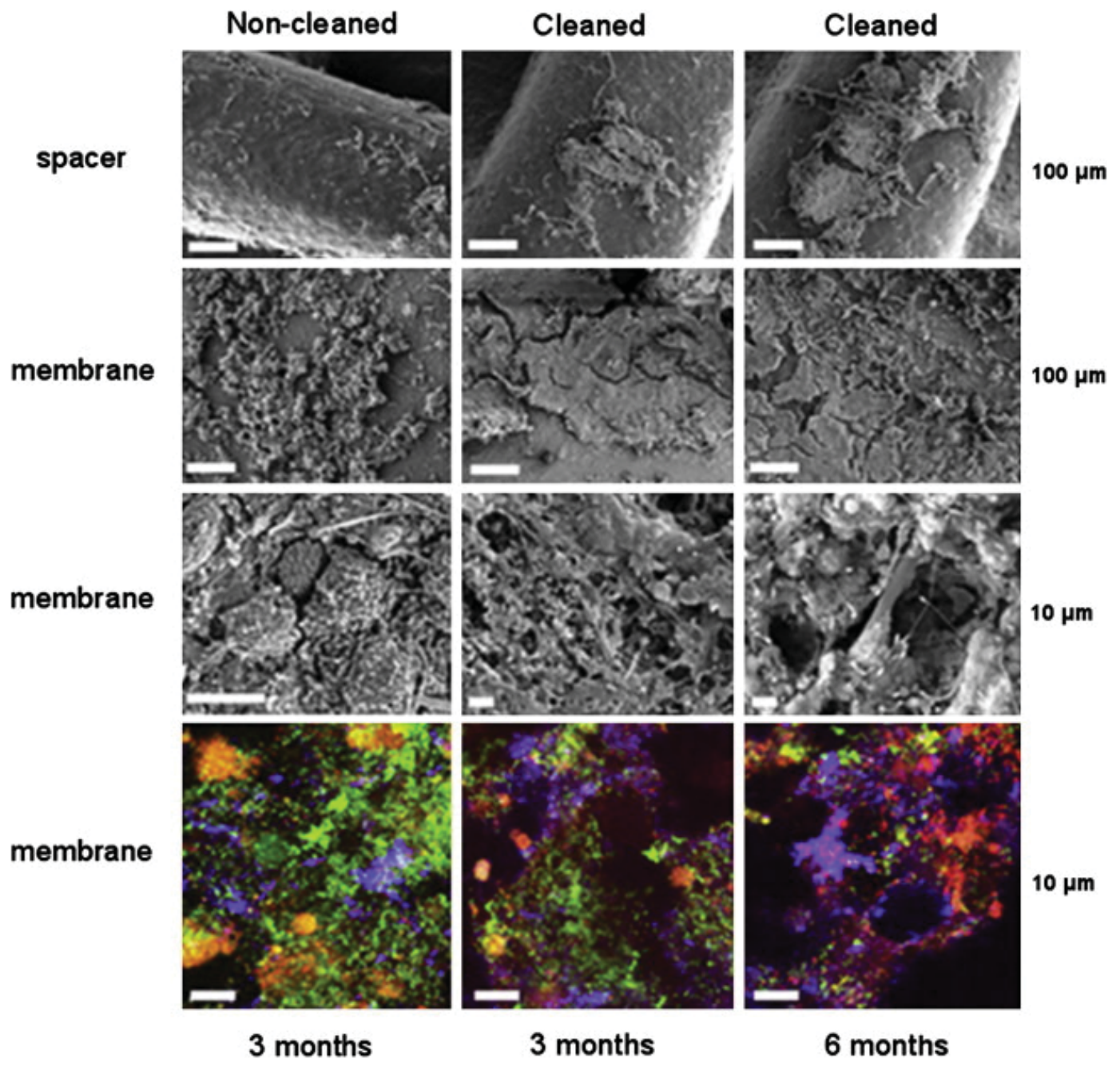

Fig. 1.5. SEM and CLSM images displayed the role of periodical chemical cleaning on the biofouling structures adhered on the RO membrane and the feed spacer. Images in subsequent vertical columns: non-cleaned, 3 months old and cleaned, 3-6 months old and cleaned; images on horizontal rows: SEM and CLSM images of biofilms adhered on the RO membrane and feed spacer surfaces [27].

As shown in Fig. 1.5, SEM and CLSM imaging displayed that chemical cleaning failed to remove biofouling from the membrane and feed spacer surfaces. Bacteria counting revealed that only small amount of biofouling was removed. The number of bacteria lowered from 6.1 x $10^{8}$ to $8.2 \times 10^{7}$ cells $/ \mathrm{cm}^{2}$ (3 months old samples) and from $2.1 \times 10^{9}$ to $3.7 \times 10^{7}$ cells $/ \mathrm{cm}^{2}$ (6 months old samples). Removal of (dead) biomass after chemical cleaning turned out to be important and was proposed to prevent re-growth of the biofilm [27]. 


\subsection{Two-phase flow cleaning for fouling mitigation}

Technical and economical analyses demonstrated that gas/liquid two-phase flow cleaning is a promising technology to keep the membrane resistance at sufficiently low levels and to increase the membrane flux for many types of membrane processes: (i) microfiltration (MF), (ii) ultrafiltration (UF), (iii) nanofiltration (NF), (iv) reverse osmosis (RO), (v) membrane distillation (MD), (vi) electrodialysis (ED), and (vii) membrane bioreactors (MBR) [28]. Also it is applicable in a multitude of membrane module types: (i) flat/planar, (ii) tubular/capillary, (iii) hollow fiber and (iv) spiral wound membranes [28].

The research on two-phase flow application in spiral wound membrane elements is limited to the first-three types of membrane modules, but the number of research papers and potential applications is increasing. Periodic two-phase flow cleaning in vertically positioned spiralwound membrane elements, showed promising results for fouling removal [29, 30].

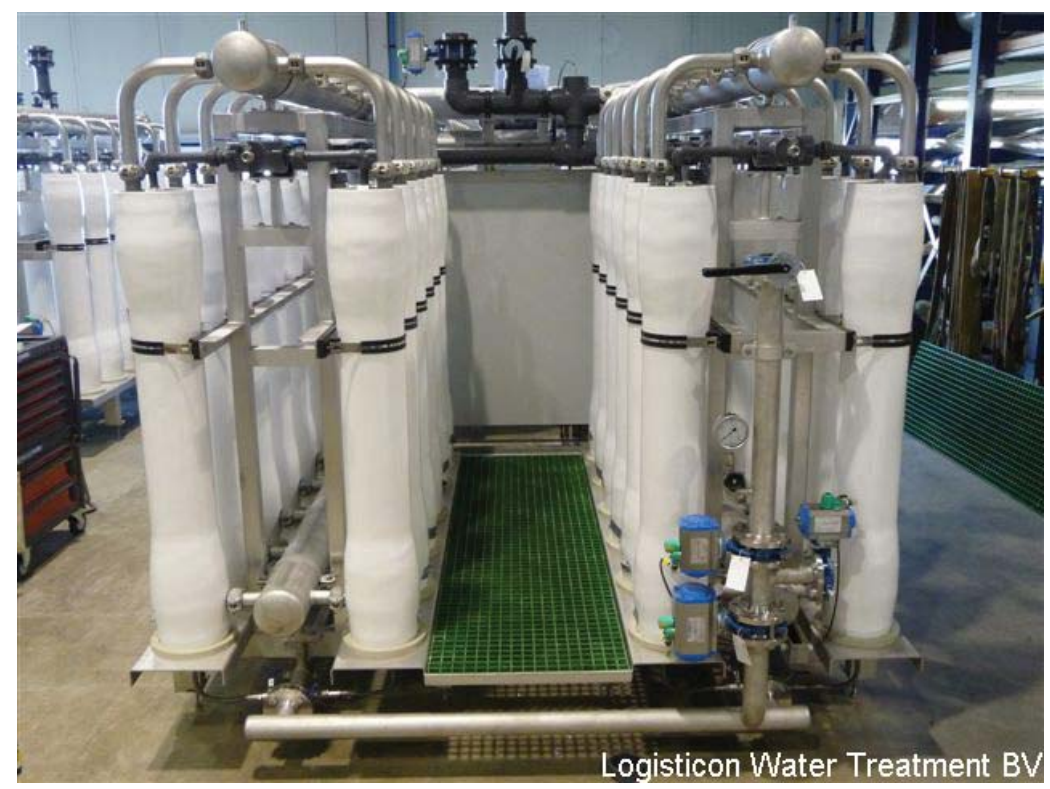

Fig. 1.6. Full scale RO installation with the first spiral wound membrane modules placed vertically for two-phase flow cleaning application for fouling removal in Botlek area, Rotterdam, the Netherlands (picture courtesy of Logisticon).

The application of two-phase flow cleaning at a full-scale RO installation showed that the technology is competitive. In technical terms, two-phase flow cleaning decreased the annual average operating feed pressure and combined this with a 95\% reduction in chemicals consumption used for cleaning. This leads to savings of 5-10\% on electricity and a $15-20 \%$ 
increase in membrane life-time. The investment on the other hand, for the installation of the two-phase flow equipment with the first spiral wound membrane modules placed vertically (Fig. 1.6), was only $1 \%$ of the total investment costs for the complete RO plant [28].

\subsection{Problem definition}

A presented above briefly, two-phase flow cleaning has been introduced in membrane systems. This gas/liquid flow cleaning is periodically carried out in vertically positioned, spiral wound membrane elements to control the effects of biofouling and particulate fouling $[30,31]$. Especially both the gas and the liquid flow are critical in determining the effectiveness of the cleaning.

Although initial studies showed the effectiveness of the process, many fundamental questions still remain unanswered, such as: (i) the mechanical/physical understanding of two-phase flow cleaning of spiral-wound membrane elements: What is the effect of bubble size, bubble shape, bubble distribution, bubble velocity, channel coverage etc. on the cleaning efficiency; (ii) the effectiveness of the two-phase flow cleaning process in relation to feed components, feed spacer geometry, feed velocity, gas/liquid ratio, feed spacer orientation, applied pressure etc; (iii) the effect of a combination of multiple anti-fouling measures on fouling control, e.g. the combination of a modified feed spacer with two-phase flow cleaning; (iv) the key factors responsible for maximum two-phase flow cleaning efficiency.

Answering these research questions will lead to the optimization of this technology in order to enhance the productivity and quality of water treatment using high-pressure membrane processes $(\mathrm{NF} / \mathrm{RO})$ as much as possible and increase its efficiency further.

\subsection{Scope and outline of the thesis}

The scope of this thesis is to understand and optimize two-phase flow cleaning in spacerfilled membrane channels used as a model for spiral-wound membrane elements in relation to the following parameters: (i) feed types and concentrations; (ii) feed spacer geometry and orientation; (iii) feed pressure and velocity; (iv) gas/liquid ratio; and (v) feed spacer surface properties. Different foulant types considered as representatives for typical organic, inorganic 
and biological foulants are used. This work contributes to provide a better understanding of the underlying mechanisms and the role of the different parameters in order to enhance the effectiveness of two-phase flow cleaning processes applied in spiral-wound membrane elements and suggest the optimum operating conditions for larger scales. Fig. 1.7 summarizes the research outline presented in this thesis.

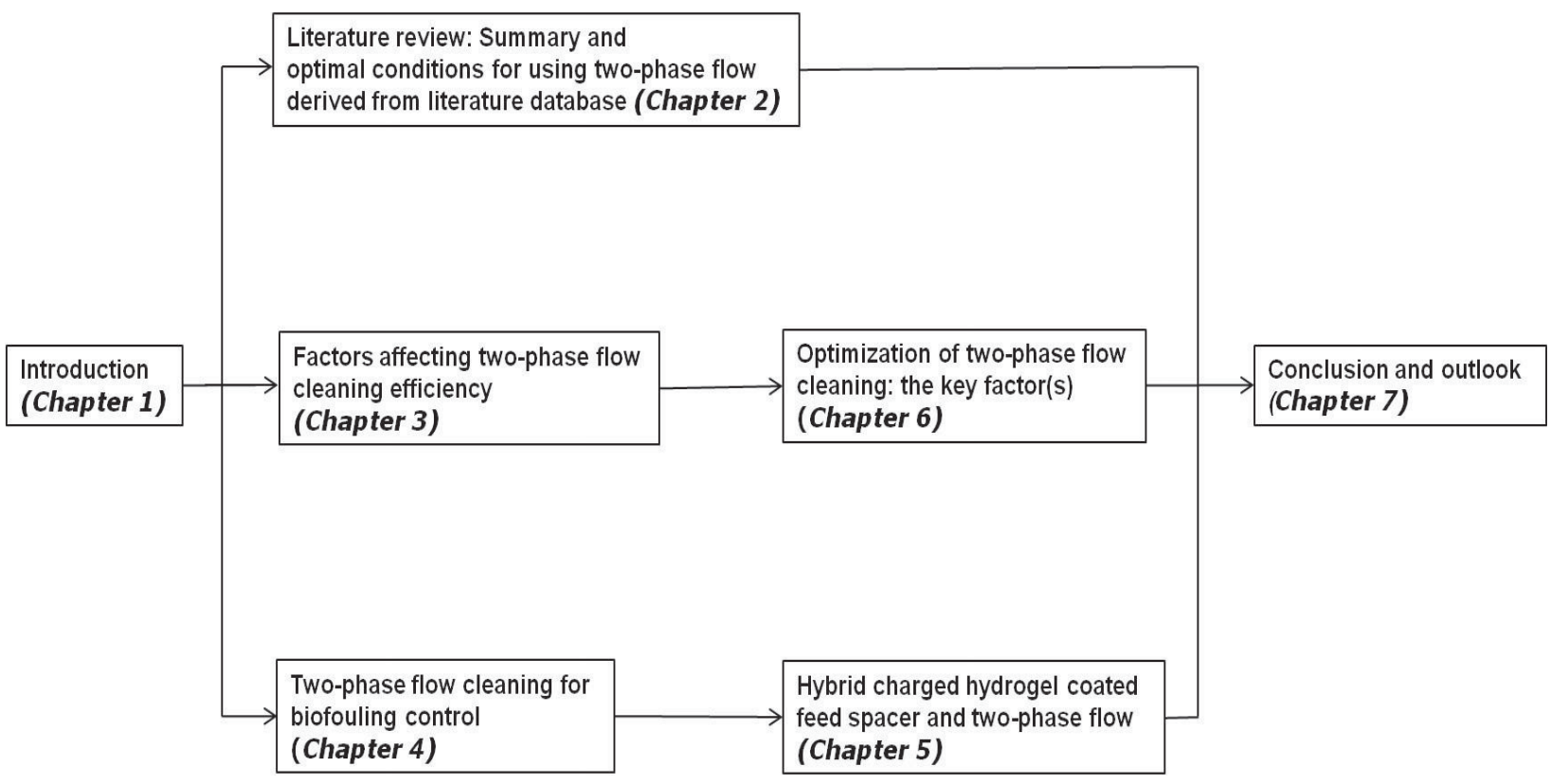

Fig. 1.7. Outline of the research presented in the thesis.

In Chapter 2, a critical and comprehensive literature study on the use of two-phase flow in membrane processes is presented. This chapter extensively describes the basic concepts of the two-phase flow process, including flow patterns in tubular and in closely spaced rectangular channels, the effect of impurities on the motion of bubbles in the membrane feed channels. A summary of more than 25 years of application of two-phase flow in membrane processes is also presented, followed by an analysis of normalized data from the literature database and a discussion of the effect of various variables (gas and liquid velocities, gas/liquid ratio, hydraulic diameter, trans-membrane pressure, and feed type) on the performance of two-phase flow cleaning processes (flux, pressure drop and rejection recoveries). A brief overview of some recent commercial applications of two-phase flow membrane processes concludes this chapter. 
Chapter 3 describes the key factors that control the effectiveness of two-phase flow cleaning, i.e. feed spacer geometry, feed type, gas/liquid ratio and liquid superficial velocity. Two types of model foulants are used, as representative for organic and rigid particle fouling. High-speed camera observation is used to measure bubble shape, distribution and velocity during two-phase flow cleaning processes.

Chapter 4 focuses on the use of two-phase flow cleaning to control biofouling in spiralwound membrane elements. In this study, the role of feed spacer geometry, feed pressure, gas/liquid ratio, cleaning duration, and liquid velocity are investigated. Optical coherence tomography (OCT) is used to investigate the structure of the biofouling and its removal using two-phase flow cleaning.

In Chapter 5, the potential of two-phase flow cleaning to control biofouling is tested using modified feed spacers. The effect of a charged coating (positive, negative and neutral) on biofouling growth and removal is investigated. This hybrid platform is expected to deliver improved biofouling control in spiral-wound membrane elements.

Chapter 6 presents an optimization study to obtain the most important factor(s) contributing to the two-phase flow cleaning efficiency. The application of a design of experiments (DOE) approach using a Taguchi method of orthogonal arrays is presented. Five levels of each of the four parameters studied (feed spacer geometry, feed types, gas/liquid ratio, feed velocity) are investigated and the key factors are presented.

Finally in Chapter 7, a conclusion of this work is presented. This is followed by an outlook in which suggestions for further studies to enhance the performance of two-phase flow cleaning in spiral wound membrane elements are given.

\section{References}

[1] P.H. Gleick, Basic water requirements for human activities: meeting basic needs, Water International, 21 (1996) 83-92.

[2] M.A. Shannon, P.W. Bohn, M. Elimelech, J.G. Georgiadis, B.J. Marinas, A.M. Mayes, Science and technology for water purification in the coming decades, Nature, 452 (2008) 301-310.

[3] C. Fritzmann, J. Löwenberg, T. Wintgens, T. Melin, State-of-the-art of reverse osmosis desalination, Desalination, 216 (2007) 1-76.

[4] L.F. Greenlee, D.F. Lawler, B.D. Freeman, B. Marrot, P. Moulin, Reverse osmosis desalination: Water sources, technology, and today's challenges, Water Research, 43 (2009) 2317-2348.

[5] L. Camacho, L. Dumée, J. Zhang, J.-d. Li, M. Duke, J. Gomez, S. Gray, Advances in Membrane Distillation for Water Desalination and Purification Applications, Water, 5 (2013) 94-196. 
[6] N. Hilal, H. Al-Zoubi, N.A. Darwish, A.W. Mohammad, M. Abu Arabi, A comprehensive review of nanofiltration membranes: Treatment, pretreatment, modelling, and atomic force microscopy, Desalination, 170 (2004) 281-308.

[7] J. Schwinge, P.R. Neal, D.E. Wiley, D.F. Fletcher, A.G. Fane, Spiral wound modules and spacers: Review and analysis, Journal of Membrane Science, 242 (2004) 129-153.

[8] P.L. Riley, C.E. Milstead, A.L. Lloyd, M.W. Seroy, M. Tagami, Spiral-wound thin-film composite membrane systems for brackish and seawater desalination by reverse osmosis, Desalination, 23 (1966) 331-355.

[9] T. Peters, Membrane Technology for Water Treatment, Chemical Engineering \& Technology, 33 (2010) 1233-1240.

[10] Y. Saif, A. Almansoori, A. Elkamel, Optimal design of split partial second pass reverse osmosis network for desalination applications, AIChE Journal, 60 (2014) 520-532.

[11] W.G.J. van der Meer, C.W. Aeijelts Averink, J.C. van Dijk, Mathematical model of nanofiltration systems, Desalination, 105 (1996) 25-31.

[12] W.G.J. van der Meer, M. Riemersma, J.C. van Dijk, Only two membrane modules per pressure vessel? Hydraulic optimization of spiral-wound membrane filtration plants, Desalination, 119 (1998) 57-64.

[13] T.J. Larson, Reverse osmosis pilot plant operation: A spiral module concept, Desalination, 7 (1970) 187-199.

[14] W.J. Koros, Y.H. Ma, T. Shimidzu, Terminology for membranes and membrane processes (IUPAC Recommendations 1996), Pure and Applied Chemistry, 68 (1996) 1479.

[15] B. Van Der Bruggen, C. Vandecasteele, T. Van Gestel, W. Doyen, R. Leysen, A review of pressure-driven membrane processes in wastewater treatment and drinking water production, Environmental Progress, 22 (2003) 46-56.

[16] S. Lee, C.H. Lee, Scale formation in NF/RO: mechanism and control, Water Science \& Technology, 51 (2005) 267-275.

[17] H.-C. Flemming, Reverse osmosis membrane biofouling, Experimental Thermal and Fluid Science, 14 (1997) 382-391.

[18] D. Paul, A.R.M. Abanmy, Reverse osmosis membrane fouling-the final frontier, Ultra Pure Water, 7 (1990) 25-36.

[19] H.C. Flemming, G. Schaule, T. Griebe, J. Schmitt, A. Tamachkiarowa, Biofouling - The Achilles heel of membrane processes, Desalination, 113 (1997) 215-225.

[20] B. Van der Bruggen, M. Manttari, M. Nystrom, Drawbacks of applying nanofiltration and how to avoid them: A review, Sep. Purif. Technol., 63 (2008) 251-263.

[21] J.S. Vrouwenvelder, D.A. Graf von der Schulenburg, J.C. Kruithof, M.L. Johns, M.C.M. van Loosdrecht, Biofouling of spiral-wound nanofiltration and reverse osmosis membranes: A feed spacer problem, Water Research, 43 (2009) 583-594.

[22] G. Trägårdh, Membrane cleaning, Desalination, 71 (1989) 325-335.

[23] W.A.M. Hijnen, C. Castillo, A.H. Brouwer-Hanzens, D.J.H. Harmsen, E.R. Cornelissen, D. van der Kooij, Quantitative assessment of the efficacy of spiral-wound membrane cleaning procedures to remove biofilms, Water Research, 46 (2012) 6369-6381.

[24] D. Kim, S. Jung, J. Sohn, H. Kim, S. Lee, Biocide application for controlling biofouling of SWRO membranes - an overview, Desalination, 238 (2009) 43-52.

[25] A. Bridier, R. Briandet, V. Thomas, F. Dubois-Brissonnet, Resistance of bacterial biofilms to disinfectants: a review, Biofouling, 27 (2011) 1017-1032.

[26] S.A. Creber, J.S. Vrouwenvelder, M.C.M. van Loosdrecht, M.L. Johns, Chemical cleaning of biofouling in reverse osmosis membranes evaluated using magnetic resonance imaging, Journal of Membrane Science, 362 (2010) 202-210.

[27] L.A. Bereschenko, H. Prummel, G.J.W. Euverink, A.J.M. Stams, M.C.M. van Loosdrecht, Effect of conventional chemical treatment on the microbial population in a biofouling layer of reverse osmosis systems, Water Research, 45 (2011) 405-416.

[28] Y. Wibisono, E.R. Cornelissen, A.J.B. Kemperman, W.G.J. van der Meer, K. Nijmeijer, Twophase flow in membrane processes: A technology with a future, Journal of Membrane Science, 453 (2014) 566-602. 
[29] E.R. Cornelissen, J.S. Vrouwenvelder, S.G.J. Heijman, X.D. Viallefont, d.K.D. van, L.P. Wessels, Air/water cleaning for biofouling control in spiral wound membrane elements, Desalination, 204 (2007) 145-147.

[30] E.R. Cornelissen, J.S. Vrouwenvelder, S.G.J. Heijman, X.D. Viallefont, D. Van Der Kooij, L.P. Wessels, Periodic air/water cleaning for control of biofouling in spiral wound membrane elements, Journal of Membrane Science, 287 (2007) 94-101.

[31] E.R. Cornelissen, X.D. Viallefont, E.F. Berendonk, L.P. Wessels, Air/water cleaning for control of particulate fouling, J. Water Supply Res. Technol. AQUA, 59 (2010) 120-127. 


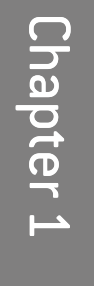




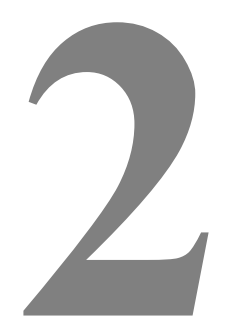

\title{
Two-phase flow in membrane processes: A critical review
}

\author{
Y. Wibisono \\ E.R. Cornelissen \\ A.J.B. Kemperman \\ W.G.J. van der Meer \\ K. Nijmeijer
}

This chapter is based on:

Y. Wibisono, E.R. Cornelissen, A.J.B. Kemperman, W.G.J. van der Meer, K. Nijmeijer,

Two-phase flow in membrane processes: A technology with a future, Journal of Membrane Science, http://dx.doi.org/10.1016/j.memsci.2013.10.072 


\begin{abstract}
Worldwide, the application of a (gas/liquid) two-phase flow in membrane processes has received ample scientific deliberation because of its potential to reduce concentration polarization and membrane fouling, and therefore enhance membrane flux. Gas/liquid flows are now used to promote turbulence and instabilities inside membrane modules in various membrane processes such as microfiltration, ultrafiltration, nanofiltration, reverse osmosis, membrane distillation, electrodialysis, and membrane bioreactors. This chapter provides a comprehensive and critical literature review of the state of the art in this research area. A total of 205 scientific papers published in peer-reviewed journals from 1989 to 2013 were collected. The data in 195 of these papers (published up to 2011) were compiled and analyzed. These data were analyzed and normalized based on gas and liquid superficial velocities, gas/liquid ratio and feed types, trans-membrane pressure and membrane module type in order to make a fair comparison and identify general characteristics. The objective was to identify key factors in the application of two-phase flows in aqueous separation and purification processes, deliver new insights in how to optimize operations for implementation of this technology in the industry, discuss the importance of energy saving, provide a brief overview of current commercial applications and suggest future directions for research.
\end{abstract}




\subsection{Introduction}

Demands for sufficient clean water are foreseen to increase rapidly in the coming decades. Membrane technology provides robust solutions in the purification and treatment of groundwater, wastewater and saline water, such as required for environmental reasons and in agriculture [1]. Overarching impacts for maintaining clean water are securing drinking water, food, energy and industrial productions [2].

Membrane processes in aqueous applications can be grouped according to the applied driving forces: (1) pressure-driven processes, namely micro-, ultra-, and nanofiltration as well as reverse osmosis, (2) concentration-driven processes, namely dialysis and forward osmosis, (3) processes driven by an electrical potential, i.e. electrodialysis, (4) processes driven by partial pressure and vapor pressure, namely pervaporation and membrane distillation, and finally (5) processes driven by differences in chemical potential, e.g. supported liquid membranes, membrane contactors, and membrane reactors. The mechanism of transport through a membrane can also be very different. For example for porous membranes, solvent transport through the membrane pores occurs under a hydrostatic pressure difference between two phases; the solutes that are larger than the pores are rejected (sieving mechanism). Typical solute sizes in the feed mixtures handled by pressure-driven membrane processes are 0.01-0.001 $\mu \mathrm{m}$ for nanofiltration, $0.2-0.005 \mu \mathrm{m}$ for ultrafiltration and 10-0.1 $\mu \mathrm{m}$ for microfiltration. In dense membranes, separation of various components in a mixture is determined by their diffusivity and solubility in the membrane matrix as caused by pressure, concentration or chemical potential gradients. If the membrane has electrical charges, separation is achieved mainly by exclusion of ions of the same charge as the fixed ions of the membrane structure [3]. Table 2.1 summarizes common membrane processes in aqueous applications with regard to membrane type, driving force, transport mechanism and areas of application.

Table 2.1. Membrane processes in aqueous applications, adapted after [4].

\begin{tabular}{|l|l|l|l|l|}
\hline $\begin{array}{l}\text { Membrane } \\
\text { process }\end{array}$ & Membrane type & Driving force & $\begin{array}{l}\text { Transport } \\
\text { mechanism }\end{array}$ & Applications \\
\hline Microfiltration & $\begin{array}{l}\text { symmetric porous } \\
\text { membrane, pore } \\
\text { radius: } 0.1-10 \mu \mathrm{m}\end{array}$ & $\begin{array}{l}\text { hydrostatic } \\
\text { pressure, } 0.05- \\
0.2 \mathrm{MPa}\end{array}$ & $\begin{array}{l}\text { sieving (size } \\
\text { exclusion) }\end{array}$ & $\begin{array}{l}\text { water purification, } \\
\text { sterilization, } \\
\text { concentrating } \\
\text { process }\end{array}$ \\
\hline Ultrafiltration & $\begin{array}{l}\text { asymmetric porous } \\
\text { membranes, pore } \\
\text { radius: } 2-10 \mathrm{~nm}\end{array}$ & $\begin{array}{l}\text { hydrostatic } \\
\text { pressure, } 0.1- \\
0.5 \mathrm{MPa}\end{array}$ & $\begin{array}{l}\text { sieving (size } \\
\text { exclusion) }\end{array}$ & $\begin{array}{l}\text { separation of } \\
\text { molecular mixtures }\end{array}$ \\
\hline
\end{tabular}




\begin{tabular}{|c|c|c|c|c|}
\hline Diafiltration & $\begin{array}{l}\text { asymmetric porous } \\
\text { structure, pore } \\
\text { radius } 2-10 \mathrm{~nm}\end{array}$ & $\begin{array}{l}\text { hydrostatic } \\
\text { pressure, } 0.1- \\
0.5 \mathrm{MPa}\end{array}$ & $\begin{array}{l}\text { sieving (size } \\
\text { exclusion) and } \\
\text { dialysis }\end{array}$ & $\begin{array}{l}\text { purification of } \\
\text { molecular mixtures, } \\
\text { artificial kidney }\end{array}$ \\
\hline Reverse osmosis & $\begin{array}{l}\text { asymmetric skin- } \\
\text { type solution- } \\
\text { diffusion } \\
\text { membrane }\end{array}$ & $\begin{array}{l}\text { hydrostatic } \\
\text { pressure, } 1- \\
10 \mathrm{MPa}\end{array}$ & $\begin{array}{l}\text { solution and } \\
\text { diffusion }\end{array}$ & $\begin{array}{l}\text { desalination of } \\
\text { seawater and } \\
\text { brackish water }\end{array}$ \\
\hline Forward osmosis & $\begin{array}{l}\text { thin film } \\
\text { composite } \\
\text { membrane }\end{array}$ & $\begin{array}{l}\text { concentration } \\
\text { gradient }\end{array}$ & $\begin{array}{l}\text { solution and } \\
\text { diffusion }\end{array}$ & $\begin{array}{l}\text { pressure retarded } \\
\text { osmosis, water } \\
\text { desalination }\end{array}$ \\
\hline Dialysis & $\begin{array}{l}\text { symmetric porous } \\
\text { membrane }\end{array}$ & $\begin{array}{l}\text { concentration } \\
\text { gradient }\end{array}$ & diffusion & artificial kidney \\
\hline Electrodialysis & $\begin{array}{l}\text { symmetric ion- } \\
\text { exchange } \\
\text { membrane }\end{array}$ & $\begin{array}{l}\text { electrical } \\
\text { potential }\end{array}$ & $\begin{array}{l}\text { Donnan } \\
\text { exclusion }\end{array}$ & $\begin{array}{l}\text { acid and base } \\
\text { production }\end{array}$ \\
\hline $\begin{array}{l}\text { Electrodialytic } \\
\text { water splitting }\end{array}$ & bipolar membrane & $\begin{array}{l}\text { electrical } \\
\text { potential }\end{array}$ & $\begin{array}{l}\text { Donnan } \\
\text { exclusion }\end{array}$ & $\begin{array}{l}\text { acid and base } \\
\text { production }\end{array}$ \\
\hline $\begin{array}{l}\text { Membrane } \\
\text { distillation }\end{array}$ & $\begin{array}{l}\text { symmetric porous } \\
\text { hydrophobic } \\
\text { membrane }\end{array}$ & vapor pressure & diffusion & $\begin{array}{l}\text { liquid - solid } \\
\text { separation }\end{array}$ \\
\hline $\begin{array}{l}\text { Membrane } \\
\text { contactors }\end{array}$ & $\begin{array}{l}\text { symmetric porous } \\
\text { or liquid } \\
\text { membrane }\end{array}$ & chemical potential & $\begin{array}{l}\text { diffusion and } \\
\text { solution }\end{array}$ & solvent extraction \\
\hline $\begin{array}{l}\text { Membrane } \\
\text { reactor }\end{array}$ & $\begin{array}{l}\text { homogeneous or } \\
\text { porous membrane }\end{array}$ & chemical potential & $\begin{array}{l}\text { selective } \\
\text { sorption and } \\
\text { diffusion }\end{array}$ & $\begin{array}{l}\text { wastewater } \\
\text { treatment, selective } \\
\text { oxidation }\end{array}$ \\
\hline Liquid membrane & $\begin{array}{l}\text { porous support } \\
\text { membrane wetted } \\
\text { by organic liquid }\end{array}$ & chemical potential & $\begin{array}{l}\text { diffusion and } \\
\text { reversible } \\
\text { reaction }\end{array}$ & $\begin{array}{l}\text { removal and } \\
\text { recovery of metals } \\
\text { and antibiotics }\end{array}$ \\
\hline Pervaporation & $\begin{array}{l}\text { homogeneous } \\
\text { asymmetric } \\
\text { membrane }\end{array}$ & vapor pressure & $\begin{array}{l}\text { solution and } \\
\text { diffusion }\end{array}$ & $\begin{array}{l}\text { separation of } \\
\text { azeotropic mixtures }\end{array}$ \\
\hline
\end{tabular}

Membrane processes in aqueous applications, especially those in pressure-driven processes, suffer from solute buildup on the membrane wall (i.e. concentration polarization) and membrane fouling [5]. Concentration polarization is the development of a concentration gradient across the boundary layer near the membrane surface [6]. The concentration gradient occurs due to a difference in mass transport between bulk solution and membrane. In pressure-driven membrane processes, a concentration profile develops because of the accumulation of mass at the membrane wall, as the mass transport through the membrane is slower than in the bulk. In other membrane processes in which transport across the membrane occurs by diffusion rather than by convection, e.g. pervaporation or dialysis, a concentration profile develops because of a decrease of mass at the membrane wall because transport through the membrane is faster than in the bulk [7]. Another critical issue of membrane processes in aqueous applications is membrane fouling, which can be distinguished into 20 
inorganic, particulate, microbial and organic fouling [8-10]. Fouling causes deposits on the membrane surface or blocks the pores, thereby limiting permeation. Fouling results in an increasing pressure drop over the membrane and an uneven flow distribution over the total membrane surface; this leads to increased energy consumption, lower production and therefore higher operating costs. Fouling also requires the use of chemicals to clean the membrane, which in turn deteriorates the membrane and lowers its lifetime. To overcome this problem, a great deal of research in membrane process technology took place, next to progress in developments in membrane material and membrane surface modifications, e.g. tangential-flow instead of dead-end filtration [11, 12], operation below critical flux [13], promotion of instabilities in the flow by using a secondary flow or turbulence promoters [1416], dynamic filtration by moving parts or by vibrations [17] and inducing multiphase flow inside membrane elements. The term multiphase is used to refer to any fluid consisting of two or more phases, i.e. solid, liquid, and gas, moving together in a conduit [18]. In membrane processes, gas-liquid two-phase flow [19] and gas-liquid-solid three-phase flow are used to enhance flux and rejection. However, the use of solid (ion-exchange resin) particles in threephase flow is likely to encourage clogging of membrane flow channels, and these particles are also difficult to remove from the membrane module [20]. Although the use of granulate material to abrade fouling layers appears to be effective as flux enhancer, it also carries a high risk of damage to the membrane sheet in e.g. membrane bioreactor (MBR) applications [21]. On the other hand, a gas-liquid two-phase flow is easy to discharge at the upstream side, and there is less chance of clogging; moreover, the gas bubbles promote secondary flows when they are applied in membrane channels.

In 2003, Cui et al. [22] published a thorough review of the use of gas bubbles to enhance membrane processes. Since then, a vast body of literature on the use of two-phase flow in membrane processes has appeared. In the last decade, a significant amount of papers on this topic has been published as shown in Fig. 2.1, with on average sixteen papers published every year.

Scientists from more than sixteen countries/regions contributed to these peer-reviewed papers, as shown in Fig. 2.2. Two-phase flow research is predominantly carried out in the UK, France, China (including Taiwan), North America (US and Canada) and the Netherlands. The early research on two-phase flow in cross-flow filtration was done in Japan, the UK dominated by the research group of Cui at Oxford University, and Cabassud and coworkers at 
INSA Toulouse, France. These latter two groups share about 25 research papers, covering mostly MF and UF processes. However, there is a distinction between their research, with the coverage of CFD simulation by Cui's group [23-25], and the broader scope of application in NF and capillary membranes by Cabassud's group [26-30]. The group of Taiwan's Tamkang University studied the effect of module position (inclination) in two-phase flow MF or UF [31-42], and researchers in Mainland China mostly worked on MBR aeration [43-48]. The application of two-phase flow in MBR aeration has been extensively reported by the research of Judd et al. at Cranfield University in the UK [49-54], by Fane's group, both formerly at UNSW in Australia [55-61] and currently at NTU in Singapore [62-66], by Psoch et al. in the USA [67-73], and by Canadian groups [74-79]. The Dutch researchers joined the MBR aeration research field with groups in Wageningen [80-86]. At KWR and later also at the University of Twente (in the Membrane Science and Technology group) the application of two-phase flow in high-pressure membrane processes (nanofiltration and reverse osmosis) using spiral-wound membrane modules was investigated [87-93].

Because of this fast developing field, a new comprehensive and critical review of recent developments in the use of two-phase flow in membrane processes is essential.

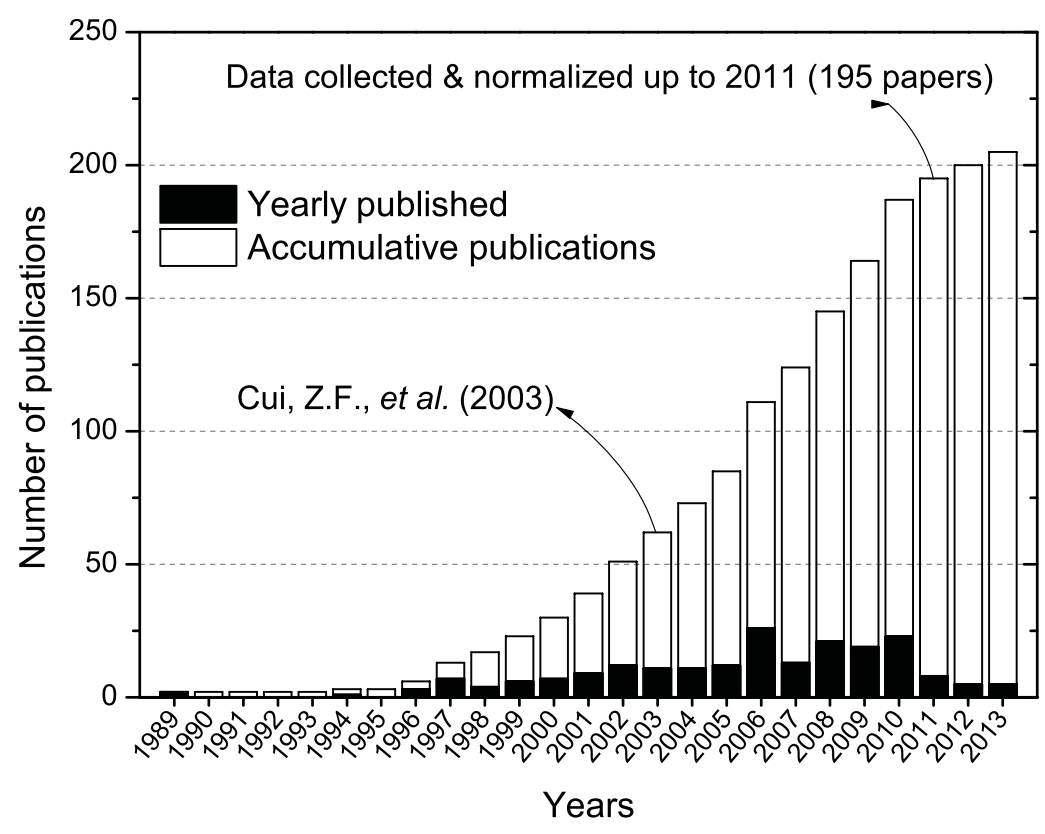

Fig. 2.1. Peer-reviewed papers on the topic of two-phase flow in membrane processes, from 1989 to 2013 (up to March 2013). 


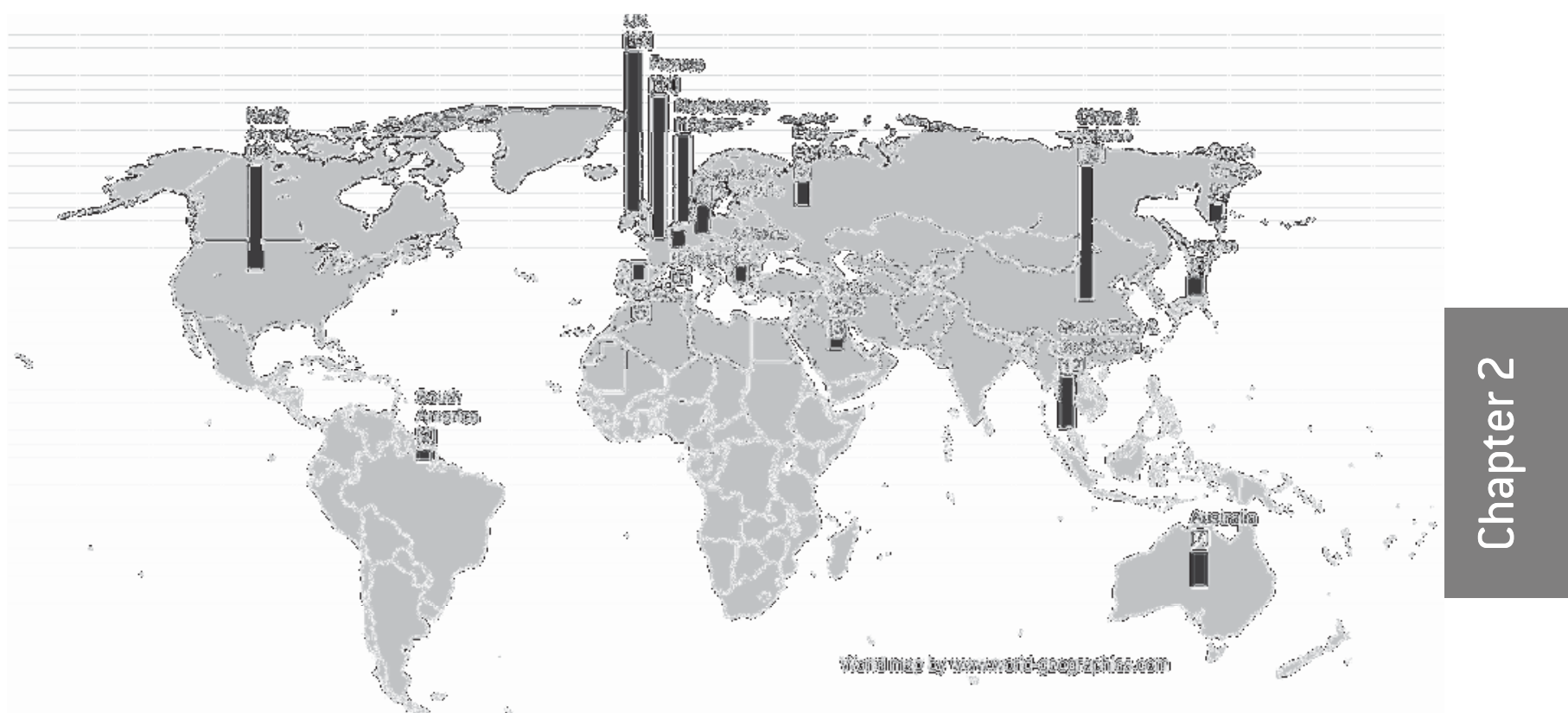

Fig. 2.2. Worldwide research on application of two-phase flow in membrane processes up to 2011; numbers within square brackets show the number of publications from the region/ country.

We performed such an extensive literature study and the results are summarized in this review chapter. We performed our literature research with the aid of the bibliographic software tool EndNote and three science-specific search engines, namely Scifinder, Scopus and Scirus. Dominant keywords we used were: air sparging, gas sparging, air flush, air scour, two-phase flow, gas-liquid flow, aeration, bubble flow, air/water cleaning (all combined with "membrane processes"). We collected 205 scientific papers published in peer-reviewed journals between 1989 and 2013 (up to March 2013) and we analyzed the data from 195 of these papers (published up to 2011).

The 25 years' experience as reported in the literature shows that two-phase flow is widely used in both submerged applications, for instance in MBRs (which employ micro- or ultrafiltration membranes) and non-submerged membrane processes, for instance in microfiltration (MF), ultrafiltration (UF), nanofiltration (NF), reverse osmosis (RO), membrane distillation (MD), and electrodialysis (ED). We normalized the data we collected in our database on the basis of two aspects: (i) embedded variables (membrane pore size, feed type and concentration, gas type); and (ii) process parameters (module position, flow direction, gas/liquid ratio, and trans-membrane pressure) as possible factors that enhance performance (flux/rejection/selectivity) (see Fig. 2.3). 
The final aim of our analysis was to identify key factor(s) in two-phase flow in aqueous separation and purification, and provide the fundamental understanding of this technology required to obtain optimal parameter(s) in two-phase flow of membrane modules.

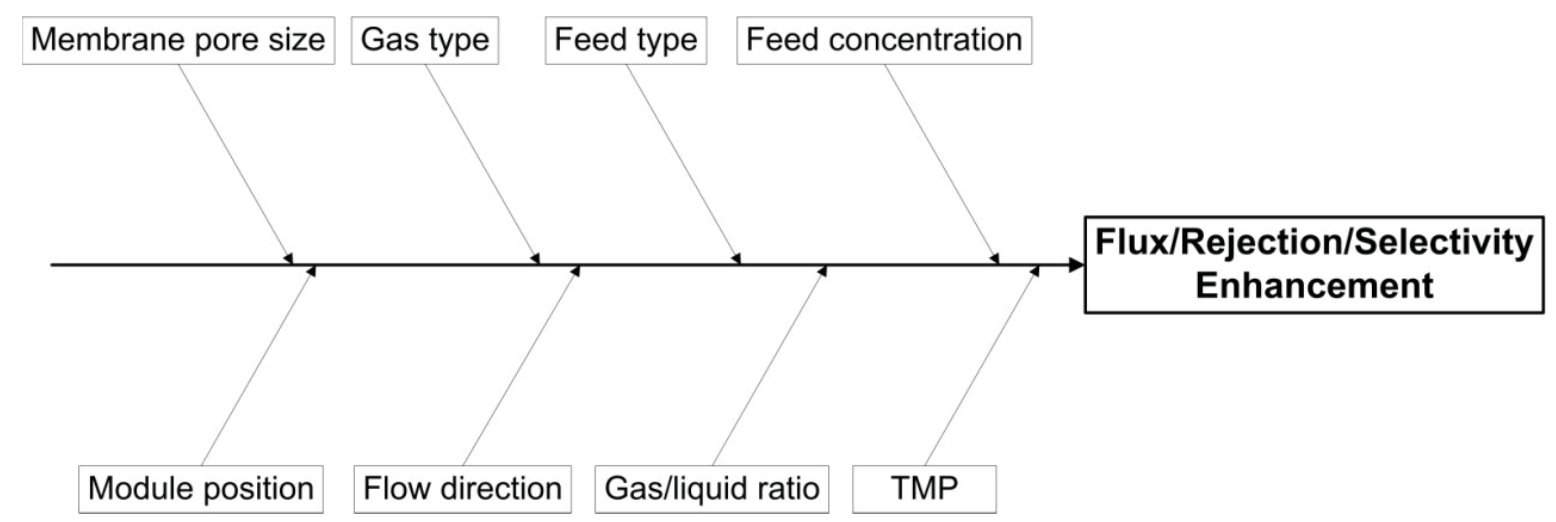

Fig. 2.3. Variables in two-phase flow in membrane processes.

This review chapter consists of six sections, and is organized as follows:

Section 2.2 focuses on the basic concepts of the two-phase flow process, including flow patterns in tubular channels (tubular or hollow-fiber membranes) and in closely spaced rectangular channels (applicable for flat-sheet or spiral-wound membranes). This section also describes the effect of impurities (particles and dissolved surface active solutes) on the motion of gas bubbles in the channels, and on membrane processes. Section 2.3 summarizes the application of two-phase flow in various membrane processes in order to enhance process outcomes, i.e. flux, rejection, selectivity and minimize pressure drops. A concise list of twophase flow techniques collected from the literature is also presented.

Section 2.4 presents an analysis of normalized data from the database and discusses the effect of gas and liquid velocities, gas/liquid ratio, hydraulic diameter, trans-membrane pressure, and feed type on flux, pressure drop and rejection. Section 2.5 briefly describes current industrial applications of this technology, focused on membrane bioreactors and the drinking water industry. Section 2.6 gives a summary of the review and provides a perspective on two-phase flow in membrane processes. 


\subsection{Two-phase flow in membrane elements}

\subsubsection{Introduction}

Unlike single-phase flow, one of the typical distinctions of two-phase flows is that they often create instabilities within the flow. The instabilities that may occur are caused by channel geometries, operating conditions (pressure, temperature, flow rate, and flow frequency), and boundary conditions (interfacial tension) [94].

In membrane processes, gas-liquid two-phase flow is intentionally used to create hydrodynamic instabilities in the channels. These instabilities disturb concentration polarization, sweep away formed cake and remove biofouling from membrane surfaces or the feed spacers in spiral-wound membrane elements. The flow instabilities and gas-liquid exchange processes rely on size and spatial distribution of the bubbles [95]. Furthermore, the geometric distribution of the phases (flow pattern) is an important consideration that determines the efficiency of the two-phase flow. Additionally, as aqueous membrane processes are mostly used for the filtration of fluids containing dissolved particles, such as to remove various colloidal impurities from regular water or wastewater [96], also the effect of dissolved surface-active agents on bubble shape, size and mobility needs to be considered. Finally, when gas and liquid are in contact with each other in a two-phase flow, the boundary between them is influenced by physical effects, such as inertia, capillary forces or shear [97].

\subsubsection{Two-phase flow patterns}

In two-phase flow, mass, momentum, and energy transfer processes and as such the effectiveness of the two-phase flow, are very sensitive to the geometric distribution or topology of the components within the flow [98]. The geometric distribution depends on the volume fraction of gas and liquid, the velocity differences between the phases, the fluid properties, and slip velocity (the velocity of the gas phase relative to that of the liquid phase) because of the geometry of the channel [99]; however, it is not merely a matter of laminar or turbulent flow [100].

A specific type of geometric distribution of the phases (gas and liquid) is called a flow pattern. The characterization of and transitions between flow patterns are often presented in the form 
of a flow pattern map using dimensional coordinates (such as superficial gas and liquid velocities) or non-dimensional parameters with generalized coordinates [101]. However, such generalizations only have a limited value as several transitions are present in most flow pattern maps but the corresponding instabilities are governed by different sets of fluid properties [98].

In membrane processes, bubbles form in stagnant liquids (in submerged/airlift membrane systems) and in flowing liquids (non-submerged membrane processes). The operational modes of the flowing gas/liquid in membrane processes based on the direction of the gas flow, as adapted from [102], can be described as follows:

- Co-current flow: Gas and liquid flow in the same direction. Application: aeration in membrane bioreactors [69], air sparging in spiral-wound modules [87, 88], air sparging (vertically upward and downward) in flat-sheet or tubular microfiltration (MF) and ultrafiltration (UF) [103].

- Counter-current flow: Gas flows in the opposite direction as the liquid. Application: membrane contactors and membrane distillation [104].

A very large quantity of literature on experimental and theoretical work has been published for co-current flow of gases and liquids in vertical (upward), horizontal, and inclined pipes, with relatively little work on countercurrent and co-current vertical downward flows [100, $101,105]$ and also fewer studies of flows in narrow rectangular channels $[106,107]$. Table 2.2 depicts basic models of fully-developed flow patterns in tubular and rectangular narrow channels, both in vertical upward flow and horizontal channel orientation. The illustrations show different flow patterns as a function of liquid superficial velocities $\left(u_{L}\right)$ and gas/liquid ratio $\left(\theta=\frac{u_{G}}{u_{L}+u_{G}}\right)$. Each flow pattern is numbered; its description is included in the table.

In co-current vertical upward tubular channels, the following flow patterns can be distinguished for fully developed gas-liquid flows [101, 105]:

1. Bubble flow: The gas phase is approximately uniformly distributed as discrete bubbles in a continuous liquid phase, but with some tendency to concentrate toward the center of the pipe. 
2. Plug flow: The gas phase occurs in intermittent plugs or pistons with defined phase boundaries, sometimes designated as Taylor bubbles. Taylor bubbles are separated by slugs of continuous liquid which bridge the tube and contain small gas bubbles.

3. Slug flow: The gas phase moves as intermittent large bullet-shaped bubbles with less clear phase boundaries, with similar conditions as plug flow but with higher flow rates.

4. Churn flow: This is a more chaotic, frothy and disordered slug flow, in which bulletshaped Taylor bubbles become narrow and distorted. The continuity of the liquid in the slug between successive Taylor bubbles is repeatedly destroyed by a high local gas concentration in the slug.

5. Annular flow: The liquid phase moves as a continuous thick layer along the channel walls and the gas phase occupies the core of the channel; some droplets or small bubbles may be observed.

Flow patterns for fully developed gas-liquid flows in co-current horizontal tubular channels are described as follows [100, 105]:

6. Stratified smooth flow: The flow rates of the gas and liquid phase are relatively low, with the liquid flowing along the bottom of the tube and the gas flowing over a smooth liquid/gas interface.

7. Stratified wavy flow: This is similar to stratified flow, but with an increase of the gas flow rate; the liquid/gas interface is rippled or wavy.

8. Bubble flow: This is prevalent at high ratios of liquid flow rate to gas flow rate. The gas is dispersed as bubbles which move at a velocity similar to the liquid and tend to concentrate near the top of the tube at lower liquid velocities.

9. Plug flow: Alternate plugs of gas and liquid move along the upper part of the tube.

10. Slug flow: This is similar to plug flow, with alternate large bullet-shaped gas bubbles moving along the upper part of the tube. This can cause severe vibrations in the tube.

11. Annular flow: The liquid flows as a thin film along the tube wall and the gas flows in the core, while some liquid may be entrained as droplets in the gas core. 
Table 2.2. Models of basic flow patterns in tubular and rectangular narrow channels.

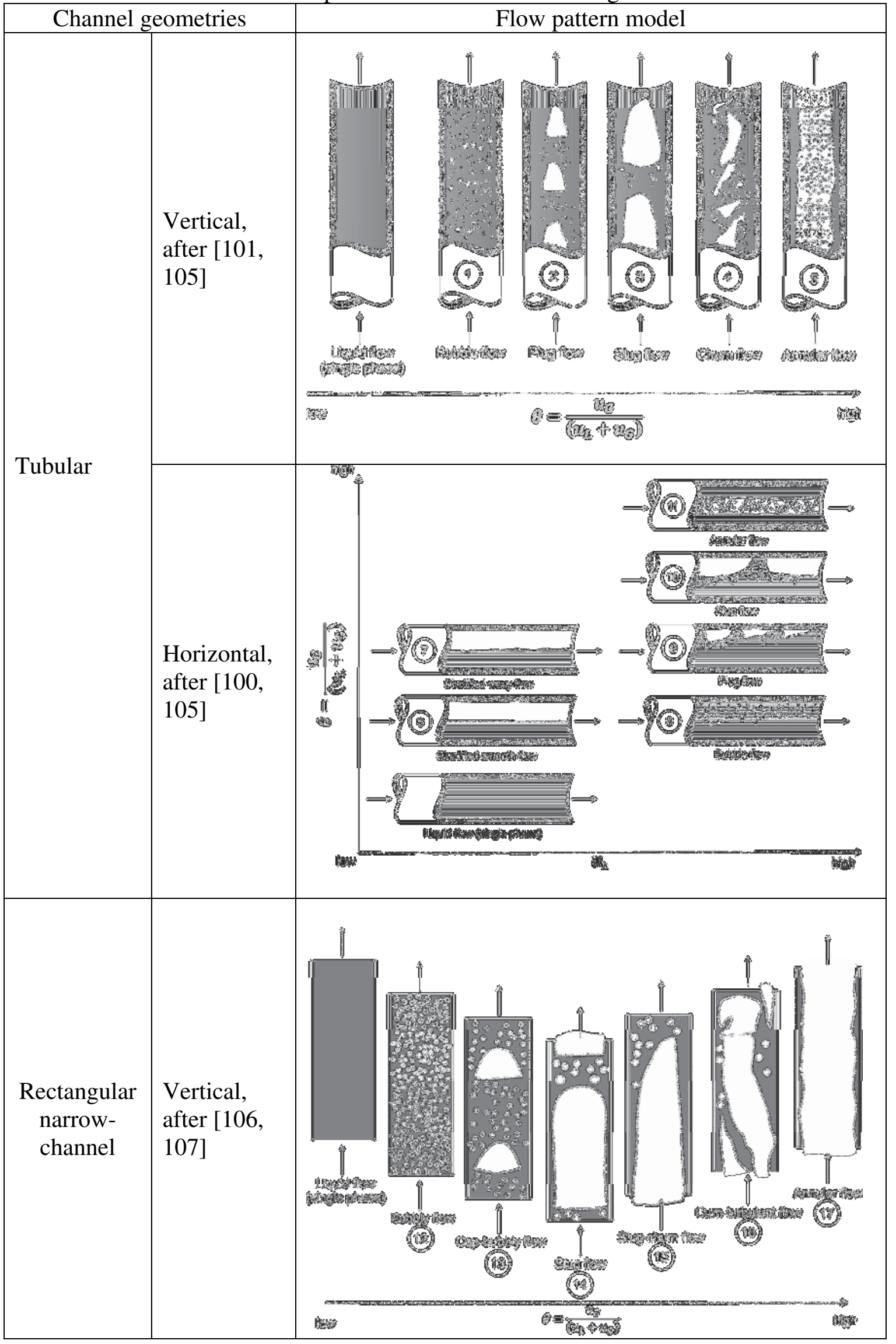




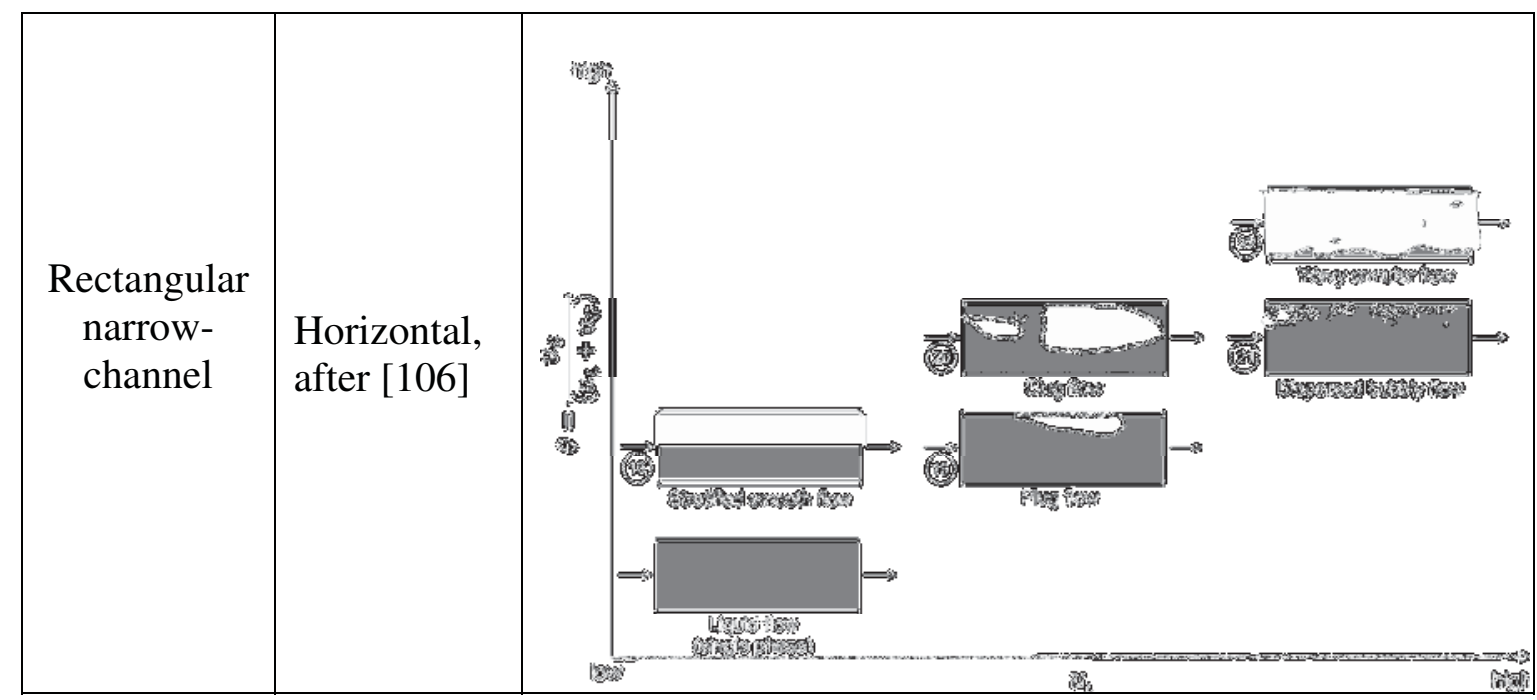

In co-current vertical upward rectangular narrow channels, the observed flow patterns for gas-liquid flow can be described as [106, 107]:

12. Bubbly flow: Small discrete bubbles are reasonably uniformly distributed in the axial direction in a continuous flowing liquid phase.

13. Cap-bubbly flow: As the gas flow rate increases, the confinement of the walls causes the growing bubbles to become flattened and distorted which makes them appear as small caps. Coalescence of bubbles may produce larger caps with widths up to $60 \%$ of the channel width.

14. Slug flow: Large Taylor bubbles with sizes of more than $75 \%$ of the channel width are separated by liquid slugs that bridge the channel section and often carry small bubbles.

15. Slug-churn flow: The individual slug bubbles begin to interact with one another, and each preceding wake deforms the smooth interface of the next slug. This causes the start of a churn-type action, but the individual slugs can still be identified.

16. Churn turbulent flow: This is similar to slug flow but is much more chaotic, frothy and disordered. The bullet-shaped slug bubbles become narrower and distorted until they are no longer recognizable.

17. Annular flow: This comprises a solid gaseous core, continuous in the axial direction, with a liquid film surrounding the core. 
Finally, in co-current horizontal rectangular narrow channels, the following flow patterns can be distinguished [106]:

18. Stratified smooth flow: The liquid flows along the bottom of the channel with a continuous gas flow along the top. No stratified wavy patterns visible.

19. Plug flow: Elongated smooth plugs of gas move along the top part of the channel. With greater liquid flows, the long gas slugs become smaller and have a large bulb at the front of the plug and a tail at the end.

20. Slug flow: At higher gas rates, the transition from stratified to slug flow has a more chaotic appearance with entrained bubbles mixed with the larger gas slugs. This flow is similar to the slug flow seen in vertical flows except that the liquid film on the bottom is slightly thicker than the film near the top of the channel.

21. Dispersed bubbly flow: Once the slug and plug bubbles break apart, they spread further throughout the channel section as the liquid flow rate increases.

22. Wavy annular flow: At very high gas velocities, the liquid film at the bottom of the channel section becomes rough and wavy; droplets are entrained in the gaseous core.

Flow patterns produce different bubble shapes as discussed above [108, 109]. Bubble shape, along with bubble size and distribution, are influenced by hydrodynamic forces e.g. drag, added-mass (the inertial force), buoyancy and shear-induced lift forces [110]. In order to enhance the wall shear stress on the membrane surface, slug bubbles are more efficient than dispersed bubbles [111]. In submerged membranes, however, bubble flow is more effective [112]. Since the flow pattern is related to the gas/liquid ratio, this ratio should be maintained such that slug or bubble flow occurs. If this ratio is too high, e.g. the annular flow pattern will be the dominant one, which is less effective.

\subsubsection{Influence of particles and dissolved surface active solutes}

Membrane processes in aqueous applications are mostly used to separate solid impurities (particles, possibly containing surface-active agents) or dissolved components from liquid suspensions. In order to enhance hydrodynamic instabilities, gas bubbles are used in the upstream side of the system, and experience impurities in the feed solutions as well. The 
above-described flow patterns are ideal and occur in clean water (Table 2.2.); however, liquids often contain dissolved solutes that can affect bubble motion and flow patterns (Fig. 2.4). Impurities lead to a decrease of the interfacial energy and interfacial tension and the bubble interface can become deformed in fluids that contain impurities, i.e. particles or surfactants (dissolved surface active solutes).

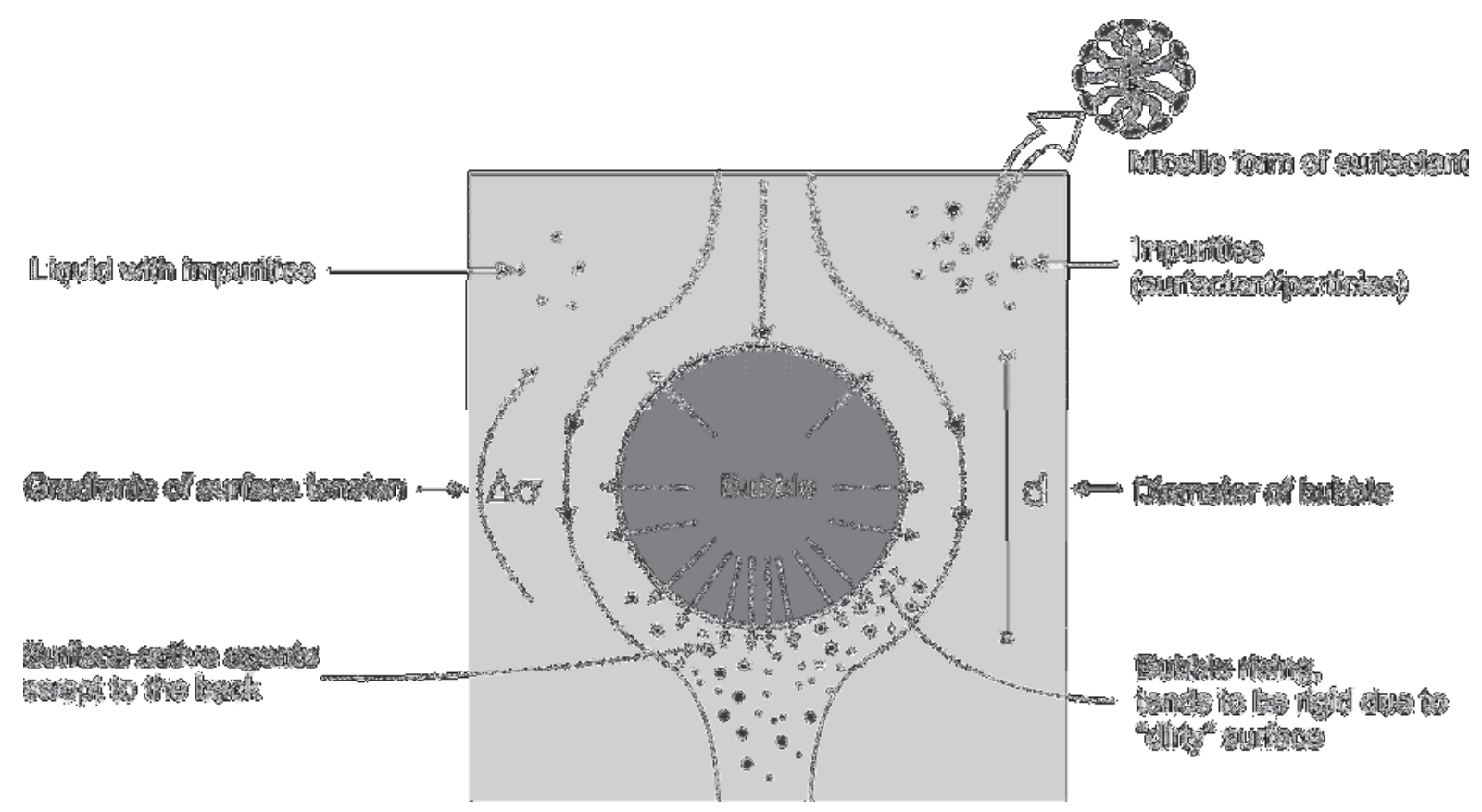

Fig. 2.4. Interface of rigid bubble formed by surface impurities, adapted from [113].

When rising in extremely clean fluids, small bubbles have very clean interfaces, and are mobile (rotating or circulating during rising). However, ultrapure liquids do not occur in practice and one must accept the presence of surface-active contaminants in most systems even though the amount of impurities may be so small that there is no measurable change in the bulk liquid properties [109]. As shown in Fig. 2.4, when a bubble rises through a stagnant liquid that contains impurities, shear forces move these surface impurities to the wake region of the bubble. This causes a gradient in the interfacial tension $(\sigma)$, which opposes the motion of the interface, and may slow down and even immobilize the bubble. Bubbles with a small diameter $(d)$ behave as rigid spheres when rising in a contaminated environment.

Bubbles with larger diameters behave differently; they rise faster and form either spherical caps or wobbling ellipsoidal shapes, depending on the cleanliness of the liquid bulk. 
Fig. 2.5 below gives a complete overview of bubble shape, size and behavior during rising, based on Hadamard-Rybezinsky theory [114].

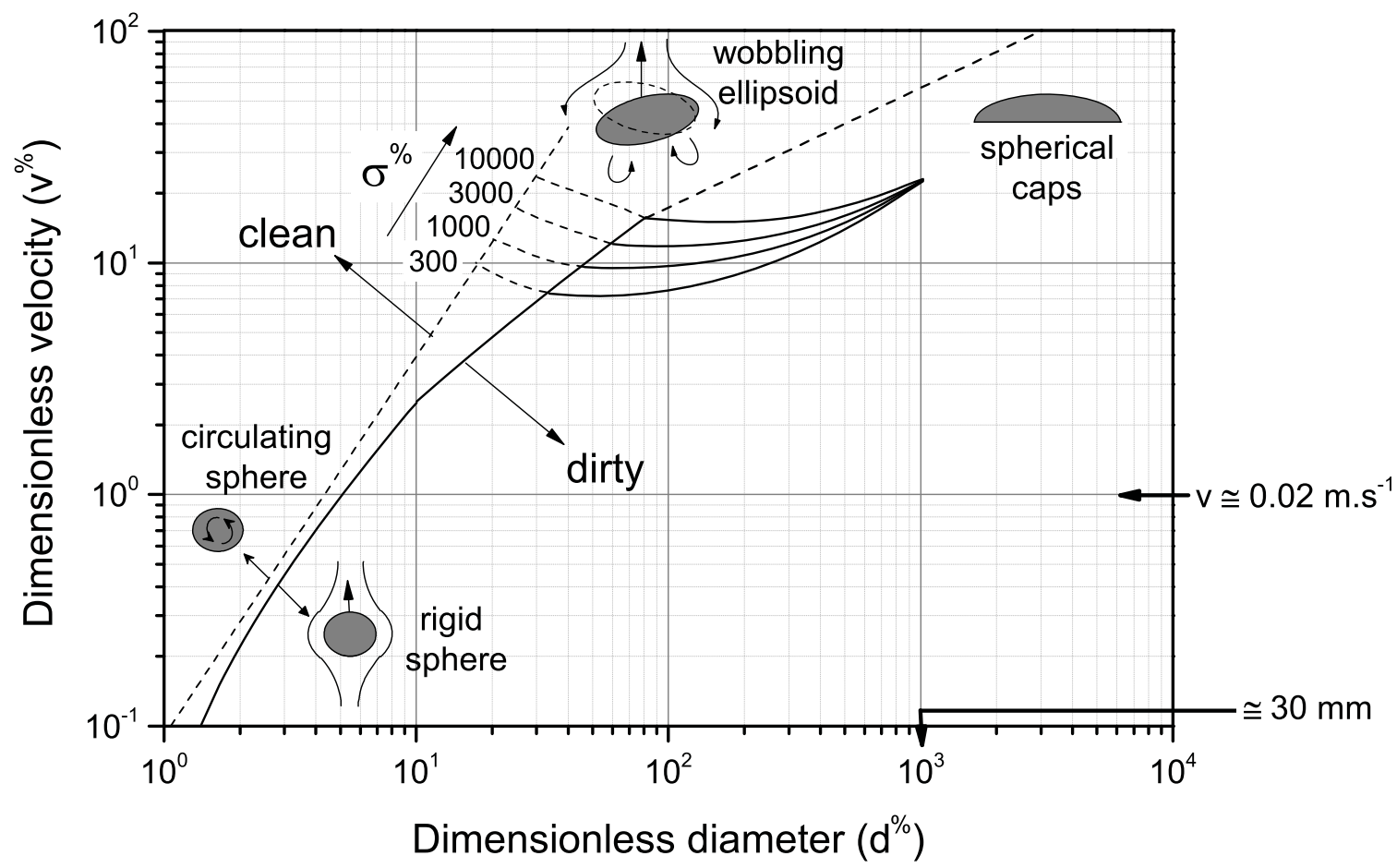

Fig. 2.5. Effect of impurities on bubble shape, size and mobility, adapted from [113].

Fig. 2.5. shows the velocity or mass transfer coefficient as a function of bubble diameter. The numbers given are all dimensionless and represent a ratio (denoted in \%). The dimensionless diameter is the ratio of the bubble diameter to a reference diameter; the dimensionless velocity is the ratio of the bubble velocity to a reference velocity. The reference value only depends on the physical properties of the bubble and the liquid (water), and on the gravitational acceleration.

The reference values for air bubbles dispersed in water are given by [113]:

- Density of continuous phase (water), $\rho=997 \mathrm{~kg} / \mathrm{m}^{3}$

- Density of dispersed phase (air), $\rho_{d}=1.19 \mathrm{~kg} / \mathrm{m}^{3}$

- Dynamic viscosity of continuous phase (water), $\eta=9 \cdot 10^{-4} \mathrm{~Pa} \mathrm{~s}$ 
- Dynamic viscosity of dispersed phase (air), $\eta_{d}=1.9 \cdot 10^{-5} \mathrm{~Pa} s$

- Interface tension, $\sigma=0.072 \mathrm{~N} / \mathrm{m}$

- Reference diameter, $d_{r e f}=\left[\frac{\eta^{2}}{\rho g \Delta \rho}\right]^{1 / 3}$, approximately $d_{r e f} \approx 30 \mu \mathrm{m}$, in which $\eta$ is the dynamic viscosity of the gas $(\mathrm{Pa} \mathrm{s}), \rho$ is the density of the gas $\left(\mathrm{kg} / \mathrm{m}^{3}\right), \mathrm{g}$ is acceleration due to gravity $\left(\mathrm{m} / \mathrm{s}^{2}\right)$, and $\Delta \rho$ is the modulus of the density difference between the phases $\left(\mathrm{kg} / \mathrm{m}^{3}\right)$.

- Reference velocity, $v_{r e f}=\left[\frac{g \Delta \rho \eta}{\rho^{2}}\right]^{1 / 3}$, with a typical value of $v_{r e f} \approx 0.02 \mathrm{~m} / \mathrm{s}$, in which $\eta$ is the dynamic viscosity of the gas (Pa s), $\rho$ is the density of the gas $\left(\mathrm{kg} / \mathrm{m}^{3}\right), \mathrm{g}$ is acceleration due to gravity $\left(\mathrm{m} / \mathrm{s}^{2}\right)$, and $\Delta \rho$ is the modulus of the density difference between the phases $\left(\mathrm{kg} / \mathrm{m}^{3}\right)$.

- Reference interface tension, $\sigma_{r e f}=\left[\frac{g \Delta \rho \eta^{4}}{\rho^{2}}\right]^{1 / 3}$, in which $\eta$ is the dynamic viscosity of the gas $(\mathrm{Pa} \mathrm{s}), \rho$ is the density of the gas $\left(\mathrm{kg} / \mathrm{m}^{3}\right), \mathrm{g}$ is acceleration due to gravity $\left(\mathrm{m} / \mathrm{s}^{2}\right)$, and $\Delta \rho$ is the modulus of the density difference between the phases $\left(\mathrm{kg} / \mathrm{m}^{3}\right)$. This number is a measure of the resistance of the interface against deformation (since the interfaces of bubbles are deformed by interfacial tension during movement in the water).

The formulas of the dimensionless numbers are given below [113]:

- Dimensionless diameter number, $d^{\%}=\frac{d}{d_{r e f}}$

- Dimensionless velocity number, $v^{\%}=\frac{v}{v_{\text {ref }}}$

- Dimensionless interface number, $\sigma^{\%}=\frac{\sigma}{\sigma_{r e f}}$; approximately $\sigma^{\%}=3.3 \cdot 10^{3}$ for air bubbles dispersed in water.

In Fig. 2.5, the dimensionless diameter plotted along the horizontal axis has the range $1<d^{\%}<10^{3}$ (approximately $30 \mu \mathrm{m}<d<30 \mathrm{~mm}$ ). For non-spherical bubbles, the diameter is 
that of a sphere with the same volume, $V\left(m^{3}\right): d=\left(\frac{6}{\pi} V\right)^{1 / 3}$. The dimensionless velocity is plotted along the vertical axis within the range $10^{-1}<v^{\%}<10^{2}$ (approximately $2 \times 10^{-3} \mathrm{~m} / \mathrm{s}<$ $d<2 \mathrm{~m} / \mathrm{s}$ ). The velocity of circulating spherical bubbles (small bubbles with extremely clean interfaces) follows the dashed line; however, this line is no more than an upper limit for the velocity (based on Hadamard-Rybezinsky theory), and not measurable in practice. On the right-hand side, the solid line represents the velocity of rigid spheres, which have a lower velocity (bubble with equal diameter) in a liquid with impurities. Between these two lines lies the transition region to wobbling ellipsoids; the velocity increases about three times because the bubble interface becomes mobile. The transition between mobile and rigid interfaces is not sharp, and covers a diameter range of about a factor of three because of the dependency on the surface tension of the feed solution. Higher velocities are achieved by bubbles with a higher interfacial number $\left(\sigma^{\%}\right)$, which are more resistant to interfacial deformation due to liquid impurities (for example, it is easier to deform the interface of a bubble with $\sigma^{\%}=300$ than of a bubble with $\left.\sigma^{\%}=10000\right)$. In the wobbling ellipsoid and spherical cap regimes, the velocity decreases slowly with increasing bubble diameter, and there is no clear transition (shown as a bold dashed line) [113].

The Bond and Newton approximation roughly predicts the diameter of a bubble [109]:

- The diameter of a rigid sphere bubble in "dirty" liquids is $d^{\%} \approx 8 \sigma^{\% 1 / 4}$.

- The transition diameter from rigid to mobile is $d^{\%} \approx 2 \sigma^{\% \%^{1 / 2}}$ which predicts a transition diameter of about $1 \mathrm{~mm}$ at which a bubble becomes largely mobile.

A general formula to calculate the approximate velocity based on bubble diameter is given by Davies and Taylor: $v^{\%}=0.711 \sqrt{d^{\%}}$ or $v=0.711\left[\frac{g \Delta \rho d}{\rho}\right]^{1 / 2}$ [109]. Based on the defined diameter of each bubble size and shape, the velocity of rising bubbles can be calculated. For example, in the case of an air bubble rising in stagnant water, the following numbers are defined [114]: $v_{r e f}=2.1 \cdot 10^{-2} \mathrm{~m} / \mathrm{s}, d_{r e f}=4.7 \cdot 10^{-5} \mathrm{~m}, \sigma=3.3 \cdot 10^{3}$, and $\eta^{\%} \leq 0.5$, which is the viscosity ratio between the phases. For different defined diameters as examples, the following velocities are obtained:

- $\quad$ Rigid sphere: $d=5 \cdot 10^{-4} \mathrm{~m} \rightarrow v=5.5 \cdot 10^{-2} \mathrm{~m} / \mathrm{s}$; 
- $\quad$ Circulating sphere: $d=5 \cdot 10^{-4} \mathrm{~m} \rightarrow v=8 \times 10^{-2} \mathrm{~m} / \mathrm{s}$;

- Wobbling ellipsoid: $d=5 \cdot 10^{-3} \mathrm{~m} \rightarrow v=0.25 \mathrm{~m} / \mathrm{s}$;

- $\quad$ Spherical cap: $d=5 \cdot 10^{-2} \mathrm{~m} \rightarrow v=0.5 \mathrm{~m} / \mathrm{s}$.

From the above calculations, the velocity of wobbling ellipsoids and spherical bubbles rising in stagnant water is five to ten times higher than that of rigid spherical bubbles. Due to the presence of impurities in the water, theoretically gas tends to form wobbling ellipsoids and spherical-cap shapes, consequently rising at a higher velocity.

When the bubble size is known, it is possible to predict bubble-induced shear stress. Many studies also report the occurrence of standing eddies behind ellipsoidal bubbles, and instabilities observed in the bubble's path [110]. Furthermore, bubble surface mobility affects bubble oscillation, bubble breakup and coalescence, bubble-bubble or bubble-wall interaction, and heat and mass transfer with surrounding liquids. Even though the above-described mobility of bubble surfaces is based on bubbles rising in stagnant water, this theory is also relevant for optimizing bubble size and distance to the walls to obtain optimal fouling control and cleaning [115]. Following the Lockhart-Martinelli paper published in 1949 [116], many researchers confirmed bubble-induced local stress and shear-induced stress on the channel wall; the average friction coefficient and wall shear stresses and thus the effect on fouling (control) are consequently mainly determined by the gas-liquid mass flow ratio, channel diameter [117], and liquid velocity [118].

\subsection{Application of two-phase flow in various membrane processes}

The literature reviewed revealed that two-phase flow has been widely used in low-pressure membrane processes, i.e. MF and UF, with most applications in MBRs. Few applications in high-pressure membrane processes are reported, but this number is increasing. Research on two-phase flow in other membrane processes also exists, i.e. membrane contactors (e.g. membrane distillation), membrane electrodialysis and ion exchange membranes.

Most of the literature in our database concerns two-phase flow applied in tubular membranes, either with large diameters or capillaries. It is followed by hollow-fiber and flat-sheet membrane modules. Less than $5 \%$ of the studies concerns work with spiral-wound membrane elements (see Fig. 2.6). This can be explained by the fact that the earliest studies were carried 
out with MF and UF systems, which employed tubular, capillary or hollow-fiber packed modules, later followed by other membrane processes, for instance NF and RO which use spiral-wound modules. The recent application of two-phase flow in NF and RO systems uses mostly spiral-wound membrane elements.

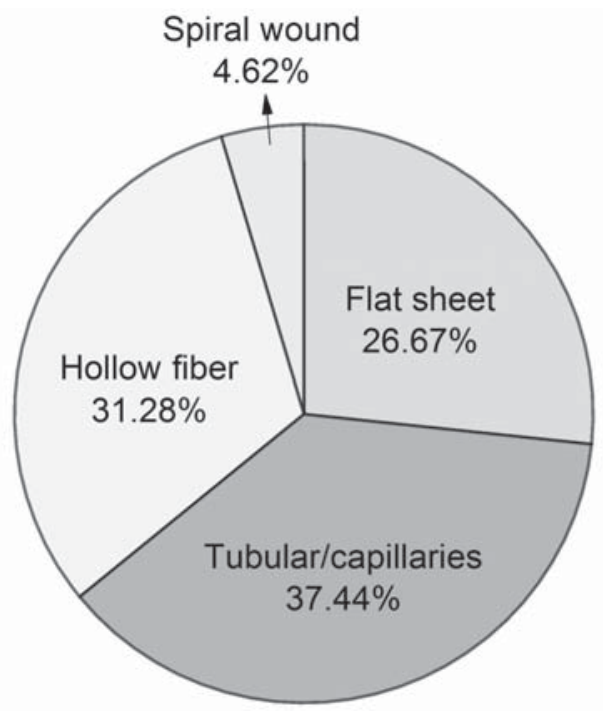

Fig. 2.6. Types of membrane elements used in two-phase flow membrane processes.

The following sub-sections summarize two-phase flow in various membrane processes (MF, UF, NF, RO, MD, ED) and modules (flat channel, tubular module, hollow-fiber module, and submerged membrane). The mechanisms of fouling formation and development differ for the different membrane processes [119]. Fouling caused by particles and organic fouling are mostly found in MF/UF, submerged membranes and MD processes, whereas biofouling is the prevailing fouling type in NF/RO systems and mineral precipitation (scaling) widely occurs in saline feed solutions. Fouling formation in pores and intrusion into pores also differ for the different membrane processes. Surface attachment of biological substances and caking of small particles are common on membranes surfaces containing smaller pores; however, complete pore blocking may occur in membranes with larger pores. This means that the action of countermeasures such as using a two-phase flow also differs for different membrane processes and membrane module geometries.

The following summary is categorized on the basis of the aforementioned considerations and each sub-section is primarily based on chronologic order of the literature. 


\subsubsection{Microfiltration}

Because of its relatively large pore size, all possible fouling mechanisms may occur in $\mathrm{MF}$ membranes, from cake formation to pore blocking. For example, during filtration of natural waters, two types of materials are commonly found, i.e. particulates (particle size greater than $0.45 \mu \mathrm{m}$ ) and dissolved components (both colloidal and truly dissolved components, with particle sizes smaller than $0.45 \mu \mathrm{m})$. Particulate matter that is larger than the pores in $\mathrm{MF}$ (pore radius $0.1-10 \mu \mathrm{m}$ ) and UF (pore radius 2-10 $\mathrm{nm}$ ) membranes forms a cake at the membrane surface. Some of the dissolved matter can enter the pores, clogging pores or adsorbing within the pores thereby reducing the pore diameter (pore constriction) [120, 121].

With respect to two-phase flow cleaning, significant flux enhancements were observed in almost all of the published research. Cake layers formed at membrane surfaces were reported to be removed by two-phase flow cleaning [40]. However, in cases where internal fouling occurred due to the intrusion of particles inside the pores, the gas bubbles were not able to remove this [122] and back flushing provided a stronger effect of flux enhancement $[38,123]$.

\subsubsection{Tubular membranes}

The first reported attempt of using a two-phase flow in MF was carried out by Imasaka et al. in 1989 [124], who studied the effect of two-phase flow in five vertically connected membrane modules in which 200 microporous ceramic tubular membranes were bundled. The liquid velocity, $V_{L}$, varied between $0.26-2.01 \mathrm{~m} / \mathrm{s}$, and the gas flow rate, $Q_{G}$, ranged from $7.8 \cdot 10^{-4}-7.6 \cdot 10^{-3} \mathrm{Nm}^{3} / \mathrm{s}$. The highest permeate flux was reached at a gas flow rate of $7.6 \cdot 10^{-3} \mathrm{Nm}^{3} / \mathrm{s}$, and the lowest at a gas flow rate of $7.8 \cdot 10^{-4} \mathrm{Nm}^{3} / \mathrm{s}$; increasing the gas velocity enhanced the permeate flux, $J$, up to $460 \%$.

Vera et al. [125] tested air sparging injection into a cross-flow stream in order to reduce fouling in tubular inorganic membranes with $0.14 \mu \mathrm{m}$ pore size and an effective filtration area of $0.0075 \mathrm{~m}^{2}$. Two suspensions were used, a ferric hydroxide suspension and biologically treated wastewater. These authors reported that at 1 bar driving pressure and 1 $\mathrm{m} / \mathrm{s}$ liquid cross-flow velocity, $V_{L}$, air sparging in the vicinity of $1 \mathrm{~m} / \mathrm{s}$ reduced the resistance by a factor of 2 for ferric hydroxide and by a factor of 4 for wastewater. In a subsequent paper [126], the same group proposed the use of dimensionless numbers to express the effect 
of gas sparging in tubular membranes. The dimensionless number approach was aimed at generalizing parameters over a wide range of operating conditions. The generalized shear stress number, $N_{s}{ }_{s}$, and the equivalent fluid density, compare the shear stress against the membrane wall with the driving pressure. This number is equivalent to the gas/liquid velocity ratio and related to bubble shape and size. The second dimensionless number is the resistance number, $N f$, which compares the convective cross-flow transport with the transport through a layer, of which the resistance is the sum of all the resistances that limit mass transport. By using these two dimensionless numbers, the authors were able to show that in biologically treated wastewater filtration, air sparging completely removed the solid phase, mainly containing bacteria, which was collected as a compressible cake on the membrane wall. This in contrast to air sparging in the filtration of a ferric hydroxide suspension, where air sparging was less effective because of the occurrence of irreversible fouling (pore blockage).

Mercier-Bonin et al. [127] investigated the effect of gas-liquid flow on the separation of casein micelles from soluble proteins in skimmed milk using a multi-channel tubular ceramic membrane system under constant trans-membrane pressure (TMP). This membrane had a 0.1 $\mu \mathrm{m}$ mean pore diameter with a membrane area of $0.0383 \mathrm{~m}^{2}$. Both single-phase and twophase flows failed to disrupt the cake of micelles because of densification of the cake structure due to the large pressure increase (TMP). In both single-phase and two-phase flow, permeate fluxes remained below a critical value of the shear stress, showing that the major hydrodynamic parameter involved in the flux improvement was the wall shear stress. The same authors conducted further research under constant flux conditions [128], and reported irreversible fouling, in the form which led to a more tightly packed and less porous cake structure, with gas bubbles not being able to disrupt it. Mercier-Bonin and Fonade [129] also investigated the effect of two-phase flow on enzyme filtration through an MF membrane. A monotubular membrane with a pore size of $0.2 \mu \mathrm{m}$ and effective area of $0.0353 \mathrm{~m}^{2}$ was used; the solutions were an invertase/yeast mixture and an invertase-only solution. The researchers observed that bubble size and shape affected the recovery of enzyme from the enzyme-yeast mixtures with an increase in mass flux of $25 \%$, and $13 \%$ higher enzyme recovery. Sur and Cui [130] reported flux enhancements from $10 \%$ to $135 \%$ due to continuous two-phase flow during yeast filtration using a multi-tubular membrane module. The operational conditions were a yeast concentration of 0.01-10 $\mathrm{wt}^{\%}$, TMP of 0.5-4.0 bar, a liquid cross-flow velocity of $0.36-1.8 \mathrm{~m} / \mathrm{s}$, and a gas superficial velocity of $0.18-1.02 \mathrm{~m} / \mathrm{s}$. 
The application of a gas-liquid two-phase flow in microfiltration of dispersed particle solutions was investigated by Mikulasek et al. [131] and Pospišil et al. [132] who used a titanium dioxide solution. They reported flux enhancements of up to $90 \%$, and demonstrated that in cross-flow microfiltration of dispersions, the continuous gas-liquid two-phase flow was able to maintain a high and constant permeate flux during the entire experimental run. Comparing gas sparging and back flushing, Fadaei et al. [133] concluded that gas sparging is the proper choice to disrupt external fouling in microfiltration using tubular modules by stripping off the cake layer from the membrane surface. However, when internal fouling occurs, gas bubbles do not enter the pores and back flushing results in stronger flux enhancements.

Chiu and James [134] investigated the effect of various superficial gas and liquid velocities in multi-channeled star-shaped ceramic membranes. Each membrane had seven star channels with an outer diameter of $4.6 \mathrm{~mm}$ and an inner diameter of $2.8 \mathrm{~mm}$, a nominal pore diameter of $0.2 \mu \mathrm{m}$ and a membrane filtration area of $0.03 \mathrm{~m}^{2}$. The model suspension contained titanium dioxide particles; the average particle size was $3.0 \mu \mathrm{m}$. The employed superficial liquid velocities were in the range of $0.6-3.4 \mathrm{~m} / \mathrm{s}$ and the superficial gas velocities were in the range of 0.3-3.4 m/s. A maximum flux enhancement of $171 \%$ was reached at a superficial gas velocity of $1 \mathrm{~m} / \mathrm{s}$ and a superficial liquid velocity of $0.6 \mathrm{~m} / \mathrm{s}$.

Youravong et al. [122] studied the effect of gas sparging on the permeate flux, fouling and quality of clarified pineapple wine. A tubular ceramic membrane with a pore size of $2.0 \mu \mathrm{m}$ and effective area of $75 \mathrm{~cm}^{2}$ was used; the system was operated at a trans-membrane pressure of 2 bar and a cross-flow velocity of $2.0 \mathrm{~m} / \mathrm{s}$. Compressed nitrogen gas was injected into the inlet of the feeding system and varied from 0 to $1.1 \mathrm{~m} / \mathrm{s}$ to achieve a gas/liquid ratio, $\theta$, of 0 0.35 . It was observed that a relatively low gas sparging $(\theta=0.15)$ increased the permeate flux to $138 \%$ compared to the system without gas flow (see Fig. 2.7). Gas sparging however, did cause a loss of alcohol content in the wine. A gas injection ratio of 0.15 provided a higher flux enhancement than a ratio of 0.25 or 0.35 . Higher gas injection ratios tend to decrease reversible fouling, but not irreversible fouling and the density of the cake layer increased with increasing gas injection ratio. 


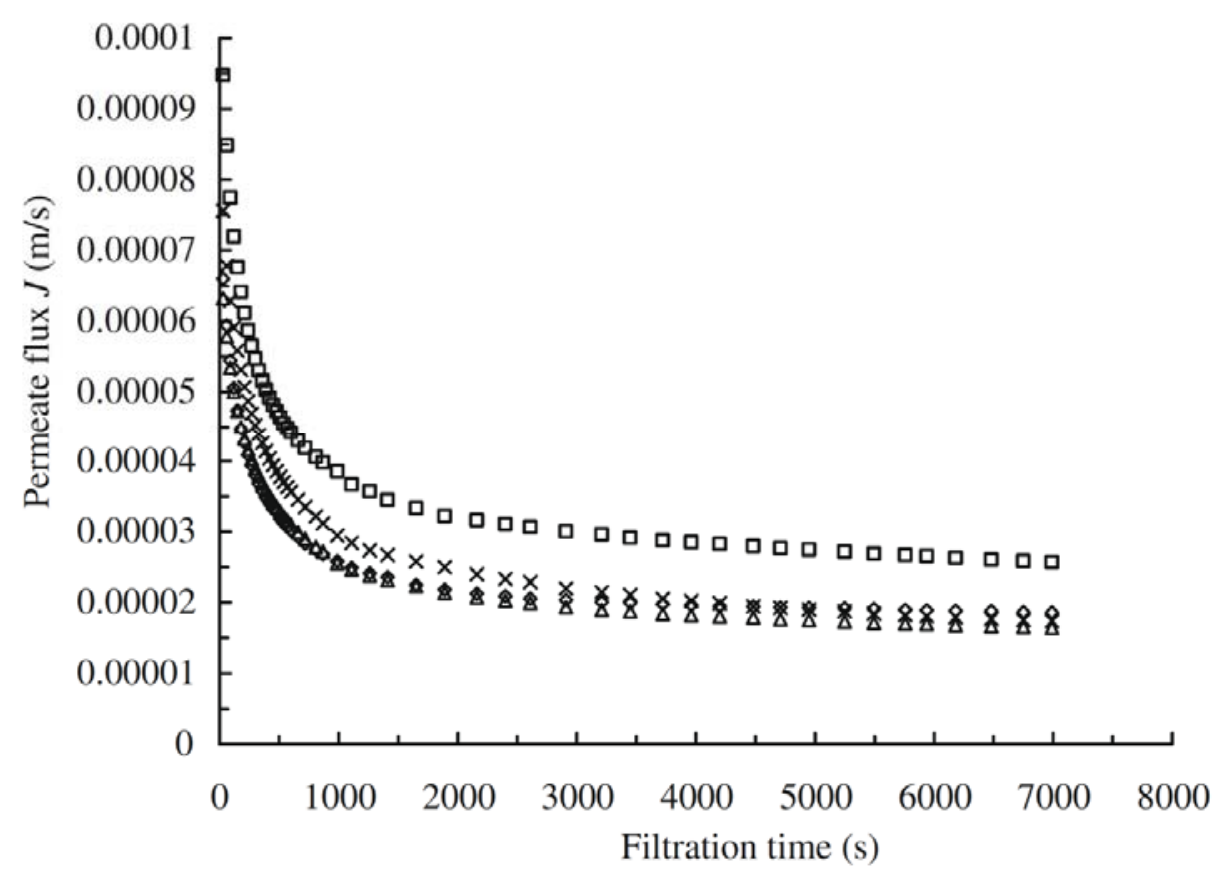

Fig. 2.7. Flux enhancement due to gas sparging during microfiltration of pineapple wine $(\diamond$ : without gas; $\square$ : gas injection ratio $\theta=0.15 ; \triangle$ : gas injection ratio $\theta=0.25 ; \times$ : gas injection ratio $\theta=0.35$ ) [122].

\subsubsection{Flat-sheet membranes}

The use of two-phase flow in MF membrane processes using flat membrane modules was first studied by Mercier-Bonin et al. [135]. They investigated the filtration performance, i.e. flux and energy consumption, when air was continuously injected during cross-flow filtration of a commercially available baker's yeast suspension. Horizontally or vertically mounted flatsheet ceramic membranes with a pore size of $0.14 \mu \mathrm{m}$ and filtration area of $0.06 \mathrm{~m}^{2}$ were used in the experiments. The liquid superficial velocities were varied from 0.3 to $1.4 \mathrm{~m} / \mathrm{s}$ and the air velocities were within the range of 0 to $0.8 \mathrm{~m} / \mathrm{s}$. The maximum flux improvement of $280 \%$ was achieved at a gas/liquid ratio, $\theta$, of 0.5 .

Hwang and Hsu [40] studied the effect of flow patterns on the performance of air-sparged cross-flow MF of a yeast suspension. A mixed cellulose ester membrane with a mean pore size of $0.1 \mu \mathrm{m}$ and filtration area of $0.11 \mathrm{~m}^{2}$ was used. The liquid superficial velocities were set in the range of $0.1-0.5 \mathrm{~m} / \mathrm{s}$ and gas superficial velocities were within the range of 0.02 to $0.08 \mathrm{~m} / \mathrm{s}$, corresponding with a gas/liquid ratio, $\theta$, of 0.039 to 0.444 . The air flow pattern was observed and recorded using a video camera. The authors observed that the filtration 40 
performance was affected by the gas/liquid flow pattern (or wall shear stress) rather than by fluid velocities; a slug flow pattern was found to be more effective for enhancing the flux than a bubbly flow pattern. At the end of the experiment, the dry mass of the cake formed on the filter membrane was analyzed by using a moisture titrator. The conclusion was that over $40 \%$ of the cake mass can be reduced by air-sparging at the used operating conditions (see Fig. 2.8).

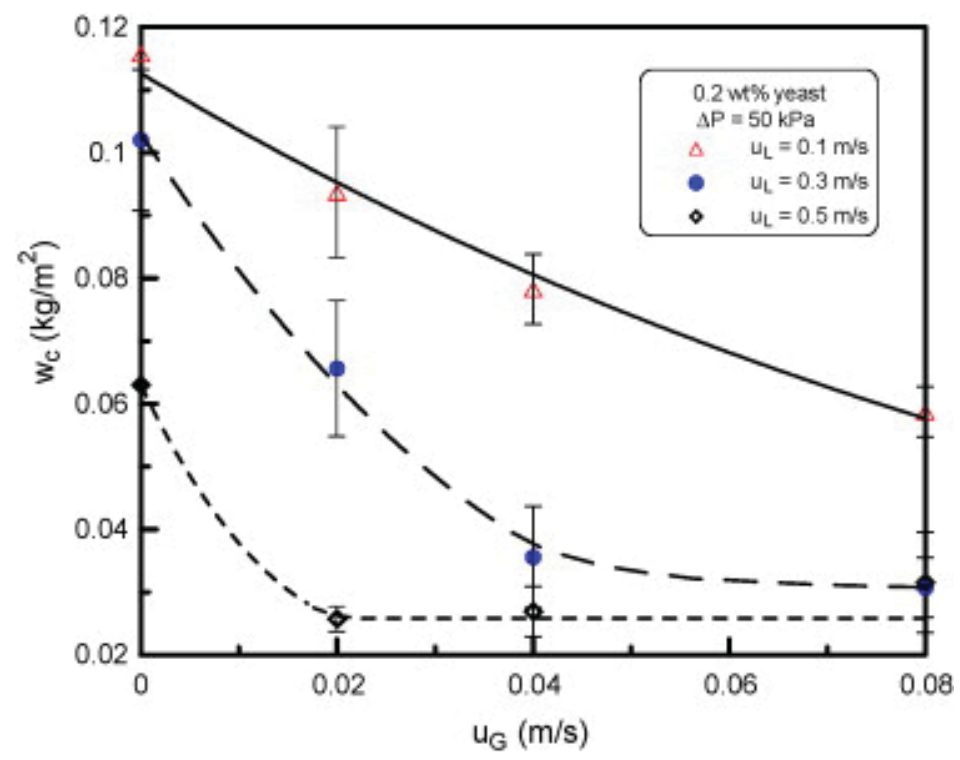

Fig. 2.8. Yeast cake mass under various flow conditions for both liquid and gas [40].

As shown in Fig. 2.8, an increase in gas velocity led to a decrease in cake mass, attributable to the increase in wall shear stress. During filtration at a low suspension (liquid) velocity $\left(\mathrm{u}_{\mathrm{L}}=\right.$ $0.1 \mathrm{~m} / \mathrm{s}$ ), the cake mass decreased continuously with increasing gas velocity; however, at a higher liquid velocity $\left(\mathrm{u}_{\mathrm{L}}=0.5 \mathrm{~m} / \mathrm{s}\right)$, the cake mass decreased until a certain point was reached, which was at a lower gas velocity than for the higher liquid flow rate. Clearly, there is a limit to the decrease in cake mass obtainable by air sparging; no further efficacy can be reached by increasing the air velocity once that limit is reached. The structure of the compressed particles becomes more compact due to two-phase flow, and this effect is more significant as liquid velocity increased. This implies that a higher wall-shear stress is required to reduce the cake mass significantly. As found for MF tubular modules, the maximum flux enhancement with MF flat modules occurred at a gas/liquid ratio of 0.3-0.5 (slug bubbles). The cake mass was easily removed, but internal pore clogging was unaffected. 
In a further study [41], the same group reported that a higher sparged-air velocity led to a lighter cake due to higher shear stress acting on the membrane surface. The same group used SEM to show the difference in particle-packing structure of the fouling between single-phase and two-phase flow [42]. A smaller particle size in the cake was found to cause a higher average specific cake filtration resistance and a lower pseudo-steady filtration flux.

\subsubsection{Submerged membranes}

Shimizu et al. [136] were among the first to report the use of a cross-flow stream over a submerged membrane surface by air bubbling, which is generated by a diffuser in the feed underneath the membrane. The air bubbles flow upward along the membrane surface together with the fluid and induce a moderate shear stress which generates the back-transport of filtered colloidal particles from the membrane surface. A tubular alumina membrane with a pore size of $0.5 \mu \mathrm{m}$ was used. The air diffusers were placed in the $0.63 \mathrm{~m}^{3}$ bioreactor vessel containing fermented domestic-wastewater-derived activated sludge with a mixed liquor suspended solid (MLSS) of 3-20 kg/m ${ }^{3}$. The bubble strength, $V_{a}$, i.e. the air bubble flow rate per unit projected membrane area for the base, was set between 0 and $300 \mathrm{~m}^{3} / \mathrm{m}^{2} \mathrm{~h}$. The relationship between the bubbling strength and the steady state flux, $J_{s s}$, was observed as $J_{s s} \propto V_{a}^{0.3}$. The increase of flux as a function of air-liquid two-phase flow velocity, $V^{*}$, was expressed as $J_{s s} \propto V^{* 1.0}$, meaning that flux enhancement is linear with the two-phase flow velocity.

Chang et al. [56] compared the filtration behavior of $5 \mu m$ dry yeast particles with $0.2 \mu \mathrm{m}$ polypropylene hollow fibers for different fiber orientations. Fibers with a diameter of 0.65 $\mathrm{mm}$ were oriented axially and transversely with the flow direction. As a simulation of aeration in a submerged system, the superficial velocity of the air was set to $0.2 \mathrm{~m} / \mathrm{s}$. The flux enhancements were observed in both orientations, with $13.4 \%$ enhancement at axial and $26 \%$ enhancement at transverse orientation.

Hwang et al. [38] compared four hydrodynamic methods to mitigate particle fouling and enhance flux in a submerged membrane system. The methods were applied by increasing filtration pressure, increasing aeration intensity, increasing filtration pressure stepwise, and periodic backwashing of the fouled membrane. Increasing the filtration pressure caused the 42 
flux to decrease by up to $30 \%$ because of more severe membrane blocking. Aeration could reduce the particle deposition on the membrane surface by $50 \%$, but had no noticeable effect on irreversible membrane fouling. A stepwise increasing pressure could remove as much as $40 \%$ of the membrane's internal fouling, and a periodic backwash significantly enhanced the flux by up to $70 \%$.

A similar conclusion was reached by Qaisrani and Samhaber [123], who conducted MF of a commercial yeast suspension with a concentration of $10 \mathrm{~g} / \mathrm{L}$ using a submerged flat-sheet membrane with a nominal pore size of $0.2 \mu \mathrm{m}$. Five filtration methods were employed, i.e. dead-end, enhanced cross-flow, air bubbling, backflushing, and a combination of backflushing and air bubbling. Each filtration and cleaning experiment consisted of different stages, i.e.: initial pure water flux determination, yeast suspension filtration, water rinsing at zero TMP to remove lose particle, chemical-in-place (CIP) cleaning using detergent, rinsing with pure water, conditioning with $\mathrm{HCl}$ solution, water rinsing and finally pure water flux determination. The membrane cleaning efficiency of each filtration mode was compared in terms of membrane permeability recovery (reported as percentage membrane recovery). The combination of backflushing and air bubbling was found to be most effective both in terms of fouling control and membrane cleaning time (see Fig. 2.9).

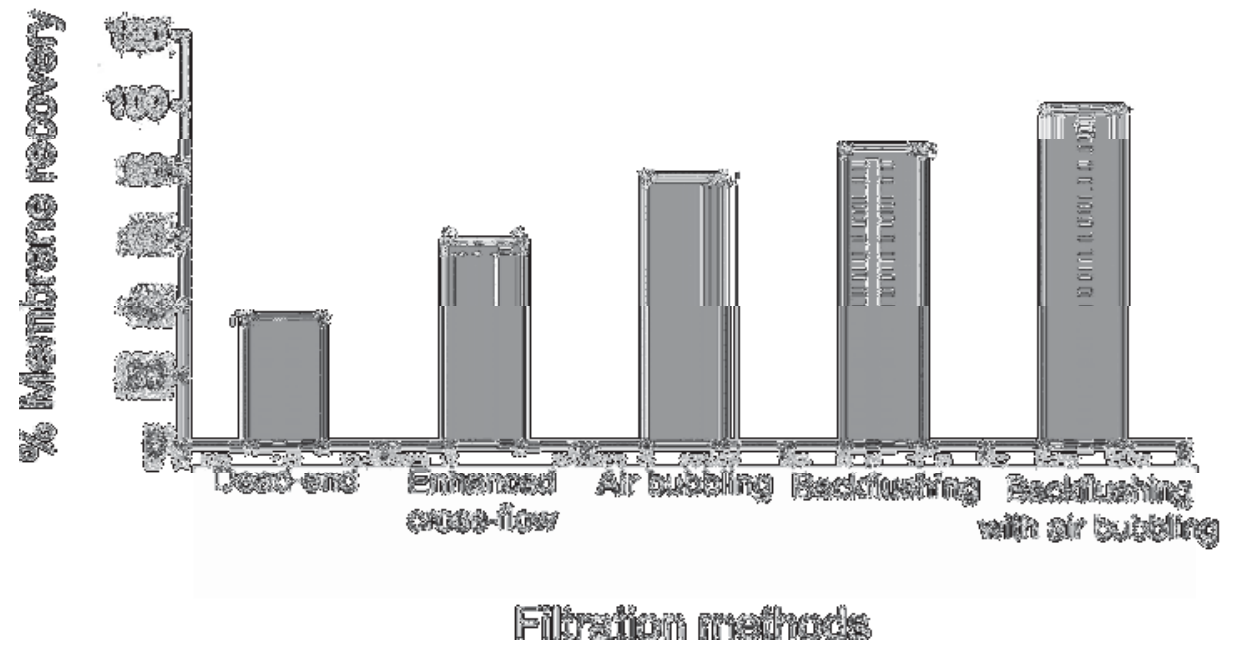

Fig.2.9. Membrane recovery for five modes of filtration [123].

As shown in Fig. 2.9, the combination of backflushing and air bubbling reduced particle deposition by up to $98.5 \%$ which is the maximum compared with other filtration methods 
applied in that particular study, whereas a lower membrane recovery was reached for enhanced cross-flow, air bubbling alone, and backflushing alone with values of 69, 78 and $87 \%$, respectively. Application of the cleaning procedure in dead-end mode resulted in a membrane permeability recovery of only $40 \%$.

\subsubsection{Ultrafiltration}

UF technology has seen significant developments. It is a low-pressure process, and as such has relatively low energy consumption. The lower energy consumption means fewer costs on the one hand, whereas on the other hand, UF can also remove all bacteria and almost all viruses. Membrane fouling, nevertheless, is considered its most significant problem. Using natural waters as a feed, UF fouling can be categorized as: (i) particle fouling, (ii) organic fouling by natural organic matter (NOM), and (iii) biofouling, which stems from aquatic organisms such as algae [137]. As for MF processes, the findings below summarize the most relevant literature on air sparging in UF. As shown for MF, also in UF, two-phase flow cleaning easily removes cake-form fouling, but does not remove dissolved material that blocks the pores.

\subsubsection{Tubular membranes}

Cui and Wright [19] were the first to investigate two-phase flow in UF by injecting air during filtration of bovine serum albumin (BSA) and dextran solutions. A tubular membrane with a MWCO of $100 \mathrm{kDa}$ and effective filtration area of $0.0267 \mathrm{~m}^{2}$ was mounted vertically and horizontally. A range of trans-membrane pressures from 0.5 to 1.5 bar, gas flow rates of up to $1 \mathrm{~L} / \mathrm{min}$, and liquid flow rates of between 1 and $3 \mathrm{~L} / \mathrm{min}$ were used. The authors reported that air sparging successfully increased the permeate flux and rejection ratio, explained by disturbance of the concentration polarization layer. They also found that membrane orientation influenced the effectiveness of air sparging; a vertical orientation gave a 10-20\% higher flux than a horizontal position. In a subsequent paper [103], the same authors published their findings regarding gas-liquid two-phase cross-flow UF under co-current downward flow conditions, and compared the results with those in co-current upward crossflow operation. The experiments were carried out using a $50 \mathrm{kDa}$ MWCO tubular membrane 
module with a surface area of $0.2 \mathrm{~m}^{2}$ which contained twelve membrane tubes with a length of $1 \mathrm{~m}$ each and an internal diameter of $5 \mathrm{~mm}$. Dextran solutions with an average molecular mass of $260 \mathrm{kDa}$ and a concentration between 1 and $10 \mathrm{~g} / \mathrm{L}$ were used in the experiments. Liquid velocities were in the range of $0.141-0.778 \mathrm{~m} / \mathrm{s}$; compressed air was used as the gas phase at a range of velocities between 0 and $0.353 \mathrm{~m} / \mathrm{s}$. The TMP range was from 0.5 to 2.5 bar, and the temperature was set to around $25^{\circ} \mathrm{C}$. Significant flux enhancements up to $320 \%$ were observed during co-current two-phase flow downward operation, compared with the conventional non-sparged mode. The flux enhancement was most significant when concentration polarization was more severe, and a low gas flow rate was most effective to enhance the process in the liquid laminar flow region. Both upward and downward flow resulted in significant flux enhancement not affected by the time. At lower superficial velocities, e.g. at $u_{\mathrm{G}}=0.009 \mathrm{~m} / \mathrm{s}$, the flux enhancement was very similar for both modes of operation, however at higher superficial gas velocities, e.g. $u_{\mathrm{G}}=0.182 \mathrm{~m} / \mathrm{s}$, a larger flux enhancement was observed for the system with co-current downward flow. In downward flow, the absolute velocity of the bubbles is lower due to the counter-acting effect of the buoyancy force and liquid flow. Consequently, the residence time of a bubble inside the membrane module is longer and its enhancing effect is larger. The effect occurred at higher gas flow rates (resulting in large bubbles and consequently stronger buoyancy forces). When the gas flow rate was too low, the injected gas did not form a continuous dispersed bubble flow and in that case the life time of a bubble is short and the gas velocity is as fast as the liquid velocity, giving the same effect as in co-current upward flow.

Cui et al. [138] proposed a new membrane process known as airlift cross-flow filtration, which possesses the advantages of enhanced cross-flow filtration without the need for a recirculating pump. The gas stream is injected into the lower end of the vertical membrane module, and produces the airlift that drives the liquid flow tangentially across the membrane surface while simultaneously making use of the enhancing effect of gas bubbles on the membrane process. The two-phase flow mixture was separated afterwards, with the liquid flowing back downward gravitationally through a non-sparged downcomer as an internal circulator. The TMP was controlled by varying the outflow of compressed air from the gasliquid separator. Tubular membranes with $100 \mathrm{kDa} \mathrm{MWCO}$, an internal diameter of $0.0127 \mathrm{~m}$ and length of $1.2 \mathrm{~m}$ were used in the system. All experiments were performed using dyed dextran at a fixed concentration of $1.9 \mathrm{~g} / \mathrm{L}$. At a TMP of 1.09 bar and a relatively low gas 
superficial velocity of $1.3 \cdot 10^{-3} \mathrm{~m} / \mathrm{s}$, the flux in airlift operation was about $30 \%$ higher compared with conventional single-phase flow UF with a similar apparatus as the one used in this airlift system.

Further research by the same group [139] was carried out to characterize the fractionation of human serum albumin (HSA) and human immunoglobulin G (IgG) by gas-sparged UF. Vertically mounted tubular PVDF membranes, with $100 \mathrm{kDa}$ MWCO and an effective membrane area of $0.011 \mathrm{~m}^{2}$, were used in all UF experiments. The mixtures of HSA and $\operatorname{IgG}$ were used as the test media, with $\mathrm{HSA} / \mathrm{IgG}$ concentration ratios of 4.5/0.0, 4.5/1.0, 1.0/1.0, $0.5 / 1.0$ and $0.0 / 1.0 \mathrm{~g} / \mathrm{L}$. The solutions were tested at a $\mathrm{pH}$ range of 4.7 to 8.5 . The liquid flow rate was between 0.25 and $1.0 \mathrm{~L} / \mathrm{min}$, the air flow rate between 30 and $150 \mathrm{~mL} / \mathrm{min}$, and the TMP between 0.2 and 0.8 bar. Reversed selectivity of the HSA/IgG mixture was obtained for solutions with $\mathrm{pH}>7.0$; the recommended $\mathrm{pH}$ for fractionation of $\mathrm{HSA} / \mathrm{IgG}$ mixtures is 8.0. At a $\mathrm{pH}$ of 4.7, aggregation of the two proteins occurred which resulted in no proteins being transferred. Gas sparging significantly enhanced the selectivity of the fractionation of $\mathrm{HSA} / \mathrm{IgG}$, at about a six-fold increase compared with unsparged operation. No protein damage was observed during gas sparging at the optimal operating conditions of $\mathrm{pH} 8.0$, a TMP of 0.3-0.4 bar, a liquid cross-flow rate $0.5 \mathrm{~L} / \mathrm{min}$ and an air-sparging rate of 30-50 $\mathrm{mL} / \mathrm{min}$. In their subsequent paper [140], the same authors reported that both bubble size and frequency had a significant influence on the permeate flux of cross-flow UF using tubular membranes. Two regions could be identified, an increasing flux associated with smaller bubbles and a plateau region with larger slugs. Flux enhancement occurred at bubbling frequencies lower than $1 \mathrm{~Hz}$. The authors suggest that increasing the frequency further may not improve the mass transfer further, but may result in bubble coalescence or change the flow pattern to churn flow or annular flow.

Ghosh and Cui [141] succeeded in developing a model of gas-sparged UF to predict the permeate flux by calculating the mass transfer in three different zones near the gas slug. These different zones are (a) the film zone, where there is a falling film flow, (b) the wake zone, which is a region of free turbulence, and (c) the liquid slug zone, in which the flow can be either laminar (streamline) or turbulent depending on the bulk fluid flow. The results suggest that gas sparging is more effective at higher trans-membrane pressures and higher feed concentrations. However, whereas increasing the liquid flow rate leads to increased flux enhancement in single-phase flow, it has a negative effect in gas-sparged ultrafiltration. 
Mercier et al. $[142,143]$ studied gas slug flows in the filtration of a bentonite suspension and yeast suspension using tubular zirconia-coated alumina membranes with an average pore size of $20 \mathrm{~nm}$ and an effective area of $0.0353 \mathrm{~m}^{2}$. The range of the liquid flow rate was $0.2-1 \mathrm{~m}^{3} / \mathrm{h}$ and of the gas flow rate was $0.1-1.5 \mathrm{~m}^{3} / \mathrm{h}$. The authors reported a $200 \%$ flux increase during bentonite filtration and a $170 \%$ flux increase during yeast filtration when they used a liquid velocity of $0.79 \mathrm{~m} / \mathrm{s}$ and gas velocity of $0.6 \mathrm{~m} / \mathrm{s}$ at a TMP of $1.05 \cdot 10^{5} \mathrm{~Pa}$. The filtration results confirmed that gas slug flow was able to disturb external fouling caused by bentonite and yeast deposits. In their subsequent paper [144], the same group presented the characterization of slug flow hydrodynamics in two sizes of tubular membranes (diameters of 6 and $15 \mathrm{~mm}$ ) using a conductance probe. This technique allowed the identification of two geometries within the flow structure in the terms of void fractions, velocities, and length of Taylor bubbles and liquid slugs. The results showed that the flux enhancement was predominantly due to the increased wall shear stress, induced by continuous gas sparging inside the tubular filtration module. The intermittent succession of Taylor bubbles and liquid slugs resulted in additional fouling removal because of an enhancement in mass transfer due to reversal of the wall shear stress, variation of the pressure in the bubble wake and a high level of local turbulence.

Abdel-Ghani [145] investigated the use of air bubbling to produce a foam from a feed solution of an aqueous polymer to be filtrated by a tubular UF membrane. The polymer used as solution was PVP K90 with an MWCO of $300 \mathrm{kDa}$, with concentrations of 2.5, 5 and 10 $\mathrm{g} / \mathrm{L}$. The experiments were carried out in a tubular membrane module containing eighteen membrane tubes connected in series and with an MWCO of $100 \mathrm{kDa}$ and a total surface area of $0.76 \mathrm{~m}^{2}$. The membrane module was oriented horizontally since polymer foams are stable and the gravitational force does not cause the foam bubbles to collapse inside the membrane tubes. The operating TMP ranged between $0.7 \cdot 10^{5}$ and $2.1 \cdot 10^{5} \mathrm{~Pa}$ and air flow rates ranged from 6 to $100 \mathrm{~L} / \mathrm{min}$. The work demonstrated that the foam of a macromolecular solution such as PVP could be separated and concentrated in a tank using UF membranes. The presence of foam enhanced the permeate flux up by up to $25 \%$ higher compared with the flux with no foam present in the solution, under these specific experimental conditions. The enhancement was more pronounced at higher feed concentrations, TMPs and air flow rates. The use of two-phase flow in UF of another water-soluble polymer was carried out by Cheng and Pan [35] who used a multichannel monolithic membrane to filtrate a PVA solution (Mw 
$=72 \mathrm{kDa}$ ). The membrane module consisted of nineteen flow channels, each with a diameter of $2.5 \mathrm{~mm}$. The membranes contained $\mathrm{TiO}_{2}-\mathrm{ZrO}_{2}$ as support layer and $\mathrm{Al}_{2} \mathrm{O}_{3}$ as filtrate layer, and had an MWCO of $15 \mathrm{kDa}$. The liquid velocity ranged from 0.268 to $0.536 \mathrm{~m} / \mathrm{s}$, the TMP from 100 to $400 \mathrm{kPa}$, and the air velocity was $0.179 \mathrm{~m} / \mathrm{s}$ distributed by gas distributors with three different pore sizes $(25,30$ and $60 \mu \mathrm{m})$. Gas sparging applied without gas distributor at a superficial velocity of $0.536 \mathrm{~m} / \mathrm{s}$ was able to enhance the steady-state flux by $8 \%$. The flux increase was $30 \%$ and $53 \%$, respectively, when the 60 and $30 \mu \mathrm{m}$ gas distributor was used. The smaller gas distributor allowed more uniform distribution of the bubbles, rather that the larger one. Without the gas distributor, channeling occurred and the effect of two-phase flow became insignificant. Sulaiman and Aroua [146] reported cake layer reduction by nitrogen gas sparging during UF of skim latex serum using a $100 \mathrm{kDa}$ MWCO PVDF tubular membrane with a membrane area of $0.0471 \mathrm{~m}^{2}$. The flow rates were $1-1.6 \mathrm{~L} / \mathrm{min}$ for the liquid and $0-0.5 \mathrm{~L} / \mathrm{min}$ for the gas. A maximum of $145 \%$ flux enhancement was reported when the liquid flow rate was $1.4 \mathrm{~L} / \mathrm{min}$ at a gas flow rate of $50.5 \mathrm{~L} / \mathrm{min}$ and a TMP of 0.89 barg. In a following paper [147], the same authors reported that they achieved a flux enhancement of $146 \%$ with the same system, but at a higher TMP of $1.9 \cdot 10^{5} \mathrm{~Pa}$.

Typical two-phase flow processes use tubular membrane modules that are positioned vertically, but Cheng et al. [37] investigated the effect of placing them at an angle. The used tubular membrane module contained a zirconia-carbon membrane with $15 \mathrm{kDa}$ as MWCO, a 6- $m m$-internal diameter and an effective membrane area of $75.4 \mathrm{~cm}^{2}$. The position of the membrane module could be adjusted, with inclination angles set to $0^{\circ}, 30^{\circ}, 45^{\circ}, 60^{\circ}$ and $90^{\circ}$; an inclination angle of $0^{\circ}$ stands for a horizontally installed module and $90^{\circ}$ for a vertically installed one. The superficial liquid velocities were in the range of $0.168-0.672 \mathrm{~m} / \mathrm{s}$, the superficial gas velocities were $0-0.0 .32 \mathrm{~m} / \mathrm{s}$, the TMP was $0.5-3$ bar and the feed solution temperature in all experiments was kept at $30^{\circ} \mathrm{C}$. The tested solute was dextran, and the solvent was distilled water. The results showed that during single-liquid-phase UF, regardless of the velocity of the liquid, the difference between the permeate fluxes at various inclination angles was small. With the addition of a gas phase to the system, the permeate fluxes as well as the effect of inclination on the permeate flux became greater than in the single-liquidphase UF (see Fig. 2.10). 


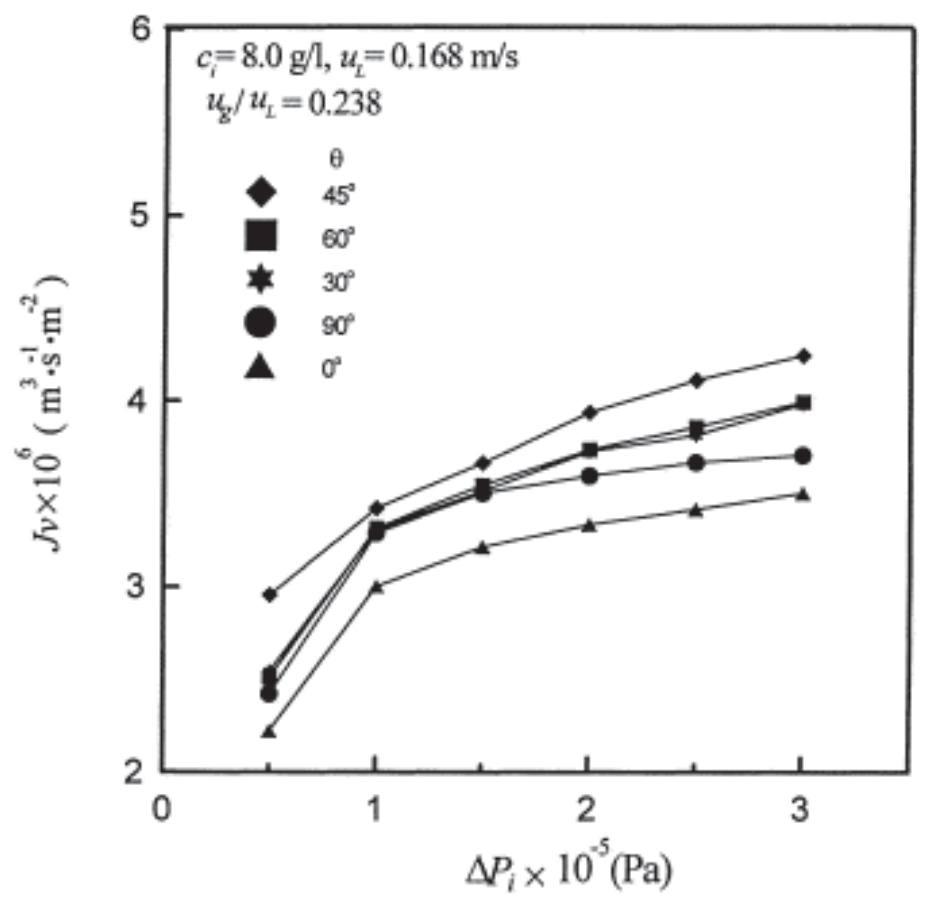

Fig. 2.10. Effect of inclination angle on permeate fluxes for gas/liquid two-phase flow ultrafiltration in tubular modules [37].

As shown in Fig. 2.10, the achieved permeate flux enhancements from high to low are for an inclination of $45^{\circ}, 60^{\circ}, 30^{\circ}, 90^{\circ}$ and $0^{\circ}$, respectively. Correlation calculations showed that the optimal inclination angle for the highest flux enhancement is about $53^{\circ}$. A further study by one of the authors [31] explored the same membrane systems and conditions as previously described, with inclination angles close to the calculated optimum, i.e. $50^{\circ}$ and $55^{\circ}$. The author reported that from the experimental data, the optimal inclination angle, which produces the highest flux enhancement, is between $45^{\circ}$ and $60^{\circ}$. The flux enhancement in inclined tubes is greater than in vertical or horizontal tubes; the gas slug velocity in tubes with the same diameter of $6 \mathrm{~mm}$ as investigated by the same group [34] is also greater than in vertical or horizontal tubes.

A combination of a two-phase flow and another technique to enhance UF filtration was proposed by Vatai et al. [148], who studied the simultaneous use of a static mixer and air sparging during cross-flow UF of an oil/water emulsion. A tubular membrane module was used, made from $\mathrm{ZrO}_{2}$ with a nominal pore size of $6.8 \mathrm{~mm}$, length of $250 \mathrm{~mm}$ and diameter of $6.8 \mathrm{~mm}$. A static mixer consisting of 36 mixing elements with a diameter of $6.35 \mathrm{~mm}$ was placed in the membrane module. A stable oil/water emulsion was prepared from water- 
soluble cutting oil, with an oil concentration of $5 \mathrm{wt} \%$. All experiments were carried out at $50^{\circ} \mathrm{C}$, with the TMP ranging from 50 to $300 \mathrm{kPa}$, liquid flow rates of 100 and $150 \mathrm{~L} / \mathrm{h}$ and an air flow rate of 20 to $100 \mathrm{~L} / \mathrm{h}$. The results indicate that air sparging during UF of an oil/water emulsion is not very effective under the given operating conditions. However, a combination of air sparging and a static mixer resulted in a higher permeate flux with lower energy consumption.

\subsubsection{Hollow-fiber membranes}

The application of gas sparging in UF membrane processes employing hollow-fiber membrane modules was first investigated by Bellara et al. [149]. They studied ultrafiltration of a dextran suspension with a concentration range of 10-40 g/L and human serum albumin with a concentration range of 2-20 g/L. To compare the result obtained using tubular membrane that they performed in the previous work [19], a bundle of 3600 fibers with a fiber diameter of $0.2 \mathrm{~mm}$ each, an MWCO of $30 \mathrm{kDa}$ and an effective surface area of $0.6 \mathrm{~m}^{2}$ was used for dextran filtration. Another bundle of 480 fibers with a fiber diameter of $0.5 \mathrm{~mm}$ each, an MWCO of $200 \mathrm{kDa}$ and an effective surface area of $0.2 \mathrm{~m}^{2}$ was used for albumin filtration. In the dextran filtration, the gas used was pressurized air at $6.5 \cdot 10^{-4}-1.6 \cdot 10^{-3} \mathrm{~L} / \mathrm{s}$, and the liquid was recirculated at $0.02 \mathrm{~L} / \mathrm{s}$. The maximum flux enhancement of $30 \%$ was observed when gas bubbles entered the hollow fibers at $1.6 \cdot 10^{-3} \mathrm{~L} / \mathrm{s}$, and the feed concentration was 40 $\mathrm{g} / \mathrm{L}$ dextran. In the albumin experiments, the gas flow rate was $6 \cdot 10^{-4}-1.2 \cdot 10^{-3} \mathrm{~L} / \mathrm{s}$ whereas the used liquid flow rates were $0.011 \mathrm{~L} / \mathrm{s}$ and $0.02 \mathrm{~L} / \mathrm{s} .63 \%$ flux enhancement occurred at a TMP of $45 \mathrm{kPa}$, a gas flow rate of $1.2 \cdot 10^{-3} \mathrm{~L} / \mathrm{s}$, and an albumin concentration of $10 \mathrm{~g} / \mathrm{L}$. The authors observed a much lower permeate flux enhancement in the dextran filtration in the hollow-fiber system than in the tubular membrane. This can be explained by the high shearing rates in hollow fibers, caused by bubbles with a high surface-to-volume ratio (slug), which suppresses concentration polarization. This lowers the sieving coefficient, which increases the apparent membrane rejection ratio. In a subsequent paper [150], the same authors used a similar membrane process for mixtures of BSA and lysozyme, aiming at the fractionation of the two proteins. Hollow-fiber membrane modules at the scale of a pilot plant (with a fiber length of $0.265 \mathrm{~m}$ ) were used in this study. Two different types of membrane were chosen, with an MWCO of $200 \mathrm{kDa}$ (effective surface area of $0.2 \mathrm{~m}^{2}$, internal fiber 
diameter of $0.5 \mathrm{~mm}$ ) and an MWCO of $150 \mathrm{kDa}$ (effective surface area of $0.35 \mathrm{~m}^{2}$, internal fiber diameter of $0.2 \mathrm{~mm}$ ). This UF process using hollow-fiber modules was effective as a means of fractionating mixtures of BSA and lysozyme. For a solution with a concentration of $1 \mathrm{~g} / \mathrm{L}$ of each protein, using a $200 \mathrm{kDa}$ membrane at a TMP of 25 and $75 \mathrm{kPa}$, gas sparging at a frequency of $2 \mathrm{~Hz}$ enhanced the selectivity by a factor of 3-4. However, the lysozyme purity of the permeate was more than $95 \%$ for all experiments, either using gas sparging or not.

Slug flow in hollow fibers was first characterized by Cabassud et al. [151]. They investigated slug bubbles in hollow fibers made of cellulose acetate, with a mean pore diameter of 0.01 $\mu \mathrm{m}$. The fiber's inner diameter was $0.93 \mathrm{~mm}$, and the module contained 15 fibers, hence the effective membrane area was $0.00526 \mathrm{~m}^{2}$. A clay suspension was used at concentrations ranging from 0.9 and $5.2 \mathrm{~g} / \mathrm{L}$. The liquid superficial velocity was set to $0.5 \mathrm{~m} / \mathrm{s}$ and gas velocities varied between 0 and $1 \mathrm{~m} / \mathrm{s}$. A flux enhancement of $216 \%$ was observed during filtration of a clay suspension with a concentration of $0.93 \mathrm{~g} / \mathrm{L}$, TMP of 0.6 bar, and gas velocity of $0.8 \mathrm{~m} / \mathrm{s}$. A steady gas flow was more effective than an intermittent one. During the intermittent mode, particles that deposited during intervals without gas flow, were subsequently more difficult to remove when air was injected again. Authors from the same group presented calculations [152] at the same conditions and showed that air injection lowered the cake's specific resistance and raised cake porosity and cake thickness. This allows higher permeation fluxes. The authors also concluded that injecting air significantly reduces the energy consumption, particularly at low gas velocities, independent of the liquid velocity [153]. The same authors also saw that the gas-liquid two-phase flow in capillaries with an inner diameter less than $4 \times 10^{-3} \mathrm{~m}$ consisted of a succession of gas and liquid slugs rising in the pipe. Gas slugs rose faster than the mean flow and the velocity of the gas slugs was related to the mean velocity of the flow [26].

Authors from the same group reported on the use of air sparging in the treatment of spring water [154] and natural river water [155]. Air and nitrogen gas sparging can be used during spring water treatment to raise the $\mathrm{pH}$ to the required value of nearly 8.2 without adding chemicals. Two-phase flow makes it possible to maintain essential minerals in the spring water, while filtration using chemical treatment changed the water composition. However, the flux enhancement was very low and the permeate flux appeared independent of the air flow rate, since spring water filtration shows very little fouling. The next paper concerned experiments with ultrafiltration of river water; air sparging is more interesting for the 
treatment of waters with a high degree of fouling or a low critical flux. Flux enhancement was found to be mainly linked to mixing and turbulence created by the bubbles in the liquid phase.

Serra et al. [156] studied the application of air sparging to increase the backwash efficiency in hollow-fiber modules. The modules, operated in dead-end and outside-in mode, consisted of ten hollow-fiber membranes made of cellulose-ester. The experiments were carried out using a bentonite suspension and untreated river water. Air was injected into the feed compartment either in combination with a reversed flux of permeate or together with the feed stream. The efficiency of the rinse phase was greatly improved by the use of air, which acts as a piston and flushes out most of the module's free volume. Due to the presence of air, the initial feed concentration inside the module can be reduced by up to $70 \%$. Another paper, by Guigui et al. [157] reported on the application of air sparging to enhance backwash efficiency for an inside-out hollow-fiber module operated in dead-end mode. A bundle of 2000 hollow fibers made of a cellulose derivative with an effective area of about $7.2 \mathrm{~m}^{2}$ was used. A synthetic suspension of $0.2 \mathrm{~g} / \mathrm{L}$ clay particles served as a model for surface waters. Air was added to the permeate water inside the fiber lumen at the bottom of the module, with superficial gas velocities from 0 to $0.5 \mathrm{~m} / \mathrm{s}$. Backwashing with two-phase flow was able to remove the particle cake from the membrane surface with a maximum particle removal of $130 \%$ compared with conventional backwashing without air. A further study by this group, by Bessiere et al. [158], proposed a combination of air-assisted backwash with rinsing to enhance UF for inside-out hollow-fiber modules. This procedure consisted of several steps. After the module had been drained by gravity, air was flushed through the module prior to inducing two-phase flow by injecting air into the concentrate compartment at the top of the module. At the same time, ultrafiltered permeate flowed across the membrane, as in conventional backwash. The next step consisted of a water-only backwash with the water exiting at the top of the module. Before starting the next filtration cycle, the module was flushed with raw water in order to remove all air bubbles from the system. Backwashing with two-phase flow greatly improved the removal of particulates leading to a reduction in cumulative fouling. Remize et al. [159] showed that air-assisted backwash lowered the amount of remaining particulate fouling (i.e. not yet removed at the end of the backwashes). The air-assisted backwash therefore provides significant fouling removal in long-term UF operation for drinking water production. 
Single-phase and gas-sparged hollow-fiber UF experiments for dextran suspensions were carried out by Smith et al. [160]. The module consisted of ten individual polysulfone hollow fibers with an MWCO of $50 \mathrm{kDa}$ and an effective filtration area of $0.033 \mathrm{~m}^{2}$. The liquid superficial velocities were $0.38,0.72$ and $0.99 \mathrm{~m} / \mathrm{s}$, and the gas-sparging frequencies were 0.5 , 1, 2 sparges (sparging period of $4 \mathrm{~s}$ ) per minute and continuous sparging. The filtration flux increased with frequency, a maximum enhancement of $102.5 \%$ was obtained. In their next paper [161], the same authors published a simplified boundary layer theory to predict the filtration flux for gas-slug-enhanced hollow-fiber UF for the same conditions as the previous experiments. The model slightly under-predicted the experimental results. Following this, in a consecutive paper [162], the authors reported an estimation of upper and lower flux limits for gas-sparged UF with hollow-fiber membranes. They developed a physicochemical model for flux prediction comprising an approximate solution of the flow problem, and assuming controlled gas bubble distribution, coupled with a one-dimensional, integral method for boundary layer analysis and flux models. The average of the upper and lower bound flux values gave a good approximation of the experiment flux, but a better approximation with an adapted boundary layer analysis was reported by the same group in a later paper [163].

Majewska-Nowak et al. [164] investigated UF of two model solutions of organic pollutants (dye) and mineral pollutants (kaolin grains) by using a bundle of hollow-fiber membranes. The membrane module consisted of 140 hollow fibers with a diameter of $1.2 \mathrm{~mm}$ and an effective surface area of $0.1 \mathrm{~m}^{2}$, made of polysulfone with an MWCO of $10 \mathrm{kDa}$. The process ran at a TMP of $50 \mathrm{kPa}$ and a gas flow rate of $0-160 \mathrm{~L} / \mathrm{h}$. The permeability of the module during UF of the kaolin solutions was about 50\% larger than during UF of the dye solutions. The reason was that kaolin particles do not penetrate into the membrane pores and likely accumulate at the surface of the membrane; therefore, gas bubbles could easily remove them from the membrane surface. However, the authors also reported that the permeate flux increase is quite small (up to 25\%). Li et al. [165] studied the use of gas sparging for the recovery of protease from pretreated yellowfin tuna spleen extract using UF with hollow fibers made of polysulfone, with an MWCO of $30 \mathrm{kDa}$ and an effective filtration area of 0.01 $\mathrm{m}^{2}$. Cross-flow rates were varied from 17 to $70 \mathrm{~L} / \mathrm{h}$, with gas injection factors of $0,0.15,0.30$, 0.46 and 0.61 (see Fig. 2.11). 


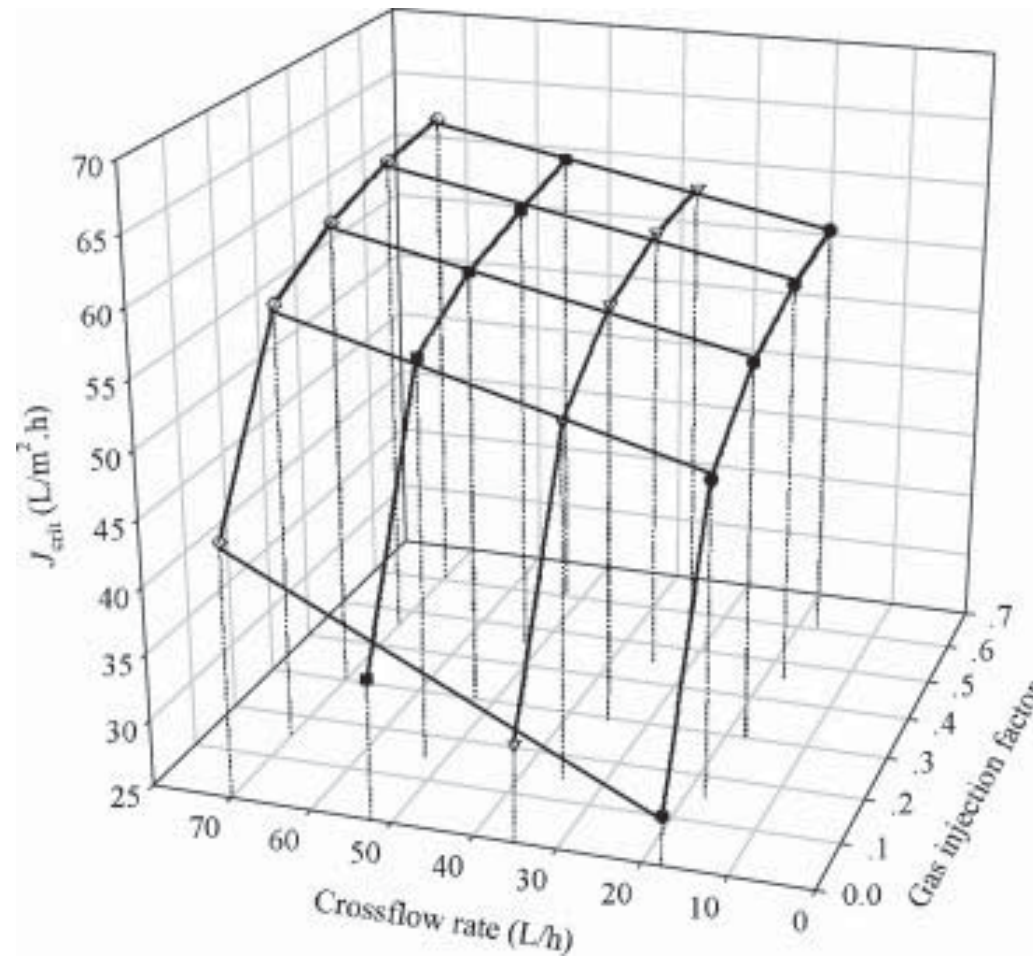

Fig. 2.11. Effect of gas injection factor and cross flow rate on critical flux during ultrafiltration of pretreated yellowfin tuna spleen extract (liquid flow rate: $\bullet 17.55 \mathrm{~L} / \mathrm{h}, \nabla$ $34.99 \mathrm{~L} / \mathrm{h}, \quad 52.49 \mathrm{~L} / \mathrm{h}$, and $\diamond 69.98 \mathrm{~L} / \mathrm{h})[165]$

As shown in Fig. 2.11, the gas injection factor of 0.15 had the strongest effect on the critical flux with an enhancement of up to $69 \%$ (from 28.8 to $48.8 \mathrm{~L} / \mathrm{m}^{2} \mathrm{~h}$ ) at a low cross-flow rate of 17.55 L/h. Higher gas injection factors did not show any advantage over this optimal gas injection factor, e.g. the enhancement is only $10 \%$ when the gas injection factor increased from 0.15 to 0.30 . The authors argued that gas sparging was more effective in a system where flux decline was dominated by concentration polarization rather than by fouling. Cheng and $\mathrm{Wu}$ [36] studied gas-liquid two-phase flow in a hollow-fiber UF membrane module and discussed the influence of operating parameters on the mass transfer coefficient. They used aqueous solutions of Dextran T500 as feed, and measured the permeate fluxes at different feed concentrations, superficial liquid velocities, superficial gas velocities, and transmembrane pressures. The experiments were conducted with a bundle of 250 hollow-fiber membranes, with an inner diameter of $0.5 \mathrm{~mm}$, in the module. The membranes were made of polysulfone with a $30 \mathrm{kDa}$ MWCO, $0.153 \mathrm{~cm}$ length, and $0.06 \mathrm{~m}^{2}$ effective area. The feed concentrations were $2-16 \mathrm{~g} / \mathrm{L}$, the trans-membrane pressures were $58.8-156.8 \mathrm{kPa}$, the solution temperature was kept at $30^{\circ} \mathrm{C}$, the liquid superficial velocities were $0.1-0.3 \mathrm{~m} / \mathrm{s}$, 54 
and the gas superficial velocities were $0.01-0.15 \mathrm{~m} / \mathrm{s}$, corresponding to a gas to liquid ratio $(\theta)$ of 0.03 to 0.6 . The authors found that the flux increases with an increase in liquid velocity, gas velocity, and trans-membrane pressure, and decreases with an increase in the feed concentration. The most significant flux enhancement was achieved when the system operated at a lower liquid velocity. A resistance-in-series model combined with a modified gel polarization model was used to calculate the mass transfer coefficient of this gas-liquid two-phase flow; a dimensional analysis technique was applied to derive a correlation for the mass transfer coefficient. Advantages of the use of hollow-fiber modules over tubular modules with respect to the gas/liquid phase distribution were reported by Verberk and van Dijk [166]. These researchers investigated the distribution of water and air over a tubular membrane module with an inner diameter of $5.2 \mathrm{~mm}$ and a capillary membrane module containing 567 capillary membranes with an inner diameter of $1.5 \mathrm{~mm}$. The air velocity ranged from 0 to $1.8 \mathrm{~m} / \mathrm{s}$ and the water velocity was between 0 and $1.3 \mathrm{~m} / \mathrm{s}$ in the capillary membrane module. In the tubular module, the velocity range of the water was between 0.1 and $0.6 \mathrm{~m} / \mathrm{s}$, whereas the air velocity ranged from 0 to $0.8 \mathrm{~m} / \mathrm{s}$. The distribution of air and water over the cross-sectional area of in the capillary membrane module was found to be more evenly distributed than in the tubular module.

A conclusion is that two-phase cleaning in hollow-fiber or capillary modules increases performance more than in tubular modules because of a better gas/liquid phase distribution. In small tubes (hollow fiber/capillary), gas slugs rise faster, leading to a higher shear rate than in tubular membranes. However, the effect is not always positive because slug bubbles with a high surface-to-volume ratio may suppress the concentration polarization layer, thereby reducing the apparent membrane flux. However, the overall effect is to a large extend dependent on feed type and conditions [149].

\subsubsection{Flat sheet membranes}

Li et al. [167] were the first who reported on gas sparging applied in flat-sheet UF membrane modules. They used polysulfone and polyethersulfone membranes with an MWCO of 100 $\mathrm{kDa}$ and an effective filtration area of $0.0054 \mathrm{~m}^{2}$. Four types of proteins - human serum albumin (HSA, $69 \mathrm{kDa}$ ), human immunoglobulin $\mathrm{G}(\mathrm{IgG}, 160 \mathrm{kDa})$, bovine serum albumin (BSA, $67 \mathrm{kDa}$ ) and lysozyme (Lys, $14 \mathrm{kDa}$ ) - were chosen as feeds (as single solutions of 
HSA and IgG; and binary mixtures of HAS/IgG and BSA/Lys). The liquid flow rates were 0.25 and $0.5 \mathrm{~L} / \mathrm{min}$, and the air flow rates were within the range of $0-200 \mathrm{~mL} / \mathrm{min}$. A maximum of a 50\% increase in permeate flux was reported. In a subsequent paper [168], authors from the same group used the same flat-sheet membrane module and air sparging to fractionate BSA/Lys mixtures and obtained similar findings as in their studies with tubular and hollow fibers. Gas sparging was able to enhance protein fractionation with flat-sheet membranes. The injection of gas bubbles resulted in a decreased transmission of both BSA and lysozyme, with a very significant decrease for BSA. A significant increase in selectivity was observed at low gas flow rates $\left(1.67 \cdot 10^{-6} \mathrm{~m}^{3} / \mathrm{s}\right)$; selectivity was found to be insensitive to a further increase in the gas flow rate. The authors mentioned that this was due to the fact that local mixing within the module induced by two-phase flow for a given liquid flow rate cannot be increased significantly by increasing the gas flow rate.

Cheng and Lin [33] investigated the flux behavior of an inclined flat-membrane cross-flow UF module, with an inclination of $0^{\circ}$ (horizontal, flow above membrane), $90^{\circ}$ (vertical membrane) and $180^{\circ}$ (horizontal, flow below membrane). The membrane used was a $10 \mathrm{kDa}$ MWCO cellulose ester membrane with an effective membrane area of $784 \mathrm{~mm}^{2}$. The tested solution was dextran in distilled water, kept at $30^{\circ} \mathrm{C}$, operated in dead-end and cross-flow mode with liquid velocities of $0,0.02$ and $0.05 \mathrm{~m} / \mathrm{s}$. Compressed air was used as gas phase, with velocities of $0,0.002,0.019$ and $0.053 \mathrm{~m} / \mathrm{s}$. The TMP was adjusted to $200 \mathrm{kPa}$. The filtration flux was reported to be maximal at an inclination of $180^{\circ}$ and minimal at $0^{\circ}$ inclination. The gas slugs were located closer to the membrane surface when the membrane was installed at $180^{\circ}$ inclination, meaning that the gas slugs disturb the concentration boundary layer more effectively. In a subsequent paper [32], the authors investigated the effect of flow channel height on gas-sparging cross-flow UF in a flat-plate membrane module under the same experimental conditions. They reported that gas sparging can effectively increase the flux at any membrane inclination in a narrow channel height of $2 \mathrm{~mm}$. With a large channel height of $10 \mathrm{~mm}$, the shear stress caused by gas sparging was lower than in the narrow channel, unless the gas velocity was high enough.

Several researchers studied the effect of gas type on the efficiency of gas sparging to enhance the flux in the flat-sheet UF membrane process. Um et al. [169] used nitrogen gas injection to achieve flux improvement in cross-flow UF of an oil emulsion. A polysulfone-based flatsheet UF membrane with an MWCO of $100 \mathrm{kDa}$ and an effective area of $2750 \mathrm{~mm}^{2}$ was used 56 
in the study. A commercial cutting oil diluted to $5 \mathrm{wt} \%$, served as the emulsion oil. Compressed nitrogen gas was injected at a rate of $3.3 \cdot 10^{-3} \mathrm{~L} / \mathrm{s}$ under 1 bar pressure to form bubbles. Gas bubble injection was found to promote two possible effects: a positive effect of flux enhancement due to turbulence promoting disruption of concentration polarization, and a negative effect of decreasing the effective membrane area due to the presence of bubbles on parts of the membrane. Here, an increase in gas fraction lead to the creation of adequately sized and sufficient bubbles, so in that case the positive effect was be predominant. Wang et al. [170] used a UF membrane made of regenerated cellulose with an MWCO of $10 \mathrm{kDa}$ and an effective filtration area of $0.0108 \mathrm{~m}^{2}$. Four test solutions were used - lipase (38 kDa), bovine serum albumin $(67 \mathrm{kDa})$, dextran $(64-76 \mathrm{kDa})$ and creatinase $(49 \mathrm{kDa})$ - with a mean superficial fluid velocity of $0.23 \mathrm{~cm} / \mathrm{s}$. Two types of gas were used, namely compressed air and $n$-hexadecane, with a gas injection ratio of 0.33 . The $n$-hexadecane/water two-phase flow was shown to result in a permeate flux enhancement of up to $25 \%$ and up to $17 \%$ with an air/water two-phase flow, compared with single-phase flow during UF of a lipase solution with an initial concentration of $0.63 \mathrm{mg} / \mathrm{cm}^{3}$ (see Fig. 2.12 below).

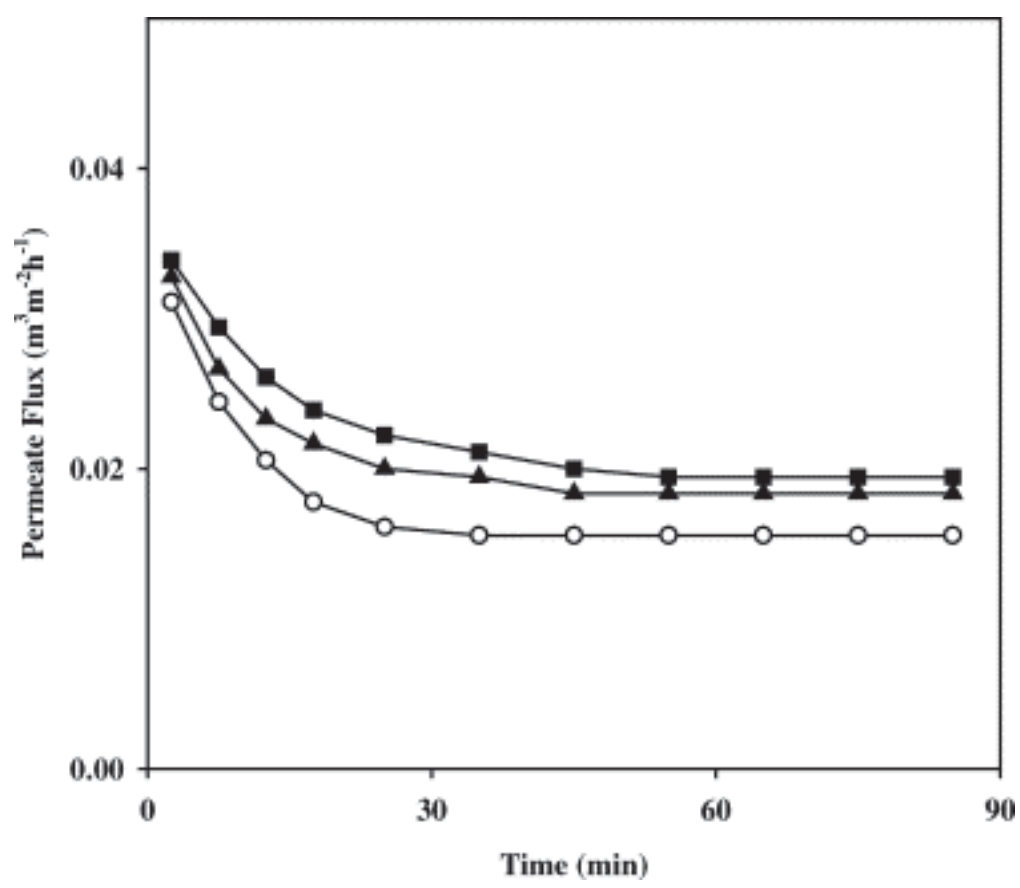

Fig.2.12. Permeate fluxes for conventional single-phase flow $(\bigcirc)$, air/water flow $(\triangle)$ and nhexadecane/water flow ( $\boldsymbol{\square})$, during UF of a lipase solution with a mean superficial fluid velocity $\left(\mathrm{u}_{\mathrm{L}}+\mathrm{u}_{\mathrm{G}}\right)=0.23 \mathrm{~cm} / \mathrm{s}, \Delta \mathrm{P}=207 \mathrm{kPa}$ and gas injection ratio $\theta=0.33$ [170] 
Arnal et al. [171] used air sparging for membrane cleaning of flat-sheet UF membranes after long-term use for surface water filtration. They combined the air with different chemical solutions (hydrogen peroxide, sodium hydroxide, and sodium hypochlorite) with the aim of testing both hydraulic and chemical actions simultaneously. They reported that air bubbles improve the cleaning efficiency of the chemical solutions by $270 \%$ (sodium hypochlorite/air) at $25^{\circ} \mathrm{C}$.

For flat channels, one of the most important aspects to be considered is channel height. Twophase flow cleaning may provide a significant flux improvement when the shear stress is sufficient to disturb the fouling layer. The bubble shear stress in the flat channel strongly depends on the gas/liquid ratio and slug bubbles are only formed at a particular channel height.

\subsubsection{Submerged membranes}

Choksuchart et al. [172] investigated the enhancement of surface water clarification during UF using an immersed membrane system. They used synthetic suspensions of clay to represent suspended solid fractions in ground or surface water. Ferric chloride was used as coagulant salt. The clay concentrations were varied between 0.1 and $5.0 \mathrm{~g} / \mathrm{L}$. A $5.0 \mathrm{~g} / \mathrm{L}$ suspension of clay was used to provide water turbidities in the range of 250-2000 NTU. The experiments were carried out with two membrane modules consisting of 18 and 180 fibers, immersed in a 6-L-contactor tank. The air flow rate ranged between 0 and $200 \mathrm{~L} / \mathrm{h}$. Without air bubbling, the critical flux decreased with increasing clay concentration because of a thick deposit on the membrane surface, but even a low air flow rate of $50 \mathrm{~L} / \mathrm{h}$ made it possible to maintain a relatively constant value of the critical flux. It was also found that while ferric chloride increases floc size, air bubbles induce floc breakage; the effect was greater in the sparsely filled module with 18 fibers than in the tightly packed module with 180 fibers.

As most commonly submerged membrane modules do not have shells (the membranes are directly exposed to the bulk feed solution), Ghosh [79] however, studied the effect of module design with two types of shelled modules on aeration performance of immersed hollow-fiber UF membranes. Two types of modules were used, a tubular Perspex shell with two rows of circular holes of $5 \mathrm{~mm}$ diameter and $25 \mathrm{~mm}$ placed from each end, and another tubular 
Perspex shell with 36 uniformly distributed holes with a diameter of $10 \mathrm{~mm}$, arranged in nine rows along the length of the shell. The shells had a length of $200 \mathrm{~mm}$, an inner diameter of 25 $\mathrm{mm}$ and an outer diameter of $30 \mathrm{~mm}$, within which the hollow fibers were potted with epoxy resin (see Fig. 2.13).

The used hollow-fiber membranes had an MWCO of $150 \mathrm{kDa}$, an inner diameter of $1.2 \mathrm{~mm}$, and an outer diameter of $2 \mathrm{~mm}$ and were made from hydrophilic polyethersulfone. The experiments were operated in outside-in mode, using Dextran as feed solution with concentrations of 10,20 and $40 \mathrm{~kg} / \mathrm{m}^{3}$. The gas sparging rate was $1.83 \cdot 10^{-5}, 3 \cdot 10^{-5}$ and $\left.4.33 \cdot 10^{-5}\right) \mathrm{m}^{3} / \mathrm{s}$, with a duration of $30 \mathrm{~min}$. The author concluded that gas-sparging is able to enhance permeability in submerged hollow-fiber modules for UF of macromolecular solutions. The effectiveness of gas sparging increased with increasing feed concentration in the experiments. The enhancement depended on the gas flow rate employed, but the results indicate that once the gas flow had increased to a certain level, a further increase in gas flow rate did not increase the permeability further. Modules with fewer holes showed a more positive effect of gas sparging, as in the other modules, gas bubbles escaped through the shell holes, thereby diminishing the bubbles' hydrodynamic effect.
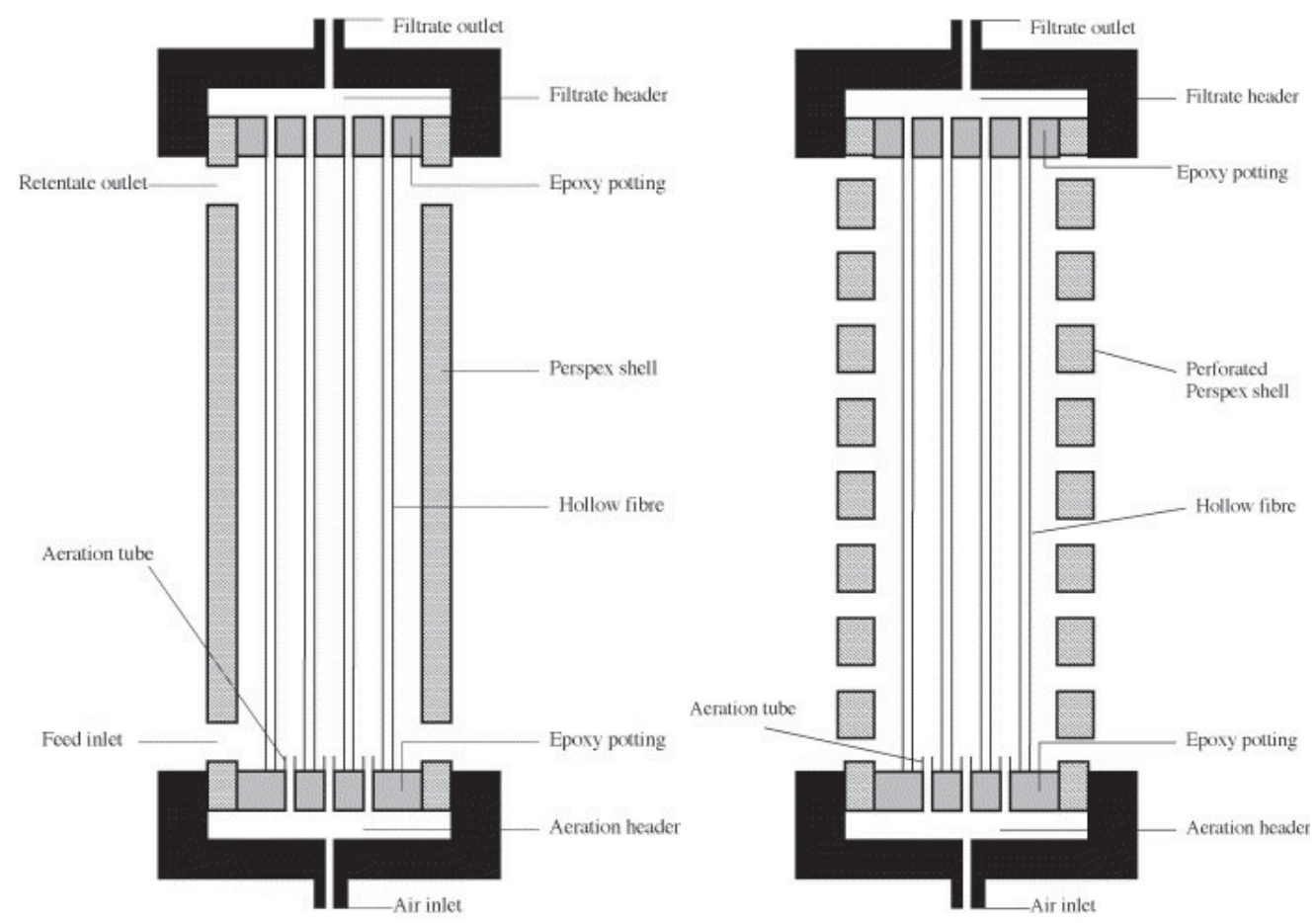

Fig. 2.13. Two types of shelled modules used to study the effectiveness of aeration in submerged hollow-fiber membranes [79]. 
Tian et al. [112] investigated the influence of air-bubbling mode (continuous and intermittent bubbling), air flow rate and air bubble size on fouling of immersed hollow-fiber membranes for UF of river water. The membrane fibers were made of PVDF, and had an inner diameter of $0.85 \mathrm{~mm}$ and outer diameter of $1.45 \mathrm{~mm}$. The mean membrane pore size was $0.01 \mu \mathrm{m}$, and the effective membrane area was $0.002 \mathrm{~m}^{2}$. The experiments were done at a constant flux of $60 \mathrm{~L} / \mathrm{m}^{2} \mathrm{~h}$, and the initial TMP of the membrane modules was $18 \pm 1 \mathrm{kPa}$. The air flow was set to $1.0,2.5,5.0$ or $7.5 \mathrm{~m}^{3} / \mathrm{m}^{2} \mathrm{~h}$, and four types of air diffusers were used to generate air bubbles with spherical shapes and diameters of 3.5, 5.0, 6.5 and $8.0 \mathrm{~mm}$. Two modes of air bubbling were evaluated, i.e. continuous bubbling and intermittent bubbling (with a time sequence of 1 $\mathrm{min}$ on/9 $\mathrm{min}$ off, equal to the filtration mode of $9 \mathrm{~min}$ on/1 $\mathrm{min}$ off). Continuous bubbling was found to be more effective in removing fouling than intermittent bubbling. The optimum air flow rate was determined as $5.0 \mathrm{~m}^{3} / \mathrm{m}^{2} \mathrm{~h}$ when considering the alleviating effect on membrane fouling and energy consumption together. Smaller bubble sizes were more effective in mitigating membrane fouling.

Yuliwati et al. [173] used the response surface methodology (RSM) to optimize process conditions in submerged UF membranes for refinery wastewater treatment. They investigated the effect of air bubble flow rate (ABFR), hydraulic retention time (HRT), mixed liquor suspended solid (MLSS) concentration and $\mathrm{pH}$ on membrane performance. Hollow-fiber PVDF membranes were used, with an inner diameter of $0.55 \mathrm{~mm}$, outer diameter of $1.1 \mathrm{~mm}$, and average pore size of $34.05 \mathrm{~nm}$. An experimental design based on RSM was used in a total of 28 experiments. ABFR was set to $0.3,1.2,2.1,3.0$ and $3.9 \mathrm{~mL} / \mathrm{min}$, HRT ranged from 120 to $360 \mathrm{~min}$, MLSS concentrations were fixed between 1.5 and $7.5 \mathrm{mg} / \mathrm{L}$ and $\mathrm{pH}$ values ranged from 3.5 to 9.5. The authors observed that a submerged UF process using PVDF membranes has a great potential for the treatment of refinery-produced wastewater. A full factorial design and central composite design of RSM was used to determine significant variables and optimum condition for submerged UF with respect to flux and COD removal. Optimum conditions were achieved at an ABFR of $3.75 \cdot 10^{-5} \mathrm{~L} / \mathrm{s}$, an HRT of $4.6 \mathrm{~s}$, an MLSS concentration of $4.5 \mathrm{~g} / \mathrm{L}$ and a $\mathrm{pH}$ of 6.5 , resulting in flux of $145 \mathrm{~L} / \mathrm{m}^{2}$ and COD removal of $90.28 \%$.

At least two aspects are important in the use of two-phase flow in submerged-membrane UF: (i) gas flow rate, and (ii) bubble size. From the findings reported in the literature, higher gas flow rates increase the gas-to-liquid volume ratio, thereby increasing membrane surface 60 
sweeping by the gas. With respect to bubble size, smaller bubble size also enhances the accessibility of the membrane surface due to their uniform distribution over the surface and the prevention of channeling. Larger sized bubbles without the occurrence of channeling can be achieved by increasing the gas fraction so then the bubble induced shear stress can be enhanced and fouling can be controlled more effectively. Since most submerged membranes are used in aerobic membrane bioreactors, one should also be aware that aeration does not only enhance hydrodynamics, but could also affect the biomass.

\subsubsection{Nanofiltration}

The process characteristics of nanofiltration (NF) are between those of UF and reverse osmosis (RO) with typical low to moderate rejection of monovalent ions and high rejection of substances with a molecular weight above the MWCO of the membrane, which is usually in the range of $150-300[174,175]$. Along with RO, NF is increasingly used in drinking water treatment, seawater desalination, wastewater reclamation and for the production of water for industrial purposes. Because of the intensive use of NF in large-scale plants and operation at high pressures, compact and highly packing density modules are chosen, namely either spiralwound membrane modules or hollow-fiber/capillary membrane modules. Possible causes of fouling in NF include precipitation of substances which have exceeded their solubility, deposition of colloidal matters, chemical reaction of solutes at the membrane boundary layer, adsorption of low molecular mass compounds at the membrane polymer, irreversible gel formation of macromolecular substances and colonization by bacteria [176]. Due to these different fouling characteristics, two-phase flow cleaning in NF is different than in MF and UF.

The first work on two-phase flow to enhance the performance of NF membranes was published by Ducom et al. [28], who studied two-phase flow in flat-sheet NF membranes with surfactant stabilized and non-stabilized oil-in-water emulsions. These authors reported that in the case of stabilized $10 \%$ oil-in-water emulsions, a $120 \%$ flux enhancement occurred by using an air-sparging flow rate of $1 \mathrm{~m} / \mathrm{s}$ and a liquid velocity of $0.12 \mathrm{~m} / \mathrm{s}$, at a TMP of 4 bar. The flux enhancement increased to $240 \%$ for the same flow conditions, but at a TMP of 4.5 bar for the non-stabilized $10 \%$ oil-in-water emulsions. In the case of non-stabilized oil-inwater emulsions, an oil layer immediately forms at the membrane surface from, but this layer 
is easily removed by two-phase flow. Stabilized oil-in-water emulsions on the other hand causes pore blocking type of fouling, which is much more difficult to remove. In the case of solutions containing only salts in water without any suspended solids, only a very small improvement was obtained by two-phase flow cleaning [30]. Particle size in the feed solution appears to play an important role in the effectiveness of air sparging; very fine particles or very diluted and homogenous solutions tend to cause pore plugging which is very difficult to reverse by air sparging. Authors from the same group [27] tested two-phase flow in a flatsheet nanofiltration membrane and characterized the air/water two-phase flow by using a video system in order to understand how air sparging enhances the flux. Both image analysis and numerical modeling were performed. Importantly, this study determined wall shear stress and pressure distribution in space and time, in relation to the frequency of two-phase flow. Using the same module, authors from the same group used nine microprobes, which were distributed on the module surface to measure and characterize wall shear stress [29, 177] in the presence of gas/liquid two-phase flow. The higher the gas velocity, the greater the flux increase and the wall shear stress at the membrane surface

Drews et al. [115] calculated the dependence of wall shear stress on bubble diameter and liquid velocity. They concluded that the efficiency of cleaning is not merely dependent on bubble size (wall shear stress can decrease with bubble size), but also on membrane spacing (the greatest shear was reached in the narrowest channel), aeration intensities (increased aeration intensity led to increased permeability) and start-up strategies (i.e. classification of particles, as fine particles tend to result in pore blocking and low initial fluxes relative to larger particles which provide high initial fluxes and lead to coarse cakes that protect pores from further plugging). Membrane spacing is not only important for plate-type membrane modules but also for tube-type membrane modules. Verberk and Van Dijk [178] performed air/water two-phase flow in capillary $\mathrm{NF}$ at a temperature of $20^{\circ} \mathrm{C}$, TMP of 2 bar and recirculation velocity of $1.5 \mathrm{~m} / \mathrm{s}$. A permeate flux enhancement and an increase in retention were observed when $0.34 \mathrm{wt} \%$ saltwater $\left(\mathrm{MgSO}_{4}\right)$ solution fed at a constant liquid velocity of $0.5 \mathrm{~m} / \mathrm{s}$ was injected with air (see Fig. 2.14).

As shown in Fig. 2.14, permeate fluxes of the $\mathrm{MgSO}_{4}$ solution were 31-51\% lower than the clean water flux (CWF), owing to the combined effect of osmotic pressure and concentration polarization. The injection of air caused an increase in the permeate flux ranging from 11$17 \%$. Air sparging also promotes retention although only a small retention increase was 
observed. The increase of permeate flux and retention reflected the importance of concentration polarization which decreases significantly when air is injected into the water flow. This study confirmed that capillary NF combines the advantages of (i) good rejection of the membranes leading to high water quality and (ii) good hydraulic cleaning possibility, especially when using air/water two-phase flow.

It can be concluded that concentration polarization of saltwater solutions or oily solutions close to the NF membrane surface can be disrupted by two-phase flow cleaning; however, the improvement is lower than that for solutions containing suspended solids. Nevertheless, the disruption of concentration polarization may prevent the further precipitation of minerals on the membrane surface.
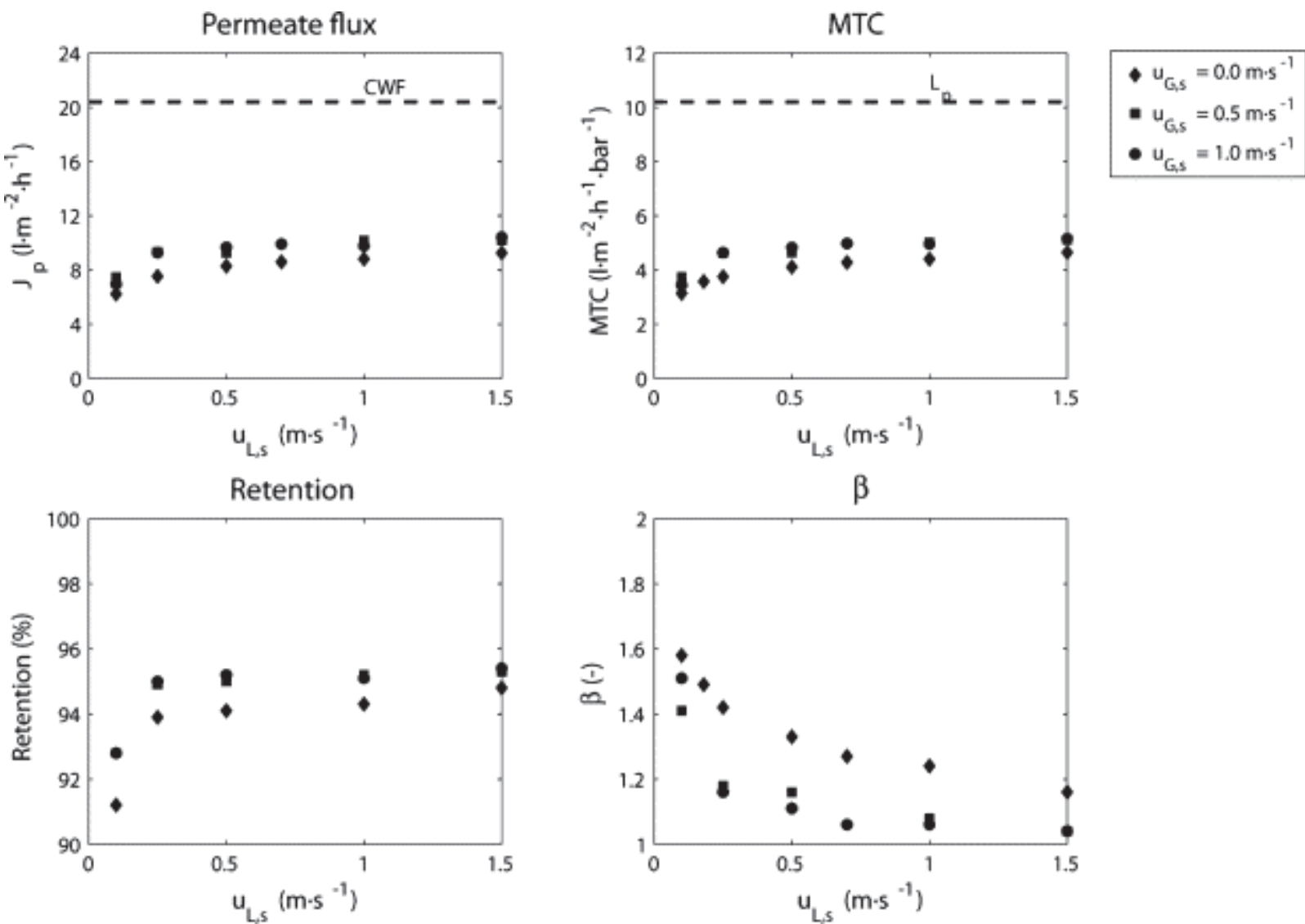

Fig. 2.14. Permeate flux, retention, mass transfer coefficient (MTC) and concentration polarization $(\beta)$ as function of the superficial liquid velocity $(0.5 \mathrm{~m} / \mathrm{s})$ for different superficial air velocities $\left(\mathrm{TMP}=2 \mathrm{bar} ; \mathrm{MgSO}_{4}\right.$ concentration=0.34 wt\%) [178]. 


\subsubsection{Reverse osmosis}

Biofilm growth is the most problematic fouling type in reverse osmosis (RO) systems; it leads to a flux drop and increased operational costs. An analysis of 150 membrane samples collected all over the world showed that more than $50 \%$ of the fouling consisted of biological and organic foulants [179]. When solid particles, organic and inorganic substances are removed during pre-treatment, biofouling remains. Even if $99.9-99.99 \%$ of all bacteria are eliminated by pre-treatment, a few will enter the RO system, adhere to surfaces and multiply at the expense of biodegradable substances [180]. This makes biofouling the main target for two-phase flow cleaning in RO processes.

Cornelissen et al. [87, 88] was among the few researchers who used two-phase flow in a high-pressure membrane process employing spiral-wound membrane modules. They used two-phase flow coupled with chemical dosing (daily $1 \mathrm{~g} / \mathrm{L} \mathrm{CuSO}{ }_{4}$ during 30 minutes) to inactivate and remove biomass. The study was performed using three vertically positioned spiral-wound membrane modules tested in parallel; one was a reference (REF) module into which only air/water two-phase flow was introduced (indicated by arrows) when the pressure drop increased by more than $150 \%$, the second was a daily air/water two-phase flow module (AWC) at an air to water ratio of 2:1 and the third a module treated daily with copper sulfate (CSD). The experiment ran for 110 days, and showed that an air/water two-phase flow is effective in controlling the pressure drop (Fig. 2.15).

Visual observations revealed that the bulk of the organic and inorganic matter was removed within the first few minutes of two-phase flow in this study. In a subsequent paper [91], the same authors confirmed that two-phase flow in high-pressure spiral-wound membrane processes was also able to remove particle-type fouling.

A further investigation by Vrouwenvelder et al. [181] validated two-phase flow in spacerfilled channels by using a tool called membrane fouling simulator (MFS) and similar flow cells at the lab scale. Vrouwenvelder [182] used an air-water flow to generate a high shear flow to remove voluminous and filamentous biofilm structures attached in the feed spacer channels of the vertically positioned membrane fouling simulators. Bubble flows were produced by compressed air at a pressure of $150 \mathrm{kPa}$ and at linear liquid velocities between 0.041 and $0.245 \mathrm{~m} / \mathrm{s}$. Air-water flow cleaning lowered the pressure drop, decreased the biomass concentration, and produced a smaller friction factor. 

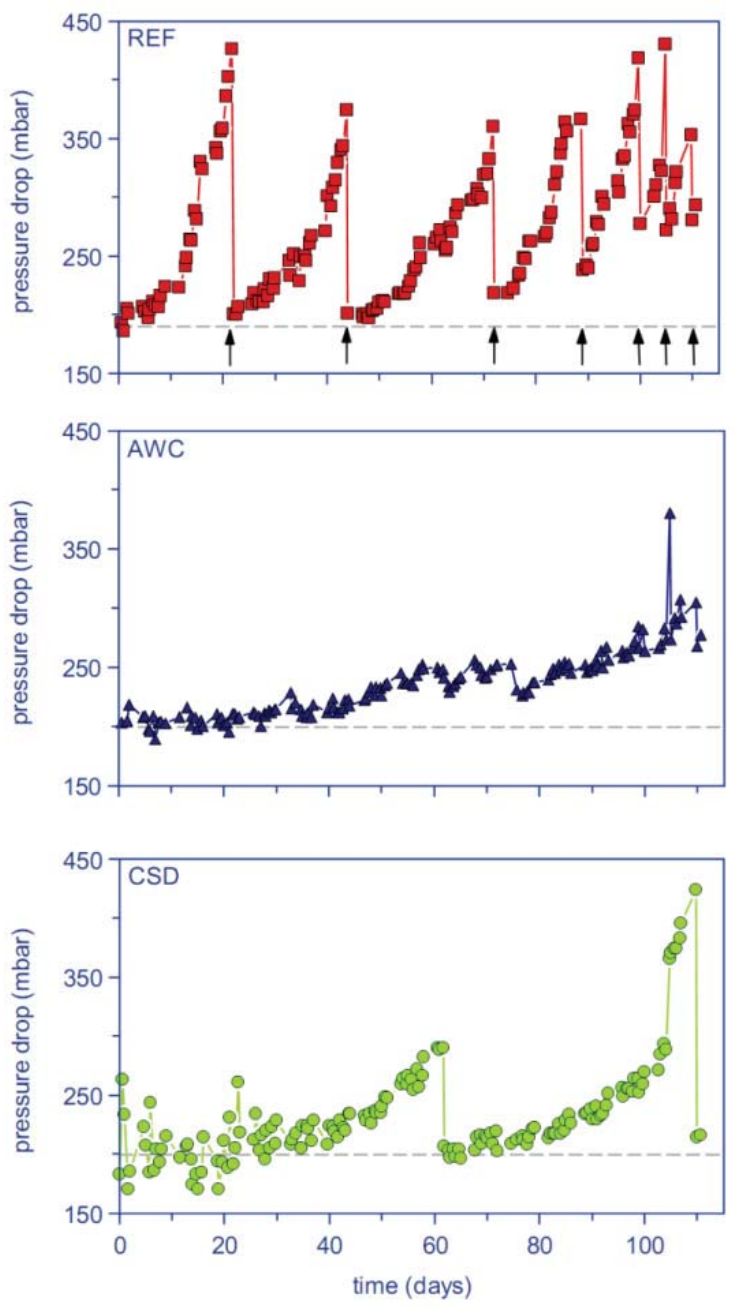

Fig. 2.15. Pressure drop in time without (REF) and with (AWC) air/water two-phase flow and copper sulfate dosing (CSD) in 110 days [88].

Fundamental studies on air-water flow behavior inside spacer-filled narrow channels were published by Cornelissen et al. [89], who reported that two-phase flow is able to remove fouling and that the size of the bubbles is equal to the size of the diamond of the feed spacer. A further study by Willems et al. [90] used a high-speed camera and found that the bubble size was almost independent of spacer geometry and material; within this study, the range of liquid velocities varied between $0.05 \mathrm{~m} / \mathrm{s}$ and $0.7 \mathrm{~m} / \mathrm{s}$, the gas velocity was kept constant at $0.05 \mathrm{~m} / \mathrm{s}$, and the work was carried out at room temperature. The bubble size was similar for all spacers studied at a given Reynolds number which was based on the water velocity and the hydraulic diameter of the spacer. In a consecutive paper [92], the same authors used particle imaging velocimetry (PIV) to measure liquid velocity profiles in a two-phase flow 
through spacer-filled channels. They observed unsteady instantaneous velocity profiles when a bubble passed through a spacer; this condition is desirable, since this will disturb the concentration polarization layer. Wibisono et al. [183] reported that bubble size depends on the air-water ratio; higher ratios produce larger bubbles, although large bubbles tend to form flattened ellipses with long tails following the shape of the diamond spacer. They also reported that air-water flows are able to remove model foulant particles attached to membrane and feed spacer surfaces, such as in monodispersed polystyrene, colloidal silica and humic acid solutions. Authors from the same group reported in their successive paper [184] that spacer geometries, i.e. spacer shape and thickness, may affect the performance of air-water cleaning in spacer-filled narrow channels.

In summary, two-phase flow cleaning is able to remove voluminous and filamentous biofilm structures attached to membrane and feed spacer surfaces, lowers the pressure drop and decreases biomass concentration more than by application of chemical cleaning. However, further improvements in two-phase flow cleaning may be possible by optimizing the twophase flow process in RO systems and using modified RO modules.

\subsubsection{Membrane bioreactors}

Two major advantages of employing aeration in aerobic membrane bioreactors (MBRs) is the delivery of oxygen for substrate oxidation, biomass respiration, nitrification and at the same time providing agitation to ensure high mass transfer rates and complete mixing in the tank (see Fig. 2.16) [185].

As aeration is understood to be the most important parameter in the design and operation of an MBR, two-phase flow in membrane processes is most frequently carried out in MBR applications. Aeration in MBRs not only improves membrane performance by reducing fouling but also reduces the energy consumption [57]. An enormous amount of publications on MBR and aeration was produced by many researchers worldwide. The papers focused on for instance altered operating conditions [47, 54, 67, 68, 186-193], hydrodynamics in the system [38, 48, 50, 59, 60, 63, 72, 74, 75, 77, 78, 111, 188, 194-205], fiber movement and configuration [55, 61], energy assessment [53, 57] or fouling mitigation [38, 39, 45, 49-52, 62, 67-69, 73, 76, 80-86, 189, 190, 194, 203, 206-212]. 


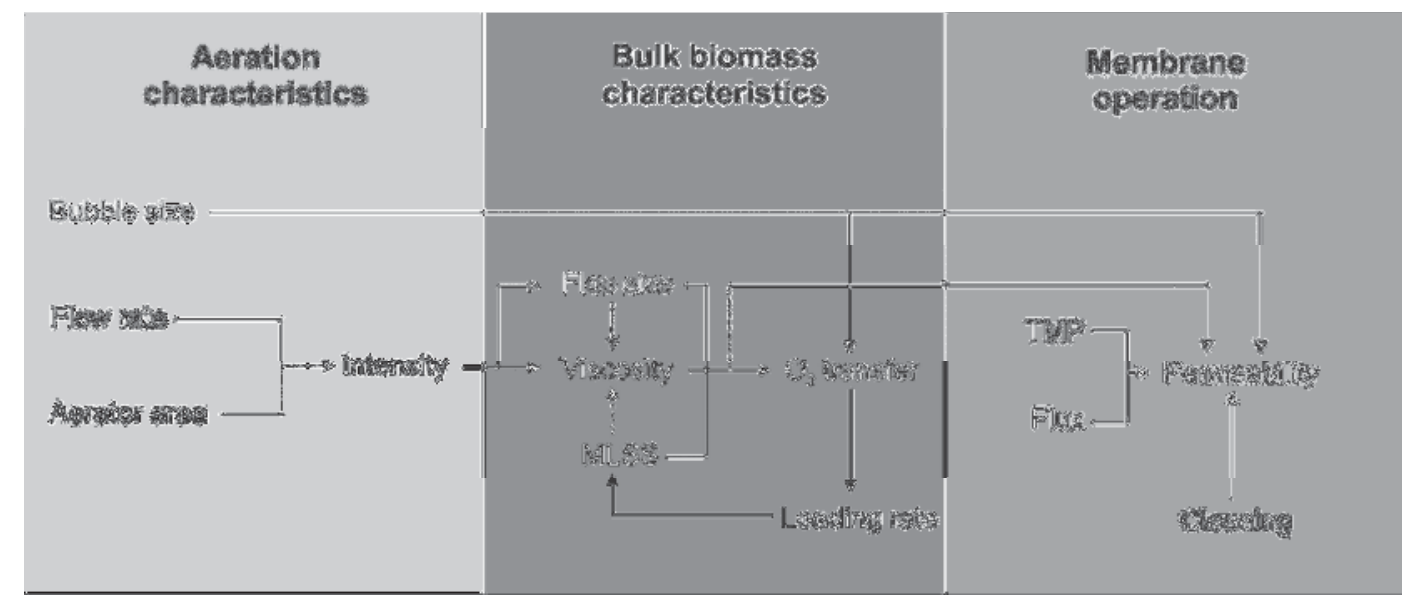

Fig. 2.16. The relationships between aeration and various system facets and parameters in immersed MBRs [185].

This present review does not provide a detailed overview of aeration and two-phase flow in MBRs; detailed information on aeration as an effective strategy to control fouling in MBRs can be found elsewhere [213-216]. For example, Braak et al. [213] highlighted a need to quantify the predominant mechanisms that improve MBR performance, i.e.: (i) turbulence, which has a positive effect on the enhancement of back-transport, (ii) fiber movement, which increases the probability for the membrane to benefit from air sparging and allows a higher shear stress to be induced by the liquid, and (iii) air shear stresses, which can have both a positive and a negative impact and in which a balance must therefore be found between the increase of shear stresses that allow the removal of foulants from the membrane and preserving the integrity of the mixed liquor. Drews [215] noted that optimizing MBR tank, sparger and module geometries could help with respect to energy and operational cost savings.

\subsubsection{Membrane contactors and membrane distillation}

A membrane contactor employs a membrane which promotes contact between phases [217]. In case one of the phases is a liquid, applications include membrane distillation, blood oxygenators, evaporative cooling, pervaporation, membrane emulsifiers, olefin/paraffin separation, membrane absorbers, membrane degassers and oxygen distillation [218-220]. 
A variation of separation based on membrane contactors is direct-contact membrane distillation (DCMD). In DCMD, a heated non-wetting solution flows on one side on the module; the vapor phase of the solution diffuses through the pores, and is then condensed at the other side of the membrane [217, 221]. In membrane distillation, a flux decline may occur owing to deposition of particles, colloids, emulsions, suspensions, macromolecules, microorganism growth etc. [222]. The use of gas sparging was reported to enhance the flux in direct-contact membrane distillation [104, 223], vacuum membrane distillation [224] and submerged-membrane distillation bioreactors (MDBR) [65].

Problems resulting from membrane fouling in membrane distillation are considerably less severe than in pressure-driven membrane processes such as MF and UF. However, fouled membrane surfaces and salt deposition on the membrane surface can lead to wetting of the pores and decrease the effective membrane area. This leads to a flux decline and to low separation factors [222]. One of the first papers reporting the use of air bubbling in membrane distillation was produced by Ding et al. [104]. They studied the application of DCMD for concentrating the extract of traditional Chinese medicine (TCM) and mitigated the occurring fouling. A plate-and-frame membrane module, with a spacer in its feed and permeate flow channels for better fluid dynamics, was used to perform DCMD. The membrane was a hydrophobic membrane made of PTFE and had a pore size of $0.2 \mu \mathrm{m}$, a thickness of $60 \mu \mathrm{m}$ and an effective area of $0.005 \mathrm{~m}^{2}$. The TCM extract to be concentrated was heated to $43-62^{\circ} \mathrm{C}$ and pumped to the module; another pump was used to circulate the permeate water (maintained at $25^{\circ} \mathrm{C}$ ) at the permeate side of the membrane module, the permeate tank and the coil in a chiller. The velocity of the feed and permeate flow in the membrane module ranged from 0.07 to $0.13 \mathrm{~m} / \mathrm{s}$. The concentration ratio $(\mathrm{CR})$ was defined as the ratio of the volume of initial extract to the volume of concentrated extract, and was used as an indication of concentrating performance of the experiments. To mitigate membrane fouling, a fan was used to create gas bubbling at the feed side of the membrane module and also to generate gas sparging at the permeate side for gas backwashing of the membrane. The authors observed a sharp flux decline right after the air was introduced into the feed circulation and the flux remained at much lower level when air was continuously injected. The bubbles occupied part of the liquid-contacting area in the membrane, thus reducing the effective membrane area and when gas entered the membrane pores, this reduced the partial pressure of water vapor within the pores, thus reducing the driving force. To reduce these effects, intermittent gas sparging 
at the feed side at intervals of $20 \mathrm{~min}$ and lasting only $2 \mathrm{~min}$, and gas backwashing by intermittent inputting of air on the permeate side of membrane module was applied. The gas stream penetrated into the membrane pores, and blew away deposited foulants from the membrane surface at the feed side. Backwashing was done with a gas phase, since the membrane used in DCMD is hydrophobic.

Fig. 2.17 shows the effect of using gas bubbling on the DCMD performance used to concentrate TCM extracts: (a) at the feed side with an initial TCM concentration of $1.35 \mathrm{~g} / \mathrm{L}$, and (b) intermittent gas backwashing at the permeate side.

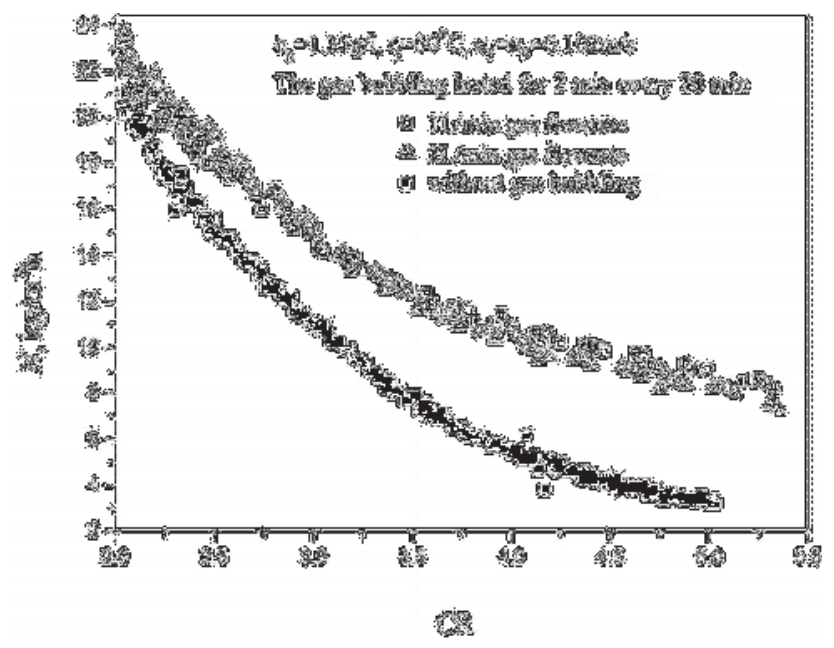

(a)

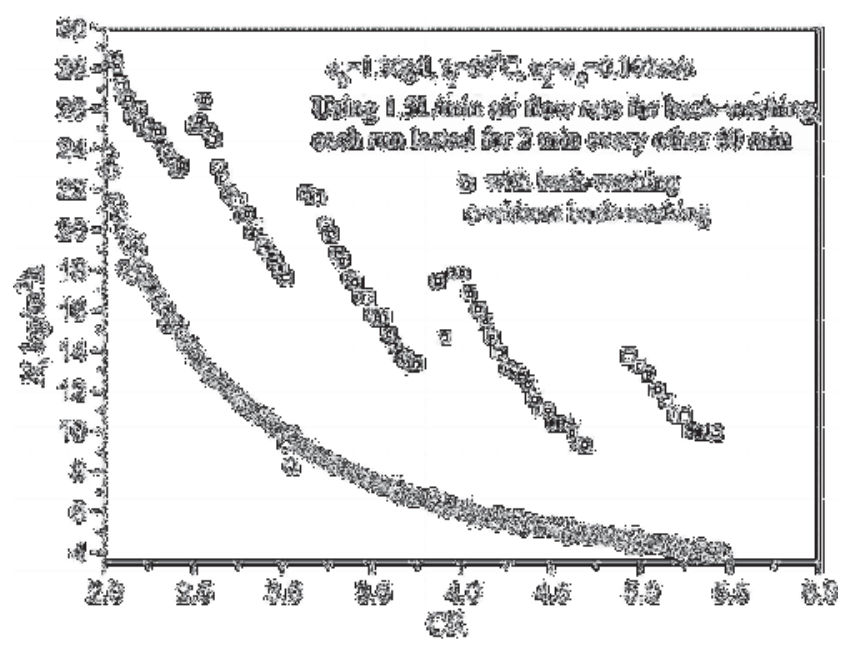

(b)

Fig. 2.17. Performance of DCMD using gas bubbling on: (a) the feed side, and (b) the permeate side (CR: concentration ratio) [104]. 
As is clear in Fig. 2.17a, a rapid flux decline occurred in the beginning of the experiment, after which the flux decline slowed down, as a result of the very low-flux level at this time. Using gas bubbling at the feed side resulted in a higher flux in the beginning of the experiment, and was followed by a much slower flux decline. With gas bubbling, it took 400 min to increase the concentration ratio from 2.0 to 6.0; without gas bubbling, it took $600 \mathrm{~min}$. Very similar trends were observed with gas bubbling at 1 and $2 \mathrm{~L} / \mathrm{min}$, meaning that increasing the gas flow rate does not result in further process enhancement. When comparing the flux behavior with and without gas backwashing, it is clearly shown in Fig 2.17b that backwashing is able to restore the flux partly. Gas backwashing was not able to restore the flux fully; this is related to having to limit the used gas pressure to avoid breakage of flatsheet membranes. Hollow-fiber membranes are expected to allow higher flux recovery during gas backwashing in DCMD, since they are self-supported and can withstand higher gas pressures. In a subsequent paper [223], the same authors conducted experiments to confirm the feasibility and effectiveness of fouling limitation by intermittent gas bubbling in the same systems. Toward this aim, they kept the foulant concentration (or the CR) constant. The effects of gas flow rate, bubbling duration in each cycle and MD duration in each cycle were investigated. The gas bubbling cleaning efficiency was enhanced by increasing the gas flow rate, gas bubbling duration and decreasing the membrane distillation duration. The overall conclusion was that gas bubbling in the feed liquid may improve the fouling behavior in DCMD.

Another type of membrane distillation is termed vacuum membrane distillation (VMD), in which a vacuum is applied at the permeate side of the membrane module by means of a vacuum pump. The applied vacuum pressure is lower than the saturation pressure of the volatile molecules to be separated from the feed solution, and condensation takes place outside of the membrane module [222]. Gas bubbling in VMD was applied by Wu et al. [224] who employed a hydrophobic PVDF hollow-fiber microporous membrane, and compared the performance of air-bubbling vacuum membrane distillation (AVMD) with conventional VMD. Compressed air was injected into the lumen side of the hollow-fiber membranes, together with the hot feed solution, at the inlet of membrane module. The permeate flux increased with increasing air flow rate and/or feed temperature. When tested at $75^{\circ} \mathrm{C}$, a feed flow rate of $120 \mathrm{~L} / \mathrm{h}$, and a vacuum pressure of $0.0085 \mathrm{MPa}$, the permeate flux was $22 \mathrm{~kg} / \mathrm{m}^{2} \mathrm{~h}$ In conditions of induced gas bubbles and at a feed flow rate of $60 \mathrm{~L} / \mathrm{h}$, the permeate flux 
increased to $40 \mathrm{~kg} / \mathrm{m}^{2} \mathrm{~h}$. The flux declined in both processes (with and without air bubbling) as the feed concentration increased from $3.5 \mathrm{~g} / \mathrm{L}$ to $300 \mathrm{~g} / \mathrm{L}$. However, with air bubbling, the flux decline was much slower. SEM pictures confirmed that there was much more salt deposition on the membrane surface without air bubbling than with air bubbling. A hybrid process combining membrane distillation in a submerged membrane bioreactor (MDBR) operated at elevated temperatures was developed and tested by Phattaranawik et al. [65]. MDBR was used in wastewater treatment with the aim to: (i) achieve improved permeate quality in a single compact process, and (ii) degrade non-volatile, hardly biodegradable organic species by retaining these species in the reactor. However, the raised operating temperature in MDBR was found to accelerate severe fouling and flux decline. The authors observed that adding two inlets for air sparging at $2.5 \mathrm{~L} / \mathrm{min}$ each near the potting at the center of the membrane bundle induced more turbulence at the membrane surface. Relative stable fluxes were observed over fifteen days with an average value of $5.16 \mathrm{~L} / \mathrm{m}^{2} \mathrm{~h}$. To sum it up, two-phase flow at elevated temperatures is able to remove deposited salt and foulants from the membrane surface at the feed side in membrane distillation. The flux enhancement is greater at higher gas flow rates, and when gas bubbles are able to enter the membrane pores, the effect on flux enhancement is improved.

\subsubsection{Ion-exchange membrane processes}

The principle of ion-exchange membrane separation processes is based on the combination of transport of electrical charges and transport of mass. One example is electrodialysis (ED), in which particularly the operating current density is restricted by concentration polarization (termed limiting current density). Concentration polarization in ED is caused by differences between the ion transport number in the electrolyte solution and in the ion exchange membrane. The fluid flow in ED modules mainly takes place in flat channels with rectangular cross-sections; the membranes form the walls and the channels are filled with spacer material. The spacers promote turbulence and provide mechanical stability to the module. However, the use of non-conductive spacers leads to higher costs and to a spacer shadow effect [225]. To overcome these drawbacks of spacers, Balster et al. [226] proposed the use of air sparging to promote turbulence in a spacer-free ED channel. The effect of air sparging on mass transfer was evaluated by limiting current density and cell resistance measurements at 
different gas/liquid ratios at a constant flow velocity in a simplified bipolar membrane ED system, containing a single dilution and concentration channel pair. Bipolar and cation exchange membranes were used, placed in a membrane module with an area of $100 \mathrm{~cm}^{2}$. Air flow was controlled and mixed with the liquid stream before entering the stack, with the gas/liquid ratio ranging from 0 to 0.9 (see Fig. 2.18).

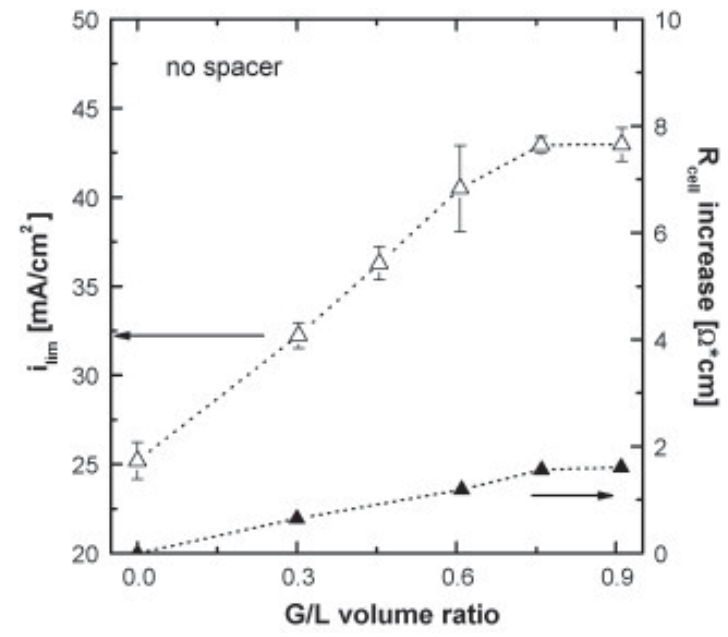

(a)

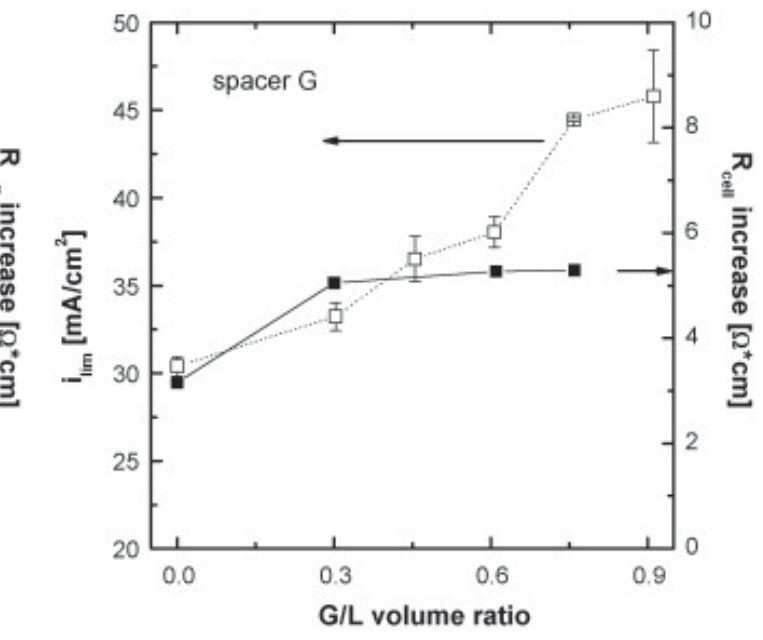

(b)

Fig. 2.18. Dependence of limiting current density and cell resistance $\left(R_{\text {cell }}\right)$ increase on $G / L$ ratio for (a) the empty-cell configuration (spacer-free), and (b) the single-layer spacer configuration [226].

As shown in Fig. 2.18a, air sparging in a spacer-free feed channel promoted a linear increase in limiting current density up to $70 \%$ compared to single phase flow and a cell resistance of less than $2 \Omega \mathrm{cm}$ until a $\mathrm{G} / \mathrm{L}$ ratio of approximately 0.75 . Further increase of the G/L ratio did not lower the limiting current density more. Fig. $2.18 \mathrm{~b}$ shows that applying air sparging in a single-layer spacer configuration with a porosity $\varepsilon$ of 0.75 , increasing the $\mathrm{G} / \mathrm{L}$ ratio resulted in an increase of the limiting current density, with the greatest enhancement of $50 \%$ and a cell resistance of $5 \Omega \mathrm{cm}$ being achieved at a $\mathrm{G} / \mathrm{L}$ ratio of 0.9 . The advantage of two-phase flow is shown as a low increase in resistance combined with an achieved mass transfer increase of more than $70 \%$ using.

Bunce et al. used two-phase flow in an electrolysis application with ion-exchange membranes for remediation of acid mine drainage [227]. A solution of synthetic acid mine drainage, containing $\mathrm{FeSO}_{4} / \mathrm{H}_{2} \mathrm{SO}_{4}$ and $\mathrm{CuSO}_{4} / \mathrm{H}_{2} \mathrm{SO}_{4}$, in flow cells of which the anode and cathode 
compartment were separated was treated by an electrolytic reduction process using ion exchange membranes. In the case of $\mathrm{FeSO}_{4} / \mathrm{H}_{2} \mathrm{SO}_{4}$ and at constant flow rate, the $\mathrm{pH}$ of the effluent from the catholyte increased significantly with increasing current and a variety of cathodes because of electrolytic reduction of $\mathrm{H}^{+}$ions to elemental hydrogen. To avoid fouling of the electrodes by iron hydroxides, air sparging was introduced into the catholyte effluent. At a current of $80 \mathrm{~mA}$, almost $100 \%$ iron removal was obtained. Min et al. applied twophase flow in microbial fuel cells (MFCs) [228]. An MFC produces electricity directly from the degradation of organic matter rather than indirectly from organic materials with biologically generated hydrogen. An MFC ordinarily consists of two chambers, one anaerobic (anode) and one aerobic (cathode). In the anaerobic chamber, the substrate is oxidized by bacteria and electrons are transferred to the anode by an exogenous electron carrier, a mediator (such as potassium ferric cyanide, thionine, or neutral red), or directly from the bacterial respiratory enzyme to the electrode. The anaerobic chamber is connected internally to the aerobic chamber by a proton-conducting material, in this study a proton exchange membrane. This membrane was clamped between the flattened ends of the two glass tubes, fitted with rubber gaskets. Oxygen diffusion from the cathode chamber through the membrane might limit microbial activity; therefore, nitrogen was sparged into the anode chamber to limit the effects of oxygen diffusion. Nitrogen gas sparging at a rate of 7-8 $\mathrm{mL} / \mathrm{min}$ increased the overall Coulombic efficiency from only $19 \%$ without sparging to up to $55 \%$.

Overall, concentration polarization in ion-exchange membrane processes is mitigated by twophase flow. Two-phase flow can enhance the hydrodynamics in ED stacks, even without spacers. Two-phase flow improves the limiting current density; the higher gas/liquid ratio, the greater the effect will be.

\subsubsection{Summary}

Generally, the use of two-phase flow in membrane processes, whether driven by pressure, concentration, electrical potential, partial pressure or chemical potential, is able to limit fouling and enhance the fluxes. In low-pressure membrane processes, such as MF and UF, two-phase flow also can increase rejection, improve macromolecule fractionation, and maintain essential ingredients or minerals or proteins (leaving them undamaged) [139, 150, 
154, 168]. Combining gas sparging and mechanic turbulent promoters may enhance the performance of the membrane process $[148,226]$. It was also reported that addition of a third phase, i.e. a solid phase, may increase the fluxes; however, the application of a three-phase flow is highly dependent on the type of module, mode of operation mode, feed type, and the particle size of the solid phase [20, 70, 229].

Two-phase flow can significantly limit fouling in the form of porous cakes deposited on the surface of membranes. The effect is less strong for the application of two-phase flow to dense cake layers and salt precipitates on the membrane surface, or to very fine particles which plug membrane pores. The efficacy depends on particle deposition probability, cake mass and average specific filtration resistance [39].

Module shape also affects two-phase flow performance; the efficiency of cleaning is higher in hollow-fiber modules than in tubular modules, and higher in narrow channels than in large channels in flat-sheet modules. This is caused by the higher shear force induced by bubbles in small channels than in larger ones $[115,160,178]$. While most researchers conclude that slug bubbles are able to enhance fluxes better than smaller bubbles, some reported that in the case of submerged membranes, smaller bubbles are better because these are distributed more uniform. This in contrast to coarse bubbles that lead to channeling[112]. However, larger bubbles are beneficial due to their enhanced bubble-induced shear stress on the membrane surface to control fouling. A better distribution of such larger bubbles can be achieved by increasing the gas hold up. Finally, two-phase flow performance is very dependent on: (i) membrane module shape, (ii) position of the modules, (iii) gas/liquid ratio, (iv) velocity of liquid and gas, (v) feed type, (vi) intensity of bubbling, and (vii) type of membrane process. The net energy balance of a two-phase flow is generally positive, meaning that the energy demands are lower because of the reduction in fouling [53, 135, 178].

Next to experimental investigations, several computational studies were conducted as well using different approaches: volume of fluid (VOF), Eulerian two-fluid model, $k-\varepsilon$ RNG turbulent model; the latter accurately simulated shear stresses induced by gas slugs for conditions of high liquid and low gas flow rates [23, 25, 58, 60, 163, 201, 230, 231]. However, it goes beyond the scope of this review to discuss these in detail.

Table 2.3 gives a concise overview of the two-phase flow applications in membrane processes as covered in this review. 
Table 2.3. Overview of research using two-phase flow to enhance membrane processes, from 1989 to 2011

\begin{tabular}{|c|c|c|c|c|c|c|c|c|}
\hline $\begin{array}{c}\text { Membrane } \\
\text { material }\end{array}$ & $\begin{array}{c}\text { Channel } \\
\text { width or } \\
\text { diameter } \\
*\end{array}$ & $\begin{array}{c}\text { Module } \\
\text { and flow } \\
\text { orientation }\end{array}$ & $\begin{array}{c}\text { Feed } \\
\text { suspension }\end{array}$ & $\begin{array}{l}\text { Liquid } \\
\text { rate } * *\end{array}$ & $\begin{array}{c}\text { Gas } \\
\text { rate } * *\end{array}$ & $\begin{array}{c}\text { Maximum } \\
\text { enhancem } \\
\text { ent } * * *\end{array}$ & $\begin{array}{c}\text { Flow } \\
\text { pattern }\end{array}$ & Refs. \\
\hline \multicolumn{9}{|c|}{ Flat sheet membranes } \\
\hline PSf & $2 \mathrm{~mm}$ & $\begin{array}{l}\text { Upward } \\
\text { vertical }\end{array}$ & $\begin{array}{l}\text { BSA- } \\
\text { lysozyme } \\
\text { mixture } \\
\end{array}$ & $0.5 \mathrm{~L} / \mathrm{min}$ & $\begin{array}{l}0-0.1 \\
\mathrm{~L} / \mathrm{min}\end{array}$ & $\begin{array}{l}450 \% \\
\text { (MTC) }\end{array}$ & $\begin{array}{l}\text { Bubble } \\
\text { flow }\end{array}$ & [168] \\
\hline PSf, PES & $2 \mathrm{~mm}$ & $\begin{array}{l}\text { Upward } \\
\text { vertical }\end{array}$ & $\begin{array}{l}\text { HSA, IgG, } \\
\text { BSA, } \\
\text { lysozyme }\end{array}$ & $\begin{array}{l}0.25-0.5 \\
\mathrm{~L} / \mathrm{min}\end{array}$ & $\begin{array}{l}0-0.2 \\
\mathrm{~L} / \mathrm{min}\end{array}$ & $50 \%$ (Flux) & $n s$ & [167] \\
\hline $\mathrm{ZrO}_{2}, \mathrm{TiO}_{2}$ & $0.6 \mathrm{~mm}$ & Horizontal & $\begin{array}{l}\text { Yeast } \\
\text { suspension }\end{array}$ & $\begin{array}{l}3.3-16.7 \\
\mathrm{~L} / \mathrm{min}\end{array}$ & $\begin{array}{l}0-10 \\
\mathrm{~L} / \mathrm{min}\end{array}$ & $\begin{array}{l}95 \% \\
\text { (Rejection) }\end{array}$ & $n s$ & [135] \\
\hline PS & $3 \mathrm{~mm}$ & Horizontal & $\begin{array}{l}\text { Oil } \\
\text { emulsion }\end{array}$ & $1.5 \mathrm{~m} / \mathrm{s}$ & $\begin{array}{l}0.2 \\
\mathrm{~L} / \mathrm{min}\end{array}$ & $\begin{array}{l}400 \% \\
\text { (Flux) }\end{array}$ & $n s$ & [169] \\
\hline PPA & $5 \mathrm{~mm}$ & $\begin{array}{l}\text { Upward } \\
\text { vertical }\end{array}$ & $\begin{array}{l}\text { Stabilized } \\
\& \text { non- } \\
\text { stabilized } \\
\text { oil-in-water } \\
\text { emulsion }\end{array}$ & $0-0.4 \mathrm{~m} / \mathrm{s}$ & $0-1 \mathrm{~m} / \mathrm{s}$ & $\begin{array}{l}240 \% \\
\text { (Flux) }\end{array}$ & $\begin{array}{l}\text { Bubble } \\
\text { flow, } \\
\text { slug } \\
\text { flow }\end{array}$ & {$[28]$} \\
\hline$n s$ & $5 \mathrm{~mm}$ & $\begin{array}{l}\text { Upward } \\
\text { vertical }\end{array}$ & $\begin{array}{l}\text { Clay } \\
\text { suspension }\end{array}$ & $\begin{array}{l}0.08-0.24 \\
\mathrm{~m} / \mathrm{s}\end{array}$ & $\begin{array}{l}0-0.4 \\
\mathrm{~m} / \mathrm{s}\end{array}$ & $\begin{array}{l}110 \% \\
\text { (Flux) }\end{array}$ & $\begin{array}{l}\text { Bubble } \\
\text { flow, } \\
\text { slug } \\
\text { flow } \\
\end{array}$ & [29] \\
\hline $\begin{array}{l}\text { PA layer in } \\
\text { PSf }\end{array}$ & $5 \mathrm{~mm}$ & $\begin{array}{l}\text { Upward } \\
\text { vertical }\end{array}$ & $\begin{array}{l}\mathrm{CaCl}_{2} \\
\text { suspension }\end{array}$ & $\begin{array}{l}0.12-0.24 \\
\mathrm{~m} / \mathrm{s}\end{array}$ & $\begin{array}{l}0-0.6 \\
\mathrm{~m} / \mathrm{s}\end{array}$ & $\begin{array}{l}85 \% \\
\text { (Rejection) } \\
0 \%((\text { Flux }))\end{array}$ & $n s$ & {$[30]$} \\
\hline $\begin{array}{l}\text { PA layer in } \\
\text { PSf }\end{array}$ & $5 \mathrm{~mm}$ & $\begin{array}{l}\text { Upward } \\
\text { vertical }\end{array}$ & Electrolyte & $0-0.24 \mathrm{~m} / \mathrm{s}$ & $\begin{array}{l}0-0.4 \\
\mathrm{~m} / \mathrm{s}\end{array}$ & $n s$ & $\begin{array}{l}\text { Bubble } \\
\text { flow, } \\
\text { slug } \\
\text { flow }\end{array}$ & [177] \\
\hline $\begin{array}{l}\text { Cellulose } \\
\text { ester }\end{array}$ & $16 \mathrm{~mm}$ & $\begin{array}{l}0^{\circ}, 90^{\circ}, \\
180^{\circ} \\
\text { inclination }\end{array}$ & $\begin{array}{l}\text { Dextran } \\
\text { solution }\end{array}$ & $0-0.05 \mathrm{~m} / \mathrm{s}$ & $\begin{array}{l}0-0.053 \\
\mathrm{~m} / \mathrm{s}\end{array}$ & $\begin{array}{l}150 \% \\
\text { (Flux) }\end{array}$ & $\begin{array}{l}\text { Slug } \\
\text { flow }\end{array}$ & {$[33]$} \\
\hline $\mathrm{Al}_{2} \mathrm{O}_{3}$ & $n s$ & $\begin{array}{l}\text { Upward } \\
\text { vertical }\end{array}$ & $\begin{array}{l}\text { Wastewater } \\
\text { mixture }\end{array}$ & $\begin{array}{l}0.35 \\
\mathrm{~L} / \mathrm{min}\end{array}$ & $\begin{array}{l}0.4 \\
\mathrm{~L} / \mathrm{min} \\
\end{array}$ & $\begin{array}{l}95 \% \\
\text { (Rejection) }\end{array}$ & $n s$ & [232] \\
\hline $\begin{array}{l}\text { Regenerated } \\
\text { cellulose }\end{array}$ & $1 \mathrm{~mm}$ & $\begin{array}{l}\text { Upward } \\
\text { vertical }\end{array}$ & $\begin{array}{l}\text { Creatinase } \\
\text { suspension } \\
\end{array}$ & $\begin{array}{l}2.3 \times 10^{-3} \\
\mathrm{~m} / \mathrm{s}\end{array}$ & $\begin{array}{l}2.3 \mathrm{x} \\
10^{-3} \mathrm{~m} / \mathrm{s}\end{array}$ & $\begin{array}{l}74 \% \\
\text { (Rejection) }\end{array}$ & $\begin{array}{l}\text { Slug } \\
\text { flow }\end{array}$ & {$[170]$} \\
\hline $\begin{array}{l}\text { Cellulose } \\
\text { acetate }\end{array}$ & $n s$ & $\begin{array}{l}\text { Upward } \\
\text { vertical }\end{array}$ & $\begin{array}{l}\text { Yeast } \\
\text { suspension }\end{array}$ & $\begin{array}{l}0.75- \\
1.25 \\
\mathrm{~L} / \mathrm{min}\end{array}$ & $\begin{array}{l}0.5-1.5 \\
\mathrm{~L} / \mathrm{min}\end{array}$ & $\begin{array}{l}199.82 \% \\
\text { (Flux) }\end{array}$ & $n s$ & [233] \\
\hline $\begin{array}{l}\text { Cellulose } \\
\text { acetate }\end{array}$ & $n s$ & $n s$ & $\begin{array}{l}2,3 \\
\text { butanediol } \\
\text { broth }\end{array}$ & $1 \mathrm{~L} / \mathrm{min}$ & $\begin{array}{l}0.5-1 \\
\mathrm{~L} / \mathrm{min}\end{array}$ & $\begin{array}{l}146 \% \\
\text { (Flux) }\end{array}$ & $n s$ & [234] \\
\hline $\begin{array}{l}\text { PDMS } \\
\text { microsieves }\end{array}$ & $\begin{array}{l}50 \mu \mathrm{mx} 80 \\
\mu \mathrm{m}\end{array}$ & $n s$ & $\begin{array}{l}\text { BSA } \\
\text { solution }\end{array}$ & $\begin{array}{l}0.17 \\
\mathrm{~L} / \mathrm{min}\end{array}$ & $\begin{array}{l}0.013- \\
0.042 \\
\mathrm{~L} / \mathrm{min}\end{array}$ & $40 \%$ (Flux) & $n s$ & [235] \\
\hline Ceramic & $n s$ & $\begin{array}{l}\text { Upward } \\
\text { vertical }\end{array}$ & $\begin{array}{l}\text { Zeolite } \\
\text { suspension }\end{array}$ & $\begin{array}{l}6.7 \times 10^{-5} \\
\mathrm{~m} / \mathrm{s}\end{array}$ & $\begin{array}{l}8.5 \times 10^{-4} \\
\mathrm{~m} / \mathrm{s}\end{array}$ & $\begin{array}{l}200 \% \\
\text { (Flux) } \\
\end{array}$ & $n s$ & [236] \\
\hline $\mathrm{Al}_{2} \mathrm{O}_{3}-\mathrm{SiO}_{2}$ & $n s$ & $\begin{array}{l}\text { Upward } \\
\text { vertical }\end{array}$ & $\begin{array}{l}\text { Artificial } \\
\text { polluted } \\
\text { water }\end{array}$ & $\begin{array}{l}0.168 \mathrm{x} \\
10^{-3} \mathrm{~m} / \mathrm{s}\end{array}$ & $\begin{array}{l}4.47 \mathrm{x} \\
10^{-3} \mathrm{~m} / \mathrm{s}\end{array}$ & $\begin{array}{l}100 \% \\
\text { (Rejection) }\end{array}$ & $n s$ & [237] \\
\hline$n s$ & $2-10 \mathrm{~mm}$ & $0^{\circ}$ (flow & Dextran & $0.05 \mathrm{~m} / \mathrm{s}$ & $0-0.05$ & $135 \%$ & Slug & [32] \\
\hline
\end{tabular}




\begin{tabular}{|c|c|c|c|c|c|c|c|c|}
\hline & & $\begin{array}{l}\text { above } \\
\text { membrane) } \\
, 90^{\circ}, 180^{\circ} \\
\text { (flow } \\
\text { below } \\
\text { membrane) }\end{array}$ & solution & & $\mathrm{m} / \mathrm{s}$ & (Flux) & flow & \\
\hline$n s$ & $1 \mathrm{~mm}$ & Horizontal & $\begin{array}{l}\text { PMMA } \\
\text { solution }\end{array}$ & $\begin{array}{l}0.1-0.5 \\
\mathrm{~m} / \mathrm{s}\end{array}$ & $\begin{array}{l}0.04- \\
0.12 \\
\mathrm{~m} / \mathrm{s}\end{array}$ & $75 \%$ (Flux) & $n s$ & [42] \\
\hline PSf & $n s$ & $\begin{array}{l}\text { Upward } \\
\text { vertical }\end{array}$ & $\begin{array}{l}\text { Surface } \\
\text { water }\end{array}$ & $\begin{array}{l}2.67 \\
\mathrm{~L} / \mathrm{min}\end{array}$ & $\begin{array}{l}2.5 \\
\mathrm{~L} / \mathrm{min}\end{array}$ & $\begin{array}{l}>500 \% \\
\text { (Flux) } \\
\text { couple with } \\
\mathrm{NaOH}\end{array}$ & $n s$ & {$[171]$} \\
\hline$n s$ & $2 \mathrm{~mm}$ & Horizontal & $\begin{array}{l}\text { Yeast } \\
\text { suspension }\end{array}$ & $\begin{array}{l}0.1-0.5 \\
\mathrm{~m} / \mathrm{s}\end{array}$ & $\begin{array}{l}0.02- \\
0.08 \\
\mathrm{~m} / \mathrm{s}\end{array}$ & $15 \%$ (Flux) & $\begin{array}{l}\text { Bubble } \\
\text { flow, } \\
\text { slug } \\
\text { flow }\end{array}$ & {$[40]$} \\
\hline$n s$ & $1 \mathrm{~mm}$ & Horizontal & $\begin{array}{l}\text { PMMA } \\
\text { suspension }\end{array}$ & $\begin{array}{l}0.1-0.5 \\
\mathrm{~m} / \mathrm{s}\end{array}$ & $\begin{array}{l}0.049 \\
\mathrm{~m} / \mathrm{s}\end{array}$ & $30 \%$ (Flux) & $\begin{array}{l}\text { Bubble } \\
\text { flow, } \\
\text { slug } \\
\text { flow }\end{array}$ & [41] \\
\hline PSf & $n s$ & $\begin{array}{l}\text { Upward } \\
\text { vertical }\end{array}$ & $\begin{array}{l}\text { Clay } \\
\text { suspension }\end{array}$ & $n s$ & $\begin{array}{l}0.06- \\
0.34 \\
\mathrm{~m} / \mathrm{s} \\
\end{array}$ & $\begin{array}{l}103 \% \\
\text { (Flux) }\end{array}$ & $n s$ & [159] \\
\hline $\begin{array}{l}\text { Mixed } \\
\text { cellulose } \\
\text { ester }\end{array}$ & $n s$ & $\begin{array}{l}\text { Upward } \\
\text { vertical }\end{array}$ & $\begin{array}{l}\text { PMMA } \\
\text { suspension }\end{array}$ & $n a$ & $\begin{array}{l}0- \\
0.054 \\
\mathrm{~L} / \mathrm{min}\end{array}$ & $\begin{array}{l}400 \% \\
\text { (Flux) }\end{array}$ & $\begin{array}{l}\text { Bubble } \\
\text { flow }\end{array}$ & [211] \\
\hline$n s$ & $n s$ & Horizontal & $\begin{array}{l}\text { Yeast/BSA } \\
\text { suspension }\end{array}$ & $\begin{array}{l}0.1-0.5 \\
\mathrm{~m} / \mathrm{s}\end{array}$ & $\begin{array}{l}0-0.06 \\
\mathrm{~m} / \mathrm{s}\end{array}$ & $\begin{array}{l}200 \% \\
\text { (Flux) }\end{array}$ & $\begin{array}{l}\text { Bubble } \\
\text { flow }\end{array}$ & [238] \\
\hline$n s$ & $600 \mathrm{~mm}$ & $\begin{array}{l}\text { Upward } \\
\text { vertical }\end{array}$ & $\begin{array}{l}\text { Activated } \\
\text { sludge }\end{array}$ & $n a$ & $\begin{array}{l}1.2- \\
9.6 \\
\mathrm{~L} / \mathrm{min} \\
\end{array}$ & $n s$ & $\begin{array}{l}\text { Bubble } \\
\text { flow }\end{array}$ & {$[111]$} \\
\hline \multicolumn{9}{|c|}{ Tubular membranes } \\
\hline Ceramic & $3.8 \mathrm{~mm}$ & $\begin{array}{l}\text { Upward } \\
\text { vertical }\end{array}$ & $n s$ & $n s$ & $\begin{array}{l}47-458 \\
\times 10^{-6} \\
\mathrm{~L} / \mathrm{min}\end{array}$ & $n s$ & $n s$ & $\begin{array}{l}{[20,} \\
124]\end{array}$ \\
\hline PVDF & $12.7 \mathrm{~mm}$ & $\begin{array}{l}\text { Upward } \\
\text { vertical }\end{array}$ & $\begin{array}{l}\text { Dextran, } \\
\text { dyed } \\
\text { dextran, } \\
\text { BSA } \\
\text { solutions }\end{array}$ & $1-3 \mathrm{~L} / \mathrm{min}$ & $\begin{array}{l}0-1 \\
\mathrm{~L} / \mathrm{min}\end{array}$ & $\begin{array}{l}\text { Dextran: } 60 \\
\% \text { (Flux) } \\
\text { Dyed } \\
\text { dextran: } \\
113 \% \\
\text { (Flux) } \\
\text { BSA: } 91 \% \\
\text { (Flux) }\end{array}$ & $n s$ & [19] \\
\hline Polymeric & $5 \mathrm{~mm}$ & $\begin{array}{l}\text { Downward } \\
\text { vertical }\end{array}$ & Dextran & $\begin{array}{l}2-11 \\
\mathrm{~L} / \mathrm{min}\end{array}$ & $\begin{array}{l}0-5 \\
\mathrm{~L} / \mathrm{min}\end{array}$ & $\begin{array}{l}320 \% \\
\text { (Flux) }\end{array}$ & $\begin{array}{l}\text { Slug } \\
\text { flow }\end{array}$ & [103] \\
\hline $\mathrm{Al}_{2} \mathrm{O}_{3}$ & $7 \mathrm{~mm}$ & $\begin{array}{l}\text { Upward } \\
\text { vertical }\end{array}$ & $\begin{array}{l}\text { Activated } \\
\text { sludge }\end{array}$ & $\begin{array}{l}2.33 \\
\mathrm{~L} / \mathrm{min}\end{array}$ & $\begin{array}{l}300 \\
\mathrm{~L} / \mathrm{min}\end{array}$ & $75 \%$ (Flux) & $n s$ & [136] \\
\hline PVDF & $12.7 \mathrm{~mm}$ & $\begin{array}{l}\text { Upward } \\
\text { vertical }\end{array}$ & $\begin{array}{l}\text { Dyed } \\
\text { dextran }\end{array}$ & $0.5 \mathrm{~L} / \mathrm{min}$ & $\begin{array}{l}0.01 \\
\mathrm{~L} / \mathrm{min}\end{array}$ & $30 \%$ (Flux) & $n s$ & {$[138]$} \\
\hline PVDF & $12.7 \mathrm{~mm}$ & $\begin{array}{l}\text { Upward } \\
\text { vertical }\end{array}$ & $\begin{array}{l}\text { HSA-IgG } \\
\text { mixture }\end{array}$ & $0.5 \mathrm{~L} / \mathrm{min}$ & $\begin{array}{l}0.03- \\
0.05 \\
\mathrm{~L} / \mathrm{min} \\
\end{array}$ & $70 \%$ (Flux) & $n s$ & [139] \\
\hline PVDF & $12.7 \mathrm{~mm}$ & $\begin{array}{l}\text { Upward } \\
\text { vertical }\end{array}$ & $\begin{array}{l}\text { HAS- } \\
\text { dextran } \\
\text { mixture }\end{array}$ & $1 \mathrm{~L} / \mathrm{min}$ & $\begin{array}{l}0.0067 \\
-0.5 \\
\mathrm{~L} / \mathrm{min}\end{array}$ & $\begin{array}{l}\text { HAS: } 75 \% \\
\text { (Rejection) } \\
\text { Dextran: } \\
100 \% \\
\text { (Rejection) }\end{array}$ & $\begin{array}{l}\text { Bubble } \\
\text { flow, } \\
\text { slug } \\
\text { flow }\end{array}$ & {$[140]$} \\
\hline
\end{tabular}




\begin{tabular}{|c|c|c|c|c|c|c|c|c|}
\hline $\mathrm{Zr}_{2} \mathrm{O}_{3}$ & $15 \mathrm{~mm}$ & $\begin{array}{l}\text { Upward } \\
\text { vertical }\end{array}$ & $\begin{array}{l}\text { Bentonite } \\
\text { suspension }\end{array}$ & $\begin{array}{l}3.3-16.6 \\
\text { L/min }\end{array}$ & $\begin{array}{l}1.6-25 \\
\mathrm{~L} / \mathrm{min}\end{array}$ & $\begin{array}{l}200 \% \\
\text { (Flux) }\end{array}$ & $\begin{array}{l}\text { Slug } \\
\text { flow }\end{array}$ & [142] \\
\hline $\mathrm{Zr}-\mathrm{Al}_{2} \mathrm{O}_{3}$ & $15 \mathrm{~mm}$ & $\begin{array}{l}\text { Upward } \\
\text { vertical }\end{array}$ & $\begin{array}{l}\text { Yeast } \\
\text { suspension }\end{array}$ & $4.9 \mathrm{~L} / \mathrm{min}$ & $\begin{array}{l}3.3-6.6 \\
\mathrm{~L} / \mathrm{min}\end{array}$ & $\begin{array}{l}>250 \% \\
\text { (Flux) }\end{array}$ & $\begin{array}{l}\text { Slug } \\
\text { flow }\end{array}$ & [143] \\
\hline $\mathrm{ZrO}_{2} /$ carbon & $60 \mathrm{~mm}$ & $\begin{array}{l}0^{\circ}, 30^{\circ}, 45^{\circ} \text {, } \\
60^{\circ}, 90^{\circ} \\
\text { (horizontal } \\
\text { - vertical } \\
\text { upward) }\end{array}$ & $\begin{array}{l}\text { Dextran } \\
\text { solution }\end{array}$ & $\begin{array}{l}0.168- \\
0.672 \mathrm{~m} / \mathrm{s}\end{array}$ & $\begin{array}{l}0-0.32 \\
\mathrm{~m} / \mathrm{s}\end{array}$ & $\begin{array}{l}\text { The highest } \\
\text { flux } \\
\text { obtained } \\
\text { with } 53^{\circ} \\
\text { inclination }\end{array}$ & $\begin{array}{l}\text { Slug } \\
\text { flow }\end{array}$ & [37] \\
\hline$n s$ & $109 \mathrm{~mm}$ & Horizontal & $\begin{array}{l}\text { PVP } \\
\text { solution }\end{array}$ & $n s$ & $\begin{array}{l}0-100 \\
\mathrm{~L} / \mathrm{min}\end{array}$ & $\begin{array}{l}125 \% \\
\text { (Flux) }\end{array}$ & $n s$ & [145] \\
\hline $\mathrm{ZrO}_{2}$ & $6 \mathrm{~mm}$ & $\begin{array}{l}\text { Upward } \\
\text { vertical }\end{array}$ & $\begin{array}{l}\text { Polymer } \\
\text { suspension }\end{array}$ & $\begin{array}{l}0.2-0.6 \\
\mathrm{~m} / \mathrm{s}\end{array}$ & $\begin{array}{l}0.2-0.4 \\
\mathrm{~m} / \mathrm{s}\end{array}$ & 94\% (Flux) & $\begin{array}{l}\text { Slug } \\
\text { flow }\end{array}$ & [239] \\
\hline Carbon & $6 \mathrm{~mm}$ & $\begin{array}{l}\text { Upward } \\
\text { vertical }\end{array}$ & $\begin{array}{l}\text { Ferric } \\
\text { hydroxide } \\
\text { suspension, } \\
\text { dextran } \\
\text { solution, } \\
\text { wastewater } \\
\text { effluent } \\
\end{array}$ & $2 \mathrm{~m} / \mathrm{s}$ & $0-3 \mathrm{~m} / \mathrm{s}$ & $\begin{array}{l}70 \% \\
\text { (Rejection) }\end{array}$ & $\begin{array}{l}\text { Taylor } \\
\text { bubbles } \\
\text { flow }\end{array}$ & [126] \\
\hline $\mathrm{ZrO}_{2}$ & $6 \mathrm{~mm}$ & $\begin{array}{l}\text { Upward } \\
\text { vertical }\end{array}$ & $\begin{array}{l}\text { Ferric } \\
\text { hydroxide } \\
\text { suspension, } \\
\text { wastewater } \\
\text { effluent }\end{array}$ & $3 \mathrm{~m} / \mathrm{s}$ & $\begin{array}{l}0-3.7 \\
\mathrm{~m} / \mathrm{s}\end{array}$ & $\begin{array}{l}150 \% \\
\text { (Flux) }\end{array}$ & $\begin{array}{l}\text { Taylor } \\
\text { bubbles } \\
\text { flow }\end{array}$ & [125] \\
\hline $\begin{array}{l}\mathrm{ZrO}_{2} / \mathrm{TiO}_{2} \\
\text { multichannel } \\
\text { monolithic }\end{array}$ & $2.5 \mathrm{~mm}$ & $\begin{array}{l}\text { Upward } \\
\text { vertical }\end{array}$ & $\begin{array}{l}\text { PVA } \\
\text { solution }\end{array}$ & $0.536 \mathrm{~m} / \mathrm{s}$ & $\begin{array}{l}0.179 \\
\mathrm{~m} / \mathrm{s}\end{array}$ & $55 \%$ (Flux) & $n s$ & [35] \\
\hline $\begin{array}{l}\text { PVDF } \\
\text { multitubular }\end{array}$ & $5 \mathrm{~mm}$ & $\begin{array}{l}\text { Upward } \\
\text { vertical }\end{array}$ & $\begin{array}{l}\text { Yeast } \\
\text { suspension }\end{array}$ & $\begin{array}{l}0.36-1.8 \\
\mathrm{~m} / \mathrm{s}\end{array}$ & $\begin{array}{l}0.18- \\
1.02 \\
\mathrm{~m} / \mathrm{s} \\
\end{array}$ & $\begin{array}{l}135 \% \\
\text { (Flux) }\end{array}$ & $n s$ & [130] \\
\hline PES & $9.5 \mathrm{~mm}$ & $\begin{array}{l}\text { Upward } \\
\text { vertical }\end{array}$ & $\begin{array}{l}\text { Wastewater } \\
\text { effluent }\end{array}$ & $n s$ & $5 \mathrm{~L} / \mathrm{min}$ & $43 \%$ (Flux) & $n s$ & [49] \\
\hline $\mathrm{ZrO}_{2} /$ carbon & $6 \mathrm{~mm}$ & $\begin{array}{l}0^{\circ}, 30^{\circ}, 45^{\circ}, \\
50^{\circ}, 55^{\circ}, \\
60^{\circ}, 90^{\circ} \\
\text { (horizontal } \\
\text { - vertical } \\
\text { upward) }\end{array}$ & $\begin{array}{l}\text { Dextran } \\
\text { solution }\end{array}$ & $\begin{array}{l}0.168- \\
0.672 \mathrm{~m} / \mathrm{s}\end{array}$ & $\begin{array}{l}0.04- \\
0.32 \\
\mathrm{~m} / \mathrm{s}\end{array}$ & $\begin{array}{l}146 \% \\
\text { (Flux) }\end{array}$ & $\begin{array}{l}\text { Slug } \\
\text { flow }\end{array}$ & {$[31]$} \\
\hline Ceramic & $15 \mathrm{~mm}$ & $\begin{array}{l}\text { Upward } \\
\text { vertical }\end{array}$ & $\begin{array}{l}\text { Invertase- } \\
\text { yeast } \\
\text { mixture }\end{array}$ & $\begin{array}{l}4-17 \\
L / \min \end{array}$ & $\begin{array}{l}0.23- \\
11.17 \\
\mathrm{~L} / \mathrm{min} \\
\end{array}$ & $\begin{array}{l}140 \% \\
\text { (Flux) }\end{array}$ & $n s$ & [129] \\
\hline Ceramic & $6 \mathrm{~mm}$ & $n s$ & $\begin{array}{l}\mathrm{TiO}_{2} \\
\text { suspension }\end{array}$ & $1 \mathrm{~m} / \mathrm{s}$ & $\begin{array}{l}0-2.36 \\
\mathrm{~m} / \mathrm{s}\end{array}$ & $\begin{array}{l}>200 \% \\
\text { (Flux) }\end{array}$ & $\begin{array}{l}\text { Slug } \\
\text { flow }\end{array}$ & [131] \\
\hline PVDF & $12.5 \mathrm{~mm}$ & $\begin{array}{l}\text { Upward } \\
\text { vertical }\end{array}$ & $\begin{array}{l}\text { Skim latex } \\
\text { serum }\end{array}$ & $1.4 \mathrm{~L} / \mathrm{min}$ & $\begin{array}{l}0.5 \\
\mathrm{~L} / \mathrm{min}\end{array}$ & $\begin{array}{l}145.33 \% \\
\text { (Flux) }\end{array}$ & $n s$ & [146] \\
\hline PES & $n s$ & $\begin{array}{l}\text { Upward } \\
\text { vertical }\end{array}$ & $\begin{array}{l}\text { Mixed } \\
\text { liquor of } \\
\text { activated } \\
\text { sludge }\end{array}$ & $n a$ & $5 \mathrm{~L} / \mathrm{min}$ & $43 \%$ (Flux) & $n s$ & [50] \\
\hline $\begin{array}{l}\mathrm{Al}_{2} \mathrm{O}_{3} \\
\text { multichannel }\end{array}$ & $4.35 \mathrm{~mm}$ & $\begin{array}{l}\text { Upward } \\
\text { vertical }\end{array}$ & Skim milk & $\begin{array}{l}20.33 \\
\mathrm{~L} / \mathrm{min}\end{array}$ & $\begin{array}{l}1.67- \\
23.17 \\
\mathrm{~L} / \mathrm{min} \\
\end{array}$ & $\begin{array}{l}115 \% \\
\text { (Flux) }\end{array}$ & $n s$ & [127] \\
\hline$n s$ & $\begin{array}{l}5.2 \mathrm{~mm} \\
(1.5 \\
\text { capillary) }\end{array}$ & $\begin{array}{l}\text { Upward } \\
\text { vertical }\end{array}$ & Water & $\begin{array}{l}0.1-0.6(0- \\
1.3 \mathrm{~m} / \mathrm{s})\end{array}$ & $\begin{array}{l}0-0.8 \\
(0-1.8 \\
\mathrm{m} / \mathrm{s}) \\
\end{array}$ & $n s$ & $n s$ & [166] \\
\hline $\begin{array}{l}\mathrm{Al}_{2} \mathrm{O}_{3} \\
\text { multichannel }\end{array}$ & $4.35 \mathrm{~mm}$ & $\begin{array}{l}\text { Upward } \\
\text { vertical }\end{array}$ & $\begin{array}{l}\text { Skimmed } \\
\text { milk }\end{array}$ & $\begin{array}{l}16.67 \\
\mathrm{~L} / \mathrm{min}\end{array}$ & $\begin{array}{l}10.07- \\
16.38\end{array}$ & $n s$ & $n s$ & [128] \\
\hline
\end{tabular}




\begin{tabular}{|c|c|c|c|c|c|c|c|c|}
\hline & & & & & $\mathrm{L} / \mathrm{min}$ & & & \\
\hline $\mathrm{Al}_{2} \mathrm{O}_{3}$ & $6 \mathrm{~mm}$ & $\begin{array}{l}\text { Upward } \\
\text { vertical }\end{array}$ & $\begin{array}{l}\mathrm{TiO}_{2} \\
\text { suspension }\end{array}$ & $0.5-4 \mathrm{~m} / \mathrm{s}$ & $\begin{array}{l}0.2-3 \\
\mathrm{~m} / \mathrm{s}\end{array}$ & $\begin{array}{l}90 \% \\
\text { (Flux) }\end{array}$ & $\begin{array}{l}\text { Bubble } \\
\text { flow, } \\
\text { slug } \\
\text { flow, } \\
\text { churn } \\
\text { flow }\end{array}$ & [132] \\
\hline PVDF & $12.5 \mathrm{~mm}$ & $\begin{array}{l}\text { Upward } \\
\text { vertical }\end{array}$ & $\begin{array}{l}\text { Skim latex } \\
\text { serum }\end{array}$ & $\begin{array}{l}1-1.6 \\
\mathrm{~L} / \mathrm{min}\end{array}$ & $\begin{array}{l}0.3-0.5 \\
\mathrm{~L} / \mathrm{min}\end{array}$ & $\begin{array}{l}146.34 \% \\
\text { (Flux) }\end{array}$ & $n s$ & [147] \\
\hline Polymeric & $6.35 \mathrm{~mm}$ & $\begin{array}{l}\text { Upward } \\
\text { vertical }\end{array}$ & $\begin{array}{l}\text { Synthetic } \\
\text { wastewater } \\
\text { suspension }\end{array}$ & $\begin{array}{l}0.7-1.05 \\
\mathrm{~m} / \mathrm{s}\end{array}$ & $n s$ & $n s$ & $\begin{array}{l}\text { Slug } \\
\text { flow }\end{array}$ & [67] \\
\hline $\mathrm{PP}$ & $5.5 \mathrm{~mm}$ & $\begin{array}{l}\text { Upward } \\
\text { vertical }\end{array}$ & $\begin{array}{l}\text { Activated } \\
\text { sludge }\end{array}$ & $\begin{array}{l}1.08-2.85 \\
\mathrm{~m} / \mathrm{s}\end{array}$ & $\begin{array}{l}3.5-8 \\
\mathrm{~L} / \mathrm{min}\end{array}$ & $n s$ & $n s$ & [68] \\
\hline $\begin{array}{l}\text { PVDF } \\
\text { multitubular }\end{array}$ & $5 \mathrm{~mm}$ & $\begin{array}{l}\text { Upward } \\
\text { vertical }\end{array}$ & $\begin{array}{l}\text { Yeast- } \\
\text { bentonite } \\
\text { mixture }\end{array}$ & $0.36 \mathrm{~m} / \mathrm{s}$ & $\begin{array}{l}0.18 \\
\mathrm{~m} / \mathrm{s}\end{array}$ & $\begin{array}{l}100 \% \\
\text { (Flux) }\end{array}$ & $n s$ & [229] \\
\hline $\begin{array}{l}\text { Ceramic } \\
\text { Star shape }\end{array}$ & $2.8 \mathrm{~mm}$ & $\begin{array}{l}\text { Upward } \\
\text { vertical }\end{array}$ & $\begin{array}{l}\mathrm{TiO}_{2} \\
\text { suspension }\end{array}$ & $\begin{array}{l}0.6-3.4 \\
\mathrm{~m} / \mathrm{s}\end{array}$ & $\begin{array}{l}0.3-3.4 \\
\mathrm{~m} / \mathrm{s} \\
\end{array}$ & $\begin{array}{l}171 \% \\
\text { (Flux) }\end{array}$ & $n s$ & [134] \\
\hline $\begin{array}{l}\text { Silicon } \\
\text { rubber }\end{array}$ & $1.5 \mathrm{~mm}$ & $\begin{array}{l}\text { Upward } \\
\text { vertical }\end{array}$ & $\begin{array}{l}\text { Synthetic } \\
\text { wastewater }\end{array}$ & $\begin{array}{l}0.12 \\
\mathrm{~L} / \mathrm{min}\end{array}$ & $\begin{array}{l}0-2 \\
\mathrm{~L} / \mathrm{min}\end{array}$ & $n s$ & $n s$ & [196] \\
\hline PP & $5.5 \mathrm{~mm}$ & $\begin{array}{l}\text { Upward } \\
\text { vertical }\end{array}$ & $\begin{array}{l}\text { Synthetic } \\
\text { wastewater }\end{array}$ & $\begin{array}{l}1.5-2.1 \\
\mathrm{~m} / \mathrm{s}\end{array}$ & $\begin{array}{l}8-15 \\
\mathrm{~L} / \mathrm{min}\end{array}$ & $\begin{array}{l}400 \% \\
\text { (Flux) }\end{array}$ & $\begin{array}{l}\text { Slug } \\
\text { flow }\end{array}$ & [69] \\
\hline Polymeric & $6.35 \mathrm{~mm}$ & $\begin{array}{l}\text { Upward } \\
\text { vertical }\end{array}$ & Raw water & $\begin{array}{l}0.46-2.12 \\
\mathrm{~m} / \mathrm{s}\end{array}$ & $\begin{array}{l}0.65 \\
\mathrm{~m} / \mathrm{s}\end{array}$ & $\begin{array}{l}400 \% \\
\text { (Flux) }\end{array}$ & $n s$ & [70] \\
\hline PP & $5.5 \mathrm{~mm}$ & $\begin{array}{l}\text { Upward } \\
\text { vertical }\end{array}$ & $\begin{array}{l}\text { Synthetic } \\
\text { wastewater }\end{array}$ & $\begin{array}{l}1.3-3.5 \\
\mathrm{~m} / \mathrm{s}\end{array}$ & $\begin{array}{l}1.82 \\
\mathrm{~m} / \mathrm{s}\end{array}$ & $n s$ & $n s$ & [71] \\
\hline $\begin{array}{l}\text { PA/PES } \\
\text { (capillary) }\end{array}$ & $1.5 \mathrm{~mm}$ & $\begin{array}{l}\text { Upward } \\
\text { vertical }\end{array}$ & $\begin{array}{l}\text { Synthetic } \\
\text { wastewater }\end{array}$ & $0-1.5 \mathrm{~m} / \mathrm{s}$ & $\begin{array}{l}0-1.5 \\
\mathrm{~m} / \mathrm{s}\end{array}$ & $17 \%$ (Flux) & $\begin{array}{l}\text { Slug } \\
\text { Flow }\end{array}$ & [178] \\
\hline Ceramic & $7-9 \mathrm{~mm}$ & $\begin{array}{l}\text { Upward } \\
\text { vertical }\end{array}$ & $\begin{array}{l}\text { Yeast } \\
\text { suspension }\end{array}$ & $n s$ & $0.5 \mathrm{~m} / \mathrm{s}$ & $\begin{array}{l}514 \% \\
\text { (Flux) }\end{array}$ & $\begin{array}{l}\text { Slug } \\
\text { flow }\end{array}$ & [133] \\
\hline $\mathrm{ZrO}_{2}$ & $6.8 \mathrm{~mm}$ & Horizontal & $\begin{array}{l}\text { Stabilized } \\
\text { oil/water } \\
\text { emulsion }\end{array}$ & $\begin{array}{l}1.67-2.5 \\
\mathrm{~L} / \mathrm{min}\end{array}$ & $\begin{array}{l}0.3-1.67 \\
\mathrm{~L} / \mathrm{min}\end{array}$ & $6 \%$ (Flux) & $n s$ & [148] \\
\hline Ceramic & $6 \mathrm{~mm}$ & $\begin{array}{l}\text { Upward } \\
\text { vertical }\end{array}$ & $\begin{array}{l}\text { PMMA } \\
\text { solution }\end{array}$ & $n s$ & \begin{tabular}{|l|}
$0-198$ \\
$\mathrm{~L} / \mathrm{min}$ \\
\end{tabular} & $20 \%$ (Flux) & $n s$ & [38] \\
\hline$n s$ (capillary) & $5.5 \mathrm{~mm}$ & $\begin{array}{l}\text { Upward } \\
\text { vertical }\end{array}$ & $\begin{array}{l}\text { Activated } \\
\text { sludge }\end{array}$ & $2-5.2 \mathrm{~m} / \mathrm{s}$ & $\begin{array}{l}2-5.2 \\
\mathrm{~m} / \mathrm{s}\end{array}$ & $\begin{array}{l}\text { Insufficient } \\
\text { cleaning }\end{array}$ & $\begin{array}{l}\text { Slug } \\
\text { flow }\end{array}$ & [73] \\
\hline $\mathrm{Al}_{2} \mathrm{O}_{3}$ & $6 \mathrm{~mm}$ & $n s$ & $\begin{array}{l}\text { Fresh } \\
\text { pineapple } \\
\text { wine }\end{array}$ & $2 \mathrm{~m} / \mathrm{s}$ & $\begin{array}{l}0-1.1 \\
\mathrm{~m} / \mathrm{s}\end{array}$ & $\begin{array}{l}138 \% \\
\text { (Flux) }\end{array}$ & $n s$ & {$[122]$} \\
\hline \multicolumn{9}{|c|}{ Hollow-fiber membranes } \\
\hline PSf & $0.2 \mathrm{~mm}$ & $\begin{array}{l}\text { Upward } \\
\text { vertical }\end{array}$ & $\begin{array}{l}\text { Dextran, } \\
\text { BSA } \\
\text { solutions }\end{array}$ & $\begin{array}{l}0.66-1.2 \\
\mathrm{~L} / \mathrm{min}\end{array}$ & $\begin{array}{l}0.039- \\
0.095 \\
\mathrm{~L} / \mathrm{min}\end{array}$ & $\begin{array}{l}\text { Dextran: } \\
30 \% \text { (Flux) } \\
\text { BSA: 63\% } \\
\text { (Flux) }\end{array}$ & $n s$ & [149] \\
\hline PSf & $0.2 \mathrm{~mm}$ & $\begin{array}{l}\text { Upward } \\
\text { vertical }\end{array}$ & $\begin{array}{l}\text { BSA- } \\
\text { lysozyme } \\
\text { mixture }\end{array}$ & $0.5 \mathrm{~L} / \mathrm{min}$ & $\begin{array}{l}0.05 \\
\mathrm{~L} / \mathrm{min}\end{array}$ & $\begin{array}{l}99 \% \\
\text { (Selectivity }\end{array}$ & $n s$ & [150] \\
\hline $\begin{array}{l}\text { Cellulose } \\
\text { acetate }\end{array}$ & $0.93 \mathrm{~mm}$ & $\begin{array}{l}\text { Upward } \\
\text { vertical }\end{array}$ & $\begin{array}{l}\text { Clay } \\
\text { suspension }\end{array}$ & $0.5 \mathrm{~m} / \mathrm{s}$ & $0-1 \mathrm{~m} / \mathrm{s}$ & $\begin{array}{l}110 \% \\
\text { (Flux) }\end{array}$ & $\begin{array}{l}\text { Slug } \\
\text { flow }\end{array}$ & [151] \\
\hline $\begin{array}{l}\text { Cellulose } \\
\text { acetate }\end{array}$ & $0.93 \mathrm{~mm}$ & $\begin{array}{l}\text { Upward } \\
\text { vertical }\end{array}$ & $\begin{array}{l}\text { Clay } \\
\text { suspension }\end{array}$ & $\begin{array}{l}0.5-0.9 \\
\mathrm{~m} / \mathrm{s}\end{array}$ & $0-1 \mathrm{~m} / \mathrm{s}$ & $\begin{array}{l}115 \% \\
\text { (Flux) }\end{array}$ & $n s$ & [152] \\
\hline$n s$ & $0.93 \mathrm{~mm}$ & $\begin{array}{l}\text { Upward } \\
\text { vertical }\end{array}$ & $\begin{array}{l}\text { Clay } \\
\text { suspension }\end{array}$ & $0.5 \mathrm{~m} / \mathrm{s}$ & $\begin{array}{l}0-0.15 \\
\mathrm{~m} / \mathrm{s}\end{array}$ & $\begin{array}{l}110 \% \\
\text { (Flux) }\end{array}$ & $\begin{array}{l}\text { Slug } \\
\text { flow }\end{array}$ & [153] \\
\hline PSf & $1.2 \mathrm{~mm}$ & $\begin{array}{l}\text { Upward } \\
\text { vertical }\end{array}$ & $\begin{array}{l}\text { Dye \& } \\
\text { kaolin } \\
\text { suspension }\end{array}$ & $n s$ & $\begin{array}{l}0-2 \\
\mathrm{~L} / \mathrm{min}\end{array}$ & $\begin{array}{l}25 \% \text { (Flux) } \\
99.5 \% \\
\text { (Rejection) }\end{array}$ & $n s$ & [164] \\
\hline
\end{tabular}




\begin{tabular}{|c|c|c|c|c|c|c|c|c|}
\hline $\begin{array}{l}\text { Cellulose } \\
\text { acetate }\end{array}$ & $0.9 \mathrm{~mm}$ & $\begin{array}{l}\text { Upward } \\
\text { vertical }\end{array}$ & $\begin{array}{l}\text { Active } \\
\text { carbon } \\
\text { solution }\end{array}$ & $\begin{array}{l}0.087- \\
0.206 \\
\text { L/min } \\
\text { (stepwise) }\end{array}$ & $\begin{array}{l}95-136 \\
\mathrm{~L} / \mathrm{min}\end{array}$ & $\begin{array}{l}94.8 \% \\
\text { (Rejection) }\end{array}$ & $n s$ & [240] \\
\hline $\begin{array}{l}\text { Cellulose } \\
\text { ester }\end{array}$ & $\begin{array}{l}13.6-98 \\
\mathrm{~mm}\end{array}$ & $\begin{array}{l}\text { Upward } \\
\text { vertical }\end{array}$ & $\begin{array}{l}\text { Bentonite } \\
\text { suspension }\end{array}$ & $6.6 \mathrm{~L} / \mathrm{min}$ & $\begin{array}{l}14 \\
\mathrm{~L} / \mathrm{min}\end{array}$ & $\begin{array}{l}70 \% \\
\text { (Rejection) }\end{array}$ & $\begin{array}{l}\text { Slug } \\
\text { flow }\end{array}$ & [156] \\
\hline PP & $1.8 \mathrm{~mm}$ & $\begin{array}{l}\text { Upward } \\
\text { vertical }\end{array}$ & $\begin{array}{l}\text { Yeast } \\
\text { suspension }\end{array}$ & $\begin{array}{l}0.2-0.6 \\
\mathrm{~m} / \mathrm{s}\end{array}$ & $\begin{array}{l}0.2-0.4 \\
\mathrm{~m} / \mathrm{s}\end{array}$ & $94 \%$ (Flux) & $\begin{array}{l}\text { Slug } \\
\text { flow }\end{array}$ & [55] \\
\hline$n s$ & $0.93 \mathrm{~mm}$ & $\begin{array}{l}\text { Upward } \\
\text { vertical }\end{array}$ & $\begin{array}{l}\text { Spring } \\
\text { water }\end{array}$ & $0.2 \mathrm{~m} / \mathrm{s}$ & $\begin{array}{l}0.15-0.5 \\
\mathrm{~m} / \mathrm{s}\end{array}$ & $90 \%$ (Flux) & $n s$ & [154] \\
\hline$\overline{P P}$ & $\begin{array}{l}0.39-1.8 \\
\mathrm{~mm}\end{array}$ & Horizontal & $\begin{array}{l}\text { Yeast } \\
\text { suspension }\end{array}$ & $\begin{array}{l}0.2-0.4 \\
\mathrm{~m} / \mathrm{s}\end{array}$ & $\begin{array}{l}0-0.2 \\
\mathrm{~m} / \mathrm{s}\end{array}$ & $15 \%$ (Flux) & $n s$ & [56] \\
\hline$n s$ (fiber) & $0.72 \mathrm{~mm}$ & $\begin{array}{l}\text { Upward } \\
\text { vertical }\end{array}$ & $\begin{array}{l}\text { Clay } \\
\text { suspension }\end{array}$ & $n s$ & $\begin{array}{l}0-3.3 \\
\mathrm{~L} / \mathrm{min}\end{array}$ & $\begin{array}{l}98 \% \\
\text { (Rejection) }\end{array}$ & $n s$ & [172] \\
\hline$\overline{\mathrm{PSf}}$ & $0.5 \mathrm{~mm}$ & $\begin{array}{l}\text { Upward } \\
\text { vertical }\end{array}$ & $\begin{array}{l}\text { Dextran } \\
\text { solution }\end{array}$ & $\begin{array}{l}0.1-0.3 \\
\mathrm{~m} / \mathrm{s}\end{array}$ & $\begin{array}{l}0.01- \\
0.15 \\
\mathrm{~m} / \mathrm{s} \\
\end{array}$ & $\begin{array}{l}160 \% \\
\text { (Flux) }\end{array}$ & $\begin{array}{l}\text { Slug } \\
\text { flow }\end{array}$ & [36] \\
\hline $\begin{array}{l}\text { Derivative } \\
\text { cellulosic }\end{array}$ & $0.93 \mathrm{~mm}$ & $\begin{array}{l}\text { Upward } \\
\text { vertical }\end{array}$ & $\begin{array}{l}\text { Clay } \\
\text { suspension }\end{array}$ & $0.14 \mathrm{~m} / \mathrm{s}$ & $\begin{array}{l}0-0.5 \\
\mathrm{~m} / \mathrm{s}\end{array}$ & $\begin{array}{l}130 \% \\
\text { (Particle } \\
\text { removal) }\end{array}$ & $n s$ & [157] \\
\hline PVDF & $40 \mathrm{~mm}$ & $\begin{array}{l}\text { Upward } \\
\text { vertical }\end{array}$ & $\begin{array}{l}\text { Biologicall } \\
\text { y treated } \\
\text { wastewater }\end{array}$ & $3.3 \mathrm{~L} / \mathrm{min}$ & $\begin{array}{l}0-5.3 \\
\text { L/min }\end{array}$ & $n s$ & $\begin{array}{l}\text { Bubble } \\
\text { flow }\end{array}$ & [241] \\
\hline $\mathrm{PP}$ & $\begin{array}{l}0.244 \\
\mathrm{~mm}\end{array}$ & $\begin{array}{l}\text { Upward } \\
\text { vertical }\end{array}$ & $\begin{array}{l}\text { Anionic } \\
\text { and } \\
\text { nonionic } \\
\text { surfactant }\end{array}$ & $\begin{array}{l}0.25-0.5 \\
\mathrm{~L} / \mathrm{min}\end{array}$ & $\begin{array}{l}10-20 \\
\mathrm{~L} / \mathrm{min}\end{array}$ & $\begin{array}{l}90 \% \\
\text { (Rejection) }\end{array}$ & $n s$ & [242] \\
\hline$\overline{\mathrm{PSf}}$ & $1.45 \mathrm{~mm}$ & $\begin{array}{l}\text { Upward } \\
\text { vertical }\end{array}$ & $\begin{array}{l}\text { Dextran } \\
\text { solution }\end{array}$ & $\begin{array}{l}0.72-0.9 \\
\mathrm{~m} / \mathrm{s}\end{array}$ & $\begin{array}{l}1-1.2 \\
\mathrm{~m} / \mathrm{s}\end{array}$ & $\begin{array}{l}102.5 \% \\
\text { (Flux) }\end{array}$ & $\begin{array}{l}\text { Slug } \\
\text { flow }\end{array}$ & [160] \\
\hline PVDF & $2 \mathrm{~mm}$ & $\begin{array}{l}\text { Upward } \\
\text { vertical }\end{array}$ & Raw water & $\begin{array}{l}0.2-0.4 \\
\mathrm{~m} / \mathrm{s}\end{array}$ & $\begin{array}{l}0.2-0.4 \\
\mathrm{~m} / \mathrm{s}\end{array}$ & $60 \%$ (Flux) & $n s$ & {$[75]$} \\
\hline PES & $1.2 \mathrm{~mm}$ & $\begin{array}{l}\text { Upward } \\
\text { vertical }\end{array}$ & $\begin{array}{l}\text { Polysaccha } \\
\text { ride } \\
\text { solution }\end{array}$ & $n s$ & $\begin{array}{l}1.098- \\
2.598 \\
\mathrm{~L} / \mathrm{min}\end{array}$ & $\begin{array}{l}151 \% \\
\text { (Flux) }\end{array}$ & $n s$ & [79] \\
\hline PP & $\begin{array}{l}0.39-1.8 \\
\mathrm{~mm}\end{array}$ & $\begin{array}{l}\text { Upward } \\
\text { vertical }\end{array}$ & $\begin{array}{l}\text { Yeast } \\
\text { suspension }\end{array}$ & $n a$ & $\begin{array}{l}2-10 \\
\mathrm{~L} / \mathrm{min}\end{array}$ & $n a$ & $\begin{array}{l}\text { Bubble } \\
\text { flow }\end{array}$ & [61] \\
\hline Polymeric & $0.9 \mathrm{~mm}$ & $\begin{array}{l}\text { Upward } \\
\text { vertical }\end{array}$ & $\begin{array}{l}\text { Mixed } \\
\text { liquor }\end{array}$ & $n a$ & $\begin{array}{l}0-4 \\
\mathrm{~L} / \mathrm{min}\end{array}$ & $n s$ & $n s$ & [206] \\
\hline PVDF & $n s$ & $\begin{array}{l}\text { Upward } \\
\text { vertical }\end{array}$ & Wastewater & $n a$ & $\begin{array}{l}0.048- \\
0.097 \\
\mathrm{~m} / \mathrm{s}\end{array}$ & $n s$ & $n s$ & {$[51]$} \\
\hline PEI & $n s$ & $\begin{array}{l}\text { Upward } \\
\text { vertical }\end{array}$ & $\begin{array}{l}\text { Activated } \\
\text { sludge }\end{array}$ & $n a$ & $\begin{array}{l}3.3 \\
\mathrm{~L} / \mathrm{min}\end{array}$ & $\begin{array}{l}93 \% \\
\text { (Rejection) }\end{array}$ & $n s$ & [189] \\
\hline PSf & $1 \mathrm{~mm}$ & $n s$ & $\begin{array}{l}\text { Pretreated } \\
\text { yellowfin } \\
\text { tuna spleen } \\
\text { extract }\end{array}$ & $\begin{array}{l}0.2925- \\
1.16 \\
\mathrm{~L} / \mathrm{min}\end{array}$ & $\begin{array}{l}0.2925- \\
1.16 \\
\mathrm{~L} / \mathrm{min}\end{array}$ & $53 \%$ (Flux) & $n s$ & [165] \\
\hline PVDF & $0.3 \mathrm{~mm}$ & $\begin{array}{l}\text { Upward } \\
\text { vertical }\end{array}$ & $\begin{array}{l}\text { Yeast } \\
\text { suspension }\end{array}$ & $n s$ & $\begin{array}{l}0.05- \\
0.15 \\
\mathrm{~L} / \mathrm{min}\end{array}$ & $n s$ & $\begin{array}{l}\text { Bubble } \\
\text { flow, } \\
\text { slug } \\
\text { flow } \\
\end{array}$ & [197] \\
\hline PES & $\begin{array}{l}1.4-2.3 \\
\mathrm{~mm}\end{array}$ & $\begin{array}{l}\text { Upward } \\
\text { vertical }\end{array}$ & Wastewater & $0.04 \mathrm{~m} / \mathrm{s}$ & $0.2 \mathrm{~m} / \mathrm{s}$ & $n s$ & $n s$ & [208] \\
\hline$n s$ & $0.96 \mathrm{~mm}$ & $\begin{array}{l}\text { Upward } \\
\text { vertical }\end{array}$ & $\begin{array}{l}\text { Surface } \\
\text { water }\end{array}$ & $0.1 \mathrm{~m} / \mathrm{s}$ & $\begin{array}{l}0.54 \\
\mathrm{~m} / \mathrm{s}\end{array}$ & $\begin{array}{l}69 \% \\
\text { (Energy } \\
\text { consumptio } \\
\text { n decrease) }\end{array}$ & $n s$ & [158] \\
\hline PVDF & $0.8 \mathrm{~mm}$ & Upward & Wastewater & $n a$ & 298.6 & Constant & $n s$ & [212] \\
\hline
\end{tabular}




\begin{tabular}{|c|c|c|c|c|c|c|c|c|}
\hline & & $\begin{array}{l}\text { and } \\
\text { downward } \\
\text { vertical }\end{array}$ & & & $\mathrm{L} / \mathrm{min}$ & flux & & \\
\hline PVDF & $0.85 \mathrm{~mm}$ & $\begin{array}{l}\text { Upward } \\
\text { vertical }\end{array}$ & Raw water & $n a$ & $\begin{array}{l}16.67- \\
125 \\
\mathrm{~L} / \mathrm{min}\end{array}$ & $n s$ & $\begin{array}{l}\text { Bubble } \\
\text { flow }\end{array}$ & [112] \\
\hline \multicolumn{9}{|c|}{ Spiral-wound membranes } \\
\hline $\mathrm{PA} / \mathrm{PSf}$ & $n a$ & $\begin{array}{l}\text { Upward } \\
\text { vertical }\end{array}$ & Tap water & $\begin{array}{l}11.67 \\
\mathrm{~L} / \mathrm{min}\end{array}$ & $\begin{array}{l}23.33 \\
\mathrm{~L} / \mathrm{min}\end{array}$ & $n s$ & $n s$ & [87] \\
\hline $\mathrm{PA} / \mathrm{PSf}$ & $n a$ & $\begin{array}{l}\text { Upward } \\
\text { vertical }\end{array}$ & Tap water & $\begin{array}{l}11.67 \\
\mathrm{~L} / \mathrm{min}\end{array}$ & $\begin{array}{l}23.33 \\
\mathrm{~L} / \mathrm{min}\end{array}$ & $\begin{array}{l}283 \% \\
\text { (Pressure } \\
\text { drop } \\
\text { decrease) }\end{array}$ & $n s$ & {$[88]$} \\
\hline $\mathrm{PA} / \mathrm{PSf}$ & $n a$ & $\begin{array}{l}\text { Upward } \\
\text { vertical }\end{array}$ & Tap water & $\begin{array}{l}5.83 \\
\mathrm{~L} / \mathrm{min}\end{array}$ & $\begin{array}{l}11.67 \\
\mathrm{~L} / \mathrm{min}\end{array}$ & $\begin{array}{l}\text { Normalized } \\
\text { pressure } \\
\text { drop from } \\
144 \% \text { to } \\
20 \%\end{array}$ & $n s$ & [89] \\
\hline $\mathrm{PA} / \mathrm{PSf}$ & $n a$ & $\begin{array}{l}\text { Upward } \\
\text { vertical }\end{array}$ & Tap water & $\begin{array}{l}5.83 \\
\mathrm{~L} / \mathrm{min}\end{array}$ & $\begin{array}{l}11.67 \\
\mathrm{~L} / \mathrm{min}\end{array}$ & $\begin{array}{l}\text { Pressure } \\
\text { drop } \\
\text { increase } \\
\text { only 5\% }\end{array}$ & $n s$ & {$[91]$} \\
\hline PA/PSf & $n a$ & $\begin{array}{l}\text { Upward } \\
\text { vertical }\end{array}$ & Tap water & $\begin{array}{l}5.83 \\
\mathrm{~L} / \mathrm{min}\end{array}$ & $\begin{array}{l}11.67 \\
\mathrm{~L} / \mathrm{min}\end{array}$ & $n s$ & $n s$ & [243] \\
\hline
\end{tabular}

Abbreviations: $n s$ : not stated; $n a$ : not available;

$* \quad=$ channel width of flat-sheet membrane module, channel diameter of tubular and hollow-fiber module

$* *=$ difficult to convert liquid/gas flow units uniformly due to insufficient information on hydraulic diameter of channel

$* * *$ = final values of enhancement in the flux, rejection and/or feed channel pressure drop

Some values were extracted from graphs or calculated from other values and may therefore not be perfectly accurate.

\subsection{Analysis of two-phase flow in membrane modules}

\subsubsection{Introduction}

We analyzed the data we collected in our literature database (Table 2.3) to obtain general trends and possible variables of two-phase flow, which affect the flux, rejection, selectivity enhancement and/or feed channel pressure drop decrease. Table 2.4 summarizes the possible variables that influence the degree of process enhancement.

Table 2.4. Possible variables that influence the degree of process enhancement.

\begin{tabular}{|l|l|}
\hline Membranes/modules & - module position, \\
& - membrane type, \\
& - membrane pore size, \\
& - hydrodynamics in the module, \\
& - module type, \\
& - process type (UF/MF/NF/RO); \\
\hline Feed components & - feed type, \\
& - concentration, \\
& - variation, \\
& - pH;
\end{tabular}




\begin{tabular}{|l|l|}
\hline Process conditions & - feed flow, \\
& - trans-membrane pressure, \\
& - temperature; \\
\hline Two-phase flow & - type of gas, \\
& - gas/liquid ratio, \\
& - flow direction, \\
& - continuous or intermittent, \\
& - gas and liquid flow rate, \\
& - frequency of two-phase flow. \\
\hline
\end{tabular}

In the following sub-sections, an analysis is presented of different references used in this review in a more systematic way, leading to generalized trends and directions. As such it investigates for flat sheet membranes the effect of (i) gas and liquid superficial velocities on flux enhancement, (ii) gas/liquid ratio and feed types on flux enhancement and (iii) transmembrane pressure on permeation enhancement. For hollow fibers it evaluates the effect of gas and liquid flow on flux enhancement, while for spiral wound membranes it studies the influence of gas/liquid flow on the feed channel pressure drop. Finally it shortly addresses the effect of gas/liquid flow on the rejection. Data from our literature data base are systematically analyzed, correlated and interpolated using the Kriging approximation method and subsequently 3D plots are prepared [244]. Kriging is a regression method that can be used to analyze non-systematic data in 1-, 2- or 3-dimensions to estimate the spatial average over e.g. length, area or volume [245]. The Kriging method predicts spatial data from a data set of variables of interest with a spatial correlation by a weighted value, i.e. more close data points are considered to be better correlated and their weight will be higher. Using a fine grid, the results obtained with the Kriging approach provide the expected value (Kriging mean) and the variance (Kriging variance) computed for every point within a region. Further details on the theory on Kriging spatial data interpolation are found elsewhere [246, 247]. To create the presented 3D contour plots, worksheets of selected data as collected from our literature database are converted and gridded into a matrix with an algorithm using Origin data analysis software. Such a matrix is a rectangular array of $\mathrm{z}$ values whose columns are linearly mapped to $\mathrm{x}$ values and whose rows are linearly mapped to y values. 


\subsubsection{Flat sheet membranes}

\subsubsection{Effect of gas and liquid superficial velocities on flux enhancement}

Fig. 2.19 shows the correlation of gas and liquid velocities with the mean flux enhancement.

The data were collected from our literature database, selecting results obtained for the following conditions as summarized in Table 2.5.

Table 2.5. Selected conditions for flat sheet membranes

\begin{tabular}{ll}
\hline Membrane module & Flat-sheet membrane \\
\hline Module position & Vertically oriented \\
Gas type & Compressed air \\
Operating temperature & $20-30{ }^{\circ} \mathrm{C}$ \\
Trans-membrane pressure & $0.2-4.5$ bar \\
Membrane type & MF and UF membranes \\
\hline
\end{tabular}

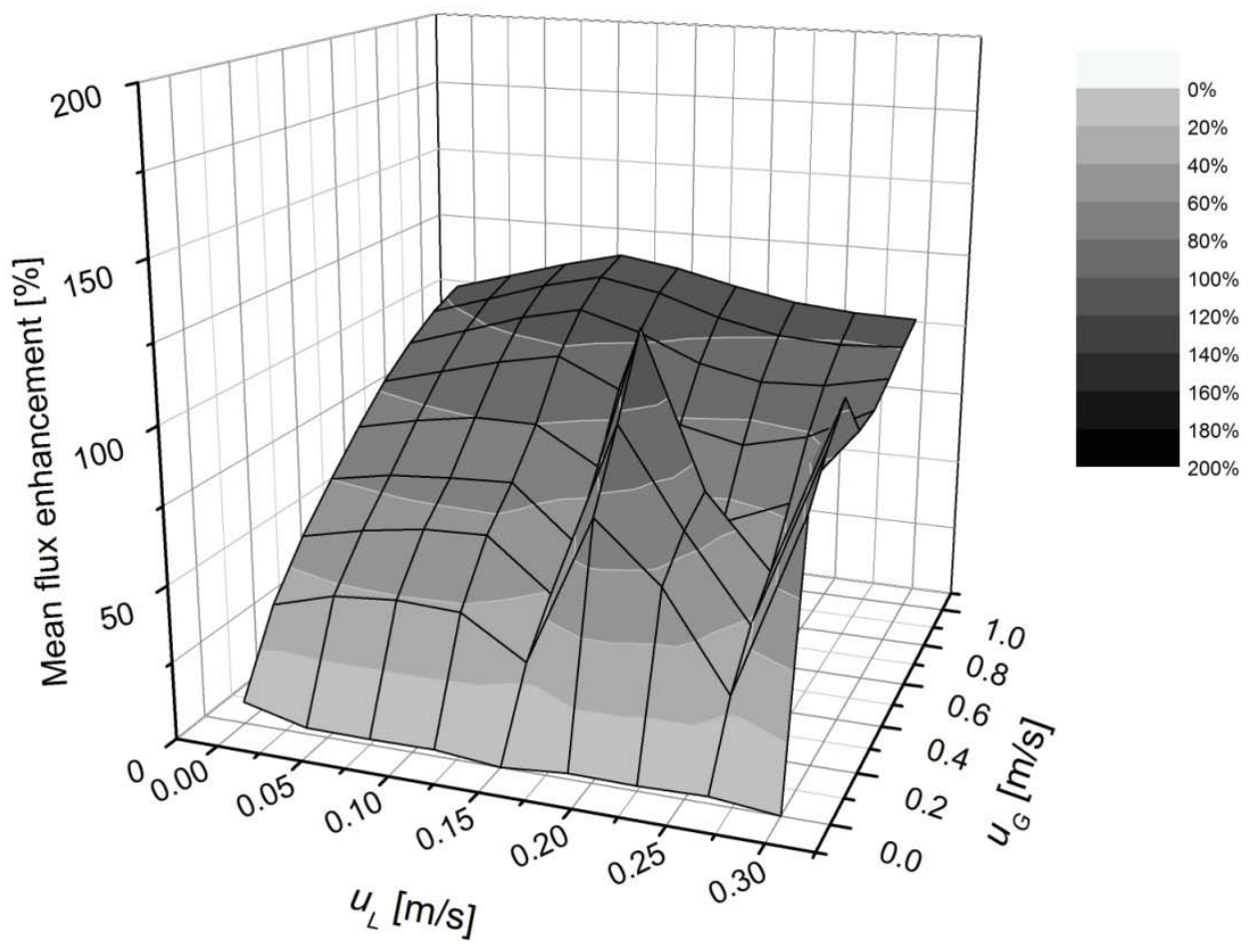

Fig. 2.19. Correlation of gas and liquid superficial velocities with mean flux enhancement (vertically positioned flat sheet membrane module). 
Fig. 2.19 shows the influence of gas $\left(\mathrm{u}_{\mathrm{G}}\right)$ and liquid $\left(\mathrm{u}_{\mathrm{L}}\right)$ velocities on the mean flux enhancement. The mean flux enhancement is almost independent on the liquid velocity, and the enhancing effect of the gas velocity is much more obvious. In general, at a specific liquid velocity, the higher the gas-to-liquid ratio is, the higher the mean flux enhancement. A peak is indicated at high liquid but low gas velocities, and in that area the mean flux enhancement is significantly higher. The peak is observed at a liquid superficial velocities $\left(\underline{u}_{\underline{L}}\right)$ of $0.2 \mathrm{~m} / \mathrm{s}$ and gas superficial velocities $\left(\mathrm{u}_{\mathrm{G}}\right)$ of $0.2-0.6 \mathrm{~m} / \mathrm{s}$. This corresponds to a gas/liquid ratio $\theta$ of 0.5 $0.75 \mathrm{~m} / \mathrm{s}$. Obviously, this is the range in which slug flow occurs, resulting in higher shear stresses and enhanced fouling control. Slug flow also occurs for instance at lower liquid superficial velocities of $0.1 \mathrm{~m} / \mathrm{s}$ and gas superficial velocities between $0.2-0.6 \mathrm{~m} / \mathrm{s}$, however the effect on the mean flux enhancement is not as high as presented here.

\subsubsection{Effect of gas/liquid ratio and feed types on flux enhancement}

The flux enhancement depends on the feed type (see Fig. 2.20). To evaluate this, we analyzed the same data (as summarized in Table 2.5) with respect to feed type, membrane type and gas/liquid ratio.

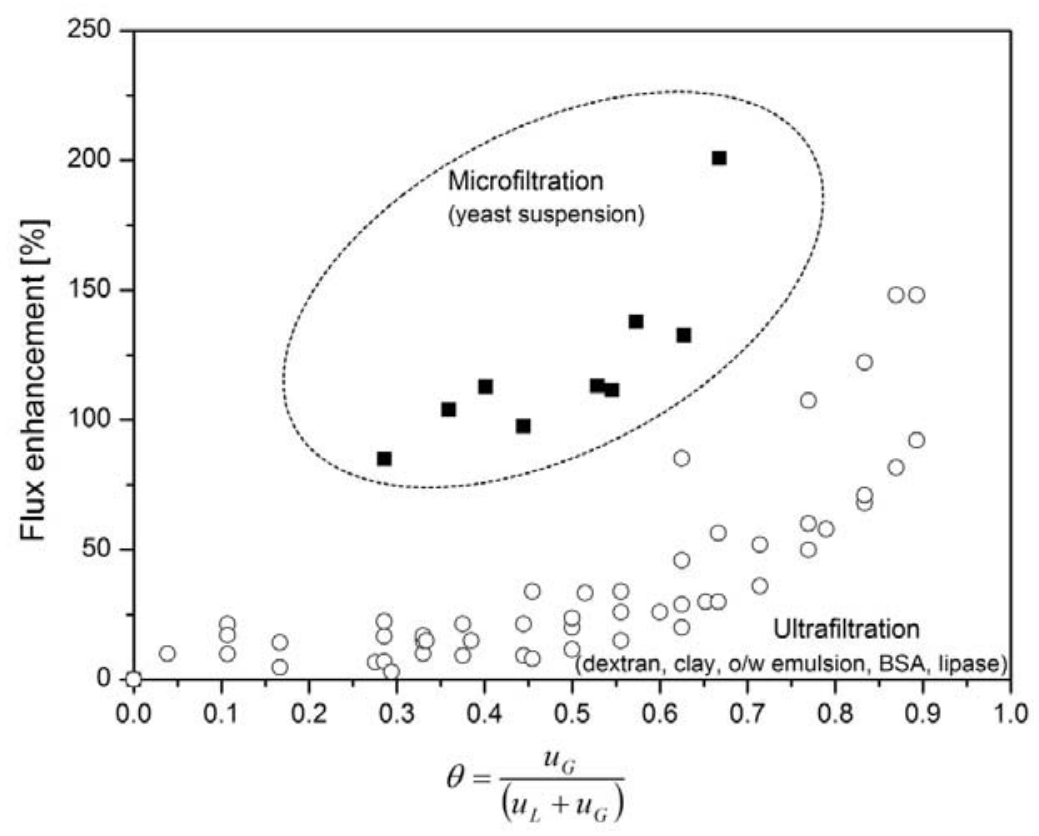

Fig. 2.20. Effect of gas/liquid ratio and feed type on flux enhancement (vertically positioned flat sheet membrane module). 
Fig. 2.20 clearly shows that in both MF and UF of several feed solutions (yeast, dextran, clay, oil-in-water emulsion, BSA and lipase), the flux enhancement and thus the permeate flux increases with increasing gas/liquid ratio. At higher gas flows, shear stresses increase leading to flux enhancement by reduced fouling. The application of gas-liquid two-phase flow is more effective in yeast filtration using MF and results in higher flux enhancements than in UF at the same gas-liquid ratios (as shown in the Figure, this occurred within a range of gas/liquid ratios, $\theta$, of $0.3-0.7$, in which slug flow occurs). Two possible reasons emerged. First, the pore sizes in MF are higher than in UF; therefore, the mass transport to the permeate side is also higher. The gas-liquid flow will easily remove cake formed on top of the membrane, significantly increasing the flux. The second reason is formed by the characteristics of yeast fed upstream of the MF process. Baker's yeast aggregates into multicellular structures when adhered to surfaces. Such agglomerates can easily be swept away by the force of the gas/liquid flow, and removed from the membrane surface.

\subsubsection{Effect of trans-membrane pressure on permeation enhancement}

To evaluate the optimal pressure in two-phase flow cleaning, we analyzed the effect of transmembrane pressure and gas/liquid ratio on the mean mass transfer coefficient (MTC) or permeation enhancement. The MTC is the mass transfer (flux) across the membrane based on the driving force (trans-membrane pressure (TMP)). To evaluate this, we collected data from our literature database on the basis of the conditions as summarized in Table 2.5 and the result is presented in Fig.2.21.

At a specific pressure, flux enhancement is stronger at high gas/liquid ratios, as at higher gas velocities, shear stresses become more effective. As shown in Fig. 2.21, the enhancing effect of gas-liquid flow is less significant at elevated TMP and is almost negligible at pressures above 2-3 bar. It is expected that gas dissolves in the liquid phase at these pressures; therefore, the wall shear stress decreases and solute buildup remains on the membrane surface. If the feed pressure is high enough, the gas will dissolve completely in some cases even resulting in a negative effect. The mean MTC enhancement by a factor of 5 occurred at a low applied pressure and a high gas/liquid ratio. 


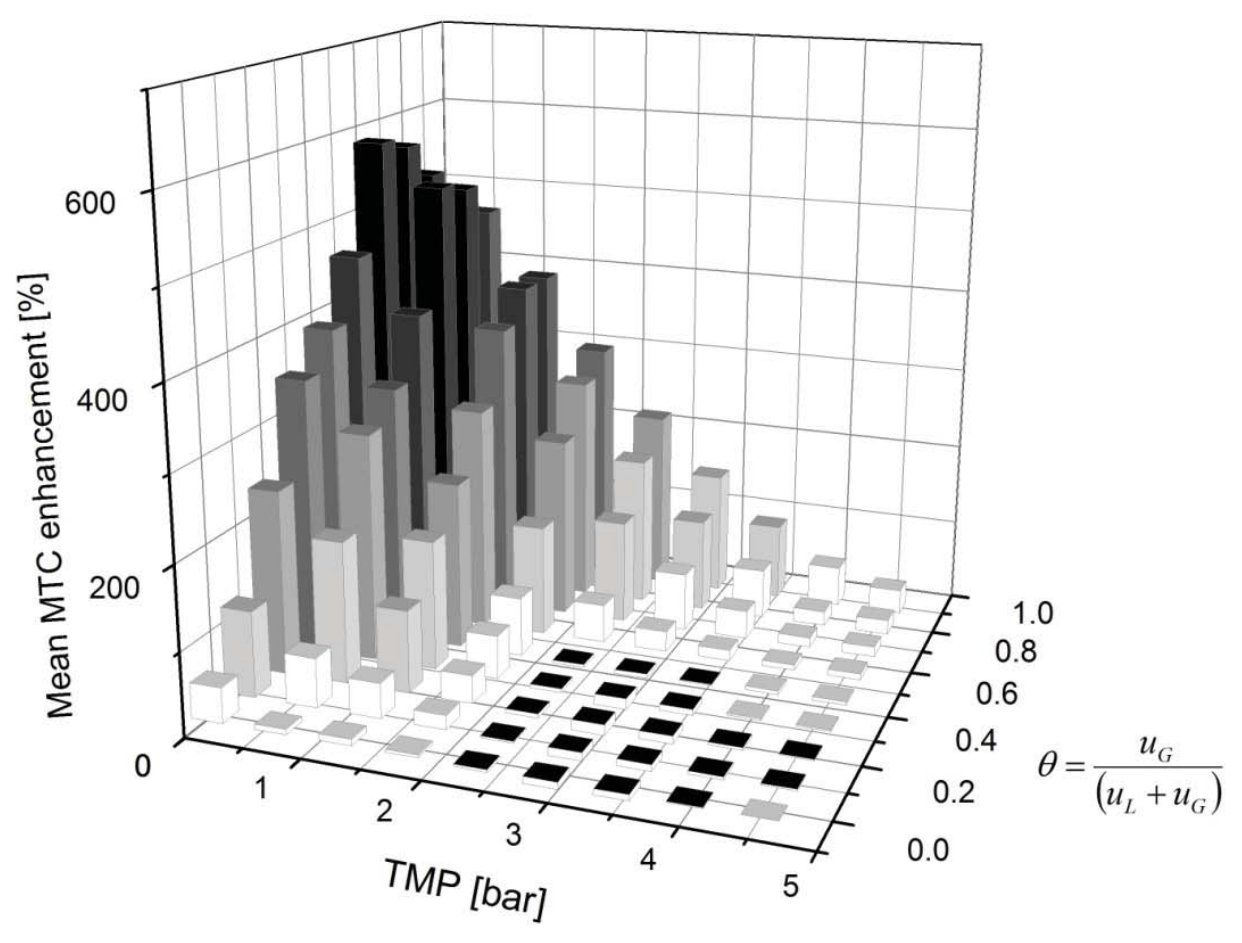

Fig.2. 21. Effect of trans-membrane pressure and gas/liquid ratio on mean MTC enhancement (vertically positioned flat-sheet membrane module).

At a specific pressure, flux enhancement is stronger at high gas/liquid ratios, as at higher gas velocities, shear stresses become more effective. As shown in Fig. 2.21, the enhancing effect of gas-liquid flow is less significant at elevated TMP and is almost negligible at pressures above 2-3 bar. It is expected that gas dissolves in the liquid phase at these pressures; therefore, the wall shear stress decreases and solute buildup remains on the membrane surface. If the feed pressure is high enough, the gas will dissolve completely in some cases even resulting in a negative effect. The mean MTC enhancement by a factor of 5 occurred at a low applied pressure and a high gas/liquid ratio.

\subsubsection{Effect of gas and liquid flow on flux enhancement in hollow fiber membranes}

The data found in literature on two-phase flow cleaning in hollow fiber configurations is summarized in Table 2.6. The result of the analysis of the effect of gas and liquid flow on flux enhancement is summarized in Fig. 2.22. 
Table 2.6. Selected conditions for hollow-fiber membranes

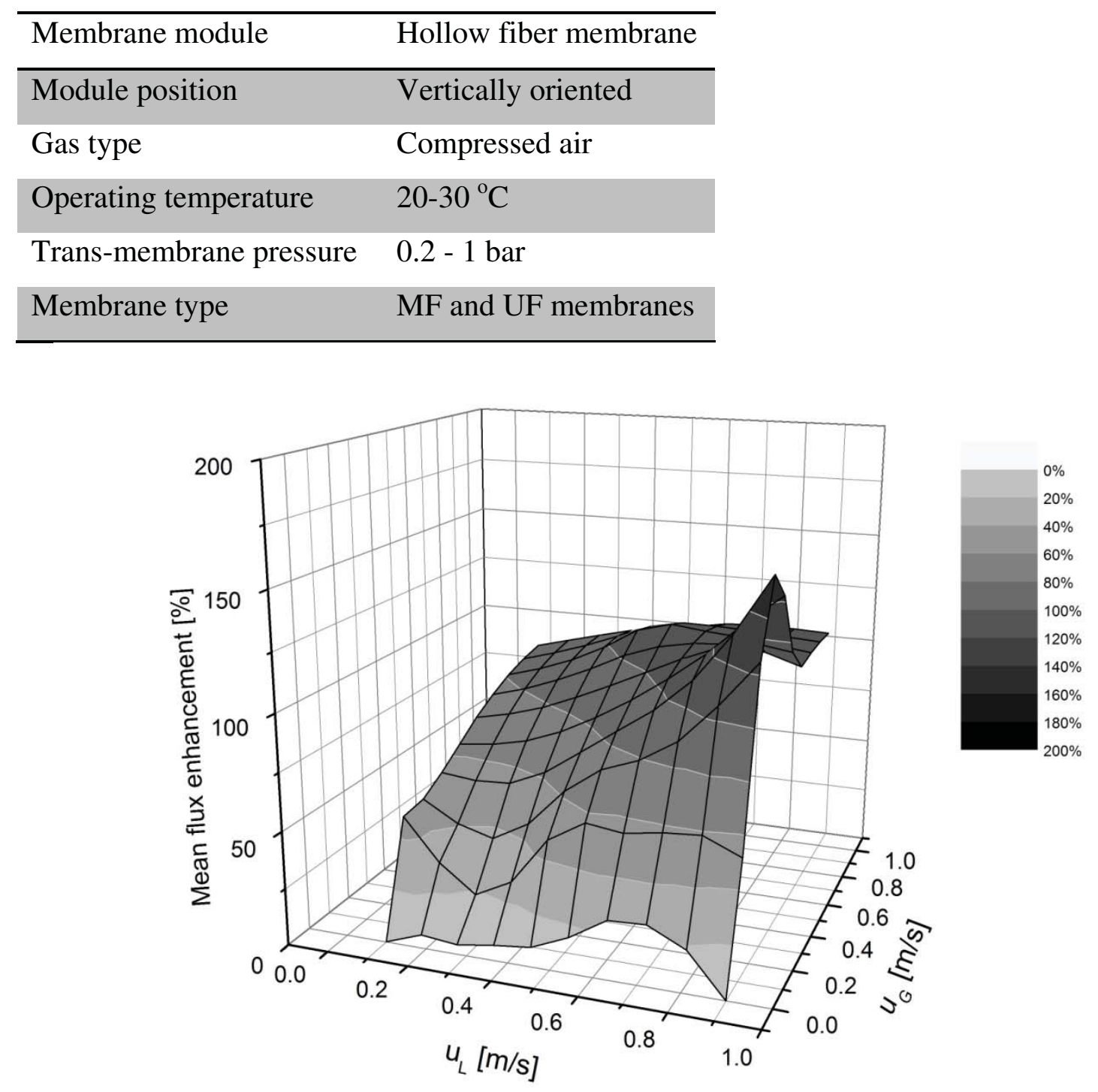

Fig. 2.22. Correlation of gas and liquid superficial velocities with flux enhancement (vertically positioned hollow-fiber membrane module).

As Fig. 2.22 shows that the mean flux enhancement depends on the gas $\left(\mathrm{u}_{\mathrm{G}}\right)$ and liquid $\left(\mathrm{u}_{\mathrm{L}}\right)$ velocities. Although the effect of gas velocity is significant, the effect of the liquid velocity however is more obvious in the case of hollow fibers rather than that of flat sheet membrane modules (Fig. 2.19). The mean flux enhancements in hollow fiber membrane configurations are greater than achieved in flat-sheet membrane modules. In hollow-fiber modules, the hydraulic diameter is much smaller; therefore, a higher wall shear stress is obtained at the 
same gas/liquid ratio. This allows removing solute cakes from the membrane surface, resulting in a greater flux enhancement. The highest mean flux enhancement was observed at a particular gas velocity in which slug flow occurs; a further increase of the gas velocity results in the formation of an annular flow and therefore does not increase the mean flux enhancement significantly.

\subsubsection{Effect of gas and liquid flow on the feed channel pressure drop in spiral wound membranes}

The presence of a gas/liquid two-phase flow in vertically positioned spiral-wound membrane modules clearly results in declogging of the spacer-filled channels [87, 182]. Both solute buildup by particles and sticky materials like biofilm were reportedly removed by the wall shear stress induced by an air/water flow. The air/water carries the fouling materials to the downstream side of the membrane module, and lowers the channel's pressure drop considerably. The characteristics of the foulants affected the performance of air/water cleaning; clogged particles were more easy to remove by gas/liquid two-phase flow cleaning than stickier materials like biofilms [87, 91]. However, as the amount of data for spiral wound membrane modules is limited, a more detailed and systematic analysis is not possible.

\subsubsection{Effect of gas and liquid flow on the rejection}

Very few papers reported on the effect of a gas/liquid two-phase flow on the membrane rejection [30, 168, 170]. Ducom et al.[30] concluded that in salt solutions, only concentration polarization occurs at the membrane surface, and the presence of a gas/liquid flow has no effect on both rejection and flux. In other solutions, solute buildup on the membrane surface forms a cake; a gas/liquid flow affects this fouling and enhances both membrane flux and rejection. During protein fractionation using gas sparged UF, Ghosh et al.[168] reported that significant increase in selectivity (rejection of one protein component) was observed at low gas flow rates, and that the selectivity is found to be insensitive to a further increase in the gas flow rate. However, due to the limited number of data available on the effect of gas/liquid flow on rejection, a more systematic analysis of this effect is not possible. 


\subsection{Industrial applications}

Two-phase flow is a well-known process in many industrial applications, notably in multiphase reactors (e.g. fluidized bed, spay dryer) and dialyzers as well as heat exchangers. Gas-liquid two-phase flows are also used in industrial membrane processes. The most popular and extensively reported application is aeration in submerged MBRs. However, a few recent publications also report on the application of a two-phase flow in industrial NF/RO, proving the potential of this technology. This section provides a brief overview describing a few examples of industrial application of submerged MBRs and NF/RO processes in drinking water industries.

\subsubsection{MBRs for wastewater treatment and reuse}

Despite the fact that the application of two-phase flow membrane bioreactors (MBRs) has been extensively studied, a fundamental understanding of this technology in MBR is still lacking. Applied aeration rates are normally just based on previous experiences and the manufacturers' recommendations [248]. Key factors in achieving a good extrapolation from lab scale to industrial scale are (i) air flow rate per membrane area, (ii) air flow rate per permeate flow rate, (iii) total liquid volume in the reactor, (iv) liquid volume in the fiber bundle, (v) air flow rate per wetted surface, and (vi) superficial air velocity [249].

Full-scale MBRs with two-phase flow systems are available from several suppliers, e.g. Microza from Asahi Kasei, Filcera from Kubota (Fig. 2.23), ZeeWeed from Zenon (GE Power and Water)[250], Membray from Toray, Puron from Koch Membrane Systems, AL-MBR from X-Flow, Spirasep UF and iSep ${ }^{\mathrm{TM}} 500 \mathrm{UF}$ from Trisep (Fig. 2.24) and Mempulse from Siemens. Recent detailed reviews of industrial submerged MBRs can be found elsewhere [251, 252].

Due to the swift growth of MBR technology, several advancements have been made leading to a lower aeration rate, a higher effective membrane area, membrane surface modifications to reduce fouling, and a larger net flux. In Europe, 154 MBR units existed in 2002, of which $85 \%$ were for industrial applications. However, both municipal and industrial sectors saw a sharp increase in the following years. In the next three years (from 2002 to 2005), the market 
growth rate was linear with an increase of at least 50 industrial units and 20 municipal units annually, and it is expected that this growth rate will be maintained in the following years [253].

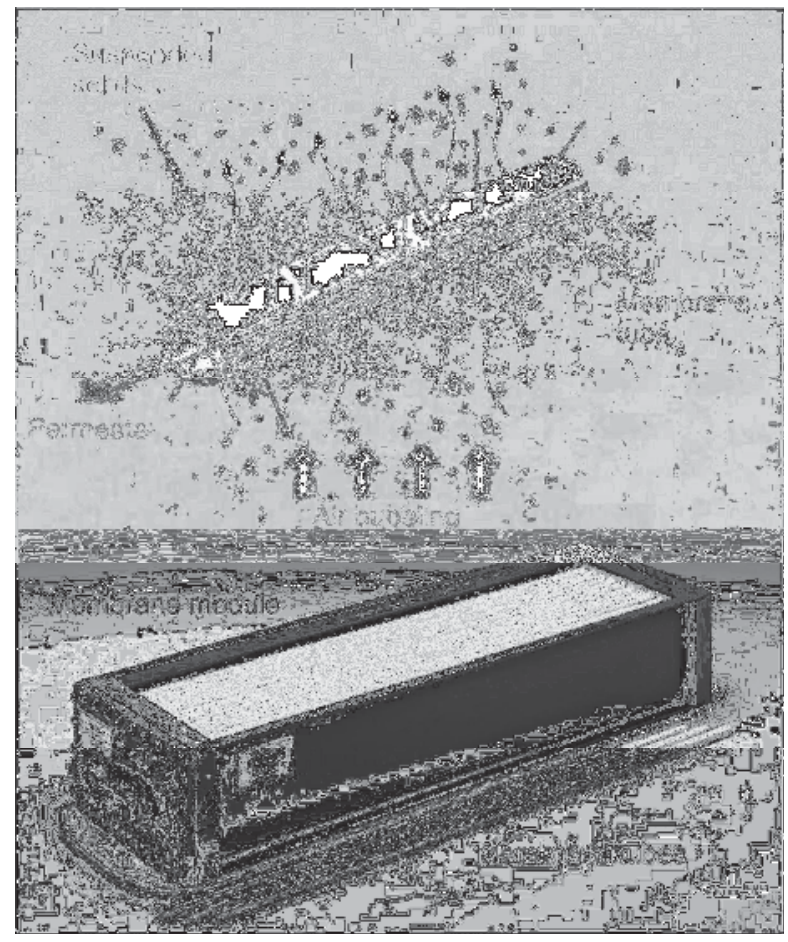

Fig. 2.23. Kubota Filcera ${ }^{\circledR}$ employing ceramic membranes and aeration.

A recent report forecasted that the worldwide MBR market will be worth US\$ 888 million by 2017, driven by stringent effluent discharge norms, the rising water scarcity and enhanced emphasis on water reuse and recycling for freshwater conservation. Major players profiled in the report include Aqua-Aerobic Systems Inc., Asahi Kasei Group, GE Water \& Process Technologies, Keppel Seghers Belgium NV, Koch Membrane Systems Inc., Kubota Corp, Pall Corp, Siemens Water Technologies, Toray Industries Inc. and Veolia Environment [254]. Global MBR operation is expected to grow from 3,879,000 $\mathrm{m}^{3} /$ day in 2011 to $12,344,000$ $\mathrm{m}^{3} /$ day by 2017 , at a predicted compound annual growth rate of $20.8 \%$ for the period 2012 2017 [255]. It was also reported that Asia-Pasific continues to remain the largest and the fastest growing regional market, driven by an increasing demand for clean water (due to rapid industrialization and high water stress levels), a growing emphasis on reuse and recycling of water, and increasing policies and legislation. In China, the total MBR capacity for 
wastewater treatment is more than $100,000 \mathrm{~m}^{3} / \mathrm{d}$. The largest MBR plant in China for municipal wastewater treatment and reuse is the Beijing Kunyu River WWTP, which has a capacity of 100,000 $\mathrm{m}^{3} / \mathrm{d}$ (constructed by Origin Water Technology Co., Ltd.), and the largest MBR plant for industrial wastewater treatment is located in Tianjin, which has a capacity of $30,000 \mathrm{~m}^{3} / \mathrm{d}$ (constructed by Motimo Membrane Inc.) [256].

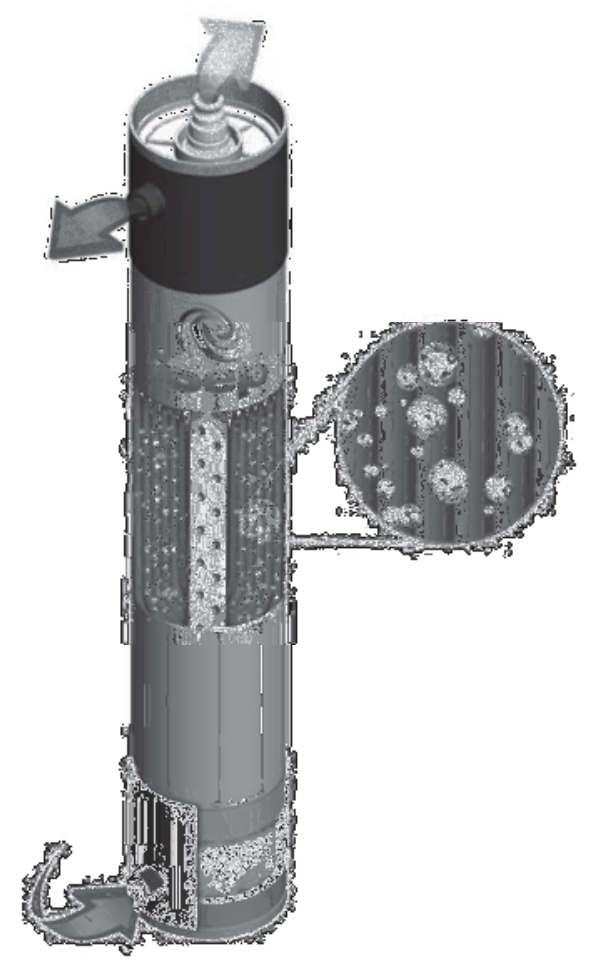

Fig. 2.24. Trisep iSep ${ }^{\mathrm{TM}} 500 \mathrm{UF}$ spiral-wound module with integrated air sparging.

\subsubsection{NF/RO processes in drinking water industries}

Membrane units in drinking water treatment also suffer from membrane fouling, typically by biofilms and particles, which increases membrane resistance. An early industrial application of two-phase flow in drinking water treatment was the AirFlush® technology used in a tubular capillary NF plant in Spannenburg, the Netherlands. The AirFlush® system is operated by Nuon Water, and consists of forty-four modules with a maximum capacity of $3000 \mathrm{~m}^{3} / \mathrm{d}$ [257].

As shown in Fig. 2.25, the system basically uses a semi-dead-end process, starting by closing the concentrate valve during the production run, so then all the feed supplied to the system is withdrawn as permeate. A small cross-flow velocity is applied to maintain flux and rejection 
at an acceptable degree. When a significant rejection drop occurs, the concentrate valve is opened. Using a combination of air and water, the concentrated water is flushed out from the module; then periodically, concentrated flow is released. During air flush operation, the concentrate valve is always opened, while the permeate valve is closed and the displacement pump is switched off. In the AirFlush ${ }^{\circledR}$ systems, the air/water ratio is about 2 to 3 , with a flushing duration of about 5 to $10 \mathrm{~s}$. The Spannenburg plant treats groundwater, with a total production of 25 million $\mathrm{m}^{3} /$ year.

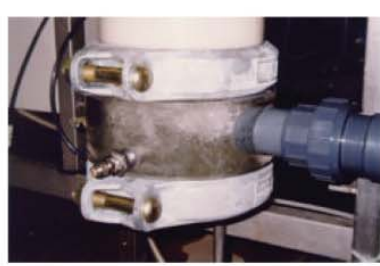

air injection in the feed flow

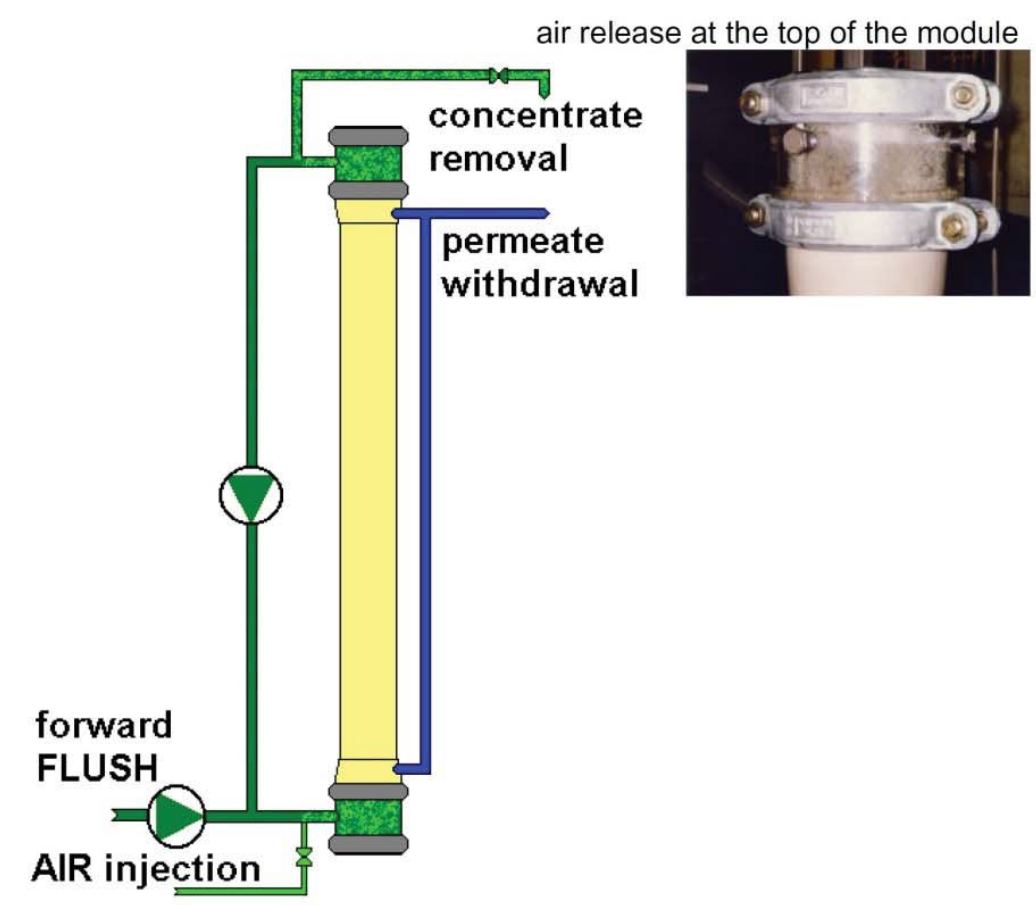

Fig. 2.25. AirFlush ${ }^{\circledR}$ system at the Spannenburg water treatment works, the Netherlands [257].

In RO, a periodic air/water cleaning process is successfully operated in a full-scale installation in the Botlek area, in the Port of Rotterdam in the Netherlands. Evides Industriewater operates this plant since January 2010; it produces nearly $1400 \mathrm{~m}^{3} / \mathrm{h}$ of demineralized water, and is considered the first and largest application of RO membranes employing air/water two-phase flow in the world (Fig. 2.26). 


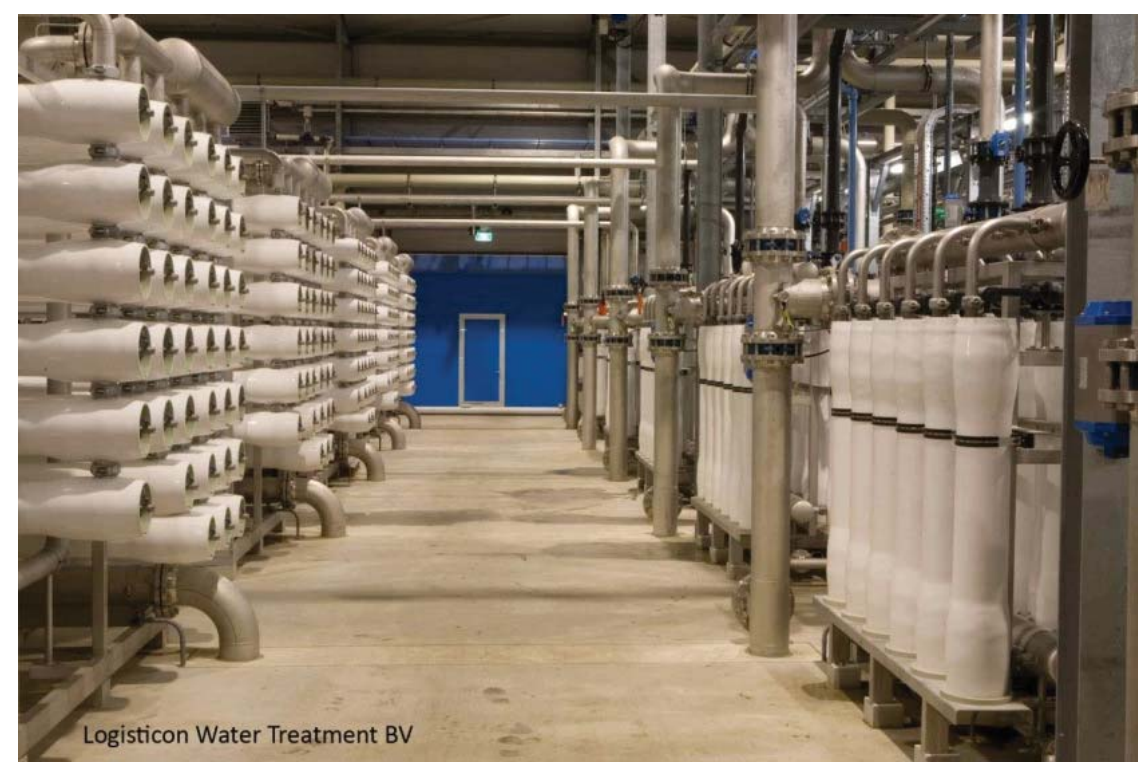

Fig. 2.26. Full-scale demineralized water plant using air/water cleaning in Botlek area, Rotterdam, the Netherlands (picture courtesy of Logisticon).

The Demineralized Water Plant (DWP) in the Botlek area uses surface water from Lake Brielse, and prior to entering the RO modules, the feed water is softened using an ion exchange resin until the calcium and magnesium concentrations are decreased to a maximum concentration of less than $10 \mu \mathrm{mol} / \mathrm{L}$, so that the $\mathrm{pH}$ of the $\mathrm{RO}$ feed water can be raised to 9.0 to improve salt rejection on the RO without any risks of scaling [258]. The first part of the installation consists of vertically positioned elements in eight parallel separate pressure tube (isolated vessel) stacks. Every stack contains 24 8-inch RO modules (Filmtec RO LE440i 8040-type). Air/water cleaning is applied in these vertical stacks; a conventional tapereddesign RO installation follows after these stacks (Fig.2. 27).

The use of air/water cleaning is aiming at a breakthrough in: (i) decreasing pre-treatment, (ii) using less chemical cleaning agents, such as acids, bases, complexing agents (e.g. EDTA), detergents, enzymes and biocides (estimated savings of 80\%), and (iii) reducing the energy consumption of the RO plant (estimated savings of $25 \%$ ). The first experiences with the fullscale operation at DWP Botlek confirm these figures. During 20 months of operating this fullscale plant, the pressure drop increase has not exceeded 0.5 bar. In the first 250 days, the DWP installation was operated on tap water from Evides WTP Berenplaat at Spijkenisse (since the pre-treatment process for surface water treatment had not been completed yet), and 
permeability (MTC) did not decline significantly. Air/water cleaning is applied curatively when the pressure drop increases by $5-10 \%$ which in practice is monthly. Air/water cleaning in the summer coincides with an algal bloom causing substantial membrane fouling. The applied air/water ratio is 10 , which comes down to $20 \mathrm{Nm}^{3} / \mathrm{h}$ air and $2 \mathrm{~m}^{3} / \mathrm{h}$ water. After 250 days of operation, the feed water is changed to pre-treated surface water from Brielse Lake, resulting in a decline of approximately $20 \%$ in membrane permeability, most probably as a result of membrane fouling [259].

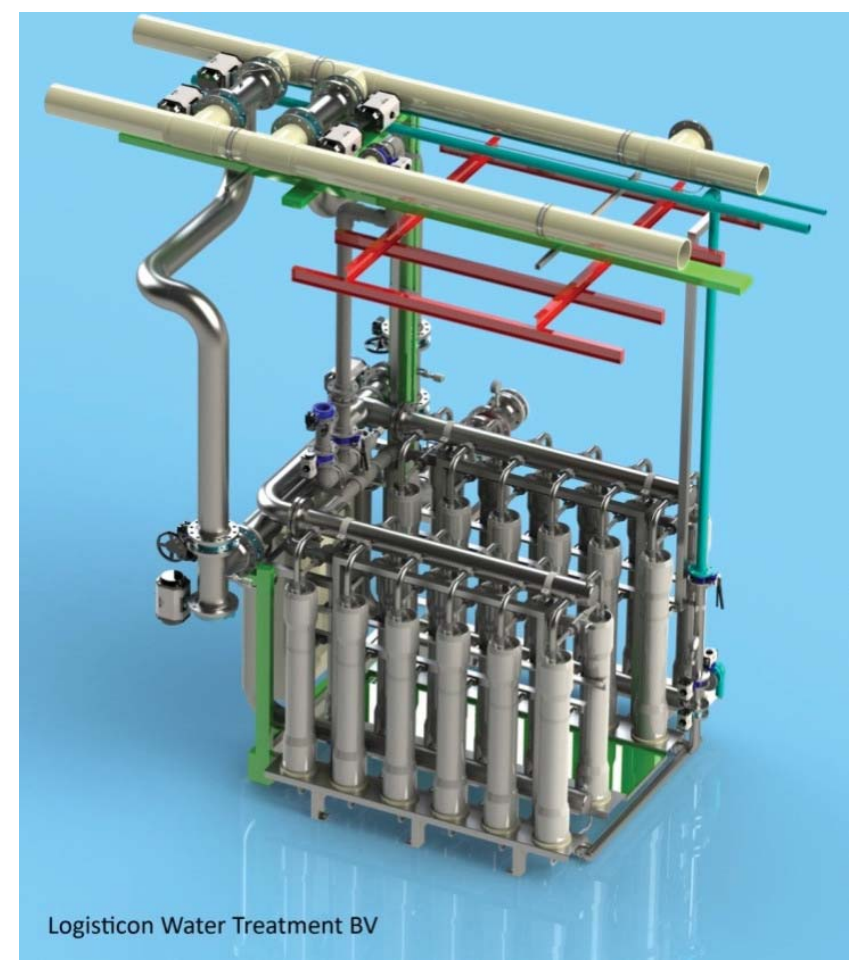

Fig. 2.27. Vertically positioned elements of the RO membrane stack in the Botlek plant in the Netherlands (picture courtesy of Logisticon).

Finally, it is worth mentioning that two-phase flow processes is also extensively used in MF/UF membranes as RO pre-treatment in the drinking water industries. The air scour mode to reduce backwash and forward flush frequency, is applied for example by vertically positioned Aquaflex/Seaflex 55 (UF, Pentair X-Flow) with air flow of $10 \mathrm{Nm}^{3} / \mathrm{h}$ per module (0.8 mm fiber) or $15 \mathrm{Nm}^{3} / \mathrm{h}$ (1.5 mm fiber) during 10 seconds[260], as well as by ZeeWeed 1500 (UF, GE Power \& Water), Kristal (UF, Hyflux) and HYDRAcap MAX (MF, 
Hydranautics) hollow fiber modules to enhance recovery and decrease capital expenses[261]. In addition to that of polymeric membrane materials, a ceramic membrane MF system was developed by Metawater (Japan), facilitating a more rigorous cleaning process using a backwash at 5 bar with compressed air at 2 bar, for very short period of 2-3 seconds [262]. Together with Dutch water treatment company PWN Technologies, Metawater have developed CeraMac module, applying 200 elements in a single pressure vessel. The Andijk III water treatment plant in the Netherlands and a demonstration plant at PUB's Choa Chu Kang Waterworks in Singapore were constructed using this unique technology[263].

\subsection{Conclusions and perspective}

The described experimental and commercial applications of two-phase flow in membrane processes show that two-phase flow cleaning can effectively improve membrane process performance. However, some aspects have to be addressed to optimize this technology in the future, especially in high-pressure membrane processes, for example optimum operation conditions, back pressure issues, energy consumption, detailed effect of bubble size and possible membrane deterioration. A brief summary and perspective are given below.

\subsubsection{Optimum operation conditions}

Our analysis of data collected from the literature yields what the optimum conditions are for using gas/liquid two-phase flow to enhance membrane process performance, i.e. flux, MTC and rejection increase, and feed channel pressure drop decrease. The following general conclusions can be drawn:

a. Vertical positioning of membrane modules has a positive effect for all types of module. In some cases, horizontal positioning (flow above/below membrane) or at a certain inclination angle of reported tubular system may give better results; however, it is more difficult to implement in those conditions with regards to the requirement of footprint area of module installation.

b. Gas/liquid ratio $(\theta)$ is the most important parameter that influences membrane process performance. However, in different membrane channel geometries, the same gas/liquid ratio gives different results because of the different flow patterns, translating into 
differences in bubble coverage of the channel area and in bubble-induced wall shear stress. Slug flow is known as the best flow pattern for improving the permeate flux in non-submerged systems, however smaller bubble flow was reported to have better performance in submerged systems.

c. Operating gas/liquid flow at low trans-membrane pressures improves the performance of the membrane process, since the size of the gas flow will be larger, which produces more wall shear stress at the membrane surface. On the other hand, at higher pressures gas will dissolve in the liquid, making air sparging less effective.

d. Gas/liquid flow is more effective at removing cake-type fouling deposited on the membrane surface than at removing attached biofilms or at decreasing concentration polarization.

e. Despite the fact that some published research was published which reported that different gas types (air, nitrogen, carbon dioxide, hexadecane) had different impacts on performance, the most important consideration is how to obtain sufficient wall shear stress to create friction on the membrane surface.

\subsubsection{Back pressure}

Application of two-phase flow in high-pressure membrane processes, such as NF and RO, was expected to result in two potential problems: (i) back pressure of dissolved gas to the permeate side and (ii) high energy requirements to achieve the necessary gas-to-liquid volume ratio [22]. When air or gas bubbles are injected into the feed flow, the gases will partly dissolve, leading to elevated concentrations of the gases in the water. Atmospheric conditions are found on the membrane's permeate side, and when the permeate is supersaturated with the gas, a boost of back pressure will occur. This back pressure influences the net driving pressure and is a disadvantage for system performance. However, this condition was not observed in NF and RO experiments by Verberk and Van Dijk [178] and Cornelissen et al. [87]. In the NF experiment by Verberk and Van Dijk, only short single filtration runs were performed, so there probably was not much dissolved air on the permeate side. In the Cornelissen et al. study [243], which ran for 212 days, no back pressure was observed either. 


\subsubsection{Energy cost}

The energy cost in two-phase flow membrane processes mainly concerns the energy needed for the pumps and compressor, and is calculated as energy per cubic meter of permeate. Verberk and van Dijk [178] made calculations and concluded that the energy cost of twophase flow capillary NF is lower than of single-phase capillary NF. This is because the air flow partially replaces the water flow and turbulence appears in the liquid flow. The calculations were based on the assumption both water and air are recirculated; when the air is recirculated, a small amount of air has to be pressurized, and this reduces the energy consumption.

Significant savings can be obtained by use of two-phase flow is being proved by its operation at the full-scale RO installation of DWP Botlek, the Netherlands. The savings include a 5$10 \%$ lower electricity bill (decrease in annual average feed pressure for $\mathrm{RO}$ ) and a 95\% reduction in chemicals used for cleaning. On the other hand, the cost of the two-phase flow installation (AWC) was only about $1 \%$ of the total investment for the DWP installation [259].

\subsubsection{Effect of bubble size}

While most researchers conclude that slug bubbles are able to enhance fluxes better than smaller bubbles, it was also reported that small bubbles are better for use with submerged membranes [112]. An initial study by Wibisono et al. [183] shows that in spacer-filled narrow channels, air bubbles break up in the flow and the bubble size follows the shape and size of the diamond spacer. A numerical study performed by Drews et al. [115] shows that the wall shear stress decreases with increasing bubble size in a narrow-channel plate $(3 \mathrm{~mm})$ in both stagnant and moving water. However, at greater plate distances (5 to $9 \mathrm{~mm}$ ), the wall shear stress increases with increasing bubble size, also both in stagnant and in moving water.

\subsubsection{Membrane deterioration}

Membrane lifetime relies on the effectiveness of cleaning and the overall effort to reduce membrane fouling [264]. Regular chemical cleaning is expected to lead to more rapid membrane degradation, especially when using alkaline or acid cleaning. Using air/water twophase flow minimizes the negative impact of chemical cleaning, especially for aqueous applications. Analysis of membrane materials showed that air/water flow does clean the 
membrane. No membrane deterioration has been observed at the DWP Botlek plant, and an expected $15-20 \%$ increase in live time was reported [259].

\subsubsection{Perspective}

Both technical and economical analyses show that gas/liquid two-phase flow is a competitive technology for reducing membrane resistance and increase membrane flux. Cleaning-in-place (CIP) saving replaced by air/water two-phase flow in drinking water plants tends to lower operating cost; therefore, this technology is foreseen to become auspicious in the coming years.

We suggest that future research on two-phase flow in membrane processes should move in the direction of better fundamental understanding of the underlying mechanisms of the effect of the different parameters in order to improve the effectiveness of two-phase flow on membrane performance. One direction should move towards fundamental studies on bubble behavior in different feed suspensions, bubble motion in different channel geometries, bubble/wall interactions (actual shear stress of the bubbles on the fouling layer), bubble-bubble interactions (break-up, collapse and coalescence), bubble/particle interactions (hydrophobicity, interfacial forces), and forces acting on isolated bubbles moving in unsteady/non-uniform flows (turbulence by pulse bubbling). The other direction should proceed to practical studies on the up-scaling of specific membrane processes and integrated membrane systems optimized for long-term operation.

\section{References}

1. Hoover, L.A., et al., Forward with Osmosis: Emerging Applications for Greater Sustainability. Environmental Science \& Technology, 2011. 45(23): p. 9824-9830.

2. Shannon, M.A., et al., Science and technology for water purification in the coming decades. Nature, 2008. 452(7185): p. 301-310.

3. Baker, R.W., Membrane Technology and Applications, 2004: John Wiley \& Sons, Ltd.

4. Strathmann, H., Membranes and Membrane Separation Processes, in Ullmann's Encyclopedia of Industrial Chemistry, 2000, Wiley-VCH Verlag GmbH \& Co. KGaA.

5. Goosen, M.F.A., et al., Fouling of reverse osmosis and ultrafiltration membranes: A critical review. Separation Science and Technology, 2004. 39(10): p. 2261-2297.

6. Koops, G.H., Nomenclature and Symbols in Membrane Science and Technology, 1995: The European Society of Membrane Science and Technology.

7. Mulder, M., Basic Principles of Membrane Technology, 1996: Kluwer Academic.

8. Nyström, M., K. Ruohomäki, and L. Kaipia, Humic acid as a fouling agent in filtration. Desalination, 1996. 106(1-3): p. 79-87.

9. Flemming, H.C. and G. Schaule, Biofouling on membranes - A microbiological approach. Desalination, 1988. 70(1-3): p. 95-119. 
10. T. Brunelle, M., Colloidal fouling of reverse osmosis membranes. Desalination, 1980. 32(0): p. 127-135.

11. Baker, R.J., et al., Factors affecting flux in crossflow filtration. Desalination, 1985. 53(1-3): p. 81-93.

12. Belfort, G., Fluid mechanics in membrane filtration: Recent developments. Journal of Membrane Science, 1989. 40(2): p. 123-147.

13. Bacchin, P., P. Aimar, and R.W. Field, Critical and sustainable fluxes: Theory, experiments and applications. Journal of Membrane Science, 2006. 281(1-2): p. 42-69.

14. Nikolov, N.D., V. Mavrov, and J.D. Nikolova, Ultrafiltration in a tubular membrane under simultaneous action of pulsating pressures in permeate and feed solution. Journal of Membrane Science, 1993. 83(2): p. 167-172.

15. Auddy, K., S. De, and S. DasGupta, Flux enhancement in nanofiltration of dye solution using turbulent promoters. Separation and Purification Technology, 2004. 40(1): p. 31-39.

16. Al-Bastaki, N. and A. Abbas, Use of fluid instabilities to enhance membrane performance: A review. Desalination, 2001. 136(1-3): p. 255-262.

17. Jaffrin, M.Y., Hydrodynamic Techniques to Enhance Membrane Filtration. Annual Review of Fluid Mechanics, 2012. 44(1): p. 77-96.

18. Kleinstreuer, C., Two-Phase Flow: Theory and Applications2004, New York, London: Taylor and Francis.

19. Cui, Z.F. and K.I.T. Wright, Gas-liquid two-phase cross-flow ultrafiltration of BSA and dextran solutions. J. Membr. Sci., 1994. 90(1-2): p. 183-189.

20. Imasaka, T., et al., Gas-liquid-solid three-phase cross-flow filtration by ceramic membrane module. Kagaku Kogaku Ronbunshu, 1989. 15: p. 681-3.

21. Siembida, B., et al., Effect of mechanical cleaning with granular material on the permeability of submerged membranes in the MBR process. Water Research, 2010. 44(14): p. 4037-4046.

22. Cui, Z.F., S. Chang, and A.G. Fane, The use of gas bubbling to enhance membrane processes. J. Membr. Sci., 2003. 221(1-2): p. 1-35.

23. Taha, T. and Z.F. Cui, CFD modelling of gas-sparged ultrafiltration in tubular membranes. J. Membr. Sci., 2002. 210(1): p. 13-27.

24. Smith, R., T. Taha, and Z.F. Cui, Using an improved $1 D$ boundary layer model with CFD for flux prediction in gas-sparged tubular membrane ultrafiltration. Water Sci. Technol., 2005. 51 : p. 69-76.

25. Taha, T., et al., Gas-sparged ultrafiltration using horizontal and inclined tubular membranesA CFD study. J. Membr. Sci., 2006. 279: p. 487-494.

26. Laborie, S., et al., Characterisation of gas-liquid two-phase flow inside capillaries. Chem. Eng. Sci., 1999. 54(23): p. 5723-5735.

27. Essemiani, K., et al., Spherical cap bubbles in a flat sheet nanofiltration module: experiment and numerical simulation. Chem. Eng. Sci., 2001. 56: p. 6321-6327.

28. Ducom, G., H. Matamoros, and C. Cabassud, Air sparging for flux enhancement in nanofiltration membranes: Application to $\mathrm{O} / \mathrm{W}$ stabilised and non-stabilised emulsions. $\mathrm{J}$. Membr. Sci., 2002. 204(1-2): p. 221-236.

29. Ducom, G., F.P. Puech, and C. Cabassud, Air sparging with flat sheet nanofiltration: A link between wall shear stresses and flux enhancement. Desalination, 2002. 145(1-3): p. 97-102.

30. Ducom, G. and C. Cabassud, Possible effects of air sparging for nanofiltration of salted solutions. Desalination, 2003. 156(1-3): p. 267-274.

31. Cheng, T.-W., Influence of inclination on gas-sparged crossflow ultrafiltration through an inorganic tubular membrane. J. Membr. Sci., 2002. 196: p. 103-110.

32. Cheng, T.W. and L.N. Li, Gas-sparging cross-flow ultrafiltration in flat-plate membrane module: Effects of channel height and membrane. Sep. Purif. Technol., 2007. 55(1): p. 50-55.

33. Cheng, T.W. and C.T. Lin, A study on cross-flow ultrafiltration with various membrane orientations. Sep. Purif. Technol., 2004. 39(1-2 Special Issue): p. 13-22.

34. Cheng, T.W. and T.L. Lin, Characteristics of gas-liquid two-phase flow in small diameter inclined tubes. Chem. Eng. Sci., 2001. 56(21): p. 6393-6398. 
35. Cheng, T.W. and S.Y. Pan, Recovery of sizing agent by gas sparging ultrafiltration. J. Chin. Inst. Chem. Eng., 2001. 32(5): p. 431-436.

36. Cheng, T.W. and J.G. Wu, Quantitative flux analysis of gas-liquid two-phase ultrafiltration. Sep. Sci. Technol., 2003. 38: p. 817-835.

37. Cheng, T.W., H.M. Yeh, and J.H. Wu, Effects of gas slugs and inclination angle on the ultrafiltration flux in tubular membrane module. J. Membr. Sci., 1999. 158(1): p. 223-234.

38. Hwang, K.J., C.S. Chan, and F.F. Chen, A comparison of hydrodynamic methods for mitigating particle fouling in submerged membrane filtration. J. Chin. Inst. Chem. Eng., 2008. 39(3): p. 257-264.

39. Hwang, K.J. and H.C. Chen, Selective deposition of fine particles in constant-flux submerged membrane filtration. Chem. Eng. J., 2010. 157(2): p. 323-330.

40. Hwang, K.J. and C.E. Hsu, Effect of gas-liquid flow pattern on air-sparged cross-flow microfiltration of yeast suspension. Chem. Eng. J., 2009. 151(1-3): p. 160-167.

41. Hwang, K.J. and S.F. Wu, Effects of Air-Sparging on the Filtration Flux and Cake Properties in Cross-Flow Microfiltration of Size-Distributed Fine Particles. Sep. Sci. Technol., 2009. 44(15): p. 3485-3505.

42. Hwang, K.J. and Y.J. Wu, Flux enhancement and cake formation in air-sparged cross-flow microfiltration. Chem. Eng. J., 2008. 139(2): p. 296-303.

43. An, Y., et al., Post-treatment of upflow anaerobic sludge blanket effluent by combining the membrane filtration process: Fouling control by intermittent permeation and air sparging. Water Environ. J., 2010. 24(1): p. 32-38.

44. Hu, S., et al., Simultaneous removal of COD and nitrogen using a novel carbon-membrane aerated biofilm reactor. Journal of Environmental Sciences, 2008. 20(2): p. 142-148.

45. Wang, Z. and Z. Wu, Distribution and transformation of molecular weight of organic matters in membrane bioreactor and conventional activated. Chem. Eng. J., 2009. 150(2): p. 396-402.

46. Zhang, F., W. Jing, and W. Xing, Modeling of cross-flow filtration processes in an airlift ceramic membrane reactor. Ind. Eng. Chem. Res., 2009. 48(23): p. 10637-10642.

47. Zhang, F., et al., Experiment and calculation of filtration processes in an external-loop airlift ceramic membrane bioreactor. Chem. Eng. Sci., 2009. 64(12): p. 2859-2865.

48. Zhang, K., Z. Cui, and R.W. Field, Effect of bubble size and frequency on mass transfer in flat sheet MBR. J. Membr. Sci., 2009. 332(1-2): p. 30-37.

49. Chang, I.S. and S.J. Judd, Air sparging of a submerged MBR for municipal wastewater treatment. Process Biochem., 2002. 37(8): p. 915-920.

50. Chang, I.S. and S.J. Judd, Domestic wastewater treatment by a submerged MBR (membrane bio-reactor) with enhanced air sparging. Water Sci. Technol., 2003. 47(12): p. 149-154.

51. Guglielmi, G., et al., Flux criticality and sustainability in a hollow fibre submerged membrane bioreactor for municipal wastewater treatment. J. Membr. Sci., 2007. 289(1-2): p. 241-248.

52. Guglielmi, G., et al., Impact of chemical cleaning and air-sparging on the critical and sustainable flux in a flat sheet membrane bioreactor for municipal wastewater treatment. Water Sci. Technol., 2008. 57(12): p. 1873-1879.

53. Verrecht, B., et al., An aeration energy model for an immersed membrane bioreactor. Water Res., 2008. 42(19): p. 4761-4770.

54. McAdam, E.J., A.L. Eusebi, and S.J. Judd, Evaluation of intermittent air sparging in an anoxic denitrification membrane bioreactor. Water Sci. Technol., 2010. 61(9): p. 2219-2225.

55. Chang, S. and A.G. Fane, Filtration of biomass with axial inter-fibre upward slug flow: Performance and mechanisms. J. Membr. Sci., 2000. 180(1): p. 57-68.

56. Chang, S., A.G. Fane, and S. Vigneswaran, Experimental assessment of filtration of biomass with transverse and axial fibres. Chem. Eng. J., 2002. 87(1): p. 121-127.

57. Fane, A.G., et al., Low pressure membrane processes - Doing more with less energy. Desalination, 2005. 185(1-3): p. 159-165.

58. Ndinisa, N.V., D.E. Wiley, and D.F. Fletcher, Computational Fluid Dynamics Simulations of Taylor Bubbles in Tubular Membranes. Chem. Eng. Res. Des., 2005. 83(1): p. 40-49. 
59. Ndinisa, N.V., A.G. Fane, and D.E. Wiley, Fouling control in a submerged flat sheet membrane system: Part I - Bubbling and hydrodynamic effects. Sep. Sci. Technol., 2006. 41(7): p. 1383-1409.

60. Ndinisa, N.V., et al., Fouling control in a submerged flat sheet membrane system: Part II Two-phase flow characterization and CFD simulations. Sep. Sci. Technol., 2006. 41(7): p. 1411-1445.

61. Wicaksana, F., A.G. Fane, and V. Chen, Fibre movement induced by bubbling using submerged hollow fibre membranes. J. Membr. Sci., 2006. 271(1-2): p. 186-195.

62. Phattaranawik, J., et al., Membrane bioreactor with bubble-size transformer: Design and fouling control. AIChE J., 2007. 53(1): p. 243-248.

63. Yeo, A.P.S., A.W.K. Law, and A. Fane, The relationship between performance of submerged hollow fibers and bubble-induced phenomena examined by particle image. J. Membr. Sci., 2007. 304(1): p. 125-137.

64. Jia, Y., R. Wang, and A.G. Fane, Hybrid PAC-submerged membrane system for trace organics removal. I. Adsorption kinetics study of PAC in a bubbled solution. Chem. Eng. J., 2009. 155(1-2): p. 155-160.

65. Phattaranawik, J., et al., Experimental study and design of a submerged membrane distillation bioreactor. Chem. Eng. Technol., 2009. 32(1): p. 38-44.

66. Wu, B., et al., Effect of adsorption/coagulation on membrane fouling in microfiltration process post-treating anaerobic digestion effluent. Desalination, 2009. 242(1-3): p. 183-192.

67. Psoch, C. and S. Schiewer, Long-term study of an intermittent air sparged MBR for synthetic wastewater treatment. J. Membr. Sci., 2005. 260(1-2): p. 56-65.

68. Psoch, C. and S. Schiewer, Critical flux aspect of air sparging and backflushing on membrane bioreactors. Desalination, 2005. 175(1 SPEC. ISS.): p. 61-71.

69. Psoch, C. and S. Schiewer, Anti-fouling application of air sparging and backflushing for MBR. J. Membr. Sci., 2006. 283(1-2): p. 273-280.

70. Psoch, C. and S. Schiewer, Direct filtration of natural and simulated river water withair sparging and sponge ball application for fouling control. Desalination, 2006. 197(1-3): p. 190-204.

71. Psoch, C. and S. Schiewer, Resistance analysis for enhanced wastewater membrane filtration. J. Membr. Sci., 2006. 280(1-2): p. 284-297.

72. Psoch, C. and S. Schiewer, Dimensionless numbers for the analysis of air sparging aimed to reduce fouling in tubular membranes of a membrane bioreactor. Desalination, 2006. 197(1-3): p. 9-22.

73. Psoch, C. and S. Schiewer, Long-term flux improvement by air sparging and backflushing for a membrane bioreactor, and modeling permeability decline. Desalination, 2008. 230(1-3): p. 193-204.

74. Berube, P.R., et al., Quantifying the shear at the surface of submerged hollow fiber membranes. J. Membr. Sci., 2006. 279(1): p. 495-505.

75. Bérubé, P.R. and E. Lei, The effect of hydrodynamic conditions and system configurations on the permeate flux in a submerged hollow fiber membrane system. J. Membr. Sci., 2006. 271(12): p. 29-37.

76. Bérubé, P.R., H. Lin, and Y. Watai, Fouling in air sparged submerged hollow fiber membranes at sub- and super-critical flux conditions. J. Membr. Sci., 2008. 307(2): p. 169180.

77. Celmer, D., J.A. Oleszkiewicz, and N. Cicek, Impact of shear force on the biofilm structure and performance of a membrane biofilm reactor for tertiary. Water Res., 2008. 42(12): p. 3057-3065.

78. Chan, C.C.V., P.R. Bérubé, and E.R. Hall, Shear profiles inside gas sparged submerged hollow fiber membrane modules. J. Membr. Sci., 2007. 297(1-2): p. 104-120.

79. Ghosh, R., Enhancement of membrane permeability by gas-sparging in submerged hollow fibre ultrafiltration of macromolecular. J. Membr. Sci., 2006. 274(1): p. 73-82.

80. Jeison, D. and L.J.B. van, Bio-layer management in anaerobic membrane bioreactors for wastewater treatment. Water Sci. Technol., 2006. 54: p. 81-86. 
81. Jeison, D. and L.J.B. van, Cake layer formation in anaerobic submerged membrane bioreactors (AnSMBR) for wastewater treatment. J. Membr. Sci., 2006. 284: p. 227-236.

82. Jeison, D. and L.J.B. van, On-line cake-layer management by trans-membrane pressure steady state assessment in Anaerobic Membrane Bioreactors for wastewater treatment. Biochem. Eng. J., 2006. 29: p. 204-209.

83. Jeison, D. and J.B. van Lier, Cake formation and consolidation: Main factors governing the applicable flux in anaerobic submerged membrane bioreactors (AnSMBR) treating acidified wastewaters. Sep. Purif. Technol., 2007. 56(1): p. 71-78.

84. Jeison, D. and J.B. van Lier, Thermophilic treatment of acidified and partially acidified wastewater using an anaerobic submerged MBR: Factors affecting long-term operational flux. Water Res., 2007. 41(17): p. 3868-3879.

85. Jeison, D., W. Van Betuw, and J.B. Van Lier, Feasibility of anaerobic membrane bioreactors for the treatment of wastewaters with particulate organic matter. Sep. Sci. Technol., 2008. 43(13): p. 3417-3431.

86. Jeison, D. and J.B. van Lier, Feasibility of thermophilic anaerobic submerged membrane bioreactors (AnSMBR) for wastewater treatment. Desalination, 2008. 231(1): p. 227-235.

87. Cornelissen, E.R., et al., Periodic air/water cleaning for control of biofouling in spiral wound membrane elements. J. Membr. Sci., 2007. 287(1): p. 94-101.

88. Cornelissen, E.R., et al., Air/water cleaning for biofouling control in spiral wound membrane elements. Desalination, 2007. 204: p. 145-147.

89. Cornelissen, E.R., et al., Optimization of air/water cleaning (AWC) in spiral wound elements. Desalination, 2009. 236(1-3): p. 266-272.

90. Willems, P., et al., Bubbles in spacers: Direct observation of bubble behavior in spacer filled membrane channels. J. Membr. Sci., 2009. 333(1-2): p. 38-44.

91. Cornelissen, E.R., et al., Air/water cleaning for control of particulate fouling. J. Water Supply Res. Technol. AQUA, 2010. 59(2-3): p. 120-127.

92. Willems, P., et al., Use of Particle Imaging Velocimetry to measure liquid velocity profiles in liquid and liquid/gas flows through spacer filled channels. Journal of Membrane Science, 2010. 362(1-2): p. 143.

93. Ngene, I.S., et al., CO 2 nucleation in membrane spacer channels remove biofilms and fouling deposits. Industrial and Engineering Chemistry Research, 2010. 49(20): p. 10034-10039.

94. Boure, J.A., A.E. Bergles, and L.S. Tong, Review of two-phase flow instability. Nuclear Engineering and Design, 1973. 25(2): p. 165-192.

95. Lohse, D. and A. Prosperetti, Controlling bubbles. Journal of Physics: Condensed Matter, 2003. 15(1): p. S415.

96. Cassell, E.A., K.M. Kaufman, and E. Matuevic, The effects of bubble size on microflotation. Water Research, 1975. 9(12): p. 1017-1024.

97. Tadrist, L., Review on two-phase flow instabilities in narrow spaces. International Journal of Heat and Fluid Flow, 2007. 28(1): p. 54.

98. Brennen, C.E., Fundamentals of Multiphase Flow, 2005: Cambridge University Press.

99. Nicklin, D.J., Two-phase bubble flow. Chemical Engineering Science, 1962. 17(9): p. 693.

100. Perry, R.H. and D.W. Green, Perry's Chemical Engineers' Handbook 8th edition, 2008: McGraw-Hill.

101. Taitel, Y., D. Bornea, and A.E. Dukler, Modelling flow pattern transitions for steady upward gas-liquid flow in vertical tubes. AIChE Journal, 1980. 26(3): p. 345-354.

102. Kulkarni, A.A. and J.B. Joshi, Bubble Formation and Bubble Rise Velocity in Gas-Liquid Systems: A Review. Industrial \& Engineering Chemistry Research, 2005. 44(16): p. 58735931.

103. Cui, Z.F. and K.I.T. Wright, Flux enhancements with gas sparging in downwards crossflow ultrafiltration: performance and mechanism. J. Membr. Sci., 1996. 117: p. 109-116.

104. Ding, Z., et al., Concentrating the extract of traditional Chinese medicine by direct contact membrane distillation. J. Membr. Sci., 2008. 310(1-2): p. 539-549.

105. Rouhani, S.Z. and M.S. Sohal, Two-phase flow patterns: A review of research results. Progress in Nuclear Energy, 1983. 11(3): p. 219-259. 
106. Wilmarth, T. and M. Ishii, Two-phase flow regimes in narrow rectangular vertical and horizontal channels. International Journal of Heat and Mass Transfer, 1994. 37(12): p. 17491758.

107. Xu, J., Experimental study on gas-liquid two-phase flow regimes in rectangular channels with mini gaps. International Journal of Heat and Fluid Flow, 1999. 20 (4): p. 422-428.

108. Grace, J.R. and D. Harrison, The influence of bubble shape on the rising velocities of large bubbles. Chemical Engineering Science, 1967. 22(10): p. 1337-1347.

109. Clift, R., J.R. Grace, and M.E. Weber, Bubbles, drops, and particles 1978: Academic Press.

110. Magnaudet, J. and I. Eames, The motion of high-Reynolds-mumber bubbles in inhomogeneous flows. Annual Review of Fluid Mechanics, 2000. 32: p. 659-708.

111. Yamanoi, I. and K. Kageyama, Evaluation of bubble flow properties between flat sheet membranes in membrane bioreactor. Journal of Membrane Science, 2010. 360(1-2): p. 102108.

112. Tian, J.Y., et al., Air bubbling for alleviating membrane fouling of immersed hollow-fiber membrane for ultrafiltration of river water. Desalination, 2010. 260(1-3): p. 225-230.

113. Wesselingh, J.A. and A.M. Bollen, Single Particles, Bubbles and Drops: Their Velocities and Mass Transfer Coefficients. Chemical Engineering Research and Design, 1999. 77(2): p. 89-96.

114. Wesselingh, J.A., The velocity of particles, drops and bubbles. Chemical Engineering and Processing: Process Intensification, 1987. 21(1): p. 9-14.

115. Drews, A., et al., Advantageous and detrimental effects of air sparging in membrane filtration: Bubble movement, exerted shear and particle classification. Desalination, 2010. 250(3): p. 1083-1086.

116. Lockhart, R. and R. Martinelli, Proposed correlation of data for isothermal two-phase, twocomponent flow in pipes. Chemical Engineering Progress, 1949. 45(1): p. 39-48.

117. Kopalinsky, E.M. and R.A.A. Bryant, Friction coefficients for bubbly two-phase flow in horizontal pipes. AIChE Journal, 1976. 22(1): p. 82-86.

118. Nakoryakov, V.E., et al., Local characteristics of upward gas-liquid flows. International Journal of Multiphase Flow, 1981. 7(1): p. 63-81.

119. Guo, W., H.-H. Ngo, and J. Li, A mini-review on membrane fouling. Bioresource Technology, 2012. 122(0): p. 27-34.

120. Howe, K.J. and M.M. Clark, Fouling of microfiltration and ultrafiltration membranes by natural waters. Environmental Science and Technology, 2002. 36(16): p. 3571-3576.

121. Duclos-Orsello, C., W. Li, and C.C. Ho, A three mechanism model to describe fouling of microfiltration membranes. Journal of Membrane Science, 2006. 280(1-2): p. 856-866.

122. Youravong, W., Z. Li, and A. Laorko, Influence of gas sparging on clarification of pineapple wine by microfiltration. J. Food Eng., 2010. 96(3): p. 427-432.

123. Qaisrani, T.M. and W.M. Samhaber, Impact of gas bubbling and backflushing on fouling control and membrane cleaning. Desalination, 2011. 266(1-3): p. 154-161.

124. Imasaka, T., et al., Gas-liquid two-phase cross-flow filtration by ceramic membrane modules. Kagaku Kogaku Ronbunshu, 1989. 15: p. 638-44.

125. Vera, L., et al., Enhancing microfiltration through an inorganic tubular membrane by gas sparging. J. Membr. Sci., 2000. 165(1): p. 47-57.

126. Vera, L., S. Delgado, and S. Elmaleh, Dimensionless numbers for the steady-state flux of cross-flow microfiltration and ultrafiltration with gas sparging. Chem. Eng. Sci., 2000. 55(17): p. 3419-3428.

127. Mercier-Bonin, M., G. Gésan-Guiziou, and C. Fonade, Application of gas/liquid two-phase flows during crossflow microfiltration of skimmed milk under constant transmembrane pressure conditions. J. Membr. Sci., 2003. 218(1-2): p. 93-105.

128. Mercier-Bonin, M., C. Fonade, and G. Gésan-Guiziou, Application of gas/liquid two-phase flows during crossflow microfiltration of skimmed milk under constant flux conditions. Chem. Eng. Sci., 2004. 59(11): p. 2333-2341.

129. Mercier-Bonin, M. and C. Fonade, Air-sparged microfiltration of enzyme/yeast mixtures: determination of optimal conditions for enzyme recovery. Desalination, 2002. 148(1): p. 171176. 
130. Sur, H.W. and Z. Cui, Experimental study on the enhancement of yeast microfiltration with gas sparging. J. Chem. Technol. Biotechnol., 2001. 76(5): p. 477-484.

131. Mikulasek, P., et al., Gas-liquid two-phase flow in microfiltration mineral tubular membranes: relationship between flux enhancement and hydrodynamic parameters. Desalination, 2002. 146(1): p. 103-109.

132. Pospisil, P., et al., Shear stress-based modelling of steady state permeate flux in microfiltration enhanced by two-phase flows. Chem. Eng. J., 2004. 97: p. 257-263.

133. Fadaei, H., S.R. Tabaei, and R. Roostaazad, Comparative assessment of the efficiencies of gas sparging and back-flushing to improve yeast microfiltration using tubular ceramic membranes. Desalination, 2007. 217(1-3): p. 93-99.

134. Chiu, T.Y. and A.E. James, Critical flux enhancement in gas assisted microfiltration. J. Membr. Sci., 2006. 281(1): p. 274-280.

135. Mercier-Bonin, M., C. Lagane, and C. Fonade, Influence of a gas/liquid two-phase flow on the ultrafiltration and microfiltration performances: case of a ceramic. J. Membr. Sci., 2000. 180(1): p. 93-102.

136. Shimizu, Y., et al., Cross-flow microfiltration of activated cludge using submerged membrane with air bubbling. J. Ferment. Bioeng., 1996. 81(1): p. 55-60.

137. Gao, W., et al., Membrane fouling control in ultrafiltration technology for drinking water production: A review. Desalination, 2011. 272(1-3): p. 1-8.

138. Cui, Z.F., S.R. Bellara, and P. Homewood, Airlift crossflow membrane filtration - a feasibility study with dextran ultrafiltration. J. Membr. Sci., 1997. 128: p. 83-91.

139. Li, Q.Y., Z.F. Cui, and D.S. Pepper, Fractionation of HSA and IgG by gas sparged ultrafiltration. J. Membr. Sci., 1997. 136(1-2): p. 181-190.

140. Li, Q.Y., Z.F. Cui, and D.S. Pepper, Effect of bubble size and frequency on the permeate flux of gas sparged ultrafiltration with tubular membranes. Chem. Eng. J., 1997. 67(1): p. 71-75.

141. Ghosh, R. and Z.F. Cui, Mass transfer in gas-sparged ultrafiltration: Upward slug flow in tubular membranes. J. Membr. Sci., 1999. 162(1-2): p. 91-102.

142. Mercier, M., C. Fonade, and C. Lafforgue-Delorme, How slug flow can enhance the ultrafiltration flux in mineral tubular membranes. J. Membr. Sci., 1997. 128: p. 103-113.

143. Mercier, M., et al., Yeast suspension filtration: Flux enhancement using an upward gas/liquid slug flow - Application to continuous alcoholic fermentation with cell recycle. Biotechnol. Bioeng., 1998. 58(1): p. 47-57.

144. Mercier-Bonin, M., et al., Hydrodynamics of slug flow applied to cross-flow filtration in narrow tubes. AIChE J., 2000. 46(3): p. 476-488.

145. Abdel-Ghani, M.S., Cross-flow ultrafiltration of an aqueous polymer foam solution produced by gas sparging. J. Membr. Sci., 2000. 171(1): p. 105-117.

146. Sulaiman, H.N.M. and M.K. Aroua, Cake layer reduction by gas sparging cross flow ultrafiltration of skim latex serum. Songklanakarin J. Sci. Technol., 2002. 24: p. 947-953.

147. Harunsyah, N.M. Sulaiman, and M.K. Aroua, Treatment of skim latex serum using gas sparged ultrafiltration. Dev. Chem. Eng. Mineral Process., 2005. 13(5-6): p. 667-674.

148. Vatai, G.N., et al., Combining air sparging and the use of a static mixer in cross-flow ultrafiltration of oil/water emulsion. Desalination, 2007. 204(1): p. 255-264.

149. Bellara, S.R., Z.F. Cui, and D.S. Pepper, Gas sparging to enhance permeate flux in ultrafiltration using hollow fibre membranes. J. Membr. Sci., 1996. 121(2): p. 175-184.

150. Bellara, S.R., Z. Cui, and D.S. Pepper, Fractionation of BSA and Lysozyme Using GasSparged Ultrafiltration in Hollow Fiber Membrane Modules. Biotechnol. Progr., 1997. 13: p. 869-872.

151. Cabassud, C., S. Laborie, and J.M. Laine, How slug flow can improve ultrafiltration flux in organic hollow fibres. J. Membr. Sci., 1997. 128(1): p. 93-101.

152. Laborie, S., et al., Flux Enhancement by a Continuous Tangential Gas Flow in Ultrafiltration Hollow Fibres for Drinking Water Production. Filtr. Sep., 1997. 34(8): p. 887-891.

153. Laborie, S., et al., Fouling control by air sparging inside hollow fibre membranes - effects on energy consumption. Desalination, 1998. 118(1-3): p. 189-196. 
154. Cabassud, C., C. Burgaud, and J.M. Espenan, Spring water treatment with ultrafiltration and stripping. Desalination, 2001. 137(1-3): p. 123-131.

155. Cabassud, C., et al., Air sparging in ultrafiltration hollow fibers: Relationship between flux enhancement, cake characteristics and hydrodynamic parameters. J. Membr. Sci., 2001. 181(1): p. 57-69.

156. Serra, C., et al., Use of air sparging to improve backwash efficiency in hollow-fiber modules. J. Membr. Sci., 1999. 161(1-2): p. 95-113.

157. Guigui, C., M. Mougenot, and C. Cabassud, Air sparging backwash in ultrafiltration hollow fibres for drinking water production. Water Sci. Technol. Water Supply 2003. 3(5): p. 415422.

158. Bessiere, Y., et al., Coupling air-assisted backwash and rinsing steps: a new way to improve ultrafiltration process operation for inside-out hollow fibre modules. Desalination, 2009. 240: p. 71-77.

159. Remize, P.J., C. Guigui, and C. Cabassud, Evaluation of backwash efficiency, definition of remaining fouling and characterisation of its contribution in irreversible fouling: Case of drinking water production by air-assisted ultra-filtration. J. Membr. Sci., 2010. 355(1-2): p. 104-111.

160. Smith, S.R. and Z.F. Cui, Gas-slug enhanced hollow fibre ultrafiltration - An experimental study. J. Membr. Sci., 2004. 242(1-2): p. 117-128.

161. Smith, S.R. and Z.F. Cui, Analysis of developing laminar pipe flow - an application to gas slug enhanced hollow fibre ultrafiltration. Chem. Eng. Sci., 2004. 59: p. 5975-5986.

162. Smith, S.R., Z.F. Cui, and R.W. Field, Upper- and lower-bound estimates of flux for gassparged ultrafiltration with hollow fiber membranes. Ind. Eng. Chem. Res., 2005. 44(20): p. 7684-7695.

163. Smith, S.R., R.W. Field, and Z.F. Cui, Predicting the performance of gas-sparged and nongas-sparged ultrafiltration. Desalination, 2006. 191: p. 376-385.

164. Majewska-Nowak, K., M. Kabsch-Korbutowicz, and T. Winnicki, The effect of gas bubble flow on ultrafiltration efficiency. Desalination, 1999. 126(1-3): p. 187-192.

165. Li, Z.Y., A. H-Kittikun, and W. Youravong, Separation of protease from yellowfin tuna spleen extract by ultrafiltration: Effect of hydrodynamics and gas sparging on flux enhancement and selectivity. J. Membr. Sci., 2008. 311(1-2): p. 104-111.

166. Verberk, J. and H. Van Dijk, Research on AirFlush: distribution of water and air in tubular and capillary membrane modules. Water Sci. Technol. Water Supply 2003. 3: p. 409-414.

167. Li, Q.Y., et al., Enhancement of ultrafiltration by gas sparging with flat sheet membrane modules. Sep. Purif. Technol., 1998. 14(1-3): p. 79-83.

168. Ghosh, R., Q. Li, and Z. Cui, Fractionation of BSA and Lysozyme Using Ultrafiltration: Effect of Gas Sparging. AIChE J., 1998. 44(1): p. 61-67.

169. Um, M.-J., et al., Flux enhancement with gas injection in crossflow ultrafiltration of oily wastewater. Water Res., 2001. 35(17): p. 4095-4101.

170. Wang, H.M., et al., Abatement of concentration polarization in ultrafiltration using $n$ hexadecane/water two-phase flow. J. Membr. Sci., 2004. 238(1-2): p. 1-7.

171. Arnal, J.M., et al., Cleaning ultrafiltration membranes by different chemical solutions with air bubbles. Desalin. Water Treat., 2009. 10(1-3): p. 175-180.

172. Choksuchart, P., M. Héran, and A. Grasmick, Ultrafiltration enhanced by coagulation in an immersed membrane system. Desalination, 2002. 145(1-3): p. 265-272.

173. Yuliwati, E., et al., Effects of process conditions in submerged ultrafiltration for refinery wastewater treatment: Optimization of operating process by response surface methodology. Desalination, 2011.

174. Nyström, M., L. Kaipia, and S. Luque, Fouling and retention of nanofiltration membranes. Journal of Membrane Science, 1995. 98(3): p. 249-262.

175. Van der Bruggen, B. and J. Geens, Nanofiltration, in Advanced Membrane Technology and Applications2008, John Wiley \& Sons, Inc. p. 271-295. 
176. Schäfer, A.I.A., N. ; Karabelas, A.J. ; Hoek, E.M.V. ; Schneider, R. ; Nyström, M., Fouling in Nanofiltration, in Nanofiltration - Principles and Applications, W.T.D. Schäfer A.I., Fane A.G., Editor 2004, Elsevier. p. 169-239.

177. Ducom, G., F.P. Puech, and C. Cabassud, Gas/liquid two-phase flow in a flat sheet filtration module: Measurement of local wall shear stresses. Can. J. Chem. Eng., 2003. 81(3-4): p. 771775.

178. Verberk, J.Q.J.C. and J.C. van Dijk, Air sparging in capillary nanofiltration. J. Membr. Sci., 2006. 284(1-2): p. 339-351.

179. Gutman, J., S. Fox, and J. Gilron, Interactions between biofilms and NF/RO flux and their implications for control $-A$ review of recent developments. Journal of Membrane Science, 2012. 421-422(0): p. 1-7.

180. Flemming, H.C., Biofouling in water systems - Cases, causes and countermeasures. Applied Microbiology and Biotechnology, 2002. 59(6): p. 629-640.

181. Vrouwenvelder, J.S., et al., The Membrane Fouling Simulator: A practical tool for fouling prediction and control. J. Membr. Sci., 2006. 281: p. 316-324.

182. Vrouwenvelder, J.S., et al., Impact of flow regime on pressure drop increase and biomass accumulation and morphology in membrane systems. Water Res., 2010. 44(3): p. 689-702.

183. Wibisono, Y., et al. The effect of bubble size in air sparging to control fouling inside spacerfilled membrane channels. in 6th IWA Specialist Conference on Membrane Technology for Water and Wastewater Treatment. 2011. Aachen: International Water Association.

184. Wibisono, Y., et al., Influence of Feed Spacer Geometries on Air/Water Cleaning in Spiral Wound Membrane Elements. Procedia Engineering, 2012. 44(0): p. 613-617.

185. Judd, S., The MBR Book: Principles and Applications of Membrane Bioreactors in Water and Wastewater Treatment2011: Elsevier Limited, Oxford.

186. Mercier-Bonin, M., et al., How unsteady filtration conditions can improve the process efficiency during cell cultures in membrane bioreactors. Sep. Purif. Technol., 2001. 22: p. 601-615.

187. Kouakou, E., et al., Gas-liquid mass transfer in a circulating jet-loop nitrifying MBR. Chem. Eng. Sci., 2005. 60(22): p. 6346-6353.

188. Martinelli, L., C. Guigui, and A. Line, Experimental analysis of mechanisms induced by a spherical cap bubble injection in submerged hollow-fibre bioreactor. Desalination, 2006. 200(1-3): p. 720-721.

189. Viero, A.F., G.L. Sant'Anna, and R. Nobrega, The use of polyetherimide hollow fibres in a submerged membrane bioreactor operating with air backwashing. J. Membr. Sci., 2007. 302(1): p. 127-135.

190. Iversen, V., et al., Impacts of membrane flux enhancers on activated sludge respiration and nutrient removal in MBRs. Water Res., 2009. 43(3): p. 822-830.

191. Lorain, O., et al., A new membrane bioreactor generation for wastewater treatment application: Strategy of membrane aeration management by sequencing aeration cycles. Desalination, 2010. 250(2): p. 639-643.

192. Modin, O., et al., Nitrate removal and biofilm characteristics in methanotrophic membrane biofilm reactors with various gas supply regimes. Water Res., 2010. 44(1): p. 85-96.

193. Jajuee, B., et al., Mass transfer characteristics of a novel three-phase airlift contactor with a semipermeable membrane. Chem. Eng. J., 2006. 125(2): p. 119-126.

194. Le-Clech, P., B. Jefferson, and S.J. Judd, Impact of aeration, solids concentration and membrane characteristics on the hydraulic performance of a membrane. J. Membr. Sci., 2003. 218(1): p. 117-129.

195. De Schepper, V., et al., Modeling the performance of a membrane bioreactor controlled by air sparging. Commun. Agric. Appl. Biol. Sci., 2006. 71: p. 111-113.

196. González-Brambila, M., O. Monroy, and F. López-Isunza, Experimental and theoretical study of membrane-aerated biofilm reactor behavior under different modes of oxygen supply for the treatment of synthetic wastewater. Chem. Eng. Sci., 2006. 61(16): p. 5268-5281.

197. Lu, Y., et al., The influence of bubble characteristics on the performance of submerged hollow fiber membrane module used in. Sep. Purif. Technol., 2008. 61(1): p. 89-95. 
198. Nguyen Cong Duc, E., et al., Local hydrodynamic investigation of the aeration in a submerged hollow fibre membranes cassette. J. Membr. Sci., 2008. 321(2): p. 264-271.

199. $\mathrm{Xu}, \mathrm{Z}$. and J. Yu, Hydrodynamics and mass transfer in a novel multi-airlifting membrane bioreactor. Chem. Eng. Sci., 2008. 63(7): p. 1941-1949.

200. Martinelli, L., C. Guigui, and A. Line, Characterisation of hydrodynamics induced by air injection related to membrane fouling behaviour. Desalination, 2010. 250(2): p. 587-591.

201. Prieske, H., et al., Optimised hydrodynamics for membrane bioreactors with immersed flat sheet membrane modules. Desalination and Water Treatment, 2010. 18(1-3): p. 270-276.

202. Fulton, B.G., et al., Distribution of surface shear forces and bubble characteristics in fullscale gas sparged submerged hollow fiber membrane modules. Desalination, 2011. 281(0): p. 128-141.

203. Khalili-Garakani, A., et al., Analyze and control fouling in an airlift membrane bioreactor: CFD simulation and experimental studies. Process Biochemistry, 2011. 46(5): p. 1138-1145.

204. Ratkovich, N., et al., Analysis of shear stress and energy consumption in a tubular airlift membrane system. Water Science and Technology, 2011. 64(1): p. 189-198.

205. Jajuee, B., et al., Measurements and CFD simulations of gas holdup and liquid velocity in novel airlift membrane contactor. AIChE Journal, 2006. 52(12): p. 4079-4089.

206. Fan, F. and H. Zhou, Interrelated effects of aeration and mixed liquor fractions on membrane fouling for submerged membrane bioreactor processes in wastewater treatment. Environ. Sci. Technol., 2007. 41(7): p. 2523-2528.

207. Downing, L.S. and R. Nerenberg, Total nitrogen removal in a hybrid, membrane-aerated activated sludge process. Water Res., 2008. 42(14): p. 3697-3708.

208. Pollet, S., C. Guigui, and C. Cabassud, Fouling and its reversibility in relation to flow properties and module design in aerated hollow fibre modules for membrane bioreactors. Water Sci. Technol., 2008. 57(4): p. 629-636.

209. Vyrides, I. and D.C. Stuckey, Saline sewage treatment using a submerged anaerobic membrane reactor (SAMBR): Effects of activated carbon addition and. Water Res., 2009. 43(4): p. 933-942.

210. Hwang, J.H., N. Cicek, and J.A. Oleszkiewicz, Achieving biofilm control in a membrane biofilm reactor removing total nitrogen. Water Res., 2010. 44(7): p. 2283-2291.

211. Hwang, K.J., H.C. Chen, and M.H. Tsai, Analysis of Particle Fouling in Constant Pressure Submerged Membrane Filtration. Chemical Engineering \& Technology, 2010. 33(8): p. 13271333.

212. Park, H.D., et al., Reduction of membrane fouling by simultaneous upward and downward air sparging in a pilot-scale submerged membrane bioreactor treating municipal wastewater. Desalination, 2010. 251(1-3): p. 75-82.

213. Braak, E., et al., Aeration and hydrodynamics in submerged membrane bioreactors. Journal of Membrane Science, 2011.379(1-2): p. 1-18.

214. Judd, S., The status of membrane bioreactor technology. Trends Biotechnol., 2008. 26(2): p. 109-116.

215. Drews, A., Membrane fouling in membrane bioreactors-Characterisation, contradictions, cause and cures. Journal of Membrane Science, 2010. 363(1-2): p. 1-28.

216. Yang, W., N. Cicek, and J. Ilg, State-of-the-art of membrane bioreactors: Worldwide research and commercial applications in North America. Journal of Membrane Science, 2006. 270(12): p. 201-211.

217. Sirkar, K.K., Membrane Contactors, in Advanced Membrane Technology and Applications2008, John Wiley \& Sons, Inc. p. 685-702.

218. Cath, T.Y., D. Adams, and A.E. Childress, Membrane contactor processes for wastewater reclamation in space: II. Combined direct osmosis, osmotic distillation, and membrane distillation for treatment of metabolic wastewater. Journal of Membrane Science, 2005. 257(1-2): p. 111-119.

219. Lawson, K.W. and D.R. Lloyd, Membrane distillation. Journal of Membrane Science, 1997. 124(1): p. 1-25. 
220. Nymeijer, D.C., et al., Composite hollow fiber gas-liquid membrane contactors for olefin/paraffin separation. Separation and Purification Technology, 2004. 37(3): p. 209-220.

221. Smolders, K. and A.C.M. Franken, Terminology for Membrane Distillation. Desalination, 1989. 72(3): p. 249-262.

222. Khayet, M., Membrane Distillation, in Advanced Membrane Technology and Applications2008, John Wiley \& Sons, Inc. p. 297-369.

223. Ding, Z., et al., The use of intermittent gas bubbling to control membrane fouling in concentrating TCM extract by membrane distillation. Journal of Membrane Science, 2011. 372(1-2): p. 172-181.

224. Wu, C., et al., Study on air-bubbling strengthened membrane distillation process. Desalination and Water Treatment, 2011.34(1-3): p. 2-5.

225. Długołęcki, P., et al., Ion conductive spacers for increased power generation in reverse electrodialysis. Journal of Membrane Science, 2010. 347(1-2): p. 101-107.

226. Balster, J., D.F. Stamatialis, and M. Wessling, Towards spacer free electrodialysis. J. Membr. Sci., 2009. 341(1-2): p. 131-138.

227. Bunce, N.J., M. Chartrand, and P. Keech, Electrochemical treatment of acidic aqueous ferrous sulfate and copper sulfate as models for acid mine drainage. Water Res., 2001. 35(18): p. 4410-4416.

228. Min, B., S. Cheng, and B.E. Logan, Electricity generation using membrane and salt bridge microbial fuel cells. Water Res., 2005. 39(9): p. 1675-1686.

229. Sur, H.W. and Z.F. Cui, Enhancement of microfiltration of yeast suspensions using gas sparging - Effect of feed conditions. Sep. Purif. Technol., 2005. 41(3): p. 313-319.

230. Delgado, S., et al., Modelling hollow-fibre ultrafiltration of biologically treated wastewater with and without gas sparging. J. Membr. Sci., 2004. 228(1): p. 55-63.

231. Ratkovich, N., et al., Experimental study and CFD modelling of a two-phase slug flow for an airlift tubular membrane. Chem. Eng. Sci., 2009. 64: p. 3576-3584.

232. Matis, K.A., et al., Air sparging during the solid/liquid separation by microfiltration: Application of flotation. Sep. Purif. Technol., 2004. 40(1): p. 1-7.

233. Gupta, B., et al., Effects of colloidal fouling and gas sparging on microfiltration of yeast suspension. Bioprocess. Biosyst. Eng., 2005. 27(6): p. 407-413.

234. Sen Gupta, B., et al., The effect of gas sparging in cross-flow microfiltration of 2,3-butanediol fermentation broth. Eng. Life Sci., 2005. 5(1): p. 54-57.

235. Gironès, M., et al., Flux stabilization of silicon nitride microsieves by backpulsing and surface modification with PEG moieties. J. Colloid Interface Sci., 2006. 299(2): p. 831-840.

236. Peleka, E.N., et al., A hybrid flotation-microfiltration cell for solid/liquid separation: operational characteristics. Desalination, 2006. 194(1-3): p. 135-145.

237. Peleka, E.N., et al., Removal of phosphates from water by a hybrid flotation-membrane filtration cell. Desalination, 2006. 198(1): p. 198-207.

238. Hwang, K.J. and L. Chen, Effect of air-sparging on the cross-flow microfiltration of microbe/protein bio-suspension. Journal of the Taiwan Institute of Chemical Engineers, 2010. 41(5): p. 564-569.

239. Derradji, A.F., et al., The effect of a static mixer on the ultrafiltration of a two-phase flow. Desalination, 2000. 128(3): p. 223-230.

240. Richter, U., et al., Feed cycling in dead end filtration. Chem. Eng. Technol., 1999. 22(12): p. 1029-1033.

241. Yu, K., et al., Critical flux enhancements with air sparging in axial hollow fibers cross-flow microfiltration of biologically treated wastewater. J. Membr. Sci., 2003. 224(1-2): p. 69-79.

242. O'Haver, J.H., et al., Packed column and hollow fiber air stripping of a contaminantsurfactant stream. J. Environ. Eng., 2004. 130(1): p. 4-11.

243. Cornelissen, E.R., et al., Influence of permeation on air/water cleaning of spiral wound membrane NF/RO elements. J. Water Supply Res. Technol. AQUA, 2010. 59(6-7): p. 378-383.

244. Kleijnen, J.P.C., Kriging metamodeling in simulation: A review. European Journal of Operational Research, 2009. 192(3): p. 707-716. 
245. Myers, D.E., Interpolation and estimation with spatially located data. Chemometrics and Intelligent Laboratory Systems, 1991. 11(3): p. 209-228.

246. Stein, M.L., Interpolation of Spatial Data: Some Theory for Kriging 1999: Springer New York.

247. Cressie, N.A.C., Statistics for spatial data1993: J. Wiley.

248. Ivanovic, I. and T. Leiknes, Impact of aeration rates on particle colloidal fraction in the biofilm membrane bioreactor (BF-MBR). Desalination, 2008. 231(1-3): p. 182-190.

249. INSA-Toulouse, Literature review on aeration and main operating conditions in membrane bioreactors, 2006, Eurombra. p. 1-50.

250. Cote, P., Z. Alam, and J. Penny, Hollow fiber membrane life in membrane bioreactors (MBR). Desalination, 2012. 288(0): p. 145-151.

251. Santos, A., W. Ma, and S.J. Judd, Membrane bioreactors: Two decades of research and implementation. Desalination, 2011. 273(1): p. 148-154.

252. Judd, S., Chapter 4 - Commercial Technologies, in The MBR Book (Second Edition)2011, Butterworth-Heinemann: Oxford. p. 289-357.

253. Lesjean, B. and E.H. Huisjes, Survey of the European MBR market: trends and perspectives. Desalination, 2008. 231(1-3): p. 71-81.

254. Global MBR market forecast to reach $\$ 888$ million by 2017. Membrane Technology, 2012. 2012(1): p. 8.

255. Report covers MBR market, trends and forecasts to 2017. Membrane Technology, 2013. 2013(1): p. 6.

256. Zheng, X., et al., Survey of MBR market: Trends and perspectives in China. Desalination, 2010. 250(2): p. 609-612.

257. Futselaar, H., H. Schonewille, and W. van der Meer, Direct capillary nanofiltration - a new high-grade purification concept. Desalination, 2002. 145(1-3): p. 75-80.

258. Pot, M.A., R. van den Berg, and J. Van Agtmaal. DWP Botlek - largest demin water plant in the Netherlands. in 6th IWA Specialist Conference on Membrane Technology for Water and Wastewater Treatment. 2011. Aachen: International Water Association.

259. Cornelissen, E.R., et al. Laboratory-scale to full-scale experiences with air/water cleaning in RO to control membrane fouling. in IWA World Conference Busan (Korea). 2012.

260. X-Flow, Technology - Vertical dead-end UF - Technology overview, 2013, Pentair X-Flow: Enschede.

261. Boutarin, L., et al., HYDRAcap ${ }^{\circledR}$ MAX: innovative micro-filtration for reverse osmosis pretreatment and water reuse. Desalination and Water Treatment, 2013. 51(25-27): p. 49724979.

262. Lehman, S.G., S. Adham, and L. Liu, Performance of new generation ceramic membranes using hybrid coagulation pretreatment. J. Environ. Eng. Manage., 2008. 18(4): p. 257-260.

263. PWN Technologies and METAWATER partner on ceramic membranes. Filtration Industry Analyst, 2013. 2013(7): p. 2.

264. Van der Bruggen, B., M. Manttari, and M. Nystrom, Drawbacks of applying nanofiltration and how to avoid them: A review. Sep. Purif. Technol., 2008. 63(2): p. 251-263. 


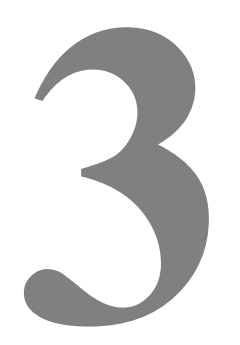

\title{
Efficiency of two-phase flow cleaning in spiral-wound membrane elements
}

\author{
Y. Wibisono \\ M. Zalewski \\ E.R. Cornelissen \\ A.J.B. Kemperman \\ W.G.J. van der Meer \\ K. Nijmeijer
}

This chapter has been submitted to Desalination as:

Y. Wibisono, M. Zalewski, E.R. Cornelissen, A.J.B. Kemperman, W.G.J. van der Meer, K.

Nijmeijer, Efficiency of two-phase flow cleaning in spiral-wound membrane elements. 


\begin{abstract}
Fouling is a major drawback in the operation of spiral-wound membrane modules for nanofiltration and reverse osmosis. Periodic two-phase flow cleaning has been effectively applied to disrupt biofilm formation and particulate deposition from the surfaces of membranes and feed spacers. This chapter reports on research that looked into the apparent important factors that control the effectiveness of two-phase flow cleaning, i.e. feed spacer geometry (thickness and orientation), feed type, gas/liquid ratio, and liquid superficial velocity. The flow channel resistance was measured by using the feed channel pressure drop, and the efficiency of two-phase flow cleaning was calculated. Direct visual observation using a high-speed camera was conducted to quantify bubble velocities. It was found that feed spacer geometry, gas/liquid ratio, liquid superficial velocity, and foulant type are important factors with regard to two-phase flow cleaning efficiency. Spacer orientation, while not a key factor, does affect the liquid superficial velocity and thereby indirectly influences the efficiency to two-phase flow cleaning.
\end{abstract}




\subsection{Introduction}

As it is a limited resource, the rising demand for clean freshwater is becoming one of the world's most urgent problems. Consequently, there is an growing number of methods that improve water disinfection, decontamination, reuse and desalination, many of which include the use of membrane processes [1]. High-pressure membrane processes, i.e. reverse osmosis (RO) and nanofiltration (NF), are increasingly used in drinking water treatment [2, 3], seawater desalination $[4,5]$, and wastewater reclamation [6], and under consideration for use in the production of water for industrial purposes [7].

The most common membrane configuration in high-pressure membrane processes is the spiral-wound membrane module [8]. Spiral-wound membrane modules offer a high packing density, and the simplicity of disposable units with compact pressure vessels for flexible configuration and retrofitting [9]. Spiral-wound membrane elements suffer from fouling due to (i) biofilm attachment and growth, (ii) colloidal particles, (iii) organic macromolecules, and (iv) precipitation caused by crystallization of salts, oxides and hydroxides. The first two are the most prevalent types of fouling in spiral-wound membranes; they result in an uneven distribution of flow within the membrane element, hampering diffusion of water to the permeate side, thereby reducing the flux and increasing the feed channel pressure drop [1012]. The feed channel pressure drop is the pressure difference between the feed inlet and the concentrate outlet due to the hydraulic resistance of the feed channel. Any fouling in the feed channel reduces the channel porosity, which increases the frictional resistance and therefore causes an increase in the feed channel pressure drop. This increased pressure drop in the feed channel leads to an increase in the required feed pressure and a reduction of the transmembrane pressure, hence reducing permeability. Moreover, it not only results in production losses, but can also cause a deterioration of the product water quality.

Controlling membrane fouling requires periodical cleaning with cleaning chemicals. Conventional chemical cleaning, however, is not effective in the prevention or elimination of biofouling in full-scale RO systems [13]. Chemical cleaning also might attack the membrane materials, thereby reducing membrane life. The use of an alternative, chemical-free cleaning process is suggested, in which air/water two-phase flow cleaning is periodically carried out in vertically positioned spiral-wound membrane elements. Such a two-phase flow application is able to remove biofilms and particulate matter from spiral-wound membrane elements, offering an effective cleaning strategy [14-16]. Fig. 3.1 shows a schematic drawing of two- 
phase flow cleaning in a fouled vertically positioned NF/RO spiral-wound membrane feed channel. The feed water flows upward from the bottom of the spiral-wound membrane elements, along the feed spacer sheet and between two membrane sheets. The gas bubble flow produces a wall shear stress, which disrupts and removes biofilms and deposited particulates.

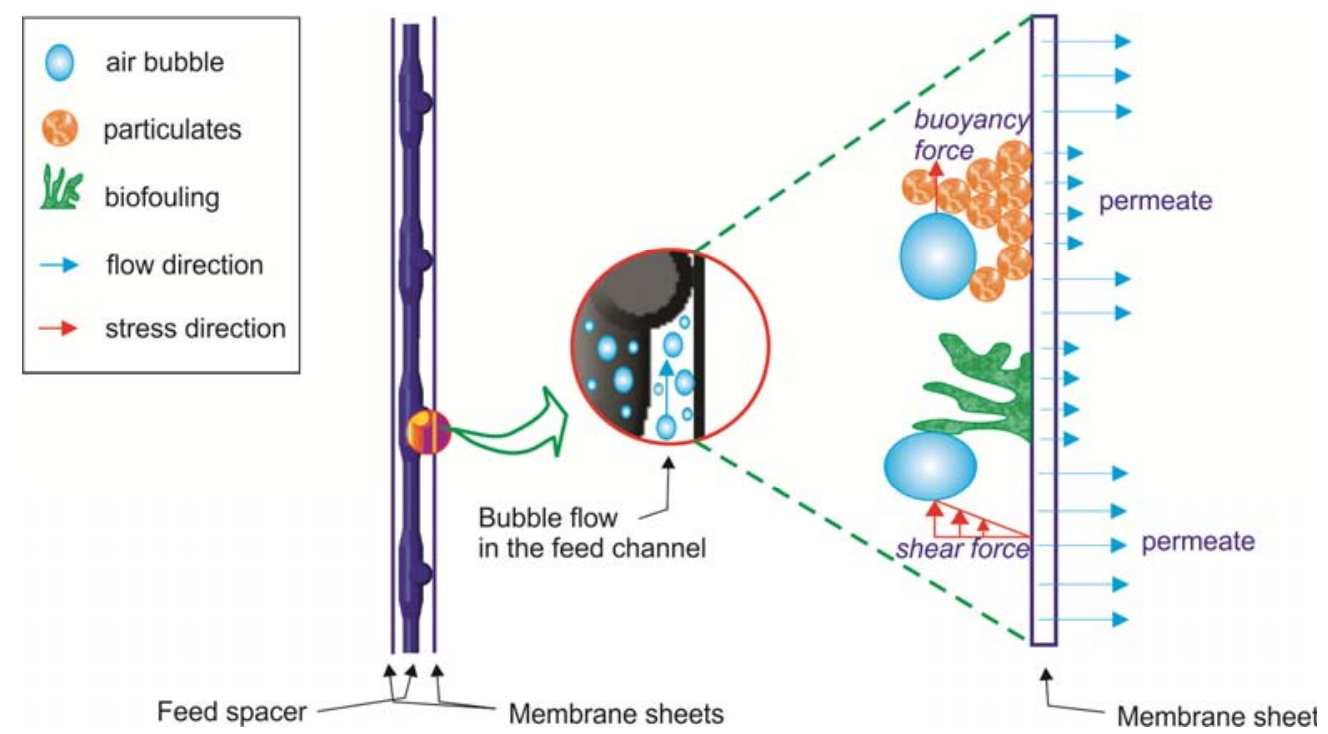

Fig. 3.1. Schematic diagram of two-phase flow cleaning for fouling removal in spiral-wound membrane feed channels.

Since biofouling is considered to be spacer-related [17], it is necessary to investigate the effect of feed spacer geometries on the efficiency of any form of fouling removal. The geometries of feed spacers in spiral-wound membrane elements are expressed by several parameters, i.e. thickness $\left(\mathrm{h}_{\mathrm{sp}}\right)$, porosity $(\varepsilon)$, filament diameter $\left(\mathrm{d}_{\mathrm{s}}\right)$, length $\left(\mathrm{L}_{\mathrm{s}}\right)$, and filament angle $(\sigma)$ relative to the feed flow [18], as shown in Fig. 3.2.

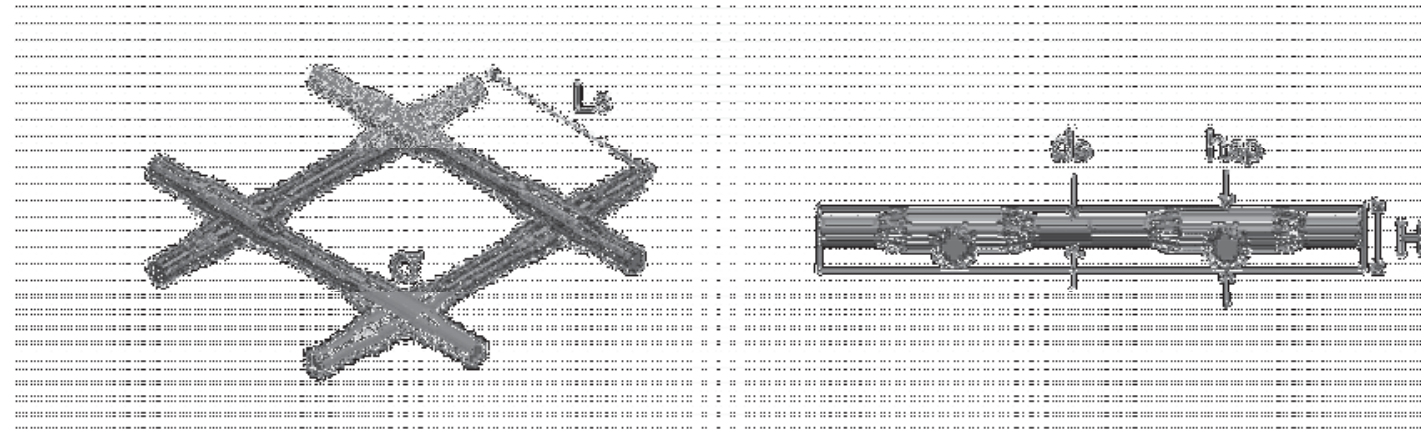

Fig. 3.2. Schematic diagrams of feed spacer geometries: thickness $\left(h_{\mathrm{sp}}\right)$, filament diameter $\left(d_{s}\right)$, length $\left(L_{s}\right)$, and filament angle $(\sigma)$ relative to the feed flow; $H$ is the channel height. 
The porosity of the feed spacer is defined as:

$$
\varepsilon=1-\frac{V_{s p}}{V_{t o t}}
$$

where $\mathrm{V}_{\mathrm{sp}}$ is the feed spacer volume $\left(\mathrm{m}^{3}\right)$ and $\mathrm{V}_{\text {tot }}$ is the total volume $\left(\mathrm{m}^{3}\right)$ of the flow channel in which the feed spacer fits exactly. The porosity of the feed spacer is mathematically linked to mesh size, filament angle and diameter. In spiral-wound membrane modules, the mesh is generally a diamond shape with a filament angle of $90^{\circ}$. The feed spacer volume and total volume are then defined as follows:

$$
\begin{aligned}
& V_{s p}=\frac{\pi}{2} d_{s}^{2} L_{s} \\
& V_{t o t}=H L_{s}^{2}
\end{aligned}
$$

where $d_{s}$ is the diameter of the feed spacer strand $(m), L_{s}$ is the length of the feed spacer strand (m), and $\mathrm{H}$ is the channel height (m).

The hydraulic diameter $\left(d_{h}\right)$ is the cross-sectional geometric characteristic of spacer-filled channels. The following definition applies to flow channels with non-circular geometries [18]:

$$
d_{h}=\frac{4 \cdot A}{C}
$$

where $\mathrm{A}$ is the cross section of flow channel and $\mathrm{C}$ is the wetted circumference, which for a rectangular channel is defined as:

$$
d_{h}=\frac{4 \cdot W \cdot H}{2 \cdot(W+H)}
$$

where $\mathrm{W}$ and $\mathrm{H}$ are channel width and height (m), respectively.

The hydraulic diameter of spacer-filled channels $\left(d_{h}^{s p}\right)$ can be derived from Eq. 3.4 and Eq. 3.5 [19], resulting in:

$$
d_{h}^{s p}=\frac{4 \cdot \varepsilon}{\frac{2}{H}+(1-\varepsilon) \cdot S_{v}^{s p}}
$$


where $S_{v}^{s p}$ is the specific surface of the spacer defined as:

$$
S_{v}^{s p}=\frac{\text { surface }}{\text { volume }}=\frac{S_{s p}}{V_{s p}}
$$

The spacer surface $\left(\mathrm{S}_{\mathrm{sp}}\right)$ can be obtained as follows:

$$
S_{s p}=2 \pi d_{s} L_{s}
$$

During a membrane autopsy of spiral-wound membrane elements taken from a pilot test with tap water, iron and silicate colloids were found along with biofilm mass [20,21]. This implied a need to examine the role of the type of dispersed particles on cleaning efficiency. Moreover, the hydrodynamic parameter of interest concerning the bubble-induced shear stress is the ratio between gas and liquid which is responsible for the flow pattern in different flow channel geometries [16]. Typically, a gas/liquid ratio $\theta$ between 0.2 and 0.9 is used for hollow-fiber membranes [22], whereas a gas/liquid ratio $\theta$ between 0.4 and 0.7 is applied in tubular membranes [23]. At such gas/liquid ratios, the formed slugs provide the highest surface shear stresses. In flat sheet membranes, the flow pattern depends on the channel gap [24, 25], and it has been suggested that the majority of the bubbles must be at least as wide as the channel gap to enhance the surface shear effect [26]. The presence of feed spacers in spiral-wound membrane modules affects the flow pattern and bubble size during two-phase flow. The bubble size can be predicted based on the feed spacer geometry and the water velocity [27]. The aim of the work described in this chapter was to identify the main factors that determine the efficiency of two-phase flow cleaning in narrow spacer-filled membrane channels. The factors we investigated were feed spacer geometry (thickness and orientation), feed type, gas/liquid ratio, and liquid velocity (i.e., the superficial velocity). The mechanisms of particle deposition and removal by two-phase flow cleaning were observed in situ using a high-speed camera.

\subsection{Experimental}

\subsubsection{Materials}

Colloids in natural waters can be divided into two groups, namely rigid (inorganic) colloids and organic macromolecules; both are considered (NF/RO) membrane foulants [28, 29]. In 
our work, we chose a bidisperse solution of polystyrene (PS) with particle sizes of $0.5 \mu \mathrm{m}$ and $3 \mu \mathrm{m}$ as a model for rigid colloidal particle foulants, and a humic acid (HA) solution to simulate organic macromolecular foulants.

The bidisperse polystyrene solution consisted of $3 \mathrm{~mL} / \mathrm{L}$ monodisperse $0.5 \mu \mathrm{m}$ polystyrene particles (Sigma-Aldrich), with the addition of $1 \mathrm{~mL} / \mathrm{L}$ of $3 \mu \mathrm{m}$ microspheres (Polybead®, Polysciences, Inc.), dyed blue to enhance the visibility of fouling. The humic acid solution consisted of $1 \mathrm{~g} / \mathrm{L}$ humic acid (Acros Organics) and $4 \mathrm{mM}$ calcium chloride (Sigma-Aldrich) to increase particle adhesion to the membrane surface. Both homogeneous model particle solutions were prepared by dispersion in $1 \mathrm{~L}$ of deionized water with a conductivity of less than $1 \mu \mathrm{S} / \mathrm{cm}$ (Milli-Q, Millipore, USA), under constant magnetic stirring for at least two hours until no more sedimentation occurred. Table 3.1 shows the properties of the model foulant solutions. The interfacial tensions of the model solutions were measured with an EasyDyne Tensiometer (Krüss GmbH, Hamburg, Germany). The prepared solutions were transferred to the feed tank of the two-phase flow setup (see Fig. 3.4) prior to the experiments. Continuous magnetic stirring was conducted throughout each experiment run to maintain a stable solution. All experiments were conducted at room temperature.

Table 3.1. Properties of the model foulant solutions.

\begin{tabular}{|c|l|c|c|c|c|}
\hline Solution & \multicolumn{1}{|c|}{ Material } & $\mathbf{D}_{\text {ave }}(\boldsymbol{\mu m})$ & $\mathbf{C}_{\mathbf{0}}(\mathbf{g} / \mathbf{L})$ & $\mathbf{p H}$ & $\boldsymbol{\gamma}(\mathbf{m N} / \mathbf{m})$ \\
\hline \multirow{2}{*}{ Bidisperse PS } & Monodisperse PS & $0.500^{\mathrm{a}}$ & 3.00 & \multirow{2}{*}{6.3} & \multirow{2}{*}{$1462 \pm 4.9$} \\
\cline { 2 - 4 } & PS dyed blue & $3.000^{\mathrm{a}}$ & 1.00 & & \\
\hline \multirow{2}{*}{$\mathrm{HA}+\mathrm{CaCl}_{2}$} & $\mathrm{HA}$ & $0.549^{\mathrm{b}}$ & 1.00 & \multirow{2}{*}{8.4} & \multirow{2}{*}{$1221 \pm 1.6$} \\
\cline { 2 - 5 } & $\mathrm{CaCl}_{2}$ & - & 0.44 & & \\
\hline
\end{tabular}

a Manufacturers' data
${ }^{\mathrm{b}}$ Mode value measured by dynamic light scattering (DLS) using a Mastersizer 2000 (Malvern Instrument Ltd., UK) at $25^{\circ} \mathrm{C}$.

Three polypropylene feed spacers were selected for this study. A $0.711 \mathrm{~mm}$ feed spacer thickness is most commonly used in spiral-wound membrane elements for surface water treatment in the Netherlands and was therefore used as a reference spacer [30]. A thinner feed spacer of $0.508 \mathrm{~mm}$ and a thicker one of $1.168 \mathrm{~mm}$ were used as variations of feed spacer thickness. All feed spacers had identical geometries, with a filament angle of $90^{\circ}$ and comparable feed spacer porosities in the range of 0.8 to 0.9 . Table 3.2 summarizes the geometric characteristics of the investigated spacers. Fig. 3.3 shows images of the spacers. 
Table 3.2. Overview of feed spacer geometries.

\begin{tabular}{|c|c|c|c|}
\hline $\begin{array}{c}\text { Spacer } \\
\text { geometry }\end{array}$ & Spacer A & Spacer B & Spacer C \\
\hline $\mathbf{h}_{\mathbf{s p}} \cdot \mathbf{1 0}^{\mathbf{3}}(\mathbf{m})$ & 0.508 & 0.711 & 1.168 \\
\hline $\mathbf{d}_{\mathbf{s}} \cdot \mathbf{1 0}^{\mathbf{3}}(\mathbf{m})$ & 0.3 & 0.35 & 0.7 \\
\hline $\mathbf{L}_{\mathbf{s}} \cdot \mathbf{1 0}^{\mathbf{3}}(\mathbf{m})$ & 1.69 & 2.86 & 3.57 \\
\hline $\boldsymbol{\sigma}$ & $90^{\circ}$ & $90^{\circ}$ & $90^{\circ}$ \\
\hline $\boldsymbol{\varepsilon}(-)$ & 0.83 & 0.90 & 0.82 \\
\hline$S_{v}^{s p} \cdot \mathbf{1 0}^{\mathbf{3}}\left(\mathbf{m}^{-\mathbf{1}}\right)$ & 13.33 & 11.42 & 5.72 \\
\hline$d_{h}^{s p} \cdot \mathbf{1 0}^{\mathbf{3}}(\mathbf{m})$ & 0.535 & 0.914 & 1.218 \\
\hline Supplier & Delstar (Naltex) & Delstar (Naltex) & Toray \\
\hline
\end{tabular}
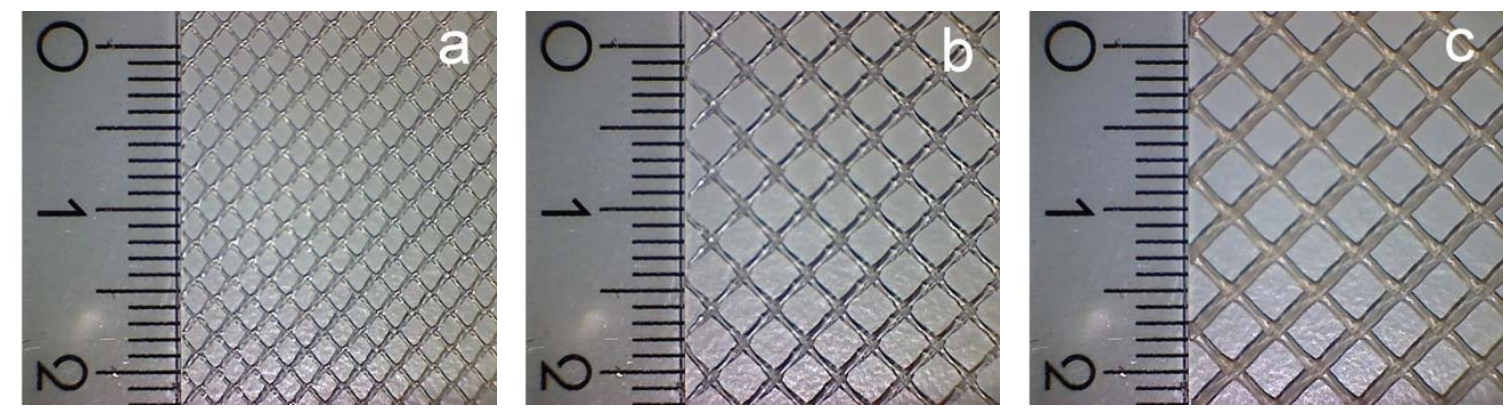

Fig. 3.3. Images of investigated feed spacers: (a) spacer A, (b) spacer B and (c) spacer C; scales are in $\mathrm{cm}$.

As permeation through the membrane does not affect the effectiveness of two-phase flow cleaning in spiral-wound elements [20], this factor was not considered in this work. A thinfilm composite polyamide NF membrane sheet (Hydranautics ESNA1-LF2-LD, Oceanside, California, USA) was used in the cell to simulate a membrane channel filled with feed spacers. The membrane is slightly negatively charged at neutral $\mathrm{pH}$ [31].

\subsubsection{Experimental setup}

Fig. 3.4 displays the experimental setup. It consists of a feed pump (Masterflex 701820, USA) delivering feed water to the system, a pressure relief valve (Parker, USA), a pressure reducer (Festo, Germany) to maintain a slightly higher gas pressure than the feed 116 
pressure for good mixing of the gas and liquid flows during cleaning, an integrated flow system, and a custom-made flow cell. The flow system is automated and consists of a differential pressure meter (El-Press) to measure the pressure drop across the flow cell, a gas flow controller (El-Flow Select), a feed flow controller (Cori-Flow M53), a digital power supply, and a readout system (E-7500), all purchased from Bronkhorst Nederland BV, The Netherlands. All data were logged simultaneously on a personal computer.

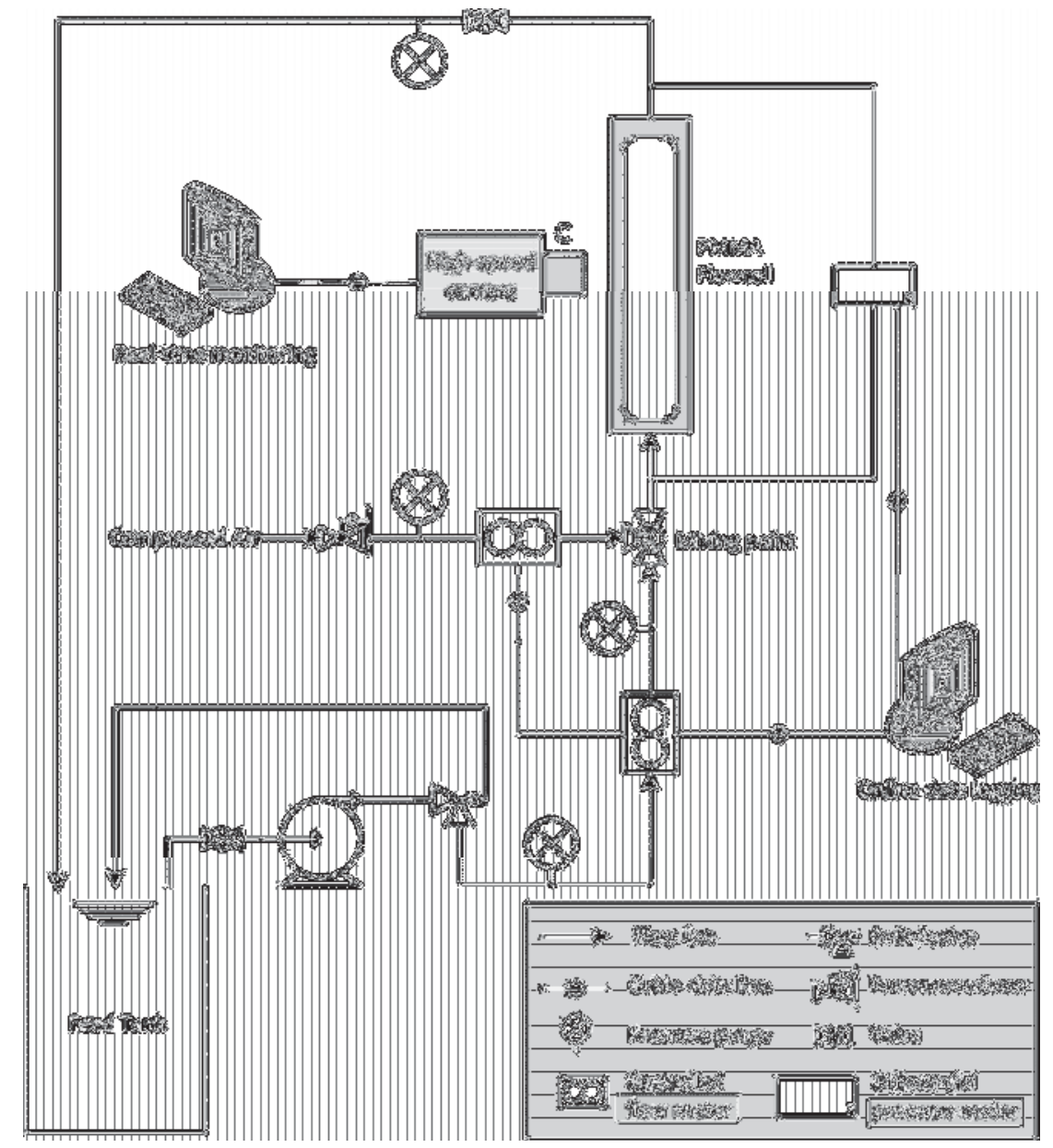

Fig. 3. 4. Two-phase flow cleaning setup.

For in-situ direct visual observation, a flow cell simulator was made from 10-mm thick poly(methyl methacrylate) (PMMA) plates. The front plate is tapered to fit a spacer-filled feed channel of $20 \mathrm{~mm} \times 170 \mathrm{~mm}$ and to define a channel height $(\mathrm{H})$ of $0.5 \mathrm{~mm}, 0.7 \mathrm{~mm}$ and a thicknesses of $1.2 \mathrm{~mm}$, exactly matching the feed spacer thicknesses used in the experiment. Six 1-mm holes $-2 \mathrm{~mm}$ apart -uniformly distribute the flow over the width of the feed channel at inlet and outlet in this cell simulator. Fig. 3.5 schematically depicts the flow cell. 


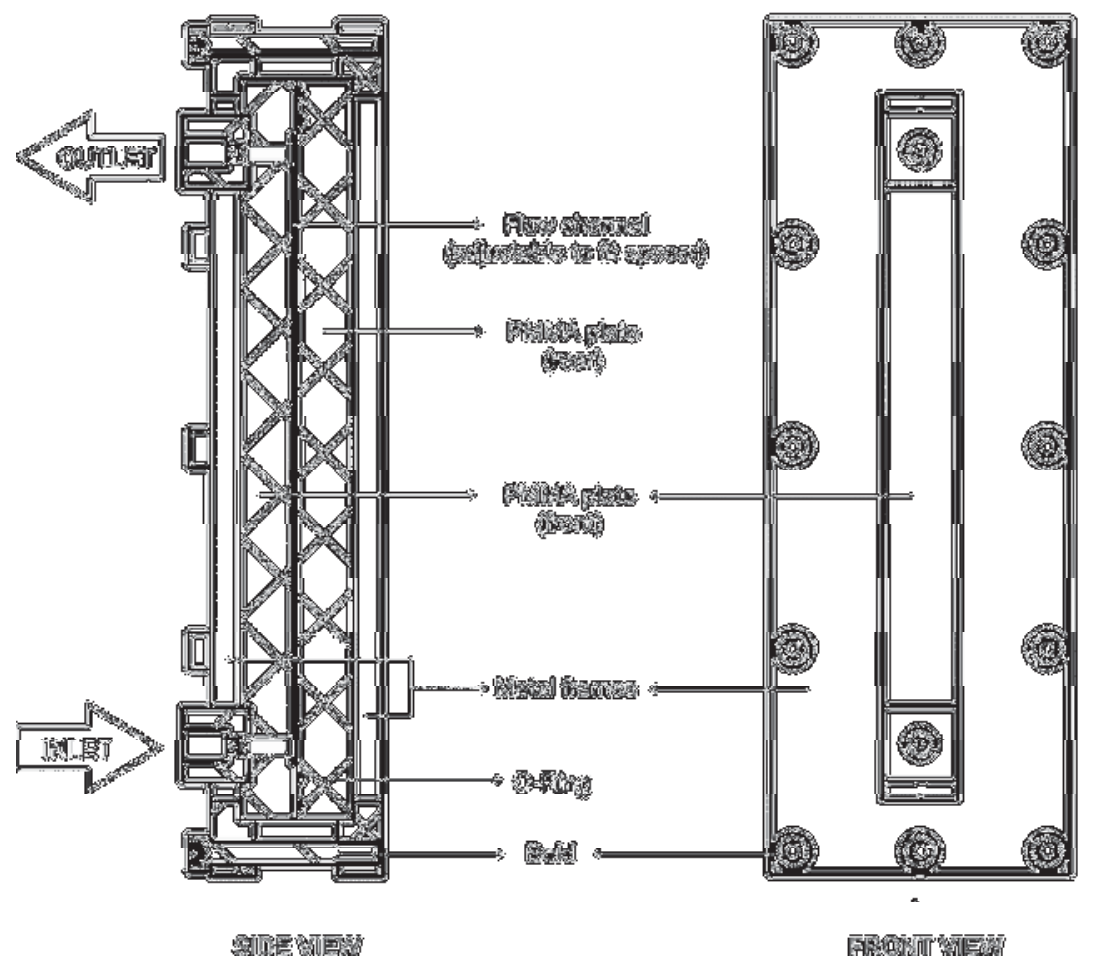

Fig. 3.5. Schematic drawing of custom-made flow cell.

\subsubsection{Operational method}

Each experiment run contained two stages: (i) a fouling stage, in which model foulants were introduced in the feed channel for a period of 24 hours, and (ii) a cleaning stage, in which air/liquid flows were introduced to remove fouling from the feed channel. In the cleaning stage, the effect of feed type (see Table 3.1), spacer geometry (see Table 3.2), spacer orientation, feed velocity, and gas/liquid ratio on the two-phase flow cleaning efficiency were investigated.

The gas/liquid ratio $(\theta)$ is defined as:

$$
\theta \equiv \frac{u_{G}}{u_{G}+u_{L}}
$$

where $u_{G}$ and $u_{L}$ are the superficial velocities of gas and liquid $(\mathrm{m} / \mathrm{s})$, respectively.

The liquid and gas superficial velocities $\left(\mathrm{u}_{\mathrm{L}}, \mathrm{u}_{\mathrm{G}}\right)$ are corrected for channel porosity and calculated using the following equations: 


$$
\begin{aligned}
& u_{L}=\frac{Q_{L}}{3.6 \cdot(\varepsilon \cdot W \cdot H)}(\mathrm{m} / \mathrm{s}) \\
& u_{G}=\frac{Q_{G}}{3.6 \cdot(\varepsilon \cdot W \cdot H)}(\mathrm{m} / \mathrm{s})
\end{aligned}
$$

where $\mathrm{Q}_{\mathrm{L}}$ is liquid flow rate $(\mathrm{L} / \mathrm{h}), \mathrm{Q}_{\mathrm{G}}$ is the gas flow rate $(\mathrm{L} / \mathrm{h}), \varepsilon$ is the porosity of the channel and $\mathrm{W}$ and $\mathrm{H}$ are the channel width and height $(\mathrm{mm})$, respectively.

The liquid velocities $\left(\mathrm{v}_{\mathrm{L}}\right)$ were set at 0.042 or $0.163 \mathrm{~m} / \mathrm{s}$, associated with linear superficial velocities $\left(\mathrm{u}_{\mathrm{L}}\right)$ of 0.07 and $0.27 \mathrm{~m} / \mathrm{s}$ for the reference feed spacer of $0.711 \mathrm{~mm}$. These values correspond to feed flows used in practice in several full-scale NF/RO installations [32]. The gas/liquid ratios $(\theta)$ were tested at 0.333 and 0.629 , associated with slug flow patterns in rectangular narrow channels as reported in the literature [25]. Two-phase flow cleaning was performed after 24 hours of fouling. All two-phase flow cleanings were performed during $60 \mathrm{~s}$, by injecting bubbles in the mixing point together with the feed solutions.

The feed channel pressure drop is a simple but sensitive parameter, which corresponds to the resistance in the feed flow channel, and is not affected by the flux [33]. All measurements were characterized via the feed channel pressure drop $(\Delta P)$ and presented as the pressure drop in the fouled channel relative to the drop in the clean channel, indicated as NPD, which is formulated as:

$$
N P D=\frac{\Delta P_{t}}{\Delta P_{0}}
$$

where $\Delta P_{t}$ is the feed channel pressure drop on time $\mathrm{t}$ (mbar), and $\Delta P_{0}$ is the initial feed channel pressure drop (mbar).

The performance of two-phase flow cleaning was evaluated in terms of cleaning efficiency $(\eta)$, which was defined as:

$$
\eta=\frac{\left(\Delta P_{t}-\Delta P_{T P F}\right)}{\left(\Delta P_{t}-\Delta P_{0}\right)} \cdot 100 \%
$$


where $\Delta P_{t}$ is the feed channel pressure drop at time $\mathrm{t}$ when two-phase flow cleaning was performed (mbar), and $\Delta P_{T P F}$ is the feed channel pressure drop after two-phase flow cleaning (mbar).

The bubble velocity was measured from the time required for the bubble front to travel from the inlet of the flow cell to the outlet. The bubble velocity $\left(v_{b}\right)$ was calculated using the following equation:

$$
v_{b}=\frac{F}{N_{F}} \cdot L_{c}(\mathrm{~m} / \mathrm{s})
$$

where $\mathrm{F}$ is the frame rate at which the image sequence is recorded (fps), and $\mathrm{N}_{\mathrm{F}}$ is the total number of frames needed for a bubble to travel over a distance $\left(\mathrm{L}_{\mathrm{c}}\right)$ between the inlet and the outlet of the flow cell (m). All experiments were performed at least three times; the data were represented as bar charts indicating the mean values and error bars representing the standard deviations.

The channel coverage of the bubbles $\left(\alpha_{c}\right)$ is an important parameter related to the spatial distribution of the bubbles. We defined the channel coverage of the bubbles as the degree of distribution of two-dimensional bubbles in the longitudinal direction parallel to the channel width (W). This was done because the velocity of a bubble is high when it travels the short distance of the flow channel length, assuming that the average bubble diameter is the same as the channel height $(\mathrm{H})$. The channel coverage by bubbles was calculated as follows:

$$
\alpha_{c}=\frac{w_{b}}{W}
$$

where $\mathrm{w}_{\mathrm{b}}$ is the width of the two-dimensional bubble and $\mathrm{W}$ is the flow channel width.

\subsubsection{Direct-visual observation and scanning electron microscopy}

A high-speed camera system, a MotionBLITZ EoSens ${ }^{\circledR}$ mini2 high-speed recording camera (Mikrotron GmbH, Germany) with 8-bit monochrome 1696 x 1710 CMOS image sensor, was employed to monitor the two-phase flow cleaning process. We used it to study (i) the fouling mechanisms such as entrapment of particles onto the spacer material and/or membrane surface 
and (ii) the behavior of a two-phase system in the spacer-filled channel, such as air bubble breakup, coalescence, and entrapment of bubbles.

The camera took a maximum of 523 frames per second (fps) at full resolution and more than 200,000 fps at reduced resolution. It was used with two types of lenses. The first one was a zoom lens (Optem Zoom 160, Qioptic Photonics, UK) with a 2.0x objective lens and a 1.0x dovetail tube, which allowed a magnification of 16 times. The second lens was a fixed lens (LM16xC, Kowa Company Ltd., Japan) which has a focal length of $16 \mathrm{~mm}$ and a main sensor size of 4/3 inch. A cold light illuminator (Euromex Microscopen BV, The Netherlands) was used to maintain light intensity in the flow cell during observation. The images and movies collected from each experiment were analyzed in image-processing freeware ImageJ v1.46r (National Institute of Health, USA) and VirtualDub v1.9.11 (www.virtualdub.org).

We used a Jeol JSM 5600 LV scanning electron microscope (SEM) to obtain more detailed images of the fouling deposited on the feed spacer and membrane surfaces.

\subsection{Results and discussion}

\subsubsection{Humic acid fouling}

Humic acid molecules in water form particles which are highly polydisperse in size. Fig. 3.6 shows the particle size and particle size distribution of a freshly prepared humic acid solution (1 g/L HA, without salt).

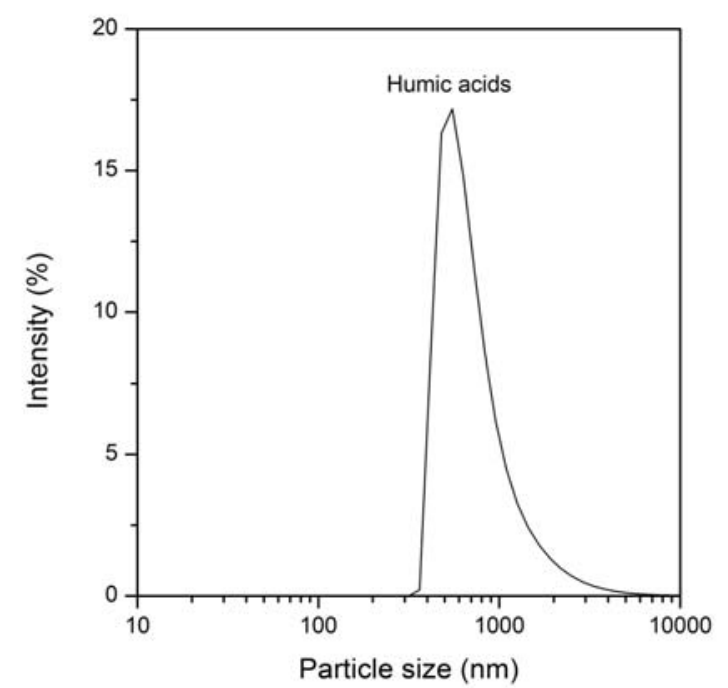

Fig.3. 6. Particle size and particle size distribution of $1 \mathrm{~g} / \mathrm{L}$ humic acid solution (without addition of salt), as determined by dynamic light scattering at $25^{\circ} \mathrm{C}$. 
Since the aim of this work was to define the main factors of the two-phase flow cleaning process, the investigation focused on the cleaning stages. As it was beneficial to enhance the fouling tendency of the humic acid, we added $\mathrm{CaCl}_{2}$ (see Section 3.2.1). According to the classical Derjaguin-Landau-Verwey-Overbeek (DLVO) theory of colloidal stability, the attachment of colloids onto a surface is defined by the net colloid-surface interaction which is the sum of attractive Van der Waals and repulsive electrical double layer interaction energy $[34,35]$. The interaction energy is strongly determined by physicochemical parameters (particle size, zeta potential, surface roughness) and solution chemistry ( $\mathrm{pH}$, ionic strength) [28]. The concentration of monovalent and divalent ions (ionic strength) plays an essential role in colloidal fouling [36-40].

Fig. 3.7 shows the increase in the normalized pressure drop (NPD) in time for humic acid solutions with various $\mathrm{CaCl}_{2}$ concentrations, using spacer B with a superficial liquid velocity of $\mathrm{u}_{\mathrm{L}}=0.27 \mathrm{~m} / \mathrm{s}$.

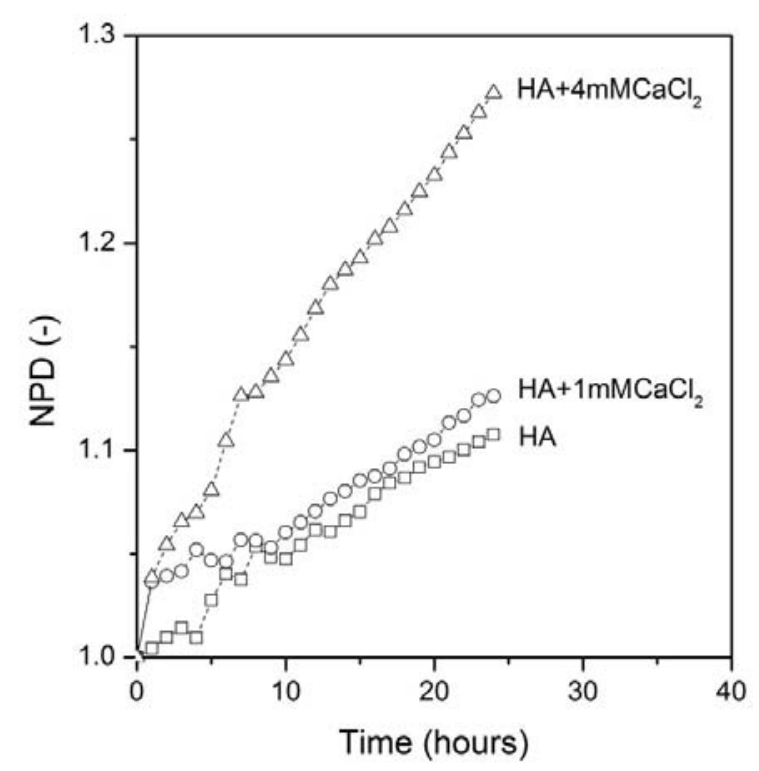

Fig. 3.7. The normalized pressure drop (NPD) development in time of $1 \mathrm{~g} / \mathrm{L}$ humic acid (HA) solutions at various $\mathrm{CaCl}_{2}$ concentrations: $\square$ : humic acid solution without addition of $\mathrm{CaCl}_{2}$; $\bigcirc$ : humic acid $+1 \mathrm{mM} \mathrm{CaCl}$ solution; $\triangle$ : humic acid $+4 \mathrm{mM} \mathrm{CaCl}_{2}$ solution. Spacer B was used, with $u_{L}=0.27 \mathrm{~m} / \mathrm{s}$.

As Fig. 3.7 shows, the NPD increased in time for all feed solutions. When $\mathrm{CaCl}_{2}$ salts are added to humic acid solutions, the $\mathrm{Ca}^{2+}$ ions bind to the carboxylate and phenolate groups of the humic acids and enhance the interaction between the humic acid molecules. The higher the $\mathrm{Ca}^{2+}$ ion concentration, the stronger the molecular interaction; the calcium ions may promote 122 
the formation of aggregates or form a physical bridge between foulants and membrane surface [41, 42]. These larger particles easily clog narrow spacer-filled channels, decrease porosity and therefore lead to a greater increase of the NPD. The steep increase of the NPD observed for $\mathrm{HA}+4 \mathrm{mM} \mathrm{CaCl}_{2}$ solution was almost $130 \%$ during 24 hours of operation. Therefore, all experiments using humic acid solutions in this research were carried out using a $\mathrm{HA}+4 \mathrm{mM} \mathrm{CaCl}{ }_{2}$ feed solution.

SEM imaging of feed spacers revealed that fouling in the spacer-filled narrow channels was responsible for the increase of the feed channel pressure drop. Fig. 3.8 shows SEM images of clean and fouled feed spacers; in the latter case, humic acid particles attached to the membrane and feed spacer surfaces are visible. Regarding the feed spacer surfaces, Fig. 3.8b shows that the majority of the humic acid particles are found at the intersection of the feed spacer filaments.

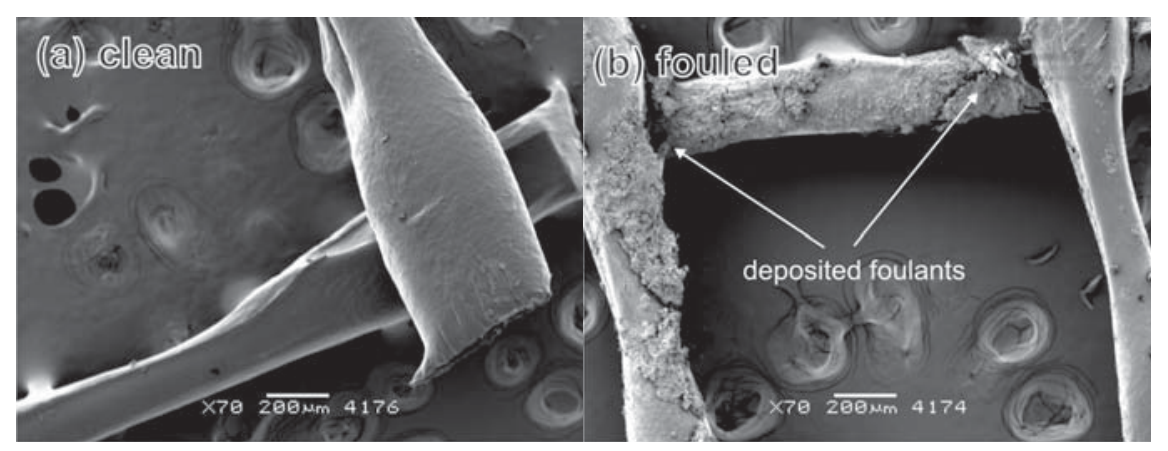

Fig. 3.8. SEM images of feed spacer B (diamond-oriented): (a) clean and (b) fouled by humic substances.

\subsubsection{Effect of feed spacer geometry}

We investigated the effect of the three different feed spacer geometries (Table 3.2) with $\mathrm{HA}+4 \mathrm{mM} \mathrm{CaCl} 2$ solutions, a feed flow velocity of $\mathrm{v}_{\mathrm{L}}=0.042 \mathrm{~m} / \mathrm{s}$ and a gas/liquid ratio of $\theta=0.629$. Fig. 3.9a shows the typical development of the NPD along the flow channel in time. As shown in Fig. 3.9a, the NPD increased in time for all feed spacers. However, the increases were more pronounced for the channel with the thinner feed spacer or shorter filament lengths (i.e. spacer A). As for spacer B, the sudden increase and subsequent slight decrease of the channel pressure drop most likely is due to the presence of a few gas bubbles trapped in the spacers in the first hours of the experiment. These bubbles were removed by the increased 
pressure in the flow cell, which then lowered the NPD. The porosities $(\varepsilon)$ of the three spacers were comparable, as were the liquid superficial velocities $\left(\mathrm{u}_{\mathrm{L}} \cong 0.07-0.08 \mathrm{~m} / \mathrm{s}\right)$. However, a smaller feed spacer thickness means a smaller channel gap, and with a smaller channel gap, blockage and particle deposition occurred more rapidly, resulting in a larger NPD for spacer A.
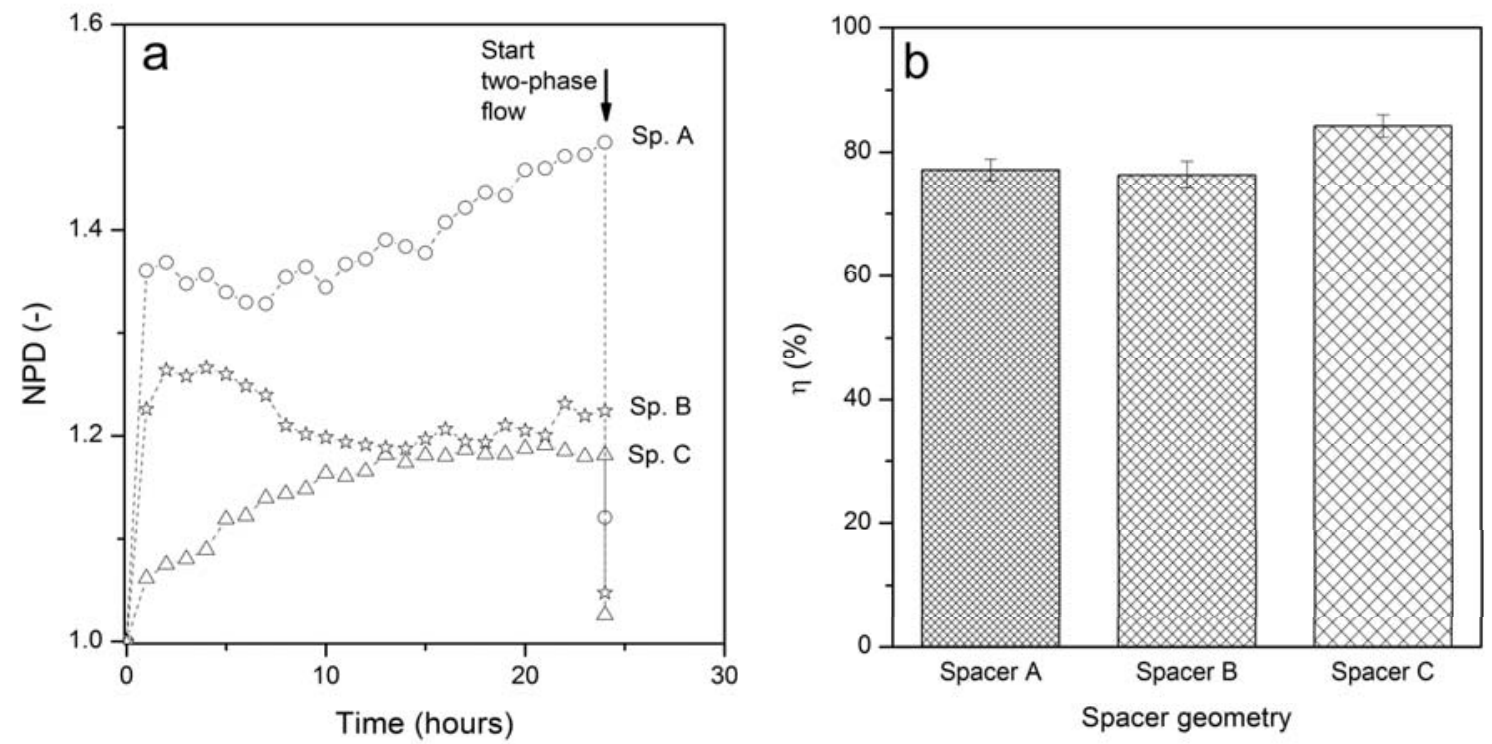

Fig. 3.9. Effect of feed spacer geometry on (a) the normalized pressure drop (NPD) in time for feed spacer $A(O)$, spacer $B(\xi)$ and spacer $C(\triangle)$, with solid arrow indicating two-phase flow cleaning and (b) the two-phase flow cleaning efficiency of feed spacers $\mathrm{A}, \mathrm{B}$ and $\mathrm{C}$, with feed $1 \mathrm{~g} / \mathrm{L} \mathrm{HA}+4 \mathrm{mM} \mathrm{CaCl}_{2}$, and feed flow velocity $\mathrm{v}_{\mathrm{L}}=0.042 \mathrm{~m} / \mathrm{s}$.

The porosity of the channels filled with spacers A, B and C is comparable, i.e. 0.83, 0.90 and 0.82, respectively. Flow velocity and shear stress, however, are related to the hydraulic diameter of the spacer. The calculated hydraulic diameters of channels filled with spacers A, $\mathrm{B}$ and $\mathrm{C}$ are $0.535,0.914$ and $1.218 \mathrm{~mm}$, respectively (see Table 3.2). The value of hydraulic diameters corresponds with the NPD development as shown in Fig. 3.9a; at the same flow velocity, i.e. the same particle loading, the larger hydraulic diameter (spacer C > spacer B > spacer A) in a smaller NPD (spacer C < spacer B < spacer A).

Fig. 3.9b illustrates the two-phase flow cleaning efficiencies. The channel with spacer $\mathrm{C}$ experienced a better cleaning efficiency than the channels with spacers A and B. Both the porosity and the hydraulic diameter of the spacer-filled channels affect the cleaning efficiency. Two-phase flow with the same gas fraction of $\theta=0.629$ produces bubble sizes determined by 
the hydraulic diameter of the channel and the length of the filaments (see Table 3.2), as was also reported in previous work [43]. The size of an ellipsoidal individual bubble usually is characterized by its aspect ratio, i.e. minor and major axis [16]. For bubbles in a spacer-filled channel, the bubble dimensions are related to the channel gap (hydraulic diameter) and the size of the diamond spacer mesh. The bubble size for a channel filled with spacer $\mathrm{C}$ is expected to be greater than for a channel filled with spacer A or B. The larger the bubble, the faster it rises (at equal superficial liquid velocities). This leads to greater friction between the bubbles and the membrane and spacer surfaces; therefore, slightly more effective cleaning is expected; Fig. 3.9b confirms that this is the case. In conclusion, the effects of the flow channel porosity and the hydraulic diameter of spacer-filled channels are important for the development of fouling but are less strong on actual two-phase flow cleaning efficiency.

\subsubsection{Effect of feed spacer orientation}

Fig. 3.10a shows the typical development of the NPD over the flow channel in time for feed spacer B oriented in the traditional way (diamond orientation) and rotated $45^{\circ}$ (parallel orientation). The feed was a $1 \mathrm{~g} / \mathrm{L} \mathrm{HA}+4 \mathrm{mM} \mathrm{CaCl}_{2}$ solution; a feed superficial velocity of $\mathrm{u}_{\mathrm{L}}=0.07 \mathrm{~m} / \mathrm{s}$ and a gas/liquid ratio of $\theta=0.629$ were used.

As shown in Fig. 3.10a, both feed spacer orientations produced comparable behaviors of the pressure drop increase. When the spacers are oriented differently, the channel porosity remains comparable as is described by Eq. (3.1). Therefore, blockage of the flow channel is expected to be very much alike for both orientations, resulting in a similar development of the NPD. However, during two-phase flow cleaning, the parallel-oriented feed spacers experienced a slightly higher cleaning efficiency (83\%) compared with the diamond-oriented spacers (78\%), as shown in Fig. 3.10b.

In-situ direct observation of two-phase flow cleaning using the high-speed camera revealed that the bubbles moved upward in a straight way for the parallel-oriented spacer, and in a zigzag manner for the diamond-oriented spacer. Fig. 3.11 shows the bubble trajectory in channels (clean channel with Milli-Q water as feed) as a function of elapsed time (in ms) with spacer B in diamond orientation (top) and parallel orientation (bottom), with a liquid superficial velocity of $u_{L}=0.07 \mathrm{~m} / \mathrm{s}$ and $\theta=0.629$. 

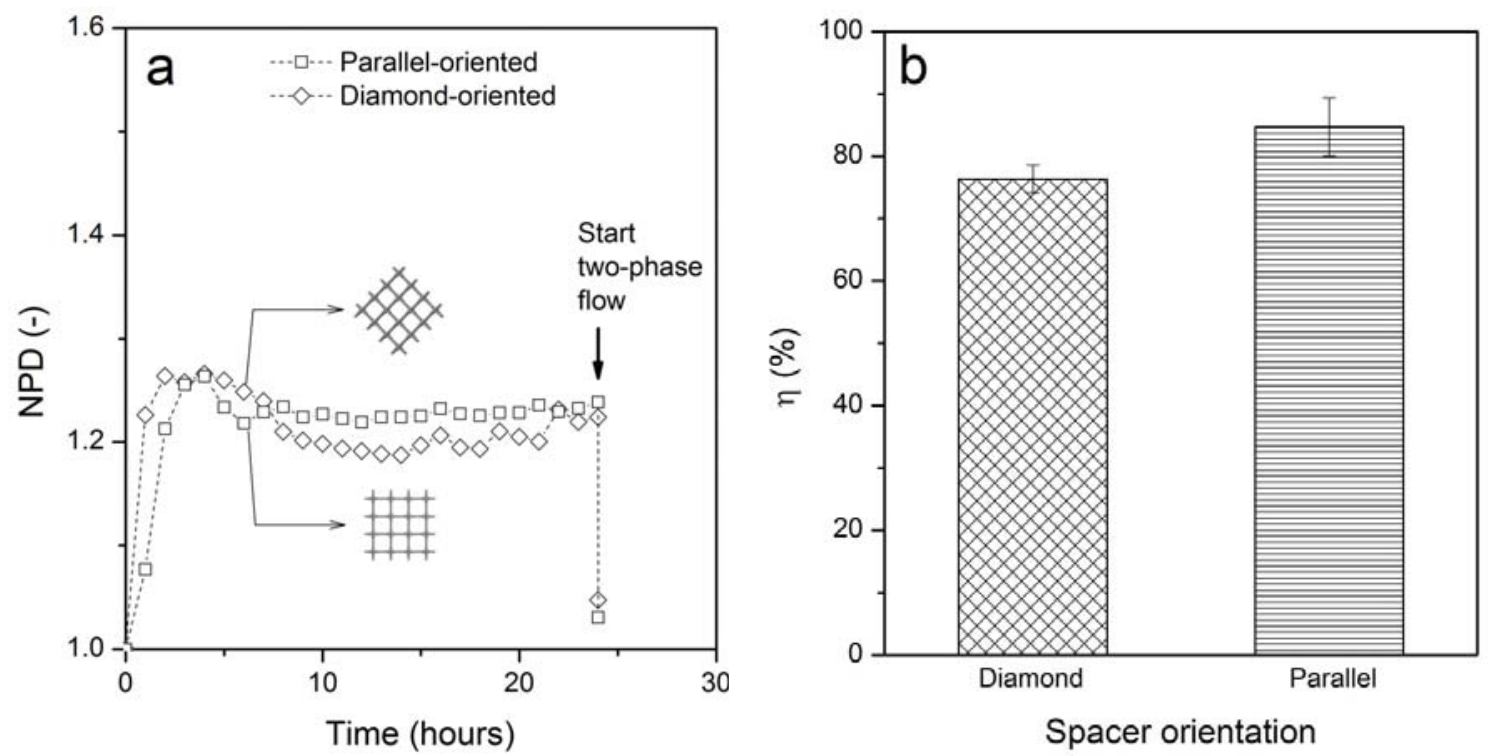

Fig. 3.10. Effect of feed spacer orientation on (a) the normalized pressure drop (NPD) in time for diamond $(\diamond)$ and parallel $(\square)$-oriented feed spacer B, with solid arrow indicating twophase flow cleaning, and (b) two-phase flow cleaning efficiency of diamond-oriented and parallel-oriented feed spacer, with $\mathrm{u}_{\mathrm{L}}=0.07 \mathrm{~m} / \mathrm{s}$ and $\theta=0.629$. Feed is $1 \mathrm{~g} / \mathrm{L}$ $\mathrm{HA}$ acid $+4 \mathrm{mM} \mathrm{CaCl}_{2}$.

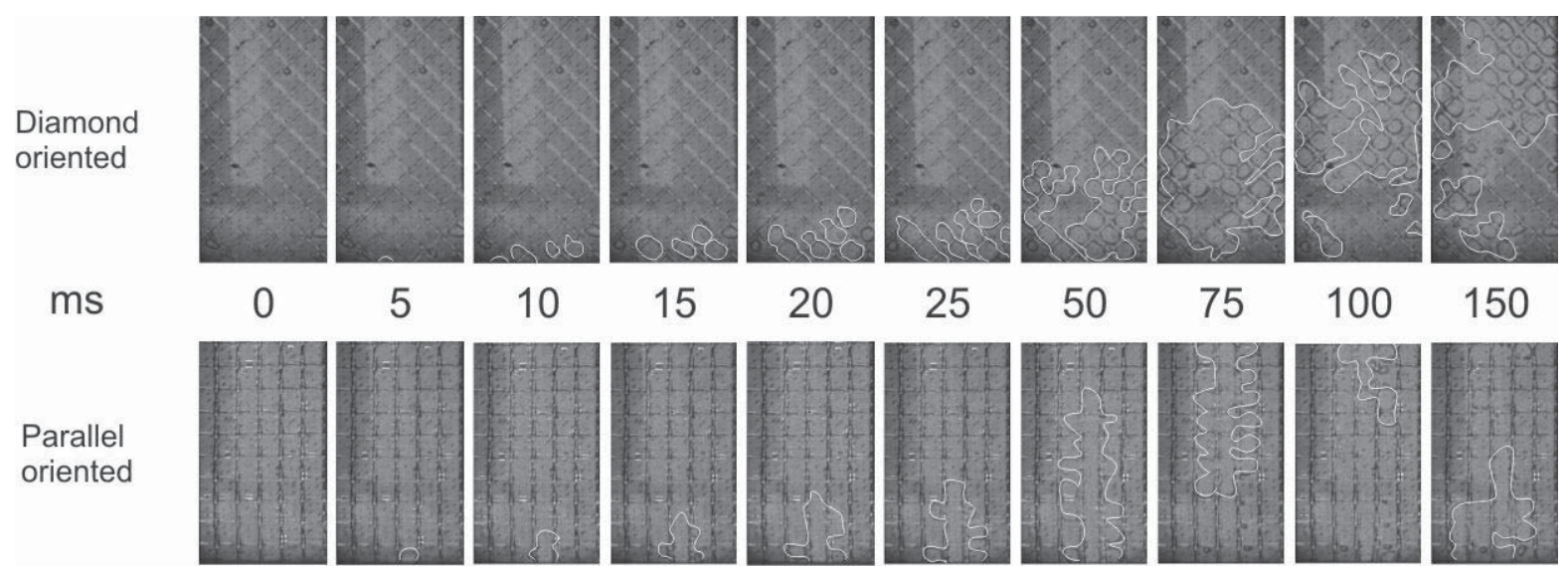

Fig. 3.11. Bubble trajectory in narrow spacer-filled membrane channel with spacer $B$ in diamond orientation (top) and parallel orientation (bottom), with $\mathrm{u}_{\mathrm{L}}=0.07 \mathrm{~m} / \mathrm{s}$ and gas/liquid ratio $=0.629$ (elapsed time in milliseconds).

As visible in Fig. 3.11, the bubbles were more broadly distributed in the diamond-oriented feed spacer, and moved slower. The bubbles in the parallel-oriented spacer were less broadly distributed (stayed at the center of the channel), and moved faster. 
The bubble trajectory in the diamond-oriented spacer followed the greater local liquid velocity. According to Da Costa et al. [19], the hydrodynamic characteristics in a spacer-filled channel are strongly dependent on the hydrodynamic angle, i.e. filament angle $(\sigma)$, the angle between two filaments facing the channel axis and can generate a change of the flow trajectory in the channel. Fig. 3.12 presents the vector flows for diamond-oriented and parallel-oriented spacers.

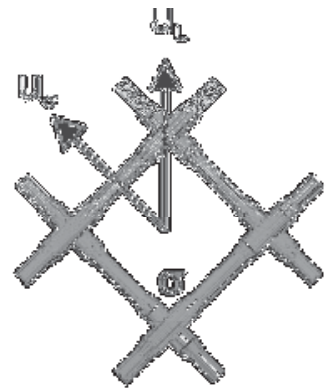

(a)

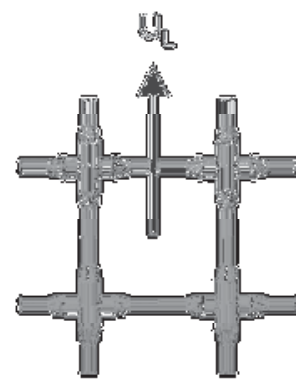

(b)

Fig. 3.12. Simplified two-phase flow directions in (a) diamond-oriented and (b) paralleloriented spacers with $\sigma$ (filament angle), $\mathrm{u}_{\mathrm{L}}$ (superficial velocity), and $\mathrm{u}_{\sigma}$ (velocity vector parallel to opposite filaments in a diamond-mesh spacer).

The velocity vector parallel to opposite filaments in a diamond-mesh spacer $\left(\mathrm{u}_{\sigma}\right)$ is defined as:

$$
u_{\sigma}=\frac{u_{L}}{\cos \frac{\sigma}{2}}
$$

where $\mathrm{u}_{\mathrm{L}}$ is the liquid superficial velocity. If the filament angle $\sigma$ equals $90^{\circ}$, the velocity vector $\mathrm{u}_{\sigma}>\mathrm{u}_{\mathrm{L}}$, resulting in a zigzag bubble trajectory for the diamond-oriented spacer as the bubbles follow the higher liquid superficial velocity in the spacer mesh. In parallel-oriented spacers on the other hand, the bubbles flow in the direction of the liquid flow, which is straight upward across the channel, resulting in a shorter travelling time relative to the bubble movement in the diamond-oriented spacer. To confirm this, we carried out a separate investigation to measure bubble velocities for both spacer orientations. Milli-Q water was used as feed, and the gas/liquid ratio was set constant at $\theta=0.629$. Fig. 3.13 displays the results. 


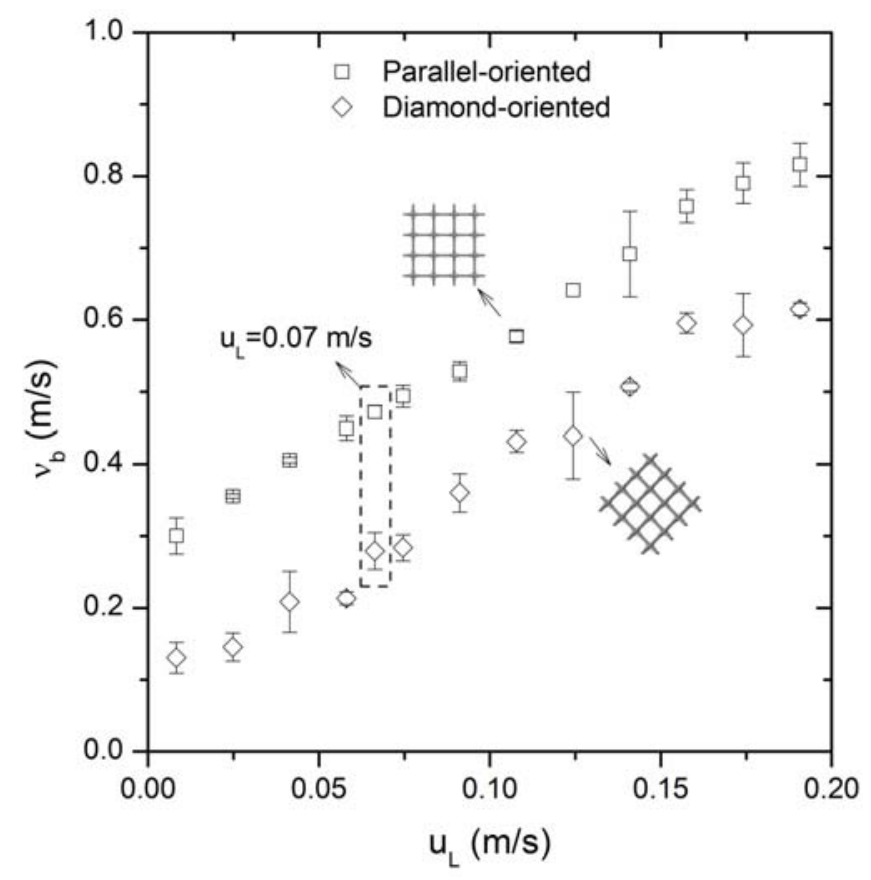

Fig. 3.13. Effect of spacer orientation and liquid velocity on bubble velocity (spacer B, $\theta=0.629, \mathrm{P}_{\text {gas }}=2$ bar $)$.

Fig. 3.13 shows that in the whole range of liquid velocities measured (up to $u_{L}=0.2 \mathrm{~m} / \mathrm{s}$ ), the bubble velocities in the channel filled with the parallel-oriented spacer were about $0.20 \mathrm{~m} / \mathrm{s}$ greater than the bubble velocities in the diamond-oriented feed spacer, in agreement with the observations visible in Fig. 3.11. In all cases the bubble velocities are larger than the liquid velocity. The higher bubble velocities for the parallel orientation resulted in better two-phase flow cleaning efficiency (Fig. 3.10b).

Channel coverage of the bubbles in diamond-oriented and parallel-oriented feed spacers is comparable, but not equal. Fig. 3.14 shows the width of two-dimensional bubbles $\left(\mathrm{w}_{\mathrm{b}}\right)$ and the channel coverage of the bubbles as defined by Eq. 3.15. The channel coverage of the bubbles in the diamond-oriented spacer is equal to $\alpha_{c}=1$. However, for the parallel-oriented spacer channel, coverage is lower $(<1)$. Fig. 3.15 illustrates the effect of an unequal bubble distribution over the channel on fouling removal. 


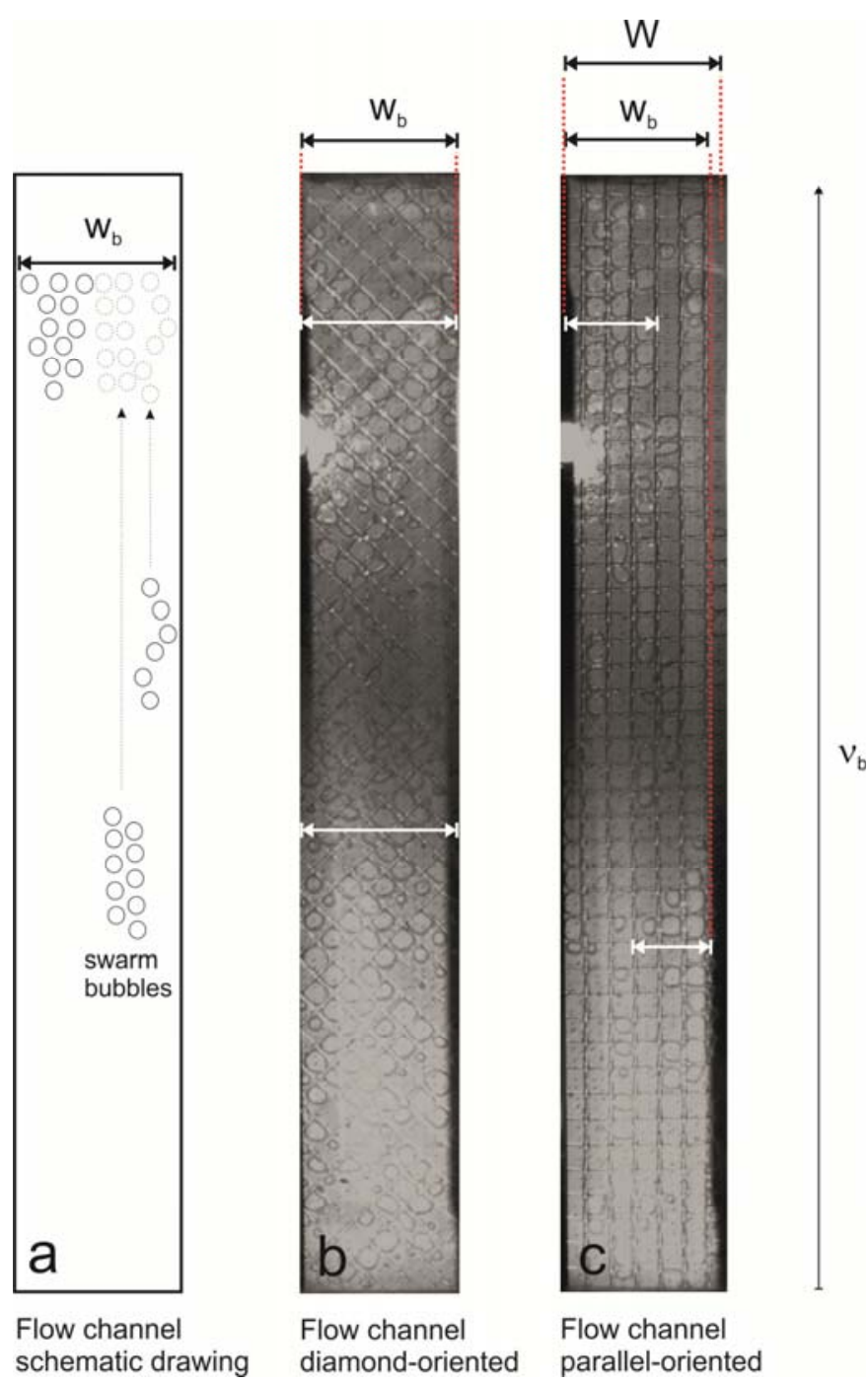

Fig. 3.14. Channel coverage of two-dimensional bubbles: (a) schematic drawing of the coverage concept, (b) flow channel filled with diamond-oriented feed spacer, and (c) flow channel filled with parallel-oriented feed spacer; $u_{L}=0.07 \mathrm{~m} / \mathrm{s}$ and $\theta=0.629$.

Almost all foulants deposited in the channel (Fig. 3.15a) were removed from the feed and membrane surfaces by the bubbles, including the region of intersecting feed spacer filaments (Fig. 3.15b). As the channel with a parallel-oriented spacer had an uneven bubble distribution, not all fouling was always removed after two-phase cleaning because the bubbles or bubble wakes did not reach the region of the remaining foulants (Fig. 3.15c).

In conclusion, spacer orientation influences the liquid superficial velocity. Therefore, rather than the orientation of spacers, it is the liquid superficial velocity which determines the cleaning efficiency of two-phase flow. 


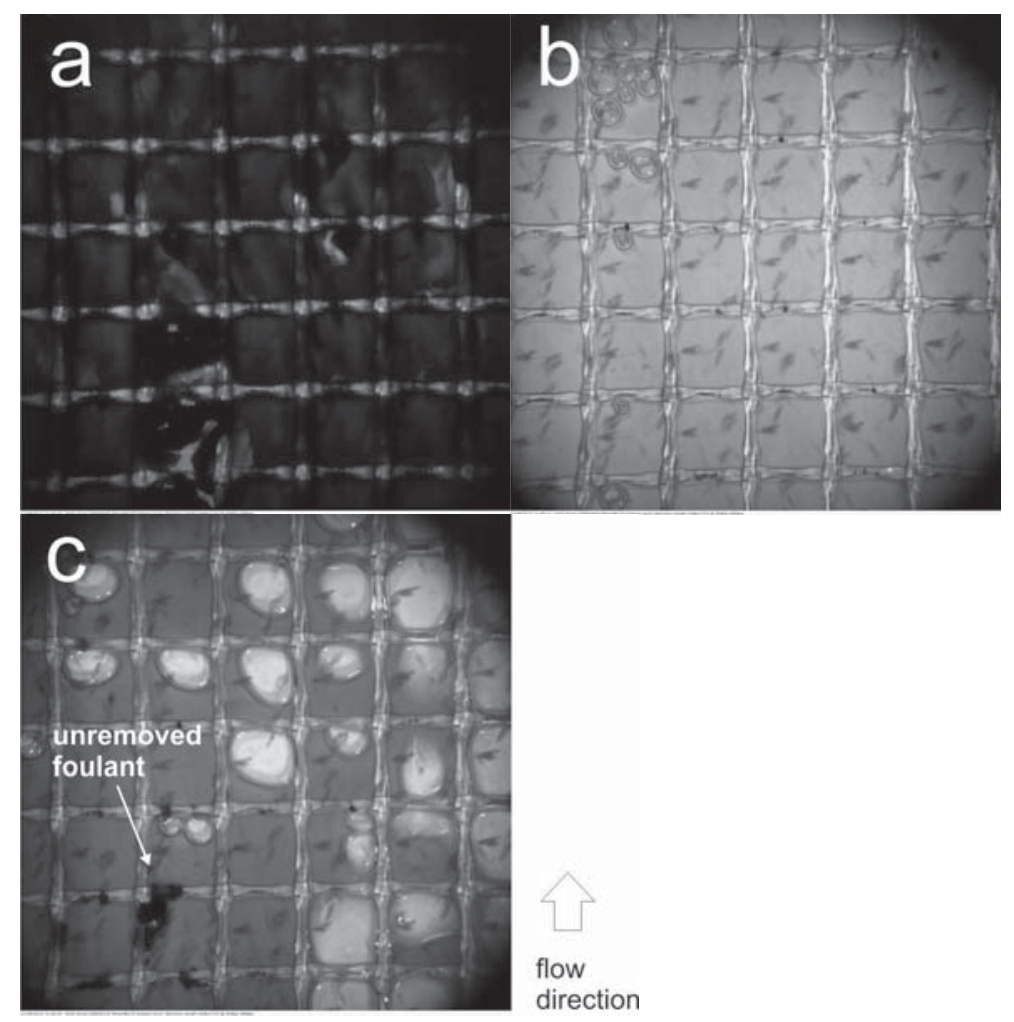

Fig. 3.15. In-situ direct visual observations of feed spacer and membrane in spacer-filled membrane channel with spacer B in parallel orientation: (a) fouled by $\mathrm{HA}+4 \mathrm{mM} \mathrm{CaCl}_{2}$, (b) cleaned by two-phase flow $\left(u_{L}=0.07 \mathrm{~m} / \mathrm{s} ; \theta=0.629\right)$, and (c) unremoved foulants due to poor bubble distribution.

\subsubsection{Effects of gas/liquid ratio and liquid velocity}

We examined the effect of the gas/liquid ratio by using two values of $\theta=0.333$ and $\theta=0.629$, with spacer $\mathrm{B}$. The feed solutions were $1 \mathrm{~g} / \mathrm{L} \mathrm{HA}+4 \mathrm{mM} \mathrm{CaCl}_{2}$ solutions; the feed velocity $\mathrm{u}_{\mathrm{L}}$ was $0.07 \mathrm{~m} / \mathrm{s}$. Fig. 3.16 shows the development of the NPD over the flow cell in time and the two-phase flow cleaning efficiencies.

As is visible in Fig. 3.16a, the development of the NPD is identical for both cases, as we used the same solutions and feed spacers. In the cleaning stage, however, the efficiency of twophase flow cleaning was greater for the higher gas/liquid velocity of $\theta=0.629$ compared with that of $\theta=0.333$ (Fig. 3.16b). Nevertheless, the difference was not significant when error margins are taken into consideration. The bubble velocity cannot have differed much at this low liquid superficial velocity $\mathrm{u}_{\mathrm{L}}(0.07 \mathrm{~m} / \mathrm{s})$; therefore, a comparable two-phase flow cleaning efficiency was expected. 

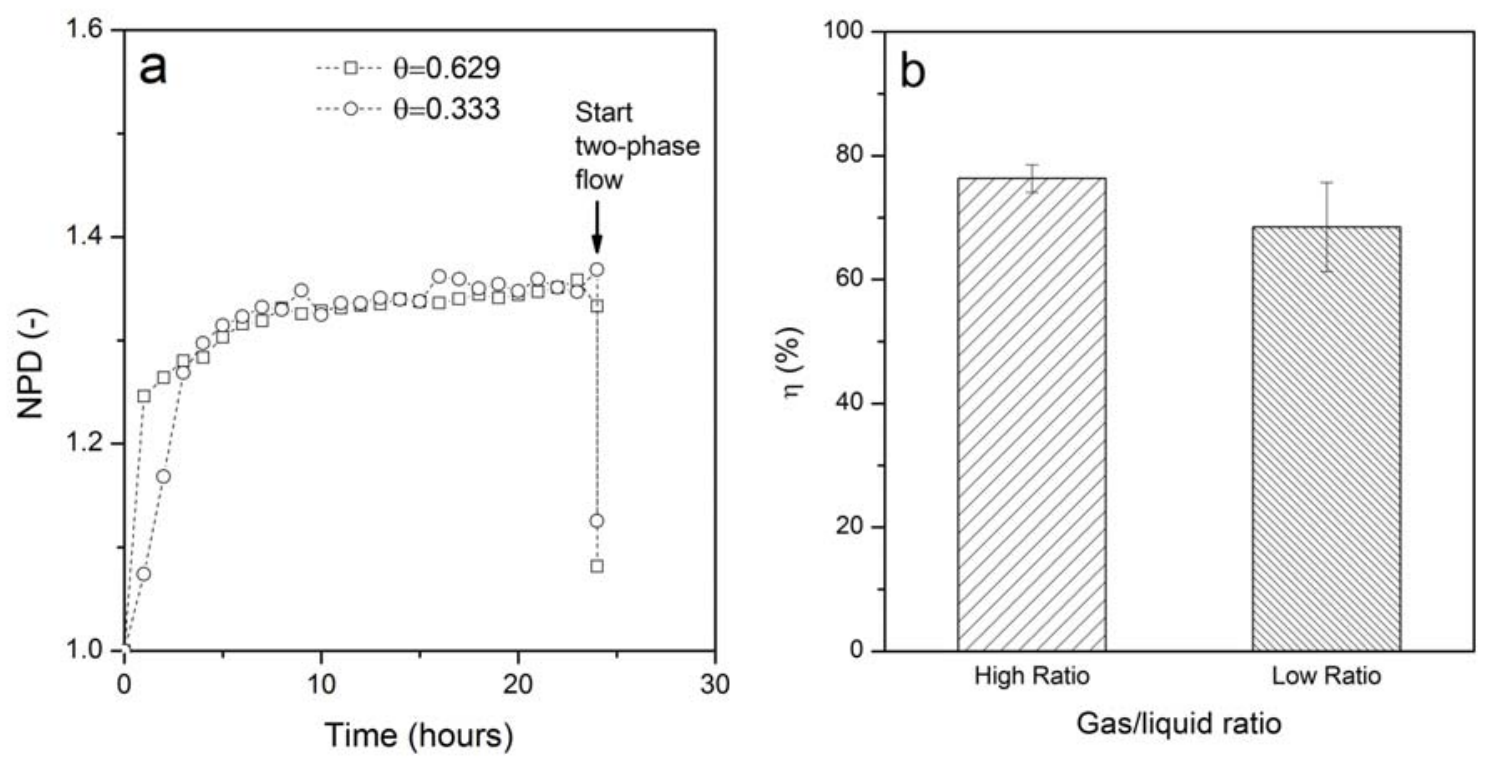

Fig. 3.16. Effect of gas/liquid ratio on (a) development of the normalized pressure drop (NPD) in time using $1 \mathrm{~g} / \mathrm{L} \mathrm{HA}+4 \mathrm{mM} \mathrm{CaCl} \mathrm{Cl}_{2}$ solutions $\left(\mathrm{u}_{\mathrm{L}}=0.07 \mathrm{~m} / \mathrm{s}\right)$ and cleaned using a gas/liquid ratio of either $0.629(\square)$ or $0.333(\bigcirc)$, with solid-arrow indicating the point of two-phase flow cleaning, and (b) two-phase flow cleaning efficiency of high $(\theta=0.629)$ and low $(\theta=0.333)$ gas/liquid ratios.

As for the influence of liquid velocity $\mathrm{u}_{\mathrm{L}}$, we investigated the development of the NPD in time over the flow cell at $0.07 \mathrm{~m} / \mathrm{s}$ and $0.27 \mathrm{~m} / \mathrm{s}$. Fig. 3.17 shows the two-phase flow cleaning efficiency for these liquid velocities. Again, the feed was $1 \mathrm{~g} / \mathrm{L} \mathrm{HA}+4 \mathrm{mM} \mathrm{CaCl}_{2}$, using spacer $B$ and a gas/liquid ratio of $\theta=0.629$.

Fig. 3.17a shows that there is first a sudden increase of the NPD of feed introduced at $u_{L}=0.07$ $\mathrm{m} / \mathrm{s}$. After around ten hours, the NPD increase levels off to a slight increase in time. The feed introduced at the higher liquid velocity of $\mathrm{u}_{\mathrm{L}}=0.27 \mathrm{~m} / \mathrm{s}$ results in a gradual and constant NPD increase. The higher liquid velocity with its higher shear stress most likely caused increased particle removal from membrane and spacer surfaces. This explains the lower NPD values compared with those observed for the lower liquid velocity. Nevertheless, more particles were gradually deposited in the feed spacer intersection over time and blocked the flow channel, thereby increasing the flow channel resistance and NPD. The greatest two-phase flow cleaning efficiency was observed (more than 90\%) for the higher liquid velocity of $\mathrm{u}_{\mathrm{L}}=0.27$ m/s (Fig. 3.17b). 

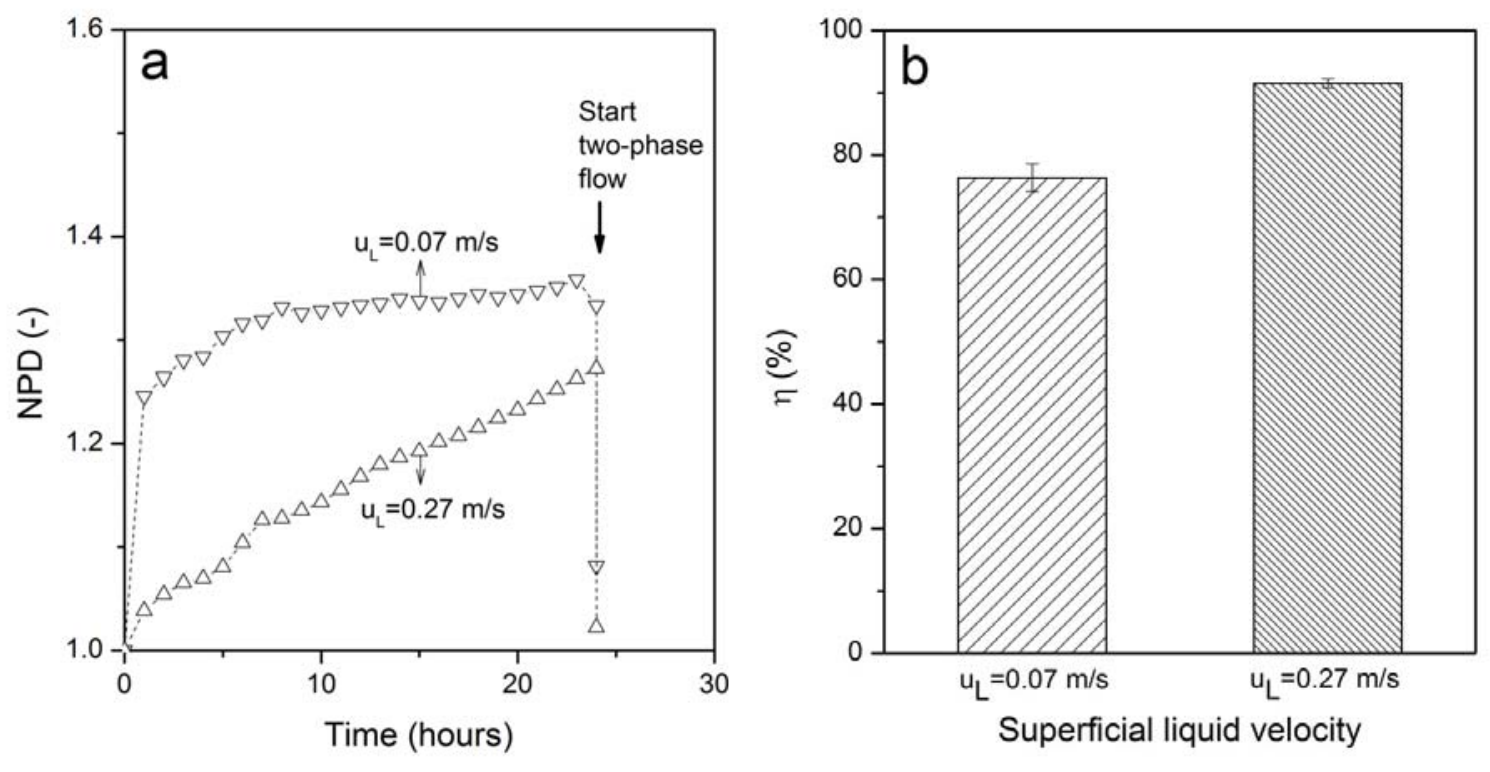

Fig. 3.17. Effect of liquid velocity on (a) the normalized pressure drop (NPD) at a liquid superficial velocity $\left(\mathrm{u}_{\mathrm{L}}\right)$ of $0.07 \mathrm{~m} / \mathrm{s}(\triangle)$ and $0.27 \mathrm{~m} / \mathrm{s}(\nabla)$, with solid arrow indicating twophase flow cleaning and (b) two-phase flow cleaning efficiency for the low $(0.07 \mathrm{~m} / \mathrm{s})$ and high $(0.27 \mathrm{~m} / \mathrm{s})$ liquid velocity. $\theta=0.629$. Feed is $1 \mathrm{~g} / \mathrm{L} \mathrm{HA}+4 \mathrm{mM} \mathrm{CaCl}_{2}$.

To confirm that the bubble velocity changed with the liquid velocity and thus influenced cleaning efficiency, we determined bubble velocity as a function of liquid velocity and gas/liquid ratios. Fig. 3.18 displays the results. The investigation was carried out with Milli-Q water and with spacer B placed in diamond orientation.

According to Fig. 3.18, the bubble velocity increases with increasing liquid velocity. At equal gas/liquid ratios $(\theta=0.629)$, a higher liquid velocity results in a higher bubble velocity which produces a higher cleaning efficiency (Fig. 3.17b). Furthermore, the higher the gas/liquid ratio, the higher bubble velocity is. Bubble velocities below $\mathrm{u}_{\mathrm{L}}=0.07 \mathrm{~m} / \mathrm{s}$, however, are not very different for both gas/liquid ratios; they differ by only about $0.1 \mathrm{~m} / \mathrm{s}$. This is why the twophase flow cleaning efficiencies as shown in Fig. $3.16 \mathrm{~b}$ at the low liquid velocity of $0.07 \mathrm{~m} / \mathrm{s}$ are almost the same.

In conclusion, both the gas/liquid ratio and the liquid velocity are important factors with regard to the efficiency of two-phase flow cleaning. 


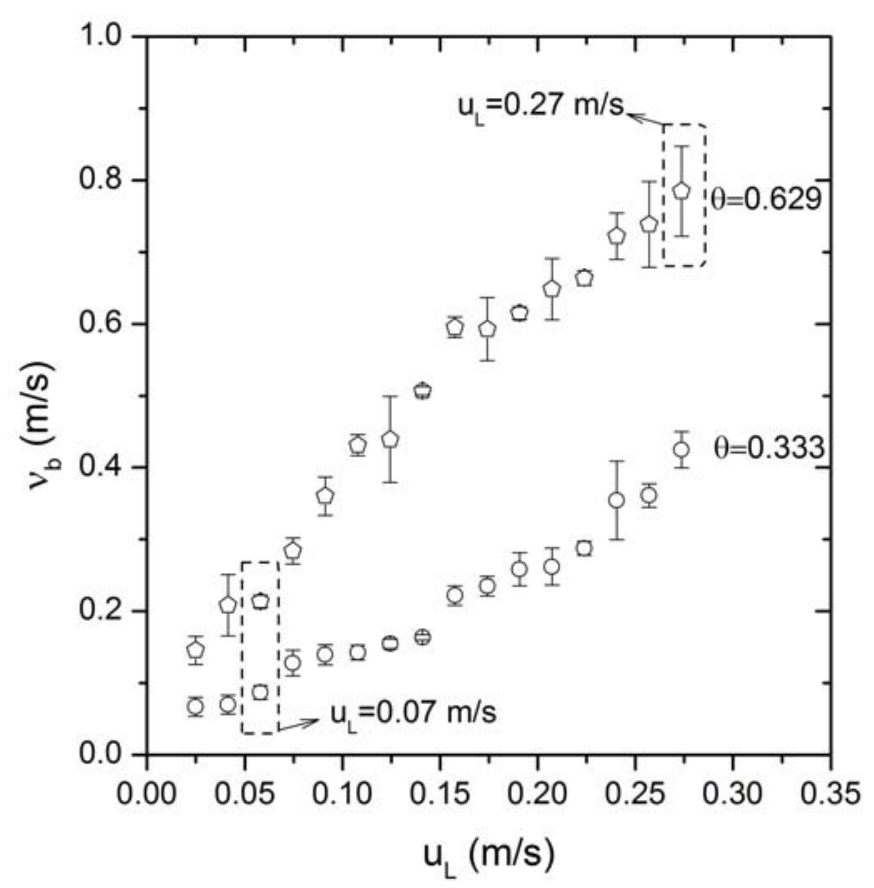

Fig. 3.18. Effect of gas/liquid ratio and liquid velocity on the bubble velocity (spacer B, diamond-oriented, $\mathrm{P}_{\text {gas }}=2$ bar).

\subsubsection{Effect of feed type}

We investigated the effect of foulant type by comparing the deposition from a bidisperse polystyrene solution (representing rigid colloidal foulants) with the deposition from a humic acid solution (macromolecules as foulants). We also studied the effect on the two-phase flow cleaning efficiency. Fig. 3.19a shows the development of the NPD in time and two-phase flow cleaning efficiency for both foulant types. The feed velocity was fixed at $\mathrm{v}_{\mathrm{L}}=0.042 \mathrm{~m} / \mathrm{s}$ $\left(\mathrm{u}_{\mathrm{L}}=0.09 \mathrm{~m} / \mathrm{s}\right)$, with spacer $\mathrm{C}$ and gas/liquid ratio $\theta=0.629$. Spacer $\mathrm{C}$ was chosen as it was found to have the highest two-phase flow cleaning efficiency (Section 3.2).

Fig. 3.19a shows that the increase of the NPD in time was higher for the bidisperse polystyrene solution than for humic acid solutions. Two factors might be responsible for this difference: particle size and interaction energy between colloidal particles and membrane surfaces. Visual observations revealed that there was more deposition of $3-\mu \mathrm{m}$ polystyrene beads than from the humic acid solutions in the feed spacer intersections. The greater deposition led to more channel blockage and increased the flow channel resistance. In the beginning, polystyrene particles were deposited in the feed spacer intersection, and in some 
cases clogged the small space between feed spacer and membrane surface. As a result, the velocity near the blockage decreased, which led to more particles being deposited in this region. Therefore, the NPD increased faster in time for polystyrene particles than for humic acid particles. The effect of the interaction energy is also important, but cannot be quantified. The only conclusion we can draw from the NPD graphs is that the larger polystyrene beads ( 3 $\mu \mathrm{m})$ resulted in a greater NPD increase than the smaller humic acid particles $(0.5 \mu \mathrm{m})$.

Fig. 3.19b depicts the effect of foulant type on the efficiency of two-phase flow cleaning. Clearly, removal of the polystyrene particles is more efficient than removal of depositions from the humic acid solutions. This can be explained when the interaction of the polystyrene particles with the membrane and spacers is weaker than that of humic acids with membrane/spacers; this would make it easier to remove the polystyrene particles compared to the humic acid depositions. Another explanation may be that larger particles undergo a greater force from the bubbles than smaller particles, and therefore are more easily removed.

It is obvious that foulant type is an important factor in the efficiency of two-phase flow cleaning. Further investigation regarding different fouling types found in spiral-wound membrane elements is essential to understand our fouling and cleaning results.
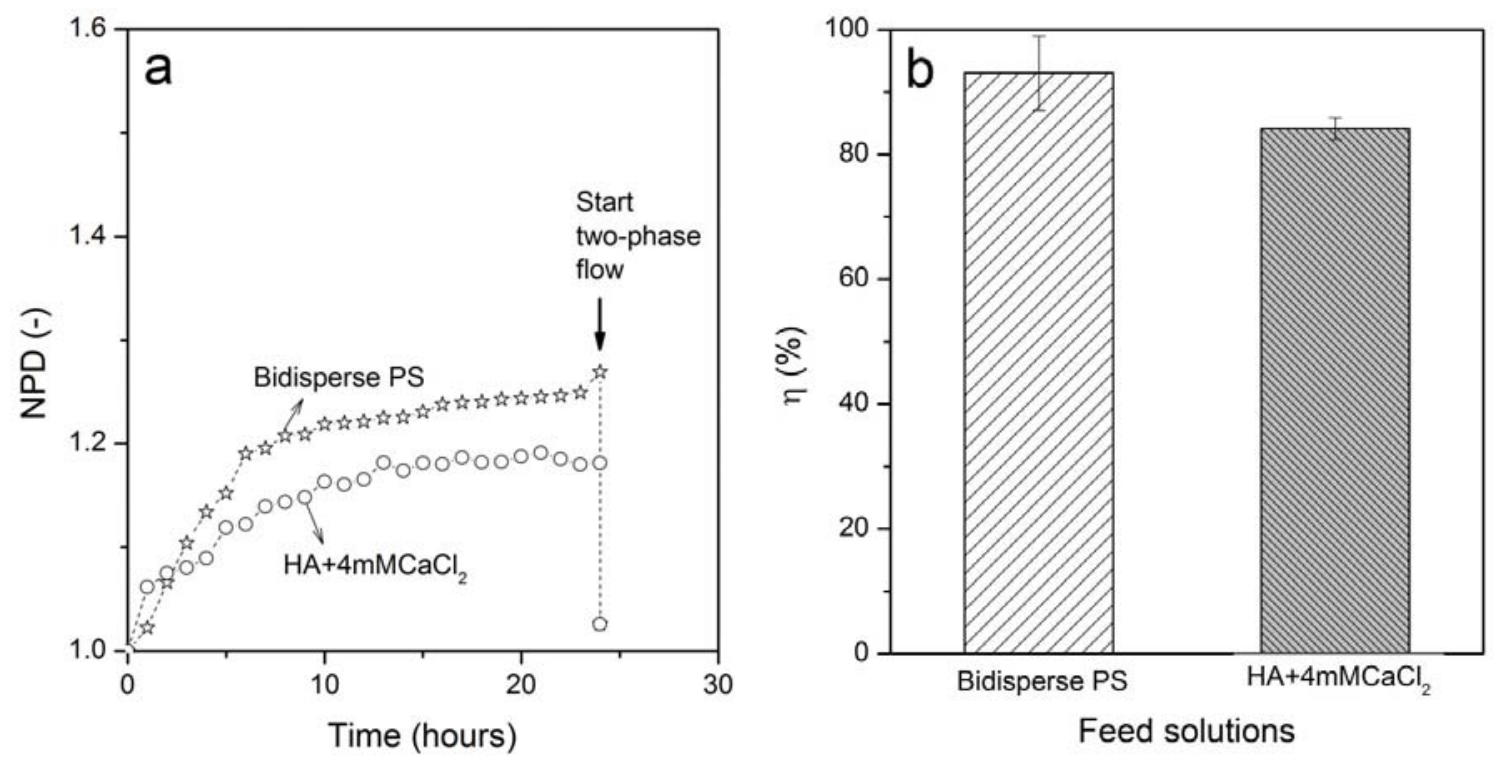

Fig. 3.19. Effect of feed type on (a) the normalized pressure drop (NPD) for bidisperse polystyrene (PS) (*) and $1 \mathrm{~g} / \mathrm{L} \mathrm{HA}+4 \mathrm{mM} \mathrm{CaCl}_{2}(\mathrm{O})$ foulants, with solid arrow indicating two-phase flow cleaning, and spacer $\mathrm{C}$, and (b) two-phase flow cleaning efficiency of bidisperse PS and $\mathrm{HA}+4 \mathrm{mM} \mathrm{CaCl} 2$ foulants. 


\subsubsection{General discussion}

We investigated several factors to elucidate which ones control the efficiency of two-phase flow cleaning, i.e. feed spacer geometry (thickness and orientation), gas/liquid ratio, liquid velocity, and feed type. We examined the fouling and cleaning stages as a function of those factors. We used the normalized feed channel pressure drop to define flow channel resistance due to fouling and cleaning and measured the efficiency of two-phase flow cleaning. Finally, we carried out in-situ direct visual observations with a high-speed camera, among other things to quantify bubble velocities.

The results show that the channel porosity and hydraulic diameter of spacer-filled channels are important factors that determine the efficiency of two-phase flow cleaning. However, bubble velocity is far more important in improving the two-phase flow cleaning efficiency, as a higher bubble velocity will exert higher shear stresses on deposited foulants. The gas/liquid ratio should be maintained in such a way that a slug-like flow pattern is formed [16] so as to generate a good bubble distribution. Channel coverage strongly depends on the geometry of the spacer-filled channel; maintaining full channel coverage by the bubbles is crucial.

These findings are relevant and potentially useful in industrial installations of spiral-wound membrane modules. To enhance the effect of two-phase flow cleaning, it may be necessary to adapt module design, by, for instance, using a thick feed spacer rather than a thinner one, or employing parallel-oriented spacers in such a way that the bubble distribution over the membrane surface is improved (e.g. by using twisted-filament spacers [44, 45] or a special design of the inlet of spiral-wound elements). During operation of two-phase flow cleaning, injecting the bubble flow with sufficient gas holdup (to manage the bubble distribution) and at a high liquid velocity (to obtain a high bubble velocity) is key. In our research, we found that colloidal-type fouling is effectively removed by two-phase flow cleaning, and macromolecular fouling slightly less well. Two-phase flow cleaning is expected to remove other types of fouling, e.g. biofouling, as well [16]. A detailed further investigation is required, using a Design of Experiment (DOE) approach, about which we reported in Chapter 6.

\subsection{Conclusions}

Two-phase flow cleaning was conducted to mitigate two types of fouling in spacer-filled membrane channels. Feed spacer geometry, gas/liquid ratio, liquid velocity, and foulant type 
all turned out to influence the efficiency of two-phase flow cleaning. The spacer geometry corresponds to channel porosity as well as to the channel's hydraulic diameter; both are critical for the performance of two-phase flow cleaning. By contrast, spacer orientation as such is not important, but does affect the liquid superficial velocity, which was found to be indirectly related to two-phase flow cleaning efficiency by its influence on bubble velocity. A further investigation using a Design of Experiments (DOE) approach is necessary to optimize two-phase flow cleaning.

\section{References}

[1] M.A. Shannon, P.W. Bohn, M. Elimelech, J.G. Georgiadis, B.J. Marinas, A.M. Mayes, Science and technology for water purification in the coming decades, Nature, 452 (2008) 301-310.

[2] T. Peters, Membrane Technology for Water Treatment, Chemical Engineering \& Technology, 33 (2010) 1233-1240.

[3] P.J. de Moel, J.Q.J.C. Verberk, J.C. van Dijk, Drinking water : principles and practices, World Scientific, New Jersey, USA, 2006.

[4] L.F. Greenlee, D.F. Lawler, B.D. Freeman, B. Marrot, P. Moulin, Reverse osmosis desalination: Water sources, technology, and today's challenges, Water Research, 43 (2009) 2317-2348.

[5] C. Fritzmann, J. Löwenberg, T. Wintgens, T. Melin, State-of-the-art of reverse osmosis desalination, Desalination, 216 (2007) 1-76.

[6] C. Tang, V. Chen, Nanofiltration of textile wastewater for water reuse, Desalination, 143 (2002) 11-20.

[7] E. Drioli, M. Romano, Progress and New Perspectives on Integrated Membrane Operations for Sustainable Industrial Growth, Industrial \& Engineering Chemistry Research, 40 (2001) 1277-1300.

[8] T.J. Larson, Reverse osmosis pilot plant operation: A spiral module concept, Desalination, 7 (1970) 187-199.

[9] J. Schwinge, P.R. Neal, D.E. Wiley, D.F. Fletcher, A.G. Fane, Spiral wound modules and spacers: Review and analysis, Journal of Membrane Science, 242 (2004) 129-153.

[10] S. Lee, J. Kim, C.H. Lee, Analysis of CaSO4 scale formation mechanism in various nanofiltration modules, Journal of Membrane Science, 163 (1999) 63-74.

[11] J.S. Vrouwenvelder, J.A.M. van Paassen, J.M.C. van Agtmaal, M.C.M. van Loosdrecht, J.C. Kruithof, A critical flux to avoid biofouling of spiral wound nanofiltration and reverse osmosis membranes: Fact or fiction?, Journal of Membrane Science, 326 (2009) 36-44.

[12] S. Lee, C.H. Lee, Scale formation in NF/RO: mechanism and control, Water Science \& Technology, 51 (2005) 267-275.

[13] L.A. Bereschenko, H. Prummel, G.J.W. Euverink, A.J.M. Stams, M.C.M. van Loosdrecht, Effect of conventional chemical treatment on the microbial population in a biofouling layer of reverse osmosis systems, Water Research, 45 (2011) 405-416.

[14] E.R. Cornelissen, J.S. Vrouwenvelder, S.G.J. Heijman, X.D. Viallefont, D. Van Der Kooij, L.P. Wessels, Periodic air/water cleaning for control of biofouling in spiral wound membrane elements, Journal of Membrane Science, 287 (2007) 94-101.

[15] E.R. Cornelissen, L. Rebour, D. van der Kooij, L.P. Wessels, Optimization of air/water cleaning (AWC) in spiral wound elements, Desalination, 236 (2009) 266-272.

[16] Y. Wibisono, E.R. Cornelissen, A.J.B. Kemperman, W.G.J. van der Meer, K. Nijmeijer, Twophase flow in membrane processes: A technology with a future, Journal of Membrane Science, 453 (2014) 566-602. 
[17] J.S. Vrouwenvelder, D.A. Graf von der Schulenburg, J.C. Kruithof, M.L. Johns, M.C.M. van Loosdrecht, Biofouling of spiral-wound nanofiltration and reverse osmosis membranes: A feed spacer problem, Water Research, 43 (2009) 583-594.

[18] G. Schock, A. Miquel, Mass transfer and pressure loss in spiral wound modules, Desalination, 64 (1987) 339-352.

[19] A.R. Da Costa, A.G. Fane, D.E. Wiley, Spacer characterization and pressure drop modelling in spacer-filled channels for ultrafiltration, Journal of Membrane Science, 87 (1994) 79-98.

[20] E.R. Cornelissen, D. Harmsen, E.F. Beerendonk, L.P. Wessels, D. Van der Kooij, Influence of permeation on air/water cleaning of spiral wound membrane NF/RO elements, J. Water Supply Res. Technol. AQUA, 59 (2010) 378-383.

[21] E.R. Cornelissen, X.D. Viallefont, E.F. Berendonk, L.P. Wessels, Air/water cleaning for control of particulate fouling, J. Water Supply Res. Technol. AQUA, 59 (2010) 120-127.

[22] C. Cabassud, S. Laborie, J.M. Laine, How slug flow can improve ultrafiltration flux in organic hollow fibres, Journal of Membrane Science, 128 (1997) 93-101.

[23] M. Mercier, C. Fonade, C. Lafforgue-Delorme, How slug flow can enhance the ultrafiltration flux in mineral tubular membranes, Journal of Membrane Science, 128 (1997) 103-113.

[24] K. Essemiani, G. Ducom, C. Cabassud, A. Line, Spherical cap bubbles in a flat sheet nanofiltration module: experiment and numerical simulation, Chem. Eng. Sci., 56 (2001) 6321-6327.

[25] J. Xu, Experimental study on gas-liquid two-phase flow regimes in rectangular channels with mini gaps, International Journal of Heat and Fluid Flow, 20 (1999) 422-428.

[26] N.V. Ndinisa, A.G. Fane, D.E. Wiley, Fouling control in a submerged flat sheet membrane system: Part I - Bubbling and hydrodynamic effects, Sep. Sci. Technol., 41 (2006) 1383-1409.

[27] P. Willems, A.J.B. Kemperman, R.G.H. Lammertink, M. Wessling, M. van Sint Annaland, N.G. Deen, J.A.M. Kuipers, W.G.J. van der Meer, Bubbles in spacers: Direct observation of bubble behavior in spacer filled membrane channels, Journal of Membrane Science, 333 (2009) 38-44.

[28] C.Y. Tang, T.H. Chong, A.G. Fane, Colloidal interactions and fouling of NF and RO membranes: A review, Advances in Colloid and Interface Science, 164 (2011) 126-143.

[29] P. Bacchin, P. Aimar, R.W. Field, Critical and sustainable fluxes: Theory, experiments and applications, Journal of Membrane Science, 281 (2006) 42-69.

[30] P.A. Araújo, J.C. Kruithof, M.C.M. Van Loosdrecht, J.S. Vrouwenvelder, The potential of standard and modified feed spacers for biofouling control, Journal of Membrane Science, 403-404 (2012) 58-70.

[31] C. Bartels, M. Wilf, W. Casey, J. Campbell, New generation of low fouling nanofiltration membranes, Desalination, 221 (2008) 158-167.

[32] J.S. Vrouwenvelder, C. Hinrichs, W.G.J. Van der Meer, M.C.M. Van Loosdrecht, J.C. Kruithof, Pressure drop increase by biofilm accumulation in spiral wound RO and NF membrane systems: role of substrate concentration, flow velocity, substrate load and flow direction, Biofouling, 25 (2009) 543555.

[33] J.S. Vrouwenvelder, C. Hinrichs, A.R. Sun, F. Royer, P.J.A.M. van, S.M. Bakker, d.M.W.G.J. van, J.C. Kruithof, L.M.C.M. van, Monitoring and control of biofouling in nanofiltration and reverse osmosis membranes, Water Sci. Technol. Water Supply, 8 (2008) 449-458.

[34] B. Derjaguin, L. Landau, Theory of the stability of strongly charged lyophobic sols and of the adhesion of strongly charged particles in solutions of electrolytes, Progress in Surface Science, 43 (1993) 30-59.

[35] E.J.W. Verwey, Theory of the Stability of Lyophobic Colloids, The Journal of Physical and Colloid Chemistry, 51 (1947) 631-636.

[36] A.J. de Kerchove, M. Elimelech, Formation of Polysaccharide Gel Layers in the Presence of Ca2+ and K+ Ions: Measurements and Mechanisms, Biomacromolecules, 8 (2007) 113-121.

[37] A.J. de Kerchove, M. Elimelech, Structural Growth and Viscoelastic Properties of Adsorbed Alginate Layers in Monovalent and Divalent Salts, Macromolecules, 39 (2006) 6558-6564.

[38] D. Nanda, K.-L. Tung, Y.-L. Li, N.-J. Lin, K.-R. Lee, C.-J. Chuang, S.-H. Huang, Effects of pH and Ionic Strength on Colloidal Fouling of Charged Nanofiltration Membranes, Journal of Chemical Engineering of Japan, 44 (2011) 476-485. 
[39] G. Singh, L. Song, Experimental correlations of $\mathrm{pH}$ and ionic strength effects on the colloidal fouling potential of silica nanoparticles in crossflow ultrafiltration, Journal of Membrane Science, 303 (2007) 112-118.

[40] W.J.C. van de Ven, K.v.t. Sant, I.G.M. Pünt, A. Zwijnenburg, A.J.B. Kemperman, W.G.J. van der Meer, M. Wessling, Hollow fiber dead-end ultrafiltration: Influence of ionic environment on filtration of alginates, Journal of Membrane Science, 308 (2008) 218-229.

[41] K. Katsoufidou, S.G. Yiantsios, A.J. Karabelas, An experimental study of UF membrane fouling by humic acid and sodium alginate solutions: the effect of backwashing on flux recovery, Desalination, 220 (2008) 214-227.

[42] W.J.C. van de Ven, I.G.M. Pünt, A. Zwijnenburg, A.J.B. Kemperman, W.G.J. van der Meer, M. Wessling, Hollow fiber ultrafiltration: The concept of partial backwashing, Journal of Membrane Science, 320 (2008) 319-324.

[43] Y. Wibisono, E.R. Cornelissen, A.J.B. Kemperman, W.G.J. Van der Meer, The effect of bubble size in air sparging to control fouling inside spacer-filled membrane channels, in: J. Pinnekamp, M. Wessling, T. Melin (Eds.) 6th IWA Specialist Conference on Membrane Technology for Water and Wastewater Treatment, International Water Association, Aachen, 2011, pp. 217-218.

[44] M.N. Chernyshov, G.W. Meindersma, A.B. de Haan, Comparison of spacers for temperature polarization reduction in air gap membrane distillation, Desalination, 183 (2005) 363-374.

[45] C. Fritzmann, M. Hausmann, M. Wiese, M. Wessling, T. Melin, Microstructured spacers for submerged membrane filtration systems, Journal of Membrane Science, 446 (2013) 189-200. 


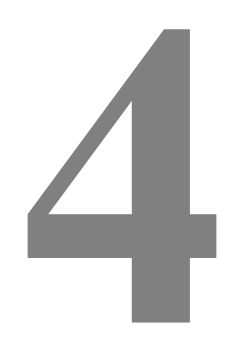

\title{
Biofouling removal in spiral-wound nanofiltration elements using two-phase flow cleaning
}

\author{
Y. Wibisono \\ K.E. El Obied \\ E.R. Cornelissen \\ A.J.B. Kemperman \\ K. Nijmeijer
}

This chapter has been submitted to Journal of Membrane Science as:

Y. Wibisono, K.E. El Obied, E.R. Cornelissen, A.J.B. Kemperman, K. Nijmeijer, Biofouling removal in spiral-wound nanofiltration elements using two-phase flow cleaning. 


\begin{abstract}
Biofouling has detrimental effects on the feed channel pressure drop and the permeate flux in high-pressure membrane processes such as NF and RO. Two-phase flow cleaning is a chemical-free technique that is able to remove such biofilms. This chapter presents a study into the effects of the gas/liquid ratio, feed spacer geometry, applied pressure and liquid velocity on the efficiency of two-phase flow cleaning in spiral-wound nanofiltration elements. A high-speed camera, optical coherence tomography and scanning electron microscopy were used to study biofouling and its removal. Our results show that two conditions must be met to ensure that a sufficiently high shear force is applied to biofilms on membrane and spacer surfaces. A good bubble distribution in the channel is the first requirement. While it is mainly the structure of the feed spacer that controls bubble flow and bubble size, a minimum gas/liquid ratio of 0.5 is necessary to achieve a good bubble distribution. The second condition is the use of a sufficiently high liquid velocity during cleaning. The bubble velocity was found to be 3.5-5.5 times as high as the used liquid velocity, and responsible for a marked improvement in the flux recovery.
\end{abstract}




\subsection{Introduction}

Biofouling is considered the biggest vulnerability of high-pressure membrane processes used for water purification, such as nanofiltration (NF) and reverse osmosis (RO). Biofouling often flourishes in filtration media and membrane systems, but inside water distribution pipes, it also poses a problem [1]. Biofouling results in operational problems such as a rapid increase of the feed channel pressure drop leading to a flux decline, and quickly reoccurs after chemical cleaning [2-4].

Biofouling in membrane processes is dominated by bacteria living in surface-associated multicellular communities known as a biofilm [5,6]. The bacteria in these biofilms are surrounded by extracellular polymeric substances (mainly polysaccharides, proteins, nucleic acids and lipids) [7]. Microorganisms are not the only cause of biofouling in membrane processes, however. Water also contains organic compounds that are for instance released into the water during an algal bloom (extracellular organic matter or EOM) or are derived from dead biomass, for example resulting from the use of biocides (autochthonous organic matter or AOM). These organic compounds constitute a nonliving form of biofouling and aggravate microbiological fouling $[8,9]$.

Traditionally, two different strategies are used to mitigate biofouling [10]. The first approach is to remove microorganisms before they enter an RO or NF system. Such a pretreatment stage (e.g. sand filtration, ultrafiltration) can be crucial to improve the quality of feed intake as it lowers the silt density index, removes algae, molds and bacteria, and decreases the concentration of total and dissolved organic carbon [11-13]. According to a market analysis, ultrafiltration pretreatment is gaining popularity in favor of conventional pretreatment, the installed ultrafiltration pretreatment capacity having exceeded 1,000,000 $\mathrm{m}^{3} / \mathrm{d}$ in 2008 [14]. However, ultrafiltration does not provide total protection against many dissolved organic compounds (notably polysaccharides and transparent exopolymer particles), and some biofouling in NF and RO system is therefore unavoidable.

The second approach is to deactivate (or kill) microorganisms chemically during a so-called "cleaning in place" or CIP treatment. Different types of chemical cleaning agents can be applied (e.g. alkaline, acids, biocides, detergents, enzymes etc.), usually suggested by the membrane manufacturer. Chemical cleaning, however, does not guarantee a flux recovery of 
$100 \%$, since it does not remove any biomass, but only deactivates it [15]. The remaining biomass will still cause operational problems, and acts as a substrate for newly attached bacteria [16]. The use of chemical cleaning agents also causes a waste problem, and frequent cleaning with aggressive agents contributes to loss of membrane integrity resulting in shorter lifetimes and an increase of operational costs [17].

A detailed study of the effects of conventional chemical treatment on the initiation and spatiotemporal development of biofouling (during short-term and long-term operation in an RO water purification plant) revealed that state-of-the-art cleaning-in-place by chemicals failed to control biofouling [18]. A combination of molecular (FISH, DGGE, clone libraries and sequencing) and microscopic (FESEM, CLSM) analyses showed that bacterial recolonization of the biofilm layers disrupted by chemical treatment starts directly after chemical cleaning by attachment and growth of primary colonizers from the intakes, and by proliferation of microorganisms that survived the chemical cleaning within the collapsed biofilm layer [18]. Microbiological studies by Costerton et al. [19] elucidated that bacteria living in such nutrient-sufficient environments are hundreds of times more resistant to antibacterial agents. Removal of all (mostly dead) biomass after a chemical cleaning is expected to prevent this rapid re-growth of biofilms [18].

Controlling the hydrodynamics around a biofilm is crucial for its disruption and detachment from surfaces [20, 21]. A novel low-cost chemical-free method for biofouling removal from membrane systems involves the use of a two-phase flow cleaning technique [22]. Two-phase flow cleaning is able to remove biofouling in spiral-wound modules, as demonstrated by a decrease in the feed channel pressure drop [23, 24]. Nevertheless, a better understanding of the underlying mechanisms of two-phase flow cleaning in various operational settings can help improve its cleaning efficiency. In this chapter, we report our findings during a study into the development of biofouling in spacer-filled rectangular flow cells simulating spiral-wound nanofiltration elements and its removal by two-phase flow cleaning.

In order to understand the development and removal of biofilms, it is important to study their development and removal in time as well as in space. The initial attachment of a biofilm occurs within minutes to hours [25], but the subsequent growth, detachment, re-growth and maturation times can be in the order of days, weeks, months and years. This depends on the 
diversity of the microbial consortia in the biofilm, nutrient inhibitors, hydrodynamics, and the geometrical characteristics of the surface to which the microorganisms are adhered [26].

These time scales are also related to a three-dimensional structure. First of all, the biofilm is heterogeneously distributed within spiral-wound membrane elements. Our scope of interest concerns three spatial scales: biofilm development and distribution in the elements including distribution of two-phase flow during biofilm removal (macroscale), the heterogeneity of a biofilm on the membrane and feed spacer surfaces (mesoscale), and observation of constituents of microbial colonies (microscale). The microscale usually is characterized by the distance between two microbial cells $(1-10 \mu \mathrm{m})$, while the mesoscale is defined by the average biofilm thickness $(10-1000 \mu \mathrm{m})[27,28]$. We therefore conducted both in-situ and ex-situ inspections of fouled membrane and spacers through use of a high-speed camera, optical coherence tomography (OCT) and scanning electron microscopy (SEM). This kind of knowledge is essential to be able to draw up guidelines for optimal biofouling removal using the two-phase flow cleaning technique and provide more insight regarding its practical applicability in large-scale installations.

\subsection{Theory}

\subsubsection{Increase of the feed channel pressure drop (FCP)}

Two types of pressure differences can be distinguished in membrane systems: the feed channel pressure drop (FCP) and the trans-membrane pressure drop or difference, also called trans-membrane pressure (TMP). The TMP results from the feed pressure and is the pressure difference between the feed side and the permeate side, applied to overcome the total resistance across the membrane. The FCP is the pressure difference between channel inlet and channel outlet due to the hydraulic resistance of the channel. The FCP is commonly described in terms of the dimensionless friction factor $(\lambda)$ and the Reynolds number $(\mathrm{Re})$. The empirical constants relating these two parameters depend on the characteristics of the feed channel and on the flow type (laminar or turbulent) of the fluid in the channel. In spiral-wound elements, the latter is determined by the type of feed spacer used (commonly diamond-mesh extruded netting). 
The FCP in spacer-filled channels can be expressed by Eqs. (4.1) - (4.3) [29]:

$$
F C P=\Delta P=\lambda \cdot \frac{\rho u^{2}}{2} \cdot \frac{L}{d_{h}}
$$

$\lambda=6.23 \operatorname{Re}^{-0.3}$

$\operatorname{Re}=\frac{\rho \cdot d_{h} \cdot u}{\mu}$

where $\Delta \mathrm{P}$ is the pressure drop $(\mathrm{Pa}), \rho$ is the liquid density $\left(\mathrm{kg} / \mathrm{m}^{3}\right), \mathrm{d}_{\mathrm{h}}$ is the hydraulic diameter of the channel $(\mathrm{m}), \mathrm{u}$ is the specific liquid velocity $(\mathrm{m} / \mathrm{s}), \mu$ is the liquid dynamic viscosity (Pa $\mathrm{s})$ and $\mathrm{L}$ is the length of the spacer-filled channel (m). Eq. (4.2) is valid for $100<\operatorname{Re}<1000$ and all types of feed spacer.

The presence of feed spacers reduces the porosity $(\varepsilon)$ or void volume in the channel, resulting in a higher specific velocity when compared with an empty channel, as follows:

$$
u=\frac{\phi}{\varepsilon \cdot W \cdot H}
$$

where $\phi$ is the volumetric flow rate $\left(\mathrm{m}^{3} / \mathrm{s}\right)$, and $\mathrm{W}$ and $\mathrm{H}$ are the feed channel width and height, respectively $(\mathrm{m})$. The porosity of the feed spacer and hydraulic diameter are estimated by using Eqs. (4.5) and (4.6), respectively [29]:

$$
\begin{aligned}
& \varepsilon=1-\frac{V_{s p}}{V_{t o t}} \\
& d_{h}=\frac{4 \cdot \varepsilon}{\frac{2}{H}+(1-\varepsilon) \cdot \frac{4}{d_{f}}}
\end{aligned}
$$

where $V_{\text {sp }}$ is the spacer volume $\left(\mathrm{m}^{3}\right)$ and $V_{\text {tot }}$ the total volume of the feed channel $\left(\mathrm{m}^{3}\right)$.

In the case of a diamond-shaped spacer with a $90^{\circ}$ angle, such as used in spiral-wound elements, the following two equations from Schock and Miquel [29] can be used:

$$
V_{s p}=\frac{\pi}{2} d_{f}^{2} L_{f}
$$




$$
V_{t o t}=H L_{f}^{2}
$$

in which $d_{f}$ is the diameter of the feed spacer filament $(m)$, and $L_{f}$ is the length of the feed spacer filament (m).

As the biofilm attaches and grows in the spacer-filled channel, the channel's porosity and hydraulic diameter decrease which results in an increase in the specific velocity and the FCP. This strongly affects the flow distribution. The increased pressure drop in the feed channel also leads to a reduction of the trans-membrane pressure, hence reducing permeability. A typical threshold above which operational problems occur in industrial systems is an increase of $15 \%$ of the FCP over the entire installation [16].

\subsubsection{FCP increase thresholds during fouling in spiral-wound elements}

For the anaerobic NF pilot system of water supply company Vitens (Spannenburg plant, the Netherlands) operating on ground water, the pressure drop increase over the lead element can be up to $100 \%$ in conditions of biofouling [30]. This increase is not equally distributed over the length of the spiral-wound membrane element, but occurs mainly in the first half [16]. Thus, the pressure drop increase per unit length is higher adjacent to the element inlet than at the outlet. This means that using a $100 \%$ increase in the FCP for a fouling simulator (flow cell) shorter than $1 \mathrm{~m}$ (a typical length for a spiral-wound membrane element) would not reflect the amount of biomass in the spiral-wound element accurately. Therefore, a better approximation of the FCP increase in the flow cell is needed.

For the clean system with no fouling, the pressure drop per unit length is the same in any segment or section of the spiral-wound element, as there is no change in the porosity:

$$
\frac{\Delta P_{0}}{L_{0}}=\frac{\Delta P_{0, s}}{L_{s}}
$$

In this equation, $\Delta \mathrm{P}_{0}$ is the pressure drop over the entire clean element or initial pressure drop, $\Delta \mathrm{P}_{0, \mathrm{~s}}$ is the initial pressure drop over a section of the entire element, $\mathrm{L}_{0}$ is the length of the entire element and $L_{s}$ is the length of the inlet section of the element (see Fig. 4.1). 


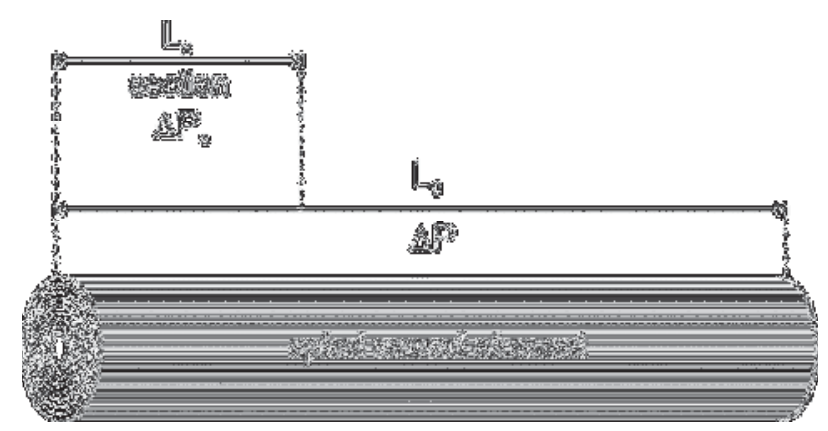

Fig. 4.1. Overview of feed channel pressure drop behavior in the lead element of spiral-wound membrane modules.

As mentioned, the pressure drop increase in conditions of biofouling often occurs only or mainly in the first section of the element $[16,24]$. Thus, the total pressure drop over the element $(\Delta \mathrm{P})$ is the summation of the pressure drop over the fouled section $\left(\Delta \mathrm{P}_{\mathrm{s}}\right)$ and the initial pressure drop over the remaining part:

$\Delta P=\Delta P_{s}+\Delta P_{0} \cdot\left(\frac{L_{0}-L_{s}}{L_{0}}\right)$

Rearranging Eqs. (4.9) and (4.10) and use of $x=\frac{L_{s}}{L_{0}}$ yields Eq. (4.11):

$\frac{\Delta P_{s}}{\Delta P_{s, 0}}=\frac{\Delta P-(1-x) \cdot \Delta P_{0}}{x \cdot \Delta P_{0}}=\frac{\frac{\Delta P}{\Delta P_{0}}-(1-x)}{x}$

This means that for an increase of $100 \%$ over the total element $\left(\Delta \mathrm{P}=2 \Delta \mathrm{P}_{0}\right)$ with fouling concentrated in $1 / 3$ to $1 / 2$ of the total length of the element, the estimated increase for the fouled section is between $300 \%$ and $200 \%$, respectively.

\subsubsection{Flux decline}

The flux of water through a membrane is expressed in terms of the total driving force and total resistance of the membrane, and can be formulated as:

$J_{v}=\frac{T M P-\Delta \pi}{\mu R_{t}}$ 
where $\Delta \pi$ is the osmotic pressure difference between the feed and permeate side $(\mathrm{Pa})$ and $\mathrm{R}_{\mathrm{t}}$ is the total resistance $\left(\mathrm{m}^{-1}\right)$.

Since the pressure in the feed channel changes, the TMP also changes from inlet to outlet in the elements. It usually is estimated based on the average pressure on the feed side:

$T M P=\frac{P_{\text {in }}+P_{\text {out }}}{2}-P_{\text {perm }}$

where $\mathrm{P}_{\text {in }}$ is the pressure at the inlet of the feed channel $(\mathrm{Pa}), \mathrm{P}_{\text {out }}$ is the pressure at the outlet of the feed channel $(\mathrm{Pa})$ and $\mathrm{P}_{\text {perm }}$ is the pressure on the permeate side $(\mathrm{Pa})$.

The osmotic pressure can be estimated using the Van 't Hoff equation [31] :

$\Delta \pi=i \cdot\left(c_{m}-c_{p e r m}\right) \cdot R \cdot T$

where $i$ is the Van 't Hoff factor of the solute (-), $\mathrm{c}_{\mathrm{m}}$ is the molar concentration of ions at the membrane on the feed side $\left(\mathrm{mol} / \mathrm{m}^{3}\right), \mathrm{c}_{\text {perm }}$ is the molar concentration of ions at the membrane on the permeate side $\left(\mathrm{mol} / \mathrm{m}^{3}\right), \mathrm{R}$ is the ideal gas constant $(8.314 \mathrm{~J} / \mathrm{mol} \cdot \mathrm{K})$ and $\mathrm{T}$ is the absolute temperature $(\mathrm{K})$.

The total resistance $\left(\mathrm{R}_{\mathrm{t}}\right)$ is the summation of all resistances across the membrane, which include the membrane resistance $\left(R_{m}\right)$, the fouling resistance $\left(R_{f}\right)$ and the resistance due to concentration polarization $\left(\mathrm{R}_{\mathrm{cp}}\right)$.

The flux decline due to biofouling can be attributed to three mechanisms working at the same time [16, 32]: (i) a reduction in the overall driving force due to the FCP increase, (ii) the increase in total resistance $\left(\mathrm{R}_{\mathrm{t}}\right)$ due to an increased fouling resistance $\left(\mathrm{R}_{\mathrm{f}}\right)$, and (iii) a reduction in the driving force for water transport due an increase in the osmotic pressure. The latter is also known as the biofilm-enhanced osmotic pressure or BEOP [33]. As the FCP increases, the outlet pressure decreases, which results in a smaller TMP according to Eq. (4.13). The second mechanism means that when the biofilm covers a large fraction of the total surface area of the membrane, it can act as a "second membrane" (an additional resistance layer), increasing the total resistance. The degree to which the flux is affected depends on the relative values of the membrane and biofilm resistance. The membrane resistance depends on the type of membrane (RO or NF). The resistance of a biofilm is dynamic, meaning that for the same biofilm thickness, the resistance changes depending on the applied TMP. This suggests that 
the biofilm's hydrogel (its matrix of extracellular polymeric substances) compacts under a higher TMP, resulting in a greater resistance [34]. If the osmotic pressure offers a significant resistance to the flux (e.g. in $\mathrm{RO}$ ), the presence of a biofilm layer on the membrane leads to an increase in solute concentrations at the membrane surface [32, 33]. As Eq. (4.14) shows, these higher concentrations result in higher osmotic pressures, which reduces the water permeate flux accordingly.

Which mechanism dominates the flux decline due to biofouling depends strongly on the membrane type and process conditions. The work of Vrouwenvelder et al. [35] on a full-scale NF installation showed that biofouling not only occurs mainly in the first half of an element [30], but also mainly in the lead element (the first element in the first pressure vessel). This means that subsequent elements are covered by a less significant biofilm layer, and thus the biofilm resistance and biofilm-enhanced osmotic pressure do not have a significant effect on the flux in those elements. In these subsequent elements, therefore only the FCP increase is affecting the flux. From this rationale, it is clear that the flux decline in a membrane installation is not as straightforward as the FCP increase. In addition, Vrouwenvelder et al. [16] have shown that there is a strong relation between biomass concentration and the normalized increase in feed channel pressure drop. This makes the FCP increase a powerful tool for determining the degree of biofouling in spiral-wound elements. It must be noted, however, that the FCP increase is strongly related to biofilms present on the feed spacer and mostly reflects their contribution to the biofouling problem, but does not provide much insight regarding the presence of biofilms on the membrane surface [36].

\subsubsection{Normalized water flux}

The average volumetric flux $\left(\mathrm{J}_{\mathrm{V}}\right)$ is calculated according to Eq. (4.15):

$$
J_{v}=\frac{\dot{m}}{\rho_{W} \cdot A_{m}}\left(\frac{L}{m^{2} \cdot h}\right)
$$

where $\dot{m}$ is the mass flow rate $(\mathrm{kg} / \mathrm{h}), \rho_{\mathrm{w}}$ is the density of water $(1 \mathrm{~kg} / \mathrm{L})$ and $\mathrm{A}_{\mathrm{m}}$ is the membrane area $\left(\mathrm{m}^{2}\right)$. 
The flux is reported as a permeability or mass transfer coefficient (MTC), which is the flux normalized for pressure and temperature, and is defined as:

$$
M T C=\frac{J_{v}}{T M P} \cdot \frac{10^{-11}}{3.6}\left(\frac{m}{P a \cdot s}\right)
$$

The TMP is averaged over the inlet and outlet pressures of the flow cell; see Eq. (4.13). For all experiments described here, the pressure on the permeate side was atmospheric $\left(\mathrm{P}_{\mathrm{perm}}=0\right.$ barg) and $\mathrm{P}_{\text {out }}$ was kept at $600 \mathrm{kPag}$. The final pressure drop (200-300\% increase) is relatively small when compared with $\mathrm{P}_{\text {out }}\left(\Delta \mathrm{P}_{\max }=20 \mathrm{kPa}\right)$. Eq. (4.13) therefore can be simplified to Eq. (4.17):

$$
T M P=P_{\text {out }}+\frac{\Delta P}{2} \approx P_{\text {out }}
$$

The use of Eq. (4.17) instead of Eq. (4.13) for the experimental conditions applied, results in a deviation of only $\pm 1.7 \%$.

\subsubsection{Concentration of nutrient solution}

To enhance the development of biofouling in the flow cells, we added nutrients to the feed water. We used Eq. (4.18) to calculate the concentration of the nutrient solution:

$$
c_{d}=\left(\frac{\phi_{f}}{\phi_{d}}\right) \cdot c_{f}
$$

where $c_{d}$ and $c_{f}$ are the concentration of carbon $(\mathrm{mg} \mathrm{C} / \mathrm{L})$ in the dosing bottle and the flow cells, respectively. $\phi_{d}$ is the flow rate of the dosing pump and $\phi_{f}$ is the total flow rate through the cells $(\mathrm{L} / \mathrm{h})$.

\subsubsection{Gas/liquid ratio}

During two-phase flow cleaning used to mitigate biofouling, the gas/liquid ratio is one of the important factors affecting the recoveries of the FCP and the flux [22]. The gas/liquid ratio $(\theta)$ used during two-phase flow cleaning is defined as: 


$$
\theta=\frac{\phi_{G}}{\phi_{G}+\phi_{L}}
$$

where $\phi_{G}$ is the actual gas flow rate $(\mathrm{L} / \mathrm{h})$ and $\phi_{L}$ is the actual liquid flow rate $(\mathrm{L} / \mathrm{h})$.

\subsubsection{Efficiency of two-phase flow cleaning}

To quantify the cleaning efficiency, we used both the FCP and the MTC. For the FCP, the efficiency is based on the recovery of the pressure drop to the initial pressure drop:

$\eta_{F C P}=\frac{\Delta P_{\text {fouled }}-\Delta P_{\text {cleaned }}}{\Delta P_{\text {fouled }}-\Delta P_{0}} \cdot 100 \%$

where $\Delta \mathrm{P}_{0}$ is the initial pressure drop at day $0, \Delta \mathrm{P}_{\text {fouled }}$ is the final pressure drop just before cleaning (approximately 300\% increased; see Section 4.2.2) and $\Delta \mathrm{P}_{\text {cleaned }}$ is the pressure drop after cleaning.

A similar approach was taken for the flux recovery, using the MTC. For $\mathrm{MTC}_{0}$, we used the value of the stabilized clean water flux during the membrane compaction experiment as reference, according to Eq. (4.21):

$\eta_{M T C}=\frac{M T C_{\text {fouled }}-M T C_{\text {cleaned }}}{M T C_{\text {fouled }}-M T C_{0}} \cdot 100 \%$

where $\mathrm{MTC}_{0}$ is the initial MTC (clean water flux during the compaction experiment), $\mathrm{MTC}_{\text {fouled }}$ is the final MTC before cleaning, and $\mathrm{MTC}_{\text {cleaned }}$ is the MTC after cleaning.

From the flux measurements, the resistance of the biofilm $\left(\mathrm{R}_{\text {biofilm }}\right.$, in $\left.\mathrm{m}^{-1}\right)$ can be estimated based on the difference between the total resistance $\left(\mathrm{R}_{\mathrm{t}}\right)$ in the presence of biofouling and the membrane resistance $\left(\mathrm{R}_{\mathrm{m}}\right)$ [34]:

$$
R_{\text {biofilm }}=R_{t}-R_{m}=\frac{1}{\mu} \cdot\left[\frac{1}{M T C_{\text {fouled }}}-\frac{1}{M T C_{0}}\right]
$$




\subsubsection{Bubble velocity}

The average bubble velocity can be calculated from the time required for the bubble front to travel a defined distance in the cell from the inlet to outlet. We used a high-speed camera to estimate this velocity according to Eq. (4.23):

$v_{b}=\frac{F}{N_{F}} \cdot L_{c}(\mathrm{~m} / \mathrm{s})$

where $\mathrm{F}$ is the frame rate at which the image sequence was recorded (fps) and $\mathrm{N}_{\mathrm{F}}$ is the total number of frames it takes the bubble to travel over a defined distance $\mathrm{L}_{c}(\mathrm{~m})$.

\subsection{Material and methods}

\subsubsection{Materials}

NF membranes (ESNA1-LF2 Hydranautics, Oceanside, California, USA) were used instead of RO membranes to limit the effect of osmotic pressure during biofouling growth and removal. The ESNA1-LF2 membrane is a thin-film composite polyamide membrane used in water purification and desalination systems. The permeate spacer was also provided by Hydranautics (Oceanside, California, USA). We obtained samples of diamond-shaped feed spacers from Naltex (Delstar Inc.). This type of feed spacer is a net-type extruded spacer commonly used in practice. Table 4.1 lists the properties of our spacer samples; we calculated the porosity and hydraulic diameter from Eqs. (4.5)-(4.8). Sodium acetate $\left(\mathrm{CH}_{3} \mathrm{COONa}\right)$, sodium nitrate $\left(\mathrm{NaNO}_{3}\right)$, anhydrous monobasic sodium phosphate $\left(\mathrm{NaH}_{2} \mathrm{PO}_{4}\right)$ and sodium hydroxide $(\mathrm{NaOH})$ were purchased from Sigma-Aldrich (Germany) and used as received.

Table 4.1. Feed spacer properties

\begin{tabular}{|c|c|c|c|c|c|}
\hline Spacer & Thickness (mm) & Material & Filament angle & Porosity $^{\#}$ & $\begin{array}{c}\text { Hydraulic } \\
\text { diameter }^{\#}(\mathbf{m m})\end{array}$ \\
\hline$\overline{\mathbf{A}}$ & 0.71 & Polypropylene & $90^{\circ}$ & 0.91 & 0.910 \\
\hline $\mathbf{B}$ & 0.51 & Polypropylene & $90^{\circ}$ & 0.85 & 0.557 \\
\hline
\end{tabular}

\subsubsection{Two-phase flow nanofiltration setup}

Fig. 4.2 shows a schematic diagram of the experimental setup. 


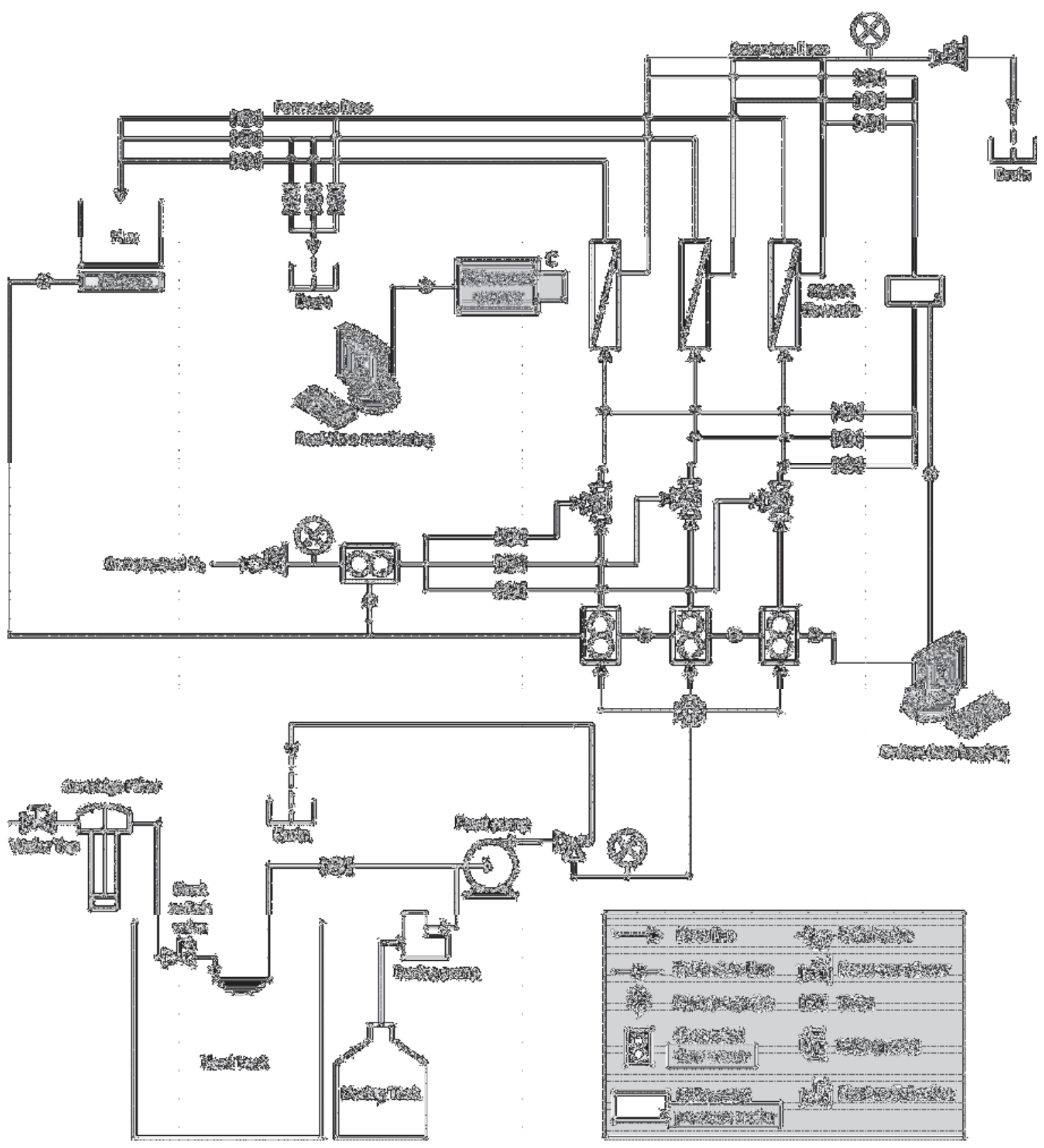

Fig. 4.2. Two-phase flow nanofiltration setup.

The feed water (tap water) was passed through a cartridge filter (1-3 $\mu \mathrm{m}$ wound polypropylene, PX01-10, Purtrex, USA). The filtered water was stored in a 60-liter tank equipped with a floater to control the water level. The tank maintained the water temperature at close to room temperature. After the tank, nutrients were added from a concentrated solution by using a peristaltic pump (Masterflex L/S pumps, Cole-Palmer Instrument Company, USA). The nutrient-rich water was further pumped and equally divided into three 
lines using a special high-pressure feed pump (Micropump GAF series, Micropump Inc., Canada: maximum flow rate $25 \mathrm{~L} / \mathrm{h}$, maximum differential pressure $1600 \mathrm{kPa}$ ). The flow rate through each line was controlled with a mass flow controller (Cori-Flow, Bronkhorst, the Netherlands: $10 \pm 0.02 \mathrm{~L} / \mathrm{h} \max$ ). Each line flowed through a vertically positioned flow cell that was shielded from direct light and simulated a spiral-wound membrane element. The pressure drop across the feed channel of the flow cell was monitored using a differential pressure sensor (EL-Press, Bronkhorst, the Netherlands: $\Delta \mathrm{P} \max =100 \pm 0.5 \mathrm{kPa}$ ). The flux was measured using a balance (Mettler-Toledo P3002). The feed side pressure (TMP) in the flow cells was controlled by a pressure reducer at the outlet. The retentate and permeate were discharged without recirculating the water. Nitrogen gas was introduced in the liquid line just before the cells, using a mass flow controller (EL-Flow, Bronkhorst, the Netherlands: $\left.500 \pm 0.25 \mathrm{~mL}_{\mathrm{n}} / \mathrm{min}\right)$.

\subsubsection{Flow cell simulator}

Fig. 4.3 shows the flow cell simulator we used in this study.
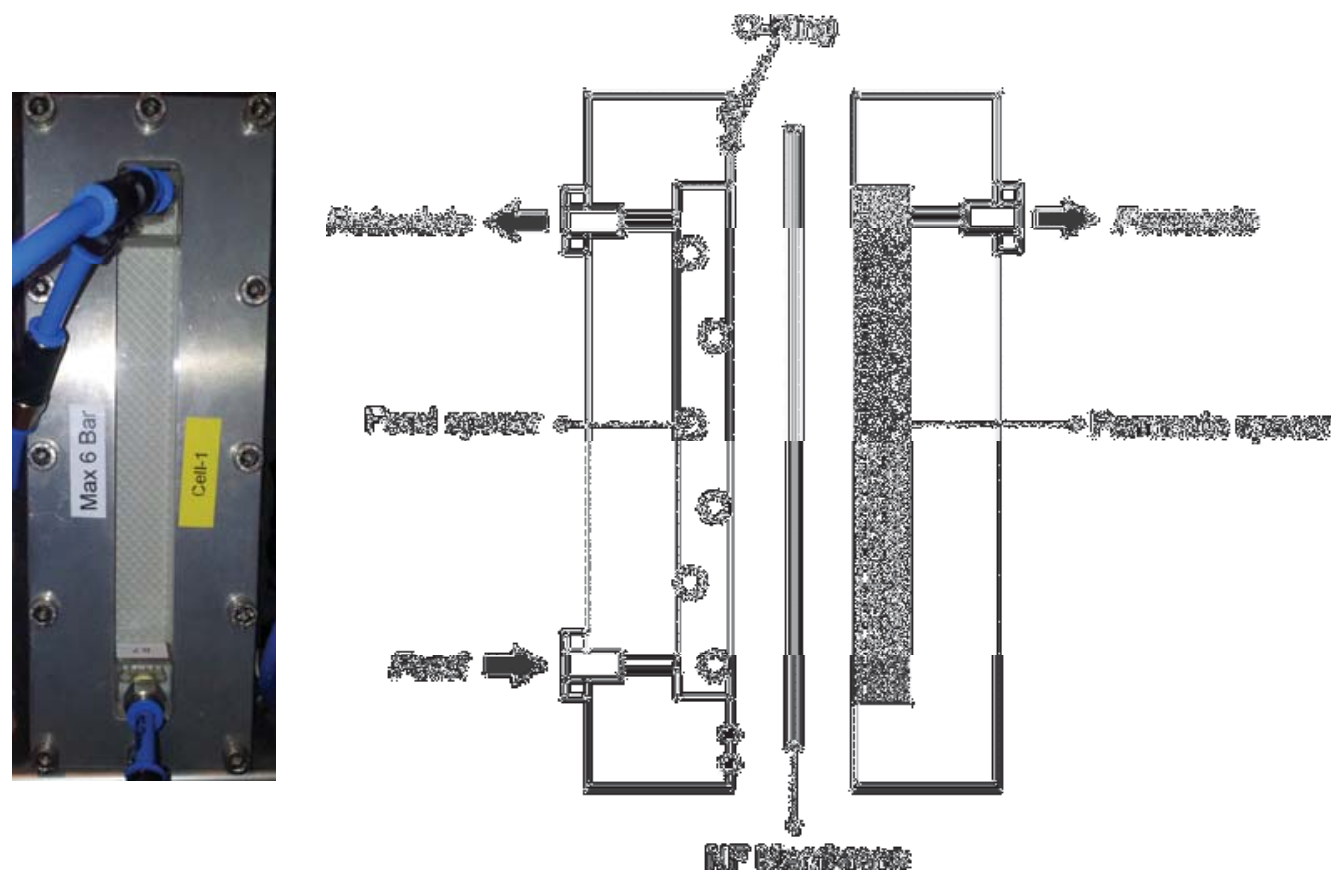

Fig. 4.3. PMMA flow cell simulators: front view of a flow cell with the stainless steel frame designed for moderate pressures up to $600 \mathrm{kPag}$ (left) and a schematic diagram of the flow cell simulator assembly without the metallic frame (right). 
The flow cells were custom-made in-house from transparent poly(methyl methacrylate) (PMMA) with a stainless steel frame to allow operation at moderate feed pressures (maximum operating pressure of $600 \mathrm{kPag}$ ). The feed channel was $2 \mathrm{~cm}$ wide and $17 \mathrm{~cm}$ long; six 1-mm holes at distances of $2 \mathrm{~mm}$ were used to distribute the flow evenly over the width of the channel at both the inlet and outlet. We used two types of flow cell, with different feed channel heights depending on the thickness of the feed spacer. A permeate spacer was placed in the permeate channel of the cell.

\subsubsection{Preliminary experiments}

We first conducted preliminary experiments to determine (a) the actual feed channel pressure drop across the spacer-filled flow cell compared with values calculated with Eq. (4.1) as derived from practice, (b) membrane compaction due to the trans-membrane pressure, using deionized water with a conductivity below $1 \mu \mathrm{S} / \mathrm{cm}$ (Milli-Q, Millipore USA), and (c) the bubble coverage and distribution in an empty and spacer-filled channel using a high-speed camera to find the optimum gas/liquid ratio. No nutrients were supplied, but the other operating conditions were similar to those of the main experiments (see Table 4.2 and also Section 4.1).

\subsubsection{Protocols main experiments}

Each main experiment consisted of two stages: (1) a fouling stage, in which the biofilm was allowed to develop on the membrane and spacer until a 300\% FCP increase over the feed channel was reached, and (2) a cleaning stage, in which the gas/liquid two-phase flow was introduced in the fouled cells. The required flow rate was set using the mass flow controllers and the pump speed. All experiments were conducted at a constant TMP; a pressure reducer was used to maintain the pressure at the outlet of the flow cells at $600 \mathrm{kPag}$.

Fresh NF membranes and feed spacers were used in each experiment. Before use, the membranes were soaked in Milli-Q water overnight to remove any preservation liquid; the feed spacers were used as received. The flow cells were properly closed and covered with black opaque foam to minimize the growth of phototrophic organisms (e.g. algae). 
During the fouling stage, the pump speed and outlet pressure were checked at least two times per day to ensure that the specific liquid velocity and TMP were maintained. The FCP and flux were recorded at least once per day for each flow cell; a valve network was used to switch between the different cells to perform the measurements. The temperature of the feed water was also recorded daily. Once the FCP of a specific flow cell had increased by approximately $300 \%$ relative to its initial value (see explanation in Section 4.2.2), the fouling stage was considered completed and the cleaning stage was started.

At the start of a cleaning stage, the flow through the two other cells was stopped, and their inlet and outlet valves were closed; we observed no change in FCP and flux. We then set the required conditions of gas/liquid ratio, specific liquid velocity and pressure for the cell to be cleaned. It was important that the pressure of the gas line was as close as possible to that of the liquid line before introducing the gas. A high pressure difference would mean a sudden shock due to the release of the gas. To avoid this, we released the gas into the atmosphere first; once a stable flow was reached at the required pressure, we introduced the gas into the designated cell. High-speed camera recording was started just before introducing the gas. During earlier preliminary studies (FCP measurements and visual observation of the membrane surface) we learned that most fluffy-type biofouling was removed by two-phase flow cleaning within 45 minutes. We therefore used a cleaning duration of 45 minutes for each flow cell for all experiments.

After completion of the cleaning, we restored the operating conditions to those of the fouling stage and measured the flux and FCP for all three cells (cleaned and not cleaned). This ensured that no changes had occurred to the other (not cleaned) flow cells. The system was then stopped again to remove the cleaned flow cell and replace it with a quick fit connection, after which fouling of the two remaining flow cells was allowed to continue. Cleaning was carried out each time the increase in FCP in a cell reached approximately $300 \%$.

Once an experiment was completed, we scrubbed the flow cells with dishwashing detergent and properly rinsed them with deionized water. The tubing and mass flow controllers were cleaned in two steps. We first recirculated an $\mathrm{NaOH}$ solution at $\mathrm{pH} 11.5$ for two hours [15], after which we introduced a two-phase nitrogen/water stream just before the mass flow controller of each individual line, and let it run for about $15 \mathrm{~min}$. Next, we flushed the systems (without the flow cells) with tap water. This procedure stripped all biofouling from previous 
experiments from the system so as to prevent that fouling caused by the previous test would affect the subsequent experimental run.

\subsubsection{Nutrient dosing}

The nutrients added during the fouling stage were sodium acetate $\left(\mathrm{CH}_{3} \mathrm{COONa}\right)$ to provide $\mathrm{C}$, sodium nitrate $\left(\mathrm{NaNO}_{3}\right)$ for $\mathrm{N}$, and anhydrous monobasic sodium phosphate $\left(\mathrm{NaH}_{2} \mathrm{PO}_{4}\right)$ for $\mathrm{P}$. They were introduced in a molar ratio of $\mathrm{C}: \mathrm{N}: \mathrm{P}=100: 20: 10$. This combination is often used to enhance biofouling growth and avoids nutrient limitation [37, 38]. The nutrients were added from a 2-liter dosing bottle at a fixed flow rate of $0.036 \mathrm{~L} / \mathrm{h}$ to meet the concentration of the dosing solution as calculated using Eq. (4.18).

A high nutrient concentration of $1 \mathrm{mg}$ Ac-C /L (comparable to a typical assimilable organic carbon level of $10 \mu \mathrm{g}$ Ac-C $/ \mathrm{L}$ as found in wastewater) was selected to accelerate biofilm growth, aiming at an experimental duration of five to six days. We assumed that the tap water did not significantly contribute to the amount of nutrients. To restrict bacterial growth in the dosing bottle, we used sodium hydroxide to increase the $\mathrm{pH}$ of the dosing solution to 11 . The $\mathrm{pH}$ of the feed water, however, did not change and remained approximately 7.8. We checked the dosage daily by measuring the weight of the bottle and prepared a fresh dosing stock solution every two days.

\subsubsection{Liquid velocity and gas/liquid ratio}

The conditions we used during the fouling stages (in term of cross-flow velocity and spacer geometry) are common for the lead elements in industrial installations [39], namely a constant liquid velocity $\left(\mathrm{u}_{\mathrm{L}}\right)$ of $0.11 \mathrm{~m} / \mathrm{s}$ during fouling and $0.11-0.44 \mathrm{~m} / \mathrm{s}$ during cleaning. As a slug flow provides greater shear forces and improves the cleaning performance of two-phase flow cleaning [22], we operated at conditions close to those that induced slug flow in the empty channel (as determined in the preliminary experiments; see Section 4.4.1), namely a gas/liquid ratio $(\theta)$ of 0.5 or 0.8 . The gas flow set by the mass flow controller is defined for $0^{\circ} \mathrm{C}$ and 1 atm; we used the ideal gas law to correct for this and obtain the actual gas flow. 


\subsubsection{Summary of experimental conditions}

Table 4.2 summarizes the conditions used during the (main) fouling experiments.

Table 4.2. Overview of the main experiments. In the fouling stage of all experiments, the dosing concentration was $1 \mathrm{mg} \mathrm{Ac}-\mathrm{C} / \mathrm{L}$ and the outlet TMP was constant at $600 \mathrm{kPag}$.

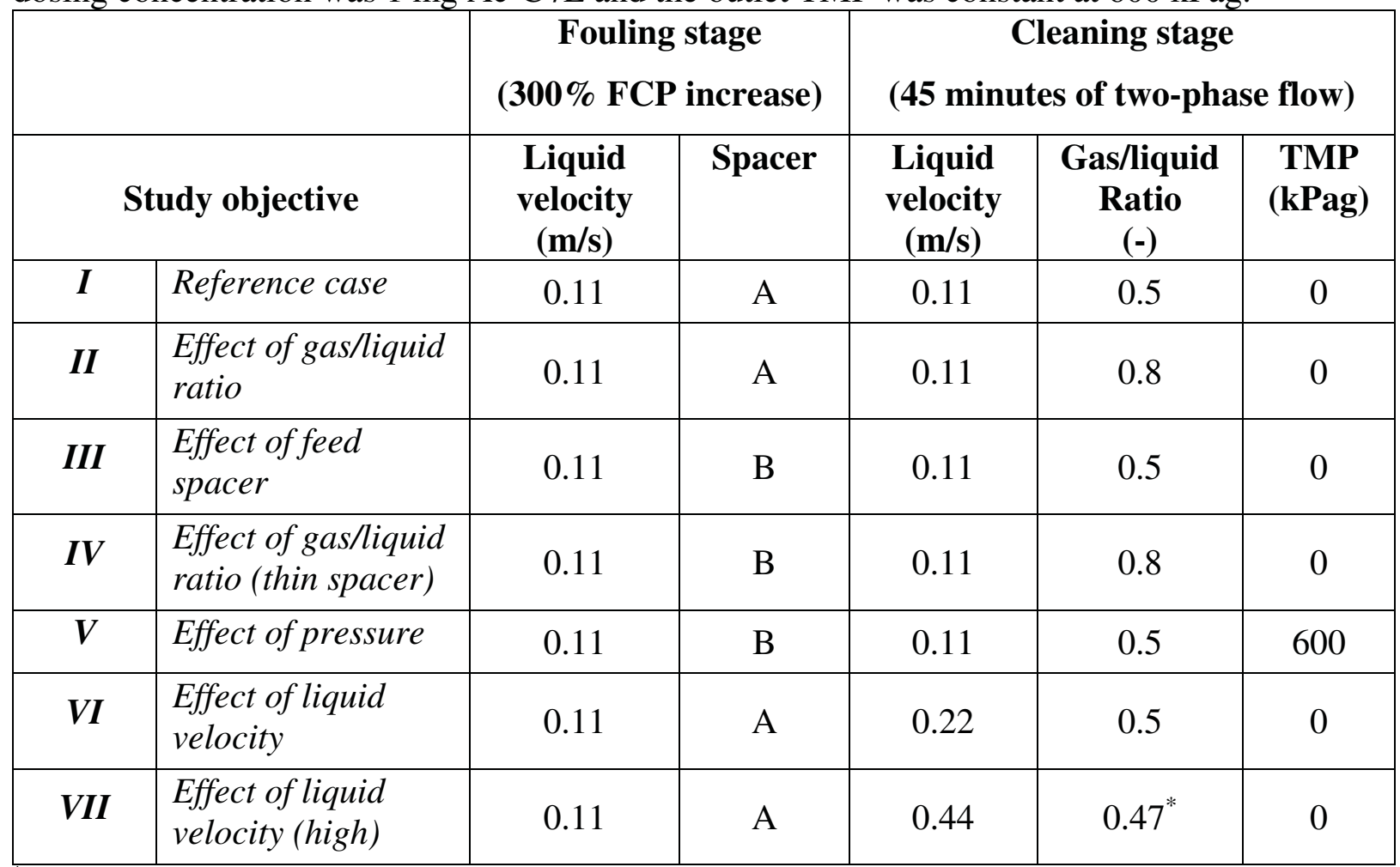

The lower gas/liquid ratio is due to limitations in the operating range of the mass flow controller.

\subsubsection{Observation of biofouling development and removal}

\subsubsection{Macroscopic scale, by high-speed camera}

The biofouling development and its removal by two-phase flow (the bubble behavior during the cleaning process) were monitored by using a high-speed camera (Eosens High-Speed CMOS, Mikrotron, Germany; max frame rate $=500 \mathrm{fps}$ ) with a fixed lens (Kowa). The flow cells were illuminated by a cold light source (Euromex, the Netherlands). This system covered the entire length of the flow cell and allowed a resolution of 160 pixels/mm at a working distance of $20 \mathrm{~cm}$. For each experiment, the bubble velocity was calculated by using Eq. (4.23). The images were processed using the freeware ImageJ v1.47k (National Institutes of Health, USA); the known spacer filament length served as a reference scale in each sequence. 


\subsubsection{Mesoscopic scale, by optical coherence tomography (OCT)}

Since biofouling is a non-uniform and dynamic phenomenon, its development and removal using a two-phase flow cleaning process were characterized on the mesoscopic scale with an optical coherence tomograph (Ganymede Spectral Domain OCT, Thorlabs GmbH, Germany). The OCT device is compact, mobile and easy to use relative to magnetic resonance microscopy (MRM) and magnetic resonance imaging (MRI), which are more complex and have high instrument, space and safety demands [40]. We also preferred OCT over confocal laser scanning microscopy (CLSM) to characterize the three-dimensional structure of biofouling, since CLSM is limited by laser penetration depth, especially in dense, scattering biofilms [41]. OCT, non-destructive (non-contact) and reliable, is able to visualize global biofilm structure and architecture at the mesoscale $(10-1000 \mu \mathrm{m})$ with high resolution and at a relatively low cost [42]. Originally developed for non-invasive, cross-sectional, optical tomographic imaging for medical purposes [43-45], OCT has also been employed recently for the visualization of biofilms in water systems and on membranes [40, 46, 47].

Prior to the investigation, the biofilms were grown inside the three parallel flow cells until the pressure drop had increased by approximately 300\%. We looked at the mesoscopic structure of biofouling occurring in flow cells in three different conditions: (i) biofouled (un-cleaned), (ii) after two-phase flow cleaning at a low liquid velocity $(0.11 \mathrm{~m} / \mathrm{s})$, and (iii) after two-phase flow cleaning at a high liquid velocity $(0.44 \mathrm{~m} / \mathrm{s})$. OCT uses a Michelson interferometer setup; it works with a low-coherence light beam that is split up, with one part illuminating the sample (light reflecting back from it) and the second part serving as reference. This OCT system uses a central wavelength of $930 \mathrm{~nm}$ and a bandwidth of $100 \mathrm{~nm}$. We kept the flow cells closed during these in-situ investigations to prevent damage to the biofouling structures in the cells. We placed the cells placed horizontally on a custom-made sample holder below the hand-held probe head, orthogonal to the optical axis. Fig. 4.4 illustrates the position of the sampled cross-section relative to the probe head.

A piece of PMMA (the same thickness as the PMMA plates used for the walls of the flow cells) was inserted into the OCT's reference arm to avoid a polarization mismatch. Light reflected by the scattering structure of the biofilm sample and the membrane surface within the field of view was then combined with the source light that had traveled a fixed length along the reference arm. The interferogram was reconstructed into the depth profile (A-scan) 158 
using Fourier transform. Series of A-scans can be assembled to create 2-D images (B-scans; xz-planes). The field of view was $7 \mathrm{~mm}$ x $2 \mathrm{~mm}$ x $1.131 \mathrm{~mm}$. For all biofouled samples, images were taken at three different spots along the flow cells: (i) adjacent to the inlet, (ii) at the center of the cells, and (iii) adjacent to the outlet. All tomograms obtained are presented as acquired. We chose the color orange to visualize the biofouling and other structures within the spacer-filled channel. (see Figs. 4.8 and 4.13).

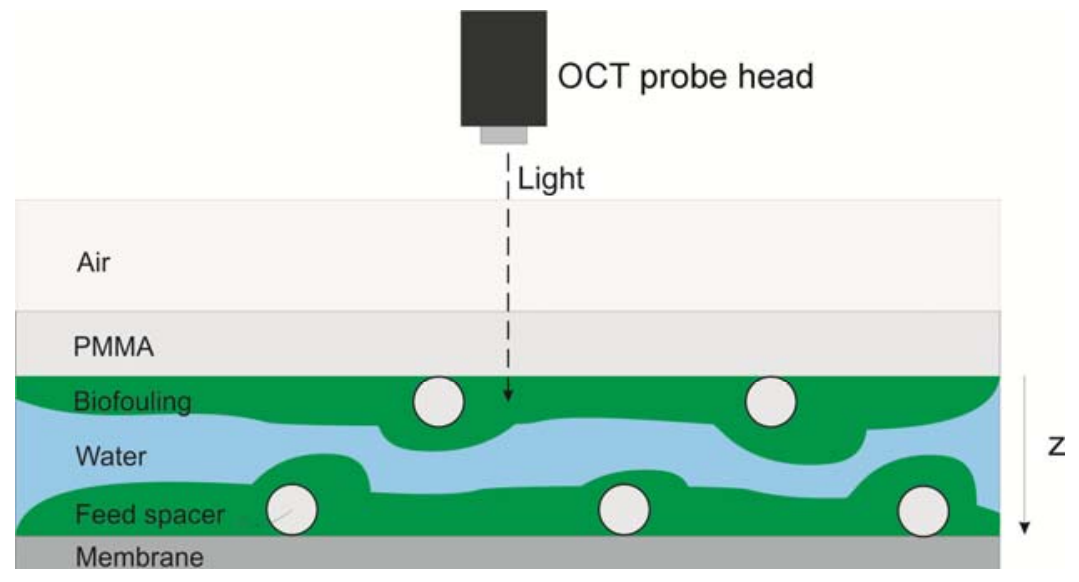

Fig. 4.4. Illustration of the horizontally positioned sample in cross-section: light passes through air (refractive index=1), a 10-mm-thick PMMA plate, the actual biofouling (partly) and a layer of water, and finally is reflected by the shiny nanofiltration membrane sheet. The $\mathrm{z}$-axis is $1.131 \mathrm{~mm}$, allowing observation penetration deeper than the feed channel depth (which was about $0.71 \mathrm{~mm}$, equal to the thickness of spacer A).

\subsubsection{Microscopic scale by scanning electron microscopy (SEM)}

SEM imaging of biological samples usually requires several specimen preparation steps: (i) preservation using cryogens or chemical fixation agents, (ii) dehydration by replacing water by organic solvents and then removal of organic fluids, and finally (iii) conducting material coating to reduce electric charge [48]. However, the use of SEM in this case was only to confirm the presence of biofouling on the membrane sheet and feed spacer on a microscopic scale, so we used dried biofouled membranes without any further preparation. The biofouled membrane and spacer samples were dried at room temperature overnight. Small pieces of the membrane and spacer were then cut and placed in an oven at $30^{\circ} \mathrm{C}$ where they remained overnight. Samples were directly placed on a SEM sample holder without sputter coating and examined at $15 \mathrm{kV}$ accelerating voltage in a low-vacuum scanning electron microscope (Jeol JSM 5600 LV). 


\subsection{Results and discussion}

\subsubsection{Preliminary experiments}

Prior to the main experiments, we tested some fundamentals in order to be able to conduct all main experiments under well-controlled appropriate conditions. First, we checked the hydrodynamic performance of the flow cells for the two selected spacers, using clean water. The FCP was measured at different liquid velocities within the velocity range that is typical for lead spiral-wound elements in practice. The obtained FCP was compared against theoretical values calculated using Eq. (4.1); Fig. 4.5a shows the results. Eq. (4.1) predicts that the liquid velocity increases with increasing FCP; this effect was greater for spacer B $(0.51$ $\mathrm{mm})$ than for spacer A $(0.71 \mathrm{~mm})$ because spacer B has a smaller hydraulic diameter. For spacer A, the theoretical values - shown as dotted lines - correspond well with the empirical values. For spacer B, there are discrepancies at liquid velocities above $0.15 \mathrm{~m} / \mathrm{s}$. However, the actual experiments with spacer B were carried out at a liquid velocity of $0.11 \mathrm{~m} / \mathrm{s}$, for which the theoretical and experimental values are in good agreement.
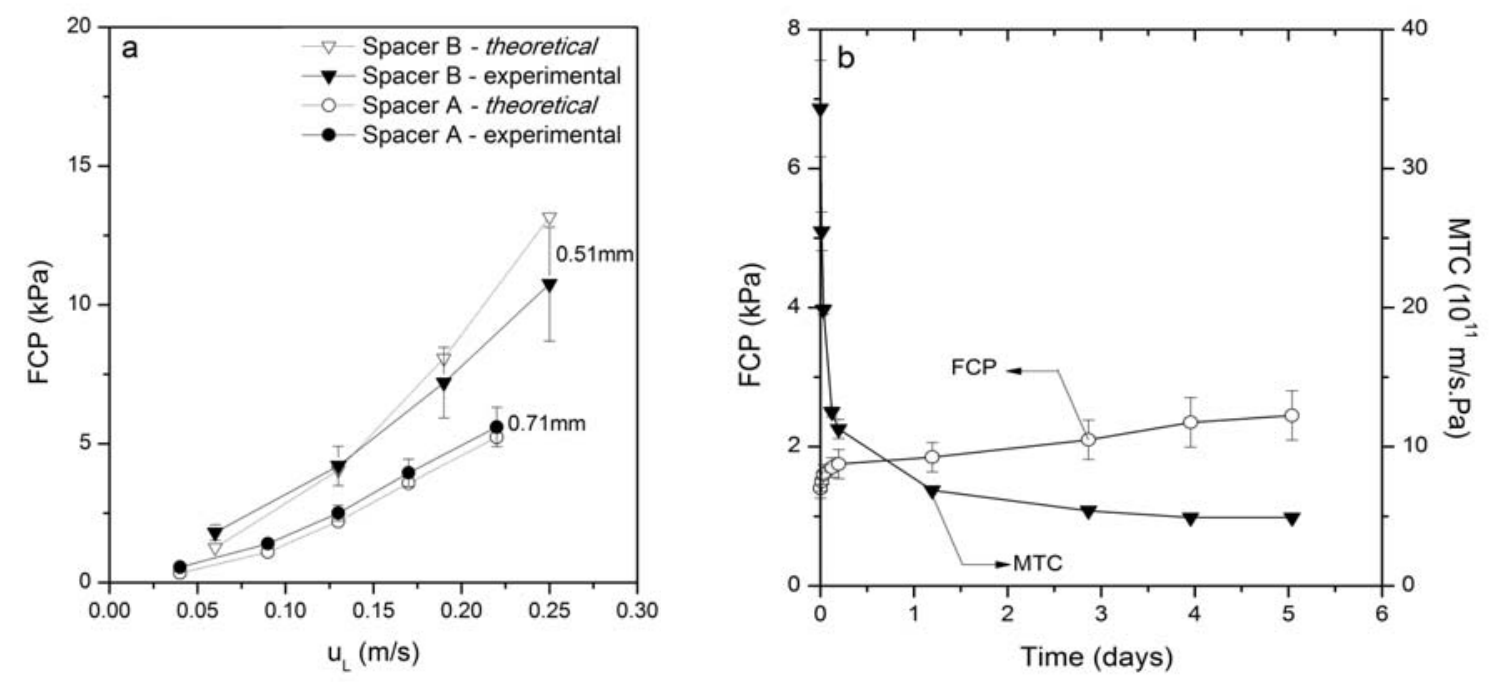

Fig. 4.5. (a) FCP development at different liquid flow velocities and an operating pressure of $600 \mathrm{kPag}$. The dotted lines with open symbols represent the pressure drop based on Eq. (1); the solid symbols are the experimental results. (b) FCP and MTC during membrane compaction test. The constant MTC value is approximately $4.9 \times 10^{-11} \mathrm{~m} / \mathrm{s} . \mathrm{Pa}$, used as the initial MTC value $\left(\mathrm{MTC}_{0}\right)$ for our main experiments. 
Secondly, compaction experiments with ultrapure water (from a Merck Millipore Milli-Q installation) were conducted over a period of five days as a control experiment. This was important since during the main experiments, nutrients were dosed to the system, which would affect the MTC and FCP. As shown in Fig. 4.5b, the MTC dropped significantly to a steady clean water flux value of $4.9 \times 10^{-11} \mathrm{~m} / \mathrm{s} . \mathrm{Pa}\left(\cong 105 \mathrm{~L} / \mathrm{m}^{2} . \mathrm{h}\right)$ after five days of operation. Upon visual inspection, no biofouling in the feed channel was seen. We used this steady value achieved with Milli-Q water as the reference flux $\left(\mathrm{MTC}_{0}\right)$ for our main experiments. The FCP slowly increased with decreasing MTC. Membrane compaction lowers the water flow rate across the membrane [49], causing a small increase of the specific liquid velocity in the channel; consequently, the FCP increases slightly. When steady state was reached, the MTC of the whole membrane remained constant with time and therefore the FCP stabilized as well.

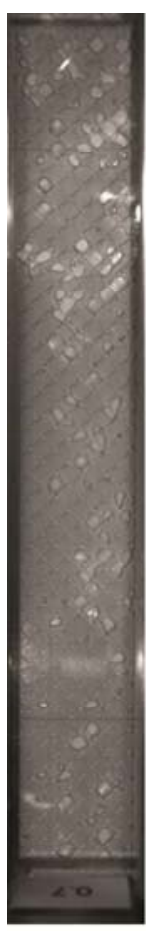

(A) $\theta=0.2$

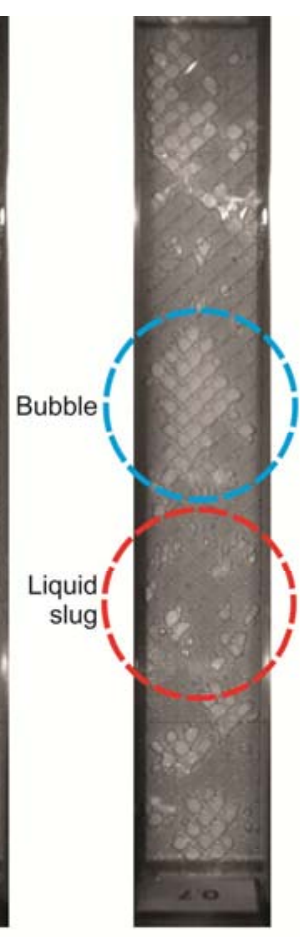

(B) $\theta=0.5$

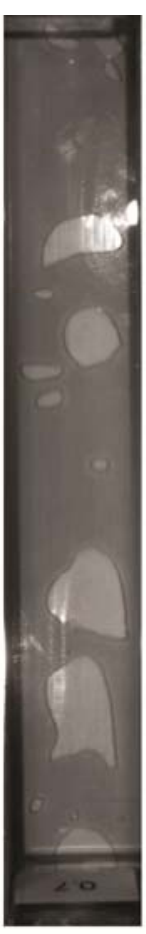

(C) $\theta=0.5$

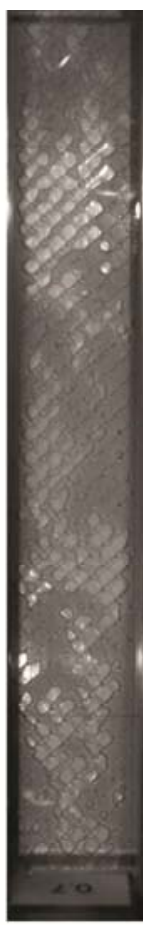

(D) $\theta=0.8$

Fig. 4.6. Bubble coverage and behavior in the flow cell at different gas/liquid ratios $(\theta)$ : $\mathrm{A}=0.2, \mathrm{~B}=0.5, \mathrm{C}=0.5$ (without feed spacer), and $\mathrm{D}=0.8$. All preliminary experiments were performed at a liquid velocity of $0.11 \mathrm{~m} / \mathrm{s}$, using spacer A and a TMP of $0 \mathrm{kPag}$.

The next preliminary experiment determined the bubble coverage and distribution in the spacer-filled channels. The effectiveness of the two-phase flow depends mainly on the flow 
regime in the system [22]; good coverage of bubbles over the full width of the feed channel is important, and requires using the optimum gas/liquid ratio $(\theta)$. The most efficient cleaning is obtained by a slug flow pattern in the channel, so we first determined the conditions (gas/liquid ratio) at which a two-phase flow resulted in a slug flow pattern in an empty channel. We then used the same gas/liquid ratio in the channel filled with a spacer. Fig. 4.6 presents observations recorded with a high-speed camera of a channel with and without spacer. Fig. 4.6 (A), (B) and (D) show the bubble coverage in a channel containing a feed spacer at gas/liquid ratios $(\theta)$ of $0.2,0.5$ and 0.8 , respectively. At a low gas/liquid ratio $(\theta=0.2)$, the gas behaved as small discreet bubbles with not much coverage (Fig. 4.6A). When the ratio was increased, we obtained better coverage. At a ratio of 0.5 , individual bubbles almost filled the width of the channel (Fig. 4.6B); the channel without feed spacer clearly showed a slug flow pattern at this gas/liquid ratio (Fig. 4.6C). Increasing the gas/liquid ratio to 0.8 only elongated the bubbles in the direction of the flow. Also, the bubbles formed at a gas/liquid ratio of 0.5 were easier to identify. We therefore selected a gas/liquid ratio of 0.5 for our main experiments.

\subsubsection{Main experiments}

The main experiments described in Table 4.2 were all conducted with addition of nutrients to obtain rapid biofilm growth in the fouling stage. During the fouling stages, the exponential development of the FCP was similar to results found by others [34, 36, 37, 50, 51]. Reproducibility of the fouling conditions in the flow cells was good. We compared the FCP and MTC developments in the fouling stage of Cases I, VI and VII (see Table 4.2). These three experiments had the same conditions in terms of hydrodynamics (spacer $A, u_{L}=0.1 \mathrm{~m} / \mathrm{s}$ ), nutrient concentration $(1 \mathrm{mg} \mathrm{Ac}-\mathrm{C} / \mathrm{L})$, and average water temperature $\left(21^{\circ} \mathrm{C}\right)$. In Fig. 4.7, each line represents for each experiment the averaged value with the corresponding deviations for the three parallel flow cells. 


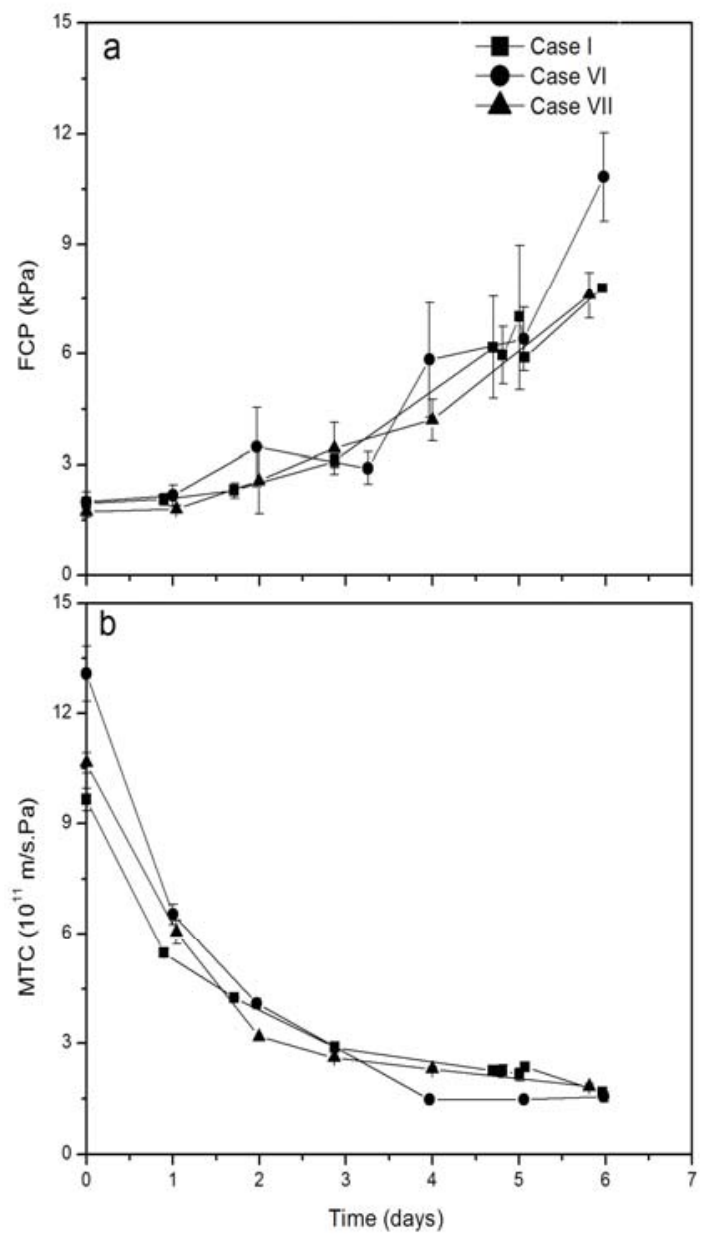

Fig. 4.7. Biofouling development for three independent experiments under the same fouling conditions (spacer $\mathrm{A}, \mathrm{u}_{\mathrm{L}}=0.1 \mathrm{~m} / \mathrm{s}$, nutrient concentration $1 \mathrm{mg} \mathrm{Ac}-\mathrm{C} / \mathrm{L}, \mathrm{T}=21^{\circ} \mathrm{C}$ ): (a) $\mathrm{FCP}$ increase, and (b) MTC decrease. Each line represents the averaged values using the three parallel flow cells for each experimental run; the deviations are shown as error bars.

For the cleaning stage, Case I served as the reference case (see Table 4.2). Fig. 4.8a shows the FCP increase, while Fig. 4.8b depicts the MTC decrease for Case I. From day 3 onward, the FCP in the three flow cells showed a significant deviation, whereas the MTC displayed less deviation. This is because the FCP is more sensitive to small changes in the feed channel (because of the small cross-sectional flow area, namely $14 \mathrm{~mm}^{2}$ for the empty channel) than the MTC. A small blockage in any single spot is likely to have a large impact on the crossflow by reducing the open area available for flow (channel porosity). Contrarily, the MTC is related to the complete surface area of the membrane which is significantly larger $(3,400$ $\mathrm{mm}^{2}$ ). Accordingly, a large amount of biomass is needed to cause changes in the MTC. 

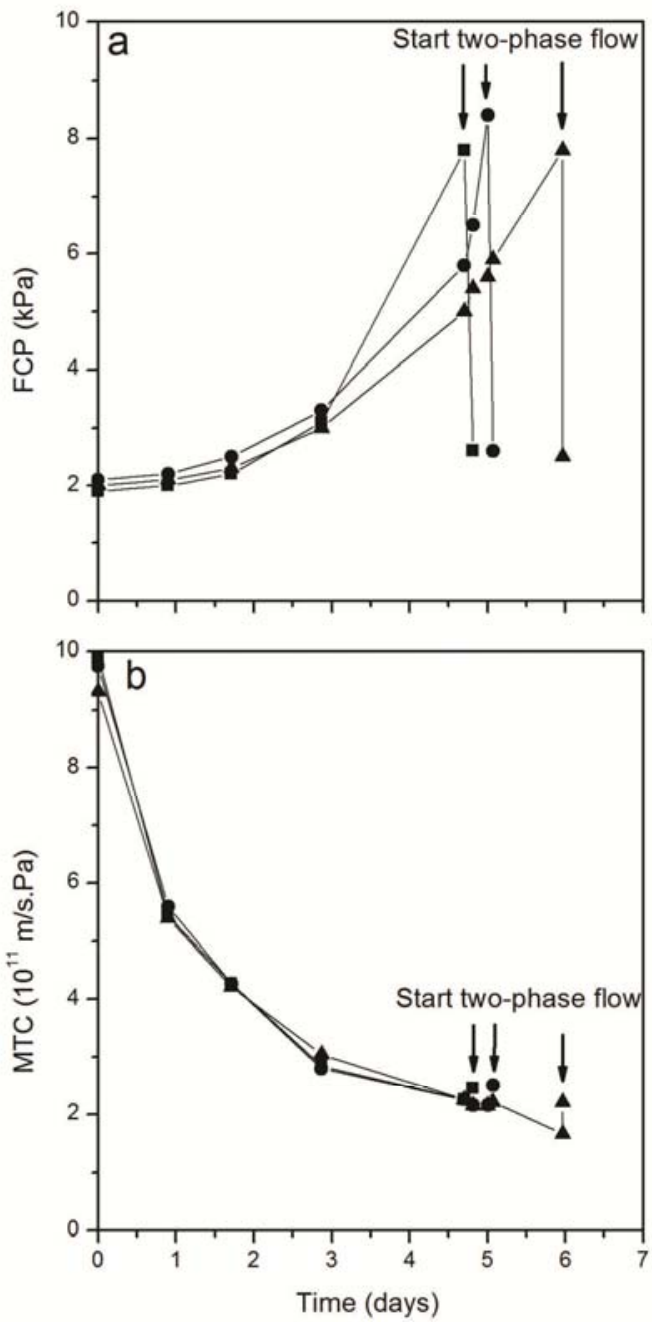

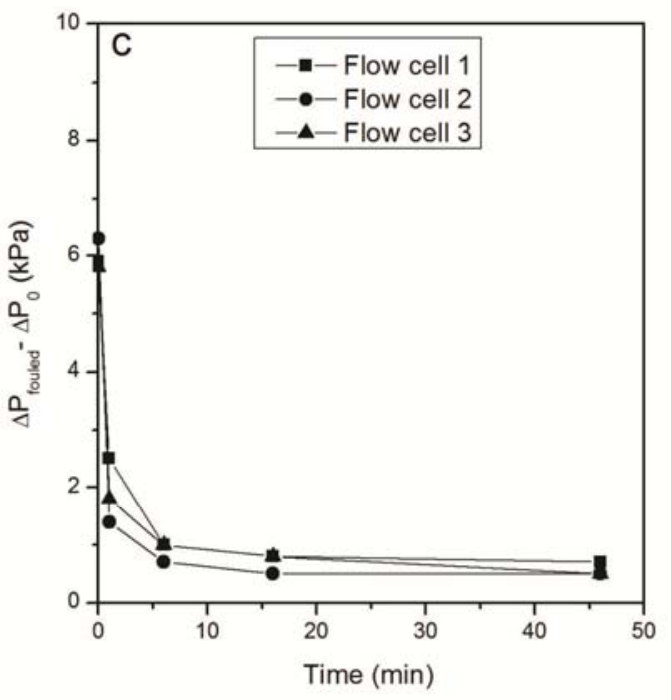

d

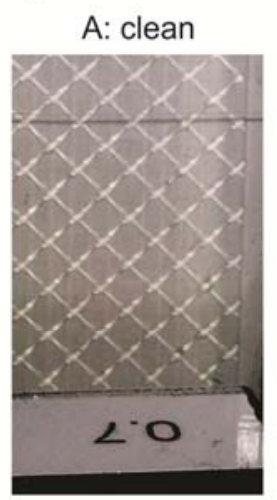

B: biofouled

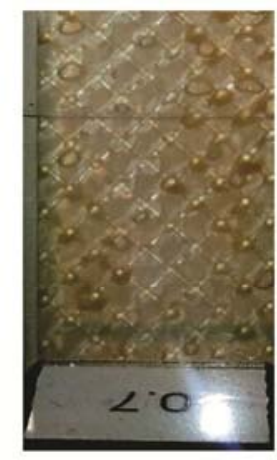

Fig. 4.8. Reference measurements (Case $I$ in Table 4.2) with dosing of $1 \mathrm{mg} \mathrm{Ac-C/L}$, $\mathrm{u}_{\mathrm{L}}=0.11 \mathrm{~m} / \mathrm{s}$, during a six-day period of fouling, showing (a) FCP increase, (b) MTC decline for each flow cell, (c) absolute FCP recovery during two-phase cleaning $\left(u_{L}=0.11 \mathrm{~m} / \mathrm{s}\right.$ and $\theta=0.5$, for about 45 minutes), and (d) visual inspection of the clean and biofouled flow cells, with A the clean system at the start (day 0) and B after biofouling (day 6).

When the pressure drop reached the required level (300\% increase), the flow cell was cleaned by introducing the gas/liquid mixture. For the reference case (Case I; gas/liquid ratio of 0.5 and liquid velocity of $0.11 \mathrm{~m} / \mathrm{s}$ ), this resulted in an almost full recovery of the FCP to the original level (Fig. 4.8a). By using Eq. (20), the FCP recovery efficiency was calculated as about $90 \%$. The high FCP recovery indicates that the biomass causing the FCP increase is easily removed. This happened quickly (in five minutes) as shown in Fig. 4.8c. These results are similar to what was found by Cornelissen et al. [24]. 
At the end of the fouling stage, the final MTC before cleaning was about $2 \times 10^{-11} \mathrm{~m} / \mathrm{s} . \mathrm{Pa}$, which is approximately $60 \%$ lower than the MTC value for the control experiment without nutrients $\left(\mathrm{MTC}_{0}=4.9 \times 10^{-11} \mathrm{~m} / \mathrm{s} . \mathrm{Pa}\right)$. We used Eq. (4.22) to calculate the average biofilm resistance and obtained the value of $2.41 \times 10^{13} \mathrm{~m}^{-1}$ (comparable to results by Dreszer et al. [34]). Upon two-phase flow cleaning, there was no significant recovery in the MTC value for any of the three cells (Fig. 4.8b); according to Eq. (4.21), the recovery was only approximately $17 \%$. Visual inspection after opening of the cells revealed that a significant amount of biomass remained deposited on the membrane; it appears that the shear forces acting on the surface of the membrane were not large enough to remove most of the biofilm.

We used SEM to investigate the biofilm on the membrane sheets and feed spacer surfaces at the microscale level.

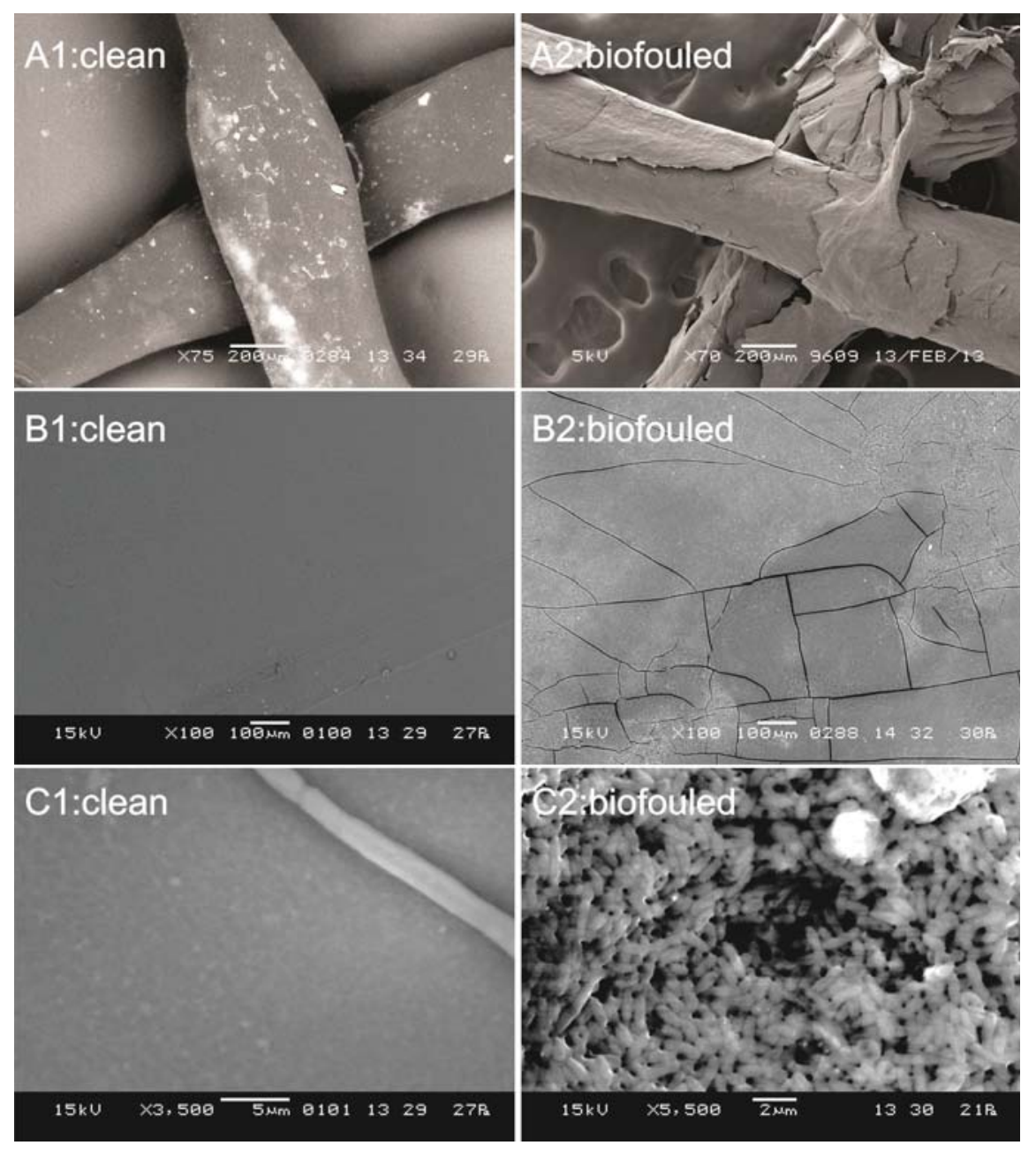

Fig. 4.9. Scanning electron micrographs of clean (A1) and biofouled (A2) feed spacers, and non-fouled (B1) and biofouled (B2) membrane sheet surfaces at low magnification (x100), and of non-fouled $(\mathrm{C} 1, \mathrm{x} 3500)$ and biofouled $(\mathrm{C} 2$, x 5500) membrane sheet surfaces at high magnification. In $\mathrm{C} 2$, colonies of bacteria are visible, a clear indication of biofouling. 
Fig. 4.9A shows SEM images of a clean (A1) and a biofouled (A2) feed spacer. Figs. 4.9B1 and $4.9 \mathrm{C} 1$ show the clean membrane before fouling; no deposits are visible on the membrane. Figs. 4.9B2 and 4.9C2 show images obtained of the fouled membranes after day 6; deposits were present on the fouled surface and large cracks were observed at low magnifications (x100). These cracks were likely caused by the drying of the membranes. At higher magnifications (x5500), large numbers of bacterial cells were visible. Such bacteria are strongly attached to the membrane surface because of Lifshifz-van der Waals, electrostatic, and acid-base forces [52].

\subsubsection{Effect of feed spacer geometry, gas/liquid ratio and applied pressure}

In the reference case (Case I), two-phase flow cleaning was effective in terms of recovery of the FCP, but not successful in restoring the MTC. We therefore explored the following strategies to improve MTC recovery: (a) changing the feed spacer type, (b) increasing the gas/liquid ratio from 0.5 to 0.8 , and (c) increasing the applied trans-membrane pressure.

First, we selected a thinner feed spacer (spacer B; see Table 4.1). The benefit of using a thinner feed spacer is that it results in a larger membrane surface area per unit module volume. However, the downside is that the effect of fouling might be more severe due to the smaller hydraulic diameter of the channel, resulting in a higher FCP. Fig. 4.10 shows that use of the thinner feed spacer made the recovery of the FCP decreases to 65\%; the MTC recovery became even less than $10 \%$ (Case III). Analysis of about 250 images taken during two-phase flow cleaning (images are condensed into a single frame during post-processing) clearly showed the occurrence of channeling; the biofouling caused a preferential trajectory of the two-phase flow through regions of lower resistance. Because of this maldistribution of bubbles over the width of the feed channel, it was hard to remove the biofilms from the channel. The effect was worse for the MTC because a significant part of the membrane surface was not cleaned, therefore limiting permeate flow.

The next strategy was to increase the gas/liquid ratio (Cases II and IV), as this might produce larger bubbles in the feed channel. For spacer A $(0.71 \mathrm{~mm})$, a minor increase of the FCP recovery occurred; see Case II vs. Case I in Fig. 4.10. The MTC recovery was almost identical to the reference experiment if we take the error margins into consideration. This suggests that 
larger bubbles do not increase the shear force along membrane surface significantly. For spacer B, the cleaning efficiency enhancement was greater at a higher gas/liquid ratio (Case IV vs. Case III). The FCP and MTC recoveries increased to $85 \%$ and $15 \%$, respectively, but overall, the two-phase flow cleaning efficiencies were almost the same as for the reference case (Case I: FCP recovery efficiency approximately 90\%, MTC recovery 17\%). The bubble distributions for spacer $\mathrm{A}$ at gas/liquid ratios of 0.5 and 0.8 (Figs. 4.6B and 4.6D) and spacer $\mathrm{B}$ at a gas/liquid ratio of 0.8 (Fig. 4.10 rightmost, Case IV) were comparable. It is clear that decreasing the spacer thickness did not significantly improve the cleaning efficiency.

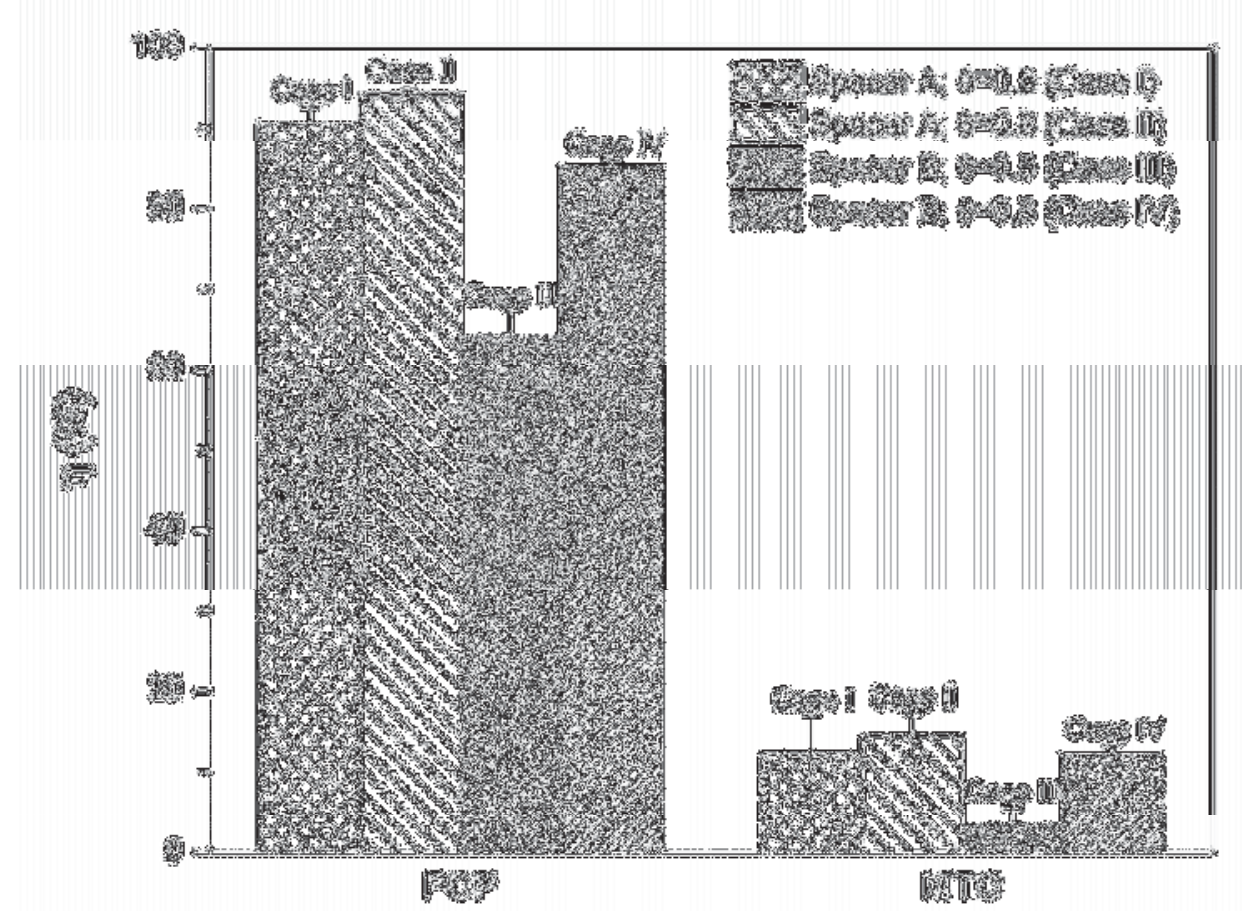

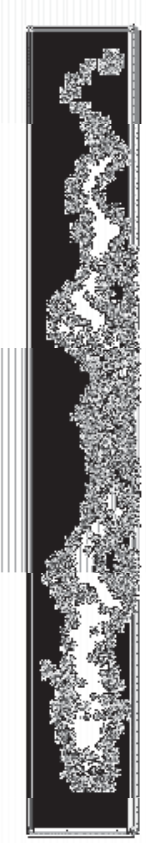

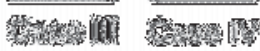

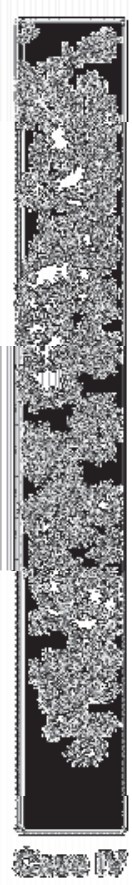

Fig. 4.10. Left: Effect of feed spacer type and gas/liquid ratio $(\theta)$ on FCP and MTC recoveries; $\mathrm{u}_{\mathrm{L}}=0.11 \mathrm{~m} / \mathrm{s}$. Right: superimposed frames showing bubble coverage for Cases III and IV.

The effect of applying a trans-membrane pressure (feed pressure) during the cleaning phase was also tested. Based on the ideal gas law, an increase of the applied pressure should lead to smaller bubbles and possibly a better bubble distribution. Furthermore, from a practical point of view, the operator of two-phase flow cleaning process would not have to reduce the applied trans-membrane pressure during cleaning but would be able to use the same pressure as used 
for filtration. To investigate the effect of applied pressure (and the expected smaller bubble size) on the cleaning efficiency, a fouling experiment was performed using spacer B, with a gas/liquid ratio of 0.5 in the subsequent cleaning stage (Case V; see Table 4.2). Fig. 4.11 displays the results. The gas/liquid ratio is based on the actual gas volume, so seven times the amount of gas was introduced to compensate for reduced volume at $600 \mathrm{kPag}$ (based on the ideal gas law at the same temperature).

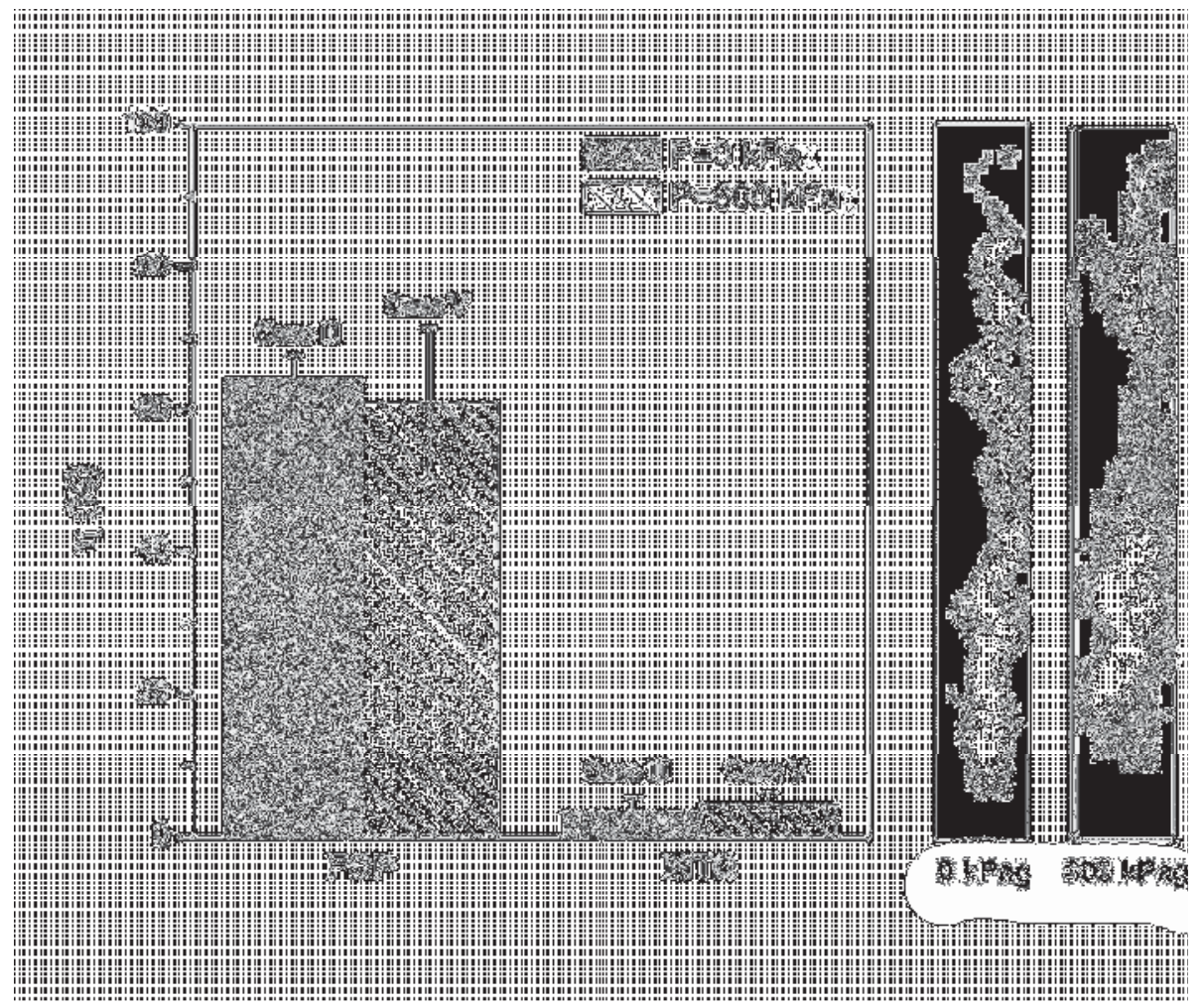

Fig. 4.11. Left: effect of applied trans-membrane pressure during the two-phase cleaning on the FCP and MTC recoveries, with spacer B. Right: superimposed frames showing bubble coverage for Cases III (0 kPag) and V (600 kPag).

Fig. 4.11 makes clear that cleaning at a pressure of $600 \mathrm{kPag}$ had the same cleaning efficiency as cleaning at $0 \mathrm{kPag}$ pressure. The results show an FCP recovery of approximately $60 \%$, and an MTC recovery of less than $10 \%$. Analysis of the image sequence revealed that the bubbles behaved the same at both pressures. Bubble size was identical, following the shape of feed spacer filaments, regardless of applied pressure.

From Figs. 4.10 and 4.11, we can conclude that maintaining good bubble coverage is the most important factor; effects of feed-spacer thickness, gas/liquid ratio or applied pressure are only 
important with regard to whether they improve or worsen bubble coverage. Nevertheless, bubble coverage is mainly important for the removal of large fluffy biofouling (recovering the FCP), but not for recovering water transport to the permeate side (MTC).

\subsubsection{Effect of liquid velocity}

We expected that increasing the liquid velocity while maintaining the same gas/liquid ratio would lead to higher bubble velocities. This should lead to greater shear forces and, likely, a better cleaning efficiency. We performed two experiments (Cases VI and VII) to investigate this. Biofouling was allowed to develop under similar conditions as in the reference case (Case I, Table 4.2). We used two different liquid velocities in the cleaning stage, i.e. $0.22 \mathrm{~m} / \mathrm{s}$ and $0.44 \mathrm{~m} / \mathrm{s}$, which was two and four times that of the reference case $(0.11 \mathrm{~m} / \mathrm{s})$. In each case, the gas flow operated at a gas/liquid ratio of 0.5 .

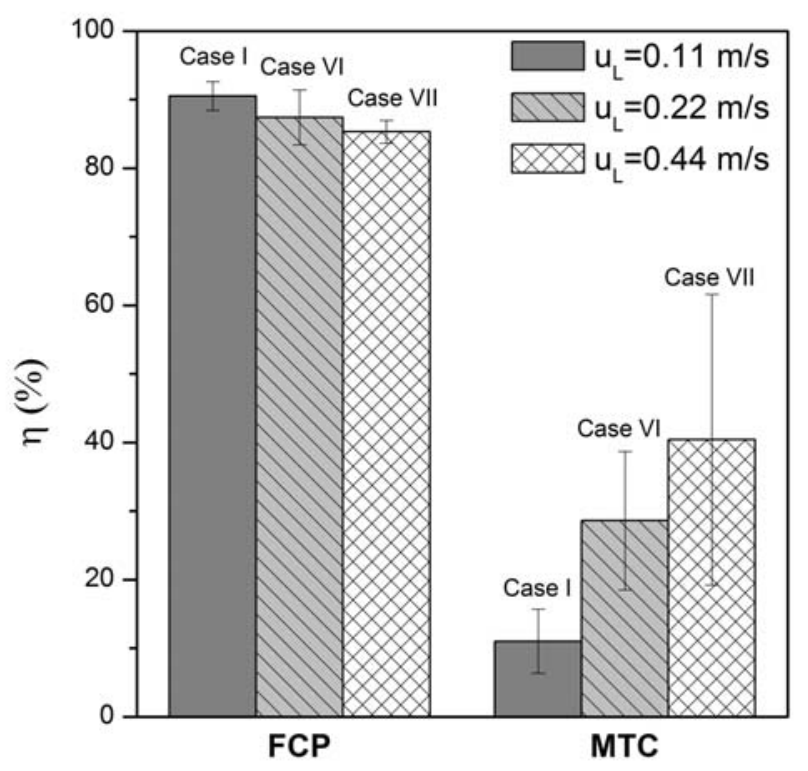

Fig. 4.12. Effect of the liquid velocity $\left(\mathrm{u}_{\mathrm{L}}\right)$ on FCP and MTC recoveries. Liquid velocities $\mathrm{u}_{\mathrm{L}}$ $0.11 \mathrm{~m} / \mathrm{s}$ (Case I), $0.22 \mathrm{~m} / \mathrm{s}$ (Case VI) and $0.44 \mathrm{~m} / \mathrm{s}$ (Case VII); spacer A. Gas/liquid ratio $\theta=0.5$.

Fig. 4.12 presents the results. As can be seen, there were no significant differences in the FCP recovery (all between 85\% and 90\%). However, increasing the liquid velocity led to a better MTC recovery. Increasing the liquid velocity from $0.11 \mathrm{~m} / \mathrm{s}$ to $0.22 \mathrm{~m} / \mathrm{s}$ enhanced the MTC recovery from about $10 \%$ to $30 \%$. By further increasing the liquid velocity to $0.44 \mathrm{~m} / \mathrm{s}$, an 
additional rise in the MTC recovery to about $40 \%$ occurred. Upon visual inspection, more biofouling was found to have been removed from the membrane surface at these greater liquid velocities.

To elucidate the effect of the liquid velocity on the MTC recovery, we repeated this experiment under similar conditions, and used using SD-OCT (Section 4.3.9.2) to image the biofouling in the flow cell before and after cleaning. Images were taken in three locations of the flow cell (near the inlet and outlet, and in the middle). Figs. 4.13 and 4.14 contain the tomograms. Fig. 4.13a shows the OCT's three-dimensional field of view during observation of the biofouling inside the flow cell ( $7 \mathrm{~mm} \times 2 \mathrm{~mm}$ x $1.131 \mathrm{~mm}$ for $\mathrm{x}, \mathrm{y}$ and $\mathrm{z}$ ). With a $\mathrm{z}$-axis of $1.131 \mathrm{~mm}$, an observation penetration deeper than the feed channel depth is allowed. Figs. $4.13 \mathrm{~b}$ and $13 \mathrm{c}$ show the two-dimensional OCT images of the biofouled cells, in which the fluffy aggregates of biofouling, thin biofilm layer, feed spacers, and membrane surfaces can be distinguished (on the basis of the intensity of back-scattered light received by the OCT probe). Fig. $4.13 \mathrm{~b}$ clearly shows how biofouling in the entire feed channel reduced the channel volume (and thereby increased the flow resistance). Fig. 4.13b also shows substantial biofouling adhered to the surface of the PMMA cover plate and around the polypropylene feed spacer filaments, which are both hydrophobic (see also Fig. 4.14a). The fluffy biofouling is responsible for the FCP increase and was removed by application of two-phase flow cleaning at any liquid velocity $\left(\mathrm{u}_{\mathrm{L}}=0.11 \mathrm{~m} / \mathrm{s}\right)($ Fig. $4.13 \mathrm{c})$. Since the flow cell was relatively short, we can assume that the shear force caused by the gas bubbles acted uniformly along the channel. This caused the fluffy biofilm to be removed from the entire channel, but a thin layer of biofilm remained after cleaning (Fig. 4.14b). This layer is responsible for the low MTC recovery; it was therefore important to increase the shear force applied to the membrane surface.

By increasing the liquid velocity to $\mathrm{u}_{\mathrm{L}}=0.44 \mathrm{~m} / \mathrm{s}$, two-phase flow cleaning removed more biofilm material from the membrane surface (compare Figs. $4.14 \mathrm{~b}$ and $4.14 \mathrm{c}$; the membrane sheet appears brighter because of its shiny top layer). Fig. $4.14 \mathrm{c}$ shows that there was still biofilm material on the feed-spacer filaments, where the attractive force between the biofilm and the hydrophobic filament surfaces most likely was stronger than the shear force induced by the bubble flow. These OCT images explain the efficiencies shown in Fig. 4.12. Use of a higher liquid velocity $\left(\mathrm{u}_{\mathrm{L}}=0.44 \mathrm{~m} / \mathrm{s}\right)$ increased the MTC recovery significantly (to about $40 \%$ ), 
at similar FCP recoveries. The greater shear forces acting on the surface of the membrane were able to remove most of the biofouling there, which led to increased MTC recovery.

a
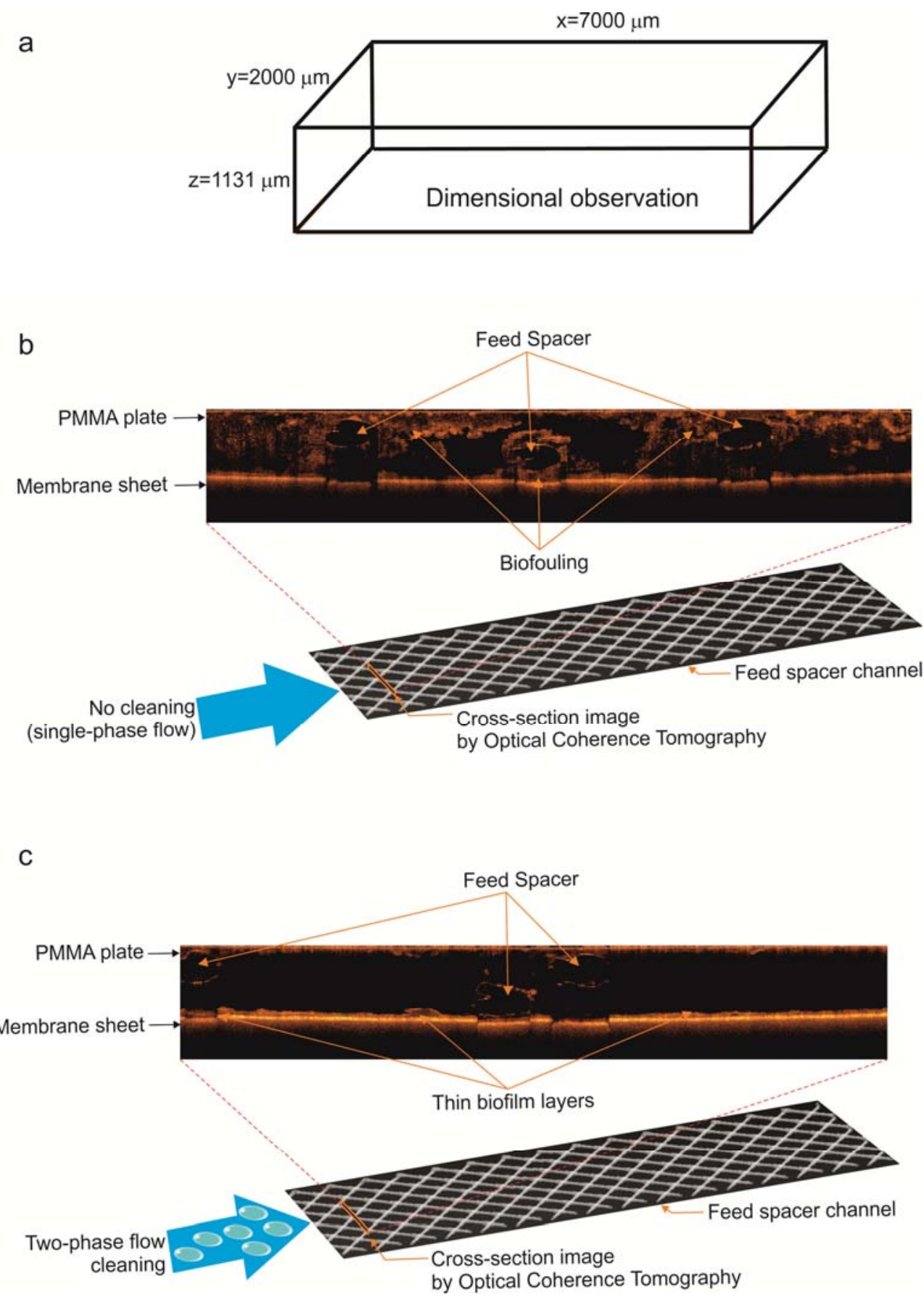

Fig. 4.13. (a) OCT's three-dimensional field of observation measures $7 \mathrm{~mm} \times 2 \mathrm{~mm} \times 1.131$ $\mathrm{mm}$, acquired for all biofouling sample along the flow cells. Illustration of B-scans (xz-planes) of the biofouled spacer-filled channel, before (b) and after (c) two-phase flow cleaning $\left(u_{L}=0.11 \mathrm{~m} / \mathrm{s} ; \theta=0.5\right)$ at inflow points. The intensity of the orange color is proportional to the intensity of detected reflection of the raw signal. The back-scattered light from the membrane sheet is brighter due to the shiny top layer of the membrane. 

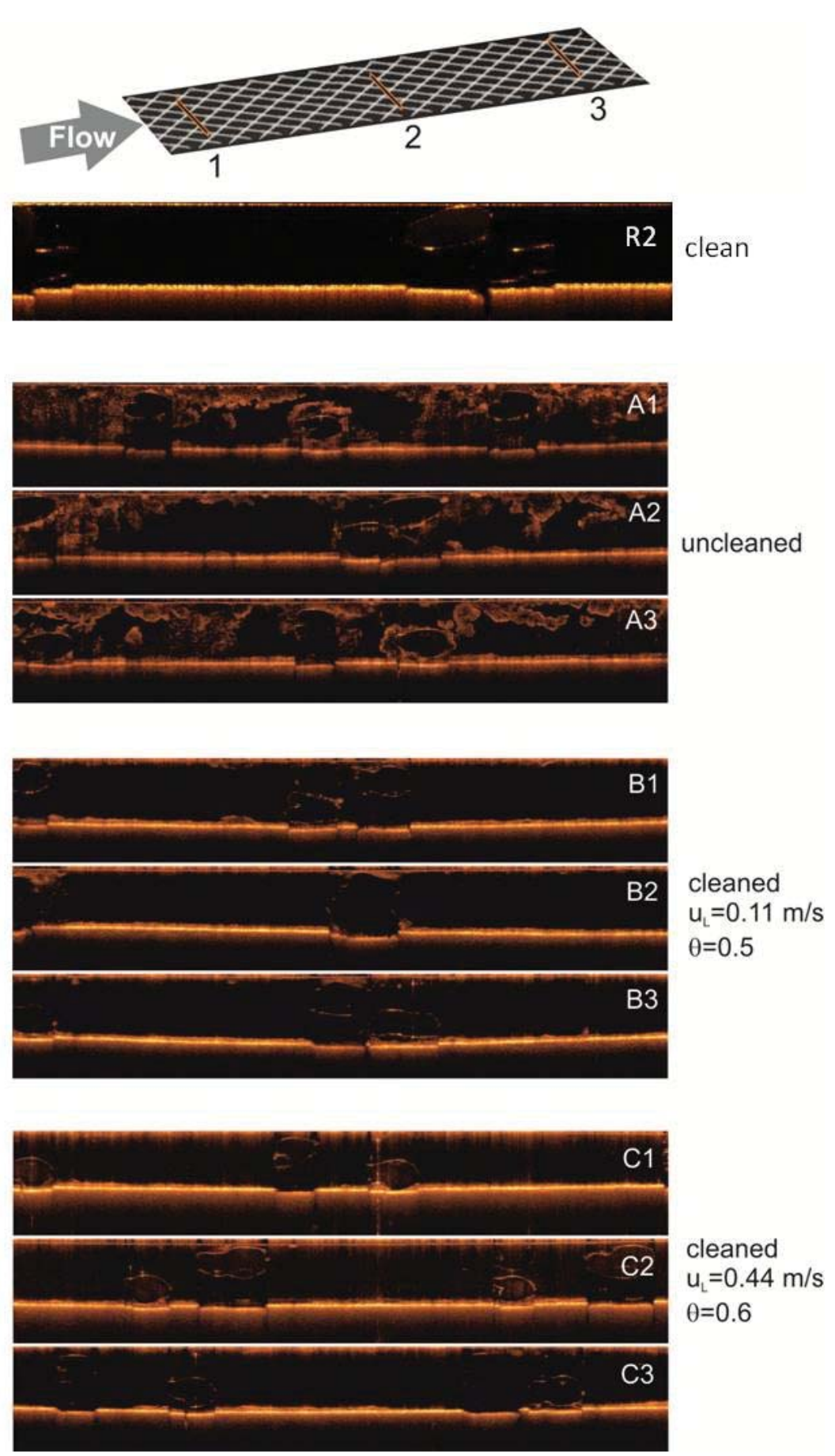

Fig. 4.14. Series of equidistant OCT B-scans $(7 \mathrm{~mm} \times 1.131 \mathrm{~mm}$, measured in air (refractive index $=1$ ) of biofouled feed channels in three regions: (1) adjacent to the inlet (A1, B1, C1), (2) in the middle of the channel (A2, B2, C2), and (3) adjacent to the outlet (A3, B3, C3). Flow cell $\mathrm{A}$ is the biofouled feed channel before cleaning, flow cell $\mathrm{B}$ was cleaned at a liquid velocity of $\mathrm{u}_{\mathrm{L}}=0.11 \mathrm{~m} / \mathrm{s}$ and a gas/liquid ratio $\theta=0.5$, and flow cell $\mathrm{C}$ was cleaned at a liquid velocity of $\mathrm{u}_{\mathrm{L}}=0.44 \mathrm{~m} / \mathrm{s}$ and a gas/liquid ratio $\theta=0.6$ (slightly higher ratio, but bubble distribution is identical, only significantly differ ratio provides significant bubble distribution difference, see Fig. 4.6). R2 is clean feed channel as reference, captured in the middle of the flow cell. The intensity of the orange is proportional to the intensity of the detected reflection of the raw signal. 
We expected that the bubble velocity within the two-phase flow plays an important role in increasing the shear force at the membrane surface. To confirm that, we analyzed all recorded high-speed camera images obtained during two-phase flow cleaning from all experiments $\left(\mathrm{u}_{\mathrm{L}}=0.11,0.22\right.$ and $\left.0.44 \mathrm{~m} / \mathrm{s} ; \theta=0.5\right)$, and used Eq. (4.23) to calculate the bubble velocities. Fig. 4.15 displays the result.

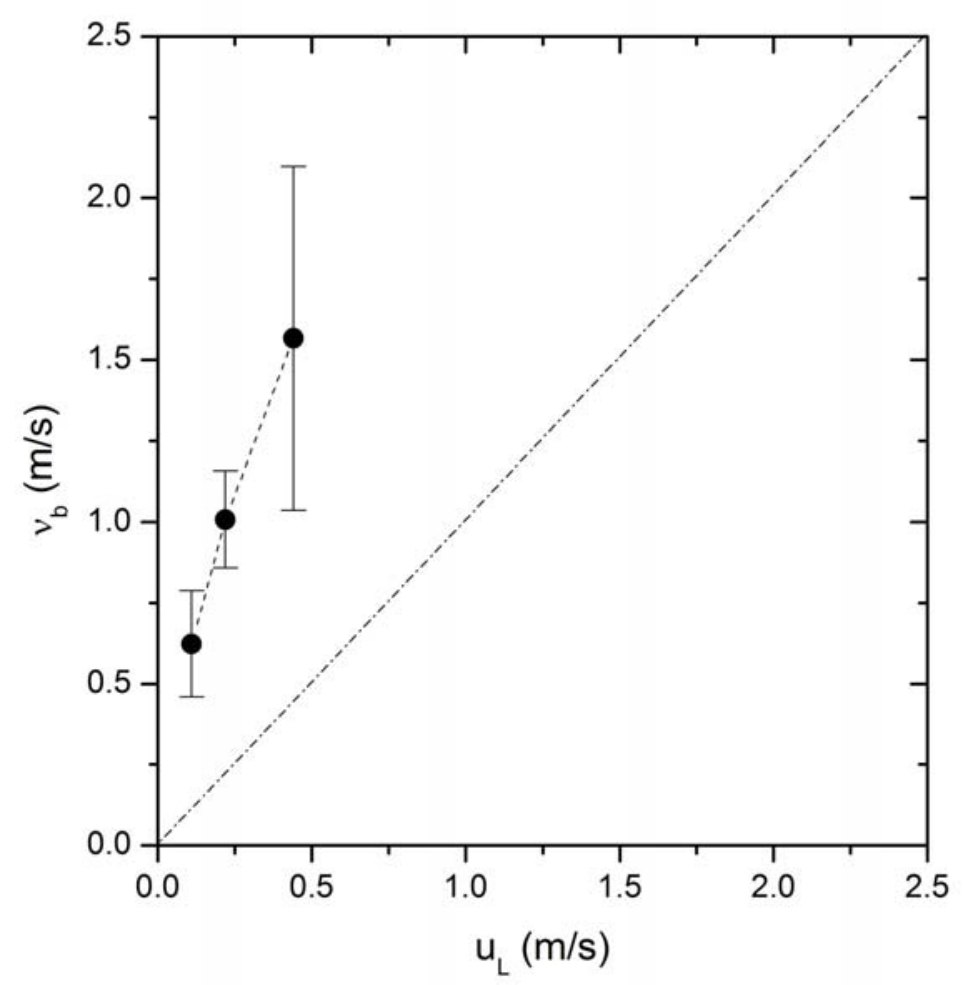

Fig. 4.15. Bubble velocity $\left(v_{b}\right)$ as a function of liquid velocity $\left(u_{L}\right)$ in the membrane cell at a gas/liquid ratio $(\theta)$ of 0.5 and for feed spacer $\mathrm{A}$ as determined by using high-speed camera images.

Fig. 4.15 shows that the measured bubble velocity was 3.5-5.5 times higher than the liquid velocity. In a separate test, we used a single phase (water only) at a high velocity $(0.44 \mathrm{~m} / \mathrm{s})$ to clean the biofouled channel. However, water alone failed to remove biofouling. We therefore conclude that the bubble velocity during two-phase flow cleaning is responsible for the high shear force that leads to removal of the biofilm from the membrane surface. The higher the bubble velocity is, the greater the achieved MTC recovery. 


\subsection{Conclusions}

Keeping the pressure drop along the feed channel under control and maintaining the flux (mass transfer coefficient) is essential in high-pressure membrane processes such as NF and RO. In practice, this often requires the periodic removal of biofouling from such systems. We investigated the effects of different conditions of two-phase flow cleaning, a chemical-free procedure, on its ability to remove biofouling from spiral-wound nanofiltration elements.

At a liquid velocity of $0.11 \mathrm{~m} / \mathrm{s}$ for a spacer with a thickness of $0.71 \mathrm{~mm}$, increasing the gas/liquid ratio from 0.5 to 0.8 led to similar cleaning efficiencies (recoveries of the FCP and MTC of about $90 \%$ and $17 \%$, respectively). Using a thinner spacer, with a thickness of 0.51 $\mathrm{mm}$, at a gas/liquid ratio of 0.5 led to a maldistribution of the bubbles, resulting in lower cleaning efficiencies (recoveries of about $65 \%$ and $5 \%$ for FCP and MTC, respectively). Increasing the gas/liquid ratio to 0.8 for this thinner spacer did not yield significantly better cleaning results either. Cleaning at a transmembrane pressure of $600 \mathrm{kPag}$ did not influence the efficiency either. It appears that it is mainly the structure of the feed spacer that controls bubble flow and bubble size.

An increase in the liquid velocity during two-phase flow cleaning produced a significantly increased bubble velocity and this was most effective in improving the MTC recovery. The largest efficiency (about $40 \%$ ) was obtained at the highest liquid velocity we used $(0.44 \mathrm{~m} / \mathrm{s})$. Visual inspection using OCT showed a significant increase in the amount of biomass removed from the membrane surface with increasing liquid velocity. The bubble velocities where found to be approximately 3.5-5.5 times higher than the liquid velocities. At identical gas/liquid ratios, the higher bubble velocity was responsible for greater shear forces on the surface of the membrane, leading to the increased cleaning efficiency.

We found that using only the FCP as an indicator for biofouling removal is insufficient as it does not reflect biofilms present on the membrane surface, but mainly indicates the presence or absence of fluffy-type fouling. The short cleaning duration (about $5 \mathrm{~min}$ ) that is required for FCP recovery reflects this and has only a small effect on the biofilm present on the membrane surface. The MTC gave a better indication about the biofilm present on the membrane surface, thus providing more insight in actual removal rates. 
In practice, both FCP and MTC must be well-managed to maintain optimum process performance (higher productivity, lower energy consumption, low cleaning cost). Two-phase flow cleaning is a good method for efficient biofouling control in spiral-wound membrane elements when two key conditions are met: a good distribution of the bubbles, and a high bubble velocity. A good bubble distribution, can be achieved by fine-tuning the gas/liquid ratio to its optimum and possibly by modifying the feed spacer shape.

\section{References}

[1] V. Chen, J. Mansouri, T. Charlton, Biofouling in Membrane Systems, in: Membrane Technology, Wiley-VCH Verlag GmbH \& Co. KGaA, 2010, pp. 25-51.

[2] H.C. Flemming, G. Schaule, T. Griebe, J. Schmitt, A. Tamachkiarowa, Biofouling - The Achilles heel of membrane processes, Desalination, 113 (1997) 215-225.

[3] R.A. Al-Juboori, T. Yusaf, Biofouling in RO system: Mechanisms, monitoring and controlling, Desalination, 302 (2012) 1-23.

[4] T. Nguyen, F. Roddick, L. Fan, Biofouling of Water Treatment Membranes: A Review of the Underlying Causes, Monitoring Techniques and Control Measures, Membranes, 2 (2012) 804-840.

[5] S.S. Branda, A. Vik, L. Friedman, R. Kolter, Biofilms: The matrix revisited, Trends in Microbiology, 13 (2005) 20-26.

[6] R.M. Donlan, Biofilms: Microbial life on surfaces, Emerging Infectious Diseases, 8 (2002) 881890.

[7] H.C. Flemming, J. Wingender, The biofilm matrix, Nature Reviews Microbiology, 8 (2010) 623633.

[8] G. Amy, Fundamental understanding of organic matter fouling of membranes, Desalination, 231 (2008) 44-51.

[9] Y. Zhang, F. Ma, G.-B. Li, Fouling of ultrafiltration membrane by algal-rich water: Effect of kalium, calcium, and aluminum, Journal of Colloid and Interface Science, 405 (2013) 22-27.

[10] J.S. Vrouwenvelder, J.C. Kruithof, M.C.M. Van Loosdrecht, Integrated approach for biofouling control, Water Science and Technology, 62 (2010) 2477-2490.

[11] T.M. Missimer, N. Ghaffour, A.H.A. Dehwah, R. Rachman, R.G. Maliva, G. Amy, Subsurface intakes for seawater reverse osmosis facilities: Capacity limitation, water quality improvement, and economics, Desalination, 322 (2013) 37-51.

[12] C. Chiellini, R. Iannelli, L. Modeo, V. Bianchi, G. Petroni, Biofouling of reverse osmosis membranes used in river water purification for drinking purposes: analysis of microbial populations, Biofouling, 28 (2012) 969-984.

[13] S. Huang, N. Voutchkov, S.C. Jiang, Investigation of environmental influences on membrane biofouling in a Southern California desalination pilot plant, Desalination, 319 (2013) 1-9.

[14] H. Kasama, Tackling the biofouling challenge, in: Market Profile, Global Water Intelligence, 2011.

[15] W.A.M. Hijnen, C. Castillo, A.H. Brouwer-Hanzens, D.J.H. Harmsen, E.R. Cornelissen, D. van der Kooij, Quantitative assessment of the efficacy of spiral-wound membrane cleaning procedures to remove biofilms, Water Research, 46 (2012) 6369-6381.

[16] J.S. Vrouwenvelder, S.A. Manolarakis, J.P. van der Hoek, J.A.M. van Paassen, W.G.J. van der Meer, J.M.C. van Agtmaal, H.D.M. Prummel, J.C. Kruithof, M.C.M. van Loosdrecht, Quantitative biofouling diagnosis in full scale nanofiltration and reverse osmosis installations, Water Research, 42 (2008) 4856-4868.

[17] S.A. Avlonitis, K. Kouroumbas, N. Vlachakis, Energy consumption and membrane replacement cost for seawater RO desalination plants, Desalination, 157 (2003) 151-158. 
[18] L.A. Bereschenko, H. Prummel, G.J.W. Euverink, A.J.M. Stams, M.C.M. van Loosdrecht, Effect of conventional chemical treatment on the microbial population in a biofouling layer of reverse osmosis systems, Water Research, 45 (2011) 405-416.

[19] J.W. Costerton, Z. Lewandowski, D.E. Caldwell, D.R. Korber, H.M. Lappin-Scott, Microbial biofilms, Annual Review of Microbiology, 49 (1995) 711-745.

[20] Y. Liu, J.H. Tay, The essential role of hydrodynamic shear force in the formation of biofilm and granular sludge, Water Research, 36 (2002) 1653-1665.

[21] P.S. Stewart, Mini-review: Convection around biofilms, Biofouling, 28 (2012) 187-198.

[22] Y. Wibisono, E.R. Cornelissen, A.J.B. Kemperman, W.G.J. van der Meer, K. Nijmeijer, Twophase flow in membrane processes: A technology with a future, Journal of Membrane Science, 453 (2014) 566-602.

[23] E.R. Cornelissen, L. Rebour, D. van der Kooij, L.P. Wessels, Optimization of air/water cleaning (AWC) in spiral wound elements, Desalination, 236 (2009) 266-272.

[24] E.R. Cornelissen, J.S. Vrouwenvelder, S.G.J. Heijman, X.D. Viallefont, D. Van Der Kooij, L.P. Wessels, Periodic air/water cleaning for control of biofouling in spiral wound membrane elements, Journal of Membrane Science, 287 (2007) 94-101.

[25] H.C. Flemming, Biofouling in water systems - Cases, causes and countermeasures, Applied Microbiology and Biotechnology, 59 (2002) 629-640.

[26] P. Stoodley , J.D. Boyle, I. Dodds, H.M. Lappin-Scott, Consensus model of biofilm structure, in: J.W.T. Wimpenny, P.S. Handley, P. Gilbert, H.M. Lappin-Scott, M. Jones (Eds.) Biofilms:

Community Interactions and Control: 3rd meeting of the Biofilm Club, 1997, pp. 1-9.

[27] E. Morgenroth, K. Milferstedt, Biofilm engineering: linking biofilm development at different length and time scales, Rev Environ Sci Biotechnol, 8 (2009) 203-208.

[28] C. Picioreanu, M.C.M. van Loosdrecht, J.J. Heijnen, Modelling and predicting biofilm structure, in: Community structure and co-operation in biofilms, Cambridge University Press, Cambridge, 2000, pp. 129-166.

[29] G. Schock, A. Miquel, Mass transfer and pressure loss in spiral wound modules, Desalination, 64 (1987) 339-352.

[30] J.S. Vrouwenvelder, J.A.M. van Paassen, J.M.C. van Agtmaal, M.C.M. van Loosdrecht, J.C. Kruithof, A critical flux to avoid biofouling of spiral wound nanofiltration and reverse osmosis membranes: Fact or fiction?, Journal of Membrane Science, 326 (2009) 36-44.

[31] R.D. Noble, S.A. Stern, Membrane separations technology: principles and applications, Elsevier, 1995.

[32] J. Gutman, S. Fox, J. Gilron, Interactions between biofilms and NF/RO flux and their implications for control-A review of recent developments, Journal of Membrane Science, 421-422 (2012) 1-7.

[33] M. Herzberg, M. Elimelech, Biofouling of reverse osmosis membranes: Role of biofilm-enhanced osmotic pressure, Journal of Membrane Science, 295 (2007) 11-20.

[34] C. Dreszer, J.S. Vrouwenvelder, A.H. Paulitsch-Fuchs, A. Zwijnenburg, J.C. Kruithof, H.C. Flemming, Hydraulic resistance of biofilms, Journal of Membrane Science, 429 (2013) 436-447.

[35] J.S. Vrouwenvelder, J.A.M. van Paassen, J.C. Kruithof, M.C.M. van Loosdrecht, Sensitive pressure drop measurements of individual lead membrane elements for accurate early biofouling detection, Journal of Membrane Science, 338 (2009) 92-99.

[36] J.S. Vrouwenvelder, D.A. Graf von der Schulenburg, J.C. Kruithof, M.L. Johns, M.C.M. van Loosdrecht, Biofouling of spiral-wound nanofiltration and reverse osmosis membranes: A feed spacer problem, Water Research, 43 (2009) 583-594.

[37] P.A. Araújo, J.C. Kruithof, M.C.M. Van Loosdrecht, J.S. Vrouwenvelder, The potential of standard and modified feed spacers for biofouling control, Journal of Membrane Science, 403-404 (2012) 58-70.

[38] W.A.M. Hijnen, D. Biraud, E.R. Cornelissen, D. Van Der Kooij, Threshold concentration of easily assimilable organic carbon in feedwater for biofouling of spiral-wound membranes,

Environmental Science and Technology, 43 (2009) 4890-4895.

[39] J.S. Vrouwenvelder, C. Hinrichs, W.G.J. Van der Meer, M.C.M. Van Loosdrecht, J.C. Kruithof, Pressure drop increase by biofilm accumulation in spiral wound RO and NF membrane systems: role 
of substrate concentration, flow velocity, substrate load and flow direction, Biofouling, 25 (2009) 543555.

[40] M. Wagner, D. Taherzadeh, C. Haisch, H. Horn, Investigation of the mesoscale structure and volumetric features of biofilms using optical coherence tomography, Biotechnology and Bioengineering, 107 (2010) 844-853.

[41] C. Staudt, H. Horn, D.C. Hempel, T.R. Neu, Volumetric measurements of bacterial cells and extracellular polymeric substance glycoconjugates in biofilms, Biotechnology and Bioengineering, 88 (2004) 585-592.

[42] B. Halan, K. Buehler, A. Schmid, Biofilms as living catalysts in continuous chemical syntheses, Trends in Biotechnology, 30 (2012) 453-465.

[43] D. Huang, E. Swanson, C. Lin, J. Schuman, W. Stinson, W. Chang, M. Hee, T. Flotte, K. Gregory, C. Puliafito, J.G. Fujimoto, Optical coherence tomography, Science, 254 (1991) 1178-1181.

[44] P. Hrynchak, T. Simpson, Optical coherence tomography: An introduction to the technique and its use, Optometry and Vision Science, 77 (2000) 347-356.

[45] A.F. Fercher, W. Drexler, C.K. Hitzenberger, T. Lasser, Optical coherence tomography principles and applications, Reports on Progress in Physics, 66 (2003) 239.

[46] C. Haisch, R. Niessner, Visualisation of transient processes in biofilms by optical coherence tomography, Water Research, 41 (2007) 2467-2472.

[47] N. Derlon, M. Peter-Varbanets, A. Scheidegger, W. Pronk, E. Morgenroth, Predation influences the structure of biofilm developed on ultrafiltration membranes, Water Research, 46 (2012) 3323-3333. [48] Y. Chao, T. Zhang, Optimization of fixation methods for observation of bacterial cell morphology and surface ultrastructures by atomic force microscopy, Appl Microbiol Biotechnol, 92 (2011) 381392.

[49] J.L. Bert, Membrane compaction: A theoretical and experimental explanation, Journal of Polymer Science Part B: Polymer Letters, 7 (1969) 685-691.

[50] W.A.M. Hijnen, E.R. Cornelissen, D. van der Kooij, Threshold concentrations of biomass and iron for pressure drop increase in spiral-wound membrane elements, Water Research, 45 (2011) 16071616.

[51] J.S. Vrouwenvelder, J. Buiter, M. Riviere, W.G.J. van der Meer, M.C.M. van Loosdrecht, J.C. Kruithof, Impact of flow regime on pressure drop increase and biomass accumulation and morphology in membrane systems, Water Res., 44 (2010) 689-702.

[52] O. Habimana, A.J.C. Semião, E. Casey, The role of cell-surface interactions in bacterial initial adhesion and consequent biofilm formation on nanofiltration/reverse osmosis membranes, Journal of Membrane Science, 454 (2014) 82-96. 


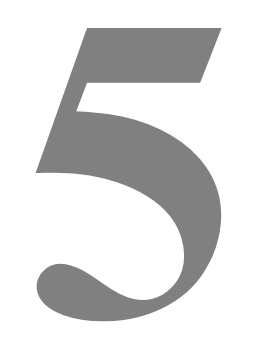

\section{Hydrogel-coated feed spacers in two-phase flow cleaning in spiral wound membrane elements: a novel platform for eco-friendly biofouling mitigation}

\begin{tabular}{r}
\hline \hline \\
Y. Wibisono \\
W. Yandi \\
M.Golabi \\
R. Nugraha \\
E.R. Cornelissen \\
A.J.B. Kemperman \\
T. Ederth \\
K. Nijmeijer
\end{tabular}

This chapter has been submitted to Water Research as:

Y. Wibisono, W. Yandi, M. Golabi, R. Nugraha, E.R. Cornelissen, A.J.B. Kemperman, T.Ederth, K. Nijmeijer, Hydrogel-coated feed spacer in two-phase flow cleaning in spiralwound membrane elements: a novel platform for eco-friendly biofouling mitigation 


\begin{abstract}
Biofouling is still a major challenge in the application of nanofiltration and reverse osmosis membranes. Here we present a platform approach for environmentally friendly biofouling control using a combination of a hydrogel-coated feed spacer and two-phase flow cleaning. Neutral (polyHEMA-co-PEG ${ }_{10} \mathrm{MA}$ ), cationic (polyDMAEMA) and anionic (polySPMA) hydrogels have been successfully grafted onto polypropylene (PP) feed spacers via plasmamediated UV-polymerization. These coatings maintained their chemical stability after 7 days incubation in neutral ( $\mathrm{pH}$ 7), acidic ( $\mathrm{pH}$ ) and basic ( $\mathrm{pH}$ 9) environments. Anti-biofouling properties of these coating were evaluated by E. coli attachment assay and nanofiltration and experiments at a TMP of $600 \mathrm{kPag}$ using tap water with additional nutrients as feed and by using optical coherence tomography. Especially the anionic polySPMA-coated PP feed spacer shows reduced attachment of $E$. coli and biofouling in the spacer-filled narrow channels resulting in delayed biofilm growth. Employing this highly hydrophilic coating during removal of biofouling by two-phase flow cleaning also showed enhanced cleaning efficiency, feed channel pressure drop and flux recoveries. The strong hydrophilic nature and the presence of negative charges on polySPMA are most probably responsible for the improved antifouling behavior. A combination of polySPMA-coated PP feed spacers and two-phase flow cleaning therefore is promising and an environmentally friendly approach to control biofouling in NF/RO systems employing spiral-wound membrane modules.
\end{abstract}




\subsection{Introduction}

Ensuring adequate clean water supply is essential for human beings, especially for drinking water and food production. Membrane technology has shown considerable progression in the past years, and is widely employed to facilitate an increase in clean water supplies via the treatment of fresh water, reuse of wastewater, and desalination of salty water [1]. High pressure membrane processes, i.e. nanofiltration (NF) and reverse osmosis (RO) are the most commonly applied membrane processes for the removal of contaminants and pathogens from drinking water supplies [2, 3]. However, despite their widespread application worldwide, biofouling remains a major obstacle since it lowers the performance of NF/RO plants [4].

Commonly practiced biofouling control by using chemical agents (alkalines, detergents, enzymes, chelating agents, acids, biocides) were found ineffective in removing biofouling completely from NF/RO spiral wound membrane channels [5, 6]. Besides promoting membrane damages [7] and being harmful to the environment [8], the use of biocides, may promote the resistance of microorganisms towards these biocides and worsens the biofouling problems [9]. Re-growth of biofouling was observed after chemical cleaning, due to the presence of dead bacteria, which served as nutrients for subsequent growth. Physical removal of remaining biomass is therefore essential to optimize biofouling control [10]. The presence of spacers in the membrane modules have a significant contribution to the occurrence of biofouling and especially the feed spacer is a source for biomass growth inducing befouling. Biofouling removal from membrane feed channels using two-phase flow was found effective and can be used as an environment and membrane friendly cleaning method $[11,12]$.

In our previous work, we investigated the role of feed spacer geometry, feed pressure, gas/liquid ratio, cleaning duration, and liquid velocity on biofouling removal in spiral wound membrane elements [11]. However, in order to reduce the occurrence of biofouling, prevention at the source is the preferred option. In this work we therefore investigate the influence of charge of the employed spacers using hydrogel coated polypropylene (PP) feed spacers, and its effect on prevention of early attachment of biofouling. Although the effect of charge on the anti-biofouling properties has been investigated before, the effect of charge of a polymer coated feed spacer filament has however, not been investigated systematically so far. Three hydrogels with different charge (neutral: HEMA-co-PEG ${ }_{10}$ MA; cationic: DMAEMA and anionic: SPMA) were selected and coated onto a polypropylene (PP) feed spacer. This 
allowed us to systematically investigate the anti-biofouling effect of the feed spacer charge using bacteria adhesion tests and biofouling evaluation in nanofiltration experiments. We aim at providing a novel eco-friendly method to control biofouling in NF/RO systems by a combination of charged hydrogel-coated PP feed spacers and two-phase flow cleaning.

\subsection{Theory of feed spacer coating}

Biofilms initially grow alongside the feed spacer, and eventually attach to membrane surface [13]. The feed spacer is responsible for the accumulation of biomass in the membrane channels. Although numerous studies on membrane surface modification [14] exist, the literature on spacer surface modification is less abundant. Surface modifications of feed spacer have been studied using metal coatings, e.g. silver and copper $[15,16]$ or functionalized polymers, e.g. polydopamine, polydopamine-g-poly(ethylene glycol) and diglyme plasma coating $[17,18]$.

The aforementioned surface coatings showed some limitations. Toxic coatings (silver, copper, biocide etc.) act similarly to chemical cleaning, the first layer of bacterial cells might be killed, but the material from dead bacteria provides nutrients for subsequent bacterial growth [16]. For polydopamine and polydopamine-g-poly(ethylene glycol) coatings, although batch adhesion tests using bacterial solutions or proteins under static conditions showed good antibiofouling properties, long-term and continuous biofouling experiments demonstrated poor biofouling inhibition [19]. The results might be related to instability of those polymers during long-term experiments. The potential of hydrophilic coatings to facilitate membrane cleaning is therefore still promising [19].

Moreover, polydopamine is amphoteric and shows different surface charges in acid or basic environments [20], and the results suggest that surface charge effects the early attachment of biofouling on the feed spacer surface, since electrostatic interactions between surfaces and the charged outer layer of cell membranes of fouling organisms can play a role.

Hydrogel-based materials have been reported to have good anti-biofouling properties and have great potential to be applied as antifouling coatings [21, 22]. Their antifouling properties might be correlated with the charge, entropic elasticity and strong surface hydration of the hydrogels [23]. Poly ethylene glycol (PEG) based coating materials are well known for their 
remarkable antifouling properties [24, 25]. Cationic polyDMAEMA has also been reported as a potential antimicrobial material [26], as has the anionic counterpart polySPMA [27, 28].

Considering that the net charge of the cell wall of most bacteria that cause biofouling is negative [29], it is important to investigate the effect of spacer charge (i.e. coating charge for coated spacers) on biofouling control. In addition, some biofouling organisms secrete bioadhessives, which also consist of charged polysaccharides and proteins.

\subsection{Experimental section}

\subsubsection{Materials}

A polypropylene (PP) feed spacer with a thickness of $0.7 \mathrm{~mm}$ was provided by Delstar Technology Inc., UK. 2-hydroxyethyl methacrylate (HEMA), polyethylene glycol methacrylate ( $\left.\mathrm{PEG}_{10} \mathrm{MA}\right)$, 3-sulfopropyl methacrylate potassium salt (SPMA), 2dimethylaminoethyl methacrylate (DMAEMA), and nutrient broth bacterial culture media were purchased from Sigma-Aldrich Sweden AB. Crystal violet, a Gram-color modified kit for Gram staining was purchased from Merck, Sweden. All chemicals were used without further purification. Bacterial attachment assays were carried out using 12-well polystyrene culture plates sterilized by gamma irradiation (VWR, Sweden). Thin film composite ESNA1LF2 NF membranes and permeate spacers were obtained from Hydranautics, Oceanside, Californa, USA. Sodium acetate $\left(\mathrm{CH}_{3} \mathrm{COONa}\right)$, sodium nitrate $\left(\mathrm{NaNO}_{3}\right)$, anhydrous monobasic sodium phosphate $\left(\mathrm{NaH}_{2} \mathrm{PO}_{4}\right)$ and sodium hydroxide $(\mathrm{NaOH})$ were purchased from Sigma-Aldrich (Germany) and used as received.

\subsubsection{Plasma-mediated UV-polymerization}

The grafting of charged hydrophilic polymers onto a PP feed spacer surface using plasma treatment of PP and UV-photopolymerization can be generally divided into two steps (Fig. 5.1). The first step is the activation of the PP surface by oxygen plasma. After 15 minutes exposure to oxygen plasma at room temperature, hydroxyl, peroxide and carbonyl functional groups are produced. The second step is the grafting of the monomers onto the activated PP surfaces by UV-polymerization $(\lambda=365 \mathrm{~nm})$. 
UV photopolymerization

\section{Plasma treatment}

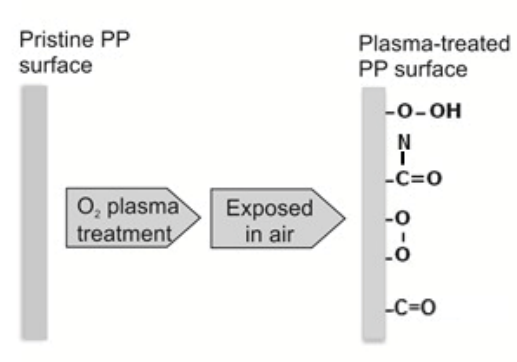

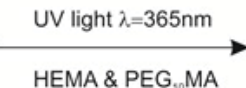

UV light $\lambda=365 \mathrm{~nm}$ DMAEMA

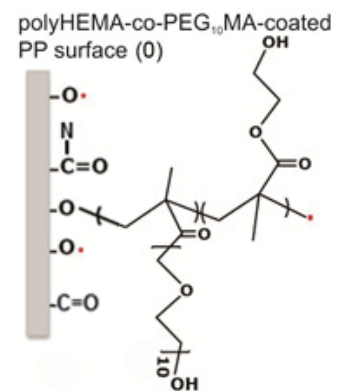

polyDMAEMA-coated PP surface (+)

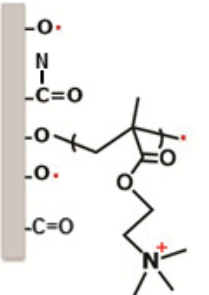

polySPMA-coated PP surface (-)

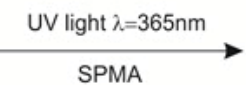

Fig. 5.1. Reaction scheme of UV-induced grafted polymerization (UV light, $\lambda=365 \mathrm{~nm}$ ) of hydrophilic polymers (polyHEMA-co-PEG ${ }_{10} \mathrm{MA}$, polyDMAEMA or polySPMA) onto a polypropylene (PP) feed spacer surface. PP is treated in oxygen plasma, followed by UV irradiation to attached the monomers (i.e. HEMA/PEG ${ }_{10}$ MA mixture, DMAEMA, or SPMA). The resulting hydrogel polymers grafted to the PP surface have different charges: polyHEMA-co-PEG ${ }_{10} \mathrm{MA}$ is neutral $(0)$, polyDMAEMA has a positive charge $(+)$ and polySPMA has a negative charge (-).

Fig. 5.2 illustrates the preparation of the modified feed spacer by coating with the hydrophilic polymers. Polypropylene feed spacer samples were sonicated for $15 \mathrm{~min}$ in acetone to remove residual chemicals from the manufacturing, dried and weighted. The samples were then treated with oxygen plasma (standard plasma-system Pico, Diener, Germany) for 15 min, under approximately $10 \mathrm{~Pa}$ oxygen partial pressure at approximately $200 \mathrm{~W}$. Samples were then immediately incubated in HEMA and PEG $_{10}$ MA, SPMA, or DMAEMA solutions in water for 24 hours at room temperature. For photopolymerization, the incubated samples were placed between two transparent quartz discs and irradiated by UV light $(\lambda=365 \mathrm{~nm})$ for 2 hours. The reaction chamber was purged with moist nitrogen gas for $1 \mathrm{~min}$ before and during 
UV-polymerization to prevent interference of oxygen and to prevent the solvent from evaporating. After irradiation, the spacer was soaked in water for 24 hours to remove unreacted monomers and other chemical residues. The samples were then dried in an incubator at $100{ }^{\circ} \mathrm{C}$ for $48 \mathrm{~h}$ and weighed. The percentage of grafting (PG) of polymer on the spacers was calculated using the following equation:

$$
P G(\%)=\frac{w_{p}-w_{0}}{w_{0}} \times 100 \%
$$

where $w_{0}$ and $w_{p}$ are the weights of the spacer before and after polymerization, respectively.

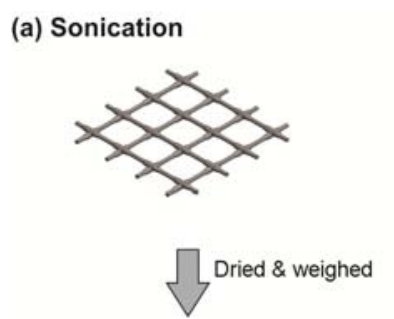

(b) Oxygen plasma treatment

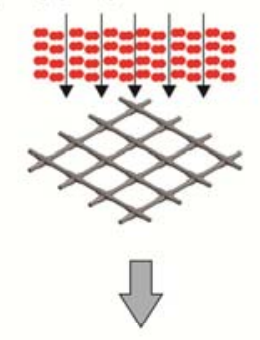

(c) Monomer incubation

HEMA \& PEG ${ }_{10} M A$ (neutral) SPMA (anionic) DMAEMA (cationic)

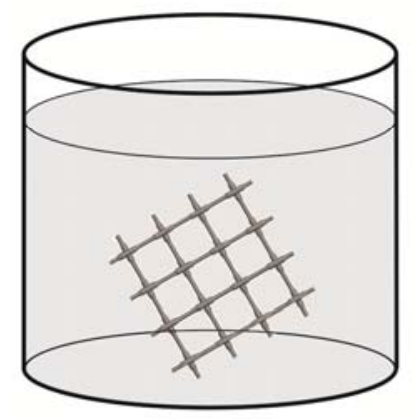

(f) Hydrogel-coated feed spacer

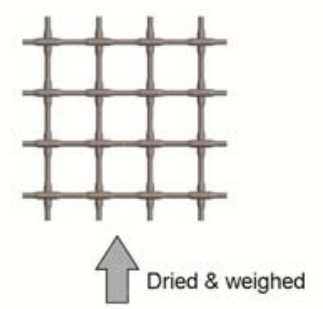

(e) Immersion in water

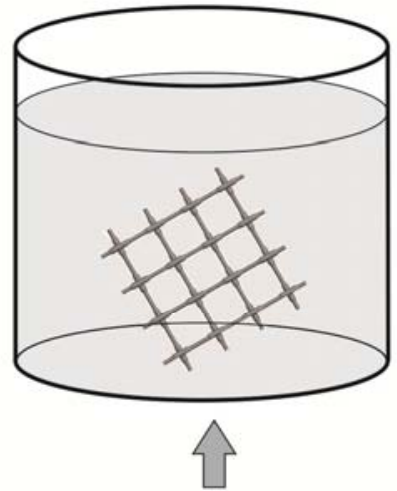

(d) UV-photopolymerization

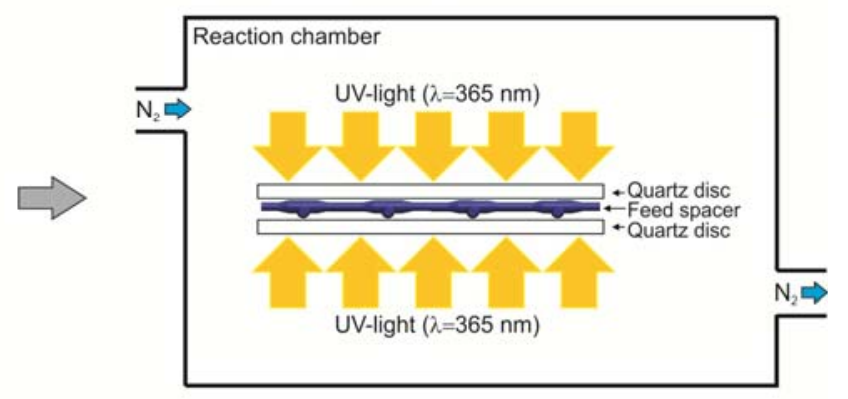

Fig. 5.2. Plasma mediated UV-polymerization of hydrophilic polymers on polypropylene feed spacers: (a) sonication, $15 \mathrm{~min}$ in acetone; (b) oxygen plasma treatment for $15 \mathrm{~min}$; (c) incubation in monomer solution (HEMA and PEG ${ }_{10}$ MA, DMAEMA, or SPMA) for 24 hours; (d) UV-polymerization $(\lambda=365 \mathrm{~nm})$ for 2 hours; (e) soaking in water for 24 hours; (f) hydrophilized feed spacer after drying. 


\subsubsection{Polymer characterization}

All pristine and hydrogel-coated polypropylene (PP) spacers were characterized using Fourier-Transform Infrared Attenuated Total Reflection (FTIR-ATR) spectroscopy using a Pike MIRacle ATR accessory with a diamond prism in a Vertex70 FT-IR Spectrometer (Bruker, Germany) equipped with a DTGS detector. The samples were pressed against the prism with a swivel tip, which is used for non-plated surfaces and makes it possible to hold the substrate by adjusting or twisting its position on the substrate surface. OPUS 7.2 software was used for data acquisition and processing. The spectra were recorded over a wavelength range $4600-600 \mathrm{~cm}^{-1}$ and at a spectral resolution of $4 \mathrm{~cm}^{-1}$. IR spectra of pristine and hydrogelcoated PP were recorded after polymerization, chemical stability test and post-filtration evaluation, respectively.

Surface roughness and topography of pristine and hydrogel-coated PP were examined by a NanoScope IVa Dimension 3100 SPM Atomic Force Microscope (AFM) (Veeco Instruments, Inc., USA). The images were recorded over an area of $5 \times 5 \mu \mathrm{m}^{2}$ in tapping mode in air at an acquisition rate of $1 \mathrm{~Hz}$.

In order to measure the wettability of the coatings, SPMA, HEMA-PEG ${ }_{10}$ MA, and DMAEMA were polymerized onto intiator-immobilized gold surfaces via surface mediated atom transfer radical polymerization (SI-ATRP). The thickness of these coatings was adjusted to $100 \AA$. The captive bubble technique was used to measure the contact angle of the hydrated polymer coatings using a Dataphysics OCA35 contact angle analyzer with software SCA22. After equilibrating the coating samples in water for $1 \mathrm{~h}$, the samples were placed facing downwards in a glass container filled with deionized water. $2 \mu \mathrm{l}$ of air was released to the polymer surfaces by a U-shaped needle under control of a computer system. Three contact angles of the bubble were measured and the values were averaged.

\subsubsection{Polymer stability test}

To evaluate the stability of the grafted polymers in water, acidic and basic environments after short and long-term immersion, hydrogel-coated spacers were incubated in water $(\mathrm{pH} \mathrm{5,7}$ and 9) for one day, one week and one month. The $\mathrm{pH}$ was adjusted by adding hydrochloric acid $(0.1 \mathrm{M})$ and sodium hydroxide $(0.1 \mathrm{M})$ to deionized water (Milli-Q). The temperature used in 
this study was $5^{\circ} \mathrm{C}$ to avoid the growth of microorganisms to exclude the effect of biofouling on the stability of the coating, as the presence of grown microorganisms might change the $\mathrm{pH}$ of system as these secrete metabolites. The weight and IR spectra of the samples were measured before and after incubation. The samples were washed several times in Milli-Q water and dried prior to the measurements. The loss of polymer coating in terms of weight loss (WL) was calculated using:

$W L=W_{f}-W_{i}$

where $W_{f}$ and $W_{i}$ are the weight of the spacer after and before incubation, respectively.

\subsubsection{Bacterial attachment assay}

Escherichia coli (CCUG 3274) were cultured in nutrient broth (NB) medium at $37^{\circ} \mathrm{C}$ by shaking at $170 \mathrm{rpm}$ for 16 hours. Fresh sterile NB medium was then added to the bacterial suspension and the optical density was adjusted to 0.1 (approximately $10^{8} \mathrm{cfu} / \mathrm{ml}$ ) at $600 \mathrm{~nm}$. Four replicates of each feed spacer sample (pristine and hydrogel-coated PPs) were placed in 12-well polystyrene plates and $4 \mathrm{ml}$ of bacterial suspension was dispensed to each well. The plates were incubated at $37^{\circ} \mathrm{C}$ and $75 \mathrm{rpm}$ for 1,4 or 24 hours. After incubation, the samples were washed several times in Milli-Q water and transferred to a new well plate. $4 \mathrm{ml}$ of crystal violet $0.3 \%$ was added to each well. After 15 min incubation at room temperature, samples were gently washed three times by Milli-Q water to remove non-bound bacterial cells and extra stain. The washed samples were immersed in a new well plate containing $4 \mathrm{ml}$ of ethanol $95 \%(\mathrm{v} / \mathrm{v})$ for $20 \mathrm{~min}$ to release crystal violet from the bacteria cell walls. The optical density (OD) of the solution in each well was measured at $540 \mathrm{~nm}$.

Four replicates of each sample, incubated with fresh sterile NB without bacteria, but otherwise treated similarly, were used as negative controls in this experiment. The optical density of crystal violet from bacteria was corrected by subtracting its mean OD from the negative control prior to statistical analysis. To obtain the images of bacteria on the spacer surfaces, the samples were fixed in $10 \mathrm{~mL}$ of $2.5 \%(\mathrm{v} / \mathrm{v})$ glutaraldehyde for $20 \mathrm{~min}$ at room temperature. After washing in Milli-Q water and air-drying, the samples were attached to the sample holder using double-sided carbon tape. The surface of the samples was sprayed by compressed gas to remove any lose particles and debris. Bacteria on the feed spacers were detected by a Phenom 
(FEI, Eindhoven, Netherlands) desktop scanning electron microscope (SEM). The SEM images were displayed as inverted images to enhance the visibility of the bacteria cells.

The relative attachment of bacteria to the hydrogel-coated samples is presented as the optical density of the bacteria at $540 \mathrm{~nm}\left(\mathrm{OD}_{540 \mathrm{~nm}}\right)$ on the spacer surface and normalized to the uncoated spacer. Error bars represent the standard deviation from 4 replicates of each sample. Statistical analysis of these data was carried out using Minitab 16 statistical software. Oneway Analysis of Variance (ANOVA) with $\alpha=5 \%$ and Tukey's HSD Post-hoc test were performed to determine the difference between hydrogel-coated and uncoated samples. Values were considered significantly different from each other when $p$-value $(p)<0.05$.

\subsubsection{Filtration tests}

Fig. 5.3 shows the schematic diagram of the filtration test set-up used. The lower part shows the feed water before entering the filtration cells. Tap water (Enschede, The Netherlands) used as feed. Before storage in a 60 liter feed tank, the feed water was filtered by a cartridge filter (1-3 $\mu$ m polypropylene wound FA10", Purtrex PX01-10, USA). The feed tank was equipped with a floating switch valve to regulate the water level. Storage of the feed water in the feed tank, resulted in a water temperature approximately equal to the room temperature. To promote accelerated biofouling growth, nutrients were added to the feed after the feed tank by using a peristaltic pump (Masterflex L/S pumps, Cole-Palmer Instrument Company, USA). The feed water was then pumped and equally distributed into three lines using a high pressure feed pump (Micropump GAF series, Micropump Inc., Canada).

In the upper part of the filtration set-up, a mass flow controller (Cori-Flow, Bronkhorst, The Netherlands: $10 \pm 0.02 \mathrm{~L} / \mathrm{h} \max$ ), regulated the flow rate within each line and allowed equal feed flow to each vertically positioned filtration cell. The filtration cells were covered from direct light to prevent growth of phototrophic organisms like algae. The feed channel pressure drop of the filtration cell was measured using a differential pressure sensor (EL-Press, Bronkhorst, The Netherlands: $\Delta \mathrm{P} \max =100 \pm 0.5 \mathrm{kPa}$ ) and the flux was measured using a balance (Mettler-Toledo P3002). The retentate and permeate lines were drained without recirculating the water. During two-phase flow cleaning, nitrogen gas was introduced in the liquid line before the filtration cells, controlled by a mass flow controller (EL-Flow, 
Bronkhorst, The Netherlands: $500 \pm 0.25 \mathrm{~mL}_{\mathrm{n}} / \mathrm{min}$ ). The filtration cells were custom-made and manufactured from PMMA plates with a stainless steel frame to allow for operation at moderate pressures (maximum operating pressure of $600 \mathrm{kPag}$ ).

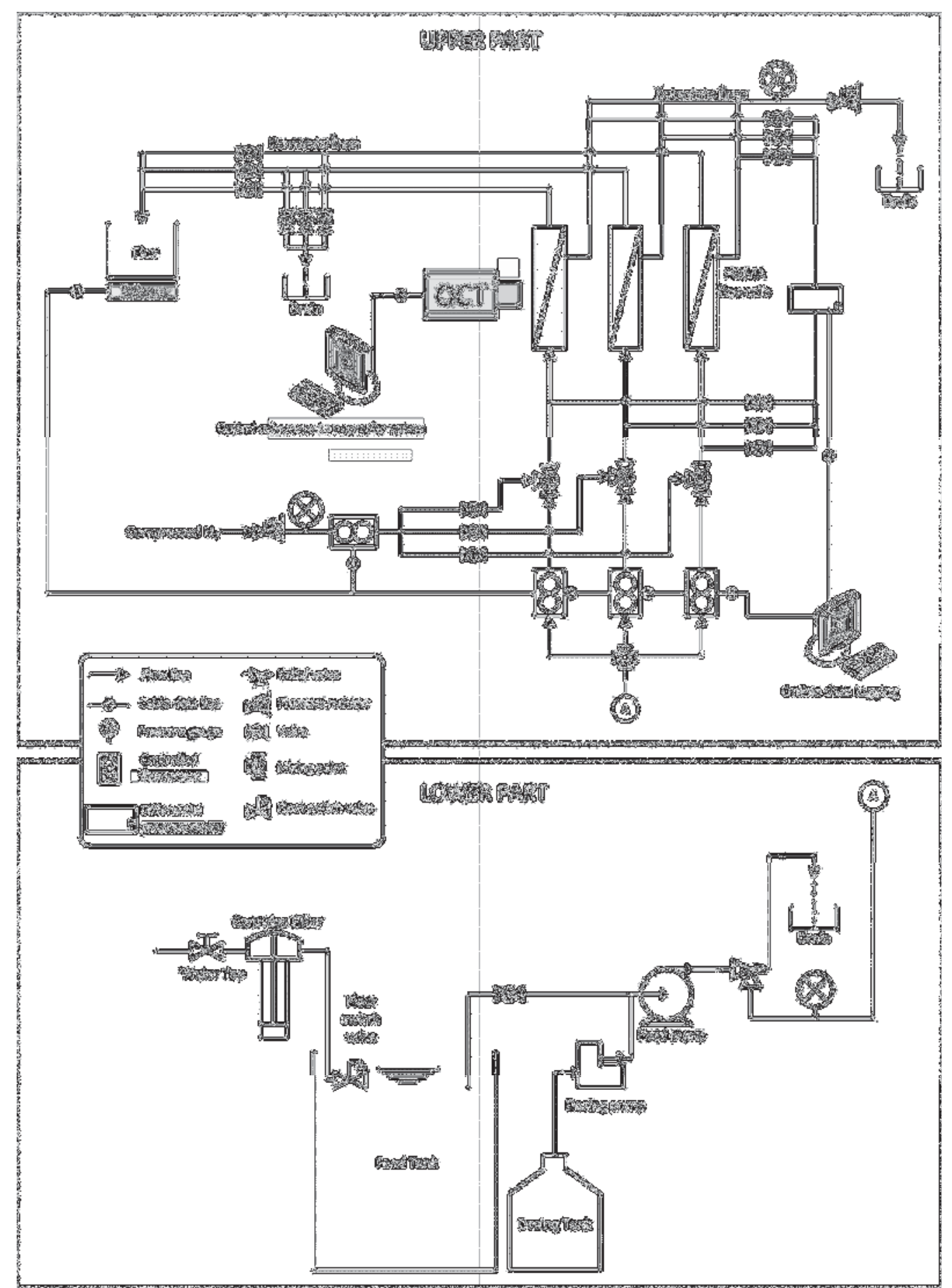

Fig. 5.3. Experimental set-up used for filtration experiments. The lower part consists of a water tap, cartridge filter, feed tank, dosing tank, dosing pump and feed pump. The upper part consists of mass flow controllers, filtration cells, differential pressure meters, balance and nitrogen gas line; all measurements were controlled and logged using a personal computer. The biofouling growth was observed daily by optical coherence tomography (OCT). 
The filtration test procedures were similar as described in our previous work [11]. Each sample of modified feed spacer was tested in two stages: (1) a fouling stage; biofouling growth in the spacer-filled channel causing at least 300\% FCP increase over the feed channel; and (2) a cleaning stage; two-phase flow cleaning to remove biofouling.

During the fouling stage, fresh NF membranes were used in each experiment and each hydrogel-coated feed spacer was tested in a separate experimental run. Prior to use, the membranes were soaked in Milli-Q water overnight to remove preservation liquid after which the filtration cells were closed. The liquid superficial velocity was set at $0.11 \mathrm{~m} / \mathrm{s}$ by mass flow controllers and pump speed, and the TMP was set at $600 \mathrm{kPag}$. To enhance biofouling growth, nutrients (sodium acetate $\left(\mathrm{CH}_{3} \mathrm{COONa}\right)$, sodium nitrate $\left(\mathrm{NaNO}_{3}\right)$, and anhydrous monobasic sodium phosphate $\left.\left(\mathrm{NaH}_{2} \mathrm{PO}_{4}\right)\right)$, were added to the feed water in a molar ratio $\mathrm{C}: \mathrm{N}: \mathrm{P}=100: 20: 10$. The nutrient concentration was set at $1 \mathrm{mg} \mathrm{Ac-C/L}$, aiming at an experimental run of approximately 6-7 days for uncoated feed spacers.

The FCP and flux were recorded at least once per day for each filtration cell, and the biofouling growth in the filtration cells was observed daily in situ using optical coherence tomography (OCT) (Ganymede Spectral Domain OCT, Thorlabs GmbH, Germany). The OCT was set at a field of view (B-scans) of $x=10 \mathrm{~mm}$ and $\mathrm{z}=1.5 \mathrm{~mm}$, with pixel size 5429x546. As shown in Fig. 5.4, the observation area is located in the middle of the filtration cell (blue square) and the red arrow indicates the scanning direction, which is identical to the flow direction. The refractive index of water (1.33) was used since the light beam passes the wetted biofouling layer in the feed channel. The acquisition time was $2.018 \mathrm{~s}$. All tomograms are presented as obtained, the orange scale intensity is proportional to the intensity of the detected reflection of the raw signal.

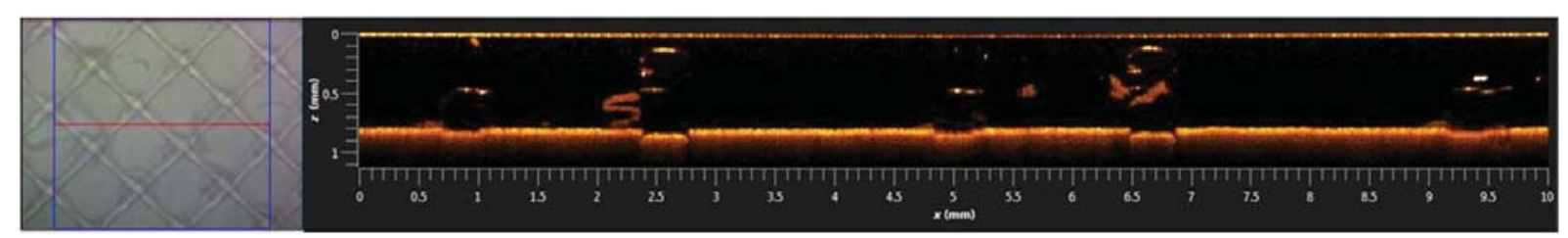

Fig. 5.4. Left: OCT observation of biofouling in the spacer-filled channels in the middle of the filtration cell; the blue square indicates the observation area and the red arrow is the scan direction, which is in the same direction as the flow direction. Right: OCT image showing a 2$\mathrm{D}$ cross-sectional view of the biofouling structure in a spacer-filled filtration channel, exactly at the red line shown in the left picture. Refractive index is 1.33 and the intensity of the detected reflection of the raw signal is presented as the orange scale intensity. Field of view (FOV): $x=10 \mathrm{~mm}$ and $\mathrm{z}=1.5 \mathrm{~mm}$, with pixel size 5429x546 and acquisition time $2.018 \mathrm{~s}$. 190 
When the FCP of a specific filtration cell increased by at least $300 \%$, the fouling stage was considered to be complete and the cleaning stage was started. During the cleaning stage, the liquid velocity was set at $0.44 \mathrm{~m} / \mathrm{s}$, and nitrogen gas was introduced into the liquid using a mass flow controller at a gas/liquid ratio $\theta=0.5$. The TMP was set at $0 \mathrm{kPag}$ during the 10 minutes of two-phase flow cleaning. FCP and flux before and after two-phase flow cleaning were measured, and the cleaning efficiency was calculated based on the recovery of the FCP to the initial pressure drop at day 0 , and the flux recovery to the clean water flux of the membrane [11].

The two-phase flow cleaning efficiency was represented as FCP-based cleaning efficiency or FCP recovery, which was calculated using:

$\eta_{(F C P)}=\frac{\Delta P_{300 \% \text { fouled }}-\Delta P_{\text {cleaned }}}{\Delta P_{300 \% \text { fouled }}-\Delta P_{0}} \cdot 100 \%$

where $\Delta \mathrm{P}_{0}$ is the initial pressure drop at day $0, \Delta \mathrm{P}_{300 \% \text { fouled }}$ is the final pressure drop determined just before two-phase flow cleaning and $\Delta \mathrm{P}_{\text {cleaned }}$ is the pressure drop after twophase flow cleaning. All $\Delta \mathrm{P}$ values are normalized to the lowest $\Delta \mathrm{P}_{0}$ of all runs.

The flux-based cleaning efficiency is presented as MTC recovery and calculated using:

$\eta_{M T C}=\frac{M T C_{\text {fouled }}-M T C_{\text {cleaned }}}{M T C_{\text {fouled }}-M T C_{0}} \cdot 100 \%$

where $\mathrm{MTC}_{0}$ is the initial MTC $=4.9 \times 10^{-11} \mathrm{~m} / \mathrm{s} . \mathrm{Pa}[11], \mathrm{MTC}_{\text {fouled }}$ is the final MTC before two-phase flow cleaning, and $\mathrm{MTC}_{\text {cleaned }}$ is the MTC after two-phase flow cleaning.

After the filtration test and subsequent two-phase flow cleaning, the feed spacers were removed from the flow cell and dried in an incubator at $100^{\circ} \mathrm{C}$ for $24 \mathrm{~h}$. The ATR-FTIR spectra of both pristine and polymer-coated PP were then recorded.

\subsection{Results and Discussion}

\subsubsection{Coating characterization}

The percentage grafting (PG) of polymer on the feed spacer was calculated using Eq. (5.1). A slight but consistent $\sim 0.32 \%$ increase in spacer weight was observed for all hydrogels (Table 
5.1). The change relative to the original spacer weight is small and will not affect the geometry of the feed spacer and its hydrodynamics in the feed channel.

Table 5.1. Percentage grafting of polymer-coated PP feed spacer.

\begin{tabular}{|l|c|}
\hline Polymer type & PG (\%) \\
\hline HEMA-co-PEG ${ }_{10}$ MA & $0.3203 \pm 0.051$ \\
\hline DMAEMA & $0.3203 \pm 0.064$ \\
\hline SPMA & $0.3205 \pm 0.054$ \\
\hline
\end{tabular}

The FTIR-ATR spectra of pristine PP, oxygen plasma-treated PP and the three hydrogelcoated PPs are shown in Fig. 5.5.

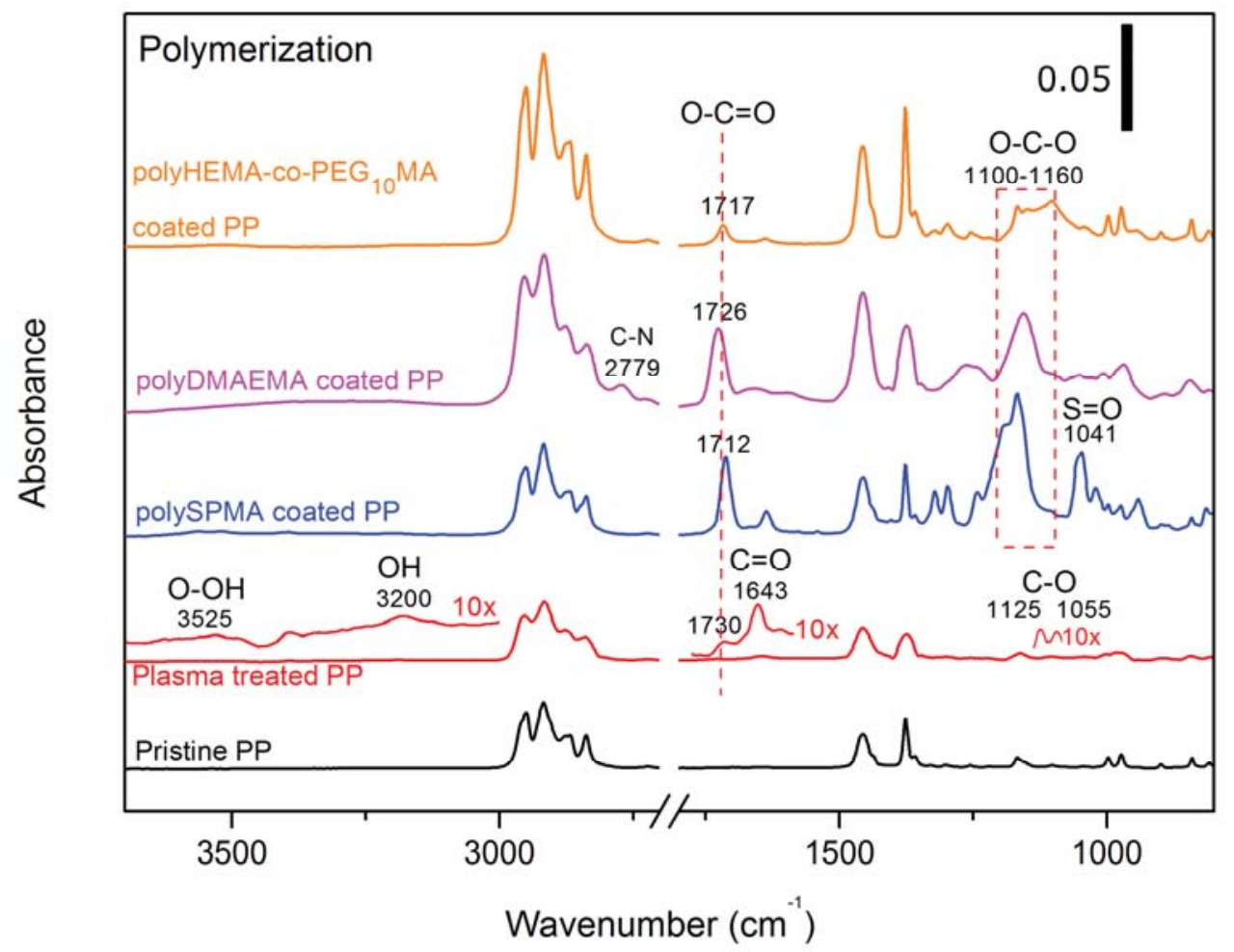

Fig. 5.5. FTIR-ATR spectra of pristine $P P$, oxygen plasma-treated $P P$ and hydrogel-coated $P P$ (polyHEMA-co-PEG ${ }_{10} \mathrm{MA}$, polyDMAEMA and polySPMA). The floating bar in right upper corner is the absorbance scale unit.

As shown in Fig. 5.5, the spectrum of pristine PP is dominated by $\mathrm{C}-\mathrm{H}$-stretching modes from $\mathrm{CH}_{2}$ and $\mathrm{CH}_{3}$ (3000-2800 $\left.\mathrm{cm}^{-1}\right), \mathrm{CH}_{2}$ and $\mathrm{CH}_{3}$ deformations $\left(1456 \mathrm{~cm}^{-1}\right.$ and $\left.1374 \mathrm{~cm}^{-1}\right)$, skeletal vibrations $\left(1162,981\right.$ and $\left.971 \mathrm{~cm}^{-1}\right)$, and $\mathrm{CH}_{2}$ rocking $\left(845\right.$ and $\left.806 \mathrm{~cm}^{-1}\right)$. After 15 192 
minutes of exposure to oxygen plasma, ester carbonyl $(\mathrm{C}=\mathrm{O})$ absorptions from aldehyde, keton and acid groups $\left(1730 \mathrm{~cm}^{-1}\right)$ and carbonyl from amides $\left(1643 \mathrm{~cm}^{-1}\right)$ are observed [30]. Weak O-H stretching bands from hydroxide $\left(3000-3200 \mathrm{~cm}^{-1}\right)$ peroxide $\left(3525 \mathrm{~cm}^{-1}\right)$ are observed as well [30]. Weak C-O stretching bands from hydroxide and peroxide are visible at 1055 and $1125 \mathrm{~cm}^{-1}$. The presence of polyHEMA-co-PEG ${ }_{10} \mathrm{MA}$, polyDMAEMA and polySPMA is confirmed by their $\mathrm{C}=\mathrm{O}$ ester carbonyl stretching peaks visible at 1712-1726 $\mathrm{cm}^{-1}$ in the FTIR spectra, which is absent in the spectrum of the pristine spacer and slowly increases in the plasma-treated PP spectrum. Sulfonate functional group $(S=O)$ from SPMA are observed in the polySPMA spectrum at $1041 \mathrm{~cm}^{-1}$. Tertiary amine $\mathrm{C}-\mathrm{H}$ stretching in polyDMAEMA is observed at $2779 \mathrm{~cm}^{-1}$. Furthermore, skeletal $\mathrm{C}-\mathrm{O}-\mathrm{C}$ vibrations of PEG, SPMA and DMAEMA are found at $1100-1160 \mathrm{~cm}^{-1}$. These results indicate that polyHEMAco-PEG ${ }_{10} \mathrm{MA}$, polyDMAEMA and polySPMA are successfully grafted on the PP spacer surface.

The surface roughness and topography of pristine and hydrogel-coated PP spacers were observed by tapping-mode AFM in air (Fig. 5.6).
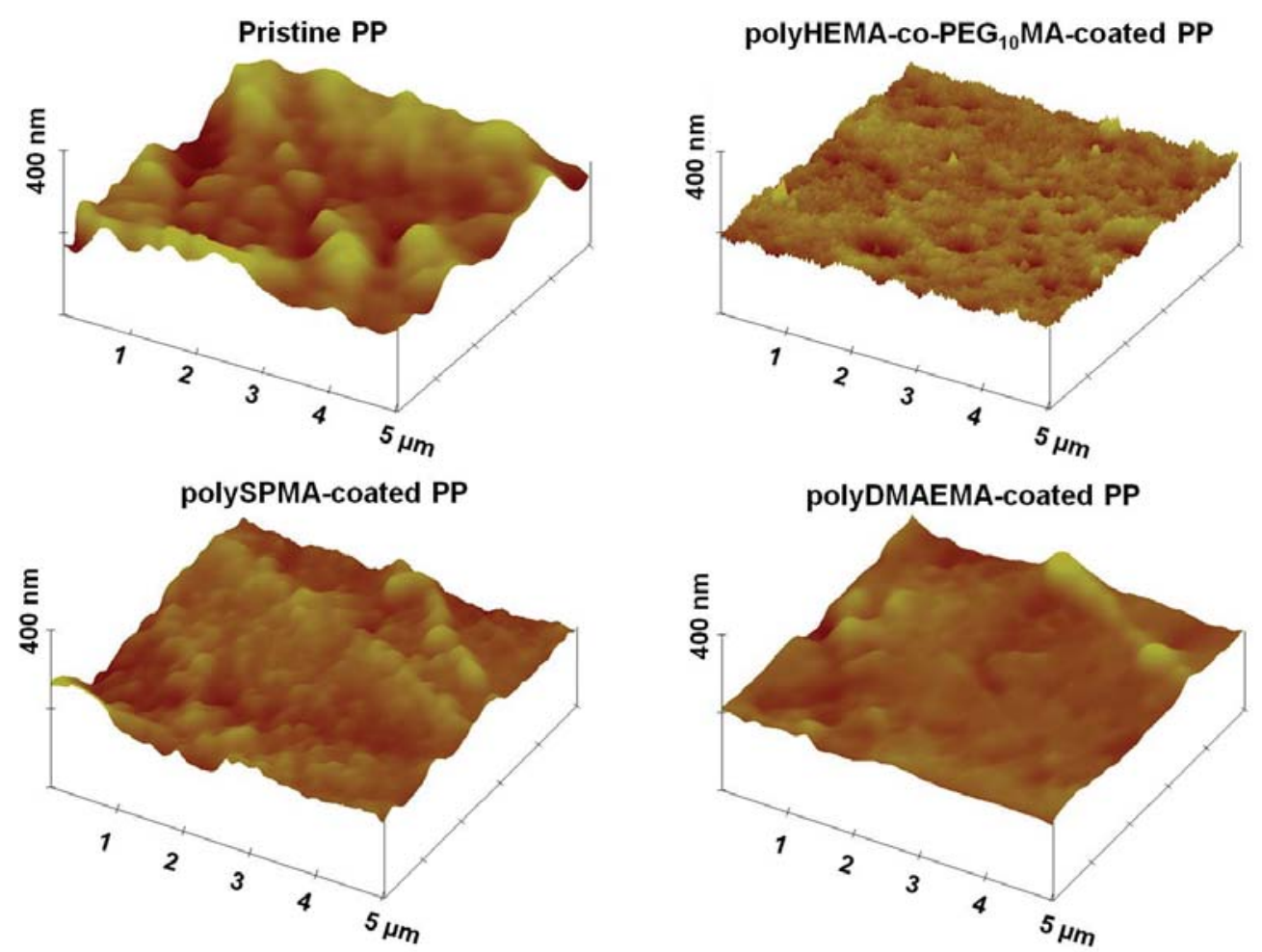

Fig. 5.6. Surface topography of pristine $P P$ and charged-hydrogel (polyHEMA-co-PEG ${ }_{10} M A$, polyDMAEMA and polySPMA) coated PP feed spacers, measured by tapping mode AFM in air over $5 \times 5 \mathrm{~m}^{2}$ areas at an acquisition rate of $1 \mathrm{~Hz}$. 
As shown in Fig. 5.6, all hydrogel-coated PP samples exhibit a relatively smooth and homogenous surface compared to pristine PP. The root mean square (RMS) roughness of pristine PP, polyHEMA-co-PEG 10 MA-coated PP, polyDMAEMA-coated PP, polySPMA coated PP is 21.5, 8.1, 10.9 and15.3, respectively. A more rough topography is observed for both the pristine PP and the oxygen plasma treated PP (not shown), compared to the coated feed spacers. Although there is a variation in RMS values of polyHEMA-co-PEG ${ }_{10} \mathrm{MA}$, polyDMAEMA, and polySPMA coated spacers, differences are minor and obviously all AFM measurements reproducibly showed that the hydrogel-coated PP feed spacers had smoother surface than the pristine PP.

\subsubsection{Coating stability}

The stability of the polymer coatings was evaluated by measuring their weight and IR spectra after incubation in water at $5{ }^{\circ} \mathrm{C}$ for 1 (data not shown), 7 and 30 days at three different $\mathrm{pH}$ values (5, 7 and 9). The weight losses were calculated using Eq. (5.2) and summarized in Table 5.2, and the IR spectra are shown in Fig. 5.7.

Table 5.2. The stability of the hydrogel polymer coating on the PP spacers evaluated by measuring the weight loss of the polymer coating only on the PP spacer after 7 and 30 days incubation in buffer solution at $\mathrm{pH} 5,7$ and 9.

\begin{tabular}{|c|c|c|c|c|c|c|}
\hline \multirow{2}{*}{ Coating } & \multicolumn{6}{|c|}{ Weight loss (mg) } \\
\cline { 2 - 7 } & \multicolumn{7}{|c|}{7 days incubation } & \multicolumn{3}{c|}{30 days incubation } \\
\cline { 2 - 7 } & $\mathrm{pH} 5$ & $\mathrm{pH} \mathrm{7}$ & $\mathrm{pH} \mathrm{9}$ & $\mathrm{pH} \mathrm{5}$ & $\mathrm{pH} \mathrm{7}$ & $\mathrm{pH} \mathrm{9}$ \\
\hline polyHEMA-co-PEG ${ }_{10} \mathrm{MA}$ & $0.13 \pm 0.07$ & $0.10 \pm 0.00$ & $0.10 \pm 0.00$ & $0.30 \pm 0.10$ & $0.20 \pm 0.00$ & $0.30 \pm 0.10$ \\
\hline polyDMAEMA & $0.10 \pm 0.00$ & $0.10 \pm 0.00$ & $0.17 \pm 0.07$ & $0.23 \pm 0.11$ & $0.20 \pm 0.00$ & $0.17 \pm 0.07$ \\
\hline polySPMA & $0.10 \pm 0.00$ & $0.10 \pm 0.00$ & $0.13 \pm 0.07$ & $0.17 \pm 0.07$ & $0.17 \pm 0.06$ & $0.17 \pm 0.06$ \\
\hline
\end{tabular}



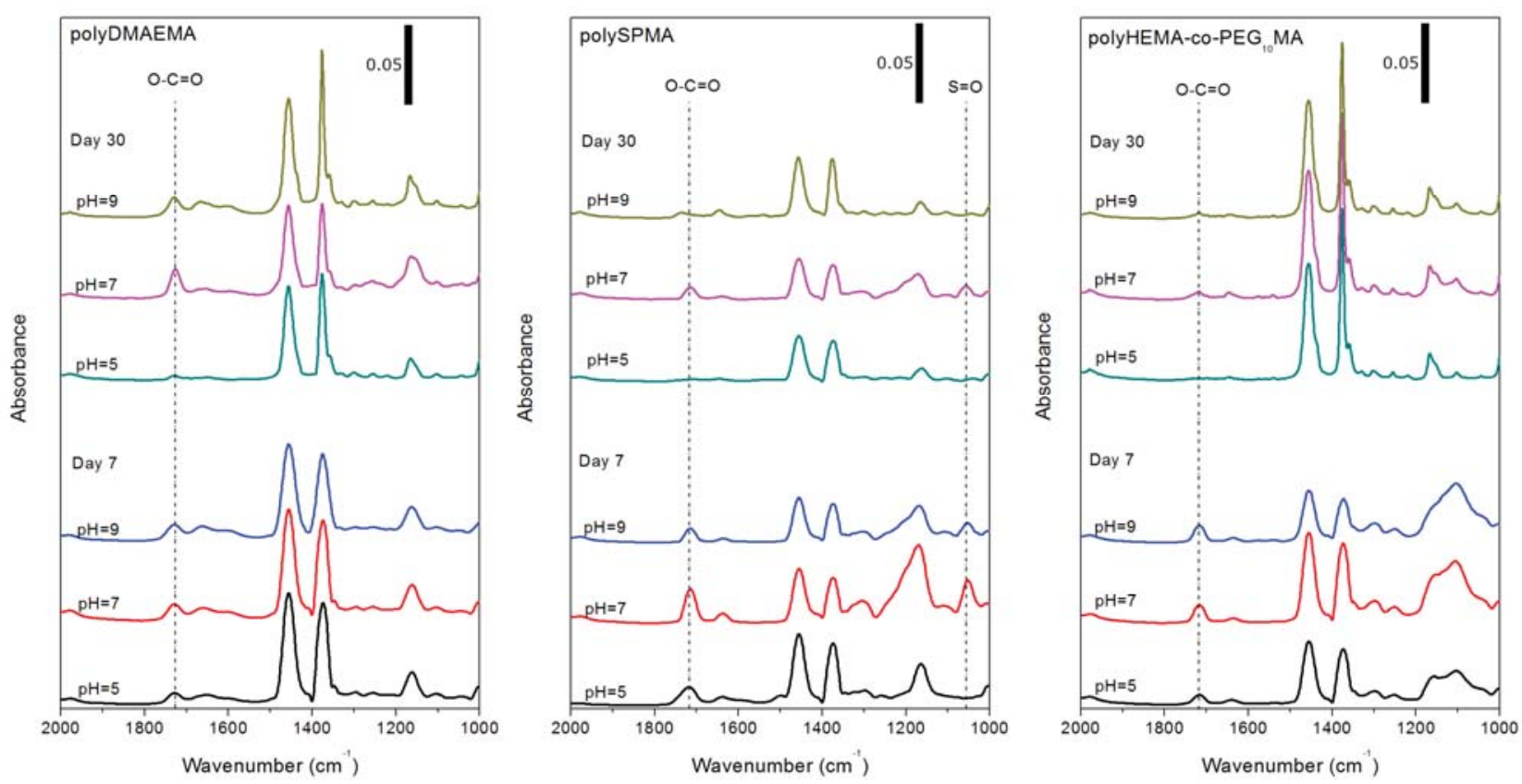

Fig.5.7. FTIR-ATR spectra of hydrogel-coated (polyHEMA-co-PEG ${ }_{10} \mathrm{MA}$, polyDMAEMA and polySPMA) PP spacers after incubation in water for 7 and 30 days at three different $\mathrm{pH}$ values (5, 7 and 9). Floating bars in the right upper corner of each spectrum is the absorbance scale unit.

At shorter incubation times ( 1 and 7 days), the coating showed good chemical stability as indicated by the only small changes (relative to untreated sample) in polymer weight (Table 5.2) and the IR spectra (Fig. 5.7). However, at longer incubation times (30 days), a change in weight and IR spectra of the coatings was clearly visible. The weight changes of the coatings were found higher in acidic and basic environment than in neutral environment ( $\mathrm{pH} 7)$. This is also visible in the stronger decrease in IR intensities for the coatings exposed for 30 days, compared to those of 7 days exposure. PolyHEMA-co-PEG ${ }_{10}$ MA suffered from significant degradation in acidic and basic environments, which is indicated by the higher weight loss and reduced $\mathrm{C}=\mathrm{O}$ ester carbonyl intensity at $1717 \mathrm{~cm}^{-1}$. In addition, oxidative degradation of the PEG chains [31] after long exposure to water and acidic and basis environment can occur, as seen as a reduction in the skeletal vibrations of PEG at $1100-1160 \mathrm{~cm}^{-1}$. Although the weight changes of polySPMA and polyDMAEMA in acidic and basic environment were lower than those of polyHEMA-co- $\mathrm{PEG}_{10} \mathrm{MA}$, the $\mathrm{C}=\mathrm{O}$ ester carbonyl intensities of polyDMAEMA and polySPMA at 1726 and $1712 \mathrm{~cm}^{-1}$ respectively, the sulfonate peak in poly SPMA at $1041 \mathrm{~cm}^{-1}$ 
and the tertiary amine of polyDMAEMA at $2779 \mathrm{~cm}^{-1}$ were all found to decrease significantly upon exposure to acidic and basic environments as well. The stronger degradation of polymers immersed in acidic and basic environments for longer times might be caused by the increased hydrolytic activity in acidic and basic environments, increasing the loss of hydrophilic polymer chain segments [32,33].

Understanding the chemical stability of polymers in membrane filtration is important as the polymeric materials might be exposed to different $\mathrm{pH}$ conditions during filtration due to water pollution and microbial activity during the filtration process. In relation to the anti-biofouling properties of hydrogel-coated PP spacers investigated in the remainder of this chapter, the obtained anti biofouling results are still representative, since the bacterial adhesion and filtration tests are conducted up to 7 days, in which the polymer coating shows a stable performance and hardly any degradation.

\subsubsection{Bacterial adhesion test}

To investigate the adhesion of bacteria on the charged hydrogel coated PP spacers, bacteria adhesion experiments using E. coli were performed. E. coli is frequently found in water and an emerging cause of water-borne diseases. It is also a very common model bacteria used in lab experiments due to its rapid growth and inexpensive handling and maintenance. Relative attachment of E. coli on both pristine and hydrogel-coated PP spacers after 1, 4 and $24 \mathrm{~h}$ of incubation is presented in Fig. 5.8.

At shorter incubation time $(1 \mathrm{~h})$, relative attachment of $E$. coli was found to be very low on polySPMA-coated PP surfaces, compared to that on pristine PP, but also compared to polyDMAEMA- and polyHEMA-co-PEG 10 MA-coated PP surfaces. The statistical analysis of these bacterial attachment data shows that the attachment on the anionic polySPMA coating differs significantly $(\mathrm{p}<0.05)$ from that on the neutral polyHEMA-co-PEGMA coating and the pristine PP spacer, but is not significantly different from the cationic polyDMAEMA coating $(\mathrm{p}>0.05)$. The bacterial attachment at the surface gradually increased when the incubation time increased. Relative to the uncoated, pristine PP spacer, the PolySPMA and polyHEMA-co-PEG ${ }_{10} \mathrm{MA}$-coated spacers show a reduced bacterial adhesion of about $50 \%$ (p $>0.05$ ) after $24 \mathrm{~h}$ of incubation. We hypothesize that this lower attachment can be associated 
with the higher degree of hydrophilicity of polyHEMA-co-PEG ${ }_{10} \mathrm{MA}$ and polySPMA. The absence of electrostatic attractive interactions between the $E$. coli cell walls and the hydrogels might also contribute to the lower degree of attachment. In addition, as the net charge of the cell walls of $E$. coli at physiological $\mathrm{pH}$ is negative [34], a repulsive electrostatic interaction between E.coli and the anionic polySPMA can also explain the lower degree of attachment of E.coli on the anionic polySPMA. The relatively high bacterial attachment found for the polyDMAEMA-coated PP spacer might probably result from attractive electrostatic interactions.

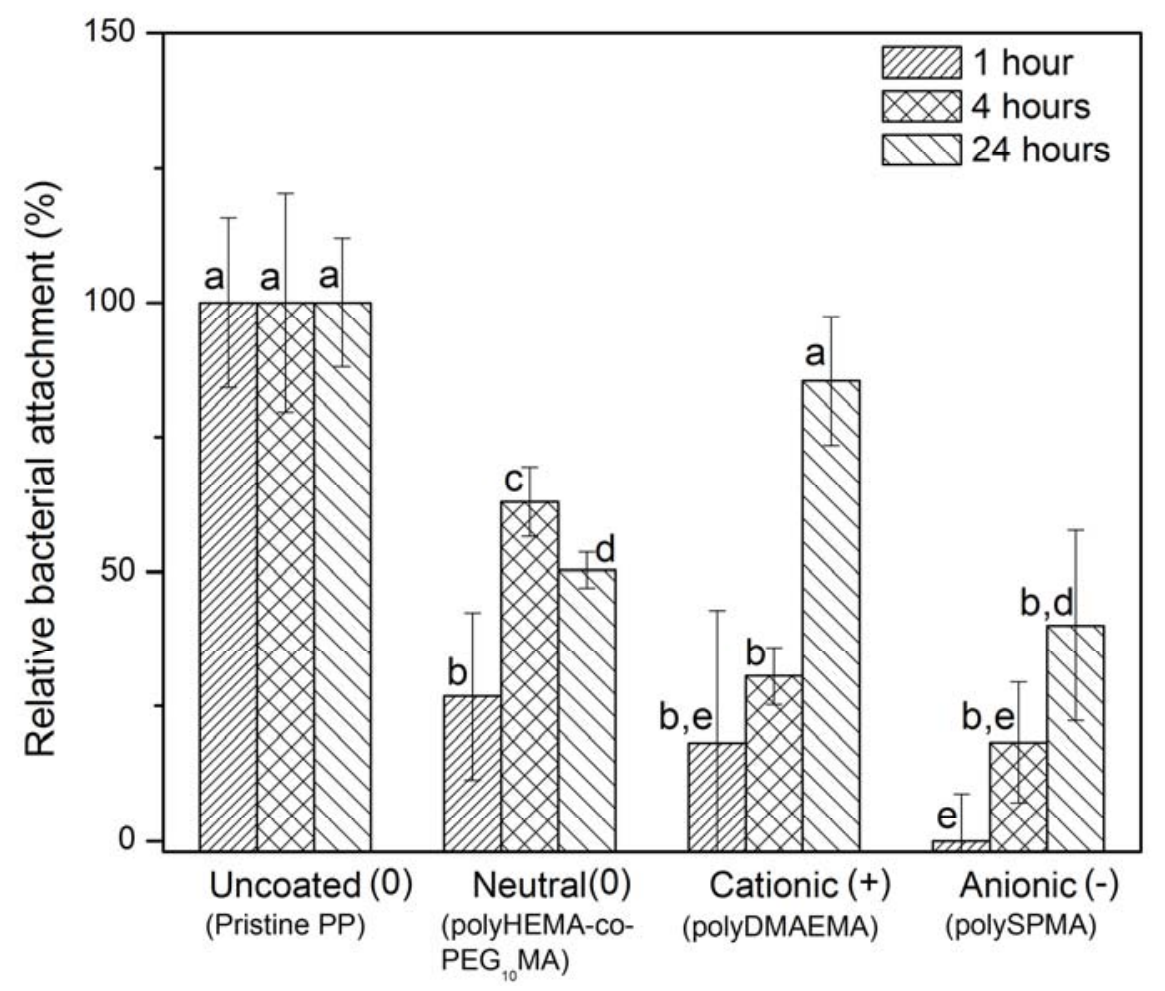

Fig. 5.8. Relative attachment of $E$. coli cells on pristine and polymer coated PP feed spacer surfaces after 1, 4, and $24 \mathrm{~h}$ of immersion in bacterial solutions at $37^{\circ} \mathrm{C}$. Error bars indicate the standard deviation obtained from four replicates. The different letters above the bars indicate whether the data are significantly different to each other at $\mathrm{p}<0.05$.

SEM imaging revealed the adhesion of $E$. coli colonies on the surface of all feed spacers investigated after $1 \mathrm{~h}$ of immersion in bacterial solutions at $37^{\circ} \mathrm{C}$ (Fig. 5.9). 


\section{Pristine PP}
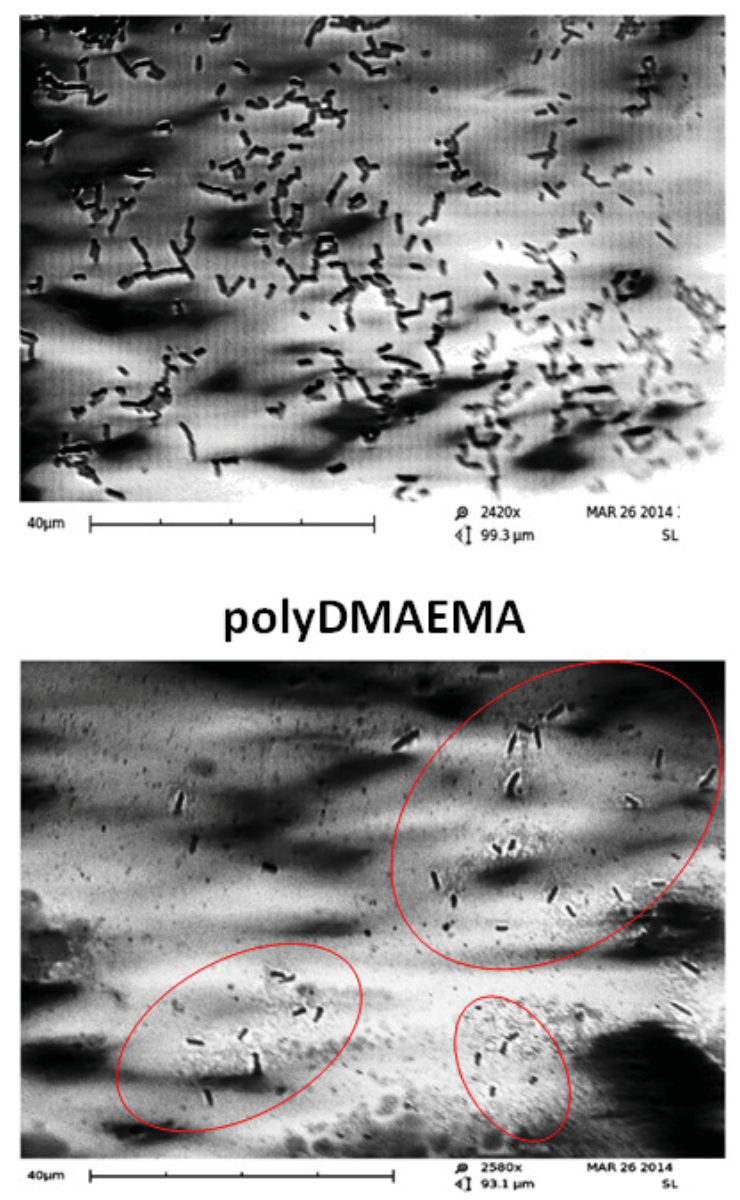

polyHEMA-co-PEG ${ }_{10} \mathrm{MA}$

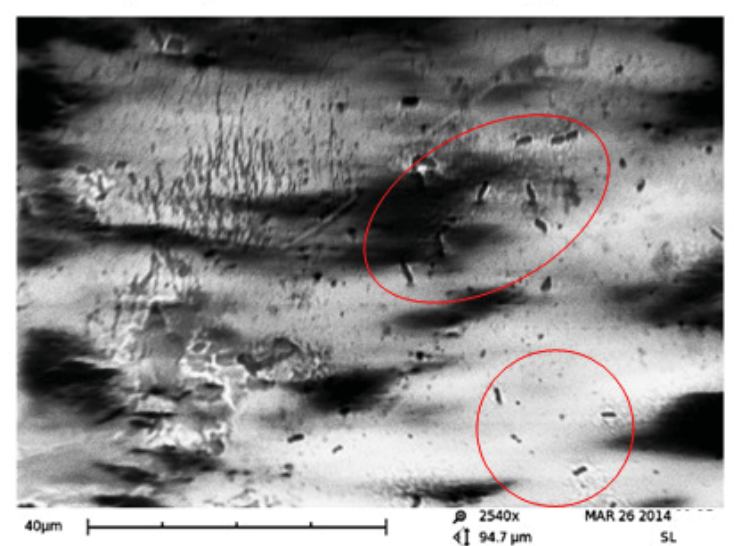

polySPMA

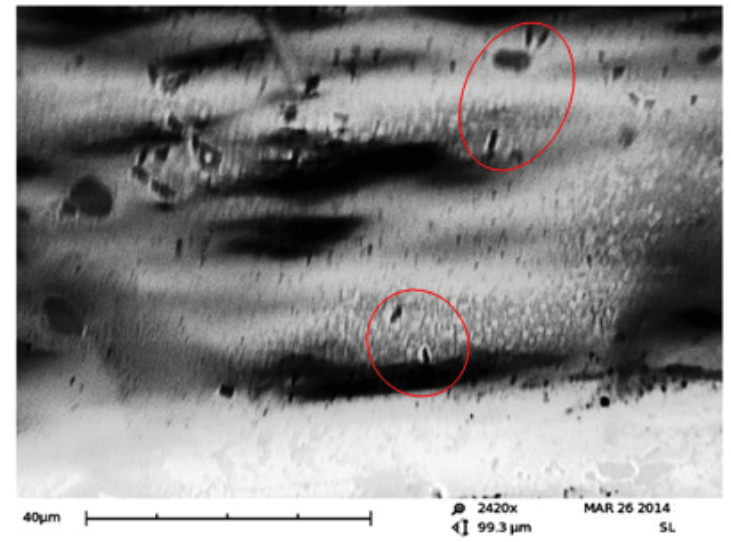

Fig. 5.9. E. coli cells attached on pristine and coated $P P$ feed spacer surfaces after $1 \mathrm{~h}$ of immersion in bacterial solutions at $37^{\circ} \mathrm{C}$ as observed by SEM (scale bar length is $40 \mu \mathrm{m}$ ). Colonies of bacteria cells adhered on polyDMAEMA-, polyHEMA-co-PEG ${ }_{10} \mathrm{MA}-$ and polySPMA-coated PP feed spacers are shown highlighted in the red circles.

As shown in Fig.5.9 (top), colonies of E. coli attach both to pristine PP and hydrogel-coated PP feed spacers. E. coli cells attached abundantly at the surface of pristine PP feed spacers compared to the hydrogel-coated PP feed spacers. Less bacteria cells were observed on the surface of the polyDMAEMA-coated and the polyHEMA-co-PEG ${ }_{10}$ MA-coated PP feed spacers, and only very few bacteria cells adhered to the surface of the polySPMA-coated PP feed spacer. The images support the aforementioned conclusion that especially the anionic polySPMA coating minimizes bacteria (E. coli) attachment. 
Another reason that can contribute to the lower degree of attachment of bacteria on the polySPMA-coated spacer, is the more hydrophilic nature of this coating. Captive bubble contact angles of polySPMA, polyHEMA-co-PEG ${ }_{10} \mathrm{MA}$ and polyDMAEMA prepared via surface mediated atom transfer radical polymerization (SI-ATRP) on intiator-immobilized gold surfaces at $100 \AA$ thicknesses were $148 \pm 1.2,138 \pm 1.8$, and $134 \pm 1.8$ degrees, respectively (as measured inside the bubble). This indicates that especially the polySPMA layer is more hydrophilic than the two others (polyDMAEMA and polyHEMA-co-PEG ${ }_{10} \mathrm{MA}$ ). Hydrophilicity is an important parameter in determining the anti-biofouling properties of surfaces; in general, more hydrophilic surfaces have better anti-biofouling properties. In this work, the contact angle of pristine PP was not measured due to small surface area and non-flat surface. However, it has been reported [35] that unmodified PP membranes have a contact angle (sessile drop contact angle measured in air) of $108^{\circ}$ which is hydrophobic. This hydrophobic surface might result in increased attachment of $E$. coli via hydrophobic interactions.

\subsubsection{Filtration test and two-phase flow cleaning}

\subsubsection{Dynamics of feed channel pressure drop and water flux}

Feed channel pressure drop and MTC dynamics during filtration (fouling stage and two-phase flow cleaning) using pristine PP spacers and the coated PP spacers are shown in Fig. 5.10.

As shown in the left panel of Fig. 5.10, the growth of biofouling in the feed spacer channels is shown as an increase in feed channel pressure drop (FCP). An exponential growth is observed for uncoated PP, polyHEMA-co-PEG 10 MA-, and polyDMAEMA- coated feed spacers. The FCP increase of the polyDMAEMA-coated feed spacer shows a significant increase between Day 2 and Day 4 especially. As the fouling stage is considered to be completed when the FCP increase is at least $300 \%$, on Day 4, two-phase flow cleaning was carried out for this polyDMAEMA-coated feed spacer. Longer operation times are required to achieve similar FCP increase for pristine PP and polyHEMA-co-PEG ${ }_{10}$ MA-coated PP feed spacers. Interestingly, a long-lasting and linear increase in pressure drop was observed for the polySPMA-coated feed spacer. In contrast to the results observed for the other spacers, the FCP increase for the polySPMA-coated feed spacer develops very slowly and only after one 
week of operation (Day 7), an FCP increase of 300\% is reached (an increase from an initial FCP of 19 mbar to 60 mbar). On the other hand, as shown in the right panel of Fig. 5.10, the MTC decrease shows a similar behavior for both uncoated and polymer-coated PP spacers. Consequently, two-phase flow cleaning is able to remove biofouling from the feed spacer channels. However, the MTC recovery due to two-phase flow cleaning is not as high as the FCP recovery (as will be discussed later; see also Fig. 5.12).
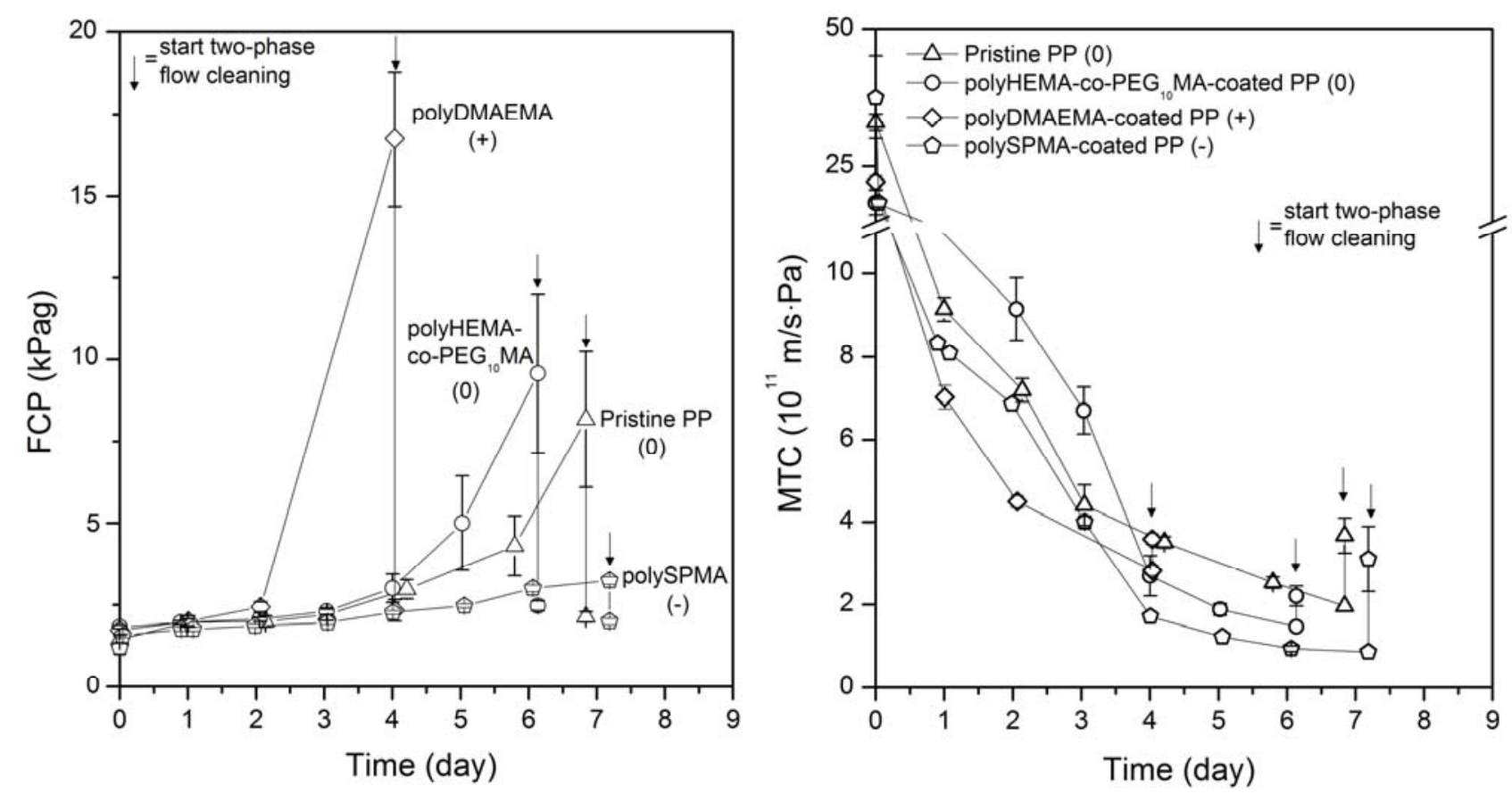

Fig. 5.10. Left: Feed channel pressure drop (FCP) during biofouling in filtration cells with different feed spacer coatings (pristine PP, polyHEMA-co-PEG 10 MA (0), polyDMAEMA (+) and polySPMA (-)), and cleaning by two-phase flow (indicated by arrow). Right: MTC dynamics (pristine PP, polyHEMA-co-PEG ${ }_{10} \mathrm{MA}$, polyDMAEMA and polySPMA spacers) during fouling stage and two-phase flow cleaning (indicated by arrow).

\subsubsection{Daily OCT observations}

The biofouling growth during the fouling stage of both uncoated and hydrogel-coated PP spacers is observed daily using optical coherence tomography (OCT). Representative tomograms are shown in Fig. 5.11.

As shown in Fig. 5.11, for pristine PP and polyHEMA-co-PEG ${ }_{10} \mathrm{MA}$-coated PP feed spacers 6 days are necessary to achieve a $300 \%$ FCP increase. The tomograpms clearly show the presence of biofouling from day 4 on in these cases, at the region between feed spacer 
filaments and membrane surface. This region has the lowest flow velocity, and layers of biofilms can develop on top of each other. From day 5 on, biofouling clearly becomes more severe on pristine PP and as well as on polyHEMA-co-PEG ${ }_{10} \mathrm{MA}$-coated PP feed spacers. After two-phase flow cleaning on Day 6, the filaments of the polyHEMA-co-PEG ${ }_{10}$ MAcoated feed spacer look cleaner than those of the pristine PP feed spacer filaments after twophase flow cleaning on day 7. This implies that biofouling attached to the polyHEMA-co$\mathrm{PEG}_{10} \mathrm{MA}$-coated PP feed spacer surface is easier to remove by two-phase flow cleaning than that on the pristine PP feed spacer.

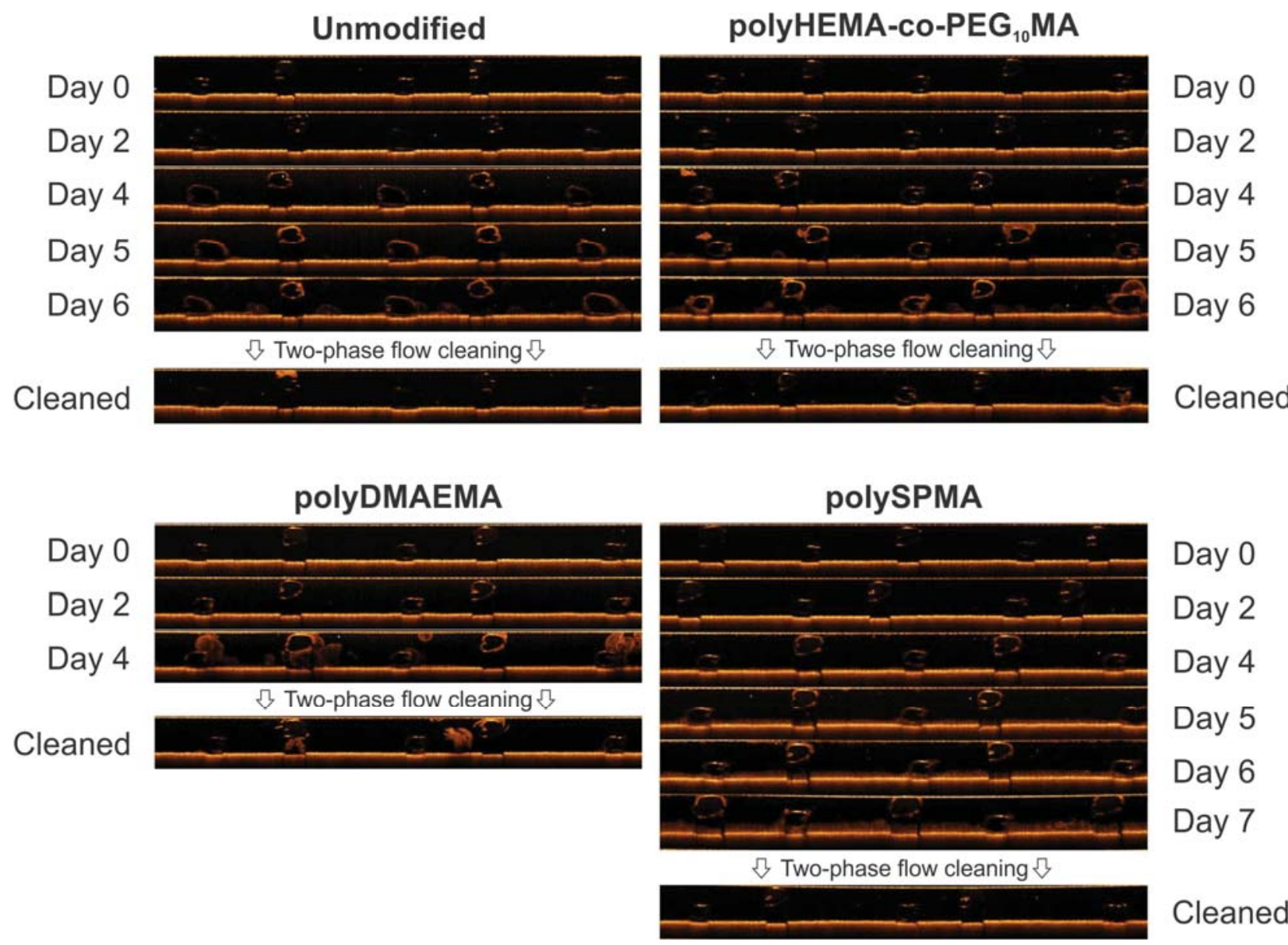

Fig. 5.11. Series of equidistant OCT images $(1.5 \mathrm{~mm}$ x $10 \mathrm{~mm}$, resolution 5429x546 pixels, measured daily using the refractive index of water (1.33)) of: pristine, polyHEMA-co$\mathrm{PEG}_{10} \mathrm{MA}$-coated, polyDMAEMA-coated, and polySPMA-coated polypropylene feed spacerfilled channels during biofouling and after two-phase flow cleaning. Two-phase flow cleaning was conducted at a liquid velocity of $u_{L}=0.44 \mathrm{~m} / \mathrm{s}$ and a gas/liquid ratio of $\theta=0.5$. The orange scale intensity is proportional to the intensity of the detected reflection of the raw signal. Pristine PP spacer: two-phase flow cleaning on day 6; polyDMAEMA-coated spacer: twophase flow cleaning on day 4; polyHEMA-co-PEG 10 MA-coated spacer: two-phase flow cleaning on day 6; polySPMA-coated spacer: two-phase flow cleaning on day 7; 
For the polyDMAEMA-coated PP feed spacer, a steep increase in FCP was observed between Day 2 and Day 4. The OCT images support this and a large biofouling matrix is clearlyobserved, mainly in the regions around the feed spacer filaments. Two-phase flow cleaning removed the majority of the biofouling, but still a lot remained. As the net charge of bacteria commonly causing biofouling is negative [29], strong adhesion to the positively charged polyDMAEMA coated spacers occurrs. Oppositely, the strong repulsion between bacteria and the negatively charged polySPMA-coated PP feed spacer account for the much better anti fouling properties of this hydrogel coated spacer. During the 7 days fouling stage, significantly biofouling development on the surface of polySPMA-coated feed spacer filaments is not observed. The effect of two-phase flow cleaning is obvious, when we compare the OCT tomogram of the cleaned polySPMA channel with the pristine channel at day 0. The hydrophilic polySPMA-coated PP feed spacer is very well suited for easy biofouling removal using two-phase flow.

\subsubsection{Efficiency of two-phase flow cleaning}

The efficiency of the applied two-phase flow cleaning in terms of FCP and MTC recovery is calculated based on both FCP and MTC data using Eq. (5.3) and Eq. (5.4) and presented in Fig. 5.12.

In terms of FCP recovery, two-phase flow cleaning is rather effective and powerful to remove a large part of the biofouling from the spacer filled channel itself, regardless of the presence or absence of a feed spacer coating. The FCP level after two-phase flow cleaning is between 0.5$0.9 \mathrm{kPag}$, although the FCP value before the two-phase flow cleaning was very high (see Fig. 10 left panel). When comparing the FCP data of all different spacers, the FCP recovery is equal for all spacer types and recoveries of 60 to $70 \%$ are obtained. 


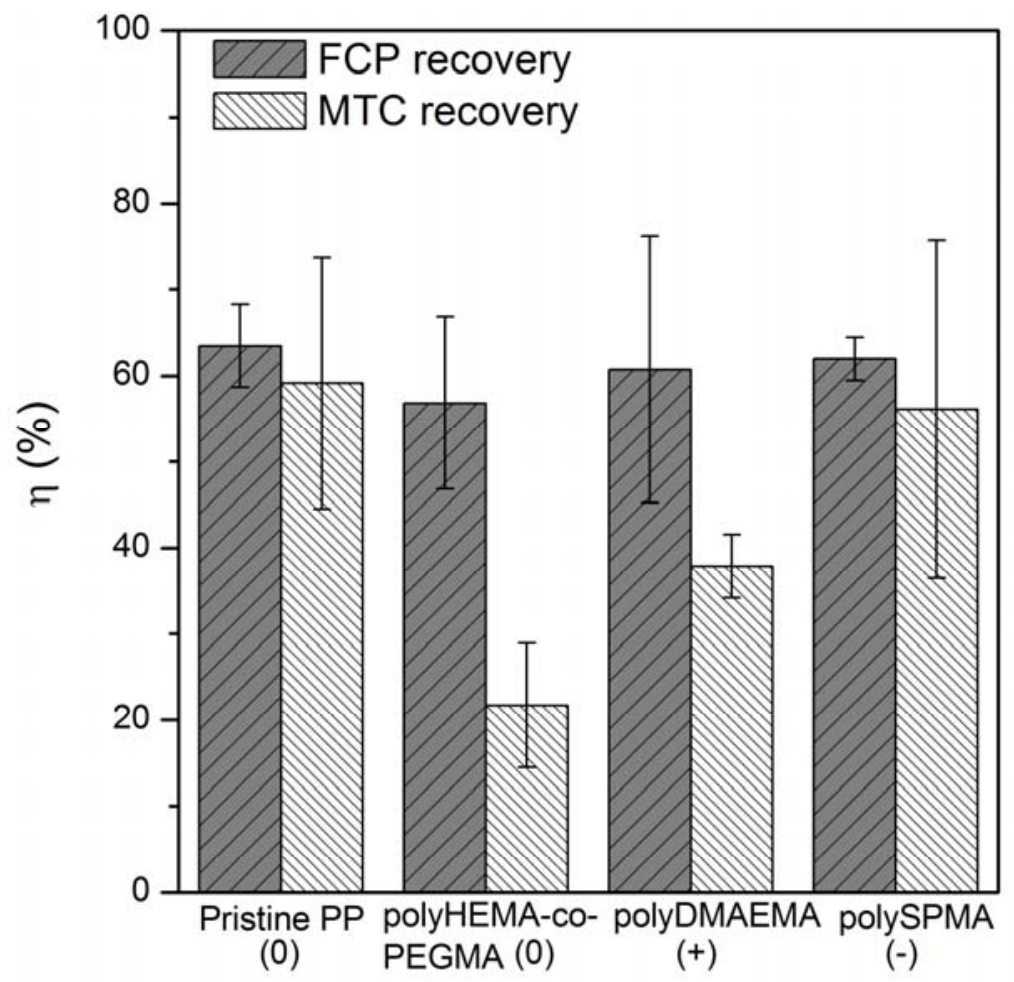

Fig. 5.12. FCP and MTC recovery by two-phase flow cleaning (pristine PP $(0)$ spacers, polyHEMA-co-PEG ${ }_{10}$ MA (0) coated, polyDMAEMA (+) coated and polySPMA (-) coated PP feed spacers).

Regarding MTC recovery, pristine PP and polySPMA-coated PP feed spacers yield flux recoveries of about $60 \%$, while polyDMAEMA- and polyHEMA-co-PEG ${ }_{10}$ MA-coated PP feed spacers generate lower flux recoveries, below 40\%. Initially, all systems had the same initial flux (as all use the same membrane). However, to reach an FCP increase of 300\%, different operation times are required depending on the type of spacer. For polySPMA-coated PP feed spacers, a 300\% FCP increase was reached after 7 days and during that period, the flux in terms of MTC value to $0.86 \cdot 10^{-11} \mathrm{~m} / \mathrm{s} \cdot \mathrm{Pa}$. After two-phase flow cleaning, the MTC recovered to approximately $3.11 \cdot 10^{-11} \mathrm{~m} / \mathrm{s} \cdot \mathrm{Pa}$, which is close to the initial $\mathrm{MTC}_{0}$ value of $4.9 \cdot 10^{-11} \mathrm{~m} / \mathrm{s} \cdot \mathrm{Pa}$. The OCT image of the polySPMA-coated PP feed spacer after cleaning supports this and shows an almost identically clean feed channel as on day 0 (see Fig. 5.11). Similar behavior is observed for pristine PP. For polyHEMA-co-PEG ${ }_{10}$ MA-coated PP feed spacers, although the MTC of the fouled system is identical to the MTC value of the fouled polySPMA-coated PP and pristine PP, the MTC recovery after two-phase flow cleaning is lower. This is the same for polyDMAEMA-coated PP spacers, since also in this case the 
filtration time to reach $300 \%$ FCP increase is relatively short, resulting in relatively high MTC values when two-phase flow cleaning was applied, resulting in low MTC recoveries.

Based on the FCP- and MTC-recovery data, especially the anionic polySPMA-coated PP feed spacers showed delayed biofouling growth and a delayed FCP increase, resulting in a reduced need for two-phase flow cleaning.

\subsubsection{Post-filtration analysis}

Foulant characteristics on the surfaces of pristine and hydrogel-coated PP spacers were evaluated by detemining the change in weight due to biofouling attachement and measuring the IR spectra of the samples after being exposed to filtration experiments up to 7 days and subsequent two-phase flow cleaning. The FTIR-ATR spectra were recorded after the samples were air dried at room temperature. Spectra are shown in Fig. 5.13.

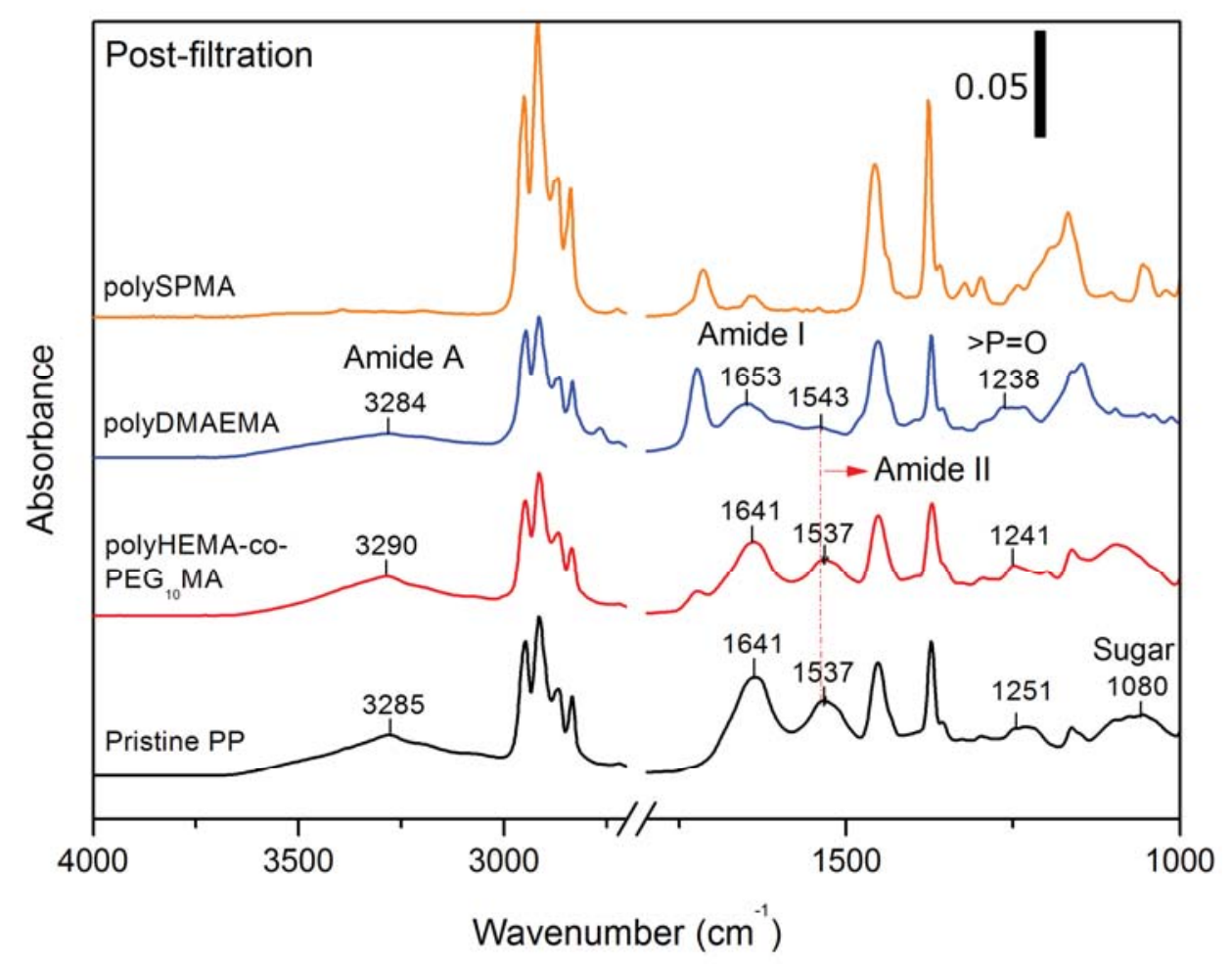

Fig. 5.13. FTIR-ATR spectra of of pristine PP and the three hydrogel-coated PP spacers after filtration experiments and two-phase flow cleaning. Floating bar in the right upper corner represents the absorbance scale unit. 
The N-H band of Amide A is normally seen at 3270-3310 $\mathrm{cm}^{-1}$ [36-39] and its specific IR frequencies depend on the structure of the amino acids presnet. For example, $\alpha$-Poly-alanine has an N-H stretching bond of the amide A near $3300 \mathrm{~cm}^{-1}$ [40], for polyglycine II this is 3303 $\mathrm{cm}^{-1}$ [41] and for Ca-poly(L-glutamate) this can be found at $3275 \mathrm{~cm}-1$ [42]. In this work, prominent signals of the N-H band of Amide A are clearly observed at $3284-3290 \mathrm{~cm}^{-1}$ on the surface of pristine PP, polyDMAEMA-coated and polyHEMA-co-PEG ${ }_{10}$ MA-coated PP spacers (Fig. 5.13). Furthermore, on these three samples, amide I and II are also observed at $1641-1653 \mathrm{~cm}^{-1}$ and $1537-1543 \mathrm{~cm}^{-1}$, respectively. These results suggest the presence of proteins on the surface of pristine PP, polyDMAEMA and polyHEMA-co- $P_{E G}{ }_{10} M A$ spacers. The presence of a phosphodiester backbone of nucleic acid is clearly found for pristine PP and polyDMAEMA surfaces, as suggested by the bands at 1236 and $1238 \mathrm{~cm}^{-1}$. In addition, the peak at $1080 \mathrm{~cm}^{-1}$ faintly found on pristine PP suggests the presence of C-O and C-O-C from sugars [39]. These results suggest the presence of biological materials on the surface of pristine PP, polyDMAEMA and polyHEMA-co-PEG ${ }_{10} \mathrm{MA}$. Interestingly, these fingerprints were not found on the surface of the polySPMA-coated PP spacers and support the previous results obtained from bacterial adhesion experiments, FCP and MTC data and OCT images.

The foulants on the surface of pristine and polymer-coated PP spacers were visualized by SEM and the images are shown in Fig. 5.14. Foulants were found to be omnipresent on the surface of pristine PP. Fouling was less dominant on the surface of polyHEMA-co-PEG ${ }_{10} \mathrm{Ma}-$ coated and polyDMAEMA-coated spacers and lowest on the anionic polySPMA-coated spacer. These images also demonstrate that the coating of hydrogels on spacer surfaces and especially the application of an anionic polySPMA coating enhance the performance of the membrane process and the effectiveness of two-phase flow cleaning. 


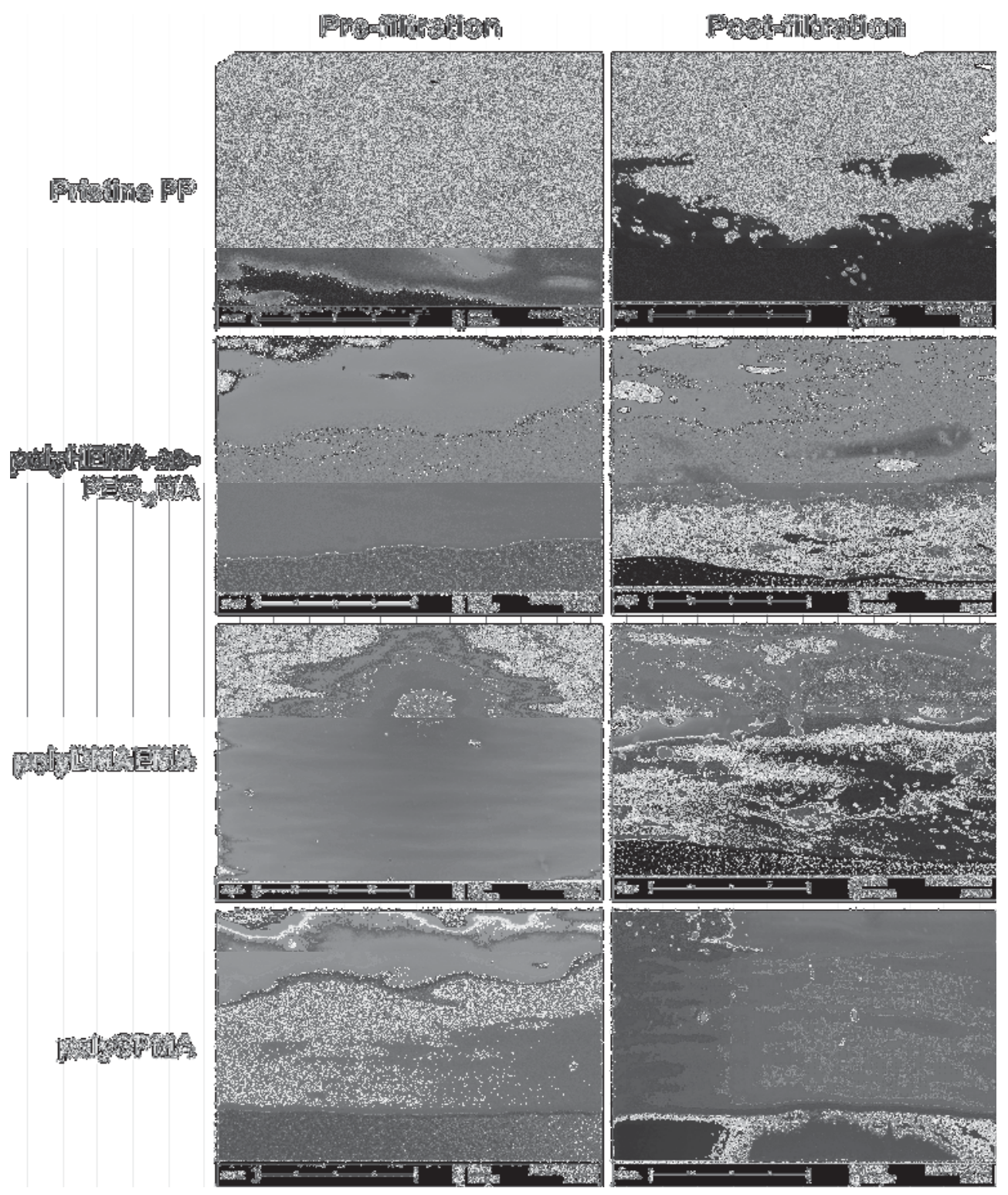

Fig. 5.14. SEM images of the surface of pristine and polymer-coated PP feed spacers before (left) and after (right) filtration/two-phase flow cleaning (scale bar length is $40 \mu \mathrm{m}$ ). Abundant amounts of biomass are observed on the pristine PP surface, while less biomass is found on the polymer-coated PP feed spacers, and especially the polySPMA-coated spacer.

\subsection{Conclusion}

PolyHEMA-co-PEG ${ }_{10}$ MA (0), polyDMAEMA (+) and polySPMA (-) were successfully coated on PP feed spacer surfaces via plasma mediated UV-polymerization. These coatings are chemically stable for at least 7 days upon immersion into neutral, acidic and basic environments. All hydrogel-coated PP samples showed improved anti-biofouling properties during bacterial adhesion tests. During filtration experiments, polyDMAEMA shows low antibiofouling properties due to hydrophobic interactions. The performance of polyHEMA-co206 
PEG $_{10}$ MA is fairly good. PolySPMA-coated PP feed spacers on the contrary show significant anti-biofouling properties. Employing this highly hydrophilic surface during removal of biofouling by two-phase flow cleaning also showed enhanced cleaning efficiency, feed channel pressure drop and flux recoveries. A combination of polySPMA-coated PP feed spacers and two-phase flow cleaning therefore is promising and an environmentally friendly approach to control biofouling in NF/RO systems employing spiral-wound membrane modules.

\section{References}

[1] M.A. Shannon, P.W. Bohn, M. Elimelech, J.G. Georgiadis, B.J. Marinas, A.M. Mayes, Science and technology for water purification in the coming decades, Nature, 452 (2008) 301-310.

[2] N. Hilal, H. Al-Zoubi, N.A. Darwish, A.W. Mohammad, M. Abu Arabi, A comprehensive review of nanofiltration membranes: Treatment, pretreatment, modelling, and atomic force microscopy, Desalination, 170 (2004) 281-308.

[3] L.F. Greenlee, D.F. Lawler, B.D. Freeman, B. Marrot, P. Moulin, Reverse osmosis desalination: Water sources, technology, and today's challenges, Water Research, 43 (2009) 2317-2348.

[4] A. Matin, Z. Khan, S.M.J. Zaidi, M.C. Boyce, Biofouling in reverse osmosis membranes for seawater desalination: Phenomena and prevention, Desalination, 281 (2011) 1-16.

[5] W.A.M. Hijnen, C. Castillo, A.H. Brouwer-Hanzens, D.J.H. Harmsen, E.R. Cornelissen, D. van der Kooij, Quantitative assessment of the efficacy of spiral-wound membrane cleaning procedures to remove biofilms, Water Research, 46 (2012) 6369-6381.

[6] S.A. Creber, J.S. Vrouwenvelder, M.C.M. van Loosdrecht, M.L. Johns, Chemical cleaning of biofouling in reverse osmosis membranes evaluated using magnetic resonance imaging, Journal of Membrane Science, 362 (2010) 202-210.

[7] V. Chen, J. Mansouri, T. Charlton, Biofouling in Membrane Systems, in: Membrane Technology, Wiley-VCH Verlag GmbH \& Co. KGaA, 2010, pp. 25-51.

[8] G.-S. Wang, Y.-C. Deng, T.-F. Lin, Cancer risk assessment from trihalomethanes in drinking water, Science of The Total Environment, 387 (2007) 86-95.

[9] L.E. Applegate, C.W. Erkenbrecher Jr, H. Winters, New chloroamine process to control aftergrowth and biofouling in permasepR B-10 RO surface seawater plants, Desalination, 74 (1989) 51-67.

[10] L.A. Bereschenko, H. Prummel, G.J.W. Euverink, A.J.M. Stams, M.C.M. van Loosdrecht, Effect of conventional chemical treatment on the microbial population in a biofouling layer of reverse osmosis systems, Water Research, 45 (2011) 405-416.

[11] Y. Wibisono, K.E. El Obied, E.R. Cornelissen, A.J.B. Kemperman, K. Nijmeijer, Biofouling removal in spiral-wound nanofiltration elements using two-phase flow cleaning, Submitted to Journal of Membrane Science, (2014).

[12] Y. Wibisono, E.R. Cornelissen, A.J.B. Kemperman, W.G.J. van der Meer, K. Nijmeijer, Twophase flow in membrane processes: A technology with a future, Journal of Membrane Science, 453 (2014) 566-602.

[13] J. Baker, T. Stephenson, S. Dard, P. Côté, Characterisation of Fouling of Nanofiltration Membranes used to Treat Surface Waters, Environmental Technology, 16 (1995) 977-985.

[14] J.S. Vrouwenvelder, D.A. Graf von der Schulenburg, J.C. Kruithof, M.L. Johns, M.C.M. van Loosdrecht, Biofouling of spiral-wound nanofiltration and reverse osmosis membranes: A feed spacer problem, Water Research, 43 (2009) 583-594.

[15] R. Hausman, T. Gullinkala, I.C. Escobar, Development of copper-charged polypropylene feedspacers for biofouling control, Journal of Membrane Science, 358 (2010) 114-121. 
[16] P.A. Araújo, J.C. Kruithof, M.C.M. Van Loosdrecht, J.S. Vrouwenvelder, The potential of standard and modified feed spacers for biofouling control, Journal of Membrane Science, 403-404 (2012) 58-70.

[17] P.A. Araújo, D.J. Miller, P.B. Correia, M.C.M. Van Loosdrecht, J.C. Kruithof, B.D. Freeman, D.R. Paul, J.S. Vrouwenvelder, Impact of feed spacer and membrane modification by hydrophilic, bactericidal and biocidal coating on biofouling control, Desalination, 295 (2012) 1-10.

[18] K. Reid, M. Dixon, C. Pelekani, K. Jarvis, M. Willis, Y. Yu, Biofouling control by hydrophilic surface modification of polypropylene feed spacers by plasma polymerisation, Desalination, 335 (2014) 108-118.

[19] D.J. Miller, P.A. Araújo, P.B. Correia, M.M. Ramsey, J.C. Kruithof, M.C.M. van Loosdrecht, B.D. Freeman, D.R. Paul, M. Whiteley, J.S. Vrouwenvelder, Short-term adhesion and long-term biofouling testing of polydopamine and poly(ethylene glycol) surface modifications of membranes and feed spacers for biofouling control, Water Research, 46 (2012) 3737-3753.

[20] Y. Liu, K. Ai, L. Lu, Polydopamine and Its Derivative Materials: Synthesis and Promising Applications in Energy, Environmental, and Biomedical Fields, Chemical Reviews, (2014).

[21] T. Ekblad, G. Bergström, T. Ederth, S.L. Conlan, R. Mutton, A.S. Clare, S. Wang, Y. Liu, Q. Zhao, F. D'Souza, G.T. Donnelly, P.R. Willemsen, M.E. Pettitt, M.E. Callow, J.A. Callow, B. Liedberg, Poly(ethylene glycol)-Containing Hydrogel Surfaces for Antifouling Applications in Marine and Freshwater Environments, Biomacromolecules, 9 (2008) 2775-2783.

[22] Y. Chang, W. Yandi, W.-Y. Chen, Y.-J. Shih, C.-C. Yang, Y. Chang, Q.-D. Ling, A. Higuchi, Tunable Bioadhesive Copolymer Hydrogels of Thermoresponsive Poly(N-isopropyl acrylamide) Containing Zwitterionic Polysulfobetaine, Biomacromolecules, 11 (2010) 1101-1110.

[23] T. Murosaki, N. Ahmed, J.P. Gong, Antifouling properties of hydrogels, Sci Technol Adv Mat, 12 (2011).

[24] M.A. Grunlan, M.L. Hawkins, M.A. Rufin, R. Murthy, I. Linossier, Antifouling medical and marine coatings prepared with amphiphilic PEG-silanes, Abstr Pap Am Chem S, 244 (2012).

[25] J.A. Prince, S. Bhuvana, K.V.K. Boodhoo, V. Anbharasi, G. Singh, Synthesis and characterization of PEG-Ag immobilized PES hollow fiber ultrafiltration membranes with long lasting antifouling properties, J Membrane Sci, 454 (2014) 538-548.

[26] G.M. Liu, D. Wu, C.C. Ma, G.Z. Zhang, H.F. Wang, S.H. Yang, Insight into the origin of the thermosensitivity of poly[2-(dimethylamino)ethyl methacrylate], Chemphyschem, 8 (2007) 2254-2259. [27] Q.Q. Guo, X.B. Cai, X.L. Wang, J. Yang, "Paintable" 3D printed structures via a post-ATRP process with antimicrobial function for biomedical applications, J Mater Chem B, 1 (2013) 6644-6649. [28] F. Wan, X. Pei, B. Yu, Q. Ye, F. Zhou, Q. Xue, Grafting Polymer Brushes on Biomimetic Structural Surfaces for Anti-Algae Fouling and Foul Release, ACS Applied Materials \& Interfaces, 4 (2012) 4557-4565.

[29] L. Bereschenko, A. Stams, G. Euverink, M. van Loosdrecht, Biofilm formation on reverse osmosis membranes is initiated and dominated by Sphingomonas spp. Applied and environmental microbiology, 76 (2010) 2623-2632.

[30] S.D. Lee, M. Sarmadi, F. Denes, J.L. Shohet, Surface modification of polypropylene under argon and oxygen-RF-plasma conditions, Plasma Pol, 2 (1997) 177-198.

[31] J. Glastrup, Degradation of polyethylene glycol. A study of the reaction mechanism in a model molecule: Tetraethylene glycol, Polym Degrad Stabil, 52 (1996) 217-222.

[32] J. Li, G. Jiang, F. Ding, The effect of $\mathrm{pH}$ on the polymer degradation and drug release from PLGA-mPEG microparticles, Journal of Applied Polymer Science, 109 (2008) 475-482.

[33] X.J. Loh, The effect of $\mathrm{pH}$ on the hydrolytic degradation of poly( $\varepsilon$-caprolactone)-blockpoly(ethylene glycol) copolymers, Journal of Applied Polymer Science, 127 (2013) 2046-2056.

[34] J. Li, L.A. McLandsborough, The effects of the surface charge and hydrophobicity of Escherichia coli on its adhesion to beef muscle, International Journal of Food Microbiology, 53 (1999) 185-193.

[35] M.S. Kang, B. Chun, S.S. Kim, Surface modification of polypropylene membrane by lowtemperature plasma treatment, J Appl Polym Sci, 81 (2001) 1555-1566.

[36] S. Krimm, A.M. Dwivedi, Vibrational Analysis of Peptides, Polypeptides and Proteins .12. Fermi Resonance Analysis of the Unperturbed Nd Stretching Fundamental in Polypeptides, J Raman Spectrosc, 12 (1982) 133-137.

208 
[37] S. Krimm, J. Bandekar, Vibrational Spectroscopy and Conformation of Peptides, Polypeptides, and Proteins, Adv Protein Chem, 38 (1986) 181-364.

[38] T.E. Creighton, Proteins : Structures and molecular properties 2nd ed., W.H. Freeman and Company, New York, 2002.

[39] M.T. Khan, C.L.D. Manes, C. Aubry, J.P. Croue, Source water quality shaping different fouling scenarios in a full-scale desalination plant at the Red Sea, Water Res, 47 (2013) 558-568.

[40] J.F. Rabolt, W.H. Moore, S. Krimm, Vibrational Analysis of Peptides, Polypeptides, and Proteins .3. Alpha-Poly(L-Alanine), Macromolecules, 10 (1977) 1065-1074.

[41] A.M. Dwivedi, S. Krimm, Vibrational Analysis of Peptides, Polypeptides, and Proteins .15. Crystalline Polyglycine-Ii, Biopolymers, 21 (1982) 2377-2397.

[42] P.K. Sengupta, S. Krimm, S.L. Hsu, Vibrational Analysis of Peptides, Polypeptides, and Proteins .21. Beta-Calcium-Poly(L-Glutamate), Biopolymers, 23 (1984) 1565-1594. 



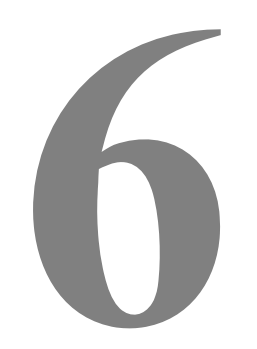

\section{Dominant factors controlling the efficiency of two-phase flow cleaning in spiral-wound membrane elements}

Y. Wibisono

F. Ahmad

E.R. Cornelissen

A.J.B. Kemperman

K. Nijmeijer

This chapter will be submitted to Separation and Purification Technology as:

Y. Wibisono, F. Ahmad, E.R. Cornelissen, A.J.B. Kemperman, K. Nijmeijer, Dominant factors controlling the efficiency of two-phase flow cleaning in spiral-wound membrane elements 


\begin{abstract}
Two-phase flow cleaning has been successfully applied to control fouling in spiral wound membrane elements. This study focuses on its experimental optimization using a Taguchi Design of Experiment method (L-25 orthogonal arrays) to elucidate the influence of different parameters and to reveal the important factor(s) affecting the cleaning efficiency of two-phase flow cleaning. All possible combinations of the factors, i.e. feed type, spacer geometry, gas/liquid ratio and liquid velocity, each at five levels were evaluated. The main effect of each factor on the efficiency of two-phase flow cleaning was measured by determining the performance response and by calculating the mean signal-to-noise ratio. An analysis of variance (ANOVA) was applied to calculate the relative contribution of each factor on the efficiency of two-phase flow cleaning. The results showed that the feed type is by far the most essential factor contributing to the cleaning efficiency. The spacer geometry is ranked second, followed by the gas/liquid ratio and the liquid velocity, which both have an only very minor effect. In terms of a practical application, the operator should consider first the type of foulant prior to taking a decision on whether or not two-phase flow cleaning will be effective. Once the feed type is defined, the use of the highest gas/liquid ratio, the highest liquid velocity and the thickest feed spacer (diamond type) are recommended to achieve maximum two-phase flow cleaning efficiency.
\end{abstract}




\subsection{Introduction}

About $80 \%$ of the world's inhabitants does not have access to clean water for drinking and sanitation [1], although technological investments on modern water treatment systems via the use of alternative water sources such as saline water and recycling used water, has increased significantly the reliability of future supply [2]. Conventional treatment processes, e.g. coagulation-flocculation-sedimentation, adsorption and chlorination, fail to get rid of all contaminants in potable water sources and triggered the development of advanced water treatment approaches such as the use of membranes [3]. Membrane technology is now being used widely for purification of water and waste water, providing superiority in terms of a small foot print, short construction times, cost effectiveness, clean, easy and long term reliable operation while producing high rejection rates for contaminants [4]. Nanofiltration (NF) and low pressure reverse osmosis (RO) membranes are among the most efficient to treat water for drinking purposes, due to an adequate rejection of divalent and multivalent ions (water softening) combined with a lower rejection of monovalent ions such as sodium chloride (low changes in water salinity). Meanwhile NF and low pressure RO have an increased rejection of dissolved organic contaminants and produce high water fluxes at a relatively low feed pressure [5]. Yet, a major shortcoming of the application of membranes in water and wastewater treatment is membrane fouling. Membrane fouling in NF/RO systems employing spiral wound membrane modules causes feed channel pressure drop increase and permeate flux decline, leading to extensive expenses on pumping energies and cleaning chemicals.

Two-phase flow cleaning can effectively remove fouling in spiral-wound membrane elements often used in NF/RO systems, and hence enhance membrane process performance [6, 7]. In our previous study [8], we have shown that feed spacer geometry, gas/liquid ratio, liquid velocity and foulant type all turned out to affect the two-phase flow cleaning efficiency. The spacer geometry determined the channel porosity and channel hydraulic diameter, and hence influenced the two-phase flow cleaning efficiency. The gas/liquid ratio was crucial to generate a good bubble distribution with full channel coverage by the bubbles. The liquid superficial velocity affected the bubble velocity, and thus is an important parameter to improve the twophase flow cleaning efficiency. Moreover, from our previous chapter we concluded that colloidal-type of fouling was easier to remove from spacer-filled membrane channels compared to macromolecular fouling. In another work [9], we have reported that two-phase flow cleaning was able to mitigate biofouling in spacer-filled membrane channels. 
Despite these observations, a systematic study, investigating the specific contribution and importance of each of these parameters on the efficacy of two-phase flow cleaning in spiralwound membrane elements is missing still. Understanding of the dominant factors and mutual interactions between the different parameters in this case is essential to further improve the process performance of NF and RO membrane processes for drinking water production and waste water treatment. In order to obtain a systematic understanding of the effect of the relevant factors in two-phase flow cleaning, we investigated the influence of foulant type, spacer geometry, gas/liquid ratio and liquid velocity, each at five different levels, on the efficiency of two-phase flow cleaning applied in spacer-filled membrane channels. The Taguchi method, a developed optimization method to analyze experimental results and find possible correlations, is employed. We study and report the importance of the different factors on their ability to promote high efficiency two-phase flow cleaning.

\subsection{Experimental}

\subsubsection{Materials}

Five different foulants were selected, serving as representative model foulant. Sodium alginate (SA) and humic acid (HA) were selected as model organic foulants. Alginate and humic acid have been identified as major organic components in natural water and they have been extensively used to study membrane fouling in pressure-driven membrane processes [10]. Both sodium alginate (Sigma-Aldrich) and humic acid (Acros Organics) were received in powder form and used as received. Fresh solutions of sodium alginate and humic acid were prepared prior to each experiment by dispersing $1 \mathrm{~g}$ of sodium alginate or humic acid powder, respectively, in $1 \mathrm{~L}$ of deionized water with a conductivity of less than $1 \mu \mathrm{S} / \mathrm{cm}$ (Milli-Q, Millipore, USA), under constant magnetic stirring for at least two hours until no more sedimentation occurred. $4 \mathrm{mM}$ or $10 \mathrm{mM}$ calcium chloride (Sigma-Aldrich) was added to the solutions to increase particle adhesion to the membrane surface $[8,11]$.

Dry yeast (Dr. Oetker, Bielefeld, Germany) was selected as model foulant for colloidal particle fouling. An untreated yeast suspension was prepared by mixing $3 \mathrm{~g}$ of dry yeast into $0.3 \mathrm{~L}$ deionized water and then stirring for half an hour to complete dissolution. Yeast washing was conducted according to a procedure described by Ye et al. and Çulfaz et al. [12, 13], as follows: the unwashed yeast was centrifuged at a speed of 2,500 rpm for $10 \mathrm{~min}$. The 
suspension liquid was then drawn out using a syringe and discharged, while the yeast sediment was collected by a lab spoon. The above process was repeated twice. Washed yeast was then dried under airflow for $24 \mathrm{~h}$. After the washing process, the weight ratio of dry washed yeast to dry unwashed yeast was found to be $70 \%$. All yeast concentrations in our experiments were concentrations based on dry washed yeast. Yeast solutions were prepared by dissolving $1 \mathrm{~g}$ washed and dried yeast in $1 \mathrm{~L}$ of deionized water (Milli-Q, Millipore, USA), under constant magnetic stirring until complete dissolution. Particle size and distribution of all solutions containing alginates, humic acids or yeast, were determined using a Zetasizer Nano ZS and Mastersizer 2000 (Malvern).

To create biofouling, tap water was enriched with nutrients. The nutrients added were sodium acetate $\left(\mathrm{CH}_{3} \mathrm{COONa}\right)$ to provide $\mathrm{C}$, sodium nitrate $\left(\mathrm{NaNO}_{3}\right)$ for $\mathrm{N}$ and anhydrous monobasic sodium phosphate $\left(\mathrm{NaH}_{2} \mathrm{PO}_{4}\right)$ for $\mathrm{P}$ addition respectively. Nutrients were added at a molar ratio of $\mathrm{C}: \mathrm{N}: \mathrm{P}=100: 20: 10$ to enhance biofouling growth. All nutrients were purchased from Sigma-Aldrich and used as received.

Commercially available thin-film composite polyamide NF membrane sheets (Hydranautics ESNA1-LF2-LD, Oceanside, California, USA) were used. The same membranes were used in all our previous studies $[8,9,14]$. The ESNA1 is a low-pressure nanofiltration membrane and is widely applied in water reclamation applications. The membranes were extensively rinsed with and soaked in Milli-Q water before use.

Five different spacers were selected, all commonly used in practice in spiral wound membrane modules. The five spacers differed in terms of thickness and filament angle. An overview of the spacer geometries is presented in Table 6.1. The pictures of the different spacers and corresponding spacer code are shown in Fig. 6.1.

Table 6.1. Selected spacer geometries used in this study.

\begin{tabular}{|c|c|c|c|c|c|}
\hline \multirow[b]{2}{*}{$\begin{array}{l}\text { Channel gap } \\
\left(10^{3} \mathrm{~m}\right)\end{array}$} & \multicolumn{3}{|c|}{ Spacer Geometries } & \multirow[b]{2}{*}{ Supplier } & \multirow[b]{2}{*}{$\begin{array}{l}\text { Spacer } \\
\text { code }\end{array}$} \\
\hline & $\begin{array}{l}\text { Average Thickness } \\
\left(10^{-3} \mathrm{~m}\right)\end{array}$ & Shape & Filament Angle & & \\
\hline \multirow[b]{2}{*}{0.5} & $0.508^{\mathrm{a}}$ & Diamond & $90^{\circ}$ & Naltex & $\mathrm{A}$ \\
\hline & $0.508^{\mathrm{a}}$ & Diamond & $60^{\circ}$ & Naltex & $\mathrm{B}$ \\
\hline \multirow{2}{*}{0.7} & $0.800^{\mathrm{b}}$ & Diamond & $90^{\circ}$ & Trisep & $\mathrm{C}$ \\
\hline & $0.650^{\mathrm{b}}$ & Diamond & $90^{\circ}$ & Hydranautics & $\mathrm{D}$ \\
\hline 1.2 & $1.2^{\mathrm{b}}$ & Diamond & $90^{\circ}$ & Toray & $\mathrm{E}$ \\
\hline
\end{tabular}

\footnotetext{
${ }^{\mathrm{a}}$ Manufacturers' data
${ }^{\mathrm{b}}$ Measured using a digital caliper
} 

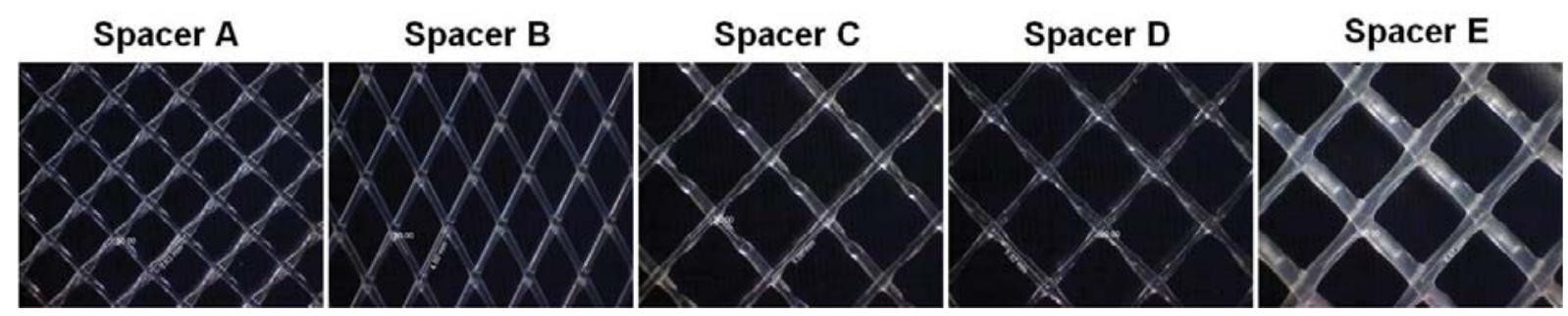

Fig. 6.1. Images of investigated feed spacers.

\subsubsection{Liquid velocity and gas/liquid ratio}

The foulant type and feed spacer geometry as described above are categorized as discrete factors, as these only have discrete values, one state or another. The liquid velocity and gas/liquid ratio on the other hand are categorized as continuous factors, as these can be adjusted in a continuous manner over a wide range of values to carry out the experiments [15]. Cross-flow velocities selected in our experiments are common for lead elements in industrial installations [16], i.e. a constant liquid velocity $\left(u_{L}\right)$ of $0.04-0.116 \mathrm{~m} / \mathrm{s}$. Moreover, the gas/liquid ratio is an important factor affecting the recovery of the feed channel pressure drop (FCP) and the flux [6]. The gas/liquid ratio $(\theta)$ used during two-phase flow cleaning is defined as:

$$
\theta \equiv \frac{u_{G}}{u_{G}+u_{L}}
$$

where $u_{G}$ and $u_{L}$ are the superficial velocities of the gas and the liquid $(\mathrm{m} / \mathrm{s})$, respectively. The gas/liquid ratio ranged from 0.167-0.629, associated with bubble and slug flow patterns in two-phase flow [6]. The gas flow set by the mass flow controller is defined at $0^{\circ} \mathrm{C}$ and $1 \mathrm{~atm}$; the ideal gas law was used to correct for this and obtain the actual gas flow.

\subsubsection{Experimental factors and levels}

Four different experimental factors were investigated: (1) feed type, (2) liquid velocity, (3) gas/liquid ratio, and (4) spacer geometry. All factors were tested at 5 different levels. Table 6.2 summarizes the experimental factors and their corresponding levels as selected for this study. 
Table 6.2. Experimental factors and corresponding 5 levels studied.

\begin{tabular}{|l|c|c|c|c|c|}
\hline \multirow{2}{*}{ Factors } & \multicolumn{5}{|c|}{ Levels } \\
\cline { 2 - 6 } & 1 & 2 & 3 & 4 & 5 \\
\hline Feed type & $\begin{array}{c}\text { Tap water }+ \\
1000 \mu \mathrm{g} \\
\mathrm{C} / \mathrm{liter} \\
\mathrm{C}: \mathrm{N}: \mathrm{P} \\
100: 20: 10)\end{array}$ & $\begin{array}{c}\text { Humic acid } \\
1000 \mathrm{ppm}+ \\
4 \mathrm{mM} \mathrm{CaCl} \mathrm{C}_{2}\end{array}$ & $\begin{array}{c}\text { Sodium } \\
\text { alginate } \\
1000 \mathrm{ppm}+ \\
4 \mathrm{mM} \mathrm{CaCl}\end{array}$ & $\begin{array}{c}\text { Humic acid } \\
1000 \mathrm{ppm}+ \\
10 \mathrm{mM} \\
\mathrm{CaCl}_{2}\end{array}$ & $\begin{array}{c}\text { Washed } \\
\text { yeast, } 1000 \\
\mathrm{ppm}\end{array}$ \\
\hline Liquid velocity (m/s) & 0.04 & 0.06 & 0.07 & 0.082 & 0.116 \\
\hline Gas/liquid ratio (-) & 0.167 & 0.33 & 0.412 & 0.5 & 0.629 \\
\hline Spacer geometry & $\mathrm{A}$ & $\mathrm{B}$ & $\mathrm{C}$ & $\mathrm{D}$ & $\mathrm{E}$ \\
\hline
\end{tabular}

\subsubsection{Operational protocol}

All measurements were characterized by their feed channel pressure drop (FCP or $\Delta P$ ). The feed channel pressure drop is a simple but sensitive parameter that corresponds to the resistance in the feed flow channel and is not affected by the flux [17].

Each experiment consisted of two stages: (1) a fouling stage, in which the fouling on the membrane and spacer was allowed to develop until a certain FCP increase over the feed channel was reached (approximately 100\% FCP increase for colloidal fouling (humic acid, sodium alginate, yeast) and 300\% FCP increase for biofouling, relative to its initial value), and (2) a cleaning stage, in which gas/liquid two-phase flow was introduced to the fouled cells. Once the FCP of the flow cell had increased until a certain level as set before $(100 \%$ or $300 \%$ FCP increase), the fouling stage was considered complete and the cleaning stage was started. The cleaning stage was conducted for $60 \mathrm{~s}$ for all experiments, comparable to what we used in our previous work [8]. After completion of the two-phase flow cleaning, the operating conditions were restored to those of the fouling stage and the FCP of the cleaned flow cell was measured again. Exact details of the experimental conditions, set-ups and flow cell simulators used for both colloidal/organics fouling and biofouling experiments are described in our previous work $[8,9]$.

The performance of two-phase flow cleaning was evaluated in terms of cleaning efficiency $(\eta)$, which is defined as:

$$
\eta=\frac{\left(\Delta P_{t}-\Delta P_{T P F}\right)}{\left(\Delta P_{t}-\Delta P_{0}\right)} \cdot 100 \%
$$


where $\Delta P_{0}$ is the initial feed channel pressure drop (mbar), $\Delta P_{t}$ is the feed channel pressure drop at time t (100\% FCP increase for colloidal fouling and 300\% FCP increase for biofouling, relative to $\Delta P_{0}$ ) when two-phase flow cleaning was performed (mbar). $\Delta P_{T P F}$ is the feed channel pressure drop after two-phase flow cleaning (mbar).

\subsubsection{Taguchi Method}

The modern methods of design and analysis of experiments involving multiple factors (parameters or variables) and replicated trials were first developed by Fisher [18]. Fisher called his method for the systematic and efficient investigation on the relevance of a parameter on an output variable in a multiple parameter system 'factorial design in experimentation', which later popularly became well known as 'factorial design of experiments' [19]. A full factorial design includes all possible combinations of factors, hence it requires a large number of experiments when it involves a significant number of factors, such as is often the case in manufacturing industries. Taguchi proposed a versatile approach on the design of experiments that allowed the selection of the smallest set of experiments from all possibilities, still providing sufficient information on the effect of a certain parameter and cross effects of different parameters. Hence the Taguchi approach reduces the number of experiments significantly without excluding the influence of all factors, nor neglecting consistency and reproducibility [20]. The Taguchi method provides a shortcut to design experiments based on a set of orthogonal arrays [21]. A comprehensive explanation of this design of experiments approach using the Taguchi method can be found elsewhere [15].

As we have 4 controllable factors (feed type, liquid velocity, gas/liquid ratio and spacer geometry) with 5 different levels each (see Table 6.2), an L-25 orthogonal array (OA) for the Taguchi method and design of experiments was selected. In a conventional full factorial design, this would require a total number of $5^{4}=625$ experimental trials to study 4 controllable factors each at 5 levels. Using the Taguchi method, only 25 experiments are necessary, hence this decreases drastically the experimental time, while, when performed systematically, still provides the necessary information. Each experiment was repeated twice under the same conditions to investigate noise effects with respect to two-phase flow cleaning efficiency. Noise factors are those factors that do influence the response but cannot be controlled in the actual application, such as humidity, ambient temperature or operators [20]. To take into account these noise factors and to avoid any influence of the experimental set-up 218 
on the output data, the experiments were conducted randomly (not in sequence) at different times. Table 6.3 summarizes the L-25 orthogonal arrays of the 25 experimental trials and the combination of the different factors and their corresponding levels.

Table 6.3. Structure of the Taguchi L-25 orthogonal array scheme [22].

\begin{tabular}{|c|c|c|c|c|}
\hline \multirow[b]{2}{*}{$\begin{array}{l}\text { Experiment } \\
\text { trial }\end{array}$} & \multicolumn{4}{|c|}{ Factors and their levels* } \\
\hline & Feed Type & $\begin{array}{c}\text { Liquid } \\
\text { velocity } \\
(\mathrm{m} / \mathrm{s})\end{array}$ & $\begin{array}{l}\text { Gas/liquid } \\
\text { ratio (-) }\end{array}$ & $\begin{array}{c}\text { Spacer } \\
\text { geometry }\end{array}$ \\
\hline 1 & 1 & 1 & 1 & 1 \\
\hline 2 & 1 & 2 & 2 & 2 \\
\hline 3 & 1 & 3 & 3 & 3 \\
\hline 4 & 1 & 4 & 4 & 4 \\
\hline 5 & 1 & 5 & 5 & 5 \\
\hline 6 & 2 & 1 & 2 & 3 \\
\hline 7 & 2 & 2 & 3 & 4 \\
\hline 8 & 2 & 3 & 4 & 5 \\
\hline 9 & 2 & 4 & 5 & 1 \\
\hline 10 & 2 & 5 & 1 & 2 \\
\hline 11 & 3 & 1 & 3 & 5 \\
\hline 12 & 3 & 2 & 4 & 1 \\
\hline 13 & 3 & 3 & 5 & 2 \\
\hline 14 & 3 & 4 & 1 & 3 \\
\hline 15 & 3 & 5 & 2 & 4 \\
\hline 16 & 4 & 1 & 4 & 2 \\
\hline 17 & 4 & 2 & 5 & 3 \\
\hline 18 & 4 & 3 & 1 & 4 \\
\hline 19 & 4 & 4 & 2 & 5 \\
\hline 20 & 4 & 5 & 3 & 1 \\
\hline 21 & 5 & 1 & 5 & 4 \\
\hline 22 & 5 & 2 & 1 & 5 \\
\hline 23 & 5 & 3 & 2 & 1 \\
\hline 24 & 5 & 4 & 3 & 2 \\
\hline 25 & 5 & 5 & 4 & 3 \\
\hline
\end{tabular}

* Actual values for Levels 1-5 used in the tests can be found in Table 6.2.

The main effect of each controllable factor was defined as the performance response (PR), which is the mean of the cleaning efficiency of each duplicate $\left(\eta_{1}\right.$ and $\left.\eta_{2}\right)$. The corresponding signal-to-noise ( $\mathrm{S} / \mathrm{N})$ ratio is defined as the ratio of the power of a signal (response) to the power of the noise (error). We choose 'the higher, the better' to define how the factors contribute to the efficiency of two-phase flow cleaning. The S/N ratio (SNR) of this "the higher, the better' approach [15] is then defined as:

$$
S N R=-10 \log \left[\frac{1}{n}\left(\sum_{i=1}^{n} \frac{1}{y_{i}^{2}}\right)\right]
$$


where $n$ is the number of trials ( $\mathrm{n}=2$ in this study) and $y_{i}$ is the observed performance response (PR in this study).

Since the Taguchi method replaces a full factorial set of experiments by a leaner and faster partial factorial set of experiments, the confidence interval of the results is based on the variance. For this purpose, an analysis of variance (ANOVA) was used. Comparison of the different variances subsequently allows determining the relative contribution of each of the different factors. The analysis of variance was conducted using Design-Expert v6.0 software (Stat-Ease Inc., Minnesota, US), which calculates the degree of freedom, the sum of square, the variance (mean squares), the experimental error, the totals of the results and the percentage contribution of each controllable factor.

\subsection{Results and Discussion}

\subsubsection{Particle size and particle size distribution}

Fig. 6.2 shows the particle size and particle size distribution of the different foulants used in this study: freshly prepared humic acid, sodium alginate, unwashed, and washed yeast (all at a concentration of $1 \mathrm{~g} / \mathrm{L}$, without salt).

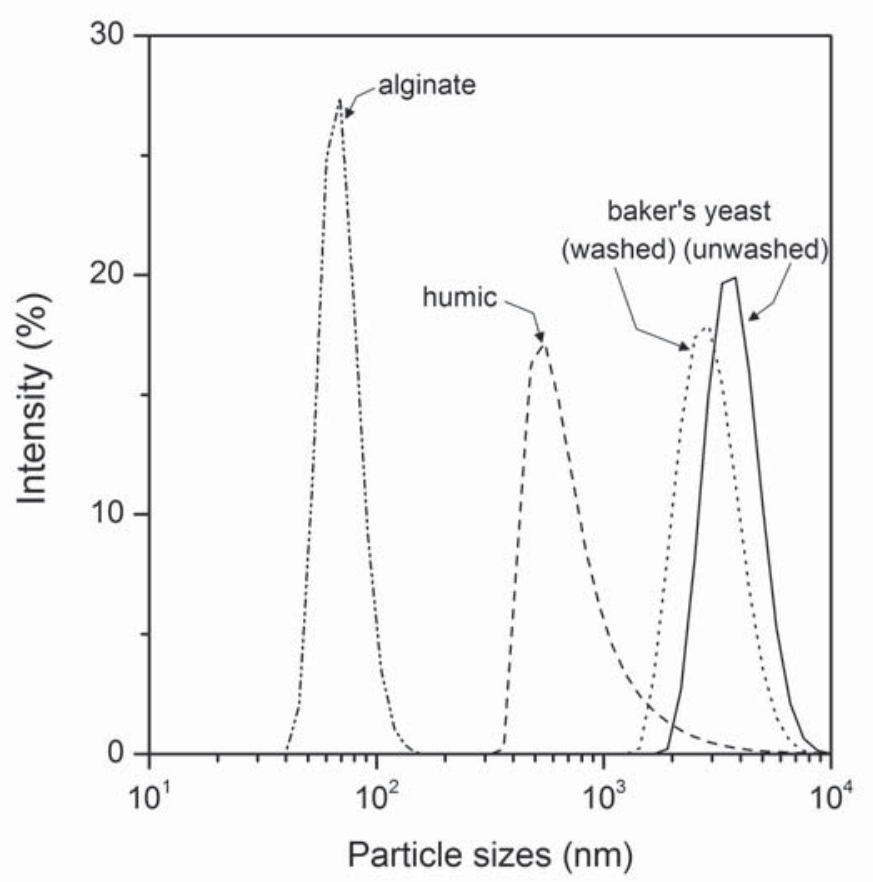

Fig. 6.2. Particle sizes and particle-size distributions of colloid particles (without salt added) used as feed suspensions as determined by dynamic light scattering at $25^{\circ} \mathrm{C}$. 
After washing, the average particle size of the yeast particles shifted from approximately 3.80 $\mu \mathrm{m}$ to slightly smaller sizes (approx. $2.88 \mu \mathrm{m}$ ). The yeast particles are the biggest particles used. The humic acid particles are $0.55 \mu \mathrm{m}$ and the alginate particle size is $0.068 \mu \mathrm{m}$. Prior to the experiments, $\mathrm{CaCl}_{2}$ was added to the humic acid and sodium alginate solutions to enhance the fouling tendency of the colloids. The added $\mathrm{Ca}^{2+}$ ions enhance the interaction between the humic acid or sodium alginate molecules $[8,23]$, resulting in an increased fouling tendency. A higher fouling rate is desirable, as the objective of this study is to define the dominant factor(s) determining the efficiency of the two-phase flow cleaning process. Hence the investigation focuses on the cleaning stages and not on the fouling stage in itself. Shorter fouling stages shorten the duration of the experiments. It is worth mentioning that two-phase flow cleaning might be less efficient in real applications, compared to the cleaning efficiency obtained for this accelerated fouling study. This is due to the specific characteristics of the fouling layer formed. Accelerated fouling may result in film structures different than the ones obtained in natural fouling. Parameters like structure, compactness etc. determine the specific effectiveness of two-phase flow cleaning in removing fouling. Nevertheless, the results obtained from this study in terms of dominant factors remain valid.

\subsubsection{Pressure drop recovery}

Fig. 6.3 shows the pressure drop recovery in terms of two-phase flow cleaning efficiency for all 25 experiments (in duplicate) as calculated using Eq. 2. The results of the duplicates are shown as standard error.

As shown in Fig. 6.3, the two-phase flow cleaning efficiency varies between approximately $15 \%$ and $93 \%$. As the error bars clearly show, the noise factors are not very significant and do not disturb the response, except for experiments 3, 6, 22 and 23. However, in the Taguchi method, this deviation is included in the signal-to-noise ratio analysis. When the trend is similar, the noise factor is not considered significant.

Furthermore, two-phase flow cleaning is a valuable technology to remove fouling in spacerfilled membrane channels regardless of foulant type, spacer geometry, gas/liquid ratio and liquid velocity, although the efficiency in some cases does depend to a large extent on the input values selected. None of the results shows a total (100\%) recovery of the pressure drop, meaning that some fouling remained in the feed channels for all combination of factors. 


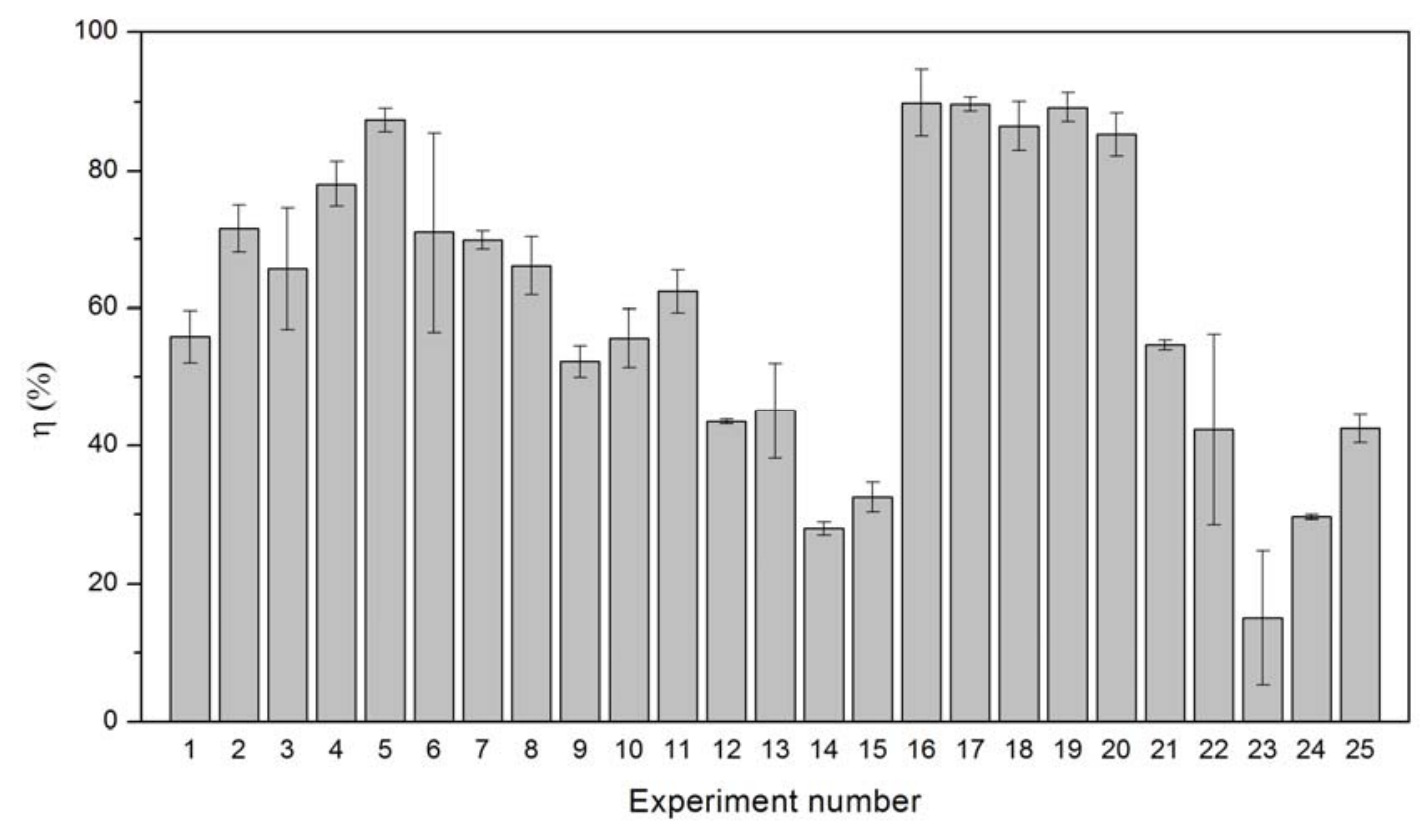

Fig. 6.3. Two-phase flow cleaning efficiency of each experiment (all experiments performed in duplicate, shown as error bars). Numbers on the $\mathrm{X}$-axis correspond to the experiment number, as summarized in Table 6.3.

\subsection{3. $\mathrm{S} / \mathrm{N}$ ratio analysis}

The Taguchi method using orthogonal arrays (OA) is a powerful tool for analyzing the influence of controllable factors on the performance response PR (i.e. two-phase flow cleaning efficiency in this study). Table 6.4 summarizes for each experiment the different set values and corresponding obtained experimental data. In Table 6.4, each column represents the L-25 orthogonal array based on the standard OA as shown in Table 6.3. The very left column shows the experiment number, each number in a row represents a combination of factor levels. The next four columns are the controllable factors tested in this study: feed type, liquid velocity, gas/liquid ratio $(\theta)$ and spacer geometry. The four columns on the right are the responses obtained from the experimental trials. $\eta_{1}$ is the two-phase flow cleaning efficiency of the experiment and $\eta_{2}$ is the duplicate of the same experiment. The performance response (PR) is the mean value of the two running efficiencies $\left(\eta_{1}\right.$ and $\left.\eta_{2}\right)$, and shows the nominal response of each experimental trials. The very right column is the signal-to-noise ratio (SNR), calculated using Eq. 6.3. The SNR is calculated from the PR value and represents the deviation of the response due to noise factors. In this work noise factors include small variations in room temperature, humidity, uniformity of the feed solutions, interaction of foulants with membrane/feed spacer surfaces and influence of operating conditions on the membranes. 
Table 6.4. Selected values of controllable factors, corresponding calculated two-phase flow cleaning efficiency of the duplicate experiments $\left(\eta_{1}\right.$ and $\left.\eta_{2}\right)$, performance response (PR) value and signal-to-noise ratio (SNR) obtained for the 25 experiments carried out in this study.

\begin{tabular}{|c|c|c|c|c|c|c|c|c|}
\hline Exp. trial & Feed type & $\begin{array}{c}\text { Liquid } \\
\text { velocity }\end{array}$ & $\begin{array}{c}\text { G/L ratio } \\
(\theta)\end{array}$ & Spacer & $\eta_{1}$ & $\eta_{2}$ & PR & SNR \\
\hline 1 & $\begin{array}{c}\text { Tap water + C:N:P } \\
100: 20: 10\end{array}$ & $0.04 \mathrm{~m} / \mathrm{s}$ & 0.167 & A & 53.15 & 58.54 & 55.85 & 34.9 \\
\hline 2 & $\begin{array}{c}\text { Tap water + C:N:P } \\
100: 20: 10\end{array}$ & $0.06 \mathrm{~m} / \mathrm{s}$ & 0.33 & B & 73.86 & 69.07 & 71.47 & 37.1 \\
\hline 3 & $\begin{array}{c}\text { Tap water + C:N:P } \\
\text { 100:20:10 }\end{array}$ & $0.07 \mathrm{~m} / \mathrm{s}$ & 0.412 & $\mathrm{C}$ & 71.87 & 59.44 & 65.66 & 36.3 \\
\hline 4 & $\begin{array}{c}\text { Tap water + C:N:P } \\
\text { 100:20:10 }\end{array}$ & $\begin{array}{c}0.082 \\
\mathrm{~m} / \mathrm{s}\end{array}$ & 0.5 & $\mathrm{D}$ & 75.72 & 80.41 & 78.07 & 37.8 \\
\hline 5 & $\begin{array}{c}\text { Tap water + C:N:P } \\
\text { 100:20:10 }\end{array}$ & $\begin{array}{c}0.116 \\
\mathrm{~m} / \mathrm{s}\end{array}$ & 0.629 & $\mathrm{E}$ & 88.59 & 86.13 & 87.36 & 38.8 \\
\hline 6 & $\begin{array}{l}\text { Humic acid } 1000 \mathrm{ppm} \\
\quad+4 \mathrm{mM} \mathrm{CaCl}_{2}\end{array}$ & $0.04 \mathrm{~m} / \mathrm{s}$ & 0.33 & $\mathrm{C}$ & 60.68 & 81.20 & 70.94 & 37.0 \\
\hline 7 & $\begin{array}{l}\text { Humic acid } 1000 \mathrm{ppm} \\
+4 \mathrm{mM} \mathrm{CaCl}_{2}\end{array}$ & $0.06 \mathrm{~m} / \mathrm{s}$ & 0.412 & D & 70.75 & 68.84 & 69.80 & 36.9 \\
\hline 8 & $\begin{array}{l}\text { Humic acid } 1000 \mathrm{ppm} \\
+4 \mathrm{mM} \mathrm{CaCl}_{2}\end{array}$ & $0.07 \mathrm{~m} / \mathrm{s}$ & 0.5 & $\mathrm{E}$ & 63.10 & 69.05 & 66.08 & 36.4 \\
\hline 9 & $\begin{array}{l}\text { Humic acid } 1000 \mathrm{ppm} \\
+4 \mathrm{mM} \mathrm{CaCl}_{2}\end{array}$ & $\begin{array}{c}0.082 \\
\mathrm{~m} / \mathrm{s}\end{array}$ & 0.629 & A & 50.64 & 53.89 & 52.27 & 34.4 \\
\hline 10 & $\begin{array}{l}\text { Humic acid } 1000 \mathrm{ppm} \\
+4 \mathrm{mM} \mathrm{CaCl}_{2}\end{array}$ & $\begin{array}{c}0.116 \\
\mathrm{~m} / \mathrm{s}\end{array}$ & 0.167 & B & 52.65 & 58.68 & 55.67 & 34.9 \\
\hline 11 & $\begin{array}{l}\text { Sodium alginate } 1000 \\
\mathrm{ppm}+4 \mathrm{mM} \mathrm{CaCl}_{2}\end{array}$ & $0.04 \mathrm{~m} / \mathrm{s}$ & 0.412 & $\mathrm{E}$ & 60.22 & 64.56 & 62.39 & 35.9 \\
\hline 12 & $\begin{array}{l}\text { Sodium alginate } 1000 \\
\mathrm{ppm}+4 \mathrm{mM} \mathrm{CaCl}_{2}\end{array}$ & $0.06 \mathrm{~m} / \mathrm{s}$ & 0.5 & A & 43.28 & 43.79 & 43.54 & 32.8 \\
\hline 13 & $\begin{array}{c}\text { Sodium alginate } \\
1000 \mathrm{ppm}+4 \mathrm{mM} \\
\mathrm{CaCl}_{2}\end{array}$ & $0.07 \mathrm{~m} / \mathrm{s}$ & 0.629 & B & 40.25 & 49.95 & 45.10 & 33.1 \\
\hline 14 & $\begin{array}{c}\text { Sodium alginate } 1000 \\
\mathrm{ppm}+4 \mathrm{mM} \mathrm{CaCl}_{2}\end{array}$ & $\begin{array}{c}0.082 \\
\mathrm{~m} / \mathrm{s}\end{array}$ & 0.167 & $\mathrm{C}$ & 27.38 & 28.74 & 28.06 & 29.0 \\
\hline 15 & $\begin{array}{l}\text { Sodium alginate } 1000 \\
\mathrm{ppm}+4 \mathrm{mM} \mathrm{CaCl}\end{array}$ & $\begin{array}{c}0.116 \\
\mathrm{~m} / \mathrm{s}\end{array}$ & 0.33 & D & 34.08 & 31.00 & 32.54 & 30.2 \\
\hline 16 & $\begin{array}{l}\text { Humic acid } 1000 \mathrm{ppm} \\
\quad+10 \mathrm{mM} \mathrm{CaCl}_{2}\end{array}$ & $0.04 \mathrm{~m} / \mathrm{s}$ & 0.5 & B & 93.18 & 86.44 & 89.81 & 39.1 \\
\hline 17 & $\begin{array}{l}\text { Humic acid } 1000 \mathrm{ppm} \\
\quad+10 \mathrm{mM} \mathrm{CaCl}{ }_{2}\end{array}$ & $0.06 \mathrm{~m} / \mathrm{s}$ & 0.629 & $\mathrm{C}$ & 88.95 & 90.29 & 89.62 & 39.0 \\
\hline 18 & $\begin{array}{l}\text { Humic acid } 1000 \mathrm{ppm} \\
\quad+10 \mathrm{mM} \mathrm{CaCl}_{2}\end{array}$ & $0.07 \mathrm{~m} / \mathrm{s}$ & 0.167 & D & 84.00 & 89.00 & 86.50 & 38.7 \\
\hline 19 & $\begin{array}{l}\text { Humic acid } 1000 \mathrm{ppm} \\
\quad+10 \mathrm{mM} \mathrm{CaCl}_{2}\end{array}$ & $\begin{array}{c}0.082 \\
\mathrm{~m} / \mathrm{s}\end{array}$ & 0.33 & $\mathrm{E}$ & 90.59 & 87.74 & 89.17 & 39.0 \\
\hline 20 & $\begin{array}{l}\text { Humic acid } 1000 \mathrm{ppm} \\
\quad+10 \mathrm{mM} \mathrm{CaCl}{ }_{2}\end{array}$ & $\begin{array}{c}0.116 \\
\mathrm{~m} / \mathrm{s}\end{array}$ & 0.412 & A & 87.49 & 83.08 & 85.29 & 38.6 \\
\hline 21 & Yeast $1000 \mathrm{ppm}$ & $0.04 \mathrm{~m} / \mathrm{s}$ & 0.629 & $\mathrm{D}$ & 55.16 & 54.19 & 54.68 & 34.8 \\
\hline 22 & Yeast $1000 \mathrm{ppm}$ & $0.06 \mathrm{~m} / \mathrm{s}$ & 0.167 & $\mathrm{E}$ & 32.62 & 52.14 & 42.38 & 32.5 \\
\hline 23 & Yeast $1000 \mathrm{ppm}$ & $0.07 \mathrm{~m} / \mathrm{s}$ & 0.33 & $\mathrm{~A}$ & 8.19 & 22.01 & 15.10 & 23.6 \\
\hline 24 & Yeast $1000 \mathrm{ppm}$ & $\begin{array}{c}0.082 \\
\mathrm{~m} / \mathrm{s}\end{array}$ & 0.412 & B & 29.43 & 29.95 & 29.69 & 29.5 \\
\hline 25 & Yeast 1000 ppm & $\begin{array}{c}0.116 \\
\mathrm{~m} / \mathrm{s}\end{array}$ & 0.5 & $\mathrm{C}$ & 41.05 & 43.93 & 42.49 & 32.6 \\
\hline
\end{tabular}


Both the signal-to-noise ratio (SNR) and the maximum performance response (PR) rely on the approach 'the higher, the better'. The 'signal' in the signal-to-noise ratio is the value of the desired output parameter (mean). The "noise" represents the value of the undesired output parameter (standard deviation). Therefore, the SNR is the ratio of the mean and the standard deviation. The use of highest SNR means a smaller variability. Since the experimental design is orthogonal, the effect of each factor at all different levels can be, for instance the mean PR and SNR for the feed type at level 1,2,3,4, and 5, and can be calculated by averaging the PR and SNR values in Table 6.4 for the experiments 1-5, 6-10, 11-15, 16-20 and 21-25, respectively. In a similar manner, the mean PR and SNR values for all other factors at all levels can be calculated as well. The main contribution of each controllable factor to the performance response (in \%) and the corresponding SNR values are shown in Fig. 6.4.

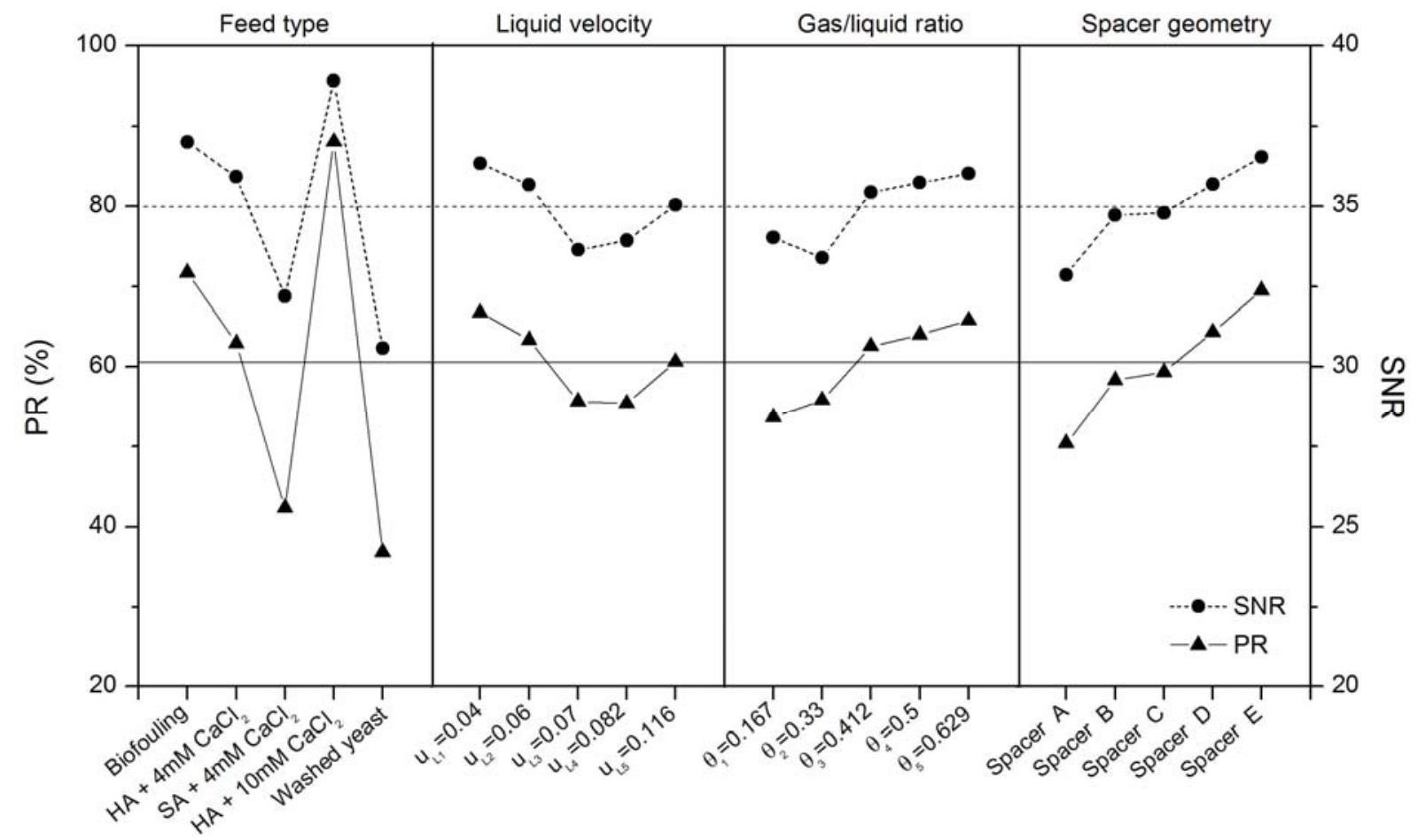

Fig. 6.4. Variation of cleaning efficiency and signal-to-noise $(S / N)$ ratio $S N R$ for the controllable factors investigated. $\mathrm{HA}=$ humic acid; $u_{\mathrm{L}}=$ liquid velocity $[\mathrm{m} / \mathrm{s}], \theta=$ gas/liquid ratio. The two horizontal lines represent the mean PR and SNR of all controllable factors.

The strength of this approach and more specifically Fig. 6.4 is that it immediately shows the relevant variables that control and determine the performance. In terms of application this means that Fig. 6.4 directly shows the possibilities an operator of a membrane water 
purification plant has on how and to what extent to increase the cleaning efficiency of twophase flow cleaning resulting in increased flux values. Fig. 6.4 shows that the PR and SNR values vary with all controllable factors and that in general the PR and SNR values show similar trends. However, the effect of the feed type (foulant) is by far the most dominant, compared to the other factors. So, in order to increase the efficiency of two-phase flow cleaning, the highest effect can be expected when the feed type and foulant is controlled. Also control of the other three factors (liquid velocity, gas/liquid ratio and spacer type) does have an effect, but the response is less strong and the increase in efficiency is less.

Two-phase flow cleaning works effectively to remove fouling by humic acids with added 10 $\mathrm{mM} \mathrm{CaCl}_{2}$. On the other hand, the cleaning efficiency is lowest for removing fouling caused by washed yeast and alginates. The two-phase flow cleaning efficiencies for $\mathrm{HA}+4 \mathrm{mM} \mathrm{CaCl} \mathrm{C}_{2}$ and biofouling are fairly better.

When $\mathrm{CaCl}_{2}$ is added to humic acid solutions, $\mathrm{Ca}^{2+}$ ions bind to the carboxylate and phenolate groups of the humic acids and enhance the interaction between the humic acid molecules. The higher the $\mathrm{Ca}^{2+}$ ion concentration, the stronger this molecular interaction; the calcium ions may promote the formation of aggregates or form a physical bridge between foulants and membrane surface [8]. These larger particles easily clog narrow, spacer-filled channels, decrease porosity and therefore lead to a greater increase in the FCP in case $\mathrm{HA}+10 \mathrm{mM} \mathrm{CaCl}_{2}$ solutions are used when compared to the use of a $\mathrm{HA}+4 \mathrm{mM} \mathrm{CaCl}$ feed solution. These bigger, clogged particles are at the same time more easy to remove by twophase flow cleaning, hence the cleaning efficiency is higher for $\mathrm{HA}+10 \mathrm{mM} \mathrm{CaCl}_{2}$ solutions than for $\mathrm{HA}+4 \mathrm{mM} \mathrm{CaCl}_{2}$ feed solutions.

Fouling by organic macromolecules, including humic acids and alginates, is developed by binding of the carboxylic functional groups. The presence of $\mathrm{Ca}^{2+}$ ions facilitates a more complex binding and increases foulant-foulant intermolecular interactions. The adhesion forces of alginates are much stronger than those of humic acids in the presence of $\mathrm{Ca}^{2+}$ ions, and alginates form a cross-linked network by intermolecular bridging [24, 25]. Also the foulant-membrane surface intermolecular interactions are enhanced when $\mathrm{Ca}^{2+}$ ions are present, inducing a strong interaction between the carboxylic groups of the organic macromolecular particles (humic acids and alginates) and the functional groups on the membrane surface and the feed spacer [26]. Since the adhesion forces of alginates are much 
stronger than those of humic acids [26], alginate binding to the membrane surface is also much stronger. Consequently, when a hydrodynamic force is applied to remove this fouling, as in two-phase flow cleaning, the effect of the bubbles on removal of alginate fouling is less than when removing humic acid fouling. In addition, the presence of divalent $\mathrm{Ca}^{2+}$ ions also induce the formation of gel-like structures in the case of alginates [27] that are more difficult to remove by two-phase flow cleaning as well.

Regarding biofouling removal, as we found in our previous work [9], the use of a feed solution consisting of tap water with addition of a high concentration of nutrients (1 mg Ac-C /L) is able to accelerate biofilm growth in spacer-filled membrane channels. However, the use of this nutrient concentration produces a thick, but fluffy biofilm in the feed channel in relatively short times of only 5-7 days, that can also be easily removed by two-phase flow cleaning, hence resulting in a relatively good biofilm removal of approximately $70 \%$. The use of a lower amount of nutrients would decrease the biofilm growth, and produce more dense biofouling layers. However, that would take too much experimental time for this study, while not adding essential information at this stage. Nevertheless, the obtained results can be considered as representative in terms of dominance of the different factors.

Due to their larger size, deposition of yeast particles is driven by random Brownian diffusion of yeast cells to the NF membrane surface [28]. At the earlier stages, individual cells deposit at different locations on membrane and feed spacer surfaces, followed by the deposition and adhesion of new yeast cells onto the already deposited cells and the formation of aggregates. These aggregates are sticky and two-phase flow cleaning to a large extent fails to remove all aggregates completely from the feed spacer channels.

Although a continuous factor, as shown in Fig. 6.4, the effect of the liquid velocity on the two-phase flow cleaning efficiency is less essential. The efficiency is highest when the liquid velocity is lowest $\left(\mathrm{u}_{\mathrm{L}}=0.04 \mathrm{~m} / \mathrm{s}\right)$, showing a minimum when $\mathrm{u}_{\mathrm{L}}=0.07-0.082 \mathrm{~m} / \mathrm{s}$. Liquid velocities used were always equal in both the fouling and corresponding cleaning stage for each specific experiment. When the lowest liquid velocity is applied during the fouling stage, shear forces are low, and hence more fouling can develop in the feed spacer channel. Consequently a 100\% FCP increase was obtained faster, and a thick but less compact fouling was formed. This thick fouling layer can be easily removed by two-phase flow cleaning, leading to the highest cleaning efficiency. At intermediate velocities $\left(\mathrm{u}_{\mathrm{L}}=0.06-0.082 \mathrm{~m} / \mathrm{s}\right)$, the 
formed fouling layer is more compact. At these intermediate velocities, however, shear forces are not so dominant and two-phase flow cleaning is not so efficient yet, which is visible as a minimum in Fig. 6.4. At the highest liquid velocity $\left(\mathrm{u}_{\mathrm{L}}=1.116 \mathrm{~m} / \mathrm{s}\right)$ investigated however, a more dense fouling layer is formed during the fouling stage. Also during the cleaning stage, this high liquid velocity is applied. This significantly affects the gas bubble velocity as well (as shown in [8]) and creates additional and higher shear forces on the fouling layer, and hence the cleaning efficiency is increased again.

The effect of gas/liquid ratio is obvious, although less dominant than the foulant type. As found in many applications of two-phase flow cleaning processes, a higher gas/liquid ratio promotes higher cleaning efficiency [6]. A higher gas/liquid ratio introduces more bubbles, and consequently more shear and a better cleaning efficiency is obtained.

For the discrete variable spacer type, the efficiency increases going from spacer A to E. The highest cleaning efficiency is found when the thickest spacer $(1.2 \mathrm{~mm})$ is used. However, not only the spacer thickness is responsible for the higher cleaning efficiency, also e.g. the filament length and length, hydraulic diameter and the specific spacer surface chemistry and area play a role. As it is a discrete factor, a specific trend in terms of the individual and combined effects of these spacer characteristics cannot be distinguished at this stage. The results are in agreement with what we found in our previous work [8].

\subsubsection{ANOVA analysis}

In order to define the variance and significance of the contribution of each controllable factor, an ANOVA was performed on the experimental data. The results are summarized in Table 6.5.

Table 6.5. Analysis of variance (ANOVA) for the performance response (PR).

\begin{tabular}{lccccc}
\hline Controllable factors & $\begin{array}{c}\text { Degrees of } \\
\text { freedom }\end{array}$ & $\begin{array}{c}\text { Sum of } \\
\text { squares }\end{array}$ & Variance & $\begin{array}{c}\text { Percent } \\
\text { contribution }\end{array}$ & $\begin{array}{c}\text { Process } \\
\text { influencing rank }\end{array}$ \\
\hline Feed type & 4 & 8900.76 & 2225.19 & 78.11 & 1 \\
Liquid velocity (m/s) & 4 & 478.27 & 119.57 & 4.20 & 4 \\
Gas/liquid ratio & 4 & 563.02 & 140.75 & 4.94 & 3 \\
Spacer geometry & 4 & 1014.29 & 253.57 & 8.90 & 2 \\
Error & 8 & 438.16 & 54.77 & 3.85 & \\
Total & 24 & 11394.5 & & 100 & \\
\hline
\end{tabular}


Table 6.5 presents the degrees of freedom, the sum of squares, the variance (mean squares), the percentage contribution and the process influence rank of each controllable factor on the output performance response (i.e. two-phase flow cleaning efficiency). By definition, the degrees of freedom for a factor equals the number of levels for that specific factor minus 1 [20]. ANOVA reveals that the feed type contributes for more than $78 \%$ to the two-phase flow cleaning efficiency, while the contributions of all other factors are (far) less than $10 \%$. The feed type therefore is the major, essential factor determining the efficiency. Flux enhancement and fouling removal efficiency increase can therefore best be reached by changing the feed (as far as that is possible in practical applications), as this has by far the highest impact. As presented in Table 6.5, the spacer geometry is ranked second, followed by the gas/liquid ratio and the liquid velocity, which both have an only very minor effect. In terms of practical applications however, especially these last two parameters are the easiest to change, as these are two operating parameters, while the other two factors are usually system characteristics that cannot be easily changed.

\subsubsection{Final remarks}

The Taguchi method and the subsequent calculation of the SNR and ANOVA for all combinations of controllable factors is a valuable, efficient tool to predict optimum conditions for a certain process, without running a full set of experiments changing each variable individually. At a later stage a subsequent additional confirmation experiment can be conducted.

In this study the objective was to determine the dominant factor determining the two-phase flow cleaning efficiency in spiral-wound membrane elements. As half of the controllable factors tested here are discrete factors (feed type and spacer geometry) the results of the optimization analysis do not directly give precise insights in the specific improvements of these two factors regarding two-phase flow cleaning efficiency, but they do show the relevance of the different factors. Only continuous factors (in this case the gas/liquid ratio and the liquid velocity) can be directly and easily optimized using this analysis.

More practically, in order to use the results of this study in practical applications of two-phase flow cleaning, the operator or engineer should consider first the type of foulant prior to taking 
a decision on whether or not to clean by two-phase flow. Once the feed type is defined, the use of the highest gas/liquid ratio, the highest liquid velocity and the thickest feed spacer (diamond type) are recommended to achieve maximum two-phase flow cleaning efficiency.

\subsection{Conclusions}

In this study, the dominant factor in terms of two-phase flow cleaning efficiency in spiralwound membrane elements was determined using a Taguchi design of experiment with a L-25 orthogonal array. Four controllable factors (feed type, feed spacer geometry, gas/liquid ratio and liquid velocity) were tested at five different levels. Analysis of responses was conducted and the signal-to-noise ratio (SNR) and an ANOVA were determined. This approach clearly revealed that the feed type is the most crucial factor determining the efficiency of two-phase flow cleaning. The spacer geometry is ranked second, followed by the gas/liquid ratio and the liquid velocity, which both have a very minor effect.

\section{References}

[1] C.J. Vörösmarty, P. McIntyre, M.O. Gessner, D. Dudgeon, A. Prusevich, P. Green, S. Glidden, S.E. Bunn, C.A. Sullivan, C.R. Liermann, Global threats to human water security and river biodiversity, Nature, 467 (2010) 555-561.

[2] J.D. Brookes, C.C. Carey, D.P. Hamilton, L. Ho, L. van der Linden, R. Renner, A. Rigosi, Emerging Challenges for the Drinking Water Industry, Environmental Science \& Technology, 48 (2014) 2099-2101.

[3] V. Likodimos, D. Dionysiou, P. Falaras, Clean water: water detoxification using innovative photocatalysts, Rev Environ Sci Biotechnol, 9 (2010) 87-94.

[4] T. Peters, Membrane Technology for Water Treatment, Chemical Engineering \& Technology, 33 (2010) 1233-1240.

[5] K.V. Plakas, A.J. Karabelas, Removal of pesticides from water by NF and RO membranes - A review, Desalination, 287 (2012) 255-265.

[6] Y. Wibisono, E.R. Cornelissen, A.J.B. Kemperman, W.G.J. van der Meer, K. Nijmeijer, Twophase flow in membrane processes: A technology with a future, Journal of Membrane Science, 453 (2014) 566-602.

[7] E.R. Cornelissen, M.A. Pot, R.C.M. Jong, J.A. De Ruijter, E.F. Beerendonk, J.M.C. van Agtmaal, One year of experience with air/water cleaning in spiral wound RO membranes for surface water treatment, in: J. Pinnekamp, M. Wessling, T. Melin (Eds.) 6th IWA Specialist Conference on Membrane Technology for Water and Wastewater Treatment, International Water Association, Aachen, 2011, pp. 219-220.

[8] Y. Wibisono, M. Zalewski, E.R. Cornelissen, A.J.B. Kemperman, W.G.J. Van der Meer, K. Nijmeijer, Efficiency of two-phase flow cleaning in spiral-wound membrane elements, Submitted to Desalination, (2014).

[9] Y. Wibisono, K.E. El Obied, E.R. Cornelissen, A.J.B. Kemperman, K. Nijmeijer, Biofouling removal in spiral-wound nanofiltration elements using two-phase flow cleaning, Submitted to Journal of Membrane Science, (2014).

[10] Q. She, Y.K.W. Wong, S. Zhao, C.Y. Tang, Organic fouling in pressure retarded osmosis: Experiments, mechanisms and implications, Journal of Membrane Science, 428 (2013) 181-189. 
[11] S. Lee, J. Cho, M. Elimelech, Influence of colloidal fouling and feed water recovery on salt rejection of RO and NF membranes, Desalination, 160 (2004) 1-12.

[12] Y. Ye, V. Chen, Reversibility of heterogeneous deposits formed from yeast and proteins during microfiltration, Journal of Membrane Science, 265 (2005) 20-28.

[13] P.Z. Çulfaz, M. Haddad, M. Wessling, R.G.H. Lammertink, Fouling behavior of microstructured hollow fibers in cross-flow filtrations: Critical flux determination and direct visual observation of particle deposition, Journal of Membrane Science, 372 (2011) 210-218.

[14] Y. Wibisono, W. Yandi, M. Golabi, R. Nugraha, E.R. Cornelissen, A.J.B. Kemperman, T. Ederth, K. Nijmeijer, Hydrogel-coated polypropylene feed spacers coupled to two-phase flow cleaning in spiral wound membrane elements: a novel platform for eco-friendly biofouling mitigation, Submitted to Water Research, (2014).

[15] R.K. Roy, Design of Experiments Using The Taguchi Approach: 16 Steps to Product and Process Improvement, John Wiley \& Sons, Inc., New York, 2001.

[16] J.S. Vrouwenvelder, C. Hinrichs, W.G.J. Van der Meer, M.C.M. Van Loosdrecht, J.C. Kruithof, Pressure drop increase by biofilm accumulation in spiral wound RO and NF membrane systems: role of substrate concentration, flow velocity, substrate load and flow direction, Biofouling, 25 (2009) 543555.

[17] J.S. Vrouwenvelder, C. Hinrichs, A.R. Sun, F. Royer, J.A.M. van Paassen, S.M. Bakker, W.G.J. van der Meer, J.C. Kruithof, M.C.M. van Loosdrecht, Monitoring and control of biofouling in nanofiltration and reverse osmosis membranes, Water Sci. Technol. Water Supply, 8 (2008) 449-458.

[18] F. Yates, Sir Ronald Fisher and the Design of Experiments, Biometrics, 20 (1964) 307-321.

[19] J.F. Box, R.A. Fisher and the Design of Experiments, 1922-1926, The American Statistician, 34 (1980) $1-7$.

[20] R.K. Roy, A primer on the Taguchi method, Society of Manufacturing Engineers Michigan, 1990.

[21] T.J. Robinson, C.M. Borror, R.H. Myers, Robust Parameter Design: A Review, Quality and Reliability Engineering International, 20 (2004) 81-101.

[22] P. Saudagar, R. Singhal, A statistical approach using L25 orthogonal array method to study fermentative production of clavulanic acid by Streptomyces clavuligerus MTCC 1142, Appl. Biochem. Biotechnol., 136 (2007) 345-359.

[23] W.J.C. van de Ven, K.v.t. Sant, I.G.M. Pünt, A. Zwijnenburg, A.J.B. Kemperman, W.G.J. van der Meer, M. Wessling, Hollow fiber dead-end ultrafiltration: Influence of ionic environment on filtration of alginates, Journal of Membrane Science, 308 (2008) 218-229.

[24] B. Mi, M. Elimelech, Chemical and physical aspects of organic fouling of forward osmosis membranes, Journal of Membrane Science, 320 (2008) 292-302.

[25] S. Lee, M. Elimelech, Relating Organic Fouling of Reverse Osmosis Membranes to Intermolecular Adhesion Forces, Environmental Science \& Technology, 40 (2006) 980-987.

[26] Q. Li, M. Elimelech, Organic Fouling and Chemical Cleaning of Nanofiltration Membranes: Measurements and Mechanisms, Environmental Science \& Technology, 38 (2004) 4683-4693.

[27] A.J. de Kerchove, M. Elimelech, Formation of Polysaccharide Gel Layers in the Presence of $\mathrm{Ca}^{2+}$ and $\mathrm{K}^{+}$Ions: Measurements and Mechanisms, Biomacromolecules, 8 (2007) 113-121.

[28] A. Subramani, E.M.V. Hoek, Direct observation of initial microbial deposition onto reverse osmosis and nanofiltration membranes, Journal of Membrane Science, 319 (2008) 111-125. 


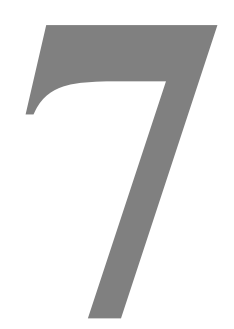

Conclusion and Outlook 


\begin{abstract}
Two-phase flow instabilities are ubiquitous in many industrial processes. While such flow instabilities are undesirable in many cases, in membrane processes two-phase flow instabilities are beneficial to control fouling phenomena. Such instabilities employed in membrane processes occur on a macroscopic scale rather than at a microscopic level such as local phenomena at the liquid/gas interface. Several parameters determine two-phase flow phenomena: (i) geometry of the channels, (ii) operating conditions, and (iii) boundary conditions [1]. In this thesis, the focus was on the potential of two-phase flow instabilities to control membrane fouling in spacer-filled narrow channels. In the following chapter, the main conclusions of the work are summarized. The chapter is concluded with a discussion on the limitations, improvements and suggestions for future research of two-phase flow in spacerfilled channels.
\end{abstract}




\subsection{Conclusions}

Chapter 2 presented a critical and comprehensive literature review on the use of two-phase flow in membrane processes and showed the following parameters enhance the flux, MTC and rejection, while decreasing the feed channel pressure drop due to the application of twophase flow: (i) vertical positioning of the membrane modules has a positive effect for all types of membrane modules, (ii) the gas/liquid ratio is the most important parameter for maximum process enhancement, yet the degree of enhancement may differ depending on the channel geometry, and (iii) operating two-phase flow at low trans-membrane pressure yields optimum process enhancement. Subsequently, the overview of commercial applications of two-phase flow in membrane processes suggests the technology is cost efficient.

In Chapter 3, several factors have been investigated to elucidate which parameters (i.e. feed spacer geometry (thickness and orientation), gas/liquid ratio, liquid velocity, and feed type) control the efficiency of two-phase flow cleaning. The results show that although the channel porosity and the hydraulic diameter of spacer-filled channels are important factors in terms of efficiency, the bubble velocity is far more important in improving the two-phase flow cleaning efficiency. A higher bubble velocity will exert higher shear stresses on deposited foulants. The gas/liquid ratio should be maintained in such a way that a slug-like flow pattern is formed, so as to generate a good bubble distribution. Channel coverage strongly depends on the geometry of the spacer-filled channel; maintaining full channel coverage by the bubbles is crucial.

A more detailed study on the effect of the different parameters in the efficiency of two-phase flow cleaning was presented in Chapter 6. A Taguchi method of L-25 orthogonal arrays was used for parameter optimization and revealed that the feed type is the key factor for feed channel pressure drop recovery. However, the use of thick feed spacers, high gas/liquid ratio and high liquid velocity are still important to maintain a good cleaning performance as well.

Biofouling removal in spiral wound nanofiltration elements was mitigated using two-phase flow cleaning and presented in Chapter 4. At a liquid velocity of $0.11 \mathrm{~m} / \mathrm{s}$ for Spacer A $(0.7$ $\mathrm{mm}$ thickness), increasing the gas/liquid ratio from 0.5 to 0.8 resulted in similar cleaning efficiencies in terms of the FCP (feed channel pressure drop) and MTC (mass transfer coefficient; about $90 \%$ and 17\%, respectively). For Spacer B (0.5 mm thickness), maldistribution of the bubbles was observed at a gas/liquid ratio of 0.5 resulting in lower 
cleaning efficiencies (about $65 \%$ and $5 \%$ for FCP and MTC, respectively). When the gas/liquid ratio was increased to 0.8 , for Spacer B the same cleaning results as in Spacer A were obtained. At the same gas/liquid ratio of 0.5, operating at a higher pressure of $600 \mathrm{kPag}$ had no influence on the results obtained for spacer B. This indicates that bubble flow and -size, which is critical for the efficiency of the process, is controlled by the structure of the feed spacer. An increase in the liquid velocity during two-phase flow cleaning was responsible for increasing bubble velocity and this was most effective in improving the MTC efficiency. The largest efficiency (about $40 \%$ ) was obtained at the highest liquid velocity $(0.44 \mathrm{~m} / \mathrm{s})$. Mesoscale visual inspections using OCT clearly showed a significant increase of biomass removed from the membrane surface with increasing velocity. The observed bubble velocities where found to be approximately 4.5 times higher than the liquid velocities. At identical gas/liquid ratio, the increased efficiency is due to increasing bubble velocity resulting in higher shear forces on the surface of the membrane. Finally, using the FCP only, as an indicator for biofouling removal was found to be insufficient. For example, the short cleaning duration required (about $5 \mathrm{~min}$ ) for FCP recovery is misleading since it does not take into account the biomass present on the membrane surface. The information provided by the MTC gave a better indication about the biofilms present directly on the membrane surface, thus providing more insight in actual removal rates.

In Chapter 5, the potential of two-phase flow cleaning to control biofouling was tested using modified feed spacers. PolyHEMA-co-PEG ${ }_{10} \mathrm{MA}$ (neutral), polyDMAEMA (cationic) and polySPMA (anionic) were successfully coated onto PP feed spacer surfaces via plasma mediated UV-polymerization. These coatings were chemically stable for at least 7 days immersion into neutral, acidic and basic environment. All hydrogel-coated PP samples showed good anti-biofouling properties during bacterial adhesion tests. During filtration tests, polyDMAEMA showed low anti-biofouling properties due to hydrophobic interactions. The performance of polyHEMA-co-PEG ${ }_{10} \mathrm{MA}$ is fairly good. PolySPMA-coated PP feed spacers on the contrary showed significant anti-biofouling properties. Employing these highly hydrophilic spacers, during removal of biofouling by two-phase flow cleaning enhances the cleaning efficiency, feed channel pressure drop and improved the flux recoveries. A combination of polySPMA-coated PP feed spacers and two-phase flow cleaning therefore is promising and this environmentally friendly biofouling control could be considered in the operation of NF/RO systems employing spiral-wound membrane modules. 


\subsection{Outlook}

Further research on this topic should focus on especially biofouling control using two-phase flow cleaning, since biofouling problems are more profound for high-pressure membrane processes. Additionally, the effect of antiscalants on the two-phase flow cleaning efficiency is important to be considered, as this affects biofouling growth [2].

In this work, a relatively high nutrient concentration $(1 \mathrm{mg}$ Ac-C/L, a concentration typically 100 times higher than used in industrial systems) was used. The use of this high concentration produced thick biofilms on the surface of the membrane, and was necessary to shorten the time of the experiment. Lower concentrations may result in more open biofilm structures due to limitations in nutrient supply [3], thus requiring lower liquid velocities to obtain similar cleaning efficiencies. However, if an open biofilm structure is created, the film resistance is most likely lower as well. In such a case, it will be harder to detect changes in the amounts of biomass attached to the membrane surface by use of the MTC. As such, for mesoscopic studies the use of OCT and for microscopic investigations, the application of CLSM (confocal laser scanning microscopy) may provide better visualization of the biofouling structure before and after two-phase flow cleaning.

Fundamental studies on bubble behavior during two-phase flow cleaning are needed for better understanding and improving the efficiency of two-phase flow cleaning. Especially the effect of $e . g$. bubble size and shape in different feed suspensions, the bubble/wall interactions (actual shear stress of the bubbles on the fouling layer), bubble-bubble interactions (break-up, collapse, and coalescence), and bubble/fouling-particle interactions (hydrophobicity, interfacial forces) is worthwhile investigating.

Since two-phase flow applied in real membrane applications also implies impurities [4], it is important to study the bubble structure and deformation in the presence of surfactants (e.g. non-ionic surfactant, anionic surfactant, base-cleaning agent and salt).

In relation to studying bubble/wall interactions, it is important to answer more scientific questions, such as "Are the thin liquid films - as postulated in slug flow patterns - the dominant factor in generating high shear forces at the membrane surface?', or 'Is the turbulence created by the bubbles sufficient to remove biofouling?'. Particle Imaging Velocimetry (PIV) or the use of shear stress sensors could be used to obtain quantitative 
information regarding the actual shear forces present at the interfaces. This information could lead to new feed spacer designs with better cleaning performance. CFD modeling can be used for process optimization.

The use of an antibiofouling coating on the surface of the feed-side spacer increases the efficacy of two-phase flow cleaning. Yet, modification of the membrane was left unmodified in this work. Once both membrane and feed spacer structure and material are optimized with respect to two-phase flow cleaning, the efficiency is expected to be higher. Many studies have been conducted to enhance the anti-biofouling properties of membranes and these strategies can be used in combination with the modification of feed spacer surfaces.

Finally, practical studies on the up-scaling of two-phase flow cleaning on NF/RO processes for water purification, waste water treatment or desalination optimized for long-term operation is essential. Key factors affecting two-phase flow cleaning as identified in this study, should be tested at larger scales to elucidate their effect on full scale NF/RO installations using real feed waters. In addition also more extensive economic evaluations need to be performed.

\section{References}

[1] J.A. Boure, A.E. Bergles, L.S. Tong, Review of two-phase flow instability, Nuclear Engineering and Design, 25 (1973) 165-192.

[2] J.S. Vrouwenvelder, S.A. Manolarakis, H.R. Veenendaal, D. van der Kooij, Biofouling potential of chemicals used for scale control in RO and NF membranes, Desalination, 132 (2000) 1-10.

[3] J.S. Vrouwenvelder, J. Buiter, M. Riviere, W.G.J. van der Meer, M.C.M. van Loosdrecht, J.C. Kruithof, Impact of flow regime on pressure drop increase and biomass accumulation and morphology in membrane systems, Water Research, 44 (2010) 689-702.

[4] Y. Wibisono, E.R. Cornelissen, A.J.B. Kemperman, W.G.J. van der Meer, K. Nijmeijer, Twophase flow in membrane processes: A technology with a future, Journal of Membrane Science, 453 (2014) 566-602. 


\section{$\underline{\text { Abbreviations and symbols }}$}

\section{Chapter 2}

\begin{tabular}{|c|c|}
\hline ABFR & air bubble flow rate \\
\hline ATP & adenosine triphosphate \\
\hline AVMD & air-bubbling vacuum membrane distillation \\
\hline AWC & air/water cleaning \\
\hline BSA & bovine serum albumin \\
\hline $\mathrm{C}_{0}$ & concentration \\
\hline $\mathrm{CR}$ & concentration ratio \\
\hline CFD & computational fluid dynamics \\
\hline CIP & cleaning in place \\
\hline COD & chemical oxygen demand \\
\hline CSD & copper sulfate dosing \\
\hline CWF & clean-water flux \\
\hline$d$ & diameter \\
\hline$d_{r e f}$ & reference diameter \\
\hline$d^{\%}$ & dimensionless diameter number \\
\hline DCMD & direct contact membrane distillation \\
\hline DWP & demineralized-water plant \\
\hline ED & electrodialysis \\
\hline EDTA & ethylenediaminetetraacetic acid \\
\hline g & acceleration due to gravity \\
\hline HRT & hydraulic retention time \\
\hline HSA & human serum albumin \\
\hline $\operatorname{IgG}$ & immunoglobulin \\
\hline$J$ & permeate flux \\
\hline MBR & membrane bioreactor \\
\hline MD & membrane distillation \\
\hline MDBR & membrane distillation bioreactor \\
\hline MF & microfiltration \\
\hline $\mathrm{MFC}$ & microbial fuel cell \\
\hline MFS & membrane fouling simulator \\
\hline MLSS & mixed liquor suspended solid \\
\hline MTC & mass transfer coefficient \\
\hline MWCO & molecular weight cut off \\
\hline $\mathrm{N}_{\mathrm{f}}$ & dimensionless resistance number \\
\hline $\mathrm{N}_{\mathrm{s}}^{\prime}$ & dimensionless shear stress number \\
\hline NF & nanofiltration \\
\hline NOM & natural organic matter \\
\hline NPOC & non-purgable organic carbon \\
\hline NTU & nephelometric turbidity unit \\
\hline PDMS & polydimethylsiloxane \\
\hline PEI & polyethylenimine \\
\hline PEM & proton exchange membrane \\
\hline PES & polyethersulfone \\
\hline PIV & particle imaging velocimetry \\
\hline PMMA & poly(methyl methacrylate) \\
\hline PP & polypropylene \\
\hline PPA & polyphthalamide \\
\hline ppm & part per million \\
\hline PSf & polysulfone \\
\hline
\end{tabular}




\begin{tabular}{|c|c|c|}
\hline PTFF & & \\
\hline PTFE & polytetrafluoroethylene & \\
\hline PVDF & polyvinylidene fluoride & \\
\hline PVA & polyvinyl alcohol & \\
\hline PVP & polyvinylpyrrolidone & \\
\hline $\mathrm{Q}_{\mathrm{G}}$ & gas flow rate & {$\left[\mathrm{Nm}^{3} / \mathrm{min}\right]$} \\
\hline $\mathrm{Q}_{\mathrm{L}}$ & liquid flow rate & {$[\mathrm{L} / \mathrm{h}]$} \\
\hline $\mathrm{R}$ & retention & {$[\%]$} \\
\hline RNG & renormalized group & \\
\hline RSM & response surface methodology & \\
\hline RO & reverse osmosis & \\
\hline TCM & traditional Chinese medicine & \\
\hline TMP & trans-membrane pressure & [bar] \\
\hline VMD & vacuum membrane distillation & \\
\hline VOF & volume of fluid & \\
\hline$u_{G}$ & gas superficial velocity & {$[\mathrm{m} / \mathrm{s}]$} \\
\hline$u_{L}$ & liquid superficial velocity & {$[\mathrm{m} / \mathrm{s}]$} \\
\hline$v$ & velocity & {$[\mathrm{m} / \mathrm{s}]$} \\
\hline$v_{r e f}$ & reference velocity & {$[\mathrm{m} / \mathrm{s}]$} \\
\hline$v^{\%}$ & dimensionless velocity number & \\
\hline UF & ultrafiltration & \\
\hline WTP & water treatment plant & \\
\hline Greek & & \\
\hline$\theta$ & gas/liquid ratio & \\
\hline$\sigma$ & interface tension & {$[\mathrm{N} / \mathrm{m}]$} \\
\hline$\sigma^{\%}$ & dimensionless interface number & \\
\hline$\Delta \rho$ & modulus of density difference of phases & {$\left[\mathrm{kg} / \mathrm{m}^{3}\right]$} \\
\hline$\rho$ & density of continuous phase & {$\left[\mathrm{kg} / \mathrm{m}^{3}\right]$} \\
\hline$\rho_{\mathrm{d}}$ & density of dispersed phase & {$\left[\mathrm{kg} / \mathrm{m}^{3}\right]$} \\
\hline$\eta$ & dynamic viscosity of continuous phase & {$[\mathrm{Pa} \mathrm{s}]$} \\
\hline$\eta_{\mathrm{d}}$ & dynamic viscosity of dispersed phase & {$[\mathrm{Pa} \mathrm{s}]$} \\
\hline$\eta^{\%}$ & dimensionless dynamic viscosity & \\
\hline Chap & & \\
\hline A & cross section of flow channel & {$\left[\mathrm{m}^{2}\right]$} \\
\hline$\sigma$ & filament angle & {$\left[{ }^{0}\right]$} \\
\hline$\alpha_{c}$ & channel coverage of the bubbles & {$[-]$} \\
\hline $\mathrm{C}$ & wetted circumference of flow channel & {$[\mathrm{m}]$} \\
\hline $\mathrm{C}_{0}$ & initial concentration & {$[\mathrm{g} / \mathrm{L}]$} \\
\hline$D_{\text {ave }}$ & average particle size & {$[\mu \mathrm{m}]$} \\
\hline$d_{h}$ & hydraulic diameter & {$[\mathrm{m}]$} \\
\hline$d_{h}^{s p}$ & hydraulic diameter of spacer-filled channel & {$[\mathrm{m}]$} \\
\hline$d_{s}$ & diameter of feed spacer strand & {$[\mathrm{m}]$} \\
\hline$\Delta \mathrm{P}_{0}$ & initial feed channel pressure drop & [mbar] \\
\hline$\Delta \mathrm{P}_{\mathrm{t}}$ & feed channel pressure drop in t-time & [mbar] \\
\hline$\Delta \mathrm{P}_{\mathrm{TPF}}$ & feed channel pressure drop post two-phase flow cleaning & [mbar] \\
\hline$\varepsilon$ & spacer porosity & {$[-]$} \\
\hline $\mathrm{F}$ & frame rate & [fps] \\
\hline$\gamma$ & interfacial tension & {$[\mathrm{mN} / \mathrm{m}]$} \\
\hline
\end{tabular}




$\begin{array}{lll}\mathrm{H} & \text { flow channel height } & {[\mathrm{m}]} \\ \mathrm{h}_{\mathrm{sp}} & \text { feed spacer thickness } & {[\mathrm{m}]} \\ \mathrm{L}_{\mathrm{c}} & \text { distance between channel inlet and outlet } & {[\mathrm{m}]} \\ \mathrm{L}_{\mathrm{s}} & \text { length of feed spacer strand } & {[\mathrm{m}]} \\ \mathrm{N}_{\mathrm{F}} & \text { total number of frames } & {[-]} \\ \mathrm{NPD} & \text { normalized pressure drop } & {[-]} \\ \mathrm{P}_{\mathrm{gas}} & \text { gas pressure } & {[\mathrm{bar}]} \\ \mathrm{Q}_{\mathrm{G}} & \text { gas flow rate } & {[\mathrm{L} / \mathrm{h}]} \\ \mathrm{Q}_{\mathrm{L}} & \text { liquid flow rate } & {[\mathrm{L} / \mathrm{h}]} \\ S_{s p} & \text { feed spacer surface } & {\left[\mathrm{m}^{2}\right]} \\ S_{v}^{s p} & \text { specific surface of the spacer } & {\left[\mathrm{m}^{-1}\right]} \\ \theta & \text { gas/liquid ratio } & {[-]} \\ \mathrm{u}_{\mathrm{G}} & \text { superficial gas velocity } & {[\mathrm{m} / \mathrm{s}]} \\ \mathrm{u}_{\mathrm{L}} & \text { superficial liquid velocity } & {[\mathrm{m} / \mathrm{s}]} \\ \mathrm{u}_{\sigma} & \text { velocity vector of } \sigma & {[\mathrm{m} / \mathrm{s}]} \\ v_{\mathrm{b}} & \text { bubble velocity } & {[\mathrm{m} / \mathrm{s}]} \\ \mathrm{v}_{\mathrm{L}} & \text { feed inlet velocity } & {[\mathrm{m} / \mathrm{s}]} \\ \mathrm{V}_{\mathrm{sp}} & \text { feed spacer volume } & {\left[\mathrm{m}^{3}\right]} \\ \mathrm{V}_{\text {tot }} & \text { total volume of flow channel } & {\left[\mathrm{m}^{3}\right]} \\ \mathrm{W} & \text { flow channel width } & {[\mathrm{m}]} \\ \mathrm{W}_{\mathrm{b}} & \text { width of two-dimensional bubble } & {[\mathrm{m}]}\end{array}$

\section{Chapter 4}

$\begin{array}{lll}\mathrm{A}_{\mathrm{m}} & \text { membrane area } & {\left[\mathrm{m}^{2}\right]} \\ c_{d} & \text { concentrations of carbon in the dosing bottle } & {[\mathrm{mgC} / \mathrm{L}]} \\ c_{f} & \text { concentrations of carbon in the flow cells } & {[\mathrm{mgC} / \mathrm{L}]} \\ c_{\mathrm{m}} & \text { molar concentration of ions on the feed side } & {\left[\mathrm{mol} / \mathrm{m}^{3}\right]} \\ c_{\text {perm }} & \text { molar concentration of ions on the permeate side } & {\left[\mathrm{mol} / \mathrm{m}^{3}\right]} \\ \mathrm{d}_{\mathrm{h}} & \text { hydraulic diameter } & {[\mathrm{m}]} \\ \mathrm{d}_{\mathrm{f}} & \text { diameter of feed spacer filament } & {[\mathrm{mm}]} \\ \mathrm{FCP}=\Delta \mathrm{P} & \text { feed channel pressure drop } & {[\mathrm{Pa}]} \\ \Delta \mathrm{P}_{0} & \text { initial feed channel pressure drop } & {[\mathrm{Pa}]} \\ \Delta \mathrm{P}_{0, \mathrm{~s}} & \text { initial pressure drop over a section of the entire element } & {[\mathrm{Pa}]} \\ \Delta \mathrm{P}_{\mathrm{s}} & \text { pressure drop over the fouled section } & {[\mathrm{Pa}]} \\ \mathrm{F} & \text { frame rate } & {[\mathrm{fps}]} \\ \mathrm{H} & \text { feed channel height } & {[\mathrm{m}]} \\ i & \text { Van 't Hoff factor of the solute } & {[-]} \\ \mathrm{J}_{\mathrm{v}} & \text { volumetric flux } & {\left[\mathrm{L} / \mathrm{m}^{2} . \mathrm{h}\right]} \\ \mathrm{L}_{0} & \text { length of the entire element } & {[\mathrm{m}]} \\ \mathrm{L}_{\mathrm{c}} & \text { distance between channel inlet and outlet } & {[\mathrm{m}]} \\ \mathrm{L}_{\mathrm{s}} & \text { length of the inlet section of the element } & {[\mathrm{m}]} \\ \dot{m} & \text { mass flow rate } & {[\mathrm{kg} / \mathrm{h}]} \\ \dot{M} & \text { mass transfer coefficient } & {[\mathrm{m} / \mathrm{Pa} . \mathrm{s}]} \\ \mathrm{N}_{\mathrm{F}} & \text { total number of frames } & {[-]} \\ \mathrm{P}_{\text {in }} & \text { pressure at the inlet of the feed side } & {[\mathrm{Pa}]} \\ \mathrm{P}_{\mathrm{out}} & \text { pressure at the outlet of the feed side } & {[\mathrm{Pa}]} \\ \mathrm{R} & \text { gas constant }(8.314) & {[\mathrm{J} / \mathrm{mol} . \mathrm{K}]} \\ \mathrm{R}_{\mathrm{cp}} & \text { resistance due to concentration polarization } & {\left[\mathrm{m}^{-1}\right]} \\ \mathrm{R}_{\mathrm{f}} & \text { fouling resistance } & {\left[\mathrm{m}^{-1}\right]} \\ \mathrm{R}_{\mathrm{m}} & \text { membrane resistance } & {\left[\mathrm{m}^{-1}\right]}\end{array}$


$\mathrm{R}_{\mathrm{t}}$

$\mathrm{P}_{\text {perm }}$

$\mathrm{T}$

TMP

$\mathrm{u}_{\mathrm{L}}$

$\mathrm{V}_{\mathrm{sp}}$

$\mathrm{V}_{\text {tot }}$

W

Greek letter

\section{$\sigma$}

$\Delta \pi$

$\eta$

$\varepsilon$

$\mu$

$\rho$

$\theta$

$\phi$

$v_{\mathrm{b}}$

total resistance

$\left[\mathrm{m}^{-1}\right]$

average pressure on the permeate side

$[\mathrm{Pa}]$

absolute temperature

$[\mathrm{K}]$

trans-membrane pressure of pressure drop [bar]

superficial liquid velocity

$[\mathrm{m} / \mathrm{s}]$

spacer volume

total volume of feed channel

$\left[\mathrm{m}^{3}\right]$

$\left[\mathrm{m}^{3}\right]$

flow channel width

$[\mathrm{m}]$

filament angle $\quad\left[{ }^{\circ}\right]$

osmotic pressures difference $\quad[\mathrm{Pa}]$

two-phase flow cleaning efficiency [\%]

spacer porosity

$[-]$

liquid dynamic viscosity

[Pa s]

liquid density

$\left[\mathrm{kg} / \mathrm{m}^{3}\right]$

gas/liquid ratio

$[-]$

the volumetric flow rate

$\left[\mathrm{m}^{3} / \mathrm{s}\right]$

bubble velocity

$[\mathrm{m} / \mathrm{s}]$

\section{Chapter 5}

FCP
$\Delta \mathrm{P}_{0}$
$\Delta \mathrm{P}_{\text {fouled }}$
$\Delta \mathrm{P}_{\text {cleaned }}$
MTC
TMP
$\mathrm{u}_{\mathrm{L}}$
$\eta$
$\theta$

\section{Chapter 6}

ANOVA
$\sigma$
$\eta$
$\Delta \mathrm{P}_{0}$
$\Delta \mathrm{P}_{\mathrm{t}}$
$\Delta \mathrm{P}_{\mathrm{TPF}}$
$\theta$
$\mathrm{SNR}$
$\mathrm{OA}$
$\mathrm{P}_{\mathrm{gas}}$
$u_{\mathrm{G}}$
$u_{\mathrm{L}}$

$\Delta \mathrm{P}=$ feed channel pressure drop

$[\mathrm{Pa}]$

initial feed channel pressure drop

$[\mathrm{Pa}]$

feed pressure drop over the fouled channel

feed channel pressure drop after two-phase flow cleaning

$[\mathrm{Pa}]$

$[\mathrm{Pa}]$

$[\mathrm{m} / \mathrm{Pa} . \mathrm{s}]$

$[\mathrm{Pa}]$

$[\mathrm{m} / \mathrm{s}]$

[\%]

$[-]$

Analysis of variance

Filament angle $\left.\quad{ }^{\circ}\right]$

Two-phase flow cleaning efficiency [\%]

Initial feed channel pressure drop [mbar]

Feed channel pressure drop in t-time [mbar]

Feed channel pressure drop post two-phase flow cleaning [mbar]

Gas/liquid ratio

$[-]$

Signal-to-noise-ratio

Orthogonal array

Gas pressure

[bar]

Superficial gas velocity

$[\mathrm{m} / \mathrm{s}]$

Superficial liquid velocity

$[\mathrm{m} / \mathrm{s}]$ 


\section{Summary}

The research presented in this thesis is about two-phase flow cleaning for fouling control in membrane processes. This comprehensive study aims at providing a better understanding of the underlying mechanisms and the role of the different parameters in order to enhance the effectiveness of two-phase flow cleaning processes applied in spiral-wound membrane elements and to determine the optimum operating conditions of NF/RO systems for water treatment.

An introduction to the thesis is presented in Chapter 1, and describes the problem definition, scope and outline of the thesis. This is followed by an extensive literature review on the use of two-phase flow in membrane processes, which is presented in Chapter 2. This chapter comprehensively describes the basic concepts of the two-phase flow process, including flow patterns in tubular and in closely spaced rectangular channels and the effect of impurities on the motion of bubbles in the membrane feed channels. A critical analysis of normalized data from the literature database is also presented. The following parameters enhance the flux, MTC (mass transfer coefficient) and rejection, while decreasing the feed channel pressure drop due to the application of two-phase flow: (i) vertical positioning of the membrane modules has a positive effect for all types of membrane modules, (ii) the gas/liquid ratio is the most important parameter for maximum process enhancement, yet the degree of enhancement may differ depending on the channel geometry, and (iii) operating two-phase flow at low trans-membrane pressure yields optimum process enhancement. Subsequently, a brief overview of some recent commercial applications of two-phase flow membrane processes concludes this chapter. Chapter $\mathbf{3}$ describes the key factors that control the effectiveness of two-phase flow cleaning. In this chapter the importance of several factors (i.e. feed spacer geometry (thickness and orientation), gas/liquid ratio, liquid velocity, and feed type) to control the efficiency of two-phase flow cleaning is investigated. The results show that although the channel porosity and the hydraulic diameter of spacer-filled channels are important factors in terms of efficiency, the bubble velocity determined by high speed camera, is far more important in improving the two-phase flow cleaning efficiency. The gas/liquid ratio should be maintained in such a way that a slug-like flow pattern is formed, so as to generate a good bubble distribution. Channel coverage strongly depends on the geometry of the spacer-filled channel; maintaining full channel coverage by the bubbles is crucial. 
Biofouling control in spiral wound nanofiltration elements using two-phase flow cleaning was investigated as well and presented in Chapter 4. In this chapter, the role of feed spacer geometry, feed pressure, gas/liquid ratio, cleaning duration, and liquid velocity are investigated. The results indicate that bubble flow and bubble size determined by gas/liquid ratio, which is critical for the efficiency of the process, is controlled by the structure of the feed spacer. An increase in the liquid velocity during two-phase flow cleaning was responsible for increasing bubble velocity and this was most effective in improving the MTC efficiency. Mesoscale visual inspections using optical coherence tomography (OCT) clearly showed a significant increase in biomass removed from the membrane surface with increasing velocity. Finally, using the FCP (feed channel pressure drop) only as an indicator for biofouling removal was found to be insufficient. For example, the short cleaning duration required (about $5 \mathrm{~min}$ ) for FCP recovery is misleading since it does not take into account the biomass present on the membrane surface. The information provided by the MTC gave a better indication about the biofilms present directly on the membrane surface, thus providing more insight in actual removal rates.

In Chapter 5, the potential of two-phase flow cleaning to control biofouling is tested using modified feed spacers. PolyHEMA-co-PEG ${ }_{10} \mathrm{MA}$ (neutral), polyDMAEMA (cationic) and polySPMA (anionic) were successfully coated onto PP feed spacer surfaces via plasma mediated UV-polymerization. These coatings were chemically stable for at least 7 days immersion into neutral, acidic and basic environment. All hydrogel-coated PP samples showed good anti-biofouling properties during bacterial adhesion tests. During filtration tests, polyDMAEMA shows low anti-biofouling properties due to hydrophobic interactions. The performance of polyHEMA-co-PEG ${ }_{10} \mathrm{MA}$ is fairly good. PolySPMA-coated PP feed spacers on the contrary showed significant anti-biofouling properties. Employing these highly hydrophilic surfaces during removal of biofouling by two-phase flow cleaning enhances the cleaning efficiency, feed channel pressure drop and flux recoveries.

A more detailed study on the effect of the different parameters on the efficiency of two-phase flow cleaning was presented in Chapter 6. A Taguchi method of L-25 orthogonal arrays was used for parameter optimization and revealed that the feed type is the key factor for feed channel pressure drop recovery, although also the other parameters play a (though less important) role. Finally, Chapter 7 concludes the thesis and suggests studies for future research to enhance the performance of two-phase flow cleaning in membrane processes. 


\section{Samenvatting}

Het hier gepresenteerde onderzoek behandelt reiniging door middel van tweefasenstroming om vervuiling te beheersen in membraanprocessen. Deze omvattende studie beoogt een beter begrip te bieden van het onderliggende mechanisme en de rol van de verschillende parameters om zodoende de effectiviteit te vergroten van in spiraalgewonden membraanelementen toegepaste tweefasenstroming in reinigingsprocessen en om de optimale bedrijfscondities van NF/RO-systemen voor waterzuivering te bepalen.

Een inleiding tot het proefschrift wordt gepresenteerd in hoofdstuk 1, en beschrijft de probleemstelling, de omvang en opzet van het proefschrift. Dit wordt gevolgd door een uitgebreide literatuurstudie over het gebruik van tweefasenstroming in membraanprocessen, welke wordt gepresenteerd in hoofdstuk 2. Dit hoofdstuk beschrijft uitvoerig de basisconcepten van het tweefasenstroming-proces, met inbegrip van stromingspatronen in buisvormige en nauw verdeelde rechthoekige kanalen en het effect van onzuiverheden op de beweging van bellen in de membraanvoedingskanalen. Een kritische analyse van de genormaliseerde data uit de literatuur is tevens gepresenteerd. De volgende parameters verhogen de flux, MTC (massa-overdrachtscoëfficiënt) en retentie, terwijl het de drukval in het toevoerkanaal door de toepassing van tweefasenstroming vermindert: (i) verticale positionering van de membraanmodules heeft een positief effect voor alle soorten membraanmodules, (ii) de gas/vloeistof verhouding is de belangrijkste parameter voor maximale procesverbetering, maar de mate van versterking kan afhankelijk van de kanaalgeometrie verschillen, en (iii) gebruik van tweefasenstroming bij lage transmembraandruk levert een optimale procesverbetering. Vervolgens sluit een kort overzicht van enkele recente commerciële toepassingen van tweefasenstroming in membraanprocessen dit hoofdstuk af.

Hoofdstuk 3 beschrijft de belangrijkste factoren die de reinigingseffectiviteit met tweefasenstroming beheersen. In dit hoofdstuk wordt het belang van een aantal factoren (bijv. geometrie van de voedingsspacer (dikte en oriëntatie), gas/ vloeistof verhouding, vloeistofsnelheid en type voeding) op de doelmatigheid van de controle van reiniging met tweefasenstroming onderzocht. De resultaten tonen aan dat, hoewel de kanaalporositeit en de hydraulische diameter van spacer-gevulde kanalen belangrijke factoren zijn in termen van efficiëntie, de belsnelheid, bepaald met een high-speedcamera, veel belangrijker is in het 
verbeteren van de reinigende werking van tweefasenstroming. De gas/vloeistof verhouding moet gehandhaafd worden op zo'n manier dat een slak-achtig stromingspatroon wordt gevormd teneinde een goede belverdeling te genereren. De kanaaldekking is sterk afhankelijk van de geometrie van de spacer-gevulde kanalen; behoud van volledige kanaaldekking door de bellen is cruciaal.

Controle van biologische vervuiling in spiraal gewonden nanofiltratie elementen met behulp van reiniging met tweefasenstroming werd ook onderzocht en gepresenteerd in hoofdstuk 4. In dit hoofdstuk worden de rol van voedingsspacergeometrie, voedingsdruk, gas/vloeistof verhouding, reinigingsduur, en vloeistofsnelheid onderzocht. De resultaten geven aan dat bellenstroming en bellengrootte, bepaald door de gas/vloeistof verhouding, wat essentieel is voor het rendement van het proces, worden geregeld door de structuur van de voedingsspacer. Een verhoging van de vloeistofsnelheid in reiniging met tweefasenstroming was verantwoordelijk voor het verhogen van de belsnelheid en dit was het effectiefst in het verhogen van de MTC-efficiëntie. Mesoschaal visuele inspecties met Optische Coherentie Tomograaf (OCT) toonden duidelijk een significant toegenomen verwijdering van de biomassa van het membraanoppervlak aan met toenemende snelheid. Tot slot, het gebruik van alleen de FCP (voedingskanaal drukval) als indicator voor verwijdering van biologischevervuiling, bleek onvoldoende. Bijvoorbeeld, de korte-duurreiniging (ongeveer $5 \mathrm{~min}$ ), vereist voor FCP herstel, is misleidend omdat het geen rekening houdt met de aanwezige biomassa op het membraanoppervlak. De informatie door de MTC-bepaling gaf een betere indicatie over de biologische vervuilingslaagjes welke direct aanwezig waren op het membraanoppervlak, waardoor het meer inzicht in de werkelijke verwijderingssnelheden verstrekte.

In hoofdstuk 5, wordt het potentieel van reiniging met tweefasenstroming om biologische vervuiling te beheersen getest met behulp van gemodificeerde voedingsspacers. PolyHEMAco-PEG10MA (neutraal), polyDMAEMA (kationisch) en polySPMA (anionisch) werden met succes aangebracht op PP-voedingsspacer oppervlakken via plasma gemedieerde UVpolymerisatie. Deze coatings zijn chemisch stabiel gedurende tenminste 7 dagen onderdompeling in neutrale, zure en basische omgeving. Alle hydrogel-gecoate PP monsters vertoonden goede anti-biologische vervuilingseigenschappen tijdens bacteriëlehechtingstesten. Tijdens filtratietests, laat polyDMAEMA lage anti-biologische vervuilingseigenschappen zien door hydrofobe interacties. PolyHEMA-co-PEG10MA presteert vrij goed. Daarentegen, polySPMA-gecoate PP-voedingsspacers toonden significante 
anti-biologische vervuilingseigenschappen. Het gebruik van deze zeer hydrofiele oppervlakken tijdens het verwijderen van biologische vervuiling door reiniging met tweefasenstroming verhoogt de reinigingsefficiëntie, drukval over het voedingskanaal en herstel van de flux.

Een meer gedetailleerde studie naar het effect van de verschillende parameters op het rendement van reiniging met tweefasenstroming werd gepresenteerd in hoofdstuk 6 . Een Taguchi methode met L-25 orthogonale reeksen werd gebruikt voor optimalisatie van parameters en liet zien dat het type voeding de belangrijkste factor voor het herstel van de drukval over het voedingskanaal is, hoewel ook de andere parameters een (zij het minder belangrijke) rol spelen. Tenslotte, Hoofdstuk 7 besluit het proefschrift en stelt studies voor toekomstig onderzoek voor om de prestaties van reiniging met tweefasenstroming in membraanprocessen te verbeteren. 


\section{Acknowledgments}

First and foremost, I must acknowledge and thank Almighty Allah, Most Gracious, for His infinite blessing, mercy, and guidance during my PhD period in the Netherlands. I could never have attained this stage of life without the faith in Him. The story of life of Prophet Muhammad, peace and blessing of Allah be upon him, also inspire and help me during any circumstances to accomplish this work.

I am higly indebted to my parents, Almarhum Bapak Rochman Budi Prijono and Ibu Siti Rochmini, and my brothers, Mas Sunu and Mas Wiwin, for their continuous support throughout my life. Bapak, this dissertation is my best gift to you, my deepest thank for all supports and courages that always boost my morale. Ibu, your love is never been ended. My sincere thank for all years of suffering, hardship, love and care. O Lord, show mercy on them as they have nourished me when I was young.

Now, it gives my great pleasure to express my gratitude to all people who have supported me and had their contributions in making this dissertation possible. My first warm and sincere thank goes to my daily supervisor, dr.ir. A.J.B. Kemperman. Antoine, thank you for always been caring, understanding and supporting me from my first day in Twente. Doing a PhD work, meanwhile taking care of my children for schooling etc. was very challenging, but with your support and understanding, live became easier.

I am deeply grateful to my supervisor and promotor, prof.dr.ir. D.C. Nijmeijer. Kitty, without your endless motivation and support, this dissertation might not be completed. Thank you for all enthusiasm, trust and contructive comments.

I would like to express my great appreciation to my third supervisor, dr.ir. E.R. Cornelissen. Emile, your knowledge and scientific experience is the basis of the results we obtained in this dissertation. Thank you for your immense support and constructive advises.

I am particularly grateful to my ex-promotor, prof.dr.ir. W.G.J. van der Meer. Walter, I am thinking now that the decision for me to stay in Twente rather than following you to Delft is a right decision. I am happy that we can finally publish an extensive review paper which we discussed during our Membrane Process Technology era. Thank you for your support and immense knowledge.

My special thanks to two persons, who always ready to help me: Greet Kamminga and John Heeks.

Greet, thank you for taking care of all non-scientific works, especially your help to find housing and arranging the permits for my family when we arrived for the first time in the Netherlands. You were retired just few weeks before my PhD defense, but I am grateful that you still help me to arrange the official procedure of my $\mathrm{PhD}$ promotie. I am happy that Audrey replaced you, and ready to help me to finish all works. Thank you, Audrey. And Greet, I wish you all the best.

The next special person is John Heeks, my two experimental set-ups never would have been built without his help. We even cycled together to the shop to find special part of the set-up. It is a pity John will not able to see my final results, but I will never forget his kind help and smiles. Thank you, John. 
It is my pleasure to acknowledge all my previous colleagues in MST/SFI/IM: Irdham, Al-Hadidi, Wika, Zeynep, Zandrie, Nieck, Rob, Erik Roesink, Wiebe, Erik Rolevink, Herman, Erik van de Ven, Marcel, Miriam, Patrick, Jigar, Mayur, Szymon, Can, Karina, Schwan, Olga, Jeroen, Enver, Anne Corine, Beata, Harro, David, Christina, Charu, Shazia, Sinem, Krzysztof, Erik Vriezekolk, Vic, Salman, Timon, Jordi, Namik, Kah Peng, Yali, Hammad, Tan, Chong Yool, Bas, Frank, Giri and Wei Chen.

Special thanks for my office mates in ME323: Harmen, Joris, Wojciech, Elif, Marlon, Sander, Ramato, and Oana. Harmen's jokes gave me a fresh mind during a busy writing period. Harmen, thank you for your accompany and kind help during our trip in Aachen and Oxford.

I am very grateful to the students who did an enormous amount of work in the lab, day and night, and even during the weekend: Khalid, Marcin and Faheem. I was enjoyed all our discussion and work together in the lab. I am happy that our work ended in good publications. Khalid, I am very happy that you graduated with cum laude and immediately after that continued to PhD. Thank you for becoming my paranimph and helping me during preparation of my defense. Marcin, I am very happy that finally you found a good job in the Netherlands. Faheem, I am imagining that you are now busy with your own Pakistani restaurant. Thank you for your very spicy but tasteful Biryani rice. I wish you all the best for your future, guys.

My sincere thanks for KWR-ers: Erwin, Jos, Danny, Bas Wols, Bas Hofs, Dirk, Jan, Roberta, and Claire-Kienhuis. I would extend my gratitude to Wetsusians and members of Clean Water Technology theme: Roel, Koos, Tony, Martijn, Marteen, Jan Arie, Sara, Adam, Hans, Claudia, Arie, Helena and Linda. Special thanks for the Vitens people: Ron Jong and Harry Leijssen. Ron, I am happy that we finally graduated in the same year. Harry, I enjoyed our work together in the lab and was fascinated by your beautiful set-up. I also would like to offer my great appreciation to fellow researchers in Linköping University, Sweden: Wetra, Mohsen, Thomas and Roni. I agree that biofouling research is always interesting.

Outside the scientific environment, the life in Enschede was very enjoyable with IMEA, PPIE, UTMuslims, IVEO and Basisschool Al Ummah communities, in which I can recharge myself. My sincere thanks to: Pak Syarif, Teh Astrid, Pak Tito, Pak Nas, Mas Diwan, Mas Faris, Pak Bayu, Mbak Liana, Mbak Marni, Alma Çatak, Muhammed Khatib, Ahmad Hanbali, Muzaffar, Momeen, and all. The list will be very long as I indebted many people during those four years life.

Finally, the life in Enschede would never been so joyable without Wie, Muh, Bib and Um. Thank you for your love, patience and pray. Our wonderful time is still going. Insha-Allah.

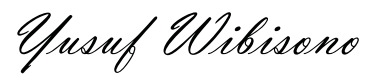




\section{About the author}

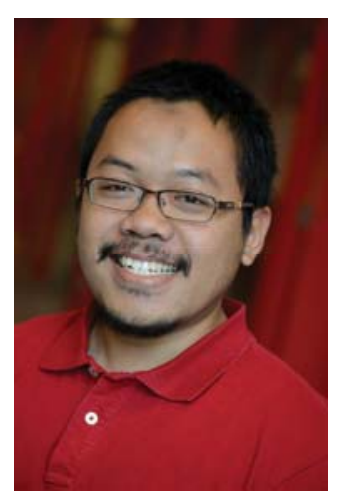

Yusuf Wibisono was born in Blitar, Indonesia on January $7^{\text {th }}$, 1980. He attended the high school at SMAN 1 Talun, Blitar, graduating in 1997. In 2002, he graduated from Bogor Agricultural University, with a B.Eng. in Agricultural and Biosystem Engineering. His final research was performed at the Centre for Research on Engineering Application in Tropical Agriculture (CREATA) on the topic of "Design and performance of induced counter flow type of cooling tower prototype", under supervision of Prof. Kamaruddin Abdullah, MSA. Starting in the same year, Yusuf has been working as Junior Lecturer in the Department of Agricultural Engineering, University of Brawijaya, Malang. In 2007, he continued his study at the International Master Program of Chemical Engineering and Materials in Chung Yuan University, Taiwan until he graduated in 2009. The Master thesis research was performed at the Centre for Membrane Technology (CMT), a Taiwan National Centre of Excellence in research and development, under supervision of Prof. Tsair-Wang Chung. The Master thesis was entitled "Computational fluid dynamics (CFD) modeling of vegetable oil degumming using tubular ceramic membrane". From April 2010 to April 2014, Yusuf joined the Membrane Technology Group at the University of Twente as a PhD student, working on the joint research programme of Dutch Water Sector (BTO), University of Twente, KWR Watercycle Research Institute and TTIW Wetsus, a centre of excellence for sustainable water technology. The research was focusing on the two-phase flow cleaning technology for fouling mitigation in spiral wound membranes and the final results are presented in this dissertation. Since April 2014, Yusuf returned back to Indonesia for becoming an assistant professor in the Department of Bioprocess Engineering, University of Brawijaya, Malang. Yusuf is a member of the European Membrane Society (EMS), International Water Association (IWA) and Indonesian Society of Agricultural Engineering (ISAE).

\section{PUBLICATIONS}

10. Y. Wibisono, K.E. El-Obied, E.R. Cornelissen, A.J.B. Kemperman, K. Nijmeijer, Biofouling removal in spiral-wound nanofiltration elements using two-phase flow cleaning, in Journal of Membrane Science (under review).

9. Y. Wibisono, W. Yandi, M. Golabi, R. Nugraha, E.R. Cornelissen, A.J.B. Kemperman, T. Ederth, K. Nijmeijer, Hydrogel-coated feed spacer in two-phase flow cleaning in spiral wound membrane elements: a novel platform for eco-friendly biofouling mitigation, in Water Research (under review).

8. Y. Wibisono, S. Widodo, Concentration boundary layer in membrane degumming:a CFD model and neural network approach. Submitted to Procedia Environmental Sciences, 2014.

7. Y. Wibisono, E.R. Cornelissen, A.J.B. Kemperman, W.G.J. van der Meer, K. Nijmeijer, Twophase flow in membrane processes: A technology with a future, Journal of Membrane Science, Volume 453, 1 March 2014, Pages 566-602, ISSN 0376-7388, DOI: 10.1016/j.memsci.2013.10.072. 
6. Y. Wibisono, W.A. Nugroho, T.W. Chung, Dry degumming of corn-oil for biodiesel using a tubular ceramic membrane. Procedia Chemistry, Volume 9, 2014, Pages 210-219, ISSN 1876-6196, DOI: 10.1016/j.proche.2014.05.025.

5. Y. Wibisono, M. Zalewski, E.R. Cornelissen, A.J.B. Kemperman, W.G.J. van der Meer, K. Nijmeijer, Efficiency of two-phase flow cleaning in spiral-wound membrane elements, in Desalination (under review).

4. Y. Wibisono, F. Ahmad, E.R. Cornelissen, A.J.B. Kemperman, K. Nijmeijer, Dominant factors controlling the efficiency of two-phase flow cleaning in spiral-wound membrane elements, to be submitted to Separation and Purification Techonology.

3. Y. Wibisono, E.R. Cornelissen, A.J.B. Kemperman, W.G.J. Van der Meer, K. Nijmeijer, Air/water cleaning of particulates in spacer-filled channels. In Membrane Technology 13, on The Progress in Membrane Research in The Netherlands and Belgium. 2012. Belgian Membrane Group (BMG) and Dutch Membrane Society (NMG).

2. Y. Wibisono, E.R. Cornelissen, A.J.B. Kemperman, W.G.J. Van der Meer, The effect of bubble size in air sparging to control fouling inside spacer-filled membrane channels. In the 6th IWA Specialist Conference on Membrane Technology for Water and Wastewater Treatment. 2011. Aachen: International Water Association.

1. Y. Wibisono, Characteristic comparison of cooling tower filler, Journal of Agricultural Technology, Vol.6 No.3 December 2005. ISSN: 1411-5131

\section{CONFERENCES}

- Conference on Membrane Technology for Desalination: Clean Water and Energy Efficiency (MTFD) 2014, Jakarta, Indonesia (Keynote Speaker)

- $\quad$ The $5^{\text {th }}$ International Conference on Sustainable Future for Human Security (SUSTAIN) 2014, Bali, Indonesia (Invited Speaker)

- International Conference and Workshop on Chemical Engineering (ICCE) 2013, Bali, Indonesia (Invited Speaker)

- $\quad$ Euromembrane 2012 Conference, London, United Kingdom (Invited Speaker)

- $\quad$ Dutch Membrane Day 2012, Shell Amsterdam, The Netherlands (Poster Presenter)

- The $6^{\text {th }}$ IWA Specialist Conference on Membrane Technology for Water and Wastewater Treatment (IWA-MTC2011), Aachen, Germany (Invited Speaker)

- Wetsus Internal Congress 2011, Leeuwarden, The Netherlands (Invited Speaker)

- International Congress on Membranes and Membrane Processes (ICOM2011), Amsterdam, The Netherlands (Poster Presenter \& ICOM2011 Organizing Committee)

- Network Young Membranes (NYM13), Enschede, The Netherlands (Session Chair \& Organizing Committee)

- $\quad$ Netherlands Process Technology Conference 2010, Veldhoven, The Netherlands (Poster Presenter)

- $\quad$ The International Membrane Conference in Taiwan 2008 


\section{COURSES}

- Computational Fluid Dynamics of Multiphase Flow (the Netherlands Research School in Process Technology (OSPT) course)

- Particle Imaging Velocimetry (the Netherlands Research School in Fluid Mechanics (JMBC) course)

- Sustainable Process, Product, and System Design (the Netherlands Research School in Process Technology (OSPT) course)

- Advanced Course on Science, Technology and Applications of Hollow Fiber Membrane (Lecturer: Prof Neal T.S. Chung - NUS, Singapore)

- Advanced Course on Transport Phenomena in Membrane (Lecturer: Prof D.J. Lee - NTU, Taiwan)

- Advanced Course on Special Topics in Membrane (Lecturer: Prof. Winston Ho - Ohio State Univ., US)

- Advanced Course on Water and Wastewater Treatment (Lecturer: Prof. K. Fujisaki - Kyushu Institute of Technology, Japan)

- Advanced Course on Numerical Fluid Flow and Heat and Mass Transfer (Lecturer: Prof Kuo Lun Tung - NTU, Taiwan)

- Workshop on Liquid Filtration Media - Today and Future (Lecturer: Prof Richard Wakeman Loughborough Univ., UK)

- Advance Chemical Kinetics

- Advance Thermodynamics

- COMSOL Multiphysics Training 